\title{
Assessing the role of the export sector in Mexican economic development, 1965-2014
}

Citation for published version (APA):

Castillo Sanchez, J. C. A. (2018). Assessing the role of the export sector in Mexican economic development, 1965-2014. [Doctoral Thesis, Maastricht University]. Datawyse / Universitaire Pers Maastricht. https://doi.org/10.26481/dis.20180613js

Document status and date:

Published: 01/01/2018

DOI:

10.26481/dis.20180613js

Document Version:

Publisher's PDF, also known as Version of record

\section{Please check the document version of this publication:}

- A submitted manuscript is the version of the article upon submission and before peer-review. There can be important differences between the submitted version and the official published version of record.

People interested in the research are advised to contact the author for the final version of the publication, or visit the DOI to the publisher's website.

- The final author version and the galley proof are versions of the publication after peer review.

- The final published version features the final layout of the paper including the volume, issue and page numbers.

Link to publication

\footnotetext{
General rights rights.

- You may freely distribute the URL identifying the publication in the public portal. please follow below link for the End User Agreement:

www.umlib.nl/taverne-license

Take down policy

If you believe that this document breaches copyright please contact us at:

repository@maastrichtuniversity.nl

providing details and we will investigate your claim.
}

Copyright and moral rights for the publications made accessible in the public portal are retained by the authors and/or other copyright owners and it is a condition of accessing publications that users recognise and abide by the legal requirements associated with these

- Users may download and print one copy of any publication from the public portal for the purpose of private study or research.

- You may not further distribute the material or use it for any profit-making activity or commercial gain

If the publication is distributed under the terms of Article $25 \mathrm{fa}$ of the Dutch Copyright Act, indicated by the "Taverne" license above, 


\section{Assessing the Role of the Export Sector in Mexican Economic Development, 1965-2014}
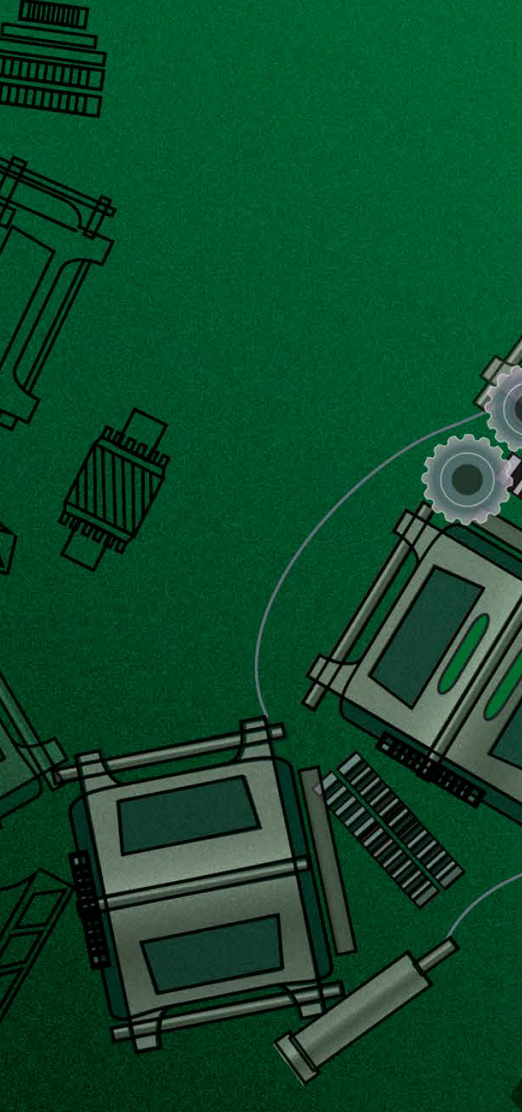

\section{Juan Carlos Castillo}


Printing: Datawyse | Universitaire Pers Maastricht ISBN 9789462959705

\section{(C)2018}

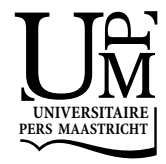

Illustration cover: Melanie Waidler

All rights reserved. No parts of this publication may be reproduced or transmitted in any form or by any means, electronic or mechanical, including photocopy, recording or otherwise, without prior written permission of the author. 


\title{
ASSESSING THE ROLE OF THE EXPORT SECTOR IN MEXICAN ECONOMIC DEVELOPMENT, 1965-2014.
}

\author{
DISSERTATION
}

to obtain the degree of Doctor at Maastricht University, on the authority of the Rector Magnificus, Prof. Dr. Rianne M. Letschert in accordance with the decision of the Board of Deans, to be defended in public on Wednesday 13 June 2018, at 10.00 hours

by

Juan Carlos Agustín Castillo Sánchez. 


\section{Supervisors:}

Prof. Dr. Adam Szirmai

Prof. Dr. Bart Verspagen.

\section{Assessment committee:}

Prof. Dr. Martin Carree (chair).

Prof. Dr. Bart Los, University of Groningen.

Prof. Dr. Roberta Rabelloti, Università di Pavia.

Prof. Dr. Carlo Pietrobelli, UNU-MERIT. 


\section{Acknowledgments.}

This book marks the end of a rather long journey that started back in February 2007, when I had the opportunity to participate in a research project on the participation of Mexico in international production networks. For myself, such an amazing (and sometimes hard) journey has not only implied living, studying and working in different and countries. It has also been a unique opportunity to advance my knowledge in international economics, understand different cultures and points of views, as well as meeting a lot of great people from different parts of the World (economists and noneconomists alike). Furthermore, this journey has been a challenging experience where, more than ever in my life, I have learned to appreciate those little (and scarce) moments that I get to spend with my family and friends in Mexico and, with all that wonderful people that I met (and had a great time with) during the different stages of our lives.

I am deeply grateful for all the things I learned over these last years and for all the support from my loved ones in difficult times. I am also indebted to those that were willing to share their advice, time, patience and wisdom no matter how lost I was. To those that spent time with me travelling over long distances, with this not only being a holiday journey or a bike ride, but also the pursuing of a two-year research master, a five-year $\mathrm{PhD}$ thesis as well as the difficult endeavor which implies start living in a foreign country from scratch. To that amazing people who, for different reasons, were not entirely able to share their time and support but that have always remained in my life as a continuous source of inspiration. I also extend my gratitude to those that trusted in my words, that had a drink with me every now and then, that laugh at my (not so good) jokes and that were willing to check on me and bring their words of wisdom no matter how unavailable, busy or worried I was. I will always be grateful to my old friends that despite the physical and time distance have always tried to be there to cheer me up and bring their love and encouragement whenever I need it. Likewise, I already have special place in my heart for those new friends that received me in their lives. You guys received me with arms wide opened not only to give me a warm and sincere hug, but also to show me the very best of you, even inviting me to spend time with your families and loved ones, after knowing (and understanding) how hard It has been for me to be away from my loved ones for so long.

It is your tangible and intangible contribution in the form of advice, piece of knowledge, inspiration, trust, support, understanding, friendship, harsh and constructive criticism, emails, text messages, phone calls, sharing a coffee, tea or a great dinner, and even some kind of old school scolding that helped me shape this final output, which is my $\mathrm{PhD}$ dissertation. Many of the great people I am referring to were able to help me with all this, despite their not necessarily being in the same city (or even country) where I was living at. It might sound boring, or even tedious, to say this but I have realized that such latter situation highly resembles one of key arguments explored by this thesis. The fact that, despite not being physically present in the country where the productive process 
takes place, many individuals from different regions of the World were able to contribute directly or indirectly to the successful completion of Mexico's final output. Just like this dissertation indicates, even though Mexico (a Mexican, in this case) is now ready to export its final output to major end markets it should be kept in mind that such final outcome would have never been produced without the increasing and continuous interaction of Mexico with individuals located in close proximity as well as those that are present elsewhere in the World. Since this thesis also aim to slice up the value added contribution embodied in Mexico's final output, this section will proceed in similar fashion. This means that in the forthcoming lines, I will try to slice up and briefly explain the invaluable contribution from supervisors, academic institutions, colleagues, friends and family that is embodied in this PhD dissertation. To all of you, I express my deepest and most sincere gratitude.

\section{To my PhD thesis supervisors, Adam Szirmai and Bart Verspagen.}

I literally have no words to express my gratitude for the continuos support and encouragement provided by my supervisors during the different stages of this $\mathrm{PhD}$ thesis. I want to thank Bart Verspagen for his willingness to help me whenever I needed and for his pushing my knowledge forward after thorough technical and theoretical discussions as well as productive feedback. I also want to thank Eddy Szirmai for his literally always being there for me during this thesis despite the existence of many issues a long the way. Hardly ever would this thesis have been produced the way it did without your time, encouragement, patience and attention to details. I will always be grateful to you, dear Eddy, for kindly approaching me just to see how you could help me, for your always being excited about the topic, for spending hours and hours trying to understand my arguments and for correctly seeing and trying to find an answer to my questions and mistakes.

It was truly an honor to be one of the PhD students from Bart and Eddy and thus, I will do my very best to proudly show at the academic world all the knowledge and motivation you have kindly transmitted me over the last five years.

\section{To my PhD assessment committee.}

I would like to sincerely thank Martin Carree, Bart Los, Roberta Rabelloti and, Carlo Pietrobelli for being part of my assessment committee. Their constructive comments and criticisms greatly improved the main arguments discussed on this dissertation.

\section{To the United Nations Industrial Development Organization (UNID0).}

My sincere gratitude goes to UNIDO for their financial support during this PhD project. I am also grateful for the opportunity they gave me to join as an intern their World Class research team. Ludovico Alcorta, Nicola Cantore, Michele Clara, Alejandro Lavopa, Charles Fang Chin Cheng and Nelson Correa are some of UNIDO's team members that I am thankful to. In particular, I would like to thank my research internship supervisor, Nobuya Haraguchi for his trust on my research project, for believing on my technical skills, and for letting me participate as a research assistant on UNIDO's 2016 Industrial Development Report. 


\section{To all the staff from the United Nations University-MERIT and Maastricht University.}

Being part of the community from UNU-MERIT and Maastricht University has been nothing but a wonderful experience. Robin Cowan, the director of UNU-MERIT's PhD program, deserves a special mention. Thank you so much Robin, for the supervision and encouragement provided not only during the early stages of the PhD but also in the years thereafter. I would also like to thank Adrian Van Zon, Tania Treibich, Neil FosterMcGregor, Michiko Iizuka, and Melissa Siegel

From the administrative staff, my gratitude goes to Marc Vleugels, Ingeborg Eijssen-de Beer, Ingrid Scheffers, Howard Hudson, Ad Notten, Monique Raedts, Mourik Jan Heupink and, Herman Pijpers. While completing the thesis, PhD students faced many technical and administrative issues. As result of the hard work and friendly attitude from UNUMERIT's staff, PhD students can enjoy a smooth life in Maastricht and, for that, I would like to thank them. Likewise, I also extend my gratitude to the staff from the Knowledge Center for their prompt and timely assistance whenever a residence permit needed to be extended.

\section{To Eveline In de Braek.}

As tradition dictates, every single PhD thesis from UNU-MERIT devotes some kind words to thank one of the pillars of the friendly and cozy environment that the institute enjoys. Someone that truly enjoys her work and is willing to assist PhD students in many more ways than her job actually requires. Not only does Eveline have a solution for every problem someone brings at her desk. More importantly, she is always there with a smile more than willing to listen and cheer you up whenever you need it. Having met you, my dear Eveline, is already one of the most precious memories that I have from Maastricht. I will never forget how kind you were with me from the very beginning and how much you have cared about my well being (both including personal and academic issues). It was your friendship and support some of the factors that definitely kept me going over these years. Danke je wel, Eveline!

\section{To the University of Groningen.}

Having received a scholarship from the University of Groningen to pursue research master studies was truly the opportunity of my life. Not only did I get the opportunity to study in competitive environment that follows high academic standards. Furthermore, it was here where I became passionate about doing research after following rather interesting lectures and listening the ground-breaking point of view from top scholars in the field of international economics. I would like to express my sincere admiration and gratitude to Bart Los, Marcel Timmer, Erik Dietzenbacher, Sjoerd Beugelsdijk and Herman de Jong. Attending your presentations, reading your high-quality papers, and receiving your thorough feedback were definitely a great source of inspiration to continue my career as a researcher. 


\section{To Marco Haan and Arthur de Boer.}

Receiving the complete support from Marco Haan and Arthur de Boer before joining the research master in Groningen was a critical step in my academic career. I would like to sincerely thank Arthur for his prompt and friendly replies to my tedious emails, for all the administrative support that he provided whenever I face all kind of issues and, for his always having a time to have small chat just to check how I was feeling in such an adventure called research master. In addition, I cannot find the words to express my most sincere gratitude to thank Marco Haan for supporting my candidacy to study in Groningen. I am also deeply grateful for all the time Marco spent providing his guidance during my "Learning and Practicing Research" project and, for his willingness to assist me during the application process to the $\mathrm{PhD}$ in Maastricht.

\section{To my research master supervisor and friend, Gaaitzen De Vries.}

Gaatizen has been one of the most important persons during my academic career. It has been his continuous encouragement and advice, thorough feedback, expertise and visionary work on international economics that have helped me advanced my career in different ways. Dear Gaaitzen, I will always be grateful for your guidance and for all the motivation you gave me to specialize on studying the maquiladora industry. Under your correct and smart supervision over these last seven years, I have learned the ways in which a prestigious young researcher should look like. Not only did you play a critical role in helping me finish our LPR project or the research master thesis. Furthermore, your support has always been there both to help me shaped the early stages of the PhD proposal and to assist me in finding new pathways where I can grow as a researcher. ¡Muchas gracias por todo, Gaaitzen!

\section{To the National Autonomous University of Mexico (UNAM).}

I would like to express my deepest gratitude to UNAM for providing me with the building blocks to become a researcher with a thorough understanding of the Mexican economy. Having studied at the one of the most prestigious Universities in Latin America has been an exceptional privilege. Thus, I sincerely commit to continue honoring UNAM as being part of it is an experience that I will proudly carry with me forever; ¡México, Pumas, Universidad!

From the academic staff at UNAM's Faculty of Economics, I would like to thank Martin Puchet Anyul, Pablo Ruiz Nápoles and their group of academics for their invitation to present my research on their "Seminario Permanente de Análisis Estructural". A rather special mention goes to Isaac Minian for inviting me to participate on his research project, for being my "Licenciatura" thesis supervisor and, for his support in the process of admission to the research master in Groningen. It is also worth mentioning that I owe to Isaac Minian the platform where I decided to specialize on the participation of Mexico in international production networks. It was his motivation, support an expertise that also helped me reach this goal in my life. 


\section{To the Instituto Nacional de Estadística y Geografía (INEGI).}

Mexico's statistical office (INEGI) provided most of the data used in this dissertation. Such detailed and timely published data allowed for a thorough analysis of Mexico's export sector. Particularly, I would like to express my deepest gratitude to INEGI's Dirección de Acesso a Microdatos for granting my research project with access to the firm-level information from the EMIME and IMMEX program. A rather special mention goes to Natalia Volkow, Liliana Martínez, Carmen Marquez, Lourdes Garrido and all the staff from "Área Enlace". Their kind support during the remote processing of numerous do-files greatly helped me finish a critical section of this $\mathrm{PhD}$ thesis.

\section{To the United Nations Conference on Trade and Development (UNCTAD).}

Having joined UNCTAD's Division on Investment and Enterprise has truly been a great experience. Here, I would like to specially thank Richard Boljwin and Bruno Casella for the opportunity and for their having trusted on my experience and skills to collaborate for the preparation of UNCTAD's 2018 World Investment Report.

\section{To all my friends and colleagues.}

First of all, I would like to thank UNU-MERIT's 2012 PhD cohort; Stefania I., Sheng, Gintare, Eva, Ayo, Tobias, Raquel, Biljana, Caroline, Thuy, Hasse, Tigist and Martin. It was truly amazing to have shared so many nice (and tough) experiences with all of you, guys. I also extend my gratitude to Danilo, Mario, Caio, Elvis, Hugo, Daniel O., Francois L., Richard B., Eduardo, Sachin, Andrea F., Andrea M., Iman, Ortrun, Mueid, Mira, Inez R., Ibrahima, Tamer, Patima, Davina, Iulia, Bart K., Tamara, Nga, Beatriz, Emmanuel, Choolwe, Gideon, Halefon, Omar R., Giulia, Francesca R., Tamer, Hassen W., Eli S., Tatenda, Juan Carlos P., Clotilde M., Sergio P., Simonne S., Fernando V., Carmen C., Francisco V., Stefania F., Eduardo F. and Jan V.

A very special and important mention goes to Francesca G., Alejandro L., Jennifer T., Giorgio, Julietta, Agustín, Elisa, Alison, Jenniffer W. and Mary. I simply cannot find the words to thank you enough, dear Maastricht friends. I also gratefully acknowledge the kind support from my paranymphs; Danilo Sartorello and Hugo Castillo.

From the great people that I met in Groningen, my most sincere gratitude goes to my dearest friends Victoria E., Néstor S., Ilian D. and Marianna P. I will hardly forget those amazing and funny moments that we shared in wonderful Groningen.

My awesome Mexican friends also deserve to be mentioned. Here, I want to thank Judith Z., Omar N., Cynthia G., Alejandra M., Ari J., Dánae B., Luis Daniel V., Mauricio S., Julio P., Marimar I., Ana Laura G., Jessica A., and Ricardo O.

\section{To my family}

I cannot thank my family enough for all the love, support, sacrifice and encouragement they have provided over these last years. Despite many difficult years, we have been able to stay together, supporting each other and trying to be there as much as we can. It has been simply their existence that has allowed me reach this stage in my life. 


\section{To the loving memory of my grandfather, Raúl Sánchez.}

Abuelo, Raúl, I know you are there up in the sky watching your wife, daughters and grand kids. It has been some time since your farewell, but I am sure that you understand that we still miss you a lot. Thank you so much for taking me to my first day in highschool, for my first day at the University, for patiently waiting with me at the airport for many hours before I could catch the flight that would take to the Netherlands and to the new stage in my life. You have been always in my heart since I started the PhD and, thus I want to dedicate this book to you. Te amamos y extrañamos mucho, Abuelo.

\section{To Virginia Martínez, Hilda Sánchez and Alvaro Orsatti.}

I would like to extend my most sincere gratitude and love to my dearest grandmother, Virginia Martínez. Dear Vicky, your guidance and protection from the moment I was born have helped cope with the all the challenges in my life. I am forever grateful for all your love and for your unconditional support throughout the different stages of my life. My aunt, Hilda, and uncle, Alvaro, also deserve a rather special mention. I owe to them my passion for economics and my determination and willingness to become a researcher. Thank you so much, dear Hilda and Alvaro, for your continuously being there to support me no matter what.

\section{To my siblings, Grisel, Fabiola, Hugo and Axel, my cousin, Bruno, and my brother in law, Rene.}

¡Hermanos! Being with all of you is perhaps one of the things I have missed the most over these last years. Having shared my life with you has been simply fantastic. Thank you so much, for all those wonderful moments we spent together, for your unconditional support and understanding, as well as your always trying to be there to cheer me up. It has been your strength and confidence that has shaped my personality and for that I will be forever grateful. ¡Los amo y extraño mucho, hermanos!

I would also like to extend my gratitude to my cousin Bruno and to my brother in law, Rene. In addition, on behalf of my family, I would also like to thank Mayela Carranza and Hugo Delgadillo for the kind support they provided in rather difficult times. I also extend this gratitude to Juan De la Orta, Guillermina Farias, Guadalupe Herrera, Paulina Fernández and Noé Santana.

\section{To my mother, Laura Sánchez Martínez.}

Mamá, Laura, you know that there is no other person more important in my life than you. Your strength and determination in always going forward has been the ultimate source of inspiration throughout my life. Even though time and distance may have torn us apart, your sincere advice, patience and protection have always been with me during every single second day that I have been abroad. My heart is filled with your unconditional love. Thank you so much for never desisting so your sons and daughter could reach their dreams. Thus, as I stand in this moment of my life, dearest Laura, you should always be aware that this important achievement is not mine but entirely yours. ¡Te amo mucho, Mamá! 


\section{Last, but not least, I would like to write down some words in my mother tongue.}

Este libro marca el final de un largo camino para mi persona. Sin embargo, también marca el inicio de otra etapa en mi vida, la cual, seguramente estará llena de retos y alegrías. Debo reconocer que este camino no ha sido sencillo y, que en más de una ocasión dude de mi persona. Por ello, me gustaría iniciar esta nueva etapa de mi vida citando algunos fragmentos del poema "No te Rindas" del escritor uruguayo Mario Benedetti, para no sólo recordar así lo afortunado que he sido para llegar hasta este momento, si no también para entender lo mucho que aún falta por recorrer...

"No te rindas, aún estas a tiempo de alcanzar y comenzar de nuevo, aceptar tus sombras, enterrar tus miedos, liberar el rastre, retomar el vuelo. No te rindas que la vida es eso, continuar el viaje, perseguir tus sueños, destrabar el tiempo, correr los escombros, $y$ destapar el cielo.

No te rindas, por favor no cedas, aunque el frio queme, aunque el miedo muerda, aunque el Sol se esconda, y se calle el viento. Aún hay fuego en tu alma, aún hay vida en tus sueños.

Abrir las puertas, quitar los cerrojos, abandonar las murallas que te protegieron, vivir la vida y aceptar el reto, recuperar la risa, ensayar un canto, bajar la guardia y extender las manos, desplegar las alas, e intentar de nuevo, celebrar la vida y retomar los cielos. Porque cada día es un nuevo comienzo. Porque esta es la hora y el mejor momento".

Geneva, Switzerland

May,2018. 



\section{Summary.}

The main objective of this thesis is to identify the existence of a process industrial upgrading in Mexico's exporting sector from 1965 to 2014. Four dimensions of upgrading are here assessed: (1) domestic content of manufacturing exports; (2) value added to output ratios; (3) labor productivity, and; (4) participation of skilled-labor. The period of time here studied starts from the first policy attempts to incentivize manufacturing production between firms Mexico and in the United States (i.e. the establishment of the Maquiladora program in 1965), until a period of time where manufacturing became widely fragmented across many countries and regions of the World economy (2014).

In order to meet this objective, this dissertation relies on specific aggregate and firmlevel information for Mexico's exporting firms. Aggregate information includes international trade statistics, national input output tables and data in terms of Mexico's national accounting systems that is also classified per manufacturing sector. Such aggregate information is also here linked with additional data provided by major multiregional input-output datasets. On the other hand, the firm-level information here used corresponds to the official panel datasets for the firms in Mexico that were registered in export promoting programs from 1990 to 2014.

Exporting firms in Mexico are here classified according to the export promotion framework that they belong to. Firms exclusively producing for exports are those included in the Maquiladora program (1965-2006), while firms producing both for exports and for the domestic market were included in the PITEX program (1985-2006). By 2007, to further strength the competitiveness of the exporting sector, policy makers merged those two export promoting programs into a single framework (known as IMMEX). In addition, this dissertation also takes into account other two types of firms: 1) the official data for firms in Mexico that are highly engaged in international production networks (i.e. the concept of Manufactura Global), and; 2) the rest of firms that are located in Mexico's domestic manufacturing.

Upgrading in exporting firms is here analyzed considering the following perspectives. I first start with the policy perspective (Chapter 2). In general lines, Chapter 2 argues that Mexico's policy framework has prioritized higher employment, output and higher levels of foreign direct investment in the exporting sector at the expense of upgrading. Official attempts to develop a network of domestic suppliers have been observed from the opening of the Mexican economy to foreign markets (1982). Nevertheless, the vast majority of exporting firms are reluctant to source inputs domestically as domestic supplier are unable to meet high quality and delivery standards.

A global perspective of manufacturing production is discussed in Chapter 3. Here, I indicate that all advanced and developing economies in the World economy are experiencing decreasing domestic content in their production for final manufacturing output. Depending on the specific characteristic of each manufacturing sector, the main 
source of such decreasing domestic content in final output could be either a higher interaction with foreign suppliers located at the country's same region, or a higher interaction with suppliers located in other major regions of the World economy. Firms operating in the sector of electronics, textiles and other manufacturing that are located in advanced and emerging economies are more prone to increase their interactions with foreign suppliers that are outside of their region of origin. For the rest of manufacturing sectors in advanced and emerging economies, and for the manufacturing production in the rest of the developing World, the main source of decreasing domestic content will be higher interaction with regional suppliers.

A long-run perspective on the aggregate evolution of the domestic content of Maquiladora exports, and on their use of highly skilled workers, is presented in Chapter 4. I indicate that such domestic content presents a continuous decline since Mexico decided to open its domestic market in 1981. Such situation was still present by the end of the Maquiladora program (2006). External shocks and key policy changes (both taking place in 1982 and 1994) as well as the composition of Maquiladora output (which is mostly consistent of electronics) largely account for this continuous decline.

Chapter 5 further assesses domestic content embodied in Mexico's final manufacturing output by taking into account the specific country of origin where value added was originally created. With this analysis, I indicate that manufacturing firms in Mexico can participate in local, regional and global value chains. Local value chains are the predominant type of organization for firms in domestic manufacturing as they mostly source their input from local producers in Mexico. Exporting firms, on the other hand, can participate in local regional or global value chains depending on the manufacturing sector being analyzed. Regional value chains are mostly observed in the textile sector in light of the increasing presence of value added coming from the United States. Global value chains are mostly observed at the electronics sector given the important participation of East Asian firms in the production for exports within this sector. The production for exports within the transport sector mostly relies on domestic suppliers and, thus, we infer that the predominant type of production here is local value chains.

Labor productivity in exporting firms is analyzed in Chapter 6. In this chapter, I show that the exporting sector does not contribute much to changes in aggregate labor productivity for total Mexican manufacturing. Manufacturing firms in the domestic sector are the ones driving changes in aggregate labor productivity. Upgrading in the exporting sector (i.e. value added to output ratios) does not play an important level in inducing aggregate productivity changes. At the firm-level, we also observe that value added to output ratio do not show any relevant variation over time.

Two main conclusions are obtained from this dissertation. The first one is that the exporting sector has transformed Mexico in a top manufacturing powerhouse for the World economy. The combination of thoroughly elaborated export promoting policies, trade agreements, unique access to the US market, as well as the intention to fully exploit the set of country-specific competitive advantages enjoyed by Mexico are the main factors that help us understand such important achievement. On the other hand, by means of any relevant indicator studied by this dissertation, Mexican manufacturing has clearly failed to induce a substantial transformation of its exporting sector towards 
more complex and technologically advanced manufacturing activities. A process of industrial upgrading that could allow the exporting sector in Mexico capture a higher amount of benefits in the current context of international fragmentation of production is still far from being present. 



\section{Table of contents}

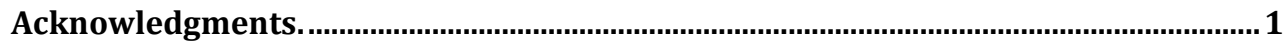

Summary

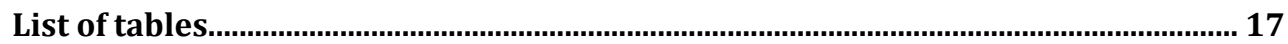

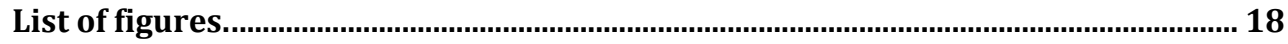

\section{Chapter 1.}

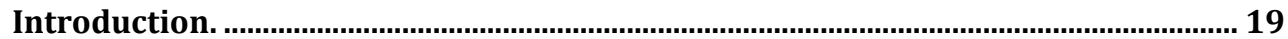

1.1 Increasing Fragmentation of Global Production. ......................................................... 19

1.2 Definition and Dimensions of Upgrading....................................................................... 20

1.3 Export Processing Zones as a Policy Instrument for Participating in International Production Networks.................................................................................. 21

1.4 Latin America's Failing Attempt to Industrialize with Export Processing

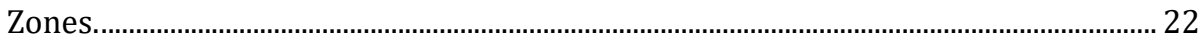

1.5 Mexico and the Success of Maquiladora Production...................................................... 22

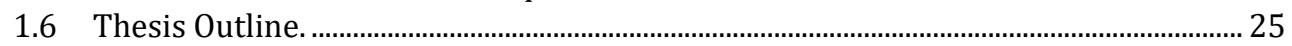

\section{Chapter 2.}

50 years of Export promoting Programs in Mexico (1965-2016): A general Framework to Understand the Evolution of Maquiladora, PITEX and the IMMEX program.

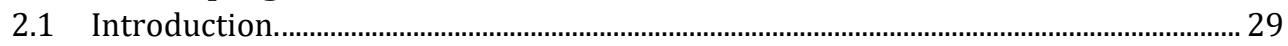

2.2 Definition and Different Investment Opportunities to Participate in the Maquiladora Program.

2.3 Origins of the Maquiladora Program and General Events in the Evolution of

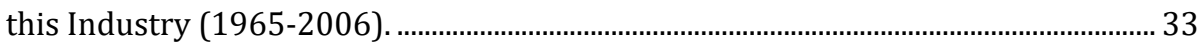

2.3.1 Restrictive Framework for Maquiladora Firms: (1965-1981)........................... 33

2.3.2 Currency Crises, Mexico's Increasing Outward Orientation and Booming Maquiladora Production: (1982-2000).

2.3.3 A NAFTA Framework for non-NAFTA countries, Industrial Emergence of China and, Drastic Contraction in Maquiladora Output (2001-2006)....... 36

2.4 Beyond the Border: the Location of Maquiladora Firms in Other Regions................ 37

2.5 The Development of Local Suppliers to Maquiladora Firms......................................... 44

2.6 Technology: Four Generations of Maquiladora Firms. .................................................. 45

2.7 Domestic Sales of Maquiladora Output........................................................................... 47

2.8 The Evolution of Maquiladora Firms through Manufacturing Sectors......................... 48

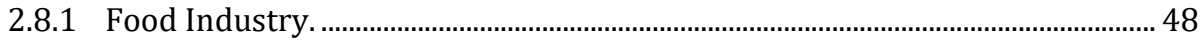

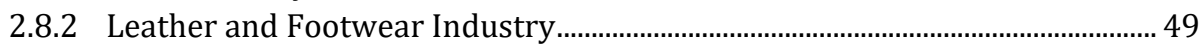

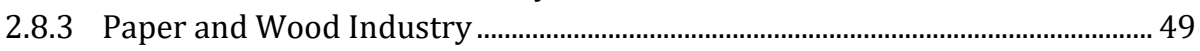

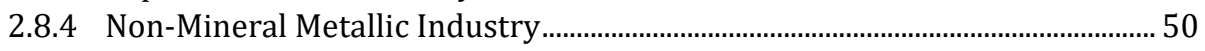




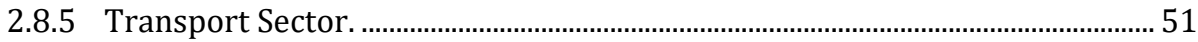

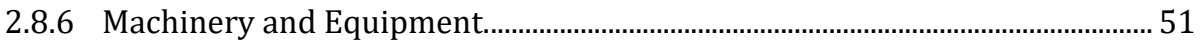

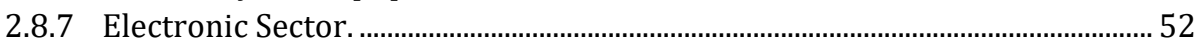

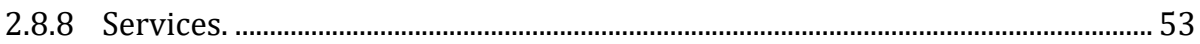

2.9 The Development of Other Export Promoting Programs (1985-2006)....................... 55

2.9.1 PITEX, DIMMEX, the Drawback System and, Carta de Crédito

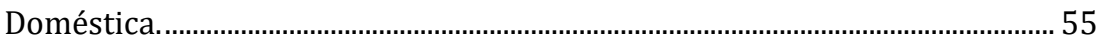

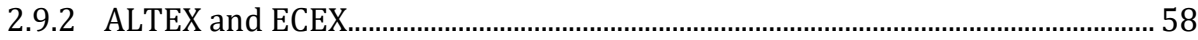

2.10 Similarities and Differences between the Maquiladora and PITEX Program........... 58

2.10.1 Duty Free Imports and Foreign Ownership .......................................................... 59

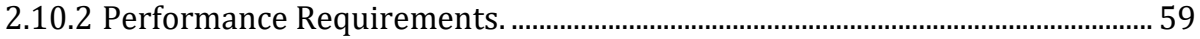

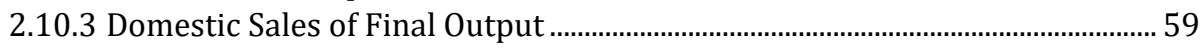

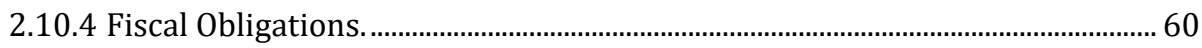

2.11 IMMEX Program (2007-present): Merging PITEX and Maquiladora firms............. 61

2.12 The Future of Mexico's Export Promoting Programs: Industrializing the

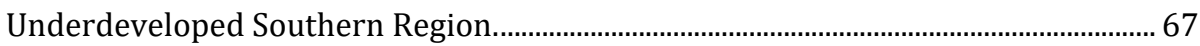

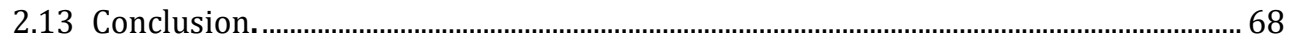

Chapter 3.

Regional Value Added Component in Manufacturing: Evidence from Top Exporters and Regions of the World Economy......................................................... 71

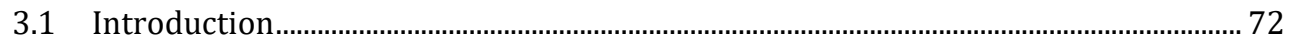

3.2 Literature Rev.: How Has Fragmentation Evolved and How We Can Measure

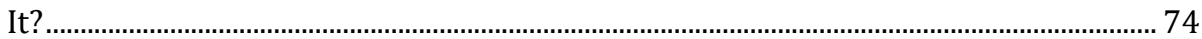

3.2.1 The Evolution of the Increasing Fragmentation of Production.......................... 74

3.2.2 How to Analyze the Increasing Fragmentation of Production? .......................... 76

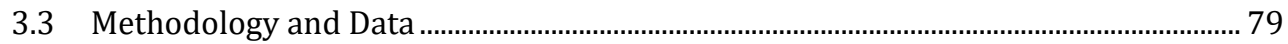

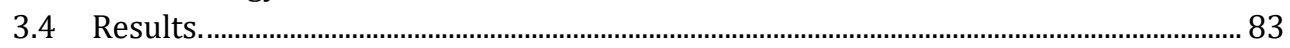

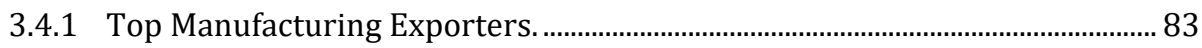

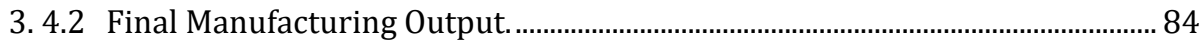

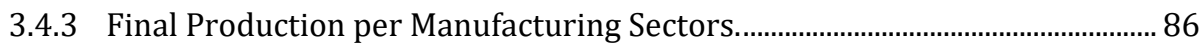

3. 4.4 Results for the Regions of the World Economy. .................................................. 95

3.5 Conclusion and Points for Discussion. ……..................................................................... 99

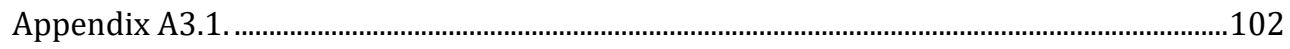

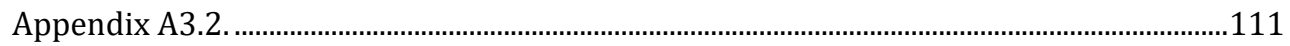

\section{Chapter 4.}

Industrial Policy and the Domestic Content of Mexico's Maquila Exports: A long-run Perspective ..............................................................................................137

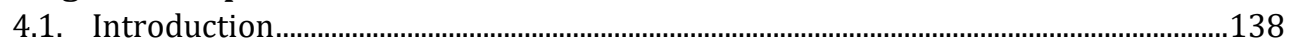

4.2. Industrial Policy and Mexican Maquiladoras: an Overview .........................................140

4.3. Database Construction and Descriptive Statistics for Maquila Industries................143

4.4. Methodology to Measure the Domestic Content of Exports Over Time .....................147

4.4.1 Measuring the Domestic Content of Maquila Exports .........................................148

4.4.2. Construction of Time Series IOTs. ……................................................................150 
4.5. The Domestic Content of Maquila Exports.

4.5.1 The Domestic Content of Maquila Exports: Aggregate and Industry Trends

4.5.2 The Domestic Content of Maquila Exports: a Disaggregation Analysis........155

4.6. Concluding Remarks.

\section{Chapter 5.}

Mexican Manufacturing and its Integration into Global Value Chains ....................159

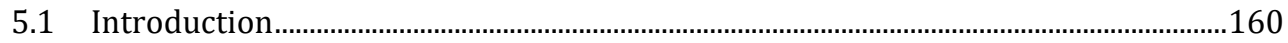

5.2 An Overview of Mexican Manufacturing .........................................................................163

5.2.1. Export Promoting Programs and the Production for Global Production Networks. .............................................................................................................. 163

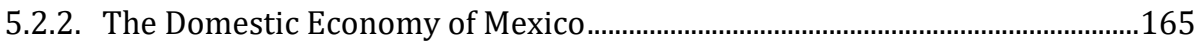

5.2.3 Competitive Advantages of Manufacturing Production in Mexico.................165

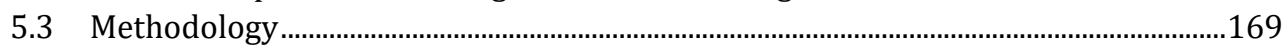

5.4 Data Construction Methods: How to Include Mexico (Domestic) and Mexico (Maquiladora/Manufactura Global) in WIOT? .............................................................170

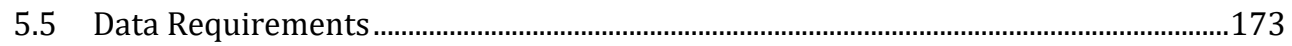

5.5.1. Data for SUTs from Mexico (Domestic) and Mexico (Maquiladora/Manufactura Global).

5.5.2 Data for the International SUTs from Mexico (Domestic) and Mexico (Maquiladora/ Manufactura Global)..................................................................175

5.6 Sectoral Shares and Sources of Intermediate Inputs.....................................................178

5.7 Results: the Structure of Value Added Contributions......................................................183

5.7.1. The Domestic Economy of Mexico...........................................................................183

5.7.2 Maquiladora Industry (1998-2006) and Manufactura Global (20072011)

5.7.3 Total Economy of Mexico (1998-2011) ……..........................................................192

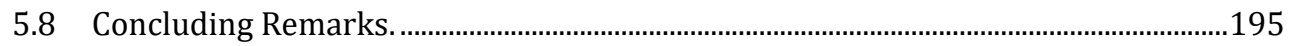

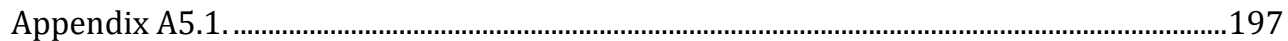

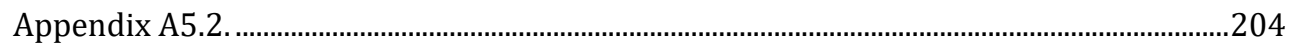

\section{Chapter 6.}

The Micro-foundations of Productivity and of Productivity Growth in

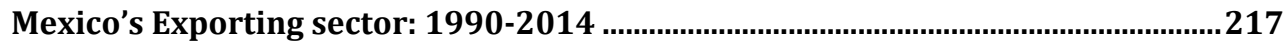

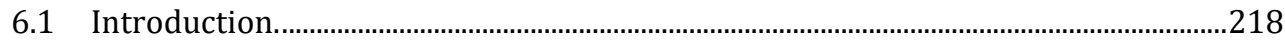

6.2 Literature Review: The Evolution of Productivity in Mexican Manufacturing........220

6.2.1 Productivity within Total Manufacturing................................................................222

6.2.2 Productivity within Domestic Manufacturing..................................................221

6.2.3 Productivity within the Maquiladora Industry..................................................223

6.3 The Productivity Contribution of the Export Sector: an Aggregate Perspective....225

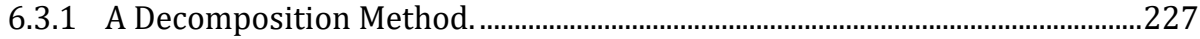

6.3.2 Decomposition of Aggregate Manufacturing Labour Productivity ................229

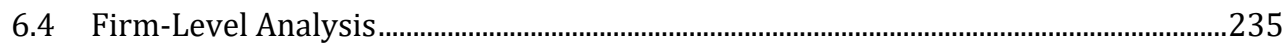

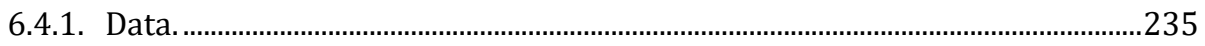


6.4.2. Identifying sub-Groups of Firms in the IMMEX Dataset. ..................................238

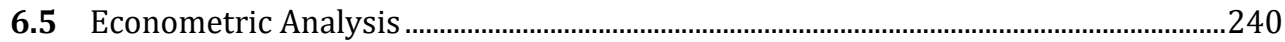

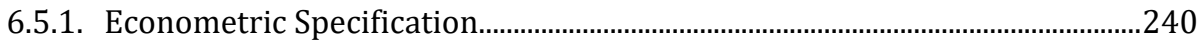

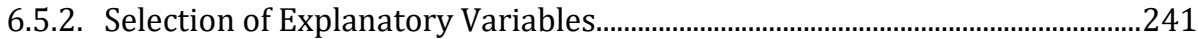

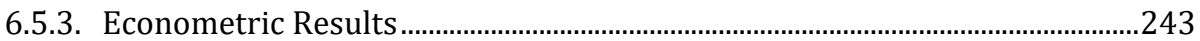

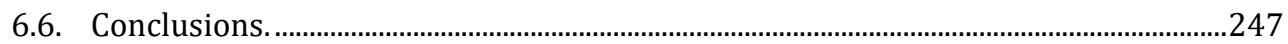

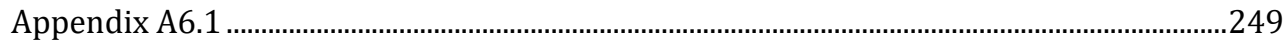

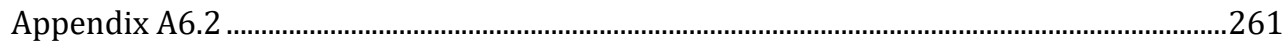

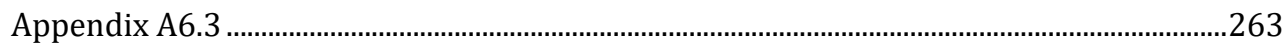

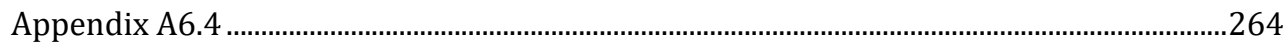

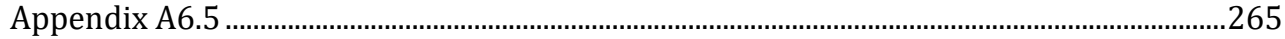

\section{Chapter 7.}

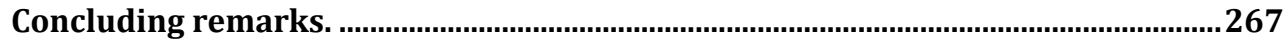

7.1 Methodological and Policy Contributions........................................................................267

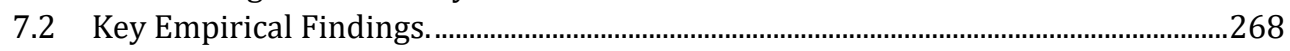

7.3 Factors (and their Implications) that Account for the Lack of Upgrading in

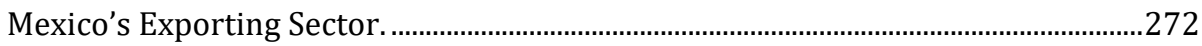

7.4 Policy Lessons from Mexico's Export Promoting Experiences........................................276

7.5 General Guidelines for the 2017-2018 Renegotiation of NAFTA: Some Insights from the Maquiladora Industry.......................................................................2

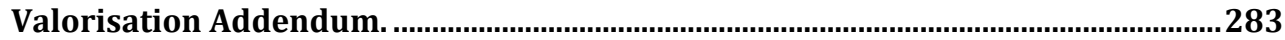

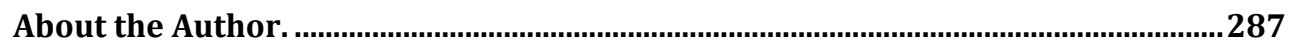

\section{General Appendix.}

Data sources used in this Dissertation..........................................................................289

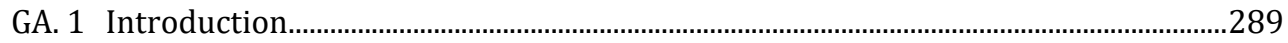

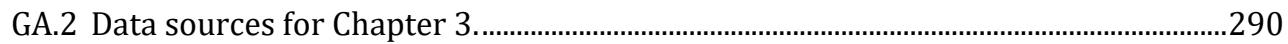

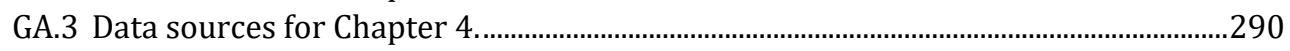

GA. 3.1 Official IOT for the Total Economy of Mexico (2003).....................................290

GA.3.2. Data from Mexico's NAS for Maquiladora and Domestic

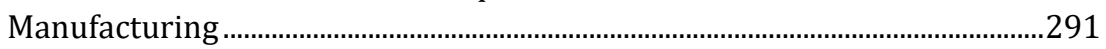

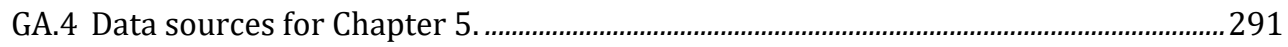

GA.4.1 World Input Output Database (WIOD): 1998-2011.......................................291

GA.4.2 NAS Data for Domestic Manufacturing (1998-2011), for Maquiladora

(1998-2006) and the Concept of Manufactura Global (2007-2011)............291

GA.4.3 International trade statistics for Maquiladora and for Domestic

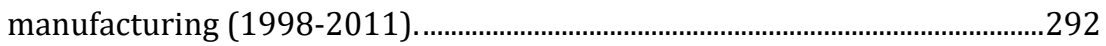

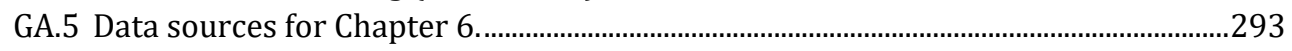

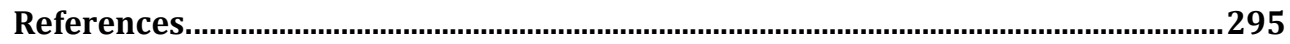




\section{List of tables.}

Table (2. 1): Location of Maquiladora firms in Mexican Regions: 1990-2006

Table (2.2): Share of Domestic Intermediate Consumption in Total Intermediate Consumption for Maquiladora (All Manufacturing Sectors in Mexican regions): 1990-2006 …................................ 40

Table (2. 3): Mexico's Exporting Firms in the Maquiladora, PITEX and IMMEX Programs. .................. 61

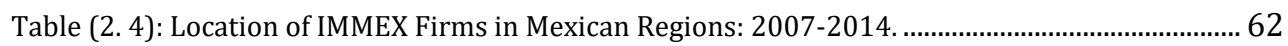

Table (2. 5): Share of Domestic Intermediate Consumption in Total Intermediate Consumption for IMMEX (All Manufacturing Sectors in Mexican Regions): 2007-2016.

Table (3. 1):Share of Value Added Contribution in Final Output (\%). Total Final Manufacturing Production. 84

Table (3. 2): Share of Value Added in Final Output (\%). Food \& Beverages ............................................ 86

Table (3. 3): Share of Value Added in Final Output (\%). Textiles and Wearing Apparel......................... 88

Table (3. 4): Share of Value Added in Final Output (\%). Wood and Paper................................................ 89

Table (3. 5): Share of Value Added in Final Output (\%). Metal Products. .............................................. 91

Table (3. 6): Share of Value Added in Final Output (\%). Petroleum, Chemical and Non-Metallic

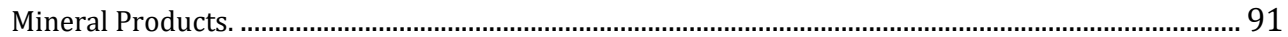

Table (3. 7): Share of Value Added in Final Output (\%). Electrical and Machinery................................. 92

Table (3. 8): Share of Value Added in Final Output (\%). Transport Equipment. .................................... 94

Table (3. 9): Share of Value Added in Final Output (\%). Other Manufacturing....................................... 95

Table (4. 1): Descriptive Statistics, Size and Domestic Input use for Maquiladora Industries............145

Table (4. 2): Expanded Input-Output Table for Mexico.......................................................................149

Table (4. 3): Domestic Content of Maquila Exports, Industry Results. ................................................153

Table (4. 4): Sources of Change in Domestic Value Added of Maquila Exports, 1981 to 2006 ...........156

Table (4. 5): Sources of Change in Domestic Value Added of Maquila Exports, 2001 to 2006............157

Table (5.1): Gross Output Shares per Manufacturing Sector: Domestic, Maquiladora and Manufactura Global.

Table (5. 2): Intermediate Inputs used in manufacturing in Mexico (Domestic), by Region of Origin (\%)

Table (5. 3): Share of Intermediate Inputs used in the Manufacturing Production from Mexico (Maquila) and Mexico (Manufactura Global).

Table (5. 4): Share of Regional Value Added Content Embodied in Final Manufacturing Output

Produced by Mexico (Domestic). Selected Manufacturing Sectors.

Table (5. 5): Share of Regional Value Added Embodied in Final Manufacturing Output Produced by Mexico (Maquiladora/M. Global). Selected Manufacturing Sectors.

Table (5. 6): Share in Value Added Content of Final Manufacturing Output by Region/Country of Origin in Mexico (Total Economy). 
Table (6. 1): Summary of Estimates of TFP and of Labor Productivity Annual Average Growth. Mexican Manufacturing.

Table (6. 2). Labor Productivity in Maquiladora, IMMEX, Domestic and Total Economy. All Manufacturing Sectors. Thousands of Mexican pesos (constant prices of 2008).

Table (6.3): Contribution to Changes in Aggregate Labor productivity (\%)

Table (6. 4): Basic Statistics for the Entire Sample (between Firms and Over Time), Maquiladora (1990-2006) and IMMEX (2008-2014) Firm-Level Datasets, All Years and All Manufacturing Sectors (Shares and Constant Mexican Pesos of 2008)...

Table (6. 5): Basic Statistics for Exports and Imported Intermediates (between Firms and Over Time), IMMEX (2008-2014), All Years and All Manufacturing Sectors (Shares and Constant Mexican Pesos of 2008).

Table (6.6): Econometric Results for IMMEX, Fixed effects Dependent variable:

Logarithm of Firm-Level Labor Productivity

Table (6. 7): Error Correction Model Estimation for Maquiladora and IMMEX

\section{List of figures.}

Figure (2. 1): Gross Output Produced in Mexico: 1981-2014. All Manufacturing Sectors. Billions of Mexican Pesos. Constant Prices of 2010 .................................................................................... 31

Figure (2. 2): Different Regional Dimensions of Maquiladora firms, 1990 and 2006........................... 43

Figure (2. 3): Different Regional Dimensions of IMMEX firms, 2008 and 2016................................... 65

Figure (3. 1): Intra-Regional and Extra-Regional Value Added Embodied in a Region's Total Final Manufacturing Output, 1990 and 2011.

Figure (4. 1): Productivity Growth and Share of non-Production Workers, 1981-2006. 146

Figure (4. 2): The Domestic Content of Aggregate Maquila Exports. . .153

Figure (5. 1): WIOT Set up with Mexico (Domestic) and Mexico (Maquiladora) ........................................ 171

Figure (5. 2): Supply and Use Tables Required for Constructing WIOT..................................................... 172

Figure (5. 3): Share of value added content of total final manufacturing output in Mexico (Domestic), by region of origin.

Figure (5. 4): Value Added Contribution (by Country of Origin) in Mexico (Maquiladora/M.

Global). Total Final Manufacturing Output.

Figure (5. 5): Value Added Contribution (by Country of Origin) in Mexico (Total Economy)

Final Manufacturing Output.

Figure (6.1. 1): Aggregate Labor Productivity in Mexican Manufacturing: 1990-2014. All Sectors. Millions of Mexican pesos (Constant Prices of 2008).

Figure (6.1. 2): Aggregate Labor Productivity Growth (\%) in Mexican Manufacturing: All Sectors. Maquiladora (1990-2006) and IMMEX (2008-2014).

Figure (7. 1): Different Dimensions of Upgrading in Mexico's Export Sector: 1981-2014. 


\section{Chapter 1}

\section{Introduction.}

The main objective of this thesis is to study the process of industrial upgrading in Mexico's export sector (maquiladora industry) at the aggregate and firm-level. In this regard, this introductory chapter presents two key arguments. The first one is that the Mexican maquiladora industry should be regarded as an exception to Latin America's failure to industrialize, given the continuous growth in output and employment that can be observed in recent decades. The second argument is that, despite success in production for exports, firms participating in the Maquiladora industry have failed to replace imported intermediates by domestically produced intermediate inputs, produced by non-maquiladora manufacturing firms. Thus, Mexico and its export sector are still far from the joining the highly-industrialized World in the way its East Asian counterparts did.

In this context, this dissertation will tackle two general research question; (1) what are the main factors at the aggregate and firm-level that explain upgrading (or the lack thereof) in Mexico's maquiladora industry over time?; (2) which are some of the key policy lessons from Mexico's exporting sector that can be used by other developing countries wishing to increase their production for exports and achieve higher levels of manufacturing employment?.

This chapter is structured as follows. Section 1.1 briefly discusses the increasing fragmentation of production, which stands as the predominant type of organization to produce manufacturing goods. Section 1.2 provides our definition of upgrading, i.e. the different dimensions from this concept that will be explored during this dissertation. Section 1.3 focuses on export processing zones as an alternative for developing countries to participate in fragmented global value chains. Section 1.4 presents the factors that account for Latin America's failed attempt to industrialize by means of export processing zones. Section 1.5 indicates the reasons why we believe the Mexican maquiladora industry is an exception to the Latin American case, which also motivates the writing of this dissertation. Finally, section 1.6 indicates the structure of this thesis.

\subsection{Increasing Fragmentation of Global Production.}

Revolutionary progress in communication and information technologies has enabled a historic (and ongoing) breakup of manufacturing production (Grossman \& RossiHansberg, 2008; Baldwin et al.,2011). This process is called "fragmentation" (Jones, 2000) and has become an important feature of the structural interdependence of the World economy (Arndt \& Kierzkowski, 2001). In this fragmentation of production, advanced and developing economies specialize in particular stages of the productive sequence according to their factor endowments or productivity levels. For instance, capital intensive countries will mainly specialize in the stages with higher technological complexity, while the less developed economies will specialize in assembling given their 
labor-intensive factor endowments. This whole situation implies that most of the manufacturing goods will be no longer completely produced by a single country but will be generated by plants in many different nations that develop different patterns of specialization.

\subsection{Definition and Dimensions of Upgrading.}

Participating in the increasing fragmentation of global production implies new challenges for developing economies. Not only should these countries seek for alternatives to join international production networks but, more importantly, they should also aim to upgrade their manufacturing production in order to foster innovation and get industrialization started. Correctly defining and measuring the process of upgrading experienced by a given developing country is, however, far from straightforward (De Vries et al., 2016). This is because such process of industrial upgrading can be measured by considering information at the firm-level and/or at the aggregate level. Let us further elaborate on this issue.

On the one hand, Porter (1990) and Kaplinsky (2000) indicated that upgrading can refer to the process by which a given firm learns how to make better products (that are also more efficiently produced) and, that implied moving from low-skilled to more highskilled activities. Humphrey and Schmitz (2002) went one step further and defined upgrading in the context of the competitive pressures faced by firms as a result of the emergence of global value chains. In their view, upgrading implies a shift in activities where firms seek to increase or maintain its income levels given stiff competition in international markets. Those shifts can be an increase in the skilled content of their activities and/or the transit to market niches with higher entry barriers that are somehow insulated from competitive pressures.

On the other hand, studies relying on aggregate information mostly stress the importance of value added embodied in final output as a sign of upgrading. We are here referring to all those studies that rely on Input Output tables (IOTs) and that implement methods similar to that of vertical specialization (Hummels et al., 2001) to identify domestic content in exports (De la Cruz et al, 2011; Los et al., 2013; Koopman et al., 2014; Los et al.,2016). Higher domestic content in exports implies the ability to integrate local producers of intermediate inputs in global value chains away from the simple specialization in assembling activities. Higher local content in final exports thus also implies higher benefits for the rest of economy as this induces a learning process where domestic producers acquire the capabilities to locally generate inputs of high technological complexity. Nonetheless, in my view, additional factors have to be taken into consideration when inferring upgrading (or downgrading) by simply looking at the domestic content of exports. For instance, decreasing value added content does not always have to refer to downgrading. One could imagine that in spite of declining domestic value added content, gross value added and value added per worker can be increasing. Lower value added content might simply be the logical consequence of globalized production and do not necessarily lead to decreases in the technological content of inputs. 
All these perspectives call for a careful definition of upgrading that considers its different positive aspects (that can be observed at the micro and aggregate level) and, that stresses its importance as the key strategy for developing economies to join the highly-industrialized World. In my view, the general process of industrial upgrading implies a greater use of domestic inputs with higher technological content, higher interaction of the export sector with domestic suppliers, the development of more domestic suppliers, increasing levels of labor productivity, greater use of more qualified labor and so forth. Thus, in the present dissertation we propose four key dimensions of upgrading that try to capture the aforementioned views.

The first dimension of upgrading is measures for the domestic content of exports that capture the contribution of local producers of domestic inputs and of indirect exporters. In this first dimension of upgrading, we are considering the value added contribution in final output from firms assembling intermediate inputs, as well as the value added generated by local producers that produced domestic inputs to be used in the production for exports. This first dimension of upgrading goes in line with the abovementioned aggregate studies that implement measures of vertical specialization by relying on IOTs. To study the micro tendency of this aggregate indicator we proposed the firm-level value added to output ratio as a second dimension of upgrading. Calculating for a specific firm its value added contribution, and the one from its indirect exports, that is embodied on its final output (as can be done for the sum of all firms at the aggregate level) is simple quite impossible. Therefore, this second dimension of upgrading act as a complement to the first dimension by only taking into account the gross value added generated by a given exporting firm.

Following the same stream of ideas, our third dimension of upgrading tackles measures of labor productivity at the export sector, given the expected increasing efficiency that emerges as a result of technological learning and increasing competition at international markets. Our fourth dimension of upgrading is the use of more highly-skilled labor in the production process, which is necessary to shift from low to more advanced manufacturing techniques. These last two dimensions of upgrading can be measured both at the aggregate and firm-level and are here included to the follow the aforementioned concepts proposed by Porter (1990), Kaplinsky (2000) and Humphrey and Schmitz (2002). In my view, the presence of all these four dimensions should be taken into account when inferring upgrading (or downgrading) in the manufacturing production of any given developing economy.

\subsection{Export Processing Zones as a Policy Instrument for Participating in International Production Networks.}

Export Processing Zones (EPZs) constitute an alternative for developing economies to participate in the increasing fragmentation of manufacturing production. EPZs can be defined as industrial zones where special incentives (such as tax holidays and duty free imports and exports) are provided to firms as long as most, if not all, of the processed goods are exported. Developing economies face both advantages and disadvantages if they decide to implement EPZs. According to Sargent and Mathews (2001), EPZs can benefit the host country due to their capacity to increase exports, create employment 
and provide foreign exchange. Nevertheless, the multinational enterprises (MNEs) that participate in these schemes tend to retain the most knowledge intensive manufacturing activities in the highly industrialized advanced economies. The more labour intensive fragments of the value chain are located in the export processing zones of developing countries (Gallagher and Zarsky, 2007). Therefore, the manufacturing production resulting from EPZ contributes less to GDP than ordinary exports as it mostly performs labor intensive activities, uses little domestic inputs and strongly relies on imported inputs with high technological complexity (Johanssen \& Nilsson, 1998). In this context, the challenge for the industrial development of developing economies is to successfully move from the labor-intensive activities of manufacturing to those with higher technological content.

\subsection{Latin America's Failing Attempt to Industrialize with Export Processing Zones.}

Among others, by means of EPZs, East Asian countries (Korea, Taiwan, Hong Kong and Singapore) were able to transform themselves from technologically backward and poor, to relatively modern and affluent economies (Nelson \& Pack, 1999; Gallagher \& Shafaeddin, 2010). In contrast, many Latin American countries failed to industrialize on the basis of EPZs. According to Wilson (1992) there are several factors and historical reasons to account for this issue. First of all, governments in Latin America had a deep and prolonged commitment to Import Substitution Industrialization (ISI) as the primary strategy for industrial development. Even though East Asian countries also followed ISI, they maintained an authoritarian control over the labor force and were strongly involved in the promotion of the export sector. Next, unlike East Asia, the implementation of EPZ in Latin America was never part of a national strategy of exportoriented manufacturing. EPZs in Latin America usually emerged as a development strategy for a particular region (Manaus in the Brazilian Amazon) as labor surplus region (the northern part of Mexico as a result of the end of the bracero program in the US), or a geopolitically strategic region (Arica and Punta Arenas in the northern and southern borders of Chile). Historical reasons also played an important role. Unlike Spanish domination in Latin America, Japanese colonial rule in Taiwan and Korea had left a substantial manufacturing infrastructure. Similarly, British colonial rule in Singapore and Hong Kong had left an export-oriented infrastructure of transportation and communication and financial services. The influx of entrepreneurs, professionals and skilled workers from China and North Korea to these countries as well as massive US foreign aid helped promote financial and industrial development.

\subsection{Mexico and the Success of Maquiladora Production.}

Despite the relative failure of export-oriented industrialization in most Latin American countries, the EPZ in Mexico stands out as an important exception ${ }^{1}$. Mexico's EPZ is

\footnotetext{
${ }^{1}$ According to Jenkins et al. (2001), EPZ activity in Latin America is highly concentrated in three countries; Mexico, Brazil and, The Dominican Republic. Those authors also indicate that the maquiladora program in Mexico alone accounts for over $65 \%$ of the employment in EPZs in the region.
} 
commonly referred to as "Maquiladora Industry" or simply "Maquila". Mexico's maquiladora industry is one of the oldest and one of the largest international production networks in the World. The maquiladora industry in Mexico was established during the 1960s with two plants and a limited number of employees manufacturing televisions and plastics (Carrillo, 2007). Nowadays, this industry accounts for about 55\% of Mexico's manufacturing exports, produced by 2 million workers in 5,113 maquiladora firms (INEGI, 2011). According to the Secretaría de Economía (2016), i.e. Mexico's Ministry of Economics, by 2015 Mexico was the largest exporter of manufactured goods in Latin America and produced more than half of the medium and high-tech goods generated within this same region. Similarly, the Ministry of Economics also indicates that considering the value of exports as a percentage of GDP, Mexico is the third largest exporter of medium and high-tech goods just after Germany and South Korea. The success of Mexico's exporting sector is of such importance that by 2016 it became one of the key negative targets in the US presidential election and, by 2017-2018 it will also be one of the key factors to be debated during the renegotiation of NAFTA.

In my view, country specific features, preferential access to the US market and institutional settings account for the success of the maquiladora industry (and of Mexico's export sector) when compared to the rest of countries in Latin America. Apart from its abundance of cheap labor, its growing middle class and the relative political stability in this country (one party ruling for 70 years), the most important country specific explanation for the success of Maquiladora is its proximity to the US market. The fact that foreign assembly firms could be established in the northern part of Mexico greatly facilitated the re-organization of manufacturing firms. The Mexican maquiladora is an attractive program for US firms that cannot (or do not wish to) reallocate production to East Asia. It is also an attractive program for other Asian and European firms that seek to access the US market.

Also, maquiladora production has always enjoyed preferential access to the US, even before the signing of the North American Free Trade Agreement (NAFTA). In fact, one of the primary reasons for US assembly firms to initially relocate to the northern part of Mexico during the 1960s was to benefit from US regulations that allow the free imports of final goods that contain components produced in the US. When entering the US market, those goods were only going to be taxed on the non-US value added. The increasing outward orientation from Mexico and the signing of NAFTA largely increased the preferential treatment accorded this industry.

Finally, there is one important institutional arrangement that explains the success of the Mexican export sector as a whole. Policy makers in Mexico also designed a legal framework similar to the maquiladora but aimed at supporting firms in domestic manufacturing. This is the reasoning behind the Program for the Temporary Import of Exporting Goods (PITEX). Here, the main objective was to make firms in the domestic manufacturing (that produce both for domestic consumption and for export) as competitive as the foreign assembly firms belonging to the maquiladora program. Supporting two different export promoting programs for two different types of firms is an appropriate idea, given the differences in initial conditions, different needs and challenges faced by different types of firms. Eventually those two export promoting 
programs were merged into a single framework (the IMMEX program), which was also a good idea as this was meant to increase the interaction between different types of firms and the competitiveness of the export sector as a whole. In this context, it can be argued that even though Mexico did not enjoy some of the historical features that characterized the development of East Asian countries and lacked a long-term vision to implement the maquiladora program at the national level (beyond the border region), this country succeeded in becoming a global manufacturing power by following a set of policy steps in line with the country's geographical position and endowments.

The success of maquiladora production is, however, incomplete without a process of industrial upgrading. As mentioned before, upgrading in manufacturing is the key strategy for developing economies to join the highly-industrialized World. Therefore, the main objective of this thesis is to assess the presence of different four dimensions of upgrading in maquiladora production (as proposed in section 1.2) by relying on different sources of information at the aggregate and the firm level.

Exploring the reasons that prevent a developing economy achieving a process of industrial upgrading is of prime importance. More and more developing economies are currently seeking to participate progressively more in international production networks. Nevertheless, the stiff competition triggered by major low costs producers (such as China), the control and governance of global value chains by multinational firms, as well as the continuous innovation taking place in most manufacturing sectors limit the ability of developing countries to benefit optimally from the fragmentation of production. In a nutshell, many developing economies would like to obtain more benefits from its participation in EPZs beyond higher levels of employment and foreign exchange. The experience of Mexico's export sector in the development of its maquiladora industry can contribute to this debate.

Our thesis makes a novel contribution in that it uses all the available aggregate and micro information to study Mexico's exporting sector over a long period of time. At the aggregate level, we rely on official data for maquiladora and for the IMMEX program reported in terms of Mexico's national accounting system from 1981 to 2014. We also utilize official input-output tables for maquiladora and for the domestic economy of Mexico (for the benchmark year 2003), bilateral trade statistics by country of origin for maquiladora and for the rest of economy from 1998 to 2011, as well as the latest attempt from Mexico's statistical office to analyze, at the aggregate level, the participation of Mexico in global value chains (the concept of Manufactura Global). This specific aggregate information to study Mexico's exporting sector is complemented with other multiregional input output datasets. We are here referring to the EORA dataset (1990 and 2001) and the World Input Output tables (1998-2011). Finally, we also rely on the raw microdata that was used to create aggregate information for the Maquiladora and IMMEX program. This means that we utilize the official maquiladora firm-level dataset from 1990 to 2006 and the official panel dataset for the IMMEX program (20072014). 


\subsection{Thesis Outline.}

This thesis is structured as follows. We first present our literature review on the evolution of export promoting programs in Mexico during the last 50 years (Chapter 2). Then, we analyze the domestic content of Mexico's export sector in three aggregate perspectives and one micro perspective. The first aggregate perspective is a global perspective. Here, the performance of Mexican manufacturing is analyzed in the context of the evidence from other major exporters and all the regions in the World economy (Chapter3). The second one is a historical perspective. The objective there is to analyze the evolution of the domestic content of exports of maquiladora from 1981 to 2006 (Chapter 4). The third one is the current perspective. Given the increasing existence of international production networks, we study the interaction of Mexico's export sector with other local and foreign producers (Chapter 5). Finally, we provide a micro perspective to account for the foundations of productivity growth in Maquiladora and the IMMEX from 1990-2014 (Chapter 6). In the next lines, we briefly summarize the main ideas behind each chapter included in this dissertation.

Chapter 2 presents a review of the literature on fifty years of export promoting policies in Mexico. This literature review constitutes our general framework for understanding the evolution of the Maquiladora program and of other export promoting programs in Mexico (the PITEX and IMMEX programs). In this chapter, we study the evolution of the legal framework governing the maquiladora since its inception in 1964, the observed adjustments and modifications that were implemented as a result of Mexico's opening up to foreign markets (1983), and as result of joining NAFTA (1994), the merging of the maquiladora program with PITEX firms (IMMEX program) in 2007, as well as Mexico's latest attempt to industrialize its southern region (the Special Economic Zones program released by 2016). Issues such as the location of maquiladora firms, the development of local suppliers, domestic sales and policies per manufacturing sector are discussed. In addition, this chapter discusses the main differences between firms participating in Maquiladora and those belonging to the PITEX program, as well as the policy reasoning behind the merging of those two into the IMMEX program.

Chapter 3 analyses the current context of manufacturing production for most countries in the World economy. Here, we argue that to produce final output many countries in the World economy have mostly relied on production networks located within the same region. Over the years, the increasing fragmentation of production has only helped to increase such intra-regional interaction. To analyse these trends, this chapter provides empirical evidence for the structure of value added (by country of origin) embodied in the final output generated by the World's top exporters of manufacturing goods. We extend this analysis to all the regions in the World economy (including those in Asia, Africa, Oceania, as well as Central and South America). According to our calculations, by 2011, Mexico stands as one of the top exporters of manufacturing goods (all sectors) and one of the largest exporters in the transport equipment sector. Its increasing interaction with its NAFTA counterparts largely accounts for this issue.

Chapter 4 provides the historical framework for the evolution of Maquiladora production. In this chapter, we assess the domestic value added embodied in 
maquiladora exports during the period from 1981 to 2006. The objective here is to analyze how the domestic value added in maquiladora changed at the aggregate level, as a result of external factors such as the opening up of the economy (1983), the signing of NAFTA (1994) and the industrial emergence of China (2001). We observe drastic declines in the domestic value added content of exports during 1983 and 1994, which also coincides with major currency crises in Mexico (debt crisis in 1983 and Tequila crisis in 1994). Overall, our calculations indicate a long-run decline in the aggregate domestic content of exports (from $31 \%$ in 1981 to $21 \%$ in 2006), which is largely driven by the falling domestic value added content within the electronics sector.

Chapter 5 studies the current aggregate interaction of maquiladora firms with other firms in the rest of the economy and with foreign suppliers located in major regions of the World economy. In this chapter, we decompose the final output produced by maquiladora producers into the value added contribution of domestic suppliers and other foreign suppliers by country of origin. Following the same reasoning, we also identify the value added contribution from domestic and foreign suppliers (by country of origin) that is embodied in the final output produced by domestic firms, as well as the one observed in the final output produced by all Mexican firms (maquiladora and domestic firms). To this end, the input-output tables that were used in chapter 4 are now included into a larger multiregional dataset (the World Input Output Tables). Our findings indicate that depending on the type of production (for export or domestic use) and manufacturing sector, maquiladora firms will participate in local, regional or global value chains. More importantly, in the production for exports we observed that foreign value added structure by country of origin suffered drastic changes while the value added contribution by domestic suppliers basically remained unaltered. Higher presence of East Asian value added in Mexico's export sector is here associated to US firms reallocating intermediate production to China and Asia.

Chapter 6 provides the micro level evidence for firms within the Maquiladora and IMMEX program from 1990-2014. In this chapter, we first study at the aggregate level, the contributions of exporting firms and domestic firms aggregate labor productivity over time. In our aggregate decomposition, we indicate that the non-maquiladora part of the Mexican economy is far more important to increase aggregate productivity than the maquiladora part. Our upgrading variable (value added to output ratio) shows negative and smalls contributions to changes in aggregate labor productivity levels for total manufacturing. In 24 years of analysis there is not much change in the value added output. In my view, one of the main implications from the lack of upgrading is to limit the contribution from labor productivity at the export sector to changes in the aggregate labor productivity in total manufacturing. At the firm-level, we find that the firms in the maquiladora dataset (up to 2007) are rather different from firms in the IMMEX dataset (from 2007). We identify GVC-intensive and non-GVC intensive firms in the IMMEX dataset, and find differences between them, and relative to the maquiladora firms, in terms of the microeconomic determinants of labor productivity. 
Chapter 7 presents our conclusions. This last chapter also provides some insights about the Maquiladora industry (derived from this dissertation) to be considering during the 2017-2018 renegotiation of NAFTA. 



\section{Chapter 2.}

\section{0 years of Export promoting Programs in Mexico (1965-2016): A general Framework to Understand the Evolution of Maquiladora, PITEX and the IMMEX program.}

\subsection{Introduction.}

The main objective of this literature review is to understand the different policy strategies that Mexico has followed to promote its production for exports. During the last 50 years, Mexico has devised different policy instruments to support exporting firms (both foreign and domestic owned) as well as local suppliers to these firms (indirect exporters). Such export promoting policies have changed given Mexico's different industrialization strategies, the international trade agreements that this country has signed, as well as the competitive pressures that Mexico has faced. When the engine of growth was supposed to be found in the domestic market (Import Substitution Industrialization), foreign exporting firms received limited support. Exporting firms in Mexico were supported initially within the Maquiladora program. In such export promoting program, foreign firms were entitled to import intermediate inputs and capital goods free of duty as long as their final output always reach foreign markets (i.e. there was no competition with domestic firms). Nevertheless, no additional support was provided to induce technological learning or a greater use of domestic inputs within the maquiladora program. This restrictive framework for exporting firms radically changed once the Import Substitution Strategy failed, and Mexico aimed for an industrialization strategy based on the production for foreign markets.

To ensure an increasing and successful production for exports, the Mexican government decided to renovate its Maquiladora program and to create a new program (similar to the Maquiladora) but aimed at the industrial development of direct and indirect exporters within domestic manufacturing (the PITEX program). Likewise, to induce the participation of small and medium enterprises in domestic manufacturing the Mexican government also devised other complementary policy instruments. Among those additional policy instruments we can mention the program to support production for exports with local content (DIMMEX), a drawback system for the reimbursement of import duties, credit loans to ensure domestic purchases from indirect exporters, additional tax incentives for high exporting firms (ALTEX), and a program devised for the support of exports by rather small domestic firms which lack capabilities to produce for exports (ECEX).

PITEX and Maquiladora became the cornerstones from Mexico's export promotion programs. Foreign and domestic firms in Mexico seeking to produce for exports could opt between those two promotion programs. Those firms that only aimed to produce for foreign markets could join the Maquiladora program, while those firms willing to produce final output both for exports and for the Mexican domestic market could join 
the PITEX program. Initially, firms belonging to PITEX and firms within Maquiladora faced different fiscal obligations, export-performance requirements and, different restrictions to sell output domestically. Over time, and mostly as a result of Mexico's accession to NAFTA, the rules of operation for PITEX and Maquiladora started to become more and more similar. The most important difference that still remains between those two programs is the fact that PITEX firms are mostly located in the interior of Mexico, while Maquiladora firms are mostly located in Northern states. In light of decreasing differences between the rules governing the operation of PITEX and Maquiladora firms, and given increasing competitive pressures from more efficient producers in East Asia, the Mexican government decided to merge the two export promoting programs into a major single policy framework to support exports (the IMMEX program).

To better understand the importance and success from Mexico's production for exports, we now refer to Figure (2.1). Figure (2.1) presents the evolution of Mexican manufacturing considering gross output in Mexico, the production for exports and, the production from domestic manufacturing during the period 1981-2014. More specifically, such figure indicates total gross output in Mexico, gross output from firms within Mexican domestic manufacturing (1981-2014), the corresponding gross output for Maquiladora firms (1981-2006), as well as gross output from firms within the IMMEX program (2008-2014) 2. Likewise, figure (2.1) also includes Mexico's new statistical attempt to measure the participation of firms located in Mexico within global production networks: the concept of Manufactura Global ${ }^{3}$ from 2003 to 2014.

For the case of the Maquiladora program, we can observe that its share in total manufacturing output in Mexico increased from $0.2 \%$ in 1981 to $20 \%$ by 2006 . We also see that the share of firms located in Mexico which are part of global production networks (as defined by the concept of Manufactura Global) follows a rather similar tendency to the one presented by Maquiladora production. According to our calculations in figure (2.1), the final output produced by Manufactura Global firms represented 21\% of total final output in Mexico by 2014. Finally, the final output generated by firms within the IMMEX framework represents more than $45 \%$ of total output in Mexico by 2014. We may conclude that the production for exports in Mexico has increased from less than $1 \%$ of total output (for the firms considered within the Maquiladora framework) in 1981 to almost half of the total final output in 2014 (considering the firms in the IMMEX framework).

\footnotetext{
2 Gross output refers to the output of consumer goods and capital goods, as well as the exports of intermediate goods. This definition of gross output is applicable for the case of total Mexican Manufacturing, domestic manufacturing, the IMMEX program, as well as the concept of Manufactura Global. For the specific case of Maquiladora, gross output only refers to the output of consumer goods and capital goods that are produced for exports.

3 According to section 5.2.1 in chapter 5 from this dissertation, the statistical concept of Manufactura Global includes maquiladora firms and firms within domestic manufacturing highly engaged in international production networks (2003-2006). According to Mexico's statistical office, a firm highly engaged in international production networks is the one that (among other things) mostly produces for exports and that uses at least $2 / 3$ of imported intermediate inputs in their total intermediate consumption. From 2007-2014, the same concept holds but this time they include the IMMEX firms and the firms in domestic manufacturing that meet the criteria of being highly engaged in international production networks.
} 
Figure (2. 1): Gross Output Produced in Mexico: 1981-2014. All Manufacturing Sectors. Billions of Mexican Pesos. Constant Prices of 2010.

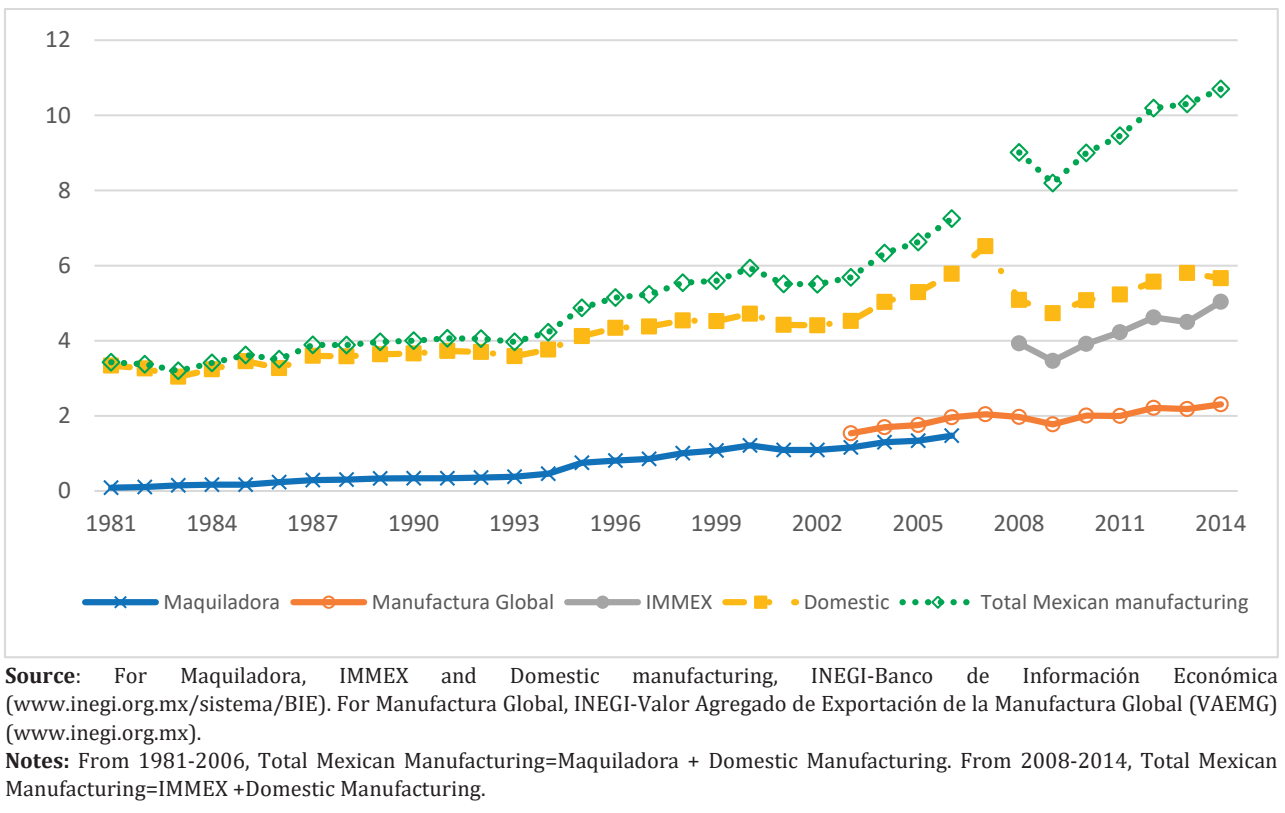

Against this background, this chapter will examine the evolution from different export promoting policies implemented in Mexico over fifty years (1965-2016) with a strong emphasis on the Maquiladora program (1965-2006), the PITEX framework (1985-2006) and the IMMEX program (2007-present). To this end, we will also separately discuss other key aspects regarding the evolution of exporting firms: location, technology, sectoral trends and so forth. Our literature review is organized as follows. Section (2.2) presents the definition of maquiladora firms as well as the different investment opportunities to participate in the export promoting program that are available for foreign exporters. Section (2.3) discusses the origin of the Maquiladora program and milestones in the evolution of this industry and of Mexican manufacturing from 1965 to the year 2006, when the Maquiladora framework officially comes to an end. Section (2.4) discusses the incentives for Maquiladora firms to locate in other Mexican regions beyond the Northern border, while section (2.5) analyzes the different attempts by the Mexican government to develop local suppliers to Maquiladora firms. Section (2.6) studies the technology available to Maquiladora firms while section (2.7) indicates the different obstacles and incentives that Maquiladora faced to sell output domestically. Section (2.8) assesses the specific context and trends in the production for exports in different manufacturing sectors. Section (2.9) is devoted to analyzing the implementation of other export promoting programs and policies that emerged with Mexico's increasing outward orientation by the mid-1980s. In this latter section, we analyze the reasoning behind the PITEX programs, the complemantary policy instruments to achieve PITEX (DIMMEX, Carta de Crédito Doméstica, etc.) as well as the implementation of smaller export promotion frameworks such as ALTEX and ECEX. 
Section (2.10) thoroughly analyzes the main similarities and differences between the Maquiladora framework and the PITEX program, as well as how those differences evolved over time. Section (2.11) discusses the emergence of IMMEX program. Section (2.12) discusses Mexico's latest attempt to promote the industrialization via exports of its poorest and technologically backward Southern regions (the concept of Zonas Económicas Especiales issued in 2016). Finally, section (2.13) concludes this literature review.

\subsection{Definition and Different Investment Opportunities to Participate in the Maquiladora Program.}

Foreign assembly firms that participate in Mexico's export promoting program (Industria Maquiladora de Exportación) are known as maquiladora ${ }^{4}$ firms. In the traditional concept of maquiladora production, foreign assembly firms located in Mexico import intermediate inputs and capital equipment from their parent firm located in an advanced economy. This process is facilitated by the fact that the maquiladora program offers duty free exemption on the imports of those items by foreign assembly firms. The main condition to obtain those duty-free imports is that maquila firms have to export their entire production. Drastic decreases in transportation and communications costs have made for the emergence of different ways of organizing manufacturing production that go beyond the traditional concept of maquiladora production. Thus, foreign and local firms seeking to participate in the maquiladora program face the following set of alternatives to organize and/or participate in this type of production.

The first option is that a foreign firm establishes a wholly-owned subsidiary in Mexico. This idea is close to the traditional concept of maquiladora. Here, the multinational firm decides to establish a subsidiary in Mexico to control and monopolize its productive processes (given its unique technology or highly specialized knowledge). The second option is that a foreign firm decides to implement a joint venture with other local firms in Mexico. Such strategy is common when foreign firms produce standardized goods or products at the end of their life-cycle. A third option is the shelter operation. In this type of organization, a foreign firm subcontracts a Mexican firm to do all the assembly and handle all the paper work (Wilson, 1992). Subcontracting means that the inputs and machinery sent by the foreign entity are not owned by the Mexican firm. A Mexican firm participating in this shelter operation is entitled to work with many different foreign clients. Similarly, Mexican firms producing for the domestic market can also pursue shelter operations by relying on their idle capacity. Shelter operations with local firms in Mexico are also an interesting option for small foreign firms that do not wish to run the risk of investing in their own Mexican maquiladora firm (Wilson, 1992).

\footnotetext{
${ }^{4}$ According to Angulo Parra (1998), the word "maquila" originally meant "wheat" in very old Spanish. A miller could convert a farmer's wheat into flour. As a payment, the miller could ask for some of portion of the wheat that was turned into flour. The portion of the wheat (maquila) that was milled and kept by the millers was then known as maquiladora. As time passed, the words "maquila" and "maquiladora" acquired an industrial sense and, now refer to a Mexican custom law regime regulated through customs decrees.
} 


\subsection{Origins of the Maquiladora Program and General Events in the Evolution of this Industry (1965-2006).}

The maquiladora industry was devised as a regional strategy for the industrial development of Northern Mexico by the mid-1960s (Wilson, 1992; Skliar, 1993). There are two main reasons that explain the origin of this industry and its initial regional character. The first one is the end of the bracero guest program in the US. During the Second World War, a great number of low-skilled Mexican workers were invited to join the US work force. When this bracero program ended, many Mexican workers returned to their country and stayed in the border region causing large unemployment. The maquiladora export promoting program was then devised as an alternative to cope with rising unemployment in Mexico's northern border region. Attracting foreign firms to benefit from Mexico's cheap labor was one of the main initial ideas behind this program.

The second reason for the emergence of the maquiladora industry in northern Mexico was the implementation of new trade policies in the US by the early 1960s. US intermediate inputs falling under the categories 806.30 and 807.00 of the US tariff schedule could be imported back to the US free of duty, if they had been assembled abroad as final or intermediate manufacturing good. Item 806.30, issued in 1956, refers to metal articles while item 807.30, issued in 1963, refers to fabricated components (Skliar 1993; CEPAL, 1996). Reimporting those items back to the US as final or intermediate goods would only imply paying US customs duties on foreign value added other than assembly. In this context, the combination of high endowments of cheap labor, the unique proximity to the US market and, preferential treatment under Mexican and US trade policies made the maquiladora strategy a feasible alternative for foreign firms seeking to reallocate production to low cost countries.

To better understand the impact of historical events in maquiladora, we will analyze the evolution of this industry in different periods. The first period is that of the restrictive framework imposed on maquiladora firms since its inception until the early 1980s. The second period covers the process by which maquiladora firms became one of the cornerstones of Mexico's increasing outward orientation (1982-2000). The last period will highlight the first important contraction in the output of this industry as a result of the emergence of more efficient low cost producers in East Asia.

\subsubsection{Restrictive Framework for Maquiladora Firms: (1965-1981).}

During this initial period, there were no official attempts to promote the technological development of maquiladora firms. The main reason for this was the fact that the maquiladora program was not in line with the Import Substitution Industrialization (ISI) policies prevailing in Mexico at that time. Providing tariff exemptions to manufacturing firms with foreign capital engaged in the maquiladora program was simply a policy contrary to the strategy of ISI. Apart from Mexico's deep commitment to ISI, other reason for the restrictive policy framework was that the Mexican government did not want any interaction or competition between domestic and maquiladora firms (which mostly operated under the traditional concept of foreign subsidiary). For instance, in line with the regulations from Mexican general Law on Foreign Investment in 1973, the government could review and control the implementation of technologies in 
maquiladoras. Also, the government was able to prohibit any foreign firm from entry if it could harm domestic industry (González, 1990). In the view of Mexican policy makers, the maquiladora program was only designed to be a temporary strategy to alleviate rising unemployment and to earn foreign currency. Mexico's engine of industrial growth was expected to be found in domestic manufacturing further supported by a booming oil industry during the 1970s.

Such lack of interaction between maquiladora and domestic manufacturing also prevented increasing local sourcing in the production for maquiladora exports. Nevertheless, foreign firms in the maquiladora program also had very little incentives to source inputs locally. This was because of the tariff penalization on the use of non-US inputs under the items 806 and 807. The US's accession to the Generalized System of Preferences (GSP) by 1976 also prevented maquiladora firms from greater local purchases of domestic inputs. Under this system, industrialized countries gave preferential treatment to the manufacturing exports from developing countries. Selected articles by the GSP were chosen provided that some conditions were met. For the case of Maquiladora, at most 35\% of the value of the goods had to be added in Mexico. The cost of labor, as well as the cost of domestically manufactured inputs, fuels and electricity could be counted in the 35\% (Schwartz, 1987).

\subsubsection{Currency Crises, Mexico's Increasing Outward Orientation and Booming Maquiladora Production: (1982-2000).}

By 1982, Mexico's debt and currency crises drastically altered its inward looking industrial development strategy. From this year onwards, Mexico formally abandoned the ISI strategy in favor of a more outward orientation. It is in this context, that maquiladora production experiences its first major policy shift by 1983. It moved from being a temporary program and an anomaly in the prevailing ISI, to be one of the key factors in the export oriented strategy of the Mexican government. According to Wilson (1992), with the devaluation of Mexican peso (which made Maquiladoras wages more attractive than Asian wages) and official encouragement, the Maquiladora industry boomed by the end of the 1980s to become one of the largest sources of foreign exchange in Mexico, after petroleum exports and before tourism.

During this second period, other important policy shifts were also observed. In 1985, Mexico joined the General Agreement on Tariffs and Trade (GATT). Such accession served as an additional push for the set of domestic and international trade reforms to be implemented in the subsequent years. By 1989, the government set additional objectives for the evolution of maquiladora production. Not only were maquiladora firms encouraged to meet its traditional objectives (higher export levels, employment, foreign investment and foreign exchange). More importantly, this industry was now seen as a tool that would stimulate technological development and that would promote investment in human capital in Mexico. All these objectives were to be realised through increasing interaction between maquiladora and domestic manufacturing firms (Government of Mexico, 1989). In few years, the Mexican government switched from blocking any kind of interaction between foreign assembly and domestic firms, to increasingly promoting a framework where both types of firms could equally develop. 
The government also implemented more incentives for the development of other types of maquiladora firms (beyond the traditional concept) and for an increasing use of domestic inputs. For instance, a maquiladora decree (issued in 1989) extended dutyfree status to service companies and subcontractors of maquiladora firms. The same decree authorized $100 \%$ exemption from the value added tax to local firms supplying inputs to maquiladora.

A key policy change for Mexico occurred in 1994 when the country joined the US and Canada in the North American Free Trade Agreement (NAFTA). NAFTA ended the special tariff treatment for US firms offshoring to Mexico under tariff items HS902, i.e. the items formerly known as 806.30 and 807.00 (Feenstra et al., 2000). Nevertheless, this change did not slow the growth of production in maquiladora firms (Bergin et al., 2009). The main reason for this is that the implementation of NAFTA not only implied the removal of trade tariffs, but also of investment barriers. Likewise, NAFTA further increased the preferential access of maquiladora firms to the US market due to the execution of the principles of national treatment and of most-favoured-nation (NAFTA Article 102). National treatment for goods means that once goods have been imported into any NAFTA member country, they will not be subject to tariff discrimination. On the other hand, most-favoured-nation treatment implied that the signatories of NAFTA have to extend trading benefits to each other equal to those accorded to any (that is, the most favoured) non-NAFTA country (Javorcik et al., 2008). In this context, non-NAFTA originated inputs had to pay Mexico's Most Favored Nation (MFN) tax, of around 35\%, while the intermediate goods originating in the NAFTA region could be imported free of duty. This whole new regulation created an important incentive for the production of parts and components in maquiladora because the inputs eligible for the tariff exemption could not only be those produced by a NAFTA country, but also those inputs produced by other regions that have been previously processed in Mexico and that include some degree of NAFTA content.

Just as in 1982, the major policy shift implemented in 1994 coincided with a major currency devaluation. Mexico's balance of payment crisis at the end of 1994 and, the subsequent Tequila crisis, implied yet another incentive for multinational firms to participate in the maquiladora porgram. This is because the highly devaluated peso made manufacturing production in Mexico cheaper (i.e. domestic inputs and wages). In this context, the combination of trade policies within NAFTA and the highly devalued Mexican currency explain the boom in maquiladora production by the end of the 1990s.

In order to better understand maquiladora's booming production by the late 1990s, let us refer to the following example by Angulo Parra (1998). In line with Mexico's legal framework, a Maquiladora firm can temporary import intermediate and capital goods to be used in their production for export, free of all duties and value added taxes. This means that a maquiladora firm can import from Taiwan, Singapore, Malaysia or any other place in the world any component it needed for producing a final good for exports without paying import duties. If this maquiladora used sufficient intermediate goods from the US, Canada or Mexico to meet NAFTA rules of origin, its output could be considered of NAFTA origin and, thus, it could also enter the US market free of duty. In this perspective, with zero tariffs, firms participating in maquiladora production could 
face no duties on their imports of intermediates (from East Asia) and exports of final output to the USA.

\subsubsection{A NAFTA Framework for non-NAFTA countries, Industrial Emergence of China and, Drastic Contraction in Maquiladora Output (2001-2006).}

Maquiladora's production boom ended during the early 2000s as result of new obligations imposed by NAFTA on its country members, the industrial emergence of major low cost producers (China's accession to the World Trade Organization) and, the 2001 US crisis.

According to NAFTA article 303, as of 2001 only North American inputs were going to be exempted from import tariffs upon entering one of the signatory countries. Non-NAFTA inputs would then be required to pay custom duties when imported. These new NAFTA regulations implied a negative scenario for maquiladora production. As mentioned before, the maquiladora legal framework had allowed for the free imports of intermediate and capital goods from anywhere in the world. This represented an important incentive for the participation of maquiladora firms in international production networks reaching beyond North America. For instance, think of the previous maquiladora example by Angulo Parra (1998). In line with the new regulations that were to be effective as of 2001, the same maquiladora firm would need to pay custom duties on their imports from Taiwan, Singapore or Malaysia, when producing a good to be exported to the US market. In particular, this was the case for firms in the electronics sector that mostly rely on the intermediate goods produced by efficient East Asian production networks. Tariff exemptions were only available if maquiladora firms used a pre-determined amount of North American inputs.

Historically, maquiladora production mostly consisted of foreign assembly firms in the electronics sector. Many of them found the new NAFTA regulations detrimental to their competitiveness. China's accession to the World Trade Organization (WTO), also scheduled to take place in 2001, represented a serious reallocation alternative for electronics maquiladoras operating in Mexico. Reallocating production from Mexico to China would allow those maquiladora firms to take advantage of even cheaper labor and of a more well defined network of suppliers than the ones available in a Mexico. If paying duties when entering the NAFTA market was unavoidable, they would prefer to pay duties when sending final goods all the way from the China to the US, rather than paying for the different intermediate goods sent to Mexico.

Under this dramatic scenario for the maquiladora industry, policy makers in Mexico issued a new legal framework in 2002 named "Programas de Promoción Sectorial" (PROSECs) or sectorial promotion programs. The main objective behind the PROSECs was to adjust the maquiladora program to the new NAFTA regulations and to prevent foreign firms within such industry from leaving the country. In order to design PROSECs, policy makers in Mexico identified those key intermediates inputs and capital goods that were more commonly imported by maquiladora firms in different manufacturing sectors. Those intermediate and capital goods identified under the PROSEC list (that were usually imported from non-NAFTA countries) could be eligible for zero (or a maximum of 5\%) custom duties upon entering Mexico (Gantz, 2004). Those firms using 
non-NAFTA inputs that were not included within the PROSECs list could request for tariff exemptions under the program known as "Regla Octava" (Dutrenit et al., 2006). Both PROSECs and Regla Octava applied to all manufacturing firms in Mexico (maquiladora and domestic manufacturing) and required previous authorization by the Ministry of Economics.

In the view of Dussels Peter and Katz (2006), the implementation of PROSECS implied the creation of a framework under which non-NAFTA countries could benefit from NAFTA. With PROSECs, the Mexican government was not only expecting to alleviate the possible threat of maquiladora firms leaving the country and thus reducing output, employment, foreign exchange and foreign investment for the economy. More importantly, PROSECs and Regla Octava would also enable the participation of Mexico within international production networks beyond the North American region.

Nonetheless, imposing duties on the use of non-NAFTA inputs had the precise objective of strengthening the North American region and protecting it from external competitors. It also represented an important opportunity for maquiladora firms to start using more US, Canadian and local inputs. Acknowledging the fact that the maquiladora mostly consists of foreign firms within the electronic sector that primarily rely on East Asian intermediate inputs, policy makers in Mexico opted for alternatives that would preserve the strategic position and competitiveness of maquiladora firms within international production networks. In this context, it can be argued that by implementing PROSECs Mexico was not only abandoning its right to tax non-NAFTA inputs within the NAFTA framework. It was also further supporting the production for export with high use of foreign inputs at the expense of local suppliers.

Notwithstanding all these changes implemented by the Mexican government, the industrial emergence of China by 2001 had a profound negative effect on maquiladoras (Sargent and Mathews, 2009). One of the main reasons for such a negative effect can be found in the similarity of the composition of US imports from Chinese and Mexican producers (Dussel Peters, 2005; Gallagher et al., 2008). Similarly, as mentioned already, reallocating production from Mexico to China ended up being a feasible alternative for many maquiladora firms that were seeking to produce under conditions not offered by Mexico (cheaper labor, better access to more technologically developed suppliers, and so forth). Those two factors, along with the 2001 US crisis largely contributed to the first major contraction in the history of the maquiladora program. In October 2000, 3,655 maquiladoras employed 1,347,803 people. By December 2003, the number of plants and employees had fallen to 2,802 and 1,050,201, respectively (a net loss of 853 maquilas and 297,602 jobs) (Sargent and Mathews, 2009). As of October 2006, maquila employment was still below the peak reached in 2000.

\subsection{Beyond the Border: the Location of Maquiladora Firms in Other Mexican Regions.}

Historically, Maquiladora firms have located in northern Mexico (right next to the border with the US). According to table (2.1), more than $80 \%$ of all maquiladora firms in Mexico were located in Northern Mexico between 1990 and 2006. Nevertheless, as will be seen in the next paragraphs, from the very beginning of the maquiladora program, 
the government in Mexico has also implemented several incentives for these firms to locate elsewhere in the country.

Table (2. 1): Location of Maquiladora firms in Mexican Regions: 1990-2006 Number of Maquiladora Firms

\begin{tabular}{ccccccc}
\hline Year & $\begin{array}{c}\text { Northern } \\
\text { Mexico }\end{array}$ & $\begin{array}{c}\text { Central } \\
\text { Mexico }\end{array}$ & $\begin{array}{c}\text { Western } \\
\text { Mexico }\end{array}$ & $\begin{array}{c}\text { Southern } \\
\text { Mexico }\end{array}$ & $\begin{array}{c}\text { Other } \\
\text { Regions }\end{array}$ & $\begin{array}{c}\text { Total } \\
\text { Mexico }\end{array}$ \\
\hline \hline 1990 & 1,658 & 23 & 44 & 16 & 48 & 1,789 \\
1991 & 1,835 & 29 & 50 & 25 & 74 & 2,013 \\
1992 & 1,938 & 26 & 36 & 30 & 99 & 2,129 \\
1993 & 1,921 & 29 & 44 & 25 & 124 & 2,143 \\
1994 & 1,827 & 31 & 49 & 31 & 126 & 2,064 \\
1995 & 1,955 & 47 & 56 & 37 & 172 & 2,267 \\
1996 & 2,172 & 192 & 59 & 42 & 88 & 2,553 \\
1997 & 2,428 & 224 & 71 & 55 & 89 & 2,867 \\
1998 & 2,569 & 296 & 86 & 74 & 105 & 3,130 \\
1999 & 2,761 & 390 & 98 & 106 & 81 & 3,436 \\
2000 & 2,962 & 419 & 113 & 131 & 78 & 3,703 \\
2001 & 2,623 & 336 & 124 & 122 & 74 & 3,279 \\
2002 & 2,393 & 291 & 127 & 89 & 76 & 2,976 \\
2003 & 2,266 & 263 & 113 & 90 & 70 & 2,802 \\
2004 & 2,307 & 240 & 96 & 89 & 76 & 2,808 \\
2005 & 2,330 & 229 & 93 & 76 & 84 & 2,812 \\
2006 & 2,324 & 209 & 97 & 74 & 79 & 2,783 \\
\hline
\end{tabular}

Source: INEGI, Banco de Información Económica (www.inegi.org.mx/sistemas/bie).

Northern Mexico: Baja California, Baja California Sur, Coahuila, Chihuahua, Durango, Nuevo León, Sinaloa, Sonora, Tamaulipas.

Central Mexico: Guanajuato, Estado de México, Distrito Federal, Puebla, Querétaro, San Luis Potosí.

Western Mexico: Jalisco

Southern Regions: Yucatán

Unique access to the US market, better infrastructure in such country as well proximity to major industrial centers in southern US are the main reason for maquiladora firms to mostly locate in Mexico's border region. At the beginning of the maquiladora program, the foreign assembly firms that established in northern Mexico were those US firms that could not afford reallocating production to East Asia (small firms and firms with low value to weight ratio) as well as those large multinationals that wanted to spread their country risk by locating additional plants outside Asia (Wilson, 1992). In 1966, those maquiladora firms were only allowed to stay within $20 \mathrm{kms}$ of the Mexican border. The initially temporary nature of the maquiladora program, the fact that it was designed to alleviate rising unemployment in northern Mexico and the prevailing ISI strategy account for this issue.

By 1972, the Mexican government allowed maquiladora firms to be located anywhere in Mexico (Urias, 1978; CEPAL, 1996). The main idea behind this policy change was that the income generated by maquiladoras located in the interior of Mexico could also be used to purchase domestic manufacturing goods. Nevertheless, maquiladora firms were still subject to strict regulations restricting competition or interaction with domestic 
manufacturing firms. This changed when Mexico abandoned the ISI strategy. By 1983, the government wanted more and more maquiladoras to locate in the interior of Mexico. According to the 1983 maquiladora decree, maquiladora firms that established themselves in the underdeveloped interior of Mexico (Southern Mexico) would be allowed to sell up to $40 \%$ of their output domestically. Maquiladoras located elsewhere could only sell up to $20 \%$ of the production domestically (Wilson, 1992).

Increasing regional income and reducing unemployment in the interior of Mexico were not the main reasons for maquiladora firms to locate beyond the border region. This time, policy makers had realized that non-border maquiladoras consistently used more domestic inputs in their production for exports than border maquiladoras (Wilson, 1992; Branon et al., 1994). According to table (2.2), such a situation still exists in 2006 and, even in 2016 considering firms operating within the IMMEX program (see table 2.5 at section 2.11). The top panel in table (2.2) shows the share of domestic intermediates in total intermediate consumption for maquiladora firms located in Northern states from 1990-2006. The bottom panel from table (2.2) shows the same share but focuses on maquiladora firms located in other Mexican regions different from the Northern area. As the reader might notice, most of the Northern- Mexican states located right next to the US border (Baja California, Sonora, Chihuahua, Coahuila, Nuevo León, Tamaulipas) use less than $2 \%$ of domestic inputs in their total intermediate consumption. One of the main reason for such small domestic intermediate consumption from maquiladora firms in border states is related to the organization of international production networks within the electronics sectors. According to Contreras and Evans (2003), by 2000 the Television industry in Northern Mexico employed more than 90,000 workers (of which 10,000 were technicians and engineers) and produced 30 million units a year (representing $90 \%$ of the total production in the North American region). The TV industry (and the electronic maquiladora industry in general) mostly relies on imported intermediate goods to produce final goods and thus, the maquiladora firms in the border region rely on a limited amount of domestic inputs.

On the other hand, in the rest of Mexican states with maquiladora production, we observe (in the bottom panel of table 2.2) that Guanajuato and Distrito Federal (i.e. Mexico City) show the highest consumption of domestic intermediate goods. In line with Ortiz and Martínez (2000), those two states, along with Jalisco, account for more than $90 \%$ of the total domestic production of footwear. Maquiladora firms located in those latter states mostly rely on the domestic inputs provided by domestic firms in the same region. As the reader might notice, this higher use of domestic inputs is unusual for maquiladora firms, but not for domestic manufacturing firms. Such higher use of domestic inputs for maquiladora firms located in the interior of Mexico was not the result of multinational firms investing in local technological capabilities. Rather, it was the result of domestic firms seeking to survive Mexico's outward orientation via maquiladora status. When non-border local firms acquired maquiladora status, they started producing for exports by relying on their own network of domestic suppliers. In contrast, foreign owned and initiated maquiladoras located in the border region continued to rely almost exclusively on foreign inputs (Wilson, 1992). 


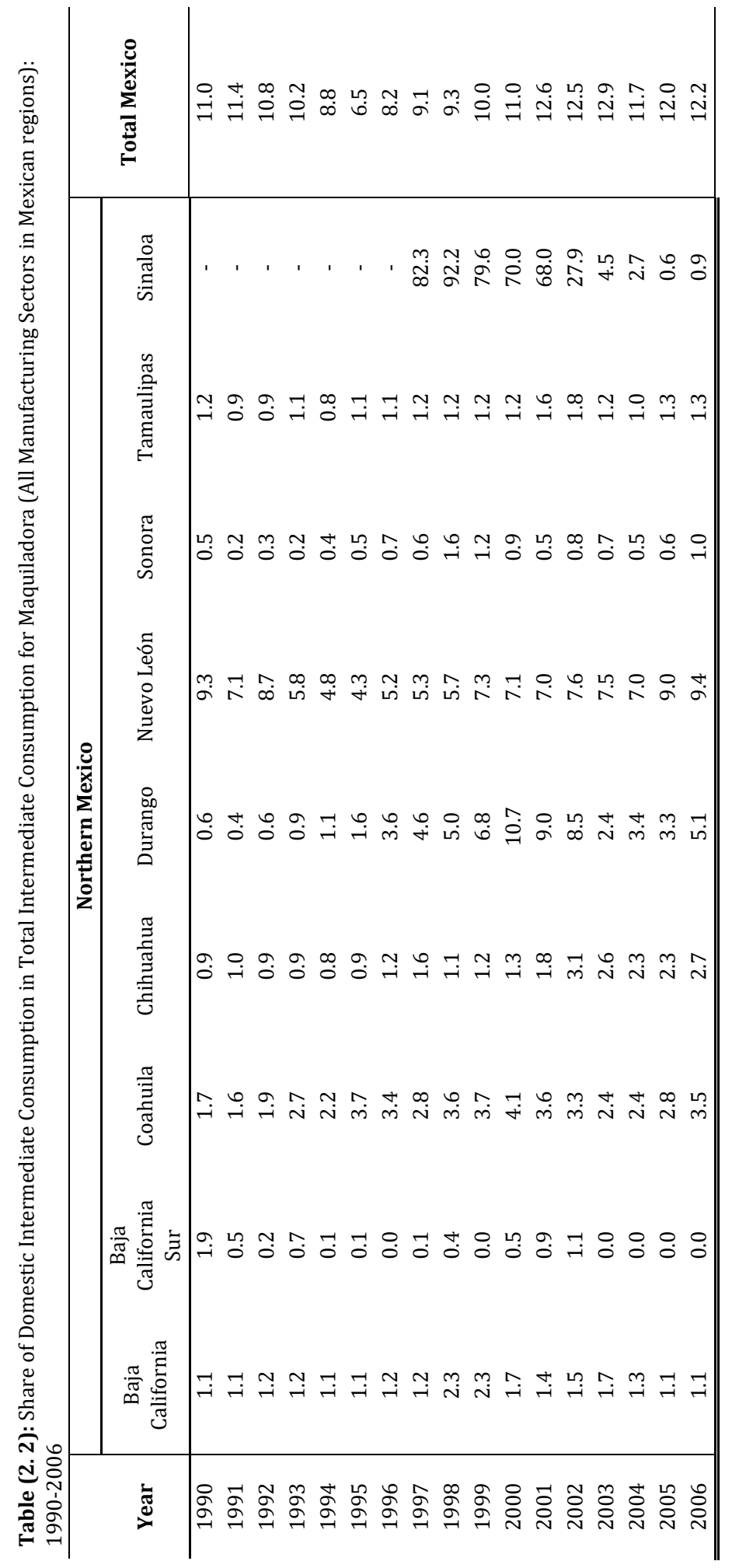




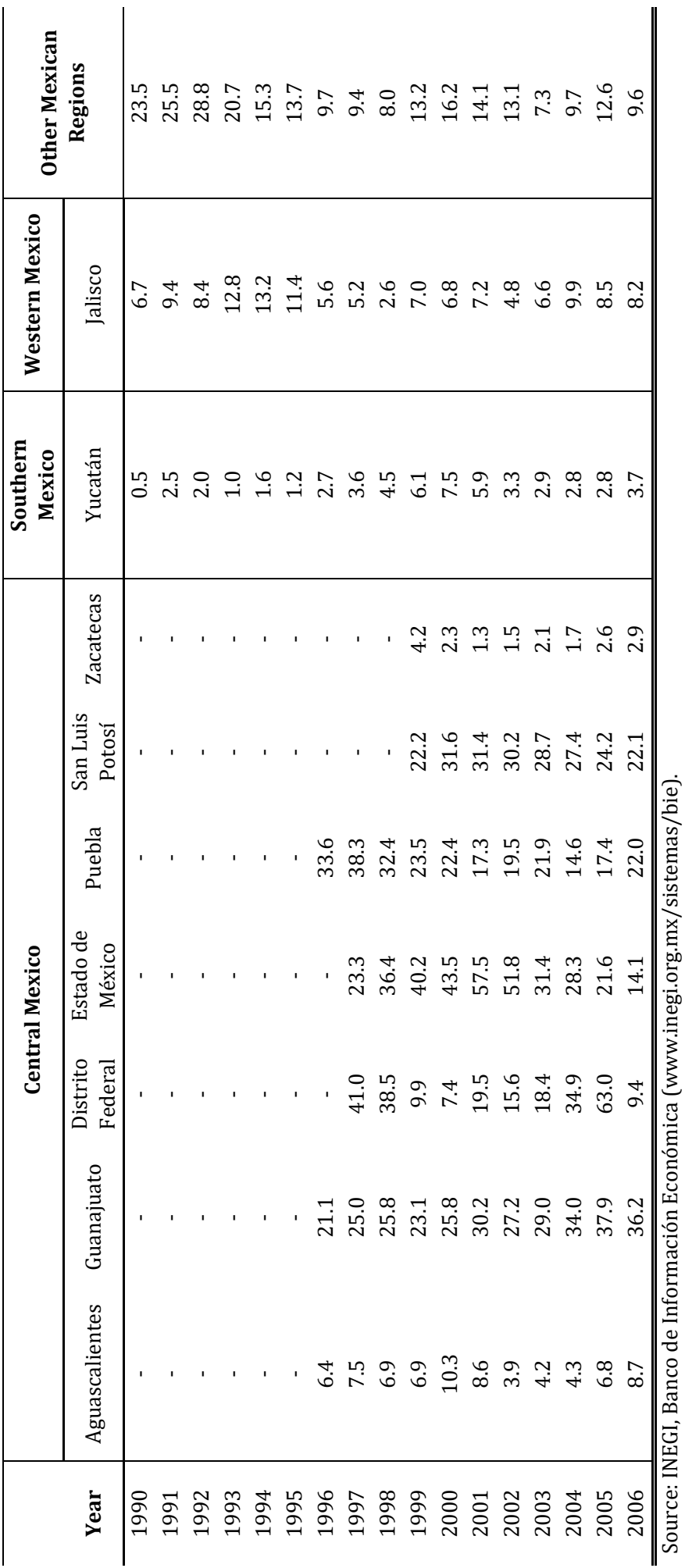


Some of the characteristics of non-border regions are also attractive for foreign assembly firms. Labor is more stable in the interior of Mexico when compared to the turnover rates in border towns. Likewise, qualified labor is more abundant in Central Mexico than in the northern region. There is higher availability of certain inputs in the interior (wood in Guadalajara, steel from Monterrey), as well as the proximity to a major final market such as Mexico City. Finally, it is worth mentioning that maquiladora firms in the interior of Mexico were also seen as a tool to stop migratory flows of lowqualified Mexicans to the US.

In order to further understand the location of maquiladora firms in different geographical regions across Mexico, we refer to the information presented in figure (2.2). Figure (2.2) is divided into 4 charts. Chart (a) contains a map with the location by 2006 of maquiladora firms according to Mexican states. Chart (b) indicates the distribution of population by Mexican states in 2005. Chart (c) presents the number of maquila firms in 1990 and 2006, while chart (d) indicates the share of domestic intermediates in total intermediate consumption. Both chart (c) and (d) present information according to Mexican state and major geographical region in Mexico.

On the one hand, by comparing chart (a) and (b) we can observe that the vast majority of maquiladora firms were not located in Mexico's most populated regions by 2006. For instance, the Mexican states with population levels between 3 and 14 million people and that are colored in red in chart (b), (i.e. the heavily populated states) have a very limited or non-existent presence of maquiladora firms (the states that are left in blank in chart a). Furthermore, as will be discussed in section 2.11, this situation is still present by 2016 in the context of the IMMEX firms ${ }^{5}$. On the other hand, chart (c) further confirms that the distribution of maquiladora firms in Central, Southern and Western Mexico has remained basically unaltered since 1990. Likewise, chart (d) also confirms that those areas with a lower presence of maquila firms (and that are heavily populated) consume far more domestic inputs than firms located in Northern Mexico.

\footnotetext{
${ }^{5}$ Section 2.12 is devoted to explaining the main reasons as to why maquiladora firms have historically been mostly located in Mexico's northern regions. In addition, the latter section also describes Mexico's current policy response to induce the location of more exporting firms in the Southern region (i.e. the project known as Zonas Económicas Especiales).
} 


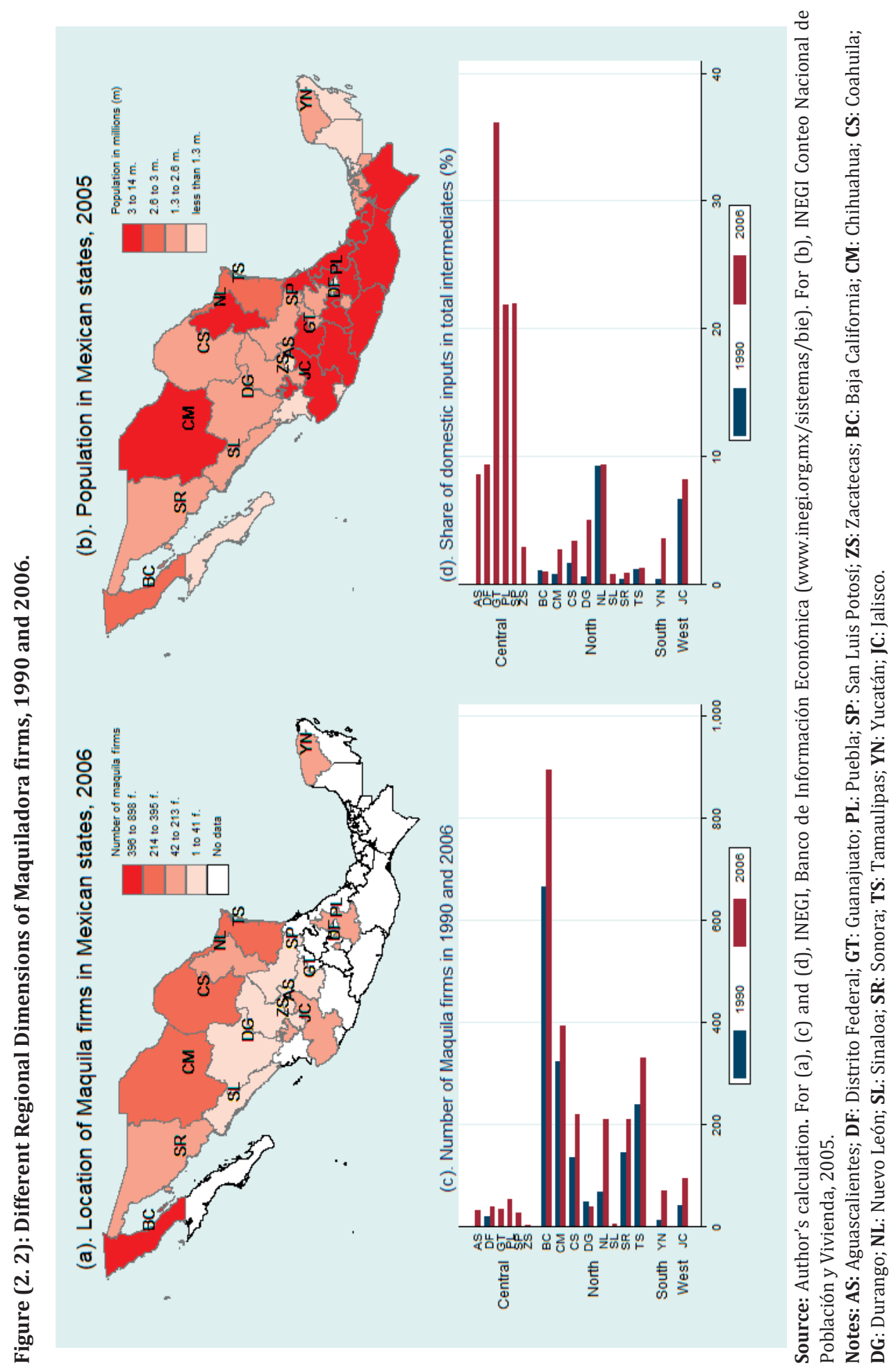




\subsection{The Development of Local Suppliers to Maquiladora Firms.}

Yet another concern of the Mexican government has been the promotion and technological development of local local firms acting as suppliers to the maquiladora industry. There are two types of such local suppliers. On the one hand, there are the local suppliers that start operations in Mexico as a result of a maquiladora firm being establishing in this country. Those local suppliers belong to a multinational firm and their objective is to produce intermediate inputs in Mexico that are complementary for the final stage of manufacturing. According to Wilson (1992), local suppliers produce productive and non-productive inputs for maquiladora firms and provide different types of services. For instance, for the key maquiladora sector (electronics) local productive inputs include industrial gases, metal chassises, varnish, wire screws, tools and so forth. Non-productive inputs include packaging materials such as cartons, dry ice, Styrofoam, rubber boots and uniforms for workers. Services include the hiring of labor, repairing machinery and equipment, and so forth.

The second type of local suppliers are those firms belonging to the domestic manufacturing of Mexico. These firms are producing for the domestic market and seek to participate in the maquiladora program as indirect exporters, since they cannot afford to or do not want to become a maquiladora firm. Unlike the first type of local suppliers, this second group of firms does not belong to multinational firms and thus, they face a great number of problems when trying to sell their inputs to maquiladora firms. Poor product quality, high prices, long delivery processes, lack of knowledge about Mexican suppliers, unavailability of specific Mexican inputs, long standing procurement relationships with other foreign firms and lack of purchasing authority by the maquiladora firm are only some of main problems faced by local suppliers (Brannon et al., 1994). Another important factor that explains the problems faced by local suppliers is the fact that foreign assembly firms reallocate production to Mexico already knowing and relying on their own network of suppliers. Similarly, maquiladora firms benefit from the proximity to competitive suppliers that are not located in Mexico, but in the US. Therefore, maquiladora firms have very little incentive to looking for additional suppliers when setting up operations in Mexico. More importantly, they are also not willing to invest in the technological development of local suppliers in Mexico, as the maquiladora program provides all the necessary means to import foreign intermediate inputs from anywhere in the world at zero tariffs. In this context, the only valid alternative for this second group of local suppliers is to mostly supply maquiladora firms with non-productive inputs and complementary services or provide the less technologically complex productive inputs.

Only limited attempts have been made to promote the integration of local suppliers into the production of maquiladora firms. As mentioned before, in 1989 local suppliers were granted maquiladora status and were also exempted from value added taxes. Similarly, in 2000 the government implemented a program for the development of these kind of producers (Dussel Peters, 2000). Nonetheless, despite these attempts, most maquiladora firms have not modified their high consumption of foreign intermediates. 


\subsection{Technology: Four Generations of Maquiladora Firms.}

During the 1960's and 1970's, rather harsh regulations were imposed to prevent the technological development of the foreign assembly firms participating in the maquiladora program. For instance, in line the 1973 Law on Foreign Investment, the Mexican government was entitled to review and control the use of technology for maquiladora firms. Furthermore, it could forbid the entry of any foreign firm that could harm the national industry (González, 1990).

It was not until the early 1980s that this restrictive framework was modified. In the course of this decade, more use of technology and higher decision making were observed in automotive and electronic maquiladoras (Wilson, 1992; Carrillo and Hualde, 1997). Despite these changes, activities in most maquiladora firms remained monotonous and were still limited to assembly. On the one hand, more technology was introduced in order not to increase local capabilities. Rather, it was introduced to obtain more precision, control and quality in maquiladoras' labor intensive activities. This implies that, in most of the cases, the old machinery was replaced by technologically more sophisticated instruments that still only needed a low qualified workforce to operate them (Carrilo and Hualde, 1997). On the other hand, regarding higher levels of autonomous decision making, it can be argued that this remained restricted to recruitment and human resource management (Carrillo and Hualde, 1997). Hardly ever did local managers participate in the selection of inputs or in the decision process of the manufactured goods to be produced as most of the technical specifications came from abroad. Along the same lines, local management had little influence, if any, on investment, finance or production technology decisions (Wilson, 1992).

According to Carrillo (2007), a shift from labor intensive activities to more complex technological procedures was observed in some maquiladora firms as a result of the boom in production during the mid-1990s and due to new regulations that reduced uncertainty and allowed for long-term planning operations (1990's Law on Foreign Investment). In line with Buitelaar and Padilla (2000), modern management systems were commonly seen in foreign assembly firms. Total quality control, just-in-time procedures, operation manuals as well as norms regarding organizational culture and labor discipline were some of those management systems observed in maquiladoras. The presence of more qualified labor and of more research and development (R\&D) departments was also documented by the mid-1990s.

China's increasing presence in global markets represented yet another incentive to promote the technological development within maquiladoras. During the early 2000s, the Mexican government provided tax incentives to maquiladora firms engaged in R\&D and created a fund to promote Mexico's software industry (Ruiz Durán et al., 2005). State governments, industry chambers, and universities were also involved in the upgrading efforts. The branch of Mexico's largest private university system in Guadalajara established institutes designed to accelerate the development of design engineering centers, software development firms, and technology intensive startups in the city's cluster of electronics firms. The government in Mexico was especially interested in attracting new companies engaged in applied research, product and process development, product testing, and high-tech manufacturing in five industries; 
biotechnology, mechatronics, information technology, health, and nanotechnology (Sargent and Mathews, 2008).

Understanding the previously described technological trajectory of maquiladora firms has been a prime concern for Mexican scholars. They have categorized maquiladora firms into four generations that differ in terms of their observed technology levels. Such categorization goes from those maquiladoras operating with low levels of technology (first generation) to those relying on high and complex technological and organizational procedures (fourth generation).

The first generation of maquiladoras (Brown \& Dominguez, 1989) mainly performed activities which required few skills and a low level of technology (assembly activities). In general, these maquiladoras appeared in the 1960s and were the dominant type of firm in the maquiladora industry until the mid-1980s (Carrillo \& Hualde, 1997). These firms were more interested in the volume of output than in the quality of production. Moreover, this first generation of firms only took advantage of the immediate benefits offered by the maquiladora program (tariff exemptions, cheap labor and geographical proximity) without any further incentive to develope technological capabilities in Mexico. Foreign managers are mostly observed in these first-generation of maquiladora firms (Dutrenit \& Vera-Cruz, 2002).

Second-generation maquiladoras possess some degree of autonomy with respect to the headquarters and also apply more sophisticated organizational procedures than the first generation of maquiladoras. These firms produce with higher quality standards, rely on more qualified labor and are concerned about improving delivery times. According to Carrillo \& Hualde, (1997), these second generation of maquiladoras mainly appeared from the mid-1980s until 1994 when the NAFTA agreement was signed. Maquiladoras of third generation are characterized by $R \& D$ activities which require highly qualified labor. This third generation of maquiladora firms has incentives to develop direct and indirect suppliers of intermediate inputs in Mexico (Carrillo \& Hualde, 2002). Higher quality and lower production costs are the main source of competitiveness for these firms. Such type of maquila firms mostly appear after the implementation of NAFTA. More Mexican managers in strategic positions is another important feature of this third generation of maquiladora firms (Dutrenit \& Vera-Cruz, 2002).

Firms that establish themselves in Mexico to coordinate activities of different subsidiaries belong to the fourth generation of maquiladoras. These maquiladora firms perform activities that are similar to those of the firm headquarters. They perform R\&D activities, coordinate direct and indirect exporters and supervise assembly in order to ensure the timely delivery of final manufacturing goods. One important feature is that these maquiladoras of the fourth generation mostly belong to the regional production network within the NAFTA region (Carrillo \& Lara, 2004). These firms based their competitiveness on logistics and on the correct synchronization of activities of the firms within the production network (Lung, 2004).

As can be seen, the emergence of different generations of maquiladoras coincides with different strategies to organize manufacturing production and with changes in Mexico's trade policies over time (Carrillo \& Lara, 2004). Different generations of maquiladora 
firms are also the result of technological innovations and of drastic reductions in transportation and communication costs. One important thing to keep in mind is that those four generations of maquiladora firms coexist with one and other. This means that the existence of one generation of maquiladora does not eliminate the other one (Contreras and Munguia, 2007). It also highlights the fact that very few maquiladora firms have actually been able to achieve a proper transition from one generation to other. Differences in the level of technology required per manufacturing sector as well as lack of incentives from multinational firms in the largest maquiladora sector (electronics) to help in the upgrading efforts account for this issue.

\subsection{Domestic Sales of Maquiladora Output}

Over time, firms in the maquiladora industry have faced different restrictions to sell their final output domestically. Those restrictions have varied over time and by 2001 they had been dropped. Foreign markets, however, are still the main destination for maquiladora's final output and this tendency has remained basically unaltered over time.

Domestic sales of maquiladora final output were initially regarded by the Mexican government as purchases of imported goods. With the implementation of the maquiladora program in 1965 those imports were initially forbidden. By 1972, maquiladora firms were allowed to sell domestically provided that their goods did not compete with domestic manufactured goods (substitute imports) and the firms payed the required taxes. Import licenses and taxes on the use of imported goods were also imposed on those domestic sales by 1977 (CEPAL, 1996).

Additional restrictions were issued on the domestic sales of maquiladora output given the opening of the Mexican economy by the early 1980s. Policy makers in Mexico feared that an open domestic market could result in the entry of a great number of imports and of maquiladora output, thus wiping out inefficient local producers. According to the maquiladora decree of 1983 , only up to $20 \%$ of their output could be sold in the local market under the condition of using at least $15 \%$ of domestic inputs (Carrillo \& Hualde, 1997).

By 1989 , the permission to sell domestically was increased to $50 \%$ of total output (CEPAL, 1996). Promoting higher final output within the maquiladora industry was not the main reason for such increasing allowance to sell domestically. More importantly, the Mexican government was creating the environment for the successful integration of maquiladora firms with other firms in North America. The signing of NAFTA required Mexico to eliminate the non-tariff barriers imposed on the maquiladora firms. Restricting Maquiladoras to sell only a portion of their output domestically was considered as a non-tariff barrier. Henceforth, as of 1994, maquiladora firms could sell up to $55 \%$ of their production locally. Furthermore, this percentage was scheduled to increase by $5 \%$ every year until 2001 , when $100 \%$ of maquila output could be sold domestically (CEPAL, 1996).

Despite the continuous removal of restrictions, maquiladora firms have also showed little willingness to sell their output in the Mexican market. According to Carrillo \& 
Hualde (1997) and Barajas et al. (2003), in 1988 only 15 maquiladoras obtained a permission to sell output domestically. Although information for domestic sales is not reported in the published statistics, Mexico's statistical office has carried out unpublished surveys, and has consistently found that maquiladoras sell less than $5 \%$ of their output in the domestic market (Verhoogen, 2008). In my view, there are three main reasons that explain why maquiladora firms sell a very limited amount of their final output in the Mexican domestic market. The first reason is historical. Maquiladora firms have historically received trade and tax exemptions provided that all of their final output was exported. Thus, in the context of international production networks, foreign assembly firms still see Mexico as a transitory location in their objective of supplying a major end market such as that of the US. In short, maquiladora firms still mostly come to Mexico to produce for the US market. The second reason is related to the import tariffs that maquiladora firms are required to pay when entering the domestic market. Even though maquiladora firms are now entitled to sell as much final output locally as they wish, they are still required to pay import tariffs. This applies to those maquiladora firms whose production does not use a sufficient amount of NAFTA inputs (tariff jump). It is also important to mention that the Mexican government maintains these additional restrictions to protect local producers and/or to encourage the joining of other export promoting programs in Mexico. The third and most important reason is precisely the existence of other export promoting programs that run parallel to the maquiladora one. For instance, the PITEX program (devised in the mid-1980s) was designed to support those firms that produce both for exports and for domestic consumption. Since this program was also devised during Mexico's opening up, foreign firms could choose between the maquiladora and PITEX programme according to their own productive objectives. The PITEX program and its relationship with the maquiladora program is discussed in detail in sections 2.9 and 2.10.

\subsection{The Evolution of Maquiladora Firms through Manufacturing Sectors.}

In this section, we present the general policy frameworks and the specific features characterizing different maquiladora manufacturing sectors. Our main objective here is to understand why some sectors are more likely to increase their demand for domestic inputs than others.

\subsubsection{Food Industry.}

According to Rama (1984), even before the opening of the Mexican economy, the food industry in this country was highly dominated by multinational firms. By establishing operations in Mexico, the main objective of these multinational firms was to produce food products, mainly using foreign inputs and demanding very little domestic inputs from Mexican agriculture. Several factors are behind this. First of all, most of the multinational firms in the food industry located in Mexico were of US origin. Therefore, those firms were used to using abundant and cheap agricultural inputs that were highly subsidized by the US government. Some of those agricultural products included wheat, soy, sorghum and milk where the US is a top producer. Similarly, the fact that those multinational firms did not specialize in the production of Mexico's top agricultural output (corn, beans and rice) and the relative backwardness of the technology employed 
in the Mexican agriculture were other incentives for the multinational firms to demand little Mexican inputs.

By 1985 the Mexican government tried to impose some restriction on agricultural imports given the country's entrance to GATT. Among others, import restrictions included $45 \%$ of tariff imports for condensed milk, 50\% for butter, $10 \%$ for sorghum, $40 \%$ for corn, wheat, soy, beer, wine and so forth (GATT, 1986). The restrictions for imports of sorghum were removed in 1994, those for wheat, milk and soy in 2003 and those for corn in 2008 (Schwentesius Rindermann and Gómez-Cruz, 2001). Given the limited presence of food multinationals within the maquiladora industry, those firms did not receive special attention in the industry's policy framework. At this regard, we can only mention the tariff exemptions on imports of milk (powder), eggs, corn (powder), sugar and so forth issued in the 2002 maquiladora decree.

\subsubsection{Leather and Footwear Industry}

At the beginning of the 1980s, as a result of the debt crisis, the leather and footwear industry began to suffer from the decline in domestic purchasing power. Nevertheless, the main negative shock for this industry came with the opening up of the domestic market and with a reform issued in 1988, in which tariffs on imports were drastically reduced and import licenses were abolished. From June 1985 to December 1988 the value of domestic production covered by import licensing fell from 99.1 to $0 \%$ and the average tariff decreased from 46.8 to $18.1 \%$. In response, imports grew from 0.2 million pairs in 1987 to 107 million pairs in 1991. This dramatic increase in imports was accompanied by a contraction in domestic production from 245.2 to 199.6 million pairs. In this new competition, Mexican shoe manufacturers were initially ill-equipped to compete with imports on price, quality and fashion content (Rabellotti, 1999).

Acknowledging the difficult situation faced by the leather and footwear industry, the Mexican government imposed several import restrictions. In 1993, countervailing duties were imposed on shoes and shoes' components imported from China, ranging from $165 \%$ to $1,105 \%$ according to the type of shoe (in the case of shoe leather, the import tariff was of 323\%) (SECOFI, 1993). Nonetheless, with NAFTA in operation, more footwear imports entered taking a larger share of the domestic market. NAFTA also brought more pressures to domestic suppliers in the footwear industry since there were great difficulties in the supply of raw materials and particularly in the supply of bovine leather (Ortiz and Martinez, 2000). In this context, many producers substituted domestic supplies with cheaper and higher quality imported supplies (Woodruff, 1998). By 2001, given China's accession to the WTO, Mexico was able to extend for a period of six years the import tariffs imposed on Chinese products (including shoes) (Secretaría de Economía, 2007).

\subsubsection{Paper and Wood Industry}

Mexico does not have the necessary forest to support its paper industry. This is because there is an insufficient domestic supply of wood pulp. According to Cortez-Ruiz (1993), approximately $25 \%$ of the Mexican territory is covered by woodlands, divided almost equally into temperate (softwood) and tropical (hardwood) forest, covering 25.5 and 
24.1 million hectares, respectively. Nevertheless, out of the total woodlands, only half of it can be actually used for wood manufacturing production. Similarly, other factors also indicate the limited role of the paper industry. At this regard, we can mention the continuous deforestation of woodlands (as a result of increasing urbanization and the expansion of other agriculture-related sectors, such as cattle rising), the fact that property rights over land are not well defined, and that many of the woodlands are located in remote and inaccessible areas.

Furthermore, wood products from Mexico were regarded by manufacturing producers as being of low quality and with non-competitive prices in international markets. This is mainly because of the fact that the wood production in Mexico has to compete with that of Canada and the Unites States. Those two latter countries are among the world's largest exporters of forestry goods. Therefore, their technology and scale of production also allows them to domestically supply forestry goods of high quality and low price.

In this background context, and as a result of Mexico's opening up to foreign trade during the 1980s, the exports of forestry goods increased from 71 millions of dollars in 1983 to 251 million in 1991; nevertheless, the imports rose from 237 million to 686 million during the same period of time. Out of those 686 millions of imports of forestry goods, 447 million were solely imports of wood pulp (Cortez-Ruiz, 1993). The Mexican government implemented several policy changes aimed at transforming the rigidity and backwardness of forestry sector (Ley forestall de 1992). Nevertheless, the signing of NAFTA increased the incentives to import forestry woods and materials from the United States and Canada further deteriorating any possible increase in the domestic consumption from the Mexican paper industry. The difficult situation observed in the forestry industry has not changed much during the more recent years. According to De la Madrid (2009), the trade deficit in forestry goods moved from 3.6 billion dollars in 2000 to 5.6 billion in 2008 (representing 38\% of the total trade deficit in Mexico). In 2008, the main imports of forestry goods were paper and cardboard, wood and manufactures of goods, wood pulp and recycled paper.

\subsubsection{Non-Mineral Metallic Industry}

The non-metallic minerals include gypsum, glass and cement. The cement industry has important linkages with manufacturing production given that its output can be used as an input for the production of other goods such as bathroom furniture, pipes and so forth. During the 1980s, the cement industry experienced a major expansion in Mexico. According to Salomón (1995), from 1983 to 1989 the exports of cement had an average growth rate of 42.6 , with most of such output being sent to southern part of the United States and with very little competition from US producers. The relative abundance of mineral resources in Mexico, the adoption of new technologies, the access to energy with preferential prices (mostly oil during the 1970s), the increasing substitution of labor for capital (late 1980s), and the strategic alliances of Mexican firms with US firms in order to distribute production in the US market (Cemex- Texas-Lehigh Cement in 1986) largely account for this issue.

After 1994, the situation in the cement industry and in the non-mineral metallic industry in general faced major changes. The implementation of NAFTA implied that the tariffs on 
imports of pure glass and pure gympsum were removed by 1994. Similarly, the tariffs on the imports of gympsum and cement were lifted in 1998, while the tariffs on imports on pure cement were eliminated in 2003. During the early 2000s, there was a significant expansion of demand from the construction industry in the US that imposed higher quality demands on the imports from Mexico. On the other hand, it Is also important to mention that the production of gympsum in Mexico (other major non-mineral metallic sector) faces important challenges given the current tendency for domestic manufacturers to import cheaper gympsum from elsewhere (Secretaría de Economía, 2013).

\subsubsection{Transport Sector.}

By 1962, Mexico establishes its first transportation decree under the highly protectionist scheme of ISI. During most of the 1960's and 1970's the Mexican government limited the participation of foreign investors in the transport sector (up to 40\%) and prohibited the imports of vehicles, and of parts and components that were locally produced (Brown, 1997). More importantly, the minimum local content for the automotive production in Mexico was $60 \%$ (Vicencio Miranda, 2007). As a result of the opening up the economy in the mid-1980's, all these restrictions were lifted. Nevertheless, according to Brown (1997), one important exception was that local automotive suppliers should produce with at least $36 \%$ of domestic content. By the mid-nineties, NAFTA further modified this framework. In line with the agreement, automotive exporters had to meet very strict rules of regional content starting with $50 \%$ in 1994 so as to reach $60 \%$ by 2001 . Mexico's advantageous geographical position (that allows for low shipping costs), its growing domestic market, low labor costs and its network of trade agreement make the country a very competitive location for automotive production. As a result of this process, the production of other important transport industries (such as the Aeronautic sector) has started to boom in the country (Carrillo and Hualde, 2013).

\subsubsection{Machinery and Equipment.}

Following the Mexican oil boom by the end of the 1970s, the government implemented an ambitious industrialization program. Such program was named "Plan Nacional de Desarrollo Industrial: 1979-1982" and its priorities were the agro-industrial sector and the domestic production of capital goods. In order to promote the production of capital goods, several policies were put in place. The government was expected to purchase $40 \%$ from the total production of machinery and equipment. Furthermore, the domestic production of machinery and equipment was to be purchased by the government at a price $15 \%$ higher than the market price. The government also offered to pay the transportation costs. Following the same stream of ideas, the government also offered fiscal credits (25\% for new investments) and preferential prices for electricity, fuel oil, natural gas, and basic petrochemical goods (Bancomext, 1979). Nonetheless, the government decided to stop this whole program due to the debt crisis faced by Mexico in 1982.

According to USITC (1993), Mexico's effective tariffs on imports of industrial machinery from the United States, based on Mexican trade data for 1990, range from 10.1 percent 
ad valorem for textile machinery to 15 percent for construction machinery, and to 16.7 percent for refrigeration and heating equipment.

Under NAFTA, Mexico eliminated duties on about 54 percent of industrial machinery imports from the United States. This included duties on about 80 percent of Mexican imports of textile. paper industries, printing trades, and farm machinery, and 85 percent of food products machinery. About 17 to 33 percent of Mexico's imports of mining machinery, oil and gas field machinery, and refrigeration and heating equipment also became duty-free immediately (USITC, 1993).

\subsubsection{Electronic Sector.}

During the 1980s, as the level of production increased, more complex technological procedures were introduced in the maquiladora firms within the electronic industry. According to Brown and Dominguez (1989), microelectronic machinery was introduced with the intention of better controlling the productive process and reducing labor costs. Such microelectronic machinery replaced some of the assembly operations and the old machinery used by the maquiladora that was initially used by the headquarters located abroad (Brown and Domínguez, 1989). Since the 1980s, local suppliers to maquiladora electrónica have faced a number of obstacles that prevented them from increasing their supply of intermediate goods to such industries. Long term relationships historically formed between foreign supplier and electronic maquiladoras, certificates for the quality of production demanded by maquiladora producers, continuous changes in the design of electronic products, modularity in the manufacturing of electronic goods, emergence of more efficient producers and important decreases in the transportation and communication costs during the last decades can explain this phenomenon.

Given the importance of the electronic industry, the Mexican government has tried to support maquiladora producers in this industry as much as possible. For instance, 2001 was a critical year for electronic maquiladoras (and for the maquiladora industry as a whole) given the US crisis and China's accession to the WTO. As already mentioned, in line with NAFTA article 303, by 2001 only NAFTA-originated inputs were to be exempted from import tariffs. This NAFTA article 303 was meant to provide higher incentives for the manufacturing production within the North American region. Therefore, this article could be used as an instrument to support local suppliers of electronic inputs to maquiladora producers.

The PROSEC program was supposed to be one of the key strategies to help Maquiladora cope with the new NAFTA regulations and with the expected industrial emergence of China. Nevertheless, in order not to lose competitiveness in the electronic industry, the Mexican government implemented by 2002 yet another program named ITA-Plus (Olliver-Fierro, 2007). In 1996, Mexico did not take part in the WTO initiative named "Information Technology Agreement" (ITA) that considers the tariff elimination on diverse final goods (including their sub-assemblies) from two sub industries: (1) computers and, (2) telecommunications. Given the difficult situation faced by electronic maquiladoras by 2001, Mexico unilaterally established the ITA-Plus. ITA-Plus completely eliminates tariffs on intermediate goods imported from any country for three sectors: computers (computers, monitors, printers, scanners), telecommunications 
(modems, cellular phones, carrier - current line systems and telephone centers, broadcasting equipment for T.V. and radio), and other consumer electronics devices (TVs, stereos, CDs, video equipments, calculators, photocopiers, register machines). Furthermore, the ITA Plus considered the tariff elimination on raw materials and inputs from sectors such as steel, plastics and chemicals only to be used in the manufacturing of electronic products in Mexico (Secretaría de Economía, 2002)

In this context, the program was named ITA-Plus because, unlike ITA, it considered not two subsectors but three subsectors within the electronic industry (computer, telecommunications and consumer electronic devices and therefore, the electronic industry as a whole) and it included tariff exemptions on raw materials to be used on the manufacturing of electronic goods. ITA only included the free imports on subassemblies, while ITA plus also included free imports on raw materials (those inputs needed to produce subassemblies).

To my view, ITA-Plus was an important boost for maquiladora producers in the electronic industry but it did not promote the domestic production of subassemblies and components for the electronic industry. This can be further confirmed by analyzing the type of inputs that are provided by local producers to the maquiladora electronica. According to Carrillo and Zárate-Cornejo (2003), the intermediate goods that local suppliers send to the maquiladora electronica are inputs for indirect use. Inputs for indirect use mean those inputs that are mainly used in the last stage of manufacturing production (i.e. those that complete the final manufacturing outcome). Thus, the main inputs sent by local producers to maquiladora electronica include corrugated fiberboard, accessories for metal casting, instruction manuals, wooden pallets, polyethylene, foam, uniforms, packaging and so forth. Carrillo and Zarate-Cornejo (2003) also indicate that local electronic suppliers do not produce for a single maquiladora firm but their customers are diversified. Similarly, there are many differences among the local suppliers of electronics in terms of the machinery and equipment, organization procedures, infrastructure, access to final support and so forth.

Finally, the size from the local suppliers providing inputs to the maquiladora electronica also confirms the limited interaction between them. The size of those local suppliers of electronic goods is small. According to estimates provided by COLEF (2002), there are only 12 firms (employing in total less than 3000 workers) that supply intermediate goods to the electronic maquiladoras in the cities of Tijuana and Mexicali. This is quite a small number if we consider that there are 40 foreign firms supplying inputs for the electronic maquiladora employing nearly 14, 000 workers.

\subsubsection{Services.}

During the beginning of the maquiladora program, multinational firms within this industry used to rely on a large amount of services offered by domestic firms. Renting of industrial units, transportation, customs tariff advice, legal advice, services for the hiring and provision of labor (mostly low qualified labor) and shelter type of services are some of most common services provided to maquila firm. All these are non-tradable services that are specific to the Mexican economy (González-Aréchiga et al., 1991). 
As the maquiladoras started expanding their operations in the mid-1980s, they started importing a higher amount of services. Multinational firms located abroad sent different kind of services to their Mexican subsidiaries (Maquiladoras) that were aimed at increasing the quality of the production and align the Maquiladoras with their organizational structure and standard procedures. The Maquiladora decree of 1989 and of 1998 indicates that those firms were allowed to import (free of duty) the following services; blue prints, manuals for labor training, equipment for the administrative performance of the firm, for control quality, for industrial security, those for hygiene and waste management purposes as well as devices for telecommunications. Similarly, the decree aimed at facilitating the entrance of foreign administrative workers and technicians to support maquiladora production.

In light of the increasing fragmentation of production, policy makers in Mexico implemented some legal changes in order to allow for the existence of more firms (both domestic and foreign owned) that could supply different types of services to maquiladoras. In 1998, the maquiladora decree recognised for the first time, the existence of the Maquiladora por servicios (services for maquiladora) and by 1997 the "Programa de Importación Temporal para Servicios Integrados a la Exportación" (services for PITEX) was implemented. The Maquiladora-Services firms and the PITEX services firms received tariff and import incentives provided that they supplied services aiming at facilitating the exports of regular maquiladora and PITEX firms respectively. Those services to facilitate exports (provided both by foreign or domestic firms) include port services, services for engineering, designing, research and repairing of machinery.

Let us indicate one example as to how services maquiladora can support the exporting activity of regular maquiladora firms. The regular (manufacturing) maquiladora firms transfer their final output to service maquiladora firms in order for those firms to perform the exporting activity. This means that exports of final output can be performed by the services maquiladora, while the regular maquiladora only focuses on the production process. The services maquiladora has to provide a certificate to the regular maquiladora firm in order for the latter firm to claim its tariff and import incentives (Gambrill, 2002). This type of service provided by the Maquiladora por servicios is quite convenient for the regular Maquiladora firms because, in that way, they can solely focus in the manufacturing process leaving the bureaucratic part of exporting to specialized Maquiladora services firms.

Finally, the IMMEX decree of 2006 further indicated the different activities that can be performed by the Maquiladora of services in order to support the exporting activity of regular Maquiladora firms. Those include; (a) storage and distribution of goods; (b) testing and classification of goods; (c) packaging, painting and polishing of goods (as long as the good is not modified); (d)embroidery, washing and ironing of textile goods; (e) waste management activities; (f) software engineering, and; (g) services to support information technologies. 


\subsection{The Development of Other Export Promoting Programs in Mexico (1985-2006).}

In line with the opening of the economy, by the mid-1980s, the Mexican government established additional export promoting programs that were to coexist with the maquiladora program. Here, we are referring to programs named PITEX, DIMMEX, Drawback System, Carta de Crédito, ALTEX and ECEX. Unlike the maquiladora program, these new export promoting programs were not only aimed at foreign firms located in Northern Mexico that wish to produce for exports. Those new programs were designed for foreign and domestic firms located anywhere in Mexico, wishing to produce both for exports and for the domestic market. Further incentivizing manufacturing production to reduce Mexico's dependence on oil exports was the main objective behind those new promotion programs. A growing consumer class in Mexico, outdated and inefficient domestic production during the early 1980s and, the existence of these new promotion programs were important factors to induce foreign companies to start producing for the domestic Mexican market (Rice, 1998). In the next paragraphs, we will explain those new programs in detail, with a strong focus on the largest and most important program, the PITEX program.

\subsubsection{PITEX, DIMMEX, the Drawback System and, Carta de Crédito Doméstica.}

Once the export oriented strategy kicked in, Mexican policy makers wanted to devise a program that was similar to the maquiladora but targeting firms in domestic manufacturing (Acevedo Garat, 1987; Gambrill, 2008). The main objective of this new program was to make firms in the domestic manufacturing of Mexico as competitive as the foreign assembly firms within the maquiladora program. In the view of policy makers, such a second maquiladora program should be attractive for new foreign firms seeking to produce both for exports and for the domestic markets, as well as for existing domestic firms already producing for the domestic market that wished to start producing for exports. More importantly, joining this new export promoting program should be a realistic option both for large firms as well as for small and medium enterprises.

In this context, by 1985, Mexican policy makers implemented this new second export promoting program (parallel to the existing maquiladora) named "Program for the Temporary Import of Goods to be Exported Back" or PITEX (Programa de Importación Temporal para Producir Artículos de Exportación) (Dussel Peters, 1995). To allow for the participation in this program from small and medium enterprises as well as large firms, PITEX conditioned tariff incentives on the basis of two different export performance requirements. For instance, firms producing for the domestic market that exported more than 500,000 dollars or at least $10 \%$ of their total output were allowed to import the following items free of duty: a) raw materials and intermediate inputs; b) packaging materials; c) fuels, lubricants and spare parts. On the other hand, firms producing for the domestic market that exported more than $30 \%$ of their total output were allowed to import free of duty items a), b) and c) as well as d) machinery and equipment and; e) devices, equipment and accessories for research purposes, for industrial safety, control quality and training of personal. In my view, having two 
different export performance requirements was a useful idea for the export development of small and medium enterprises in Mexico. Firms that could only afford to produce a limited amount of good for exports (10\% of their total output) could enjoy the basic PITEX benefits (items a, b and c). However, those firms also had an incentive to increase the scale of their production for exports beyond $10 \%$ as they could also import free of duty not only packaging materials and intermediate inputs but also machinery equipment as well as other more complex devices included in items d) and e).

Inducing more and more domestic firms to start producing for exports by means of PITEX also implied dealing with additional obstacles. By 1985, the export-oriented strategy was still something rather new and thus many domestic firms lacked the necessary capabilities and incentives to compete in international markets. Another important issue was the support for domestic suppliers. Domestic suppliers had not succeeded in producing inputs for maquiladora firms and now feared that the import incentives provided within PITEX would make domestic firms demand progressively less local inputs. One final obstacle was that the protectionist scheme had not been completely dismantled and, thus several import and ad-valorem duties still have to be paid for several items.

Acknowledging these additional obstacles, policy makers also devised by 1985 other promotion schemes that were complementary to the new PITEX program. In order to induce domestic firms to produce for exports with local content, a program named DIMMEX was implemented. DIMMEX stands for Import Duties on the Production for Exports (Derechos de Importación de Mercancías para Exportación). Here, domestic firms that bought at least $30 \%$ of their inputs domestically could obtain a DIMMEX certificate which allowed them to import intermediate goods free of duty. Nevertheless, obtaining a DIMMEX certificate did not exempt domestic firms from paying ad-valorem import tariffs of $10 \%$ or the tariff percentage established by the Mexican Custom System (if it was higher than 10\%) (Acevedo Garat, 1987). To help firms deal with this additional tariff issue, a Drawback system was also implemented in 1985. In this Drawback system, domestic firms producing for exports were allowed to ask for the full reimbursement of the import tariffs they paid, provided that their imported goods were effectively used in the production for exports (Acevedo Garat, 1987).

DIMMEX and the Drawback system were devised as the first steps to achieve PITEX status for less export oriented domestic firms. To explain such mechanism, let us refer to the example of a domestic Mexican firm in the early 1980s as described by Salinas Chavez (1990). In 1985, in light of the opening of the economy, a Mexican firm producing for the domestic market wanted to produce for exports. To produce for exports and compete in international markets, the domestic firm needed to increase its consumption of imported inputs of higher quality. As a result of the protectionist scheme lifted in 1983, this firm would find it easy to obtain import tariff exemptions by means of a DIMMEX certificate. This, because It was quite likely that this firm source more than $30 \%$ of their total intermediate inputs domestically. Though the ad-valorem import taxes were not exempted by DIMMEX, the Mexican firm could ask for a full reimbursement of those taxes using the Draw-back scheme. Even though those instruments would allow the production of more output for exports, the Mexican 
domestic firm would find desirable to avoid the payment of import tariffs and the bureaucratic procedure of the Draw-Back system.

As the firm increased its production for export (a minimum of 500,000 dollars annually or $10 \%$ of their total sales), it could apply for a PITEX scheme. By becoming a PITEX firm, not only could it import its main imported inputs free of duty, but also packaging, fuels, lubricants, machinery and equipment, instruments for control quality and so forth. PITEX also exempted firms from the need to obtain import certificates, so our Mexican firm no longer required a DIMMEX. Similarly, the draw-back system was no longer required since there were no more import taxes to be reimbursed. So, with PITEX, our Mexican firm could obtain in a single program all the benefits that were obtained separately with other policy instruments, plus important benefits for its production processes.

The benefits from PITEX and from the Drawback system could also be extended to local producers of intermediate inputs (Acevedo Garat, 1987). Furthermore, an additional program was also devised to ensure the participation of those local producers in the production for exports from domestic firms. By 1985, the Mexican government implemented a program named "Carta de Crédito Doméstica", which had the objective of issuing bank guarantees for the production of local suppliers. According to Acevedo Garat (1987) this program had already been implemented in South Korea and was expected to have the same positive outcome for local suppliers in Mexico. Carta de Crédito Domésticas (letter of credit for domestic purchases) is a bank guarantee that can be issued by an exporting firm located in Mexico to be granted to its preferred domestic suppliers. For the banking system, this letter of credit guaranteed that the exporting firm was going to purchase some determined amount of domestic inputs from local suppliers in Mexico. Therefore, local suppliers could use such letter of credit to ask for loans within the Mexican banking system in order to buy machinery, equipment and so forth.

As can be seen from this discussion, the main objective of the Mexican government was to induce more and more firms in domestic manufacturing to achieve PITEX status. Both direct and indirect exporters had the necessary complementary programs to progressively increase their production for exports and obtain more benefits as PITEX firms. Since its inception the manufacturing sectors that have mostly used the PITEX scheme are Chemical products, Basic Industries (such as steel and Iron) and, more importantly, the transport equipment (autoparts) sector. According to Ramos (1989), during the period 1985-1987 the autoparts industry in Mexico accounted for 34\% of the total imports under the PITEX scheme and $50 \%$ of the total exports under PITEX. For the same period, the corresponding figures for Chemical products and for Basic Industries were smaller than $10 \%$ respectively, while the rest of manufacturing subsectors (39 sub sectors) studied by Ramos (1989) jointly import 37\% of total PITEX imports and 25\% of total PITEX exports.

Over the years, until the creation of the IMMEX program, the general framework governing the operation of PITEX firms did not change substantially. The most important change for the PITEX program took place with the implementation of NAFTA. In line with the agreements, one additional benefit from the PITEX program was to allow foreign investors to register as a national supplier to the automotive industry (USITC, 
1998). By 2006, PITEX firms numbered 3,620 and included all motor vehicle assembly parts and most of their part suppliers. Historically, these firms tend to locate in the interior of Mexico because an important part of their sales goes to the domestic market (De la Cruz et al., 2011) and due to the proximity to a major end market such as Mexico City.

\subsubsection{ALTEX and ECEX.}

On top of the previously mentioned programs, Mexico implemented two additional export promoting schemes that aim to separately support two radically different groups of domestic firms. The ALTEX program was designed to support those highly competitive exporting firms in the domestic manufacturing sector of Mexico, while the ECEX program was prepared for the increasing participation from the rather small domestic firms in the production for exports. The main difference with respect to the above-mentioned programs was that, in this case, financial support could be provided for ALTEX and ECEX firms. Similarly, firms joining ALTEX and ECEX could also qualified and be registered as PITEX firms.

According to Dussels Peters (2000), the High-Exporting Firms program (Empresas Altamente Exportadora, ALTEX) was issued in 1986. High exporting domestic firms were those that had a dynamic and permanent participation in international markets (SECOFI, 1990). To qualify for ALTEX, a firm should export directly more than \$2 million dollars or $40 \%$ of their sales, or indirectly $50 \%$ of their sales. Some of the most relevant benefits for ALTEX firm were quick return of value added taxes and quick revisions in customs (Dussel Peters, 2000).

On the other hand, the ECEX program was issued in 1990. ECEX stands for Enterprises to Facilitate Foreign Trade (Empresas de Comercio Exterior). An ECEX firm is the one that facilitates and promotes the exports of goods that have been produced by several domestic firms of rather small size. According to Hernández Laos (2000), ECEX was aimed for those micro, small and medium firms that as individual entities lack the necessary capabilities and resources to produce for exports. An ECEX firm will then gather the final output from those small individual firms and export to international markets on their behalf. The final output exported by an ECEX firm should be homogenous, of the same quality and originally produced by micro, small and medium firms. A minimum of US\$100,000 is required to start operations as ECEX firm. After the second year of operation within ECEX program, the firm should yearly export more than US\$ 3 million and keep a positive surplus (Hernández Laos, 2000). Financial support is available for ECEX firms wishing to induce for micro firms to produce for exports.

\subsection{Similarities and Differences between the Maquiladora and PITEX Program.}

Having separately explained the main characteristic from Mexico's two major export promoting programs, we will now describe the main similarities and differences between them. On the one hand, we observe that Maquiladora and PITEX firms receive the same kind of import incentives and allow for the same levels of foreign ownership. On the other hand, we will show that those two programs differ in terms of the location 
of firms, the export requirements to receive benefits, the share of domestic sales and fiscal obligations.

\subsubsection{Duty Free Imports and Foreign Ownership}

Firms under the PITEX or Maquiladora program, being direct or indirect exporters, can temporary import various items to be used in their production for exports free of duty. Packaging materials, intermediate inputs and machinery and equipment were some of goods that could be imported duty free. Likewise, both types of firms faced no restrictions in terms of foreign ownership (up to 100\%) and could set up operations anywhere in Mexico. Finally, a firm enjoying maquiladora status could apply for PITEX benefits, and vice versa, as long as its participation in the two programs does not refer to the same good, i.e. there is no overlap of programs (Rice, 1998)

\subsubsection{Performance Requirements.}

Maquila and PITEX firms had to meet different export performance requirements to receive the corresponding benefits within each program. As mentioned before, PITEX were required to export at least $10 \%$ of their final output in order to temporararily import intermediate inputs and packaging materials free of duty. If the same PITEX firm wished to additionally import machinery and equipment free of duty, the export requirement for this was a minimum of $30 \%$ of total sales.

Maquiladora firms, on the other hand, did not have to meet any specific export performance requirement to obtain their benefits (they could export 100\% of their production if they wished to). Nevertheless, unlike PITEX firms, the only two requirements that maquiladora firms had to meet in order to continue receiving preferential treatment were 1) employing and training a certain number of Mexican workers, and, 2) complying with their fiscal obligations. According to Rice (1998), imposing labor obligations for maquila firms had the following three goals; to encourage the employment of Mexican nationals in higher level positions, to improve the technical qualifications of workers, and to contribute to the overall integration and competitiveness of the Mexican industry. No specific employee training standard existed, though. Rather, the maquiladora firm only needed to demonstrate the implementation of some training activities.

\subsubsection{Domestic Sales of Final Output}

Since its inception in 1985, firms belonging to the PITEX program were entitled to sell a higher amount of final output domestically than maquiladora firms. As mentioned in section 2.7, during the 1990s, maquiladora firms were allowed to sell progressively more output on the domestic market. By 2001, maquila firms just like PITEX finally faced no restriction to selling their output domestically. Nevertheless, when selling domestically, both maquiladora and PITEX firms were also required to pay tariffs on those imported goods that were subject to taxation (those intermediate inputs not protected by NAFTA or that came from countries with which Mexico does not have a free trade agreement). 


\subsubsection{Fiscal Obligations.}

One of the most important differences between the Maquiladora and PITEX program was related to the amount of taxes that firms within each program had to pay. In general, maquiladora firms used to pay less taxes than PITEX firms but, with the boom in production triggered by NAFTA, the maquiladora program was modified to increase the fiscal obligations of maquiladora firms.

Corporate income tax, assets tax, and value added tax (VAT) for both domestic sales and imports are the federal taxes that PITEX and maquiladoras have to comply with. The corporate income tax is a flat $34 \%$ and the assets tax is $1.8 \%$ of all business assets. The VAT is variable but on average is $10 \%$ of all sales of goods and services. According to Rice (1998), the primary fiscal benefit for maquila and PITEX firms derives from not having to pay import duties or the value added tax on the cross-border transfer of goods. Nevertheless, before 1998, PITEX firms were also required to pay income and/or asset taxes while maquiladora firms were exempted from paying these.

The main reason for PITEX firms to pay income/asset taxes was that Mexican legislation treated them as profit centers. PITEX firms were considered as traditional manufacturing firms that could be taxed on their profits and that could also be required to sell foreign currency to cover both profits and operating costs. Maquiladoras, on the other hand, used to pay little or no income /assets taxes because they were not operating as profit center buts as cost centers. Costs centers implied that maquiladora firm did not produce sufficient profits as they often leased machinery and equipment from their foreign headquarters (Rice, 1998). Similarly, maquiladoras paid income taxes on their country of origin once the foreign headquarters reported its total income (which included the one obtained by its maquiladora subsidiary).

In this context, during the mid-1980s and early 1990s, the choice between PITEX and Maquiladora status boiled down to a technical decision weighing the subtle and complicated differences in foreign exchange requirements and tax treatment (Wilson, 1992). The boom in maquiladora production that took place in the years after the implementation of NAFTA implied a drastic change in the fiscal obligation of those foreign assembly firms. By 1998, Mexican authorities no longer regarded maquiladora firms as a cost centers but as profit centers just like PITEX firms. The main implication behind this policy shift was that maquiladora firms were now supposed to pay income taxes on the basis of their World profits just like any other foreign manufacturing firm in Mexico (Gambrill, 2002).

Maquiladoras now being regarded as profit centers according to the Mexican legislation implied a severe problem for those firms. Not only were they now required to pay taxes on their income produced in Mexico but also on the income reported by their foreign headquarters mostly located in the US. In light of this problem, by 1999, Mexican and US authorities reached an agreement to avoid double taxation. Such treaty prohibited double taxation and established that as a general rule, the Mexican entity (rather than the foreign partner) was required to pay taxes on the assets located in Mexico and any income generated from the Mexican operations (Rice, 1998). To calculate income taxes, Maquiladoras firms were required to implement arm's length transfer pricing or safe 
harbor transfer pricing. Finally, given the drastic decline in maquiladora output that occurred in 2001, by 2003, Maquiladora firms were allowed apply for a tax credit resulting in a reduction of the maquiladora's income tax liability (E\&Y, 2010).

\subsection{IMMEX Program (2007-present): Merging PITEX and Maquiladora firms.}

As discussed in the previous section, the maquiladora and PITEX program had progressively reduced their differences in terms of fiscal obligations and the permission to sell domestically, tariff duties when importing intermediate and capital goods, and were subject to the same set of rules of foreign ownership. Before 2006, the largest differences between maquiladora and PITEX firms had to do with the type of production (for exports or for the domestic market), the export performance requirements that they had to meet, as well as their location within Mexico. According to Rice (1998), the PITEX program was still largely oriented towards national and foreign producers wishing to expand their operations to include export manufacturing, while the Maquiladora program was intended for pure export companies.

Table (2.3) presents the distribution of maquiladora and PITEX firms across border Mexican states as well as other Mexican states in 2006. It also shows the number of firms in 2006 that were to become part of the IMMEX framework by 2007. In this table, we observe that by 2006 nearly all maquiladora firms were located in Northern Mexico (as discussed in section 2.4), while almost 65\% of all PITEX firms were located in nonborder states. Finally, export performance requirements of $10 \%$ and $30 \%$ for the import of intermediate good and of capital goods, respectively, remained only for PITEX firms and were not applicable for maquiladoras.

Table (2. 3): Mexico's Exporting Firms in the Maquiladora, PITEX and IMMEX Programs.

\begin{tabular}{|c|c|c|c|c|}
\hline \multirow{3}{*}{ Mexican States } & \multicolumn{4}{|c|}{ Number of Plants } \\
\hline & \multicolumn{3}{|c|}{2006} & \multirow{2}{*}{$\begin{array}{c}2008 \\
\text { IMMEX }\end{array}$} \\
\hline & Maquiladoras & PITEX & IMMEX & \\
\hline Border States & 2,283 & 1,269 & 3,552 & 3,625 \\
\hline Other States & 512 & 2,351 & 2,863 & 2,560 \\
\hline Nationwide & 2,795 & 3,620 & 6,415 & 6,185 \\
\hline
\end{tabular}

Source: De la Cruz et al. (2011)

In light of the fierce competition triggered by the emergence of more efficient East Asian producers during the early 2000s, the Mexican government decided to implement a key policy change in its two major export promoting programs. As of 2007, maquiladora and PITEX firms were to operate within the same legal framework. Such new framework should also take into account those ALTEX and ECEX firms as they were also registered with PITEX status. This new single export promoting program was named 
Manufacturing Industry, Maquiladora and Export Services Program or IMMEX (Industria Manufacturera, Maquiladora y de Servicios de Exportación).

According to Gambrill (2008), the main objective behind IMMEX was to make exporting firms in the domestic economy of Mexico (i.e. those registered as PITEX) as competitive as the ones in the Maquiladora program. In the view of Mexican policy makers, this latter objective could be achieved if both domestic and exporting firms enjoy the same rules of operation and the same incentives within a single promotion program.

In line with Table (2.3), by 2006, from the total amount of firms that were to become IMMEX firms, 56\% were registered as PITEX and 44\% were maquiladora firms. Given such number of PITEX firms and the intention of the Mexican government to promote the industrial development of those firms, the export performance requirements from the PITEX program were also transferred to IMMEX. Nevertheless, this time IMMEX firms (both Maquiladora and PITEX firms) were only required to export at least $10 \%$ of their total sales (or a yearly minimum of US\$500,000) to import all the necessary intermediate inputs and capital goods free of duty and free of value added taxes. This export requirement of exporting at least $10 \%$ of total sales was maintained in order to continue to induce more domestic firms to qualify for IMMEX (Gambrill, 2008). Despite the larger number of PITEX firms initially included in IMMEX by 2006 (56\% PITEX firms and $44 \%$ maquiladora firms, according to table 2.3), it is worth mentioning that the IMMEX framework still shows some of the main characteristics of the maquiladora framework. Here, we are referring to the location of most firms in Northern Mexico and the higher consumption of domestic inputs in non-border states. Table (2.4) presents the location of IMMEX firms in different Mexican regions from 2007 to 2016. In this table, we observe that more than $60 \%$ of total IMMEX firms are located in the border region while the remaining $40 \%$ is established elsewhere in Mexico. Here, we can also indicate that, over time, more IMMEX firms decide to operate in central Mexico away from the border region. Nevertheless, such latter tendency only takes place at a relatively slow phase.

Table (2. 4): Location of IMMEX Firms in Mexican Regions: 2007-2014. Number of Establishments

\begin{tabular}{ccccccc}
\hline Year & $\begin{array}{c}\text { Northern } \\
\text { Mexico }\end{array}$ & $\begin{array}{c}\text { Central } \\
\text { Mexico }\end{array}$ & $\begin{array}{c}\text { Western } \\
\text { Mexico }\end{array}$ & $\begin{array}{c}\text { Southern } \\
\text { Mexico }\end{array}$ & $\begin{array}{c}\text { Other } \\
\text { Regions }\end{array}$ & $\begin{array}{c}\text { Total } \\
\text { Mexico }\end{array}$ \\
\hline \hline 2007 & 3,119 & 794 & 255 & 90 & 307 & 4,565 \\
2008 & 3,180 & 1,056 & 263 & 88 & 319 & 4,906 \\
2009 & 3,149 & 1,057 & 271 & 83 & 306 & 4,866 \\
2010 & 3,078 & 1,043 & 265 & 82 & 286 & 4,754 \\
2011 & 3,058 & 1,039 & 272 & 83 & 282 & 4,734 \\
2012 & 3,053 & 1,068 & 302 & 77 & 284 & 4,784 \\
2013 & 3,065 & 1,090 & 306 & 79 & 273 & 4,813 \\
2014 & 2,977 & 1,112 & 284 & 68 & 264 & 4,705 \\
2015 & 2,968 & 1,108 & 282 & 67 & 271 & 4,696 \\
2016 & 2,990 & 1,118 & 276 & 60 & 269 & 4,713 \\
\hline
\end{tabular}

Source and Notes: as described in table (2.1). 
Similarly, in line with table (2.5), IMMEX firms located in Central and Southern Mexico consume more domestic inputs than those located in the Northern region. One important thing to notice is that, as results of the merging of PITEX and maquila firms into a single program, IMMEX firms show higher use of domestic inputs than the ones observed in previous years for maquila firms. Similarly, the total use of domestic inputs for all IMMEX firms in Mexico is twice as high as the corresponding figure for the last year of the maquiladora $24 \%$ in 2008 for IMMEX and $12 \%$ for maquiladora, respectively). The reason for such higher use of domestic inputs from IMMEX firms (than the one observed in maquiladora in table 2.2) is simply the result of including firms in the sample that were previously considered to be part of the domestic economy of economy that mostly relied on domestic inputs to produce both for domestic consumption and for exports (PITEX firms).

The information presented in tables (2.4) and (2.5) can be better understood by analyzing figure (2.3). Figure (2.3) follows the same structure as the one previously described for figure (2.2). Here, we can observe that, as a result of the growth in Mexican population with respect to that of 2005 (Figure 2.2.b), some of the Mexican states that are now heavily populated also present an important concentration of IMMEX firms. This is the particular of case of Chihuahua (CM) and Nuevo León (NL). Nevertheless, apart from this, we still observe that the vast majority of IMMEX firms are not located in the Mexican regions with highest population levels. We are again referring to those Mexican states that are colored in red in the map at chart (b) but that are left in blank in the map at chart (a) (both of them in figure 2.3). In addition those states that are heavily populated and that have a limited presence of IMMEX firms (Central, Western and, Southern) are the ones that show higher levels of domestic intermediate consumption, with respect to the demand for domestic inputs observed in North. 


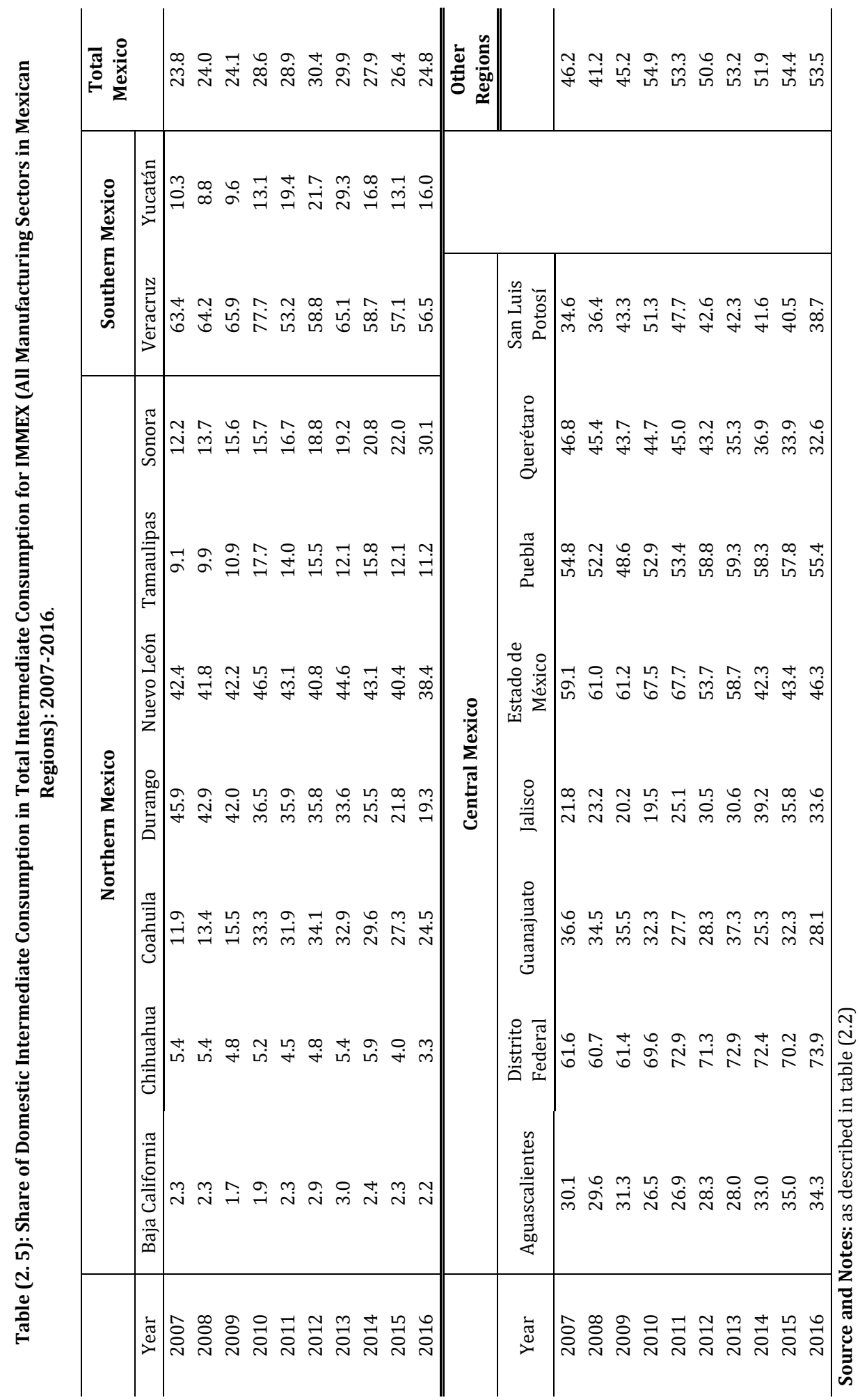




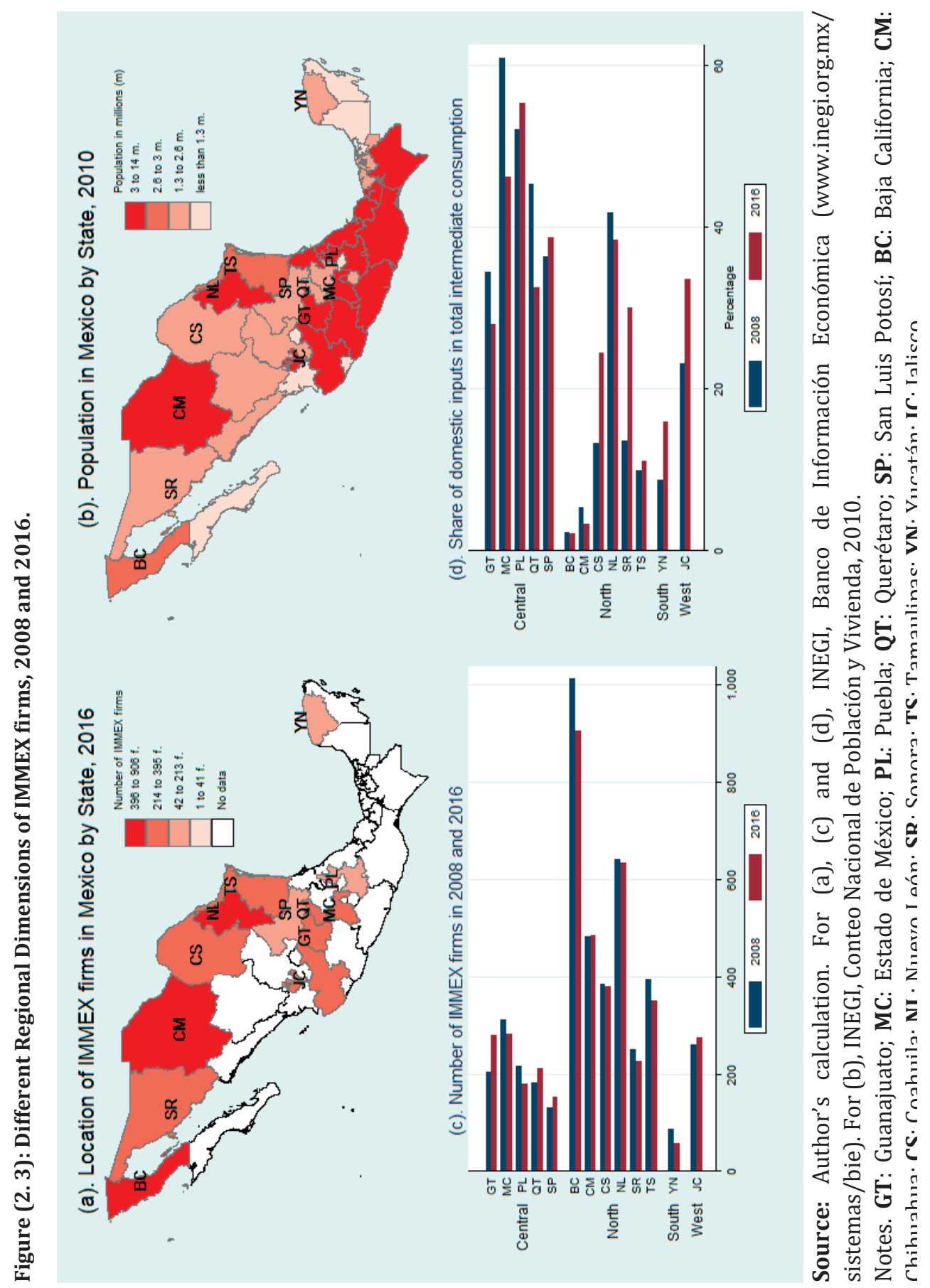


Acknowledging new and different strategies to organize global production, the Mexican government allowed for the participation of new types of manufacturing firms within the IMMEX framework. In general, 5 types of firms were to receive benefits within the IMMEX framework. The first type of firms is IMMEX Industrial which included those firms that belong to the traditional concept of Maquiladora and PITEX (i.e. firms that only transform intermediate goods into goods for exports and/or for the domestic market). IMMEX Albergue is the second type of firm and includes those firms that perform shelter operations (those firms that perform assembling operations by receiving intermediate inputs or technology from different foreign clients). IMMEX Servicios, on the other hand, refers to those firms that provide services for the operation of other IMMEX firms. Under the new IMMEX framework, those firms are allowed to directly export services to other firms outside Mexico (they only used to export indirectly via other IMMEX firms). Thus, they are also entitled to import their own intermediate goods free of duty. According to PWC (2013), IMMEX service firms perform repairing, cleaning, quality control testing, packaging, greasing activities and technological support services (back office, share service centers).

IMMEX Controladora and IMMEX Terciarización are the fourth and fifth type of firms considered within the new export promotion program. These two types were not previously considered in the PITEX program nor in the Maquiladora regime. They were created and included in the IMMEX framework, given the emergence of new and different strategies to organize global production. IMMEX Controladora refers to those firms that control and administrate the temporary imports of several firms that belong to its hierarchical structure. IMMEX Controladora is the main legal representative of those firms with regard to the fiscal and custom authorities in Mexico. This new type of firm is created in order to allow for the decentralization of bureaucratic procedures across different subsidiary firms in Mexico that belong to the same organization.

Finally, IMMEX Terciarización refers to those firms that receive imported inputs from foreign clients but have no productive capacity to transform those inputs into a good for export. Thus, these firms operate by relying on third parties. This means that a firm registered as IMMEX Terciarización will have to find other IMMEX firm or other regular domestic manufacturing firm that has the productive capacity and that is willing to transform those imported goods into a final good. Once the IMMEX firm receives the final output transformed by a third party, it exports back the production to original foreign client.

In general, all the five types of IMMEX firms are also entitled to perform "submanufactura" operations. Sub-manufactura means that IMMEX firms can transfer imported intermediate goods to other firms not belonging to the IMMEX framework. According to Gambrill (2008), the main objective behind those transfers of imported goods was to incentivize the development of local suppliers that cannot access those imports because they cannot afford to or are not willing to become a IMMEX firm. This also means that the specific benefits enjoyed by IMMEX Terciarización and IMMEX Controladora can also be extended to the rest of IMMEX firms, i.e. IMMEX Industrial firms can also act as IMMEX Terciarización if they wish the send intermediate inputs for final processing to other third parties in Mexico. 
IMMEX firms could still enjoy the benefits from the Sectoral Promotion Programs (PROSECs). As mentioned in section 2.3.3, by 2001, NAFTA required its signatory countries to impose tariffs on the imports of non-NAFTA inputs. In order not to lose the competitiveness, Mexico devised a program named PROSECs which allowed for the duty-free imports of the key intermediate goods used by maquiladora firms. Similarly, IMMEX firms also faced no restriction to selling a given percentage from their final output domestically. According to PWC (2013), any given portion of final output (with foreign content) may be sold domestically in the domestic market upon payment of the corresponding import duties on the foreign content thereof. Those imported intermediate goods that had to pay import duties were those that have not been transformed or processed in North American country to be considered of NAFTA origin. The reason for imposing those import duties was related to the fact that the Mexican government wanted to protect the production at its domestic market. Such protection would take place by limiting the foreign content of those final goods whose intermediate production mostly came from countries by which Mexico has not signed a free trade agreement (Most of the Asian countries). At this regard, for those countries where a free trade has not been executed, Mexico imposes the highest tariff at a 35\% rate and custom processing fees at $0.008 \%$. Those two tariff duties are computed on the customs value of goods, plus any other taxes according to the type of merchandise (Moore Stephens, 2017).

The benefits from ECEX and ALTEX programs were also included into the IMMEX framework. Such situation means that IMMEX firms can also apply for the benefits of ALTEX or ECEX and vice versa (PWC, 2013). As for income/asset taxes, IMMEX firms are still required to compiled with transfer pricing rules. To this end, they can rely on safe harbor rules, advanced pricing agreements, mark up method, or return on foreign assets (León-Santacruz \& Luján, 2014). Firms belonging the IMMEX could also obtain tax credits $(E \& Y, 2010)$ and apply for import duty drawback schemes (PWC, 2013).

The last important change in the IMMEX framework took place in 2014. From that year onwards, IMMEX firms were required to pay value added tax at the $16 \%$ rate on their temporary imports. IMMEX firms can apply for VAT crediting benefits provided that their imports belong to the production for global supply chains and receive a certificate from Mexican authorities (León-Santacruz \& Luján, 2014).

\subsection{The Future of Mexico's Export Promoting Programs: Industrializing the Underdeveloped Southern Region.}

As observed in figure (2.2) and (2.3), most of the manufacturing production in Mexico (both for exporters and non-exporters) is concentrated in the Northern states. Firms setting operations in Northern Mexico enjoy unique access to the US market, efficient infrastructure and close proximity to efficient suppliers also located in the US. On the other hand, an incipient industrialization process has been historically observed in Southern Mexico. Unlike Northern states, Southern Mexican states suffer from high levels of poverty, inefficient or non-existent infrastructure, and an industrial environment where no competitive techniques are being implemented. According to CEFP (2016), three major Southen Mexican states (Guerrero, Chiapas and Oaxaca) 
produce less than 7\% of Mexico's GDP but their joint population represents $15 \%$ of the Mexican population. Some of the competitive advantages offered by the Southern region (when compared to Northern Mexico) are relatively fast transportation between the Pacific and Atlantic oceans, proximity to Mexico's major oil regions, relative abundance of natural resources and low-qualified labor that is cheaper than anywhere else in Mexico.

By 2016, the Mexican government implemented a new industrial promotion program aimed at the specific industrial development of Southern states. This rather new program is called Zonas Económicas Especiales (Special Economic Zones) and its main objective is to help Southern states close their industrial gap with respect to the highly industrialized border region. Strict regional planning is required to decide where in Southern Mexico Special Economic Zones (SEZs) should be located. According to CEFP (2016), Special Economic Zones can only be located in regions with extreme poverty levels, with population levels between 50,000 and half a million people and, in areas that enjoy a good connectivity to reach domestic and foreign markets. The most important requirement for SEZ is that firms joining such scheme should produce output in line with the region's productive potential and competitive advantages. The latter means that SEZs in Southern Mexico will not specialize in the production of Electronics or Transportation equipment (currently monopolized by IMMEX firms). Rather, they might specialize in producing textiles goods or natural resources based manufacturing.

Given that the SEZs program is rather new, policy makers in Mexico have not yet clarified the precise legal framework that will govern this new industrial promotion program. Little is known as to what kind of benefits and obligations those SEZs will receive. More importantly, it is still unclear if the SEZs program will be a 2016Maquiladora strategy for the Southern region that will coexist with the current IMMEX program, in the same fashion that the old maquila strategy survived with PITEX firms. It could also be that SEZs firm will be immediately granted IMMEX status. In line with previous changes on Mexico's export promoting policies, we believed that policy makers will first observe the operation of the SEZs during some initial years before issuing a specific legal framework for those firms.

\subsection{Conclusion.}

This chapter studied the evolution of different policy instruments that Mexico has implemented to promote its production for exports over the last fifty years. The production for exports was initially supported within the Maquiladora framework by the mid-1960s. Given the ISI strategies prevailing at that time, the Maquiladora framework was only devised as a temporary program that would provide higher levels of foreign currency and employment. With the failure of ISI by important debt crises by the early 1980s, Mexico opted for an export-oriented strategy where the Maquiladora framework was to become one of the key cornerstones. Nonetheless, the Maquiladora industry was not only going to be the only export promoting framework (as was the case in the past). With Mexico's new outward orientation, policy makers devised a framework similar and parallel to the Maquiladora one, but aiming at the development of firms within its domestic manufacturing sector. This second exporting promoting 
framework (known as PITEX) was designed to induce domestic manufacturing firms to progressively increase their production for exports. With the PITEX framework, firms only producing for domestic consumption would start receiving import and tariff incentives similar to those received by Maquiladora firms provided that they started producing for foreign markets. Given the lack of competition and technological backwardness that most domestic firms faced during ISI, the government imposed different performance requirements for domestic firms seeking to participate in the PITEX. Those performance requirements for PITEX firms implied selling a certain percentage of output in foreign markets to freely import basic raw materials $110 \%$ of output in this case) and/or machinery and equipment (30\% of output in this other case). Maquiladora firms faced much higher export performance requirements (exporting $100 \%$ of total output) but also faced rather flexible requirements in other issues such as increasing the technological capabilities of Mexican workers. In my view, by imposing different export performance requirements for PITEX firms, the Mexican government was not only encouraging more domestic firms to produce for exports. More importantly, by setting realistic export performance requirements ( $10 \%$ of total output) the government was allowing the participation of more Small and Medium Enterprises in the production for foreign markets and was inducing their industrial development by setting higher performance requirements for them to obtain higher benefits $30 \%$ of total output being exported as a requirement for freely importing machinery and equipment).

In this context, it can be observed that the export promoting policy framework in Mexico moved from isolating foreign assembly firms in a temporary and restrictive framework to promoting an increasing interaction of those firms with domestic firms. By including some of key elements from the Maquiladora framework to the PITEX program, the Mexican government succeeded in continuously increasing its production for exports.

Adapting the export promoting framework (Maquiladora and PITEX) to the requirements imposed by NAFTA and to the new context of international competition explains why Mexico became one of the key manufacturing powerhouses in the world. Mexican manufacturing firms significantly benefited from the trade incentives provided by NAFTA. Nevertheless, when NAFTA opted for higher regional integration (i.e. excluding third countries from receiving NAFTA benefitS), Mexico prioritized its participation in international production networks. Even though NAFTA required its signatory members to impose tariffs on the imports from non-NAFTA countries by 2001, Mexico devised a program to exempt non-NAFTA countries that had operations in the country from these new tariffs. Such a decision was taken in light of the large number of electronics firms in Mexico (specially within the Maquiladora program) that mostly sourced their inputs from East Asia. In this context, Mexico still prioritized the traditional benefits of an outward orientation strategy (higher output, employment, and foreign direct investment), while neglecting the opportunity of inducing those firms to source more inputs locally.

Given the stiff competition triggered by more efficient foreign producers during the early 2000s, the Mexican government sought for new alternatives to further promote its production for exports. The IMMEX framework merged firms belonging to Maquiladora 
and those in PITEX into a single program. In my view, the merging was an incremental step given that both programs had progressively reduced their differences with respect to each other. The key difference between PITEX and Maquiladora, which still can be observed in the IMMEX framework, is their location in different parts of the Mexican territory (Northern region for Maquiladora and Central Mexico for PITEX), as well as the fact that one solely produces for export while the other still mostly produces for the domestic market. The Mexican government expected to increase the competitiveness of its export sector by letting all its exporting firms coexist in a single framework with the same rules of operation, same performance requirements and same incentives. To further ensure the participation of SMEs, export performance requirement remained at $10 \%$ for all firms. The latest challenge for the Mexican government is to promote the industrialization in its poorest regions (Southern Mexico) by means of the program named Special Economic Zones (2016) and to let those new firms interact with those belonging to the IMMEX framework.

We conclude that any country seeking to increase its production for export and to successfully integrate in international production networks has much to learn from the Mexican policy experience. Under certain conditions, Mexico's experience allows firms in domestic manufacturing to increase their production for exports and allows SMEs participate in foreign markets. Nevertheless, Mexico is not the example to follow, if the main objective of other countries is to increase the use domestic inputs in their production for exports. This Mexico has clearly failed to achieve. 


\title{
Chapter 3.
}

\section{Regional Value Added Component in Manufacturing: Evidence from Top Exporters and Regions of the World Economy ${ }^{\dagger, * *}$}

\begin{abstract}
This chapter analyses how the regional value added component in manufacturing evolved as result of the increasing fragmentation of production from 1990 to 2011. To this end, we decompose the final output (per manufacturing sector) from advanced and emerging economies (the top manufacturing exporters) into the value added contribution from domestic and foreign suppliers by country of origin. We also perform this analysis for all the geographical regions of the world economy (which are mostly consistent of developing economies). By relying on a new methodology proposed by Los et al. (2015) and on the multi-regional input output tables from the EORA dataset, our results indicate that, for most countries, fragmentation of production led to an increasing importance of the regional component of manufacturing value added. Only domestic firms in advanced and emerging economies producing in textiles, electronics and other manufacturing increased their network of suppliers beyond those available in their own region in a major way. The other sectors in advanced and emerging economies and most of the developing world mainly increased their regional ties as a result of increasing fragmentation. This indicates that despite significant decreases in transportation and communication costs observed in recent decade, manufacturing production has not become global but more and more regional.
\end{abstract}

Keywords: Fragmentation, Global Value Chains, World Input Output Tables, Manufacturing.

JEL codes: C67, L6, F2

\footnotetext{
† This is chapter is based on Castillo, J.C. (2016), "Regional Value Added Component in Manufacturing: Evidence from Top Exporters and Regions of the World Economy", UNIDO-Inclusive and Sustainable Development Working Paper Series, WP 14/16.

**This paper is the result of a research internship from the author at the United Nations Industrial Development Organization (UNIDO). I thank Nobuya Haraguchi, Adam Szirmai and Bart Verspagen for advice, comments and criticisms. I also gratefully acknowledge financial support from UNIDO for my $\mathrm{PhD}$ project. Comments and discussions based on UNU-MERIT's internal conference (2017).
} 


\subsection{Introduction}

In recent years, significant decreases in transportation and communication costs have led to an increasing fragmentation of manufacturing production, meaning that products are no longer produced in a single location, but instead are assembled from parts that are produced in many different locations, and which themselves can be produced in a fragmented way. In this new system of production, so it is argued, advanced economies specialize in the knowledge intensive activities of manufacturing (research and development activities, designing of the product, and so forth), while the less developed economies specialize in the labor intensive activities ones (mostly assembling of final goods) (Feenstra \& Taylor, 2014). This fragmentation has led to an increasing trade in intermediate goods among economies, which has also been reinforced by the signing of major trade agreements (the implementation of NAFTA and the European Union), as well as well as the joining of low cost producers into the World Trade Organization (the case of China).

A large body of research indicates that a main outcome of such fragmentation of production, and the increasing trade on intermediate goods among economies, has been the emergence of what has been called Global Value Chains (GVCs) (Gereffi et al.,2005; Timmer et al., 2013; Feenstra \& Taylor, 2014; Koopman et al., 2014). This concept of GVC refers to the increasing participation of foreign economies in the manufacturing production of a given country. Nowadays, more economies add value to the production of final goods in a given country. This increasing participation from foreign economies is then reflected in an increasing foreign value added contribution to the country's final manufacturing output. Nevertheless, in my view, and despite the aforementioned trends, manufacturing production is not entirely occurring at a global level but mostly taking place at the local and regional level. The value added contribution from local producers in the domestic economy usually still accounts for the largest share in the production of final output. Furthermore, most of the time, the neighboring economies of a given country (those that share the same geographical region) are precisely the economies behind the increasing foreign value added contribution observed in a country's final output. In this context, the scope for manufacturing production taking place at the global level is still limited.

A number of factors also play an important role in explaining increasing regionalization of manufacturing production. For instance, Baldwin (2006) and Baldwin \& LópezGonzález (2015) have indicated that manufacturing production is organized at the regional level by means of headquarters and factories economies. Here, technologically advanced headquarter economies (such as the US, Germany and Japan) reallocate manufacturing activities to neighboring countries (factories) within their own region. They engage in supply chain trade activities with factory economies (exporting and reimporting of intermediate goods and of goods for final sale) to reduce transportation costs and to benefit from low-wages when those factory economies are also regarded as developing countries (this is the role played by most countries in South East Asia, Eastern Europe and Mexico for the case of factory Asia, factory Europe and factory NAFTA, respectively). 
In addition, despite drastic reduction in information and communications costs, distance still matters for manufacturing production. According to Baldwin \& López-González (2015), geographical clustering in the transportation sector is necessary since this specific sector requires key technicians and managers to travel among production stages which should be located within a short travel distance from the headquarter economy. In this context, the regional aspect of the increasing fragmentation of production highlights that one of main features of this process is not simply related to more goods crossing international border. More importantly, it highlights the importance of the international mobility of managerial and of manufacturing know-how (2nd unbundling).

In light of this situation, our research will analyze how the regional component in manufacturing value added has evolved as a result of the increasing fragmentation of production. The regional component in manufacturing value added is understood as the total value added delivered by a group of countries belonging to a specific geographical region to the production of final goods in a given economy. In order to further understand the evolution of this regional component, our research separately analyzes the trends observed in the top manufacturing exporters, and, the trends for the regions of the world economy (including those in Africa and Asia, as well as Oceania and Central and South America). By doing this, we analyze both the evolution of the regional component in the case of the advanced and emerging economies (most of the top manufacturing exporters), but also the one for the other regions of the world economy (which are mostly developing economies). Our two reference years will be 1990 and 2011. This is because the first one reflects a period where fragmentation was not widespread among countries, while in 2011 this had become a global phenomenon.

In this context, we will tackle the following research questions:

1) To what extent, has the increasing fragmentation of production affected the regional component in manufacturing value added?

2) As result of increasing fragmentation, do producers from top manufacturing economies responded in the same way as producers located in the rest of the World (developing economies)?

To meet these objectives, our research will first decompose the value of final good produced by a given country into the value added contribution from domestic and foreign producers (by country of origin). Then, to analyze the regional component in manufacturing value added in a single country, we will group the foreign value added results by country of origin into different geographical categories. Finally, this decomposition is extended to take into account the intra- and extra-regional value added component in manufacturing value added across all regions of the world economy.

Our results indicate that, as a result of increasing fragmentation, only advanced and emerging economies (in specific manufacturing sectors) faced significant incentives in increasing their network of suppliers beyond those available within their own region. Most of the developing world, however, increased their regional ties. On the other hand, our results for regions of the world economy indicate that the intra-regional component 
in manufacturing value added (i.e. the value added contribution from other economies belonging to the same region as the country of analysis), was already high before the fragmentation of production became a global phenomenon. As a result of increasing fragmentation, the intra-regional component simply became higher. The extra-regional component of manufacturing value added (i.e. the value added contribution from other economies belonging to the different regions than the main country of analysis) also increased but remained always lower than the corresponding intra-regional one. All those latter results, however, are also driven by factors governing the organization of production in each manufacturing sectors (type of good being produced, the modularity of its production, the proximity to major markets and the existence of significant trade and tariff incentives, and so forth).

This paper is structured as follows. Section 3.2 presents a literature review on how the fragmentation of production has evolved over time and on the different analytical tools currently available to measure such phenomenon. Section 3.3 presents our preferred methodology to decompose the value of final goods production into the different value added contributions from domestic and foreign producers (by country of origin). This section also briefly describes the EORA multi-regional input-output dataset used in our research, the strategy we follow in order to group countries according to geographical categories, as well as our method to identify the intra-regional and extra-regional value added contribution observed in a region's final output. Section 3.4 presents our decomposition results for top manufacturing exporters considering total final manufacturing output, and the production per manufacturing sector for 1990 and 2011. This section also presents the intra-regional and extra-regional results for all the regions of the world economy for the same years. Finally, Section 3.5 presents our conclusions, points for discussion and avenues for further research.

\subsection{Literature Review: How Has Fragmentation Evolved and How We Can Measure It?}

This literature review is divided into two sub-sections. The first one briefly summarizes the evolution of fragmentation over time, while the second one deals with an explanation of the available analytical tools to analyze this process.

\subsubsection{The Evolution of the Increasing Fragmentation of Production.}

The term fragmentation was first coined by Jones and Kierkowski (2001). They refer to the splitting up of a production process into two or more stages that can be undertaken in different locations. According to Athukorala (2010), the increasing fragmentation of manufacturing production has evolved through 3 different stages. The first stage is the formative. Here, only a small amount of multinational firms in few manufacturing sectors (electronics) reallocated some parts of their production to low cost economies. The main objective was to perform labor intensive parts of manufacturing abroad. This implied assembling of imported components that were supposed to be re-exported back as final manufacturing goods. The second stage in the evolution of fragmentation involved a higher participation of countries in the production network. Similarly, along with technological improvements, the production process of a great amount of 
manufacturing goods started becoming more prone to fragmentation. In light of this situation, multinational firms start reallocating not only the labor intensive activities to developing economies but also the knowledge and capital intensive stages of manufacturing to advanced economies. Here, the main outcome was the emergence of an increasing trade on intermediate goods between countries that has grown at higher rate than that of final manufacturing goods. Finally, the last stage in the evolution of fragmentation is related to the emergence of major low cost producers and the fragmentation of a wide range of manufacturing goods (textiles, transportation, all sort of electronics and other manufacturing goods). The main outcome behind this last stage is that some developing economies (those located in East Asia) managed to successfully abandon the labor intensive activities and start producing at the knowledge and capital intensive stages of manufacturing.

Given this context of increasing fragmentation, multinational firms face two options in order to organize manufacturing production across different countries and regions. The first option is to coordinate the production process among subsidiaries of the multinational firm located in other countries. The second option is to organize the production with other firms in the market that do not belong to the multinational firm. According to Williamson (1975), the decision of organizing the production through market transactions or within the structure of the multinational firm will depend on the specificity of manufacturing good being produced. For instance, arm's length market transactions ${ }^{6}$ will be implemented when standard products are being produced. What we mean here is that this type of market transaction works well for those goods that are being widely produced (i.e. they are the in the mature stage of their product cycle) because their production is easy to describe and its production process is widely known and can be easily implemented by a large variety of suppliers.

On the other hand, the more customized the product or the service, the more likely it is to involve transaction specific investments that will take place within the firm (Gereffi et al., 2005). This is the case of the non-standardized inputs. In my view, there are several reasons why a firm may decide to keep the production of these goods within their own structure. The first issue is related to opportunistic behavior. Given that the production of those non-standardized inputs might have implied significant expenses on research and development activities, multinational firms are not willing to engage in market transactions with other potential competitors. This is because those potential competitors might take advantage of the knowledge and of the large expenses made by the multinational firm by replicating such intermediate inputs. The second issue is that the production of such inputs also implies greater coordination among the entities of the firm. Since the production of the new good is not highly codified, the multinational firm requires greater coordination and supervision of the new process in order to ensure that their subsidiaries correctly implement the process. Finally, the last reason why firms decide to keep transactions within their own structure in the case of the nonstandardized goods is related to the cost of inducing a learning process. Firms in the market might not have the necessary skills in order to implement the production

\footnotetext{
${ }^{6}$ Arm's length transactions indicate that buyers and sellers of a product act independently and have no relationship with each other
} 
process of a good according to the high standards set by the firms. Inducing a learning process for those firms in the market might be costly for the multinational so it could be a better idea to keep their activities in house.

\subsubsection{How to Analyze the Increasing Fragmentation of Production?}

The increasing fragmentation of manufacturing production has also created significant challenges for scholars and policymakers. There are two main challenges. The first one is that it has become difficult to determine which countries and regions benefit from the increasing fragmentation of production. Given the interaction of many countries and regions in production networks, we see that intermediate goods can cross borders between countries more than once. Furthermore, the growth rate of the trade on intermediate goods is now higher than the corresponding one for final goods. Therefore, it has been argued that policy makers and scholars cannot totally rely on standard international trade statistics to analyze the increasing fragmentation of production.

The second challenge is a better understanding of the main characteristics of the firms that participate in international production networks. Firms that participate in global value chains are heterogeneous, not only in terms of size, or in type of ownership (domestic or foreign owned). They are heterogeneous considering the type of good they produce, the type of trade benefits and incentives they receive, the export promoting schemes which they participate (export processing zones, for instance) or the type of manufacturing specialization they follow (whether they are mostly producing for exports or whether their production is also supplied to the domestic market). In general, policy makers and scholars require more complex statistical and analytical tools and a deeper understanding of how firms behave in the context of production networks in order to fully understand international production networks.

The reaction to these challenges has been the increasing use of other more elaborated analytical tools such as aggregate input output tables, multi-regional input output tables as well as micro data and case studies. We will explain each of them and how they have been used to analyze fragmentation.

The first one is the use of input output tables for the total economy of a given country (aggregate input-output tables). Hummels et al. (2001) introduced the concept of vertical specialization (VS). This index, by means of input-output tables (IOTs), calculates the imported input content in the manufacturing goods exported by an economy. This imported input content is reported by this index in a scale of 0 to 1 . This analytical tool was one of the pioneering works to better analyze the fragmentation of production because it allowed determining both the foreign and domestic input content embodied in a country's export. This is because the remaining part of this index of VS (the one that is not the level of imported input content) can be regarded as a measure for the domestic input content observed in the manufacturing exports of a country.

Nonetheless, despite its usefulness in assessing the domestic and foreign value added embodied in exports, the index of vertical specialization has several shortcomings. For instance, Koopman et al. (2008) and De La Cruz et al. (2011) have criticized the underlying assumption of the original index of VS initially developed by Hummels et al. 
(2001). A key assumption needed for the original formula of VS to work is that the intensity in the use of imported inputs is the same between different types of production; production for processing exports and the production for the domestic use. This assumption may not hold for economies that are highly engaged in international production networks. This is because policy preferences for firms engaged in global production networks lead to significant differences in the intensity of imported inputs (De La Cruz et al., 2011). Firms engaged in global production networks might use more imported inputs in their production for processing exports than firms that solely produce for the domestic market. Recognizing this situation, Koopman et al. (2008) posited that if a distinction between the production for processing export and the production for domestic use is not provided, then the weighted average observed in the index of VS will underestimate the share of foreign value added in a country's exports.

The second analytical tool that can be used to analyze the increasing fragmentation of production is the use of multi-regional input output tables. A multi-regional IOT is an extension of a national (aggregate) input output table. By relying on bilateral trade data, national IOT are linked across countries in order to construct a multi-regional setting of IOTs for the world economy. The multi-regional IOT disaggregates the imported goods received by a given economy (either for final or intermediate use) according to country of origin. It also indicates the domestic consumption of goods for intermediate and final use and the delivery of those goods domestically produced by county of destination. In recent years, several multi-regional IOTs have become available. Some of the most widely known databases are the Global Trade Analysis Project (GTAP) from Dimaranan et al. (2005), the EORA multi-region input output table (Lenzen et al., 2012), the World Input Output Tables (Timmer et al., 2015) and, the Trade in Value Added initiative from the OECD and WTO. The main differences among them are not only related to the number of manufacturing sectors and period of time being studied, or the amount of countries there included. More importantly, according to Tukker and Dietzenbacher (2013), the key difference between the various global input-output systems is that those were developed by following different construction philosophies.

The use of those databases has provided a great number of advantages in order to further understand the process of fragmentation. We can mention two of them. The first one is the concept of the value added exports. According to Johnson and Noguera (2012), value added exports measure the amount of value added from a given source country that is consumed in each destination (i.e., embodied in final goods absorbed in that destination). Following the aforementioned authors, at the bilateral level, the ratio of value added to gross trade is a marker for both bilateral production chains, as well as multi-country production chains in which value added transits through third countries en route from source to destination. Therefore, changes in the ratio of value added to gross trade through time are a metric for changes in the structure of cross-border supply chains. Measuring these changes is a prerequisite both for empirical work aimed at identifying the fundamental drivers of fragmentation and for calibrating models that measure the consequences of rising fragmentation.

Given such analytical context, Johnson and Noguera (2012) compute the value added content of trade for forty-two countries from 1970 to 2009. Their results indicate that, 
for the world, the ratio of value added to gross trade falls by ten to fifteen percentage points, with two-thirds of this decline in the last two decades. Across countries, declines range from zero to twenty-five percentage points, with large declines concentrated among countries undergoing structural transformation. Across bilateral trade partners, declines are larger for nearby partners and partners that adopt regional trade agreements. In their view, this whole context indicates that both policy and non-policy trade costs shape production fragmentation.

The second important contribution for the analysis of fragmentation that has been made possible due to the availability of multi-regional IOTs is the fact that now it is possible slice up the value chain in which a country participates. Koopman et al. (2014), for instance, break up a country's gross exports into various value added components by source and additional double counted terms. Those various added components include the domestic and foreign content that is embodied in final goods and intermediate inputs. The utility of this analytical tool is that it integrates all previous measures of vertical specialization and value-added trade in the literature into a unified framework. Following this framework, Koopman et al. (2014) break up the gross exports of various advanced and emerging economies for the reference year 2004. Their results provide evidence on relevant issues for fragmentation such as the domestic value added that returns home in terms of foreign imports, which is part of the double counting in official trade statistics.

Yet another method to slice up the value chain is that provided by Los et al. (2015). Those researchers indicate the value added contribution by country of origin in the final manufacturing production of several goods. Their analysis focuses on forty countries and fourteen manufacturing sectors. By relying on standard IOT techniques, their results indicate that in almost all product chains the share of value added outside the country is increasing since 1995. The share of value added outside the region has been increasing much faster though. These tendencies were only briefly interrupted by the financial crisis in 2008.

Nonetheless, despite the usefulness and widespread use of multiregional IOTs (and of the aforementioned IOT techniques), they are not exempt from problems. According to Nomaler and Verspagen (2014), there are several problems related to the aggregated nature of the input-output table that may lead to large distortions and biases. There are three main sources from such distortion when value chains are decomposed with IOT: the average nature of value added to output ratios in the tables, the emergence of production cycles in the process of aggregating several value chains into a single table, and the characteristic of the Leontief inverse matrix to even out the value added distribution. In this whole context, those authors suggest that more detailed sources of information should be used to better analyze the increasing fragmentation of production.

Firm-level datasets and the information provided by detailed case studies are the alternative to cope with the biases triggered by the use of aggregate data. For instance, firm-level domestic value added can be calculated the by adding up information in terms of domestic and imported intermediate inputs, wages, rental cost on capital, profits and so forth. Then, by relying on techniques such as firm demography, the domestic value 
added created by a given economy can be decomposed into the contribution from the firms that exit the market, those stay and so forth. Furthermore, the incorporation of firm level information into IOT settings has been proposed as the key strategy to tackle strong assumptions behind those tables as well the biases they can trigger when analyzing the fragmentation of production. According to Ahmadm and Araujo (2011), firm level data sets can improve the quality of the IOT given that they contain information for export and import intensity as well as for ownership status. This disaggregation can be then used to improve the allocation of total imports across sectors and create stronger links between imports used in exports and imports used in domestic demand.

Similarly, case studies also allow for a more comprehensive analysis of the fragmentation of production at the firm-level. Here, we are referring to study of Dedrick et al. (2010) on the Iphone and Ipad. According to those authors, while these products, including most of their components, are manufactured in China, the primary benefits go to the U.S. economy as Apple continues to keep most of its product design, software development, product management, marketing and other high-wage functions in the U.S.

Two main ideas that are relevant for the current research project emerge from this literature review. From section 3.2.1, we understand that firms will have different incentives to organize the manufacturing production across countries and regions. Those incentives are not only related to the endowments of capital, labor or knowledge available in each country, but also to the specificity of the good being produced as well as the type of market transaction that the production of this involves. From section 3.2.2, we observe that there are several methods and databases to analyze the regional component of manufacturing. Firm level datasets and case studies are by far the best alternative to analyze this given the specific and detailed information that they provide. Nevertheless, access to such information is highly limited. Therefore, to analyze fragmentation as a phenomenon impacting the World economy, our research necessarily has to rely on the information provided by multi-regional input output tables and the decomposition methods that can be implemented with those. The aggregate nature of the input-output framework and the biases they can trigger should be kept in mind when deriving conclusions from decomposition techniques. With these ideas in mind, we proceed to indicate our preferred methodology and data. This objective is met in the following lines.

\subsection{Methodology and Data}

The main objective of our research is to decompose the final production from a given country/ region into the value added contribution of foreign and domestic producers that participate in this production. To achieve this objective, our research will rely on the methodology proposed by Los et al. (2015). The main reason for this is that, in my view, the decomposition technique offered by those authors is more standard and straightforward than the decomposition studied by Koopman et al. (2014). Koopman et al. (2014) offer an interesting decomposition framework that unifies all the existing measures of vertical specialization and value added trade. Nevertheless, given the amount of countries and regions that we aim to analyze, our research is mostly interested in the value added contribution from foreign and domestic suppliers and not in the different value added categories that integrate those concepts. 
By generalizing a measure of fragmentation proposed by Feenstra and Hanson (1999), Los et al. (2015) introduce a metric that uses information from multiregional Input Output Tables to describe the international fragmentation of specific global production networks. Specifically, Los et al. (2015) decompose the value of a final product in the last stage (country) where the final manufacturing production took place. This decomposition includes the value added shares generated in all the countries that contribute to that final product. Therefore, this measure does not only take into account the value added by the immediate suppliers of intermediates, but also the value added by suppliers further upstream.

Formally, consider a particular industry $i$ located in a specific country $j$, denoted by $(i, j)$. To produce good $(i, j)$, activities in industries $s=1, \ldots, S$ in each of the countries $n=1, \ldots, N$ are needed. To decompose its value, the first step to take is to find the levels of gross output associated with the production of $(\mathrm{i}, \mathrm{j})$. Those can be estimated by applying standard input output methods to global input output tables. Global input output tables contain information on the values of intermediate input flows among all country industries in the world, as well as on the values of flows from each of these country-industries to final use in each of the countries. These tables also contain information on value added generated in each of the country industries. Combining information on value of sales and value added per dollar of sales leads to estimates of value added in each of the $S N$ industries as a consequence of final demand for product $(\mathrm{i}, \mathrm{j})$. For this, the equation that has been a standard tool in input-output analysis for over decades (Miller and Blair, 2009) can be used:

$$
\mathbf{g}=\hat{\mathbf{v}}(\mathbf{I}-\mathbf{A})^{-1}(\mathbf{F e})
$$

In this equation, $\mathbf{g}$ is the vector of value added created in each of the SN countryindustries involved in a value chain. The choice for a specific final output matrix $\mathbf{F}$ determines which value chain is considered. Final output is output delivered for household and government consumption, or investment demand (both including domestic and final foreign demand). $\mathbf{e}$ is a summation vector. $(\mathbf{I}-\mathbf{A})^{-\mathbf{1}}$ is the wellknown Leontief inverse matrix, the use of which ensures that value added contributions in all tiers of suppliers are taken into account. $\mathbf{v}$ is a vector with value added over gross output ratios, for each of the country-industries. ${ }^{7}$

The (SNXSN)-matrix $\mathbf{A}$ and the (SN)-vector $\mathbf{v}$ are obtained as $\mathbf{A}=\mathbf{Z}(\hat{\mathbf{x}})^{\mathbf{- 1}}$ and $\mathbf{v}^{\prime}=\mathbf{w}^{\prime}(\hat{\mathbf{x}})^{-\mathbf{1}}$, respectively. A gives the intermediate inputs per unit of output of gross output, while $\mathbf{v}$ represents the value added generated per unit of gross output. $\mathbf{Z}$ represents the inter-industry demand for intermediate inputs, while $\mathbf{w}$ indicates the row vector for gross value added. F stands for a final demand matrix of dimensions SNxCN (where $\mathrm{C}$ is the number of final demand categories per country) and, e represents a summation vector consisting of ones. Fe is then a (SN) vector with a single positive element, which is obtained by adding foreign and final demand for $(\mathrm{i}, \mathrm{j})$ 's product.

\footnotetext{
7 Matrices are indicated by bold capital symbols and (column) vectors by bold lowercases. Hats denote diagonal matrices with the corresponding vector on the main diagonal.
} 
In order to implement this methodology, a multiregional input-output framework is required. As mentioned in section 3.2.2, a number of multiregional IOTs are currently available.Given the objectives of this research, we will utilize the EORA database. The main reason for this is the extensive coverage of countries and manufacturing sectors as well as the rather long period of time covered by this database. As explained in Lenzen et al. (2013), the EORA multiregional input output database covers 187 countries in 8 manufacturing sectors during the period from 1990 to 2012. Such extensive coverage is rather useful for the scope of this research. Not only will this database allow us to focus on the top manufacturing exporters of the world economy, it will also let us perform a thorough analysis of the global tendencies from the increasing fragmentation of production by taking into account not only the context taking place in major regions (North America, Western Europe, East Asia) but also in the rest of the world. This means that EORA also lets us analyze the tendencies of fragmentation in regions such as Central America, South America, Central Asia, South East Asia, Eastern Europe, North Africa and the Middle East, Sub-Saharan Africa and, Oceania. Similarly, the years covered by this database allow us to analyze the fragmentation of production between two relevant periods. The first one being a year where fragmentation was not widespread (1990) and, the second being a year (2011) where major changes in the world economy had occurred and thus fragmentation of production was already regarded a more common strategy for manufacturing. Those changes are the signing of important regional trade agreements (MERCOSUR in 1991, NAFTA in 1994, China's accession to WTO in 2004, the accession of 10 countries to the European Union in 2004, and so forth) as well as the drastic drop in communication and trade costs.

Given that our main objective is to decompose the final production from a given countries and regions, our results will be divided in two main sub-sections. The first section will present the decomposition of value chain per manufacturing sectors for top 6 manufacturing exporters from the world economy in 2011 considering the 8 manufacturing sectors included in EORA as well as the total manufacturing output. The second sub-section will slice-up the value added chain observed in a region in terms of the intra-regional and extra-regional value added contribution embodied therein.

The top manufacturing exporters studied will be those that ranked in the top 6 according to export information provided by EORA for 2011. We sliced up the value chains of those top 6 countries for 2011 and 1990. This procedure means that the top manufacturing exporters analyzed for 1990 might not be the ones indicated by EORA in 1990 (recall that our reference year is 2011). We do this because our intention is to analyze the evolution of those manufacturing producers that managed to succeed by the end of the 2010s. Moreover, we further decompose the total foreign value added observed in each country according to the different value added contributions from regions of the world economy (Europe, North America, Central and South America, Africa, Asia and Oceania).

In this context, consider the regional value added contribution from countries $i$ belonging to region $j$ embodied in the final output from country $k\left(R V A_{i \in j, k}\right)$ as follows:

$$
R V A_{j, k}=\sum_{i \in j}^{i}\left(F V A_{i, k}\right)
$$


where $F V A_{i, k}$ is the foreign value added contribution from country $i$ in the final manufacturing production of country $k$ as obtained from equation 3.1.

Similarly, the total foreign value added contribution embodied in the final production from $k\left(F V A_{k}\right)$ can be defined as:

$$
F V A_{k}=\sum_{j} R V A_{j, k}
$$

Finally, the total value added delivered by foreign and domestic suppliers to the final production in $\mathrm{k}\left(T V A_{k}\right)$ will be

$$
T V A_{k}=D V A_{k}+F V A_{k}
$$

where

$D V A_{k}$ : The domestic value added contribution embodied in the final output from $k$.

On the basis of those equations, our research will determine patterns for the regional component of manufacturing for a given country. If we observe an increase in the $R V A_{j, k}$ in the region to which country k belongs (i.e where $\in j$ ), we will conclude that there is an increasing regionalization of manufacturing of production for country $k$. In this case, domestic producers will be interacting more with suppliers within their own region. On the other hand, if we observe an increase in the $R V A_{j, k}$ for regions where country k does not belong (i.e where $k \notin j$ ), our research will conclude that there is an increasing globalization of manufacturing production for country $k$. In this case, domestic producers will be interacting more with suppliers outside their own region. Finally, it is worth mentioning that in this first sub-section, the geographical regions of analysis (i.e., region $j$ that interacts with country $k$ ) will be Europe, North America (NAFTA), Central and South America, Africa, Asia and Oceania. This grouping of countries is possible due to the large amount of countries considered by the EORA dataset.

The second sub-section will slice up the value chain in a manufacturing sector for regions from the world economy. This means that we identify a region of the world economy and then we slice up the value added contribution embodied in the final manufacturing production of that region. In this case, the value added embodied in the final production from a given region is sliced up into two main components: the intraregional value added contribution, and the extra-regional value added contribution. The intra-regional value added contribution will be the sum of the domestic value added embodied in the final good produced by each country and the value added delivered by other countries within the same geographical region as reported by the main country of analysis. The extra-regional value added contribution will be the sum of the foreign value added contribution from other countries belonging to different regions, as reported by countries belonging to the main region of analysis. Formally, the intraregional value added contribution embodied in a given region $\mathrm{j}\left(I R V A_{j}\right)$, the corresponding extra-regional value added contribution ( $E R V A_{j}$ ), as well as the total value added embodied in such region $\left(T V A R_{j}\right)$ can be defined as follows: 


$$
I R V A_{j}=\sum_{k \in j}^{k}\left(D V A_{k \in j}+F V A_{i \in j, k}\right)
$$

where:

$D V A_{k \in j}$ : Domestic value added in country $k$ that belongs to region $j$,

$F V A_{i \in j, k}$ : Foreign value added contribution from country $i$ belonging to region $j$ as reported by country $k$.

$$
E R V A_{j}=\sum_{k \in j}^{k}\left(F V A_{l \notin j, k}\right)
$$

where:

$F V A_{l \notin j, k}$ : Foreign value added contribution from country $l$ not belonging to region $j$ as reported by country $k$.

Finally, the total value added embodied in the final production from a given region $j$ will be:

$$
T V A R_{j}=I R V A_{j}+E R V A_{j}
$$

This method of computing the intra-regional and extra-regional value added contribution embodied in region $j$ will be performed for all the regions of the world economy. To this end, we will follow the country categories proposed by UNIDO (2015) on the industrial development report for such year. This means that we will analyze the following regions: North America, Central America, South America, Western Europe, Eastern Europe, North Africa and the Middle East, Sub-Saharan Africa, Central Asia, South Asia, South East Asia, East Asia, and Oceania.

\subsection{Results.}

As previously mentioned, we will first focus on the value chain decomposition from the top manufacturing exporters and, later with the decomposition observed in the intraregional and extra-regional value added embodied in a region's final output. Therefore, section 3.4.1 and 3.4.2 will present the results we obtained by following equation (3.1) to (3.4) using the EORA data set. Section 3.4.3 will present the results we obtained relying on equation (3.1) and following equation (3.5) to (3.7) with the same dataset.

\subsubsection{Top Manufacturing Exporters.}

Our decomposition results for the top manufacturing exporters from each country category included in EORA follow a general tendency. When our two reference years are compared (1990 and 2011), we observe a decline in the domestic value added contribution and an increase in the foreign value added contribution. This trend empirically confirms the increasing fragmentation of production across countries and manufacturing sectors. Yet another important idea that can be inferred from our results is the fact that the organization of manufacturing production across different countries and manufacturing categories is mostly regional. This means that the increase in the foreign value added contribution from most countries (in most of the manufacturing sectors) is related to an increase in the participation of countries inside the region being analyzed (i.e. the region where our reference country belongs). For instance, in the case 
of Canada, the countries responsible for the increasing foreign value added embodied in its final output are mainly Mexico and the United States (their closest neighbors belonging to the North American region) with very few increases from countries outside the region. Below, we will further analyze and present details of how these regional tendencies work, considering total final manufacturing production as well as different product categories. As we will see, very few countries in very few manufacturing actually showed a tendency where the foreign value added from outside the region (extra-regional value added) was higher than the one produced inside the region.

\section{4.2 Final Manufacturing Output.}

Table 3.1 presents our results for the top manufacturing exporters considering the production of total final output. Table 3.1 (and the tables presented in section 3.4.3) indicates the share of domestic and total foreign value added in final manufacturing output. The total foreign value added contribution is further decomposed according to region of origin. Here, we show the share of a region's value added in the final output as reported by the country of analysis. ${ }^{8}$

Table (3. 1):Share of Value Added Contribution in Final Output (\%). Total Final Manufacturing Production.

1990

\begin{tabular}{|c|c|c|c|c|c|c|c|c|c|}
\hline \multirow{2}{*}{ Country } & \multicolumn{6}{|c|}{ Foreign Value added (FVA) } & \multirow{2}{*}{$\begin{array}{l}\text { Total } \\
\text { FVA }\end{array}$} & \multirow{2}{*}{$\begin{array}{c}\text { Domestic } \\
\text { Value } \\
\text { Added } \\
\text { (DVA) }\end{array}$} & \multirow{2}{*}{ FVA+DVA } \\
\hline & EUROPE & NAFTA & $\begin{array}{c}\text { C.S. } \\
\text { America* }\end{array}$ & Africa & Asia & Oceania & & & \\
\hline Germany & 14 & 2 & 0 & 0 & 3 & 0 & 20 & 80 & 100 \\
\hline USA & 4 & 3 & 1 & 0 & 3 & 0 & 11 & 89 & 100 \\
\hline Japan & 3 & 3 & 0 & 0 & 2 & 1 & 9 & 91 & 100 \\
\hline Italy & 15 & 2 & 0 & 1 & 2 & 0 & 21 & 79 & 100 \\
\hline China & 3 & 2 & 0 & 0 & 4 & 0 & 9 & 91 & 100 \\
\hline \multirow[t]{2}{*}{ Mexico } & 4 & 12 & 1 & 0 & 2 & 0 & 19 & 81 & 100 \\
\hline & \multicolumn{9}{|c|}{22011} \\
\hline \multirow[b]{2}{*}{ Country } & \multicolumn{6}{|c|}{ Foreign Value added (FVA) } & \multirow[b]{2}{*}{$\begin{array}{c}\text { Total } \\
\text { FVA }\end{array}$} & \multirow{2}{*}{$\begin{array}{c}\text { Domestic } \\
\text { Value } \\
\text { Added } \\
\text { (DVA) }\end{array}$} & \multirow{2}{*}{ FVA+DVA } \\
\hline & EUROPE & NAFTA & $\begin{array}{c}\text { C.S. } \\
\text { America* }\end{array}$ & Africa & Asia & Oceania & & & \\
\hline Germany & 20 & 3 & 1 & 1 & 7 & 0 & 32 & 68 & 100 \\
\hline USA & 6 & 5 & 2 & 1 & 6 & 0 & 20 & 80 & 100 \\
\hline Japan & 4 & 3 & 1 & 0 & 7 & 1 & 16 & 84 & 100 \\
\hline Italy & 21 & 2 & 1 & 1 & 6 & 0 & 33 & 67 & 100 \\
\hline China & 6 & 2 & 1 & 1 & 8 & 1 & 19 & 81 & 100 \\
\hline Mexico & 7 & 13 & 2 & 0 & 6 & 0 & 29 & 71 & 100 \\
\hline
\end{tabular}

Source: Author's calculation based on equation (3.1) to (3.4) and using EORA data set. (*) Indicates Central and South America. Due to rounding, shares might not add up to the total. Refer to appendix A3.1 for further details on these tables.

\footnotetext{
${ }^{8}$ The interested reader should refer to the appendix A3.1 to identify the share of foreign of value added contribution by specific country of origin in each of the results for the top manufacturing exporters. Detailed information is provided both for final manufacturing production as well as for each manufacturing sector included in EORA.
} 
By comparing the foreign value added (FVA) and the domestic value added (DVA) results from 1990 to 2011, we realize that on average the DVA in total final output for each country was reduced by $10 \%$. This reduction made room for an increase in the FVA. Nonetheless, by analyzing our base year (1990), we realize that a significant regional component in the FVA from each country was already present. By 1990 the largest contributors to the FVA in a given country were already the neighboring economies from such countries. So, as a result of the increasing fragmentation production, the regional interaction between countries became stronger, leading to a higher FVA.

Of our top manufacturing exporters in total final output, those that completely followed a pattern of higher regional interaction as a result of fragmentation were Germany, Italy, China and Mexico. For these countries, the foreign value added from other countries belonging to their same region accounted for at least half of the total FVA embodied in their output. All these countries also saw an increase in the value added outside the region between 1990 and 2011, but this increase never resulted in value added shares higher than the regional value added delivered by their neighbors. The United States and Japan followed a somewhat different pattern. For instance, in 1990, the regional value added from Asian countries in US final output was quite similar to that from NAFTA, both of them, however, being lower than the European share. The increasing fragmentation of production led to a higher interaction of the US with its NAFTA neighbors by 2011. Nevertheless, despite the increases of NAFTA value added in US exports, the share remained smaller than value added from Asia and Europe. In the case of Japan, by 1990, this country had a diversified regional value added structure similar to that of the United States in 1990. In the initial year, the value added from Europe and NAFTA embodied in Japanese exports was higher than the corresponding one from Asia. Nevertheless, unlike the case of the US in 2011, the increasing fragmentation of production led Japan to more strongly interact with countries within their own region. The result of this was that the value added from Asia in Japanese exports was finally higher than the one from Europe and NAFTA.

The cases of Japan and the United States illustrate an interesting issue in the fragmentation of production. During the early 1990s, Japan and the United States were already considered global manufacturing powers given that their firms were leaders in productivity, innovation and so forth. Thus, to maintain high competitive levels, those global manufacturing powers in Japan and the United States had to rely on the efficiency of other production networks not located within their region. In my view, this is the reason why by 1990 those countries had a such diversified regional value added structure. Then, as a result of the increasing fragmentation of production, the manufacturing capabilities of the neighbors from Japan and the US significantly increased, leading to higher value added contributions to their neighbors. Nevertheless, in the case of Japan, stronger regionalization was observed because a number of Asian countries became highly competitive. Furthermore, it is usually argued that Japan gave up some manufacturing production at the expense of the industrial emergence of China. In the case of the US, the manufacturing capabilities from its neighbors increased but not as much as in Asia. This is the special case of Mexico that has not successfully achieved a process of industrial upgrading that leads to a higher domestic production of 
intermediate goods. Finally, yet another reason for the stronger regionalization of production in the case of Japan, when compared to the US, is simply the fact that Japan has more neighbors within its region. This is the main reason why the US will not drastically increase their regional (NAFTA) value added when compared to Asia and Europe (at least not when considering the total final manufacturing output).

\subsubsection{Final Production per Manufacturing Sectors.}

Let us now focus in the value chain decomposition for the top 6 manufacturing exporters in each of the manufacturing sectors included in EORA. For each sector we will try to provide the specific reasons as to why there is a higher regionalization or higher globalization of manufacturing production.

\subsubsection{Food and Beverages.}

Table 3.2 presents our results for the Food and Beverages sector. In this case, most of the top manufacturing exporters in this product category experienced a strong regionalization of their manufacturing production.

Table (3. 2): Share of Value Added in Final Output (\%). Food \& Beverages

1990

\begin{tabular}{|c|c|c|c|c|c|c|c|c|c|}
\hline \multirow{2}{*}{ Country } & \multicolumn{6}{|c|}{ Foreign Value added (FVA) } & \multirow{2}{*}{$\begin{array}{l}\text { Total } \\
\text { FVA }\end{array}$} & \multirow{2}{*}{$\begin{array}{l}\text { Domestic } \\
\text { Value } \\
\text { Added } \\
\text { (DVA) }\end{array}$} & \multirow{2}{*}{ FVA+DVA } \\
\hline & \multicolumn{2}{|c|}{ EUROPE NAFTA } & \multicolumn{2}{|c|}{ C.S. America*Africa } & \multirow{2}{*}{$\begin{array}{r}\text { Asia } \\
2\end{array}$} & Oceania & & & \\
\hline France & 13 & 2 & 0 & 1 & & 0 & 18 & 82 & 100 \\
\hline Netherlands & 21 & 3 & 1 & 1 & 3 & 0 & 30 & 70 & 100 \\
\hline Germany & 11 & 2 & 1 & 1 & 2 & 0 & 17 & 83 & 100 \\
\hline USA & 3 & 3 & 1 & 0 & 1 & 0 & 9 & 91 & 100 \\
\hline China & 2 & 2 & 0 & 0 & 2 & 0 & 6 & 94 & 100 \\
\hline \multirow[t]{2}{*}{ Italy } & 11 & 1 & 0 & 1 & 1 & 0 & 15 & 85 & 100 \\
\hline & \multicolumn{6}{|c|}{2011} & & & \\
\hline \multirow[b]{2}{*}{ Country } & \multicolumn{6}{|c|}{ Foreign Value added (FVA) } & \multirow[b]{2}{*}{$\begin{array}{l}\text { Total } \\
\text { FVA }\end{array}$} & \multirow{2}{*}{\begin{tabular}{|l|} 
Domestic \\
Value \\
Added \\
(DVA)
\end{tabular}} & \multirow{2}{*}{ FVA+DVA } \\
\hline & \multicolumn{2}{|c|}{ EUROPE NAFTA } & \multicolumn{2}{|c|}{ C.S. America*Africa } & Asia & Oceania & & & \\
\hline France & 14 & 2 & 1 & 1 & 3 & 0 & 22 & 78 & 100 \\
\hline Netherlands & 27 & 4 & 3 & 2 & 8 & 1 & 44 & 56 & 100 \\
\hline Germany & 18 & 2 & 2 & 1 & 5 & 1 & 29 & 71 & 100 \\
\hline USA & 4 & 5 & 2 & 0 & 3 & 0 & 15 & 85 & 100 \\
\hline China & 3 & 1 & 0 & 0 & 4 & 0 & 9 & 91 & 100 \\
\hline Italy & 17 & 2 & 1 & 1 & 4 & 0 & 25 & 75 & 100 \\
\hline
\end{tabular}

Source: As described in Table 3.1.

The reasons for such strong regionalization are related to some specific features of this product category. In the food and beverages industry, most of the intermediate inputs have to be sourced from domestic agricultural production. The immediate processing required for most of those intermediate inputs and the relatively high non-tariff barriers usually imposed on food products also account for this (Lee and Swagel, 1997). Global retailers in the food industry have also imposed high standards for the domestic agricultural production. In order for local food producers to participate in the production network of global retailers, they have to meet high standards in terms of 
food safety (particularly pesticides residues and conditions for post-harvest processing), tight delivery times and, in some cases, even environmental and labor standards (Gereffi et al., 2005).

Considering this specific case from our top exporters in food \& beverages, there is yet another reason for the strong regionalization in this product category. This is related to the policy incentives that most of those countries receive within their own region. For instance, countries like France, Netherlands, Germany, and Italy highly benefit from the subsidies from the Common Agricultural Policy in the European Union, while the United States has benefited from subsidies within NAFTA. In this context, we can argue that factors such as immediate processing, high non-tariff barriers, regional incentives and so forth limit the scope for further fragmentation within this industry (and, thus of higher globalization of manufacturing production).

\subsubsection{Textiles and Wearing Apparel.}

Table 3.3 presents the decomposition in textiles and wearing apparel. The main tendency observed in this table is that most of the top manufacturing exporters belong to the Asian region. Just like the previous cases, we see that each of the countries considered in table 3.3 also have a higher interaction with suppliers within their own region with respect to those located outside their region. However, something that is worth mentioning is that for other countries such as Italy and Turkey, the second largest regional value added component is Asia. This situation is important given that it indicates the importance of Asian producers for other top manufacturing exporters.

In general, there are several reasons for the increasing regionalization of textile production and for relative importance of Asian firms relative to other producers. The production networks within this industry have been greatly affected by the existence of different trade agreements. For instance, according to Gereffi et al. (2005) US import quotas established by the Multi-fiber Arrangement (MFA) fueled the spread of global production networks in apparel during the 1970s. The existence of quotas prompted the rise of value-chains intermediaries in East Asia to coordinate the flow of orders from US and European buyers to a large number of factories established around the world. Once the MFA expired by 2005, global apparel production became more concentrated among the most capable firms located in major low cost producers (China, Mexico, India, Indonesia and Turkey) (Gereffi and Memodovic, 2003).

In light of the industrial emergence of those countries, some trade agreements have imposed rather strict rules of origin in some specific textile product categories. The main idea here is to protect the domestic and regional production of textiles from the increasing competition of major low cost producers. This is the case for the NAFTA that strictly protects the cotton industry. Given the abundance of cotton within this region, in order to obtain tariff exemptions, NAFTA requires firms to develop the whole productive process in a NAFTA country using NAFTA inputs (fiber forward). Nonetheless, NAFTA is quite flexible in the textile production of goods that are not abundant in the region (linen, silk and so forth) requiring firms only to assemble the textile good in NAFTA country in order to obtain tariff exemptions. 
Table (3. 3): Share of Value Added in Final Output (\%). Textiles and Wearing Apparel.

Textiles and Wearing Apparel 1990

\begin{tabular}{|c|c|c|c|c|c|c|c|c|c|}
\hline \multirow{2}{*}{ Country } & \multicolumn{6}{|c|}{ Foreign Value added (FVA) } & \multirow{2}{*}{$\begin{array}{c}\text { Total } \\
\text { FVA }\end{array}$} & \multirow{2}{*}{$\begin{array}{c}\text { Domestic } \\
\text { Value } \\
\text { Added } \\
\text { (DVA) }\end{array}$} & \multirow{2}{*}{ FVA+DVA } \\
\hline & EUROPE & NAFTA & C.S. America* & Africa & Asia & Oceania & & & \\
\hline China & 3 & 2 & 0 & 0 & 4 & 0 & 10 & 90 & 100 \\
\hline Italy & 14 & 1 & 0 & 1 & 3 & 0 & 21 & 79 & 100 \\
\hline India & 3 & 1 & 0 & 0 & 2 & 0 & 6 & 94 & 100 \\
\hline Japan & 4 & 3 & 0 & 0 & 3 & 1 & 11 & 89 & 100 \\
\hline Turkey & 11 & 1 & 0 & 0 & 2 & 0 & 14 & 86 & 100 \\
\hline Indonesia & 6 & 4 & 0 & 0 & 10 & 2 & 23 & 77 & 100 \\
\hline
\end{tabular}

Textiles and Wearing Apparel

2011

\begin{tabular}{|c|c|c|c|c|c|c|c|c|c|}
\hline \multirow{2}{*}{ Country } & \multicolumn{6}{|c|}{ Foreign Value added (FVA) } & \multirow{2}{*}{$\begin{array}{c}\text { Total } \\
\text { FVA }\end{array}$} & \multirow{2}{*}{\begin{tabular}{|c|} 
Domestic \\
Value \\
Added \\
(DVA) \\
\end{tabular}} & \multirow{2}{*}{$\begin{array}{l}\text { FVA+DVA } \\
\end{array}$} \\
\hline & EUROPE & NAFTA & C.S. America* & Africa & Asia & Oceania & & & \\
\hline China & 4 & 2 & 0 & 0 & 7 & 1 & 14 & 86 & 100 \\
\hline Italy & 20 & 2 & 1 & 2 & 9 & 0 & 33 & 67 & 100 \\
\hline India & 5 & 2 & 0 & 0 & 6 & 1 & 14 & 86 & 100 \\
\hline Japan & 5 & 2 & 0 & 0 & 10 & 1 & 18 & 82 & 100 \\
\hline Turkey & 21 & 2 & 1 & 1 & 8 & 0 & 33 & 67 & 100 \\
\hline Indonesia & 4 & 2 & 0 & 0 & 11 & 1 & 20 & 80 & 100 \\
\hline
\end{tabular}

Source: As described in Table 3.1.

Finally, global retailers also have a significant impact on the organization of production networks within the textile and apparel industry. Given the high modularity of this industry and the existence of major low cost producers, large retailers such as Wal-Mart can control and coordinate the production network by exercising their market power. This means that they are able to select their suppliers and control the production process until they reach final consumers. So, as we can see there has been an increasing tendency in the production of textiles to rely both on the regional networks of neighboring countries but also in the networks from Asia given the efficiency of the suppliers located there.

\subsubsection{Wood and Paper.}

The regional pattern in the value added contribution from top exporters of Wood and Paper is presented in table 3.4. In this table, we see that domestic producers in China and in the United States rely on European suppliers for the production of this good as much as they rely on the producers from their own region. This was observed both in 1990 and 2011. In my view, the reason why those major producers depend both on the network of neighboring economies and on the regional value added from one specific region is related to how the furniture sector is globally organized. 
Table (3. 4): Share of Value Added in Final Output (\%). Wood and Paper.

1990

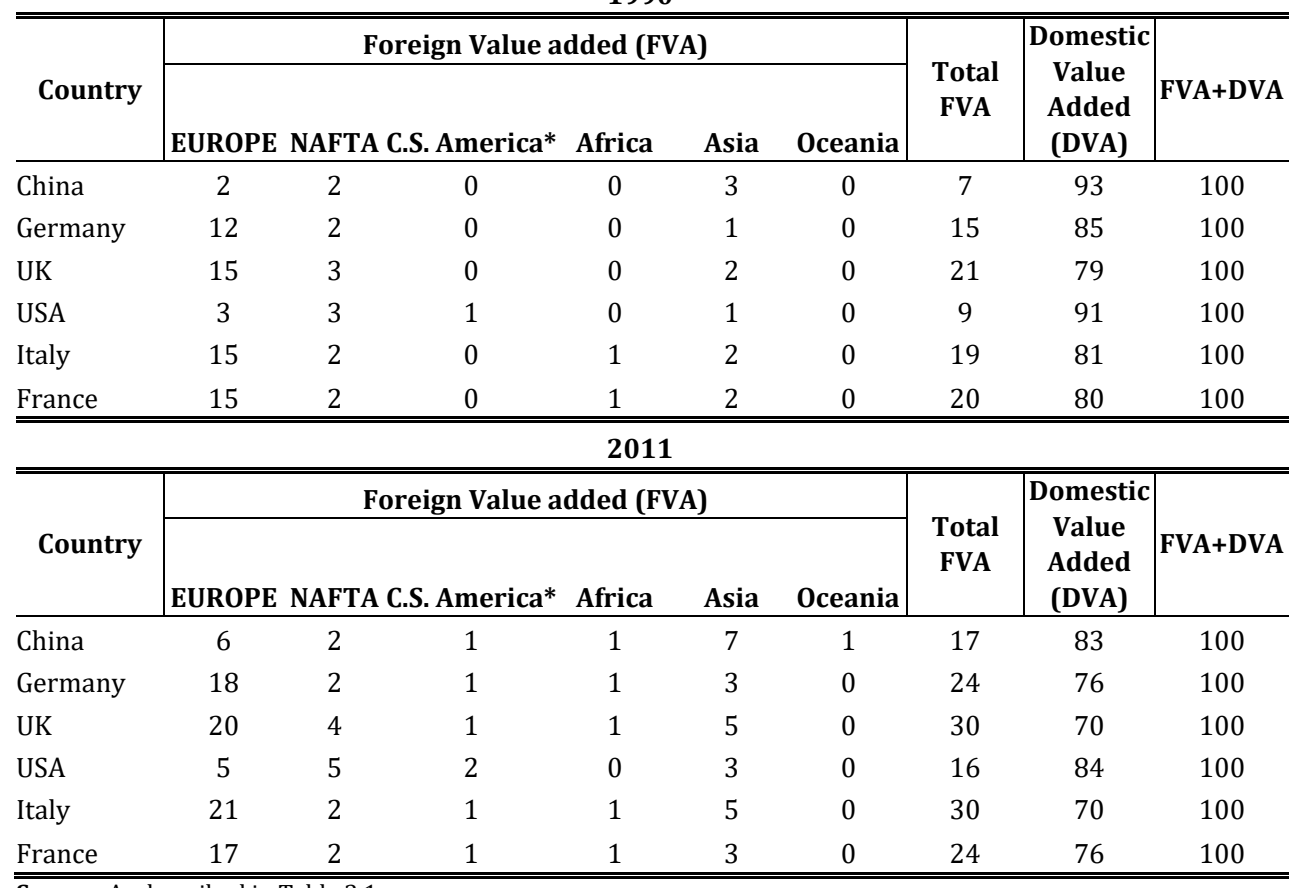

Source: As described in Table 3.1.

According to Kaplinsky et al. (2003), furniture has traditionally been a resource- and labour-intensive industry that includes both local craft-based firms and large volume producers. The mass production of furniture became a viable manufacturing strategy with the advent of flat-pack or ready-to-assemble designed furniture. The aforementioned authors also indicate that this product innovation paved the way for firms to design, manufacture and ship products in large quantities. Firms that massproduce flat-pack furniture tend to supply products for the low- to medium-price markets. Solid wood furniture manufacturers have retained important niche market segments primarily for high-end, expensive and design-led products. These specialized products tend to be purchased locally while mass-produced, large-volume products are sold locally and for export. So, in this whole context, we can see that there are two main tendencies in order to organize the production of furniture. The production will tend to be local and regional in the case of flat-pack furniture (wardrobes, desks, dining tables, chairs, etc.). This is because those goods are of large size and need to be supplied close to final markets in order to avoid significant transport costs. On the other hand, the production of furniture can be global in the case of the furniture with high modularity (that can be easily assembled by the final consumer) and in the case of those expensive and designed-led products (the quality matters for the final consumer). As can be inferred, the major industry in wood production (furniture) requires the coordination of domestic producers with suppliers within the region and with suppliers outside the region depending on different product categories. In my view, this is the main reason why US and Chinese producers rely on European suppliers as much as they do for their 
neighbouring suppliers. For instance, European suppliers might be important in the Chinese and US production of expensive and designed-led products, while regional suppliers might be more important for the production of low-cost and large volume furniture.

\subsubsection{Metal Products and Chemical Sector.}

Following the same stream of ideas, Table 3.5 and Table 3.6 presents the results for the Metal Products and the Petroleum, Chemical and Non-Metallic Mineral Products industry, respectively. We will jointly analyse these industries because they both provide raw materials and inputs for other many manufacturing sectors. For instance, the steel industry produces important inputs for car manufacturers, while the chemical industry produces plastics and rubbers. Nonetheless, as it is confirmed by table 3.5 and table 3.6, the scope for fragmentation within those industry remains limited. Both table 3.5 and table 3.6 indicate that most of the top manufacturing producers in each industry mostly depend on the production of their domestic and regional suppliers. From 1990 to 2011, the interaction with domestic suppliers was reduced at the expense of higher interaction with regional suppliers (as it is observed by the higher intra-regional value added). According to the De Backer and Miroudot (2013), this is related to the complexity in the organization of production networks within those industries. This is because their development implies large expenditures on research \& development activities, as well as high costs on safety and in transportation costs. Furthermore, in the case of pharmaceutical (chemical industry) other factors such as marketing investments as well as the different product variants, branding, adapted packaging, small volumes, should be taken into account.

Both in the case of table 3.5 and table 3.6, we realized that the production from the United States in those industries is the only one where domestic producers interact more with suppliers in other regions of the world economy than with producers in the own region. This tendency has been present since 1990 and has remained relatively unaltered until 2011. For instance, by 1990 the producers in the US metal industry already relied more on European producers rather than those located in Mexico or Canada. As a result of the increasing fragmentation of production, producers in the metal industry relied more on European and Asian suppliers and, to a lesser extent in NAFTA producers (Canada and Mexico).A similar situation occurs in the case of the production of chemicals in the US. In this case, the interaction of US producers with foreign suppliers was already diversified by 1990. This means that in that year the interaction of the US chemical industry with suppliers in Europe was as high as with Mexico and Canada. Mexican and Canadian suppliers increased their interaction with US chemical producers by 2011. However, the region that in 2011 interacted as much with US as Canada and Mexico, was Central and South America. 
Table (3. 5): Share of Value Added in Final Output (\%). Metal Products.

1990

\begin{tabular}{|c|c|c|c|c|c|c|c|c|c|}
\hline \multirow{2}{*}{ Country } & \multicolumn{6}{|c|}{ Foreign Value added (FVA) } & \multirow{2}{*}{$\begin{array}{c}\text { Total } \\
\text { FVA }\end{array}$} & \multirow{2}{*}{$\begin{array}{c}\text { Domestic } \\
\text { Value } \\
\text { Added } \\
\text { (DVA) }\end{array}$} & \multirow{2}{*}{ FVA+DVA } \\
\hline & EUROPE & NAFTA & C.S. America* & Africa & Asia & Oceania & & & \\
\hline China & 2 & 1 & 1 & 0 & 3 & 1 & 8 & 92 & 100 \\
\hline Germany & 14 & 2 & 1 & 1 & 2 & 0 & 19 & 81 & 100 \\
\hline Italy & 15 & 1 & 0 & 1 & 2 & 0 & 20 & 80 & 100 \\
\hline USA & 5 & 2 & 1 & 0 & 2 & 0 & 10 & 90 & 100 \\
\hline Japan & 3 & 2 & 1 & 1 & 3 & 1 & 10 & 90 & 100 \\
\hline France & 19 & 2 & 0 & 1 & 2 & 0 & 24 & 76 & 100 \\
\hline \multicolumn{10}{|c|}{2011} \\
\hline \multirow[b]{2}{*}{ Country } & \multicolumn{6}{|c|}{ Foreign Value added (FVA) } & \multirow[b]{2}{*}{$\begin{array}{c}\text { Total } \\
\text { FVA }\end{array}$} & \multirow{2}{*}{$\begin{array}{c}\text { Domestic } \\
\text { Value } \\
\text { Added } \\
\text { (DVA) }\end{array}$} & \multirow{2}{*}{ FVA+DVA } \\
\hline & EUROPE & NAFTA & C.S. America* & Africa & Asia & Oceania & & & \\
\hline China & 5 & 2 & 2 & 1 & 8 & 2 & 19 & 81 & 100 \\
\hline Germany & 19 & 3 & 1 & 1 & 5 & 0 & 30 & 70 & 100 \\
\hline Italy & 21 & 2 & 1 & 1 & 5 & 0 & 31 & 69 & 100 \\
\hline USA & 7 & 4 & 2 & 1 & 5 & 0 & 18 & 82 & 100 \\
\hline Japan & 4 & 3 & 2 & 1 & 8 & 3 & 21 & 79 & 100 \\
\hline France & 20 & 2 & 1 & 1 & 4 & 0 & 29 & 71 & 100 \\
\hline
\end{tabular}

Source: As described in Table 3.1.

Table (3. 6): Share of Value Added in Final Output (\%). Petroleum, Chemical and Non-Metallic Mineral Products.

1990

\begin{tabular}{|c|c|c|c|c|c|c|c|c|c|}
\hline \multirow[b]{2}{*}{ Country } & \multicolumn{6}{|c|}{ Foreign Value added (FVA) } & \multirow{2}{*}{$\begin{array}{l}\text { Total } \\
\text { FVA }\end{array}$} & \multirow{2}{*}{$\begin{array}{c}\text { Domestic } \\
\text { Value } \\
\text { Added } \\
\text { (DVA) }\end{array}$} & \multirow{2}{*}{ FVA+DVA } \\
\hline & EUROPE & NAFTA & $\begin{array}{c}\text { C.S. } \\
\text { America* }\end{array}$ & Africa & Asia & Oceania & & & \\
\hline Germany & 16 & 2 & 0 & 1 & 3 & 0 & 23 & 77 & 100 \\
\hline USA & 4 & 4 & 3 & 1 & 2 & 0 & 15 & 85 & 100 \\
\hline France & 22 & 3 & 0 & 4 & 3 & 0 & 32 & 68 & 100 \\
\hline China & 3 & 2 & 0 & 0 & 3 & 0 & 8 & 92 & 100 \\
\hline Italy & 19 & 2 & 0 & 2 & 3 & 0 & 26 & 74 & 100 \\
\hline UK & 14 & 3 & 0 & 1 & 2 & 0 & 20 & 80 & 100 \\
\hline \multicolumn{10}{|c|}{2011} \\
\hline \multirow[b]{2}{*}{ Country } & \multicolumn{6}{|c|}{ Foreign Value added (FVA) } & \multirow[b]{2}{*}{$\begin{array}{l}\text { Total } \\
\text { FVA }\end{array}$} & \multirow{2}{*}{$\begin{array}{c}\text { Domestic } \\
\text { Value } \\
\text { Added } \\
\text { (DVA) }\end{array}$} & \multirow{2}{*}{ FVA+DVA } \\
\hline & EUROPE & NAFTA & $\begin{array}{c}\text { C.S. } \\
\text { America* }\end{array}$ & Africa & Asia & Oceania & & & \\
\hline Germany & 24 & 3 & 1 & 2 & 6 & 0 & 36 & 64 & 100 \\
\hline USA & 5 & 7 & 7 & 2 & 5 & 0 & 26 & 74 & 100 \\
\hline France & 25 & 3 & 1 & 5 & 6 & 0 & 39 & 61 & 100 \\
\hline China & 6 & 2 & 1 & 1 & 7 & 1 & 17 & 83 & 100 \\
\hline Italy & 26 & 3 & 1 & 3 & 7 & 0 & 41 & 59 & 100 \\
\hline UK & 18 & 4 & 1 & 1 & 5 & 0 & 30 & 70 & 100 \\
\hline
\end{tabular}

Source: As described in Table 3.1. 


\subsubsection{Electrical and Machinery Products.}

Table 3.7 presents the results for electrical and machinery products. Just like in the case of textiles, all of the top manufacturing producers at the electronics industry increased their interaction both with suppliers within their own region as well as with suppliers located in East Asia. The interaction of domestic suppliers with countries within their own region was in most cases higher than with East Asia both in 1990 and 2011. Nevertheless, the interesting thing to be noticed from table 3.7 is the fact that the top manufacturing exporters in the electronic industry increased their interaction with regional suppliers to the same extent as they increased their interaction with East Asia. For instance, from table 3.7, we notice that Germany and the UK increased their interaction with European suppliers by 5\% from 1990 to 2011. During the same period, both countries increased their interaction with Asian suppliers by $4 \%$. A special case is France that increased its network with European suppliers by $1 \%$ and with Asian suppliers by $3 \%$ during the same period of time. For the case of the US, producers in this industry increased their interaction with Asian suppliers at the expense of lower interaction with Europe. The interaction from the US with Mexico and Canada remained basically unaltered (1\% increased from 1990 to 2011).

Table (3. 7): Share of Value Added in Final Output (\%). Electrical and Machinery.

1990

\begin{tabular}{|c|c|c|c|c|c|c|c|c|c|}
\hline \multirow{2}{*}{ Country } & \multicolumn{6}{|c|}{ Foreign Value added (FVA) } & \multirow{2}{*}{$\begin{array}{l}\text { Total } \\
\text { FVA }\end{array}$} & \multirow{2}{*}{\begin{tabular}{|c|} 
Domestic \\
Value \\
Added \\
(DVA) \\
\end{tabular}} & \multirow{2}{*}{ FVA+DVA } \\
\hline & EUROPE & NAFTA & C.S. America* & Africa & Asia & Oceania & & & \\
\hline China & 4 & 3 & 0 & 0 & 5 & 0 & \multicolumn{2}{|c|}{$12 \quad 88$} & 100 \\
\hline Germany & 11 & 2 & 0 & 0 & 3 & 0 & \multicolumn{2}{|c|}{17} & 100 \\
\hline USA & 4 & 2 & 1 & 0 & 3 & 0 & \multicolumn{2}{|c|}{9} & 100 \\
\hline Japan & 3 & 3 & 0 & 0 & 2 & 0 & \multicolumn{2}{|l|}{9} & 100 \\
\hline UK & 14 & 5 & 0 & 0 & 5 & 0 & \multicolumn{2}{|l|}{25} & 100 \\
\hline France & 18 & 3 & 0 & 1 & 4 & 0 & \multicolumn{2}{|l|}{25} & 100 \\
\hline \multicolumn{10}{|c|}{2011} \\
\hline \multirow[b]{2}{*}{ Country } & \multicolumn{6}{|c|}{ Foreign Value added (FVA) } & \multirow{2}{*}{$\begin{array}{c}\text { Total } \\
\text { FVA }\end{array}$} & \multirow{2}{*}{\begin{tabular}{|c|} 
Domestic \\
Value \\
Added \\
(DVA) \\
\end{tabular}} & \multirow{2}{*}{ FVA+DVA } \\
\hline & EUROPE & NAFTA & C.S. America* & Africa & Asia & Oceania & & & \\
\hline China & 8 & 3 & 1 & 1 & 12 & 1 & 26 & 74 & 100 \\
\hline Germany & 16 & 3 & 1 & 1 & 7 & 0 & 27 & 73 & 100 \\
\hline USA & 6 & 3 & 1 & 0 & 7 & 0 & 18 & 82 & 100 \\
\hline Japan & 4 & 3 & 0 & 0 & 7 & 1 & 15 & 85 & 100 \\
\hline UK & 19 & 5 & 1 & 1 & 9 & 0 & 35 & 65 & 100 \\
\hline France & 19 & 3 & 1 & 1 & 7 & 0 & 30 & 70 & 100 \\
\hline
\end{tabular}

Source: As described in Table 3.1. 
There are two main reasons why the increasing fragmentation of production within the electrical machinery industry allowed for a higher interaction of domestic suppliers with East Asian producers. The first one is related to the high modularity of electronics which enables activities to be undertaken across large distances. Most electronic products are characterized by high value to weight ratios resulting in the rapid and rather inexpensive delivery of intermediate and final electronic products across the globe. The coordination between the different production stages across different countries is largely done via the Internet allowing for a smooth sharing and monitoring of information (De Backer and Miroudot, 2013). The second reason is related to the continuous technological development within this industry. Here, we refer to the fact that the standardization, codification and computerization of production have allowed for a large interoperability of parts and components which in turn allows for the fragmentation of the production process across different stages (De Backer and Miroudot, 2013). The main outcome of this is that firms in the electronics industry can source their intermediate inputs from local and regional suppliers but also from other international suppliers. Due to the significant decreases in transportation and communication costs, those international suppliers can be located far away from the point of assembly (for instance, a Chinese supplier can easily deliver intermediates to producers in the US). Nonetheless, one important thing to keep in mind is that despite the high modularity observed in the electronics industry, not necessarily all firms within this industry will opt for the cheapest (and more efficient) international producer located far away. Those firms producing electronics goods of large size (freezers, flatscreens, heaters and so forth) will opt for local and regional suppliers due to the high transportation costs of exporting such final manufacturing goods. The flexibility in choosing the most efficient supplier located far away will be possible for those firms producing electronic goods of small size (tablets, cell phones, laptops and so forth).

\subsubsection{Transport Equipment Sector.}

The results for the decomposition of the transport equipment sector are presented in table 3.8. Here, most of the top manufacturing exporters show a rather high regionalization of production in their foreign value added decomposition. The interaction of the top manufacturing exporters with their network of regional suppliers was not significantly altered due to expansion of Asian suppliers in the years here considered. For instance, German manufacturers increased their network with other European producers by $7 \%$. The interaction of Mexican and Canadian manufacturers with their respective North American counterparts remained basically unaltered.

There are several reasons why the production of this industry is organized in the context of regional production networks. The first reason is related to the cost of transportation. High transportation costs make intercontinental shipping very costly especially in downstream activities, e.g. complete cars or subsystems. According to De Backer and Miroudot (2013), political pressure may also motivate lead firms in the transport sector to locate production close to end markets; the high cost and visibility of automotive products can create the risk of a political backlash if imported vehicles become too large a share of total vehicles sold. This in turn creates pressure for supplier co-location within regional production systems for operational reasons, such as just-in- 
time production, design collaboration and the support of globally produced vehicle platforms (Van Biesebroeck and Sturgeon, 2010). As a result, the supplier network in the motor vehicles' industry consists of a large number of suppliers, some of them pure local suppliers (typically lower tier suppliers), others global suppliers with a local presence (top tier suppliers).

Table (3. 8): Share of Value Added in Final Output (\%). Transport Equipment.

\begin{tabular}{|c|c|c|c|c|c|c|c|c|c|}
\hline \multirow{2}{*}{ Country } & \multicolumn{6}{|c|}{ Foreign Value added (FVA) } & \multirow{2}{*}{$\begin{array}{c}\text { Total } \\
\text { FVA }\end{array}$} & \multirow{2}{*}{$\begin{array}{c}\text { Domestic } \\
\text { Value } \\
\text { Added } \\
\text { (DVA) }\end{array}$} & \multirow{2}{*}{ FVA+DVA } \\
\hline & EUROPE & NAFTA & C.S. America* & Africa & Asia & Oceania & & & \\
\hline Germany & 18 & 3 & 0 & 0 & 3 & 0 & 25 & 75 & 100 \\
\hline Japan & 3 & 3 & 0 & 0 & 2 & 0 & 9 & 91 & 100 \\
\hline Mexico & 6 & 19 & 1 & 0 & 4 & 0 & 30 & 70 & 100 \\
\hline Canada & 6 & 28 & 1 & 0 & 6 & 0 & 41 & 59 & 100 \\
\hline South Korea & 8 & 6 & 0 & 0 & 13 & 1 & 28 & 72 & 100 \\
\hline India & 4 & 1 & 0 & 0 & 2 & 0 & 8 & 92 & 100 \\
\hline \multicolumn{10}{|c|}{2011} \\
\hline \multirow[b]{2}{*}{ Country } & \multicolumn{6}{|c|}{ Foreign Value added (FVA) } & \multirow[b]{2}{*}{$\begin{array}{l}\text { Total } \\
\text { FVA }\end{array}$} & \multirow{2}{*}{$\begin{array}{c}\text { Domestic } \\
\text { Value } \\
\text { Added } \\
\text { (DVA) }\end{array}$} & \multirow[b]{2}{*}{ FVA+DVA } \\
\hline & EUROPE & NAFTA & C.S. America* & Africa & Asia & Oceania & & & \\
\hline Germany & 25 & 3 & 1 & 1 & 7 & 0 & 37 & 63 & 100 \\
\hline Japan & 3 & 3 & 0 & 0 & 7 & 1 & 14 & 86 & 100 \\
\hline Mexico & 9 & 17 & 3 & 0 & 9 & 0 & 38 & 62 & 100 \\
\hline Canada & 8 & 28 & 1 & 0 & 9 & 0 & 46 & 54 & 100 \\
\hline South Korea & 10 & 5 & 1 & 1 & 19 & 1 & 36 & 64 & 100 \\
\hline India & 9 & 2 & 1 & 1 & 8 & 1 & 21 & 79 & 100 \\
\hline
\end{tabular}

Source: As described in Table 3.1.

Trade and tariff incentives are another reason why the production of the transport sector is organized in regional production networks. This is the particular case of NAFTA that strongly protects regional NAFTA producers from non NAFTA producers. In order to receive trade and tariff incentives, firms in the transport sector located in North American region must meet very high regional content requirements (at least $60 \%$ of intermediate inputs used in their production must be of NAFTA origin). Finally, the last important reason for the existence of regional production networks is the hierarchical structure governing the transport production sector, which demands strong cooperation and communication between firms. The value chain of motor vehicles is largely organized through a hierarchical structure, with the large automotive manufacturers positioned on top of the pyramid as lead firms responsible for design, branding, and final assembly. One level down, first-tier suppliers produce complete subsystems by cooperating with a large network of lower tier suppliers and subcontractors. Close relationships have developed especially between car assemblers and first tier suppliers as these last ones have taken up a larger role in the whole production process, including design (De Backer and Miroudot,2013).

\subsubsection{Other Manufacturing.}

Finally, table 3.9 presents the results for the decomposition of other manufacturing goods. In this case, as a result of the increasing fragmentation of production, the domestic producers considered in table 3.9 saw an increasing interaction with their 
network of regional suppliers and with those suppliers located outside their region. An interesting case is that of China that increased its interaction with Asian and European suppliers to the same extent (3\%) during the twenty years considered. European producers, such as Germany and Italy, also increased their network with suppliers outside their region as much as they did with suppliers located in the same region. Canada and the United show a similar pattern, while Thailand became progressively more integrated with Asian suppliers.

Table (3. 9): Share of Value Added in Final Output (\%). Other Manufacturing.

\begin{tabular}{|c|c|c|c|c|c|c|c|c|c|}
\hline \multirow{2}{*}{ Country } & \multicolumn{6}{|c|}{ Foreign Value added (FVA) } & \multirow{2}{*}{$\begin{array}{l}\text { Total } \\
\text { FVA }\end{array}$} & \multirow{2}{*}{$\begin{array}{c}\text { Domestic } \\
\text { Value } \\
\text { Added } \\
\text { (DVA) }\end{array}$} & \multirow{2}{*}{ FVA+DVA } \\
\hline & EUROPE & NAFTA C.S. & America* & Africa & Asia & Oceania & & & \\
\hline China & 3 & 3 & 0 & 0 & 4 & 0 & 10 & 90 & 100 \\
\hline Italy & 17 & 2 & 0 & 1 & 2 & 0 & 22 & 78 & 100 \\
\hline Germany & 13 & 2 & 0 & 0 & 3 & 0 & 18 & 82 & 100 \\
\hline USA & 4 & 3 & 1 & 0 & 3 & 0 & 10 & 90 & 100 \\
\hline Canada & 3 & 9 & 0 & 0 & 2 & 0 & 14 & 86 & 100 \\
\hline Thailand & 12 & 5 & 1 & 0 & 13 & 1 & 33 & 67 & 100 \\
\hline
\end{tabular}

\begin{tabular}{|c|c|c|c|c|c|c|c|c|c|}
\hline \multirow[b]{2}{*}{ Country } & \multicolumn{6}{|c|}{ Foreign Value added (FVA) } & \multirow{2}{*}{$\begin{array}{l}\text { Total } \\
\text { FVA }\end{array}$} & \multirow{2}{*}{$\begin{array}{c}\text { Domestic } \\
\text { Value } \\
\text { Added } \\
\text { (DVA) } \\
\end{array}$} & \multirow{2}{*}{ FVA+DVA } \\
\hline & EUROPE & NAFTA & C.S. America* & Africa & Asia & Oceania & & & \\
\hline China & 6 & 2 & 1 & 1 & 7 & 1 & 17 & 83 & 100 \\
\hline Italy & 24 & 2 & 1 & 2 & 7 & 0 & 36 & 64 & 100 \\
\hline Germany & 19 & 2 & 1 & 1 & 8 & 0 & 31 & 69 & 100 \\
\hline USA & 5 & 5 & 2 & 1 & 6 & 0 & 19 & 81 & 100 \\
\hline Canada & 4 & 9 & 1 & 0 & 4 & 0 & 19 & 81 & 100 \\
\hline Thailand & 12 & 4 & 1 & 1 & 25 & 2 & 46 & 54 & 100 \\
\hline
\end{tabular}

Source: As described in Table 3.1.

Just like the case of electronics and textiles, the modularity in the production of other manufacturing goods allows for this tendency where domestic producers can equally opt for suppliers located inside their region as well as those located far away. The fact that this industry is also globally organized by major multinational firms (such as the ones in the toy sector) also explains why domestic producers are able to seek for low cost and efficient suppliers outside their own region. Having thoroughly discussed the decomposition results per manufacturing sectors for the top manufacturing exporters, we will now present and discuss the results for the regions of the world economy.

\section{4.4 Results for the Regions of the World Economy.}

Our decomposition results for the regions of the world economy are summarized in figure 3.1a and figure 3.1b. The first figure indicates the results for 1990, while the second indicates those for 2011. Both figures refer to the decomposition results considering the total final manufacturing production produced by each region. Let us 
further explain the intuition behind these figures. The size of the bubbles represents the total value added generated inside a region in the production of final manufacturing goods. The total value added generated in each region is equal to the sum of the intraregional and extra-regional value added (see equation 3.7). The number in, or next to, a bubble (in black or white) indicates the share of manufacturing value added generated within the region for the production of final output (i.e. the intra-regional value added). Arrows show the main sources of value added coming from other regions (i.e. the extraregional value added embodied in the total final value added generated by a given region). Red numbers indicate the percentage of extra-regional value added that came from these transactions in the region's total manufacturing value added. Finally, letters in orange located close to a bubble indicate the specific name from the main region of analysis (refer to notes located below figure 3.1a).

Figures 3.1 and 3.2 only indicate the cases where the extra-regional value added embodied in final output was higher than 5\%. Detailed information about the specific sources of extra-regional value added in a region's total manufacturing production, in the 8 manufacturing sectors considered by EORA, for each of the regions of the World economy (both for 1990 and 2011) is presented in the appendix A3.2.

In order to further understand the reasoning behind figure $3.1 \mathrm{a}$ and figure $3.1 \mathrm{~b}$ let us provide one example. Consider the case of the regional final manufacturing output produced by Central America in 1990 in figure 3.1a. In 1990 the intra-regional value added in the total production from Central America was of $72 \%$. Producers in Central America largely interacted with suppliers in North America. Mexico, Canada and the US contributed $15 \%$ of total value added of Central American final goods production. Suppliers in Europe also interacted with Central American manufacturers, but to a much less extent than this region did with North America (6\%).

We now proceed to indicate the general trends observed in figure 3.1a and figure 3.1b. Most of the regions of the world economy experienced a decrease in their intra-regional value added from 1990 to 2011 . In general, intra-regional value added decreased by $5 \%$. The region that experienced the highest drop in its intra-regional value added is South Asia (a drop of 10\% from 1990 to 2011). This drop occurred at the expense of a higher interaction of this region with European suppliers. In my view, the main reason for this large drop is the fact that some of the major low cost producers of the World economy (especially in the production of textiles) belong to this region. We are referring to India, Pakistan and Bangladesh. The lower level of intra-regional value added at the expense of a higher extra-regional value added simply implies that domestic manufacturers in those three South Asian countries increased their interaction with firms located in Europe. Even though the individual contribution from each sub-region in Asia is lower than 5\% for the total value added in South Asia (and therefore no arrows are included in figure 3.1a and 3.1b), the joint contribution from Central Asia, East Asia and South East Asia is a little higher than $5 \%$.

This situation indicates that the competitive pressures faced by major South Asian low cost producers pushed them to increase their network with European suppliers but also from those located in other regions in Asia. 
Figure (3. 1): Intra-Regional and Extra-Regional Value Added Embodied in a Region's Total Final Manufacturing Output, 1990 and 2011.

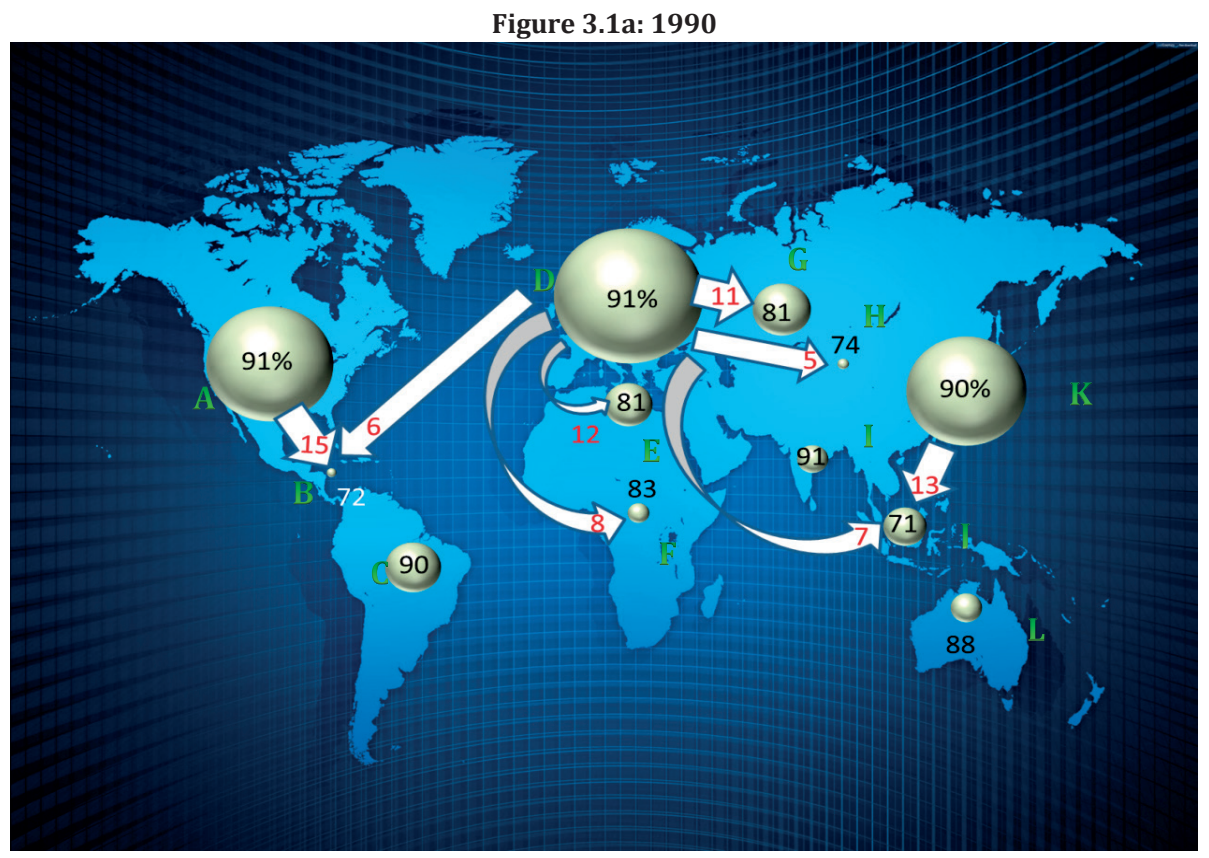

Figure 3.1b: 2011

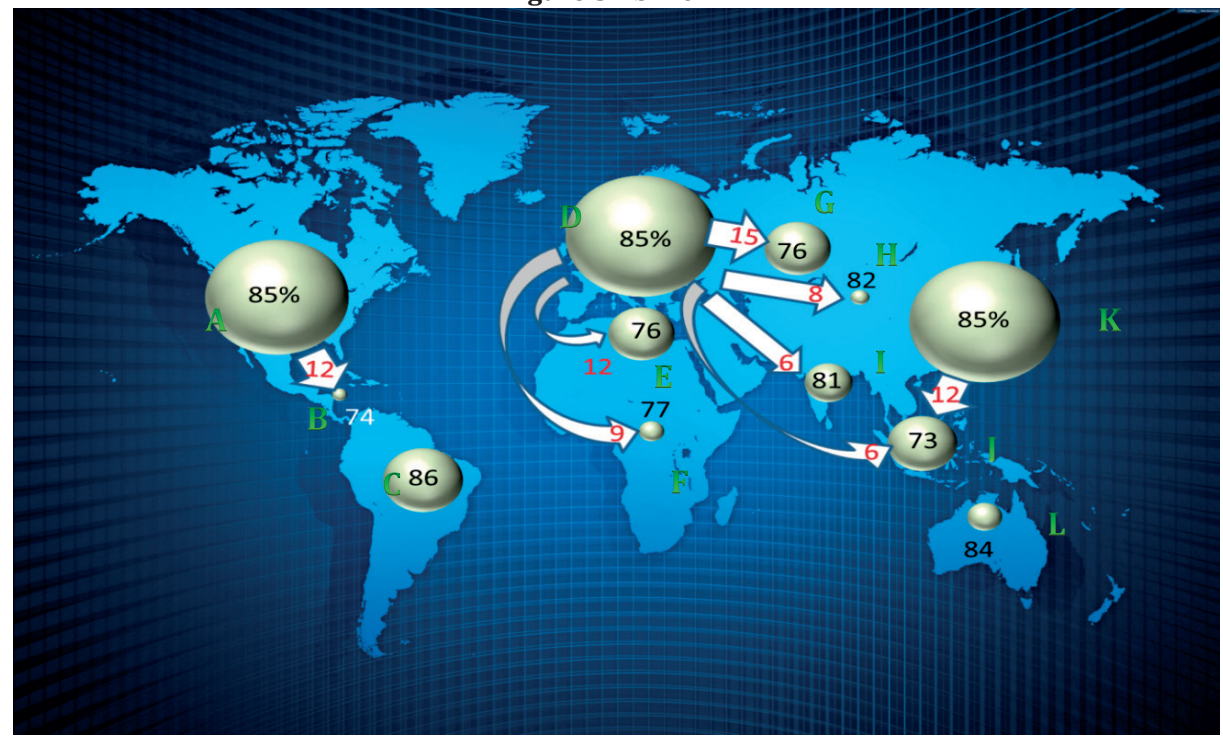

Source: Author's calculation based on equation (3.1) for the value added decomposition and, equation (3.5) to (3.6) for the interregional and extra-regional value added contribution, respectively. Geographic country categories as proposed by UNIDO (2015). A: North America, B: Central America, C: South America, D: Western Europe, E: North Africa and the Middle East, F: Sub-Saharan Africa, G: Eastern Europe, H: Central Asia, I: South Asia, J: South East Asia, K: East Asia, L: Oceania. 
Two regions in the world economy experienced increases in their intra-regional value added. This is the case of South East Asia that moved from $71 \%$ to $73 \%$ during the years here considered, and Central Asia with 74\% in 1990 and 82\% in 2011. In the case of South East Asia, we are referring again to major low cost producers for the World economy located in that region. This is the case of Indonesia, Malaysia, Vietnam, Singapore, Thailand and Philippines. As can be observed in figure 3.1 and 3.2, the higher intra-regional value added in South East Asia occurred at the expense of lower interaction with East Asian and European suppliers. This result also suggests that some technological upgrading is taking place within South East Asia. This could be particularly the case of Singapore and Vietnam that are generally regarded as countries that have followed a successful pattern of industrialization. As for the case of Central Asia, in my view, the increasing intra-regional value added observed in such regional is simply indicating that the increasing fragmentation of production led to a higher interaction of suppliers within such region. Producers in Central Asia do not export as much as manufacturing goods as other regions in Asia do. So, those producers in Central Asia did not have many pressures in looking for more competitive suppliers in other regions of Asia or from the World economy. ${ }^{9}$

Finally, one central observation from figure 3.1 and 3.2 is the relative importance of European suppliers for the manufacturing production in most of the developing World. Despite the industrial emergence of several Asian economies, most of the manufacturing producers in the developing world show increasing interaction with European suppliers. From 1990 to 2011, in most of the cases, producers in North Africa and the Middle East, in Sub-Saharan Africa, in Central Asia, in South Asia, in South East Asia and even in South America, show a strong intra-regional network of suppliers located in the European Union. The intra-regional interaction of countries in the developing world was always significantly higher than the corresponding one for Europe both in 1990 and in 2011. But our point is that, for developing economies, the increase in their interaction with intra-regional suppliers was as high as their increase in the interaction with European suppliers. In my view, the main reason for this tendency is the fact that most of the advanced economies are located in Europe. So the combined value added contribution from several global manufacturing powers will necessarily be higher than the corresponding one for countries like Japan, Canada and the US.

In a nutshell, figure 3.1 describes a story of regional fragmentation in that despite increases on the extra-regional value added component, at least $70 \%$ of the value added embodied in a given's regions final output is still generated within that same region. Furthermore, figure 3.1 reveals that regions such as Central America (B), South East Asia (J), Central Asia (H) even increased their regional ties. This latter situation indicates that different regions of world economy also respond differently to the increasing fragmentation by not increasing their interaction with extra-regional supplier but by doing it so with their immediate neighbors.

\footnotetext{
${ }^{9}$ Yet another reason for the increase in the intra-regional value added contribution from Central Asia is the fact that by 1990 those countries still belonged to the Soviet Union. So, the corresponding data for 1990 might actually indicate the tendency for interactions within the Soviet Union.
} 


\subsection{Conclusion and Points for Discussion.}

In recent years, manufacturing producers in advanced and developing economies have witnessed an increasing fragmentation of their production processes. This fragmentation has been possible due to significant decreases in transportation and communication costs which enable the organization of manufacturing across long distances. Therefore, a large amount of countries are now able to interact with each other in order to produce a given manufacturing good. This increasing interaction among countries in the production of manufacturing goods has been labeled as the emergence of global value chains, given that different countries can add value in the final production from a given economy.

Current research has extensively indicated that the main outcome behind the emergence of global value chains has been a decrease in the domestic value added from local producers in final output at the expense of an increase in the foreign value added. The analysis here goes one step further and analyzes this process in a global context. This means that we focus on how the emergence of global value chains (i.e. the increasing fragmentation of manufacturing) impacts on the domestic and foreign value added from the top manufacturing exporters per product category and the one from all regions of the world economy. We do this by slicing up the value chain in the production of final manufacturing goods. We identified the contribution of domestic and foreign suppliers by country of origin. Then, we simply aggregated the value added by country of origin into different geographical regions of the world economy.

Our research identified a general tendency for the regional component of manufacturing in the World economy to increase. When analyzing the interaction of domestic suppliers with suppliers located in the same region and with suppliers outside their region in 1990 and 2011, we realized that even before the increasing fragmentation of manufacturing, domestic producers were interacting to a substantial degree with suppliers located in the same region. In general, the increasing fragmentation of production only increased the already high regionalization of manufacturing. Thus, the starting point in the analysis of value chains should not only be how large the regional interaction of a given country is with their own neighbors. Instead, it should be how much this regional component has grown, also compared to the interaction with suppliers located in other regions of the world economy.

The top manufacturing exporters of the world economy produce for competitive endmarkets. As a result of the increasing fragmentation of production these exporters faced significant competition in terms of price and quality. In order to face this competition, domestic producers at top manufacturing countries were pushed to increase their network of suppliers beyond those available in their own region. This situation led each top exporters to an increase in the intra-regional value added embodied in the final output as well as an increase of the extra-regional value added. Depending on the specific features of each manufacturing sector, the value added from an extra regional group of countries highly specialized in a given good could grow as much as the regional value added of a top exporter, and even become higher. This is the case of the production of textiles, electronics and other manufacturing goods for the top 
manufacturing exporters. Here, the increase in the value added contribution from East Asia was higher or grew as much as the corresponding for one for the network of suppliers located in the same region as the top exporter. This higher East Asian value added was observed in some of the top manufacturing exporters of the aforementioned goods and was possible because the high modularity, low transportation and communication cost observed in these industries.

We will now discuss the intra-regional and extra-regional trends for the top manufacturing exporters in the rest of manufacturing goods. Again, in most cases, the increase in the intra-regional value added was higher than any individual extra-regional increase. This situation was possible due to the specific features governing the organization of production networks for the rest of industries. Here, we are referring to factors such as high tariff and non-tariff barriers imposed in the agricultural production, high transportation costs and proximity to end markets required by the transport industry, high safety costs for the chemical industry and so forth.

The last issue is the analysis of the impact of fragmentation in all the regions of the world economy. According to our results, the regions of the world economy responded differently as a result of the increasing fragmentation of production. In 20 years from 1990 to 2011, most regions decreased their interaction with suppliers within their own region by reducing the intra-regional value added embodied in total regional final output in 5\%. Nevertheless, regions in Asia reacted differently to this whole process. Led by the increasing specialization of major low cost producers in the production of textiles, South Asia witnessed the highest decrease in the intra-regional value added (more than $10 \%$ in 20 years). On the other hand, following the successful industrialization and technological upgrading of some of the domestic suppliers within that region, South East Asia witnessed a higher intra-regional value added. Finally, given the lack of competitive pressures for domestic producers within their own region and the possibility to organize their production across neighbors, Central Asia also increased its intra-regional value added.

Another important conclusion derived from analyzing the impact of fragmentation in the regions of the world economy is the relative importance of European suppliers for manufacturing in developing economies. Asian suppliers (especially those in South East Asia and East Asia) drastically increased their manufacturing capabilities and achieved some level of upgrading. Despite this higher importance of Asian suppliers, in my view, only the top manufacturing exporters in sectors such as electronics have higher incentives to progressively rely on the efficient production from the Asian network of suppliers. In most cases, the network of European suppliers is the second option for manufacturing producers in the developing world after their own regional network. This situation, however, reflects the large number of European advanced economies investing in manufacturing at the developing world when compared to low number of advanced economies in Asia or North America.

Our research indicates that the increasing fragmentation of production, as a global phenomenon, has had different impacts on countries and regions of the world economy. A large number of factors account for these different impacts. We can point to particular 
characteristics in the production of manufacturing good, the impact of trade barriers, the competitive pressures faced by domestic suppliers, the technical capabilities of suppliers within a country's region and so forth. Nonetheless, we should keep in mind that there still are more issues that should be taken into account in order to further understand fragmentation. Many of the top manufacturing exporters in the developing world achieved outstanding results due to the implementation of export processing zones (Mexico, Pakistan, Vietnam, China and so forth). Those countries export an important amount of manufacturing goods. However, this situation occurs at the expense of inducing producers in the export processing zone to be specialized on the low value added stages of manufacturing with limited interaction with domestic suppliers. Analyzing the evolution of those domestic suppliers in those top manufacturing exporters should be the main objective of future research.

Finally, it is worth here discussing how our research differs from that of Los et al. (2015). The results presented in this chapter seem to confirm the findings from Los et al. (2015) for a larger number of countries and considering a different dataset (i.e. a higher presence from the extra-regional valued added that is embodied in a country's final output). Nevertheless, while Los et al. (2015) stresses the importance of the growth rate of the extra-regional component with respect to the one observed for the intra-regional component, this chapter stresses the importance of changes in the participation of those two components in total final output. To further clarify this idea, let us refer to the value added decomposition results for Germany as presented in table (3.1). As can be observed, the value added contribution from Europe in Germany's final output changed from $14 \%$ to $20 \%$ from 1990 to 2011, respectively. For the case of Asia, its value added contribution in Germany's output switched from 3\% to 7\% during the same period of time. In the view of Los et al. (2015), manufacturing production in Germany has become more globally oriented since the presence of extra-regional value added from Asian producers has considerably increased (a growth rate of 130\%). The same conclusion would hold if we were to jointly consider all of the extra-regional components observed in Germany's final output. While we acknowledge the importance of the growth rate of the extra-regional component with respect to that of the intra-regional one $(130 \%$ vs $43 \%$, respectively), in my view, the predominant type of organization in German manufacturing is still regional. Even if the intra-regional component has not grown at the same considerable growth rate as the extra-regional component, this first component has clearly maintained its dominance as a share of final output: $20 \%$ versus $12 \%$ (total extra-regional contribution) in 2011. Higher extra-regional interaction of manufacturing firms in Germany did not necessarily come at the expense lower intraregional interaction. Both components increased as a result of lower interaction with domestic suppliers. Any further increase on the extra-regional component will necessarily imply an increase on the intra-regional one. More importantly, in spite of different growth rates between the extra and intra-regional component, manufacturing production will mostly remain regional given that a limited number of sectors within total manufacturing (textiles, electronics and other manufacturing) have an incentive to seek for suppliers beyond those available locally and in their own respective region. 
Appendix A3.1.

Value Chain Decomposition from Top Manufacturing Exporters.

A3.1.1 Total Final Manufacturing production

Share of value added embodied in the Reporter's final manufacturing output.

\begin{tabular}{lrrrrrrrrrrrrr} 
& \multicolumn{1}{c}{ Germany } & \multicolumn{2}{c}{ USA } & \multicolumn{3}{c}{ Japan } & \multicolumn{2}{c}{ Italy } & \multicolumn{2}{c}{ China } & \multicolumn{2}{c}{ Mexico } \\
& $\mathbf{1 9 9 0}$ & $\mathbf{2 0 1 1}$ & $\mathbf{1 9 9 0}$ & $\mathbf{2 0 1 1}$ & $\mathbf{1 9 9 0}$ & $\mathbf{2 0 1 1}$ & $\mathbf{1 9 9 0}$ & $\mathbf{2 0 1 1}$ & $\mathbf{1 9 9 0}$ & $\mathbf{2 0 1 1}$ & $\mathbf{1 9 9 0}$ & $\mathbf{2 0 1 1}$ \\
\hline Total Value Added & 100 & 100 & 100 & 100 & 100 & 100 & 100 & 100 & 100 & 100 & 100 & 100 \\
\hline EUROPE & 94.0 & 88.5 & 4.1 & 5.6 & 2.7 & 3.5 & 94.6 & 88.8 & 2.8 & 6.1 & 4.0 & 6.6 \\
\hline \hline France & 2.0 & 2.6 & 0.5 & 0.6 & 0.3 & 0.4 & 2.6 & 3.2 & 0.3 & 0.7 & 0.5 & 0.8 \\
Netherlands & 1.4 & 1.7 & 0.2 & 0.3 & 0.1 & 0.2 & 1.1 & 1.4 & 0.1 & 0.3 & 0.2 & 0.3 \\
Germany & 80.2 & 68.3 & 1.0 & 1.3 & 0.6 & 0.7 & 4.3 & 5.5 & 0.6 & 1.6 & 1.0 & 1.5 \\
Italy & 1.9 & 2.3 & 0.4 & 0.5 & 0.2 & 0.3 & 79.2 & 67.4 & 0.2 & 0.5 & 0.5 & 0.8 \\
Spain & 0.6 & 1.1 & 0.1 & 0.2 & 0.1 & 0.1 & 1.0 & 1.5 & 0.1 & 0.2 & 0.3 & 0.7 \\
Belgium & 0.9 & 1.2 & 0.1 & 0.2 & 0.1 & 0.1 & 0.9 & 1.1 & 0.1 & 0.2 & 0.1 & 0.2 \\
Sweden & 0.8 & 0.7 & 0.2 & 0.2 & 0.1 & 0.1 & 0.7 & 0.5 & 0.2 & 0.2 & 0.2 & 0.2 \\
Russia & 0.6 & 1.2 & 0.2 & 0.4 & 0.5 & 0.6 & 0.5 & 1.0 & 0.7 & 0.7 & 0.2 & 0.4 \\
UK & 1.2 & 1.7 & 0.6 & 0.6 & 0.2 & 0.3 & 1.3 & 1.6 & 0.2 & 0.6 & 0.3 & 0.5 \\
Switzerland & 0.8 & 1.7 & 0.1 & 0.3 & 0.1 & 0.2 & 0.5 & 1.0 & 0.1 & 0.3 & 0.2 & 0.4 \\
Rest of Europe & 3.6 & 6.2 & 0.5 & 0.9 & 0.4 & 0.5 & 2.7 & 4.5 & 0.3 & 0.9 & 0.4 & 0.9 \\
& & & & & & & & & & & \\
NAFTA & 2.2 & 2.7 & 91.6 & 84.9 & 3.2 & 3.1 & 1.7 & 2.2 & 2.1 & 2.3 & 93.1 & 84.4 \\
\hline USA & 2.0 & 2.3 & 89.0 & 79.9 & 2.7 & 2.4 & 1.5 & 1.9 & 1.9 & 1.8 & 11.7 & 11.8 \\
Canada & 0.2 & 0.3 & 2.2 & 3.6 & 0.4 & 0.6 & 0.1 & 0.2 & 0.1 & 0.4 & 0.6 & 1.2 \\
Mexico & 0.1 & 0.1 & 0.5 & 1.4 & 0.1 & 0.1 & 0.0 & 0.1 & 0.1 & 0.1 & 80.8 & 71.3 \\
\hline \hline
\end{tabular}

Central, South America and

\begin{tabular}{|c|c|c|c|c|c|c|c|c|c|c|c|c|}
\hline the Caribbean & 0.4 & 0.8 & 1.0 & 2.4 & 0.3 & 0.5 & 0.4 & 0.9 & 0.3 & 0.7 & 0.7 & 2.2 \\
\hline Brazil & 0.2 & 0.4 & 0.2 & 0.4 & 0.1 & 0.2 & 0.2 & 0.4 & 0.2 & 0.3 & 0.3 & 0.8 \\
\hline Argentina & 0.0 & 0.1 & 0.0 & 0.1 & 0.0 & 0.0 & 0.1 & 0.1 & 0.0 & 0.0 & 0.1 & 0.2 \\
\hline \multirow[t]{2}{*}{ Rest of countries } & 0.1 & 0.3 & 0.8 & 1.9 & 0.1 & 0.3 & 0.2 & 0.4 & 0.1 & 0.3 & 0.3 & 1.2 \\
\hline & 0.0 & 0.0 & 0.0 & 0.0 & 0.0 & 0.0 & 0.0 & 0.0 & 0.0 & 0.0 & 0.0 & 0.0 \\
\hline AFRICA & 0.5 & 0.9 & 0.3 & 0.7 & 0.2 & 0.3 & 0.9 & 1.4 & 0.1 & 0.5 & 0.1 & 0.4 \\
\hline ASIA & 2.8 & 6.7 & 2.8 & 6.1 & 93.0 & 91.2 & 2.3 & 6.4 & 94.3 & 89.6 & 2.0 & 6.2 \\
\hline China & 0.4 & 2.6 & 0.3 & 2.0 & 0.6 & 2.8 & 0.4 & 2.4 & 90.8 & 81.3 & 0.2 & 2.5 \\
\hline Hong Kong & 0.0 & 0.0 & 0.0 & 0.0 & 0.0 & 0.0 & 0.0 & 0.0 & 0.0 & 0.0 & 0.0 & 0.0 \\
\hline South Korea & 0.1 & 0.3 & 0.2 & 0.5 & 0.4 & 0.8 & 0.1 & 0.3 & 0.5 & 1.9 & 0.2 & 0.6 \\
\hline Indonesia & 0.1 & 0.3 & 0.1 & 0.2 & 0.3 & 0.9 & 0.1 & 0.3 & 0.1 & 0.6 & 0.0 & 0.3 \\
\hline India & 0.1 & 0.5 & 0.1 & 0.3 & 0.1 & 0.3 & 0.1 & 0.6 & 0.1 & 0.4 & 0.1 & 0.5 \\
\hline Singapore & 0.0 & 0.1 & 0.0 & 0.1 & 0.1 & 0.2 & 0.0 & 0.1 & 0.0 & 0.3 & 0.0 & 0.1 \\
\hline Japan & 1.3 & 1.3 & 1.7 & 1.6 & 90.6 & 83.8 & 0.7 & 0.9 & 2.2 & 3.2 & 1.2 & 1.1 \\
\hline Thailand & 0.1 & 0.2 & 0.1 & 0.2 & 0.1 & 0.3 & 0.1 & 0.2 & 0.1 & 0.3 & 0.1 & 0.2 \\
\hline Viet Nam & 0.0 & 0.0 & 0.0 & 0.0 & 0.0 & 0.1 & 0.0 & 0.0 & 0.0 & 0.1 & 0.0 & 0.0 \\
\hline Bangladesh & 0.0 & 0.0 & 0.0 & 0.0 & 0.0 & 0.0 & 0.0 & 0.0 & 0.0 & 0.0 & 0.0 & 0.0 \\
\hline Turkey & 0.3 & 0.4 & 0.0 & 0.1 & 0.0 & 0.0 & 0.3 & 0.4 & 0.0 & 0.0 & 0.0 & 0.1 \\
\hline Rest of countries & 0.3 & 1.1 & 0.4 & 1.1 & 0.8 & 2.1 & 0.4 & 1.2 & 0.4 & 1.6 & 0.2 & 0.8 \\
\hline OCEANIA & 0.1 & 0.3 & 0.1 & 0.3 & 0.6 & 1.3 & 0.1 & 0.3 & 0.3 & 0.8 & 0.1 & 0.2 \\
\hline Australia & 0.1 & 0.2 & 0.1 & 0.3 & 0.5 & 1.2 & 0.1 & 0.2 & 0.3 & 0.7 & 0.1 & 0.2 \\
\hline Rest of countries & 0.0 & 0.1 & 0.0 & 0.1 & 0.1 & 0.2 & 0.0 & 0.1 & 0.0 & 0.1 & 0.0 & 0.0 \\
\hline
\end{tabular}

Source: Author's calculation based on equation (3.1) to (3.4) and using EORA data set 
A3.1.2 Food \& Beverages

Share of value added embodied in the Reporter's final manufacturing output.

\begin{tabular}{|c|c|c|c|c|c|c|c|c|c|c|c|c|}
\hline & \multicolumn{2}{|c|}{ France } & \multicolumn{2}{|c|}{ Netherlands } & \multicolumn{2}{|c|}{ Germany } & \multicolumn{2}{|c|}{ USA } & \multicolumn{2}{|c|}{ China } & \multicolumn{2}{|c|}{ Italy } \\
\hline & 1990 & 2011 & 1990 & 2011 & 1990 & 2011 & 1990 & 2011 & 1990 & 2011 & 1990 & 2011 \\
\hline Total Value Added & 100 & 100 & 100 & 100 & 100 & 100 & 100 & 100 & 100 & 100 & 100 & 100 \\
\hline EUROPE & 94.9 & 92.4 & 90.7 & 82.8 & 94.6 & 89.0 & 3.0 & 4.2 & 1.7 & 2.9 & 96.3 & 92.0 \\
\hline France & 82.3 & 77.9 & 2.7 & 3.3 & 1.7 & 2.4 & 0.3 & 0.4 & 0.1 & 0.3 & 2.2 & 3.0 \\
\hline Netherlands & 1.2 & 1.3 & 70.0 & 55.9 & 1.9 & 2.9 & 0.4 & 0.5 & 0.1 & 0.2 & 1.1 & 1.5 \\
\hline Germany & 3.0 & 3.3 & 6.3 & 7.8 & 83.1 & 70.9 & 0.6 & 0.9 & 0.3 & 0.7 & 2.7 & 3.7 \\
\hline Italy & 1.6 & 1.6 & 1.4 & 1.8 & 1.4 & 1.9 & 0.3 & 0.4 & 0.1 & 0.2 & 85.2 & 75.4 \\
\hline Spain & 1.2 & 1.6 & 1.4 & 1.8 & 0.8 & 1.3 & 0.1 & 0.2 & 0.1 & 0.1 & 1.0 & 1.6 \\
\hline Belgium & 1.3 & 1.5 & 3.0 & 3.8 & 0.8 & 1.2 & 0.1 & 0.2 & 0.1 & 0.1 & 0.6 & 0.9 \\
\hline Sweden & 0.5 & 0.3 & 0.7 & 0.5 & 0.5 & 0.4 & 0.1 & 0.1 & 0.1 & 0.1 & 0.4 & 0.3 \\
\hline Russia & 0.5 & 0.6 & 0.5 & 0.7 & 0.4 & 0.8 & 0.1 & 0.2 & 0.6 & 0.4 & 0.3 & 0.6 \\
\hline UK & 1.1 & 1.3 & 1.7 & 2.2 & 0.8 & 1.2 & 0.4 & 0.4 & 0.1 & 0.2 & 0.8 & 1.1 \\
\hline Switzerland & 0.3 & 0.5 & 0.3 & 0.5 & 0.4 & 0.8 & 0.1 & 0.2 & 0.1 & 0.1 & 0.2 & 0.5 \\
\hline Rest of Europe & 1.8 & 2.4 & 2.8 & 4.4 & 2.8 & 5.3 & 0.4 & 0.7 & 0.2 & 0.4 & 1.9 & 3.4 \\
\hline NAFTA & 1.8 & 1.9 & 3.0 & 3.7 & 1.8 & 2.4 & 94.3 & 89.7 & 1.6 & 1.4 & 1.1 & 1.6 \\
\hline USA & 1.6 & 1.5 & 2.5 & 2.9 & 1.4 & 1.8 & 91.3 & 84.7 & 1.5 & 1.1 & 0.9 & 1.3 \\
\hline Canada & 0.2 & 0.2 & 0.4 & 0.6 & 0.3 & 0.5 & 2.5 & 3.9 & 0.1 & 0.3 & 0.1 & 0.2 \\
\hline Mexico & 0.1 & 0.1 & 0.1 & 0.2 & 0.1 & 0.1 & 0.5 & 1.1 & 0.1 & 0.0 & 0.0 & 0.1 \\
\hline
\end{tabular}

Central, South America and

\begin{tabular}{|c|c|c|c|c|c|c|c|c|c|c|c|c|}
\hline the Caribbean & 0.4 & 0.8 & 1.5 & 3.0 & 0.7 & 1.6 & 0.9 & 1.9 & 0.2 & 0.4 & 0.5 & 1.2 \\
\hline Brazil & 0.2 & 0.3 & 0.6 & 1.2 & 0.3 & 0.7 & 0.2 & 0.4 & 0.1 & 0.1 & 0.2 & 0.5 \\
\hline Argentina & 0.1 & 0.1 & 0.3 & 0.6 & 0.1 & 0.3 & 0.1 & 0.2 & 0.0 & 0.1 & 0.1 & 0.3 \\
\hline \multirow[t]{2}{*}{$\underline{\text { Rest of countries }}$} & 0.2 & 0.3 & 0.6 & 1.2 & 0.3 & 0.6 & 0.7 & 1.4 & 0.1 & 0.2 & 0.2 & 0.4 \\
\hline & 0.0 & 0.0 & 0.0 & 0.0 & 0.0 & 0.0 & 0.0 & 0.0 & 0.0 & 0.0 & 0.0 & 0.0 \\
\hline AFRICA & 0.9 & 1.3 & 1.1 & 2.1 & 0.6 & 1.3 & 0.2 & 0.5 & 0.1 & 0.3 & 0.7 & 1.2 \\
\hline ASIA & 1.8 & 3.4 & 3.4 & 7.8 & 2.2 & 5.2 & 1.4 & 3.3 & 96.2 & 94.6 & 1.3 & 3.7 \\
\hline China & 0.3 & 1.1 & 0.5 & 2.4 & 0.4 & 1.5 & 0.2 & 1.1 & 94.4 & 91.1 & 0.2 & 1.1 \\
\hline Hong Kong & 0.0 & 0.0 & 0.0 & 0.0 & 0.0 & 0.0 & 0.0 & 0.0 & 0.0 & 0.0 & 0.0 & 0.0 \\
\hline South Korea & 0.1 & 0.1 & 0.1 & 0.2 & 0.1 & 0.1 & 0.1 & 0.2 & 0.2 & 0.6 & 0.1 & 0.1 \\
\hline Indonesia & 0.1 & 0.2 & 0.3 & 0.7 & 0.1 & 0.3 & 0.1 & 0.2 & 0.1 & 0.4 & 0.1 & 0.2 \\
\hline India & 0.1 & 0.4 & 0.2 & 0.9 & 0.1 & 0.6 & 0.1 & 0.3 & 0.0 & 0.2 & 0.1 & 0.4 \\
\hline Singapore & 0.0 & 0.1 & 0.0 & 0.1 & 0.0 & 0.1 & 0.0 & 0.1 & 0.0 & 0.1 & 0.0 & 0.1 \\
\hline Japan & 0.6 & 0.5 & 0.8 & 0.8 & 0.5 & 0.5 & 0.6 & 0.6 & 1.0 & 1.1 & 0.3 & 0.4 \\
\hline Thailand & 0.1 & 0.1 & 0.2 & 0.5 & 0.1 & 0.2 & 0.1 & 0.1 & 0.1 & 0.2 & 0.1 & 0.1 \\
\hline Viet Nam & 0.0 & 0.0 & 0.0 & 0.1 & 0.0 & 0.0 & 0.0 & 0.0 & 0.0 & 0.0 & 0.0 & 0.0 \\
\hline Bangladesh & 0.0 & 0.0 & 0.0 & 0.0 & 0.0 & 0.0 & 0.0 & 0.0 & 0.0 & 0.0 & 0.0 & 0.0 \\
\hline Turkey & 0.2 & 0.2 & 0.6 & 0.6 & 0.5 & 0.7 & 0.1 & 0.1 & 0.0 & 0.0 & 0.3 & 0.4 \\
\hline Rest of countries & 0.4 & 0.7 & 0.6 & 1.4 & 0.3 & 0.9 & 0.3 & 0.7 & 0.3 & 0.8 & 0.3 & 0.8 \\
\hline OCEANIA & 0.1 & 0.2 & 0.3 & 0.6 & 0.2 & 0.5 & 0.2 & 0.4 & 0.2 & 0.4 & 0.1 & 0.4 \\
\hline Australia & 0.1 & 0.1 & 0.2 & 0.3 & 0.1 & 0.3 & 0.1 & 0.3 & 0.2 & 0.4 & 0.1 & 0.2 \\
\hline Rest of countries & 0.1 & 0.1 & 0.1 & 0.3 & 0.1 & 0.3 & 0.1 & 0.1 & 0.0 & 0.1 & 0.1 & 0.1 \\
\hline
\end{tabular}

Source: as described in table (A3.1.1) 
A3.1.3 Textiles and Wearing Apparel

Share of value added embodied in the Reporter's final manufacturing output.

\begin{tabular}{lcccccccccccc} 
& \multicolumn{1}{c}{ China } & \multicolumn{3}{c}{ Italy } & \multicolumn{2}{c}{ India } & \multicolumn{2}{c}{ Japan } & \multicolumn{2}{c}{ Turkey } & \multicolumn{2}{c}{ Indonesia } \\
& $\mathbf{1 9 9 0}$ & $\mathbf{2 0 1 1}$ & $\mathbf{1 9 9 0}$ & $\mathbf{2 0 1 1}$ & $\mathbf{1 9 9 0}$ & $\mathbf{2 0 1 1}$ & $\mathbf{1 9 9 0}$ & $\mathbf{2 0 1 1}$ & $\mathbf{1 9 9 0}$ & $\mathbf{2 0 1 1}$ & $\mathbf{1 9 9 0}$ & $\mathbf{2 0 1 1}$ \\
\hline Total Value Added & 100 & 100 & 100 & 100 & 100 & 100 & 100 & 100 & 100 & 100 & 100 & 100 \\
\hline EUROPE & 2.8 & 4.5 & 93.9 & 86.5 & 2.7 & 5.4 & 3.7 & 4.9 & 10.9 & 21.4 & 6.3 & 4.4 \\
\hline \hline France & 0.2 & 0.5 & 2.6 & 3.1 & 0.3 & 0.5 & 0.4 & 0.6 & 1.1 & 2.1 & 0.6 & 0.5 \\
Netherlands & 0.1 & 0.2 & 1.0 & 1.3 & 0.2 & 0.3 & 0.1 & 0.2 & 0.7 & 1.2 & 0.6 & 0.4 \\
Germany & 0.5 & 1.0 & 3.5 & 4.0 & 0.7 & 1.1 & 0.5 & 0.7 & 2.8 & 4.3 & 1.4 & 1.0 \\
Italy & 0.3 & 0.7 & 79.5 & 66.9 & 0.3 & 0.6 & 0.8 & 1.3 & 2.0 & 3.6 & 0.5 & 0.3 \\
Spain & 0.1 & 0.2 & 1.2 & 1.7 & 0.1 & 0.2 & 0.1 & 0.2 & 0.4 & 1.2 & 0.2 & 0.2 \\
Belgium & 0.1 & 0.2 & 0.8 & 1.1 & 0.2 & 0.3 & 0.1 & 0.2 & 0.5 & 1.0 & 0.4 & 0.3 \\
Sweden & 0.1 & 0.1 & 0.4 & 0.3 & 0.1 & 0.1 & 0.1 & 0.1 & 0.3 & 0.3 & 0.2 & 0.1 \\
Russia & 0.8 & 0.4 & 0.4 & 0.7 & 0.2 & 0.4 & 0.7 & 0.3 & 0.6 & 1.6 & 0.6 & 0.3 \\
UK & 0.2 & 0.4 & 1.1 & 1.4 & 0.3 & 0.6 & 0.2 & 0.4 & 0.7 & 1.5 & 0.6 & 0.5 \\
Switzerland & 0.1 & 0.2 & 0.4 & 0.8 & 0.2 & 0.4 & 0.1 & 0.2 & 0.3 & 0.8 & 0.2 & 0.2 \\
Rest of Europe & 0.3 & 0.6 & 3.1 & 5.1 & 0.3 & 0.7 & 0.4 & 0.6 & 1.4 & 3.8 & 0.8 & 0.7 \\
& & & & & & & & & & & \\
NAFTA & 2.4 & 1.6 & 1.5 & 1.9 & 0.8 & 1.6 & 3.0 & 2.2 & 1.1 & 1.9 & 3.7 & 2.2 \\
USA & 2.2 & 1.3 & 1.3 & 1.6 & 0.8 & 1.4 & 2.6 & 1.8 & 1.0 & 1.6 & 3.4 & 1.9 \\
Canada & 0.1 & 0.3 & 0.1 & 0.2 & 0.1 & 0.2 & 0.3 & 0.3 & 0.1 & 0.2 & 0.2 & 0.2 \\
Mexico & 0.1 & 0.1 & 0.0 & 0.1 & 0.0 & 0.0 & 0.1 & 0.1 & 0.0 & 0.1 & 0.1 & 0.0 \\
\hline \hline
\end{tabular}

Central, South America and

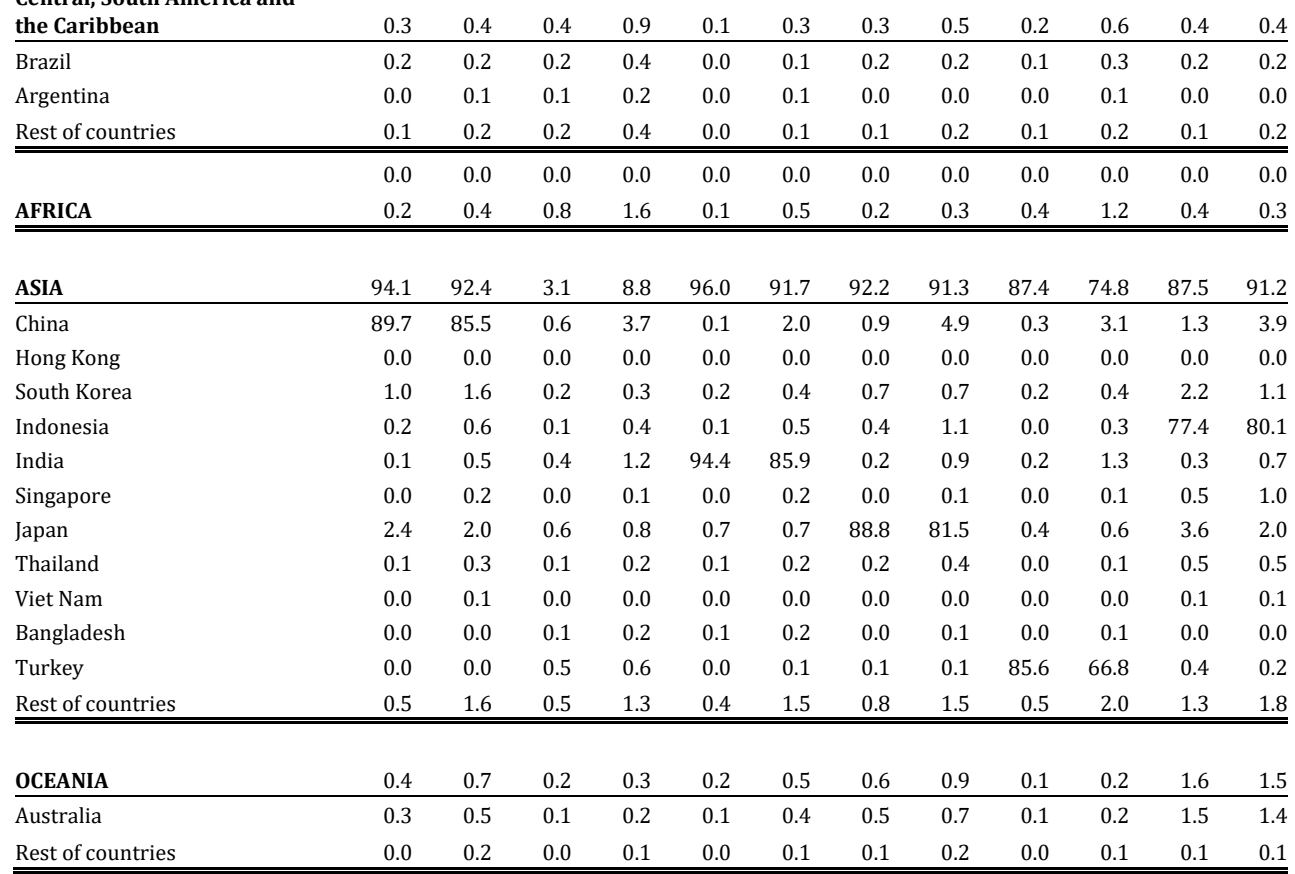

Source: as described in table (A3.1.1) 
A3.1.4 Wood and Paper

Share of value added embodied in the Reporter's final manufacturing output.

\begin{tabular}{|c|c|c|c|c|c|c|c|c|c|c|c|c|}
\hline & \multicolumn{2}{|c|}{ China } & \multicolumn{2}{|c|}{ Germany } & \multicolumn{2}{|c|}{ UK } & \multicolumn{2}{|c|}{ USA } & \multicolumn{2}{|c|}{ Italy } & \multicolumn{2}{|c|}{ France } \\
\hline & 1990 & 2011 & 1990 & 2011 & 1990 & 2011 & 1990 & 2011 & 1990 & 2011 & 1990 & 2011 \\
\hline Total Value Added & 100 & 100 & 100 & 100 & 100 & 100 & 100 & 100 & 100 & 100 & 100 & 100 \\
\hline EUROPE & 2.4 & 6.0 & 96.7 & 93.5 & 94.2 & 89.9 & 3.4 & 4.7 & 95.8 & 91.0 & 95.4 & 93.4 \\
\hline France & 0.2 & 0.6 & 1.4 & 2.0 & 2.0 & 2.4 & 0.4 & 0.5 & 2.4 & 3.1 & 80.0 & 75.9 \\
\hline Netherlands & 0.1 & 0.2 & 1.0 & 1.5 & 1.4 & 1.8 & 0.2 & 0.2 & 0.8 & 1.2 & 1.0 & 1.1 \\
\hline Germany & 0.5 & 1.5 & 85.1 & 75.8 & 3.9 & 4.8 & 0.9 & 1.2 & 4.0 & 5.3 & 4.0 & 4.4 \\
\hline Italy & 0.2 & 0.4 & 1.1 & 1.5 & 1.1 & 1.3 & 0.3 & 0.4 & 80.7 & 69.7 & 1.9 & 1.9 \\
\hline Spain & 0.1 & 0.2 & 0.3 & 0.6 & 0.4 & 0.9 & 0.1 & 0.2 & 0.8 & 1.3 & 1.2 & 1.5 \\
\hline Belgium & 0.1 & 0.2 & 0.7 & 1.0 & 1.0 & 1.3 & 0.1 & 0.1 & 0.8 & 1.0 & 1.3 & 1.5 \\
\hline Sweden & 0.1 & 0.2 & 1.6 & 1.4 & 1.6 & 1.3 & 0.3 & 0.2 & 1.5 & 1.2 & 1.4 & 1.0 \\
\hline Russia & 0.5 & 1.0 & 0.3 & 0.7 & 0.3 & 0.6 & 0.1 & 0.2 & 0.3 & 0.7 & 0.4 & 0.6 \\
\hline UK & 0.2 & 0.5 & 0.9 & 1.3 & 79.4 & 70.2 & 0.4 & 0.4 & 1.1 & 1.4 & 1.3 & 1.5 \\
\hline Switzerland & 0.1 & 0.3 & 0.7 & 1.5 & 0.3 & 0.5 & 0.1 & 0.2 & 0.5 & 1.0 & 0.4 & 0.8 \\
\hline Rest of Europe & 0.3 & 0.8 & 3.4 & 6.1 & 2.9 & 4.6 & 0.6 & 0.9 & 2.9 & 5.1 & 2.4 & 3.2 \\
\hline NAFTA & 1.6 & 2.5 & 1.5 & 2.1 & 3.1 & 3.5 & 94.0 & 89.3 & 1.5 & 2.0 & 2.0 & 1.9 \\
\hline USA & 1.4 & 1.8 & 1.3 & 1.6 & 2.7 & 2.8 & 90.8 & 83.9 & 1.3 & 1.6 & 1.7 & 1.6 \\
\hline Canada & 0.2 & 0.6 & 0.2 & 0.4 & 0.4 & 0.6 & 3.0 & 4.7 & 0.2 & 0.3 & 0.2 & 0.3 \\
\hline Mexico & 0.0 & 0.1 & 0.0 & 0.1 & 0.0 & 0.1 & 0.3 & 0.7 & 0.0 & 0.1 & 0.0 & 0.1 \\
\hline
\end{tabular}

Central, South America and

\begin{tabular}{|c|c|c|c|c|c|c|c|c|c|c|c|c|}
\hline the Caribbean & 0.2 & 0.5 & 0.2 & 0.5 & 0.3 & 0.7 & 0.8 & 1.9 & 0.4 & 0.9 & 0.3 & 0.6 \\
\hline Brazil & 0.1 & 0.2 & 0.1 & 0.3 & 0.2 & 0.4 & 0.3 & 0.7 & 0.2 & 0.5 & 0.2 & 0.4 \\
\hline Argentina & 0.0 & 0.0 & 0.0 & 0.0 & 0.0 & 0.0 & 0.0 & 0.1 & 0.0 & 0.1 & 0.0 & 0.0 \\
\hline \multirow[t]{2}{*}{$\underline{\text { Rest of countries }}$} & 0.1 & 0.2 & 0.1 & 0.2 & 0.1 & 0.2 & 0.5 & 1.1 & 0.1 & 0.3 & 0.1 & 0.2 \\
\hline & 0.0 & 0.0 & 0.0 & 0.0 & 0.0 & 0.0 & 0.0 & 0.0 & 0.0 & 0.0 & 0.0 & 0.0 \\
\hline AFRICA & 0.1 & 0.5 & 0.3 & 0.5 & 0.4 & 0.7 & 0.2 & 0.5 & 0.7 & 1.2 & 0.7 & 0.9 \\
\hline ASIA & 95.4 & 89.8 & 1.2 & 3.3 & 1.9 & 5.0 & 1.4 & 3.5 & 1.6 & 4.7 & 1.6 & 3.1 \\
\hline China & 92.9 & 82.7 & 0.2 & 1.2 & 0.3 & 1.7 & 0.2 & 1.2 & 0.3 & 1.8 & 0.3 & 1.1 \\
\hline Hong Kong & 0.0 & 0.0 & 0.0 & 0.0 & 0.0 & 0.0 & 0.0 & 0.0 & 0.0 & 0.0 & 0.0 & 0.0 \\
\hline South Korea & 0.4 & 1.4 & 0.1 & 0.1 & 0.1 & 0.3 & 0.1 & 0.3 & 0.1 & 0.2 & 0.1 & 0.1 \\
\hline Indonesia & 0.2 & 1.1 & 0.1 & 0.2 & 0.1 & 0.4 & 0.1 & 0.2 & 0.1 & 0.4 & 0.1 & 0.2 \\
\hline India & 0.0 & 0.3 & 0.0 & 0.2 & 0.1 & 0.4 & 0.0 & 0.2 & 0.1 & 0.3 & 0.1 & 0.2 \\
\hline Singapore & 0.0 & 0.2 & 0.0 & 0.1 & 0.0 & 0.2 & 0.0 & 0.1 & 0.0 & 0.1 & 0.0 & 0.1 \\
\hline Japan & 1.4 & 2.1 & 0.5 & 0.5 & 0.8 & 0.8 & 0.7 & 0.7 & 0.5 & 0.6 & 0.6 & 0.5 \\
\hline Thailand & 0.1 & 0.5 & 0.0 & 0.1 & 0.1 & 0.1 & 0.0 & 0.1 & 0.1 & 0.2 & 0.1 & 0.1 \\
\hline Viet Nam & 0.0 & 0.1 & 0.0 & 0.0 & 0.0 & 0.0 & 0.0 & 0.0 & 0.0 & 0.0 & 0.0 & 0.0 \\
\hline Bangladesh & 0.0 & 0.0 & 0.0 & 0.0 & 0.0 & 0.0 & 0.0 & 0.0 & 0.0 & 0.0 & 0.0 & 0.0 \\
\hline Turkey & 0.0 & 0.0 & 0.1 & 0.1 & 0.1 & 0.1 & 0.0 & 0.0 & 0.1 & 0.2 & 0.1 & 0.1 \\
\hline Rest of countries & 0.3 & 1.5 & 0.2 & 0.6 & 0.3 & 0.9 & 0.3 & 0.7 & 0.3 & 0.9 & 0.3 & 0.6 \\
\hline OCEANIA & 0.2 & 0.7 & 0.0 & 0.1 & 0.1 & 0.2 & 0.1 & 0.2 & 0.1 & 0.2 & 0.1 & 0.1 \\
\hline Australia & 0.2 & 0.5 & 0.0 & 0.1 & 0.1 & 0.2 & 0.1 & 0.1 & 0.1 & 0.1 & 0.1 & 0.1 \\
\hline Rest of countries & 0.0 & 0.2 & 0.0 & 0.0 & 0.0 & 0.1 & 0.0 & 0.1 & 0.0 & 0.0 & 0.0 & 0.0 \\
\hline
\end{tabular}

Source: as described in table (A3.1.1) 
Chapter 3.

A3.1.5 Metal Products

Share of value added embodied in the Reporter's final manufacturing output.

$\begin{array}{llllll}\text { China } & \text { Germany } & \text { Italy } & \text { USA } & \text { Japan } & \text { France }\end{array}$

$\begin{array}{lllllllllllll}1990 & 2011 & 1990 & 2011 & 1990 & 2011 & 1990 & 2011 & 1990 & 2011 & 1990 & 2011\end{array}$

\begin{tabular}{|c|c|c|c|c|c|c|c|c|c|c|c|c|}
\hline Total Value Added & 100 & 100 & 100 & 100 & 100 & 100 & 100 & 100 & 100 & 100 & 100 & 100 \\
\hline EUROPE & 2.4 & 5.5 & 94.7 & 89.6 & 95.6 & 90.9 & 4.6 & 6.5 & 2.9 & 4.0 & 94.2 & 91.3 \\
\hline France & 0.2 & 0.5 & 2.0 & 2.4 & 2.5 & 3.1 & 0.5 & 0.6 & 0.3 & 0.4 & 75.7 & 71.0 \\
\hline Netherlands & 0.1 & 0.2 & 1.1 & 1.3 & 0.9 & 1.1 & 0.2 & 0.2 & 0.1 & 0.1 & 1.1 & 1.2 \\
\hline Germany & 0.6 & 1.4 & 81.0 & 70.4 & 4.4 & 5.6 & 1.2 & 1.5 & 0.5 & 0.7 & 5.2 & 5.4 \\
\hline Italy & 0.2 & 0.4 & 1.5 & 1.8 & 80.1 & 69.5 & 0.4 & 0.5 & 0.1 & 0.2 & 2.7 & 2.6 \\
\hline Spain & 0.1 & 0.2 & 0.4 & 0.7 & 0.8 & 1.4 & 0.1 & 0.2 & 0.1 & 0.1 & 1.1 & 1.6 \\
\hline Belgium & 0.1 & 0.2 & 1.1 & 1.3 & 0.8 & 1.1 & 0.2 & 0.3 & 0.1 & 0.1 & 1.9 & 2.0 \\
\hline Sweden & 0.1 & 0.2 & 0.9 & 0.7 & 0.9 & 0.7 & 0.3 & 0.3 & 0.2 & 0.2 & 1.1 & 0.7 \\
\hline Russia & 0.4 & 0.8 & 1.0 & 2.1 & 0.6 & 1.3 & 0.5 & 1.2 & 0.8 & 1.3 & 0.7 & 1.0 \\
\hline UK & 0.2 & 0.5 & 1.2 & 1.6 & 1.3 & 1.5 & 0.6 & 0.6 & 0.2 & 0.3 & 1.7 & 1.8 \\
\hline Switzerland & 0.1 & 0.3 & 0.8 & 1.4 & 0.5 & 1.0 & 0.1 & 0.2 & 0.1 & 0.1 & 0.6 & 0.9 \\
\hline Rest of Europe & 0.3 & 0.7 & 3.8 & 5.9 & 2.7 & 4.5 & 0.6 & 1.0 & 0.4 & 0.6 & 2.5 & 3.2 \\
\hline NAFTA & 1.3 & 2.0 & 2.0 & 2.7 & 1.4 & 2.0 & 91.9 & 85.5 & 2.4 & 2.8 & 2.2 & 2.2 \\
\hline USA & 1.2 & 1.6 & 1.8 & 2.2 & 1.3 & 1.6 & 89.9 & 81.6 & 1.9 & 1.9 & 1.9 & $\overline{1.8}$ \\
\hline Canada & 0.1 & 0.4 & 0.2 & 0.4 & 0.1 & 0.3 & 1.6 & 3.0 & 0.4 & 0.7 & 0.2 & 0.3 \\
\hline Mexico & 0.0 & 0.1 & 0.0 & 0.1 & 0.0 & 0.1 & 0.4 & 0.9 & 0.1 & 0.1 & 0.1 & 0.1 \\
\hline
\end{tabular}

Central, South America and

\begin{tabular}{|c|c|c|c|c|c|c|c|c|c|c|c|c|}
\hline the Caribbean & 0.5 & 1.8 & 0.5 & 1.2 & 0.4 & 1.0 & 0.8 & 1.8 & 0.7 & 1.7 & 0.5 & 0.8 \\
\hline Brazil & 0.4 & 1.2 & 0.3 & 0.6 & 0.2 & 0.4 & 0.3 & 0.6 & 0.3 & 0.5 & 0.3 & 0.4 \\
\hline Argentina & 0.0 & 0.1 & 0.0 & 0.1 & 0.0 & 0.1 & 0.1 & 0.1 & 0.0 & 0.1 & 0.0 & 0.0 \\
\hline \multirow[t]{2}{*}{ Rest of countries } & 0.1 & 0.5 & 0.3 & 0.6 & 0.2 & 0.5 & 0.5 & 1.1 & 0.4 & 1.1 & 0.2 & 0.3 \\
\hline & 0.0 & 0.0 & 0.0 & 0.0 & 0.0 & 0.0 & 0.0 & 0.0 & 0.0 & 0.0 & 0.0 & 0.0 \\
\hline AFRICA & 0.2 & 0.8 & 0.8 & 1.4 & 0.7 & 1.3 & 0.3 & 0.6 & 0.5 & 1.1 & 0.9 & 1.3 \\
\hline ASIA & 94.9 & 88.2 & 1.8 & 4.7 & 1.7 & 4.6 & 2.2 & 5.1 & 92.3 & 87.7 & 2.0 & 3.9 \\
\hline China & 92.0 & 80.5 & 0.3 & 1.9 & 0.2 & 1.7 & 0.2 & 1.5 & 0.8 & 3.5 & 0.3 & 1.6 \\
\hline Hong Kong & 0.0 & 0.0 & 0.0 & 0.0 & 0.0 & 0.0 & 0.0 & 0.0 & 0.0 & 0.0 & 0.0 & 0.0 \\
\hline South Korea & 0.4 & 1.9 & 0.1 & 0.2 & 0.1 & 0.3 & 0.2 & 0.7 & 0.4 & 1.2 & 0.1 & 0.2 \\
\hline Indonesia & 0.1 & 0.5 & 0.1 & 0.2 & 0.1 & 0.2 & 0.0 & 0.2 & 0.5 & 1.0 & 0.1 & 0.1 \\
\hline India & 0.2 & 0.8 & 0.1 & 0.3 & 0.1 & 0.3 & 0.1 & 0.4 & 0.1 & 0.4 & 0.1 & 0.3 \\
\hline Singapore & 0.0 & 0.2 & 0.0 & 0.1 & 0.0 & 0.1 & 0.0 & 0.1 & 0.0 & 0.1 & 0.0 & 0.1 \\
\hline Japan & 1.8 & 2.6 & 0.8 & 0.8 & 0.6 & 0.7 & 1.3 & 1.3 & 89.6 & 79.4 & 0.9 & 0.7 \\
\hline Thailand & 0.1 & 0.2 & 0.0 & 0.1 & 0.0 & 0.1 & 0.0 & 0.1 & 0.1 & 0.2 & 0.1 & 0.1 \\
\hline Viet Nam & 0.0 & 0.1 & 0.0 & 0.0 & 0.0 & 0.0 & 0.0 & 0.0 & 0.0 & 0.0 & 0.0 & 0.0 \\
\hline Bangladesh & 0.0 & 0.0 & 0.0 & 0.0 & 0.0 & 0.0 & 0.0 & 0.0 & 0.0 & 0.0 & 0.0 & 0.0 \\
\hline Turkey & 0.0 & 0.0 & 0.2 & 0.2 & 0.3 & 0.3 & 0.1 & 0.1 & 0.0 & 0.0 & 0.1 & 0.1 \\
\hline Rest of countries & 0.3 & 1.3 & 0.2 & 1.0 & 0.3 & 0.9 & 0.3 & 0.8 & 0.7 & 1.9 & 0.3 & 0.7 \\
\hline OCEANIA & 0.6 & 1.8 & 0.2 & 0.4 & 0.1 & 0.4 & 0.2 & 0.5 & 1.1 & 2.7 & 0.2 & 0.4 \\
\hline Australia & 0.6 & 1.7 & 0.2 & 0.4 & 0.1 & 0.3 & 0.2 & 0.4 & 0.9 & 2.3 & 0.2 & 0.4 \\
\hline Rest of countries & 0.0 & 0.1 & 0.0 & 0.1 & 0.0 & 0.0 & 0.0 & 0.1 & 0.2 & 0.3 & 0.1 & 0.1 \\
\hline
\end{tabular}

Source: as described in table (A3.1.1) 
A3.1.6 Petroleum, Chemical and Non-Metallic Mineral Products

Share of value added embodied in the Reporter's final manufacturing output.

\begin{tabular}{lrrrrrrrrrrrrrr} 
& \multicolumn{1}{c}{ Germany } & \multicolumn{3}{c}{ USA } & \multicolumn{4}{c}{ France } & \multicolumn{2}{c}{ China } & \multicolumn{2}{c}{ Italy } & \multicolumn{2}{c}{ UK } \\
& $\mathbf{1 9 9 0}$ & $\mathbf{2 0 1 1}$ & $\mathbf{1 9 9 0}$ & $\mathbf{2 0 1 1}$ & $\mathbf{1 9 9 0}$ & $\mathbf{2 0 1 1}$ & $\mathbf{1 9 9 0}$ & $\mathbf{2 0 1 1}$ & $\mathbf{1 9 9 0}$ & $\mathbf{2 0 1 1}$ & $\mathbf{1 9 9 0}$ & $\mathbf{2 0 1 1}$ \\
\hline Total Value Added & 100 & 100 & 100 & 100 & 100 & 100 & 100 & 100 & 100 & 100 & 100 & 100 \\
\hline EUROPE & 93.6 & 87.9 & 3.7 & 4.7 & 90.2 & 85.6 & 2.7 & 5.7 & 92.7 & 85.5 & 93.6 & 88.8 \\
\hline \hline France & 2.3 & 2.9 & 0.4 & 0.5 & 67.8 & 60.7 & 0.3 & 0.6 & 3.1 & 3.7 & 1.9 & 2.2 \\
Netherlands & 2.0 & 2.4 & 0.2 & 0.3 & 1.8 & 1.7 & 0.1 & 0.3 & 1.5 & 2.2 & 1.4 & 1.7 \\
Germany & 77.3 & 64.3 & 0.9 & 1.0 & 5.1 & 5.1 & 0.6 & 1.3 & 5.2 & 6.2 & 3.3 & 4.1 \\
Italy & 1.5 & 1.6 & 0.3 & 0.4 & 2.1 & 1.9 & 0.2 & 0.5 & 73.7 & 59.2 & 1.0 & 1.2 \\
Spain & 0.5 & 0.8 & 0.1 & 0.2 & 1.1 & 1.4 & 0.1 & 0.2 & 1.0 & 1.6 & 0.4 & 0.9 \\
Belgium & 1.5 & 1.8 & 0.2 & 0.2 & 1.8 & 2.0 & 0.1 & 0.2 & 1.2 & 1.5 & 1.0 & 1.3 \\
Sweden & 0.7 & 0.5 & 0.2 & 0.1 & 0.7 & 0.4 & 0.1 & 0.2 & 0.7 & 0.5 & 0.7 & 0.6 \\
Russia & 1.4 & 3.3 & 0.1 & 0.3 & 2.0 & 3.0 & 0.7 & 0.9 & 1.1 & 2.1 & 0.5 & 0.9 \\
UK & 1.9 & 2.7 & 0.6 & 0.6 & 2.2 & 2.4 & 0.2 & 0.5 & 1.7 & 2.2 & 79.8 & 70.3 \\
Switzerland & 0.7 & 1.4 & 0.1 & 0.3 & 0.6 & 1.0 & 0.1 & 0.3 & 0.6 & 1.2 & 0.3 & 0.6 \\
Rest of Europe & 3.8 & 6.2 & 0.6 & 0.9 & 4.8 & 5.8 & 0.3 & 0.7 & 2.8 & 5.1 & 3.2 & 5.1 \\
& & & & & & & & & & & \\
NAFTA & 2.3 & 3.0 & 89.9 & 81.4 & 2.5 & 2.6 & 1.9 & 2.2 & 2.0 & 2.8 & 3.1 & 3.7 \\
\hline USA & 2.1 & 2.5 & 85.5 & 74.2 & 2.3 & 2.2 & 1.7 & 1.8 & 1.7 & 2.3 & 2.8 & 3.2 \\
Canada & 0.2 & 0.3 & 3.9 & 6.0 & 0.2 & 0.3 & 0.1 & 0.4 & 0.2 & 0.3 & 0.2 & 0.4 \\
Mexico & 0.1 & 0.2 & 0.6 & 1.2 & 0.1 & 0.1 & 0.1 & 0.1 & 0.1 & 0.1 & 0.1 & 0.2 \\
\hline \hline
\end{tabular}

Central, South America and the

\begin{tabular}{|c|c|c|c|c|c|c|c|c|c|c|c|c|}
\hline Caribbean & 0.4 & 0.9 & 3.0 & 6.8 & 0.4 & 0.7 & 0.2 & 0.5 & 0.4 & 1.0 & 0.3 & 0.6 \\
\hline Brazil & 0.2 & 0.4 & 0.1 & 0.3 & 0.2 & 0.3 & 0.1 & 0.3 & 0.2 & 0.4 & 0.1 & $\overline{0.3}$ \\
\hline Argentina & 0.0 & 0.1 & 0.1 & 0.1 & 0.0 & 0.1 & 0.0 & 0.0 & 0.1 & 0.1 & 0.0 & 0.1 \\
\hline \multirow[t]{2}{*}{ Rest of countries } & 0.2 & 0.5 & 2.8 & 6.4 & 0.2 & 0.3 & 0.1 & 0.2 & 0.2 & 0.4 & 0.1 & 0.3 \\
\hline & 0.0 & 0.0 & 0.0 & 0.0 & 0.0 & 0.0 & 0.0 & 0.0 & 0.0 & 0.0 & 0.0 & 0.0 \\
\hline AFRICA & 1.0 & 1.8 & 0.9 & 2.0 & 3.8 & 5.3 & 0.2 & 1.0 & 2.2 & 3.0 & 0.6 & 1.1 \\
\hline ASIA & 2.5 & 6.2 & 2.4 & 5.0 & 2.9 & 5.7 & 94.6 & 89.9 & 2.6 & 7.5 & 2.2 & 5.5 \\
\hline China & 0.5 & 2.2 & 0.2 & 1.2 & 0.4 & 1.6 & 91.6 & 82.8 & 0.4 & 2.2 & 0.3 & 1.9 \\
\hline Hong Kong & 0.0 & 0.0 & 0.0 & 0.0 & 0.0 & 0.0 & 0.0 & 0.0 & 0.0 & 0.0 & 0.0 & 0.0 \\
\hline South Korea & 0.1 & 0.2 & 0.1 & 0.2 & 0.1 & 0.2 & 0.4 & 1.2 & 0.1 & 0.3 & 0.1 & 0.3 \\
\hline Indonesia & 0.1 & 0.2 & 0.1 & 0.2 & 0.1 & 0.2 & 0.1 & 0.7 & 0.1 & 0.3 & 0.1 & 0.2 \\
\hline India & 0.1 & 0.5 & 0.1 & 0.3 & 0.1 & 0.4 & 0.0 & 0.4 & 0.1 & 0.6 & 0.1 & 0.5 \\
\hline Singapore & 0.0 & 0.1 & 0.0 & 0.1 & 0.0 & 0.1 & 0.0 & 0.2 & 0.0 & 0.1 & 0.0 & 0.2 \\
\hline Japan & 1.0 & 0.9 & 0.9 & 0.8 & 1.0 & 0.8 & 1.7 & 2.3 & 0.8 & 0.9 & 0.9 & 0.9 \\
\hline Thailand & 0.1 & 0.1 & 0.0 & 0.1 & 0.1 & 0.1 & 0.1 & 0.3 & 0.1 & 0.1 & 0.1 & 0.1 \\
\hline Viet Nam & 0.0 & 0.0 & 0.0 & 0.0 & 0.0 & 0.0 & 0.1 & 0.2 & 0.0 & 0.0 & 0.0 & 0.0 \\
\hline Bangladesh & 0.0 & 0.0 & 0.0 & 0.0 & 0.0 & 0.0 & 0.0 & 0.0 & 0.0 & 0.0 & 0.0 & 0.0 \\
\hline Turkey & 0.2 & 0.2 & 0.0 & 0.1 & 0.1 & 0.1 & 0.0 & 0.0 & 0.2 & 0.3 & 0.1 & 0.2 \\
\hline Rest of countries & 0.5 & 1.7 & 1.0 & 2.0 & 1.0 & 2.2 & 0.5 & 1.8 & 0.8 & 2.6 & 0.4 & 1.2 \\
\hline OCEANIA & 0.1 & 0.2 & 0.1 & 0.2 & 0.1 & 0.2 & 0.2 & 0.6 & 0.1 & 0.3 & 0.2 & 0.3 \\
\hline Australia & 0.1 & 0.2 & 0.1 & 0.2 & 0.1 & 0.1 & 0.2 & 0.5 & 0.1 & 0.2 & 0.1 & 0.2 \\
\hline Rest of countries & 0.0 & 0.1 & 0.0 & 0.0 & 0.0 & 0.0 & 0.0 & 0.1 & 0.0 & 0.0 & 0.0 & 0.1 \\
\hline
\end{tabular}

Source: as described in table (A3.1.1) 
Chapter 3.

A3.1.7 Electrical and Machinery

Share of value added embodied in the Reporter's final manufacturing output.

$\begin{array}{llllll}\text { China } & \text { Germany } & \text { USA } & \text { Japan } & \text { UK } & \text { France }\end{array}$

$\begin{array}{llllllllllll}1990 & 2011 & 1990 & 2011 & 1990 & 2011 & 1990 & 2011 & 1990 & 2011 & 1990 & 2011\end{array}$

\begin{tabular}{lrrrrrrrrrrrr}
\hline Total Value Added & 100 & 100 & 100 & 100 & 100 & 100 & 100 & 100 & 100 & 100 & 100 & 100 \\
\hline EUROPE & 3.9 & 8.4 & 94.0 & 89.0 & 3.9 & 5.7 & 2.8 & 3.6 & 89.2 & 84.1 & 92.3 & 89.1 \\
\hline \hline France & 0.4 & 1.0 & 1.7 & 2.1 & 0.5 & 0.6 & 0.3 & 0.4 & 2.2 & 2.5 & 74.7 & 70.2 \\
Netherlands & 0.1 & 0.3 & 1.0 & 1.2 & 0.2 & 0.2 & 0.1 & 0.1 & 1.3 & 1.6 & 1.1 & 1.1 \\
Germany & 1.0 & 2.2 & 82.7 & 72.7 & 1.0 & 1.4 & 0.6 & 0.8 & 4.1 & 4.9 & 5.0 & 5.2 \\
Italy & 0.3 & 0.7 & 1.4 & 1.7 & 0.4 & 0.5 & 0.2 & 0.2 & 1.4 & 1.6 & 2.7 & 2.4 \\
Spain & 0.1 & 0.3 & 0.4 & 0.7 & 0.1 & 0.2 & 0.1 & 0.1 & 0.4 & 0.8 & 1.0 & 1.4 \\
Belgium & 0.1 & 0.3 & 0.7 & 0.9 & 0.1 & 0.2 & 0.1 & 0.1 & 0.9 & 1.1 & 1.4 & 1.4 \\
Sweden & 0.2 & 0.3 & 0.6 & 0.5 & 0.2 & 0.2 & 0.2 & 0.1 & 0.7 & 0.6 & 0.7 & 0.5 \\
Russia & 0.6 & 0.8 & 0.4 & 0.9 & 0.2 & 0.5 & 0.5 & 0.5 & 0.4 & 0.7 & 0.5 & 0.7 \\
UK & 0.3 & 0.8 & 1.2 & 1.5 & 0.6 & 0.7 & 0.3 & 0.4 & 74.9 & 65.5 & 1.9 & 2.0 \\
Switzerland & 0.1 & 0.5 & 0.9 & 1.9 & 0.1 & 0.3 & 0.1 & 0.2 & 0.4 & 0.8 & 0.7 & 1.1 \\
Rest of Europe & 0.5 & 1.2 & 3.1 & 5.1 & 0.5 & 0.9 & 0.3 & 0.5 & 2.4 & 4.0 & 2.4 & 3.1 \\
& & & & & & & & & & & \\
NAFTA & 2.5 & 2.9 & 2.3 & 2.7 & 92.2 & 85.2 & 3.2 & 2.9 & 5.2 & 4.8 & 3.1 & 2.7 \\
\hline USA & 2.3 & 2.4 & 2.2 & 2.3 & 90.6 & 81.8 & 2.9 & 2.4 & 4.8 & 4.0 & 2.8 & 2.3 \\
Canada & 0.1 & 0.4 & 0.1 & 0.3 & 1.2 & 2.2 & 0.2 & 0.3 & 0.3 & 0.6 & 0.2 & 0.3 \\
Mexico & 0.1 & 0.1 & 0.0 & 0.1 & 0.4 & 1.2 & 0.1 & 0.1 & 0.1 & 0.2 & 0.1 & 0.1 \\
\hline \hline
\end{tabular}

Central, South America and

\begin{tabular}{|c|c|c|c|c|c|c|c|c|c|c|c|c|}
\hline the Caribbean & 0.3 & 0.8 & 0.2 & 0.5 & 0.5 & 1.2 & 0.2 & 0.4 & 0.3 & 0.6 & 0.3 & 0.5 \\
\hline Brazil & 0.2 & 0.5 & 0.1 & 0.3 & 0.1 & 0.3 & 0.1 & 0.2 & 0.1 & 0.3 & 0.2 & 0.3 \\
\hline Argentina & 0.0 & 0.0 & 0.0 & 0.0 & 0.0 & 0.1 & 0.0 & 0.0 & 0.0 & 0.0 & 0.0 & 0.0 \\
\hline \multirow[t]{2}{*}{ Rest of countries } & 0.1 & 0.3 & 0.1 & 0.2 & 0.4 & 0.8 & 0.1 & 0.3 & 0.1 & 0.3 & 0.1 & 0.2 \\
\hline & 0.0 & 0.0 & 0.0 & 0.0 & 0.0 & 0.0 & 0.0 & 0.0 & 0.0 & 0.0 & 0.0 & 0.0 \\
\hline AFRICA & 0.2 & 0.6 & 0.3 & 0.5 & 0.2 & 0.4 & 0.2 & 0.3 & 0.4 & 0.8 & 0.6 & 0.9 \\
\hline ASIA & 92.6 & 86.2 & 3.0 & 7.0 & 3.1 & 7.1 & 93.2 & 92.0 & 4.7 & 9.3 & 3.6 & 6.6 \\
\hline China & 87.8 & 74.4 & 0.4 & 2.9 & 0.3 & 2.4 & 0.5 & 3.0 & 0.4 & 3.3 & 0.4 & 2.8 \\
\hline Hong Kong & 0.0 & 0.0 & 0.0 & 0.0 & 0.0 & 0.0 & 0.0 & 0.0 & 0.0 & 0.0 & 0.0 & 0.0 \\
\hline South Korea & 0.6 & 2.8 & 0.1 & 0.4 & 0.2 & 0.6 & 0.4 & 1.0 & 0.3 & 0.6 & 0.2 & 0.4 \\
\hline Indonesia & 0.1 & 0.6 & 0.0 & 0.2 & 0.0 & 0.2 & 0.3 & 0.6 & 0.1 & 0.3 & 0.1 & 0.2 \\
\hline India & 0.1 & 0.4 & 0.1 & 0.3 & 0.1 & 0.3 & 0.0 & 0.2 & 0.1 & 0.4 & 0.1 & 0.3 \\
\hline Singapore & 0.1 & 0.4 & 0.0 & 0.2 & 0.0 & 0.2 & 0.1 & 0.2 & 0.1 & 0.3 & 0.1 & 0.2 \\
\hline Japan & 3.4 & 5.0 & 1.8 & 1.5 & 2.0 & 2.0 & 91.0 & 84.7 & 2.9 & 2.3 & 2.0 & 1.3 \\
\hline Thailand & 0.1 & 0.4 & 0.1 & 0.2 & 0.1 & 0.2 & 0.1 & 0.3 & 0.1 & 0.3 & 0.1 & 0.2 \\
\hline Viet Nam & 0.0 & 0.1 & 0.0 & 0.0 & 0.0 & 0.0 & 0.0 & 0.0 & 0.0 & 0.0 & 0.0 & 0.0 \\
\hline Bangladesh & 0.0 & 0.0 & 0.0 & 0.0 & 0.0 & 0.0 & 0.0 & 0.0 & 0.0 & 0.0 & 0.0 & 0.0 \\
\hline Turkey & 0.0 & 0.0 & 0.1 & 0.2 & 0.0 & 0.0 & 0.0 & 0.0 & 0.1 & 0.1 & 0.1 & 0.1 \\
\hline Rest of countries & 0.4 & 2.1 & 0.3 & 1.1 & 0.3 & 1.2 & 0.7 & 1.9 & 0.5 & 1.7 & 0.5 & 1.1 \\
\hline OCEANIA & 0.4 & 1.0 & 0.1 & 0.2 & 0.1 & 0.3 & 0.4 & 0.8 & 0.2 & 0.5 & 0.1 & 0.2 \\
\hline Australia & 0.4 & 1.0 & 0.1 & 0.2 & 0.1 & 0.3 & 0.4 & 0.7 & 0.2 & 0.4 & 0.1 & 0.2 \\
\hline Rest of countries & 0.0 & 0.1 & 0.0 & 0.0 & 0.0 & 0.0 & 0.1 & 0.1 & 0.0 & 0.1 & 0.0 & 0.0 \\
\hline
\end{tabular}

Source: as described in table (A3.1.1) 
A3.1.8 Transport Equipment

Share of value added embodied in the Reporter's final manufacturing output.

\begin{tabular}{|c|c|c|c|c|c|c|c|c|c|c|c|c|}
\hline & \multicolumn{2}{|c|}{ Germany } & \multicolumn{2}{|c|}{ Japan } & \multicolumn{2}{|c|}{ Mexico } & \multicolumn{2}{|c|}{ Canada } & \multicolumn{2}{|c|}{ South Korea } & \multicolumn{2}{|c|}{ India } \\
\hline & 1990 & 2011 & 1990 & 2011 & 1990 & 2011 & 1990 & 2011 & 1990 & 2011 & 1990 & 2011 \\
\hline Total Value Added & 100 & 100 & 100 & 100 & 100 & 100 & 100 & 100 & 100 & 100 & 100 & 100 \\
\hline EUROPE & 93.3 & 88.1 & 2.6 & 3.3 & 6.2 & 9.2 & 6.3 & 7.9 & 8.4 & 9.8 & 4.3 & 8.6 \\
\hline France & 2.9 & 3.3 & 0.3 & 0.4 & 0.9 & 1.1 & 0.8 & 0.9 & 0.9 & 1.0 & 0.4 & 0.7 \\
\hline Netherlands & 1.4 & 1.7 & 0.1 & 0.1 & 0.2 & 0.3 & 0.2 & 0.3 & 0.3 & 0.4 & 0.2 & 0.4 \\
\hline Germany & 75.1 & 63.4 & 0.6 & 0.7 & 1.8 & 2.3 & 1.6 & 1.9 & 2.5 & 2.8 & 1.0 & 1.9 \\
\hline Italy & 2.9 & 3.1 & 0.2 & 0.2 & 0.8 & 1.1 & 0.8 & 0.9 & 0.7 & 0.8 & 0.4 & 0.7 \\
\hline Spain & 1.0 & 1.7 & 0.1 & 0.1 & 0.4 & 0.9 & 0.2 & 0.3 & 0.2 & 0.3 & 0.1 & 0.3 \\
\hline Belgium & 1.1 & 1.3 & 0.1 & 0.1 & 0.2 & 0.3 & 0.2 & 0.2 & 0.3 & 0.3 & 0.2 & 0.4 \\
\hline Sweden & 1.3 & 1.0 & 0.2 & 0.1 & 0.3 & 0.3 & 0.4 & 0.3 & 0.7 & 0.5 & 0.2 & 0.3 \\
\hline Russia & 0.6 & 1.1 & 0.5 & 0.5 & 0.2 & 0.5 & 0.2 & 0.4 & 0.8 & 0.7 & 0.4 & 1.2 \\
\hline UK & 1.6 & 2.0 & 0.3 & 0.3 & 0.5 & 0.7 & 1.0 & 1.1 & 0.7 & 0.9 & 0.6 & 1.0 \\
\hline Switzerland & 1.0 & 2.0 & 0.1 & 0.1 & 0.3 & 0.6 & 0.2 & 0.4 & 0.3 & 0.5 & 0.2 & 0.6 \\
\hline Rest of Europe & 4.4 & 7.5 & 0.3 & 0.4 & 0.6 & 1.1 & 0.7 & 1.2 & 0.9 & 1.4 & 0.5 & 1.1 \\
\hline NAFTA & 2.7 & 3.1 & 2.9 & 2.6 & 89.0 & 78.6 & 86.7 & 81.4 & 5.7 & 4.9 & 1.2 & 2.3 \\
\hline USA & 2.4 & 2.7 & 2.5 & 2.2 & 18.5 & 15.1 & 27.1 & 25.4 & 5.2 & 4.2 & 1.1 & 2.0 \\
\hline Canada & 0.2 & 0.3 & 0.3 & 0.4 & 0.8 & 1.7 & 58.9 & 53.6 & 0.3 & 0.5 & 0.1 & 0.3 \\
\hline Mexico & 0.1 & 0.2 & 0.1 & 0.1 & 69.7 & 61.8 & 0.7 & 2.4 & 0.1 & 0.1 & 0.0 & 0.1 \\
\hline
\end{tabular}

Central, South America and

\begin{tabular}{|c|c|c|c|c|c|c|c|c|c|c|c|c|}
\hline the Caribbean & 0.3 & 0.8 & 0.3 & 0.5 & 1.0 & 2.7 & 0.5 & 1.4 & 0.5 & 0.7 & 0.2 & 0.6 \\
\hline Brazil & 0.2 & 0.4 & 0.1 & 0.2 & 0.5 & 1.4 & 0.3 & 0.8 & 0.2 & 0.2 & 0.1 & 0.2 \\
\hline Argentina & 0.0 & 0.1 & 0.0 & 0.0 & 0.1 & 0.2 & 0.0 & 0.1 & 0.0 & 0.0 & 0.0 & 0.1 \\
\hline \multirow[t]{2}{*}{ Rest of countries } & 0.1 & 0.3 & 0.1 & 0.3 & 0.4 & 1.1 & 0.2 & 0.6 & 0.2 & 0.4 & 0.1 & 0.3 \\
\hline & 0.0 & 0.0 & 0.0 & 0.0 & 0.0 & 0.0 & 0.0 & 0.0 & 0.0 & 0.0 & 0.0 & 0.0 \\
\hline AFRICA & 0.4 & 0.8 & 0.2 & 0.3 & 0.2 & 0.5 & 0.2 & 0.4 & 0.3 & 0.6 & 0.2 & 0.7 \\
\hline ASIA & 3.1 & 7.0 & 93.6 & 92.3 & 3.5 & 8.7 & 6.1 & 8.6 & 84.5 & 83.0 & 93.9 & 86.9 \\
\hline China & 0.4 & 2.6 & 0.5 & 2.5 & 0.3 & 3.5 & 0.3 & 2.8 & 1.0 & 5.8 & 0.2 & 2.3 \\
\hline Hong Kong & 0.0 & 0.0 & 0.0 & 0.0 & 0.0 & 0.0 & 0.0 & 0.0 & 0.0 & 0.0 & 0.0 & 0.0 \\
\hline South Korea & 0.2 & 0.4 & 0.3 & 0.8 & 0.3 & 0.9 & 0.3 & 0.8 & 71.9 & 64.1 & 0.3 & 1.1 \\
\hline Indonesia & 0.1 & 0.2 & 0.3 & 0.8 & 0.1 & 0.3 & 0.1 & 0.2 & 0.7 & 1.8 & 0.1 & 0.4 \\
\hline India & 0.1 & 0.4 & 0.0 & 0.2 & 0.1 & 0.5 & 0.1 & 0.3 & 0.1 & 0.5 & 91.5 & 79.2 \\
\hline Singapore & 0.0 & 0.1 & 0.0 & 0.1 & 0.0 & 0.1 & 0.0 & 0.1 & 0.1 & 0.3 & 0.1 & 0.3 \\
\hline Japan & 1.8 & 1.7 & 91.5 & 85.7 & 2.3 & 2.0 & 4.9 & 3.3 & 8.6 & 6.1 & 1.2 & 1.3 \\
\hline Thailand & 0.1 & 0.2 & 0.1 & 0.3 & 0.1 & 0.3 & 0.1 & 0.2 & 0.1 & 0.3 & 0.0 & 0.2 \\
\hline Viet Nam & 0.0 & 0.0 & 0.0 & 0.0 & 0.0 & 0.0 & 0.0 & 0.0 & 0.0 & 0.0 & 0.0 & 0.0 \\
\hline Bangladesh & 0.0 & 0.0 & 0.0 & 0.0 & 0.0 & 0.0 & 0.0 & 0.0 & 0.0 & 0.0 & 0.0 & 0.0 \\
\hline Turkey & 0.2 & 0.4 & 0.0 & 0.0 & 0.0 & 0.1 & 0.0 & 0.1 & 0.0 & 0.1 & 0.0 & 0.1 \\
\hline Rest of countries & 0.3 & 1.0 & 0.7 & 1.8 & 0.3 & 1.0 & 0.3 & 0.8 & 1.9 & 4.0 & 0.5 & 1.9 \\
\hline OCEANIA & 0.1 & 0.2 & 0.5 & 1.0 & 0.1 & 0.3 & 0.2 & 0.4 & 0.7 & 1.1 & 0.3 & 0.9 \\
\hline Australia & 0.1 & 0.2 & 0.4 & 0.9 & 0.1 & 0.2 & 0.1 & 0.3 & 0.6 & 1.0 & 0.3 & 0.8 \\
\hline Rest of countries & 0.0 & 0.0 & 0.1 & 0.1 & 0.0 & 0.0 & 0.0 & 0.0 & 0.1 & 0.1 & 0.0 & 0.0 \\
\hline
\end{tabular}

Source: as described in table (A3.1.1) 
Chapter 3.

A3.1.9 Other Manufacturing

Share of value added embodied in the Reporter's final manufacturing output.

China

Italy Germany

USA

Canada

Thailand

$\begin{array}{llllllllllll}1990 & 2011 & 1990 & 2011 & 1990 & 2011 & 1990 & 2011 & 1990 & 2011 & 1990 & 2011\end{array}$

\begin{tabular}{|c|c|c|c|c|c|c|c|c|c|c|c|c|}
\hline Total Value Added & 100 & 100 & 100 & 100 & 100 & 100 & 100 & 100 & 100 & 100 & 100 & 100 \\
\hline EUROPE & 3.0 & 5.6 & 94.6 & 88.0 & 94.5 & 87.8 & 4.0 & 5.5 & 3.3 & 4.2 & 11.7 & 12.3 \\
\hline France & 0.2 & 0.6 & 2.8 & 3.5 & 1.5 & 2.0 & 0.4 & 0.5 & 0.4 & 0.4 & 1.1 & 1.2 \\
\hline Netherlands & 0.1 & 0.2 & 1.0 & 1.3 & 1.0 & 1.3 & 0.2 & 0.2 & 0.1 & 0.2 & 0.5 & 0.6 \\
\hline Germany & 0.5 & 1.4 & 4.6 & 6.0 & 81.8 & 68.8 & 0.9 & 1.2 & 0.7 & 0.8 & 2.6 & 2.7 \\
\hline Italy & 0.2 & 0.5 & 77.6 & 64.0 & 1.9 & 2.3 & 0.5 & 0.6 & 0.4 & 0.4 & 1.0 & 1.3 \\
\hline Spain & 0.1 & 0.2 & 1.0 & 1.6 & 0.4 & 0.7 & 0.1 & 0.2 & 0.1 & 0.2 & 0.3 & 0.3 \\
\hline Belgium & 0.1 & 0.2 & 0.9 & 1.1 & 0.8 & 1.0 & 0.2 & 0.2 & 0.1 & 0.2 & 0.9 & 0.8 \\
\hline Sweden & 0.2 & 0.2 & 0.9 & 0.7 & 0.7 & 0.6 & 0.2 & 0.2 & 0.2 & 0.1 & 0.5 & 0.3 \\
\hline Russia & 1.0 & 0.8 & 0.6 & 1.2 & 0.5 & 1.0 & 0.3 & 0.7 & 0.2 & 0.4 & 0.8 & 0.8 \\
\hline UK & 0.2 & 0.5 & 1.3 & 1.6 & 0.9 & 1.3 & 0.5 & 0.5 & 0.5 & 0.5 & 1.0 & 1.2 \\
\hline Switzerland & 0.1 & 0.3 & 0.6 & 1.1 & 0.8 & 1.8 & 0.1 & 0.3 & 0.1 & 0.2 & 1.7 & 1.5 \\
\hline Rest of Europe & 0.4 & 0.8 & 3.4 & 5.9 & 4.1 & 7.2 & 0.5 & 0.9 & 0.5 & 0.7 & 1.3 & 1.6 \\
\hline NAFTA & 2.6 & 2.1 & 1.7 & 2.3 & 1.7 & 2.3 & 92.2 & 86.0 & 94.5 & 90.3 & 5.1 & 4.5 \\
\hline USA & 2.4 & 1.6 & 1.5 & 2.0 & 1.5 & 1.9 & 89.6 & 81.3 & 8.4 & 9.0 & 4.4 & 3.5 \\
\hline Canada & 0.1 & 0.4 & 0.1 & 0.3 & 0.2 & 0.3 & 2.3 & 3.6 & 86.0 & 80.9 & 0.6 & 0.9 \\
\hline Mexico & 0.1 & 0.1 & 0.0 & 0.1 & 0.0 & 0.1 & 0.4 & 1.0 & 0.2 & 0.4 & 0.1 & 0.1 \\
\hline
\end{tabular}

Central, South America and

\begin{tabular}{|c|c|c|c|c|c|c|c|c|c|c|c|c|}
\hline the Caribbean & 0.4 & 0.6 & 0.5 & 1.1 & 0.3 & 0.7 & 0.9 & 1.9 & 0.3 & 0.7 & 0.5 & 0.9 \\
\hline Brazil & 0.2 & 0.3 & 0.2 & 0.5 & 0.2 & 0.5 & 0.3 & 0.6 & 0.1 & 0.2 & 0.3 & 0.4 \\
\hline Argentina & 0.0 & 0.0 & 0.1 & 0.1 & 0.0 & 0.0 & 0.0 & 0.1 & 0.0 & 0.0 & 0.0 & 0.1 \\
\hline \multirow[t]{2}{*}{ Rest of countries } & 0.1 & 0.2 & 0.2 & 0.5 & 0.1 & 0.2 & 0.6 & 1.2 & 0.2 & 0.5 & 0.2 & 0.4 \\
\hline & 0.0 & 0.0 & 0.0 & 0.0 & 0.0 & 0.0 & 0.0 & 0.0 & 0.0 & 0.0 & 0.0 & 0.0 \\
\hline AFRICA & 0.2 & 0.5 & 0.9 & 1.5 & 0.4 & 0.7 & 0.3 & 0.6 & 0.2 & 0.3 & 0.5 & 0.8 \\
\hline ASIA & 93.5 & 90.3 & 2.3 & 6.8 & 3.0 & 8.3 & 2.5 & 5.7 & 1.6 & 4.2 & 80.9 & 79.1 \\
\hline China & 89.9 & 82.9 & 0.5 & 2.8 & 0.8 & 4.2 & 0.4 & 2.2 & 0.3 & 2.0 & 1.2 & 6.0 \\
\hline Hong Kong & 0.0 & 0.0 & 0.0 & 0.0 & 0.0 & 0.0 & 0.0 & 0.0 & 0.0 & 0.0 & 0.0 & 0.0 \\
\hline South Korea & 0.6 & 1.7 & 0.1 & 0.4 & 0.2 & 0.3 & 0.2 & 0.4 & 0.2 & 0.3 & 0.7 & 2.0 \\
\hline Indonesia & 0.2 & 0.8 & 0.1 & 0.4 & 0.2 & 0.5 & 0.1 & 0.3 & 0.1 & 0.2 & 0.6 & 1.2 \\
\hline India & 0.1 & 0.4 & 0.1 & 0.5 & 0.2 & 0.7 & 0.1 & 0.5 & 0.1 & 0.3 & 1.2 & 3.7 \\
\hline Singapore & 0.1 & 0.2 & 0.0 & 0.1 & 0.0 & 0.1 & 0.0 & 0.1 & 0.0 & 0.1 & 0.3 & 0.7 \\
\hline Japan & 2.1 & 2.4 & 0.6 & 0.9 & 1.0 & 1.0 & 1.1 & 1.0 & 0.6 & 0.6 & 6.6 & 4.8 \\
\hline Thailand & 0.1 & 0.4 & 0.1 & 0.2 & 0.1 & 0.3 & 0.1 & 0.2 & 0.1 & 0.1 & 67.4 & 53.7 \\
\hline Viet Nam & 0.0 & 0.1 & 0.0 & 0.0 & 0.0 & 0.0 & 0.0 & 0.0 & 0.0 & 0.0 & 0.0 & 0.1 \\
\hline Bangladesh & 0.0 & 0.0 & 0.0 & 0.0 & 0.0 & 0.0 & 0.0 & 0.0 & 0.0 & 0.0 & 0.0 & 0.0 \\
\hline Turkey & 0.0 & 0.0 & 0.3 & 0.3 & 0.2 & 0.3 & 0.0 & 0.1 & 0.0 & 0.0 & 0.1 & 0.1 \\
\hline Rest of countries & 0.4 & 1.5 & 0.4 & 1.1 & 0.3 & 1.0 & 0.4 & 0.9 & 0.2 & 0.5 & 2.8 & 6.7 \\
\hline OCEANIA & 0.4 & 0.8 & 0.1 & 0.3 & 0.1 & 0.2 & 0.1 & 0.3 & 0.1 & 0.3 & 1.4 & 2.5 \\
\hline Australia & 0.3 & 0.6 & 0.1 & 0.2 & 0.1 & 0.2 & 0.1 & 0.3 & 0.1 & 0.2 & 1.2 & 2.0 \\
\hline Rest of countries & 0.0 & 0.2 & 0.0 & 0.1 & 0.0 & 0.0 & 0.0 & 0.1 & 0.0 & 0.0 & 0.1 & 0.4 \\
\hline
\end{tabular}

Source: as described in table (A3.1.1) 


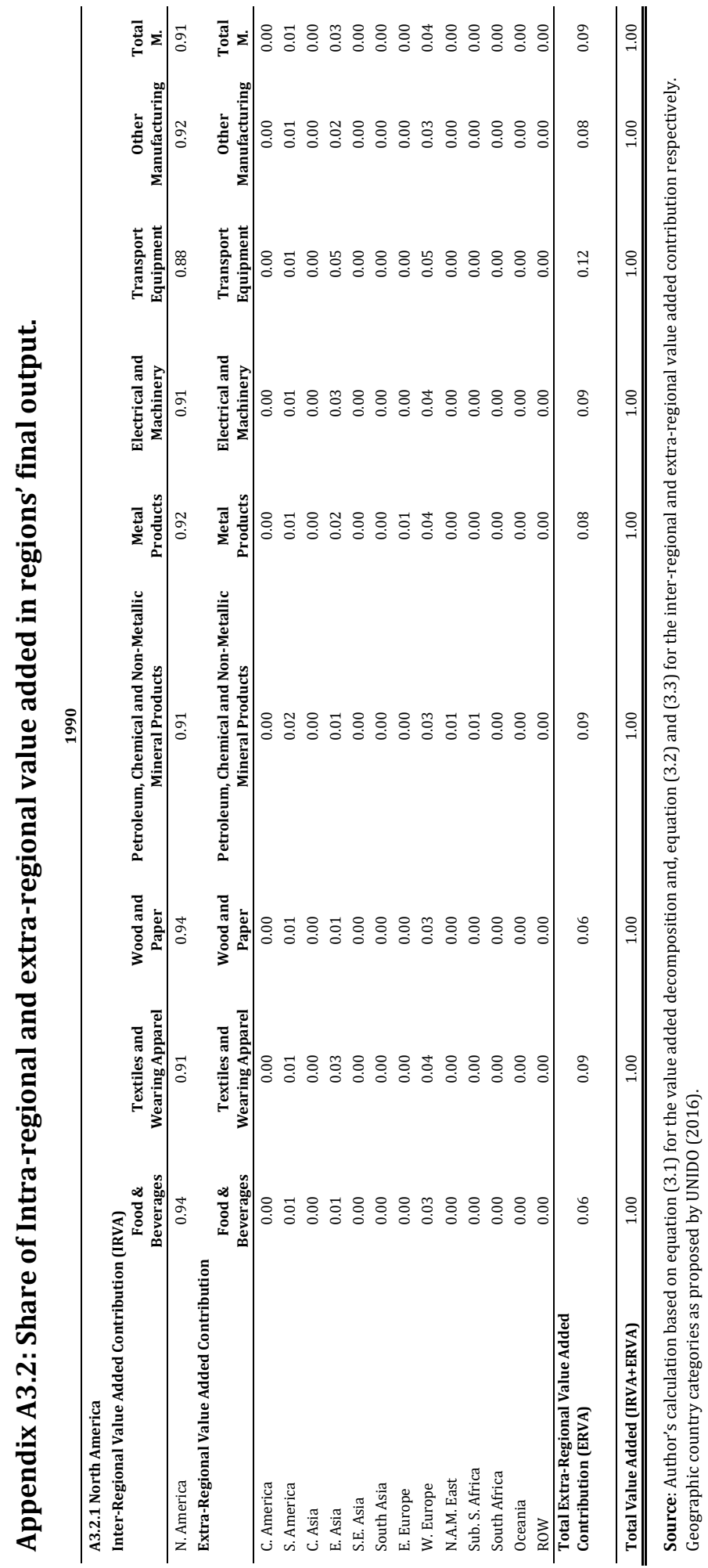




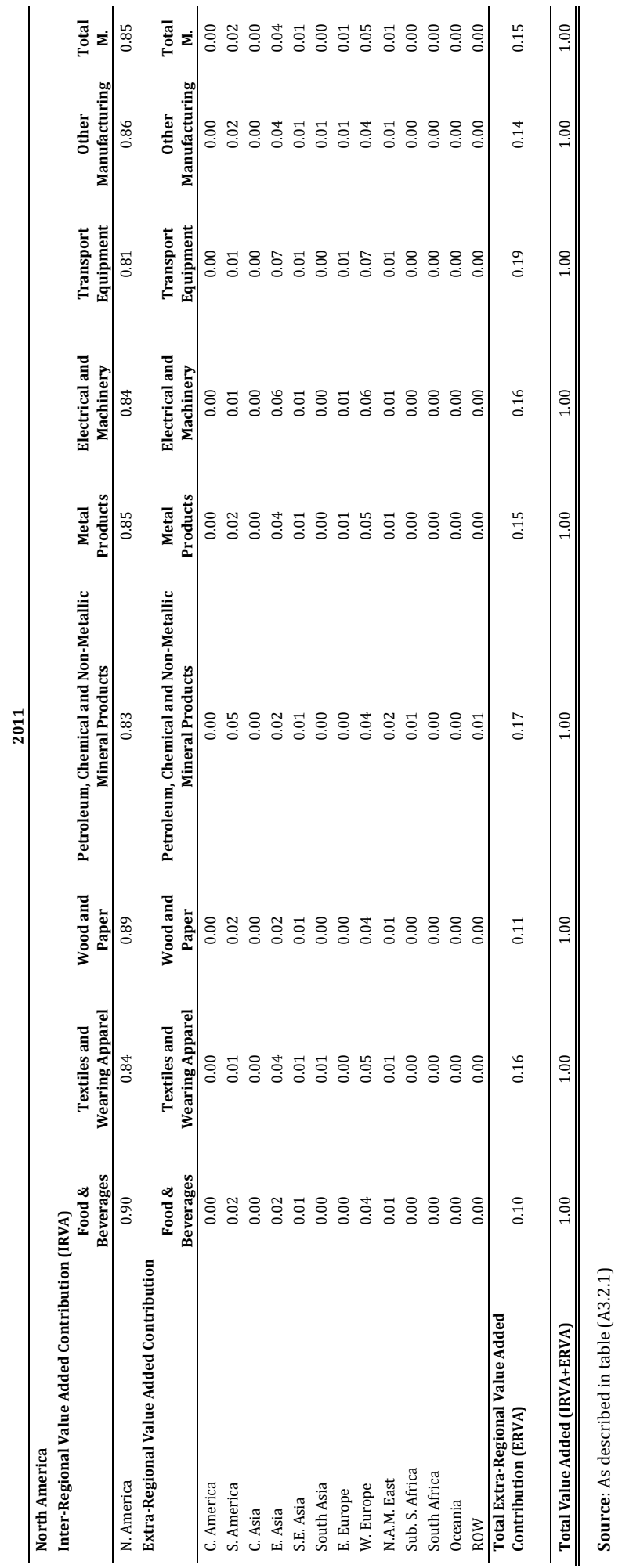




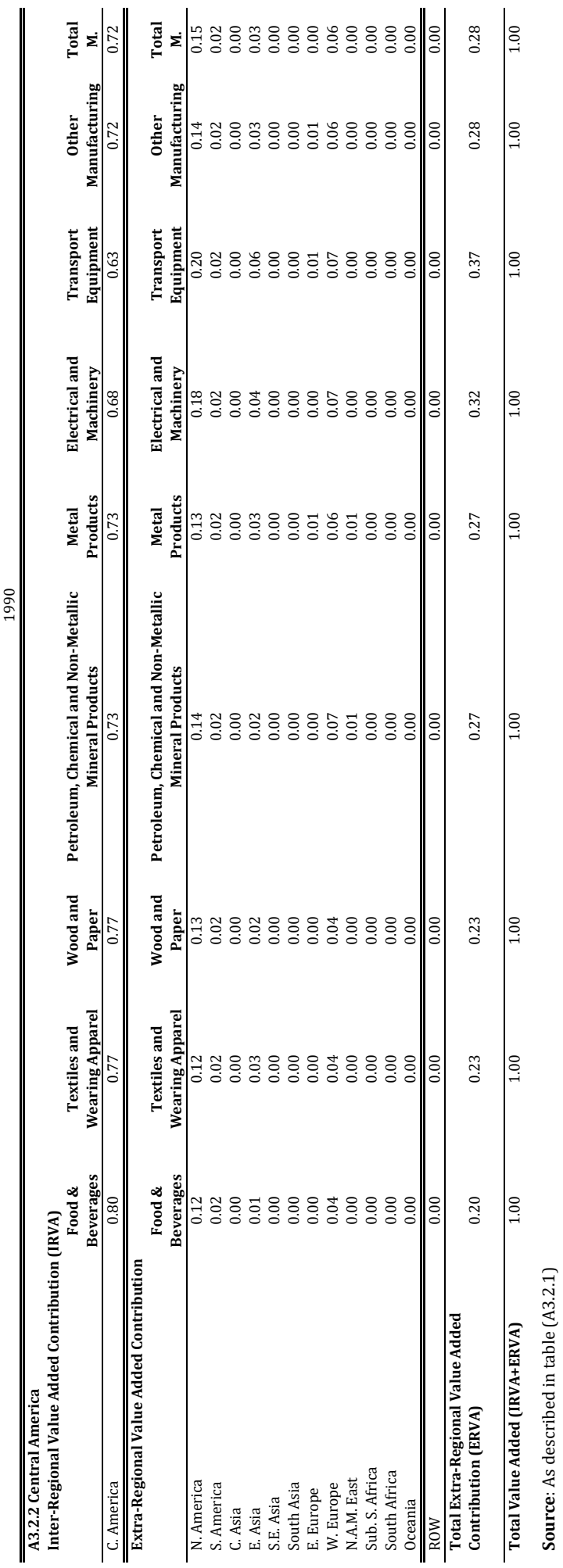




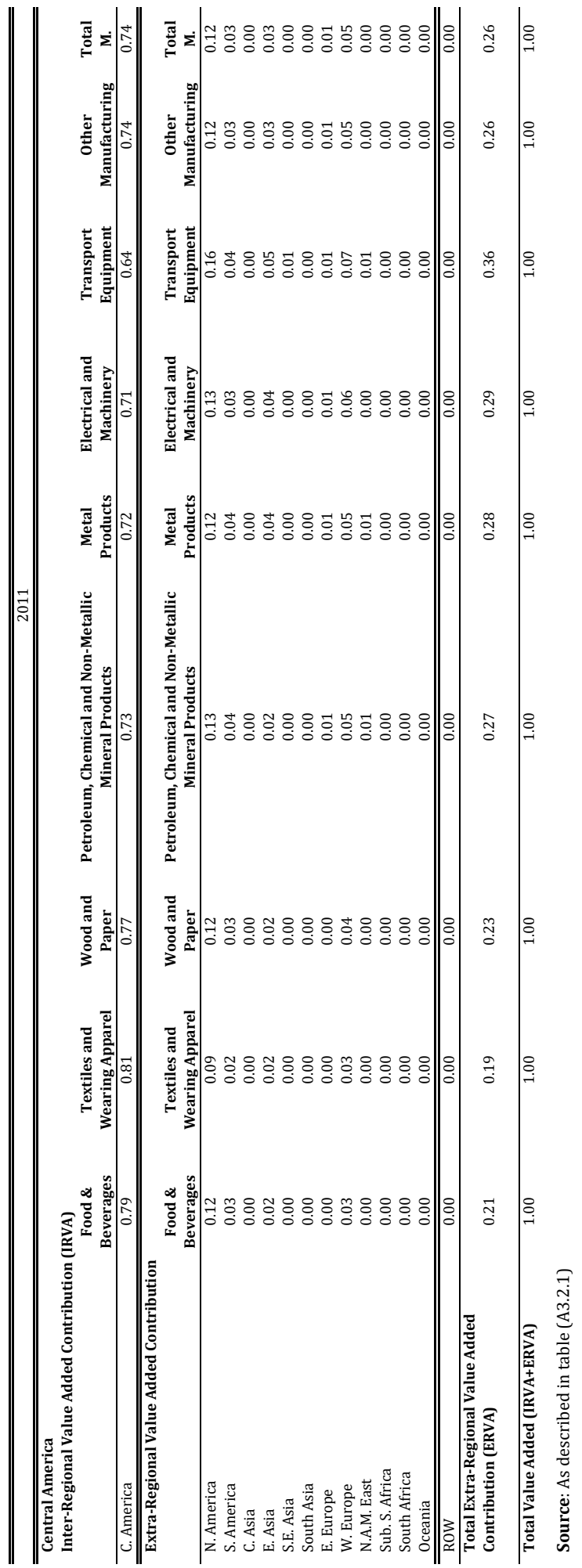




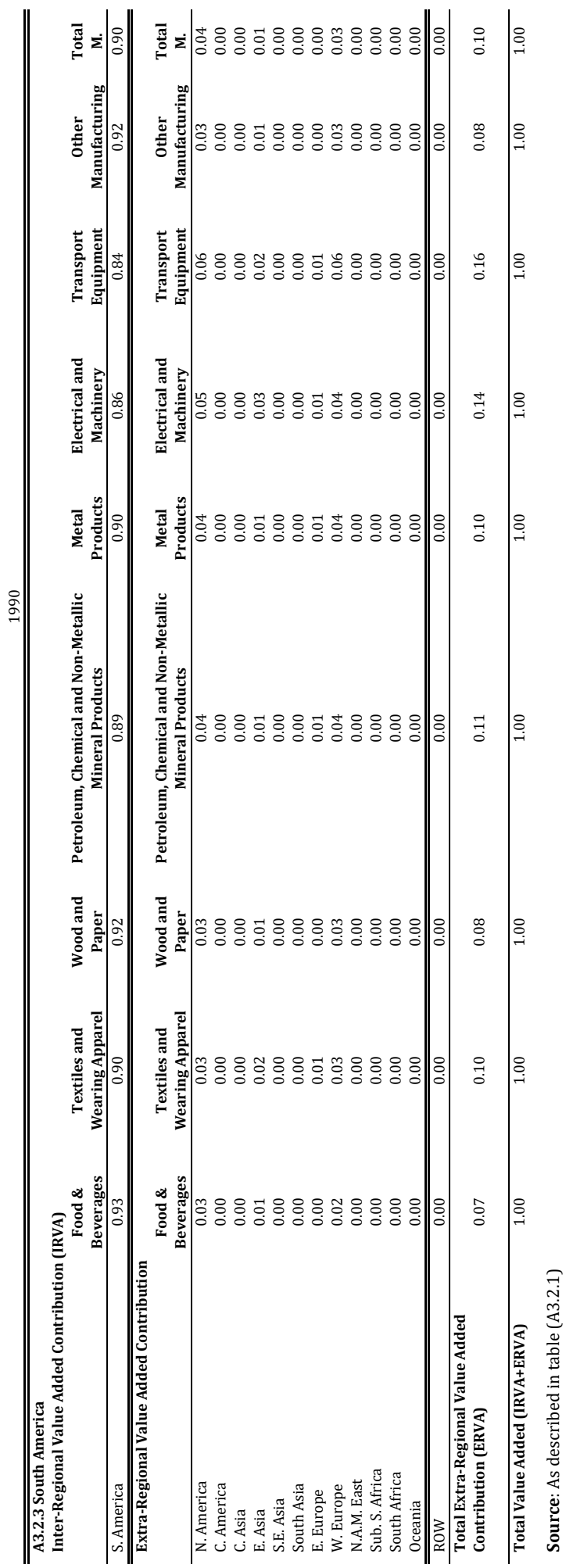




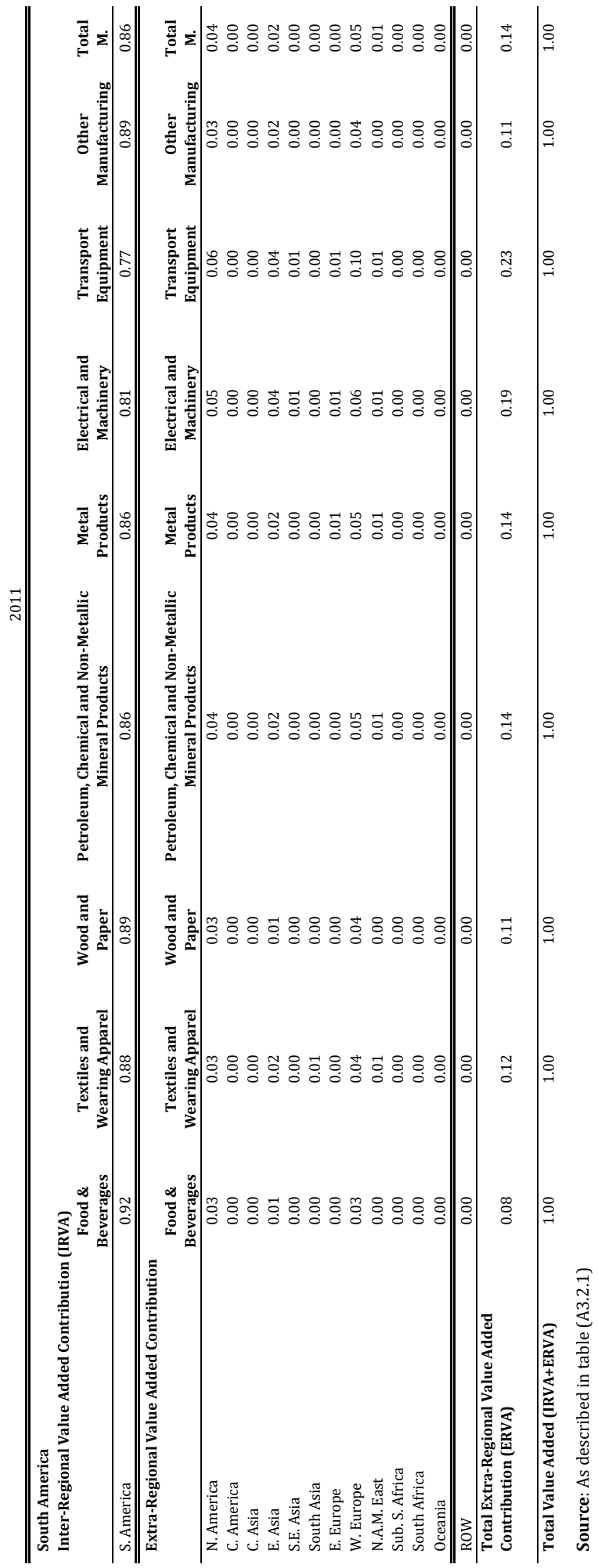




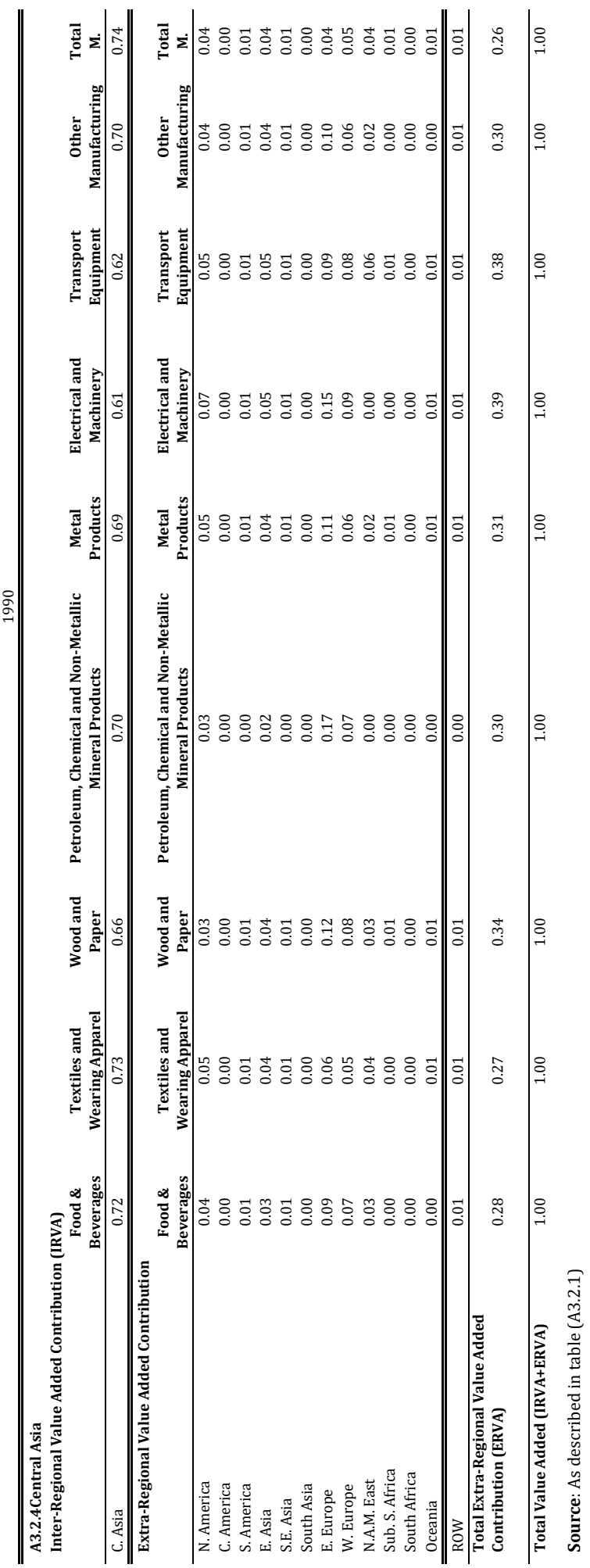




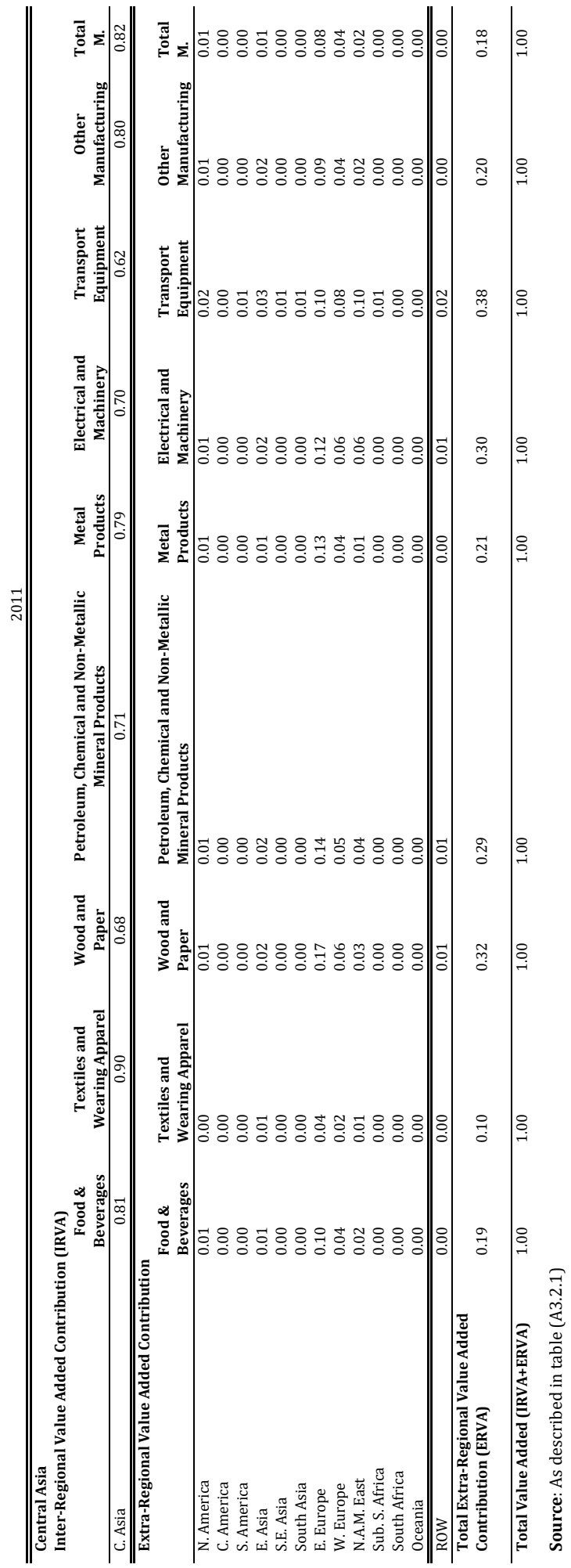




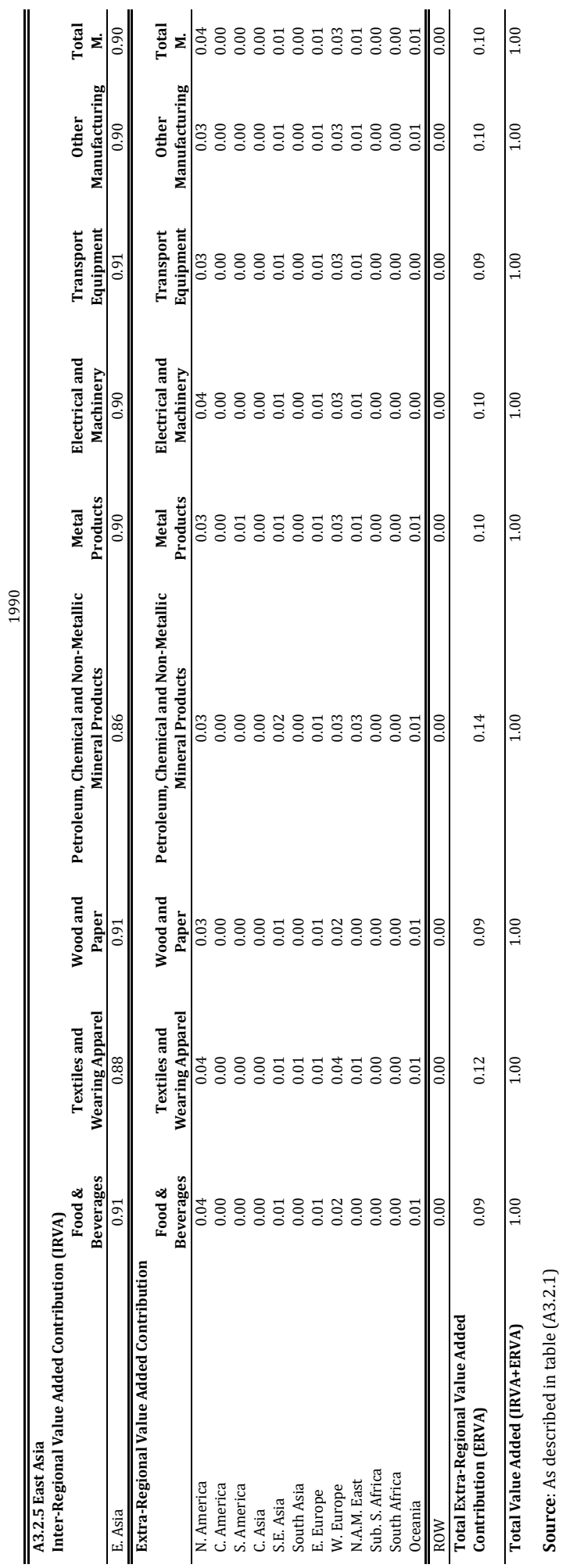




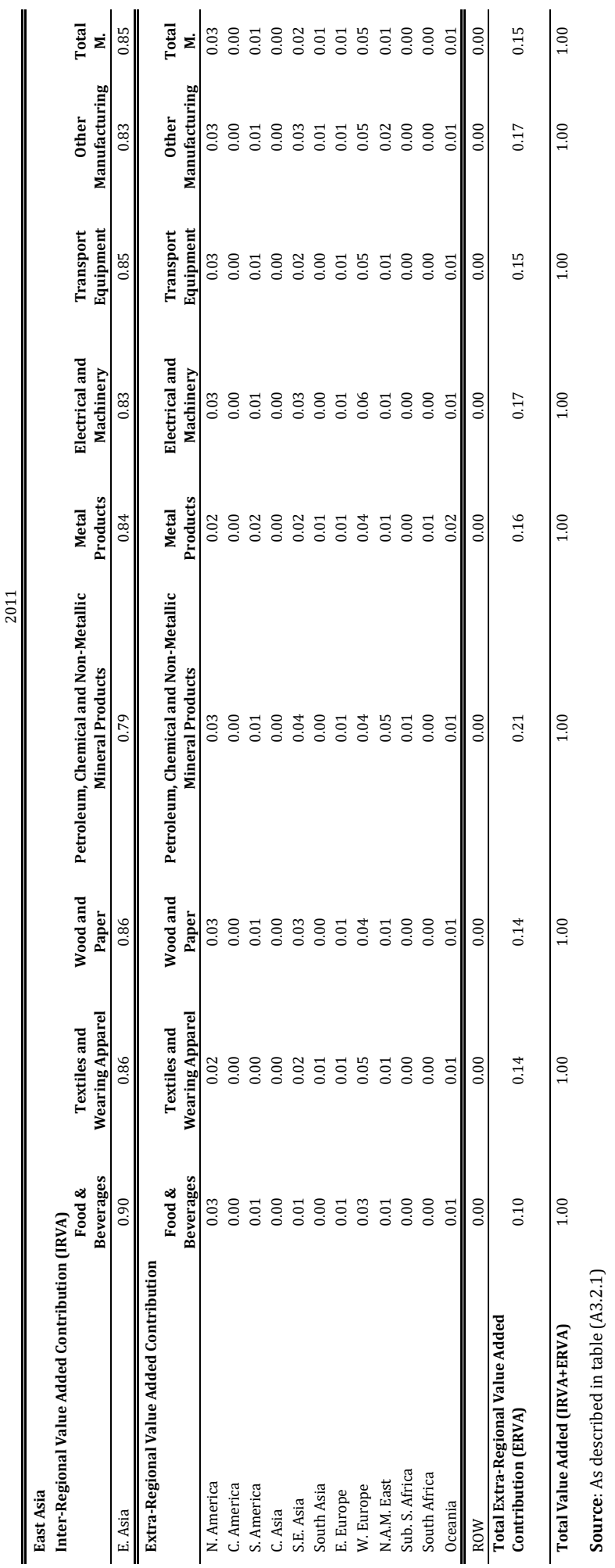




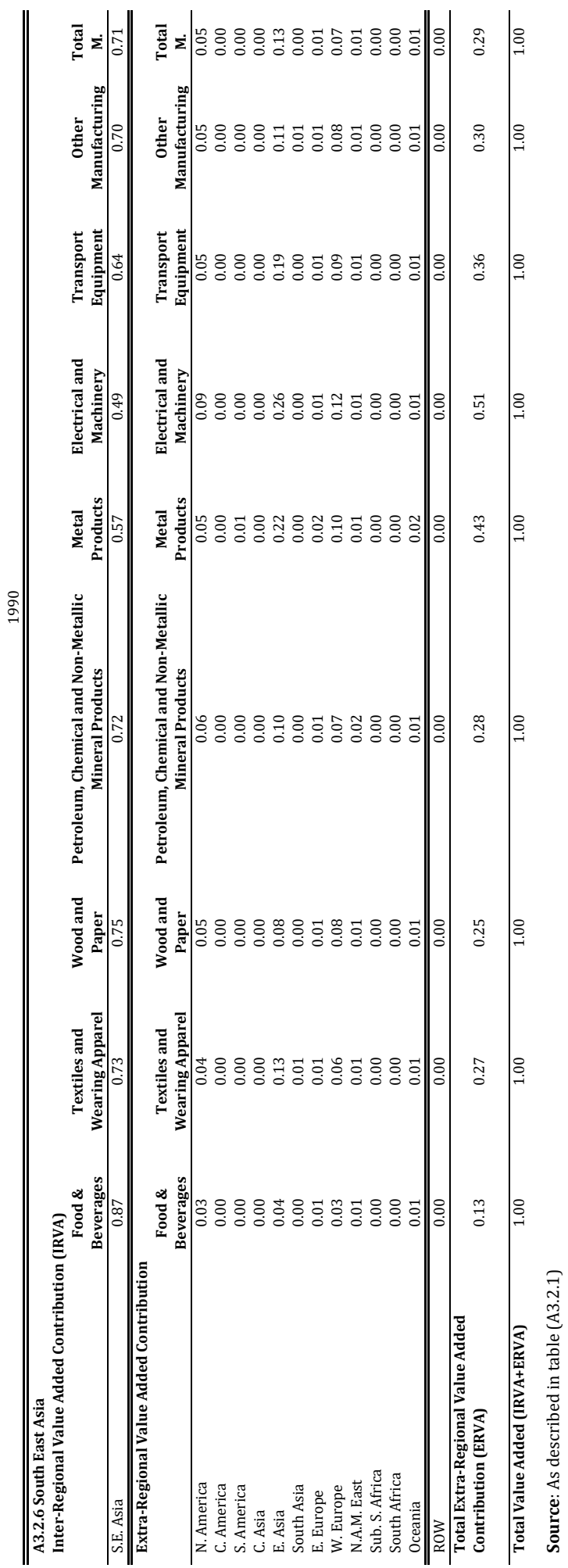




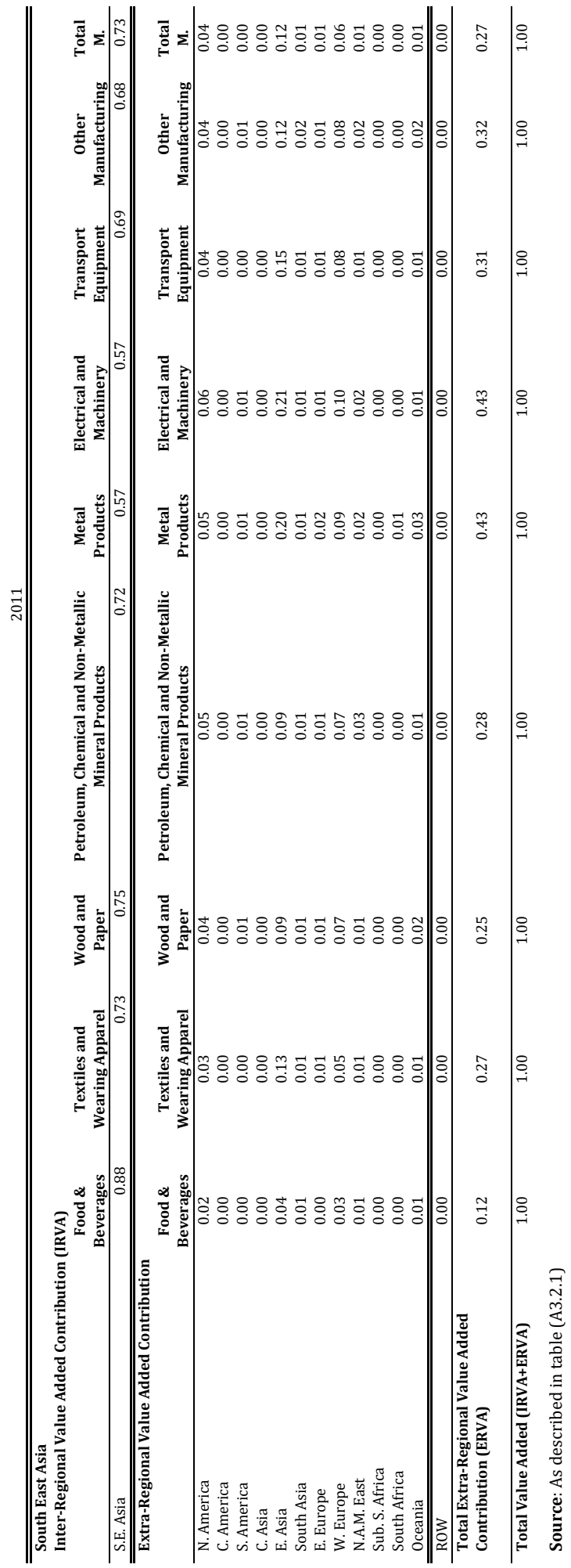




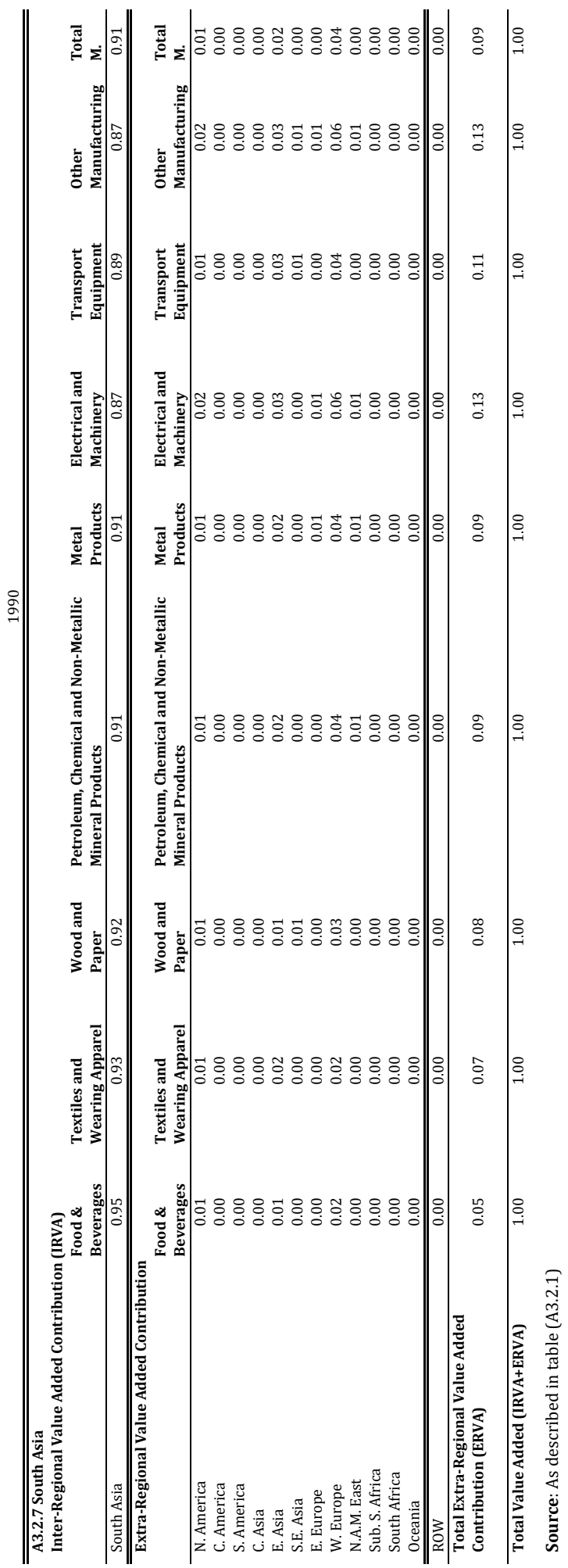




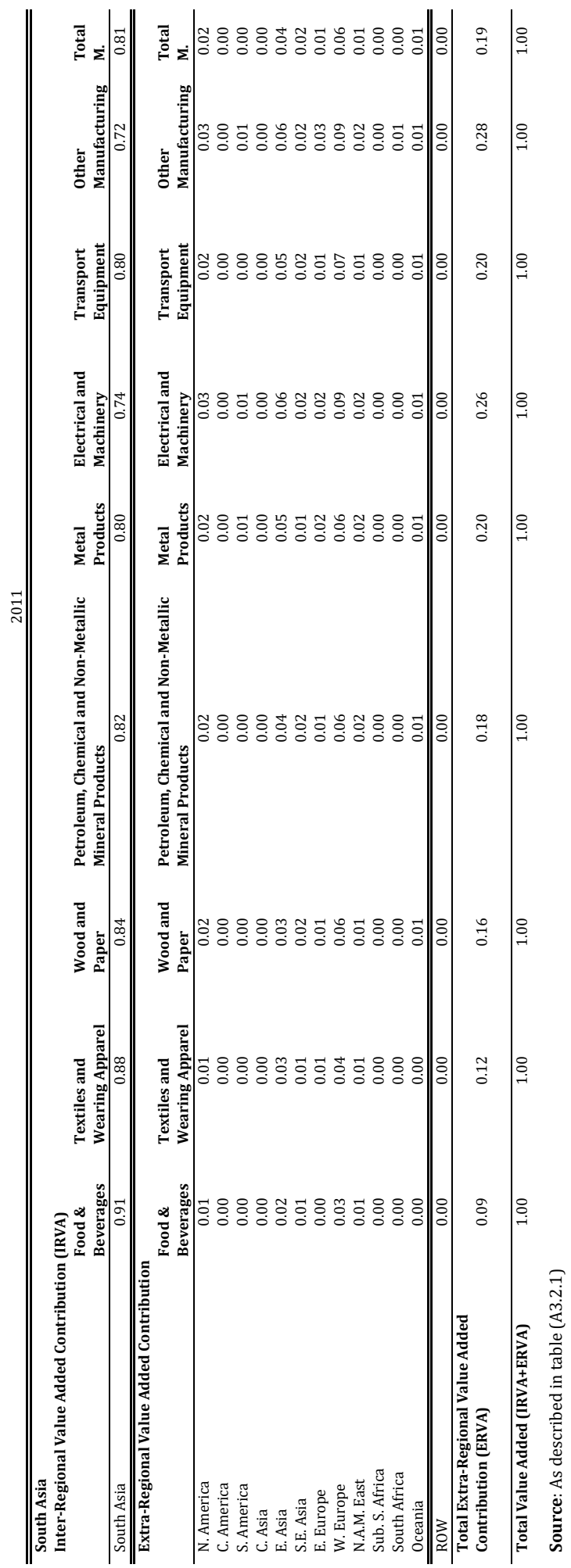




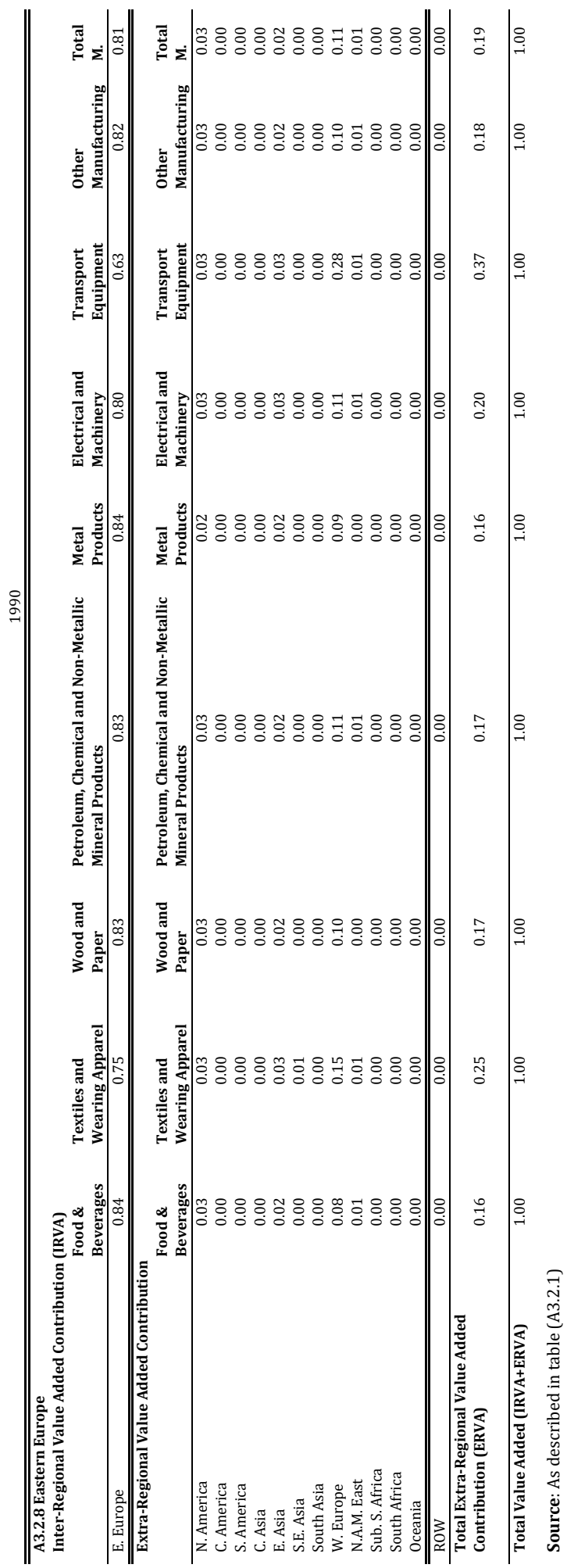




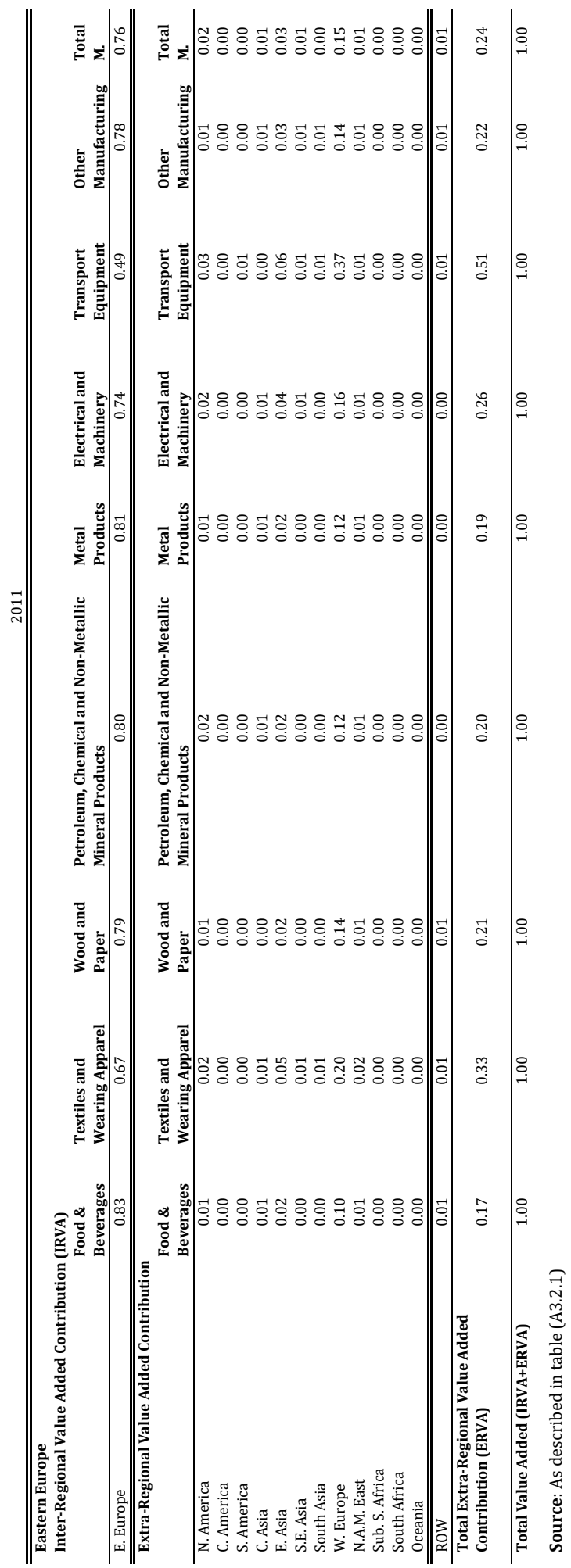




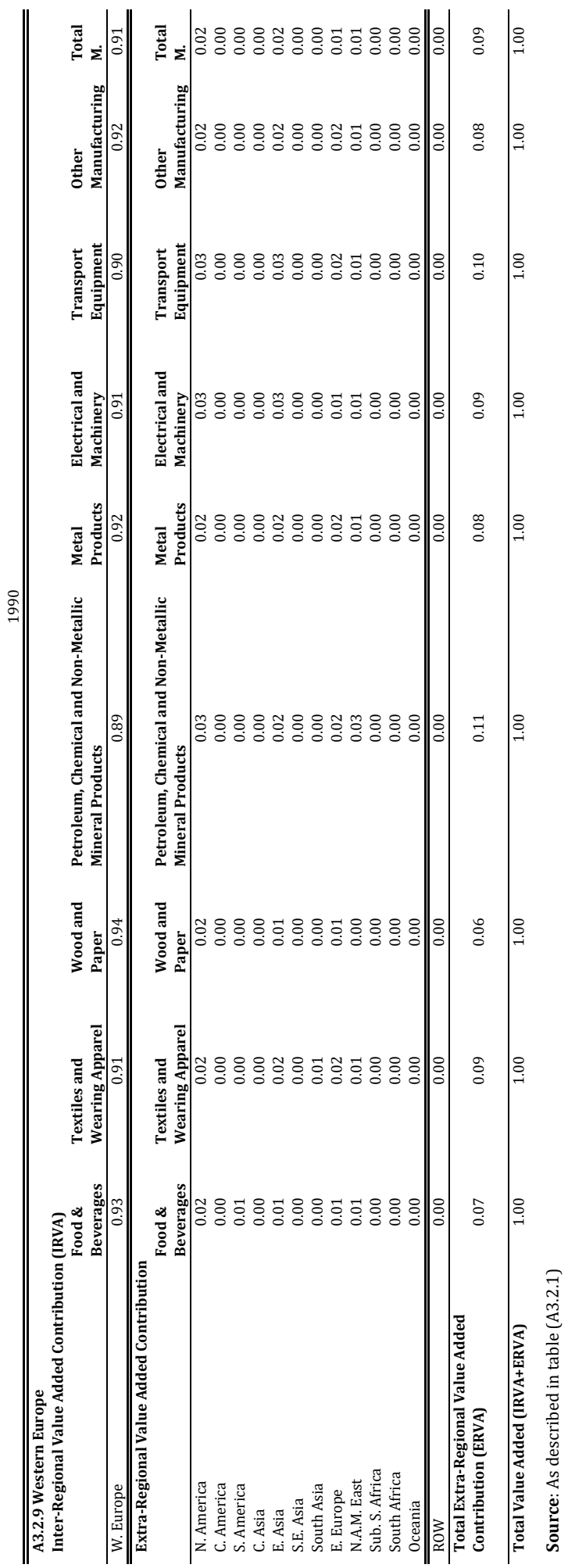




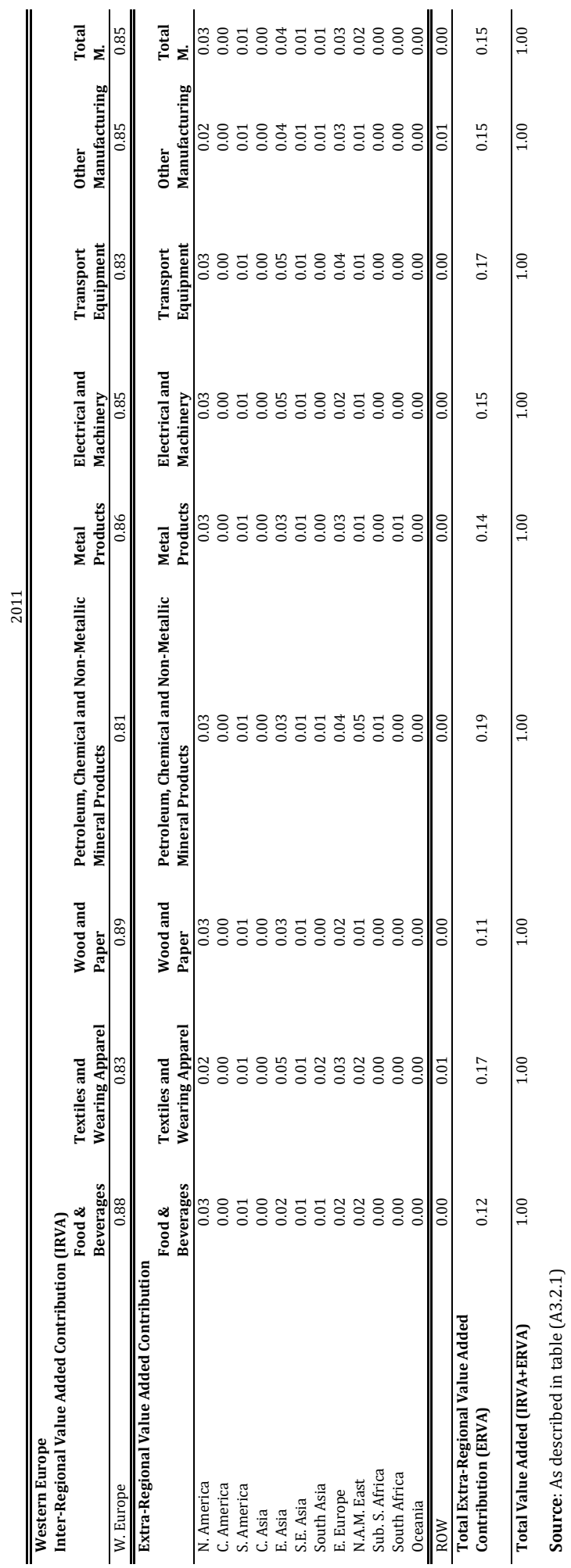




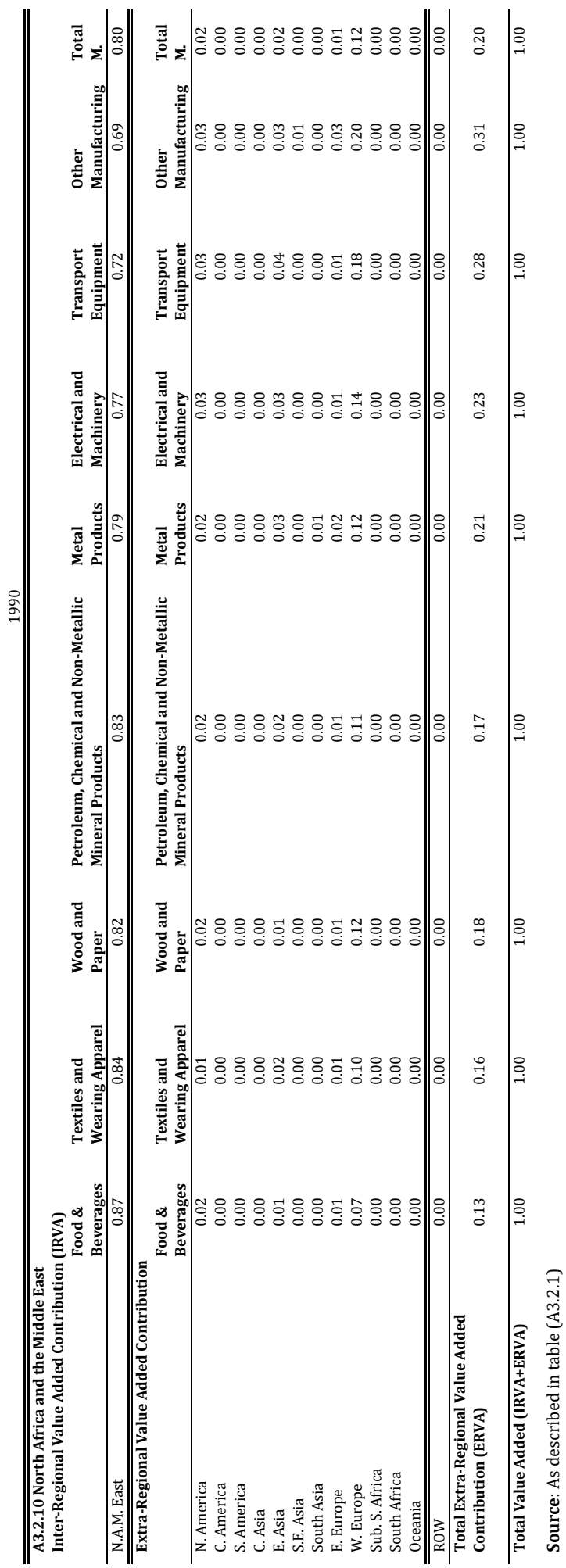




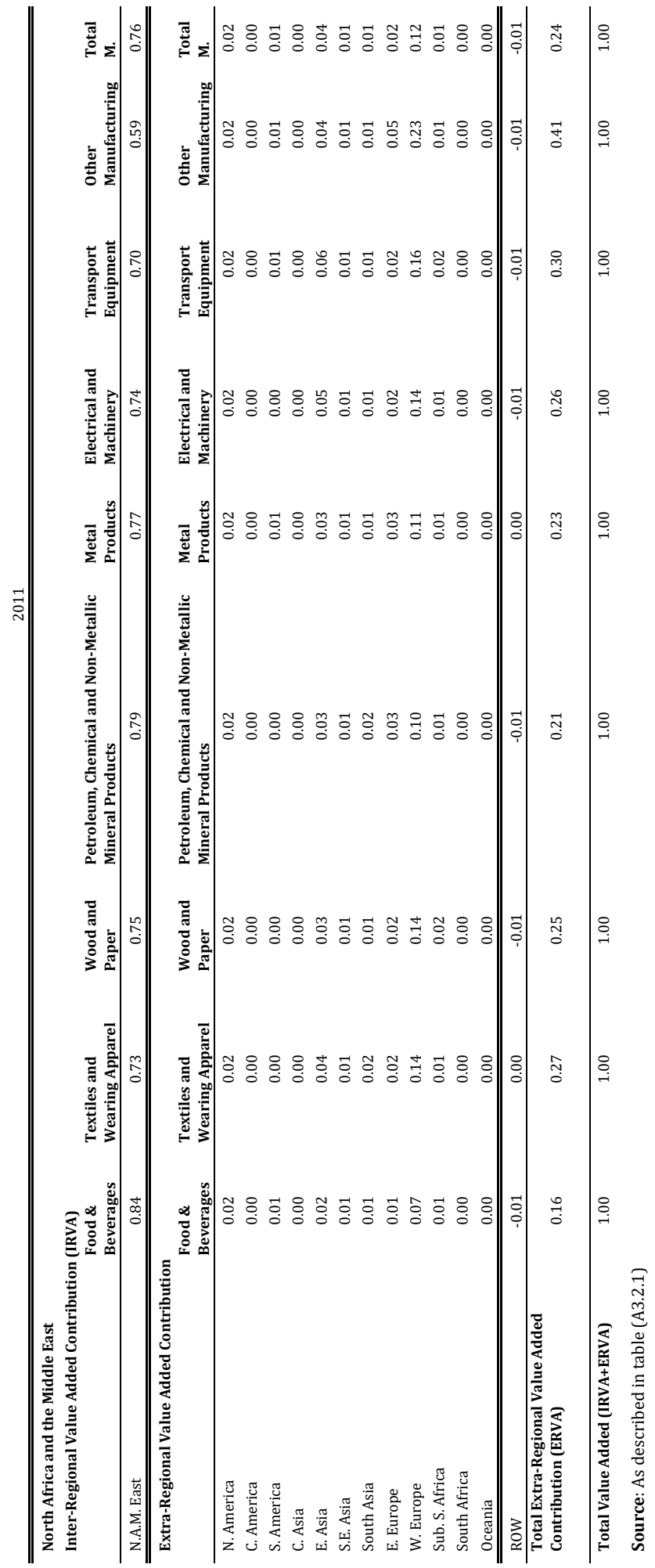




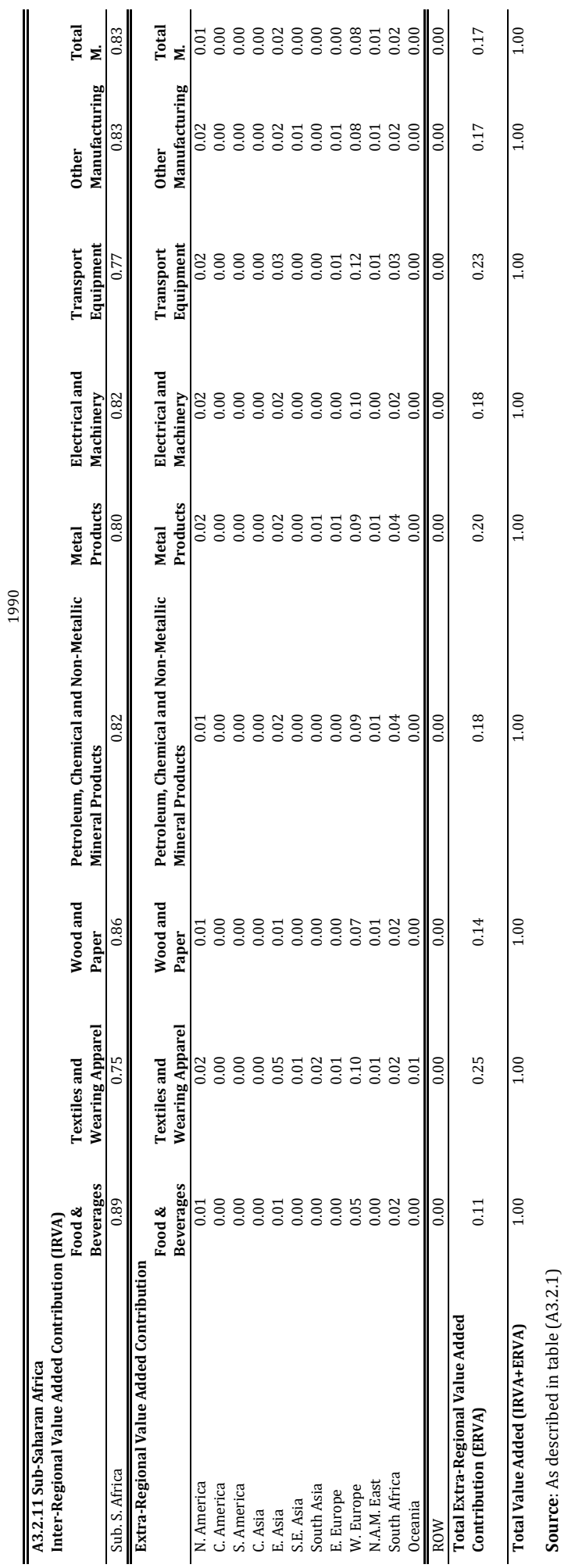




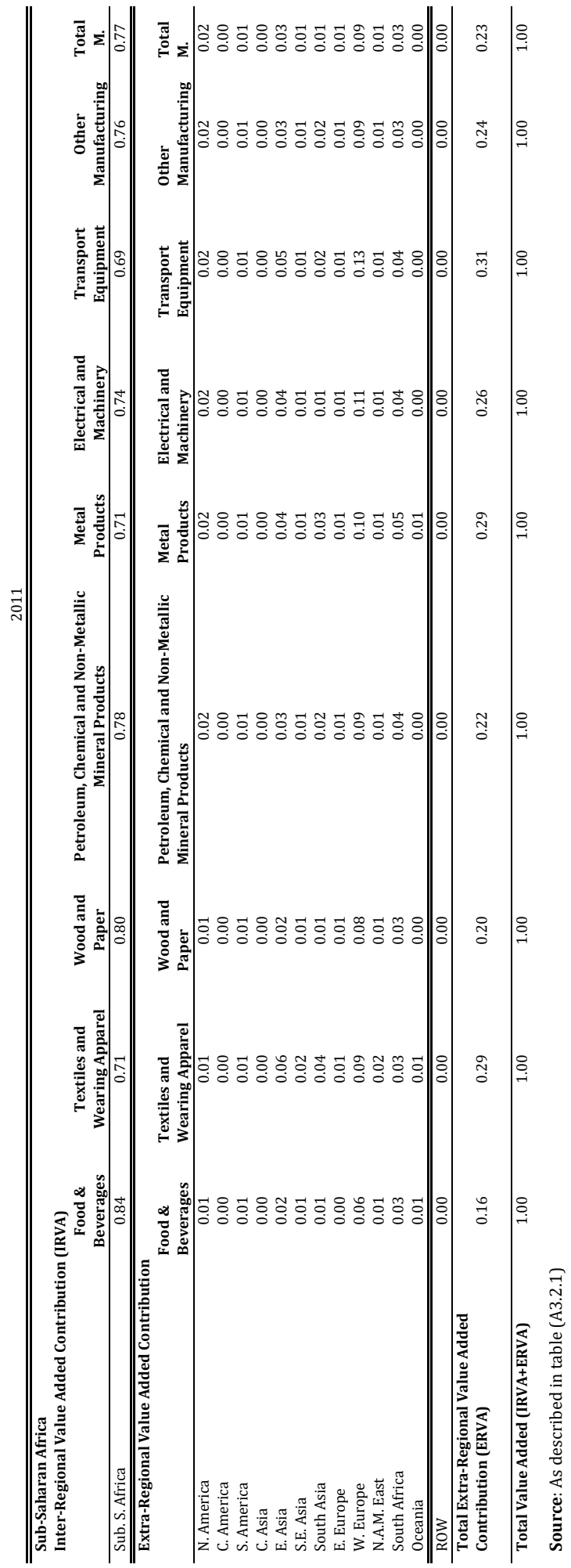




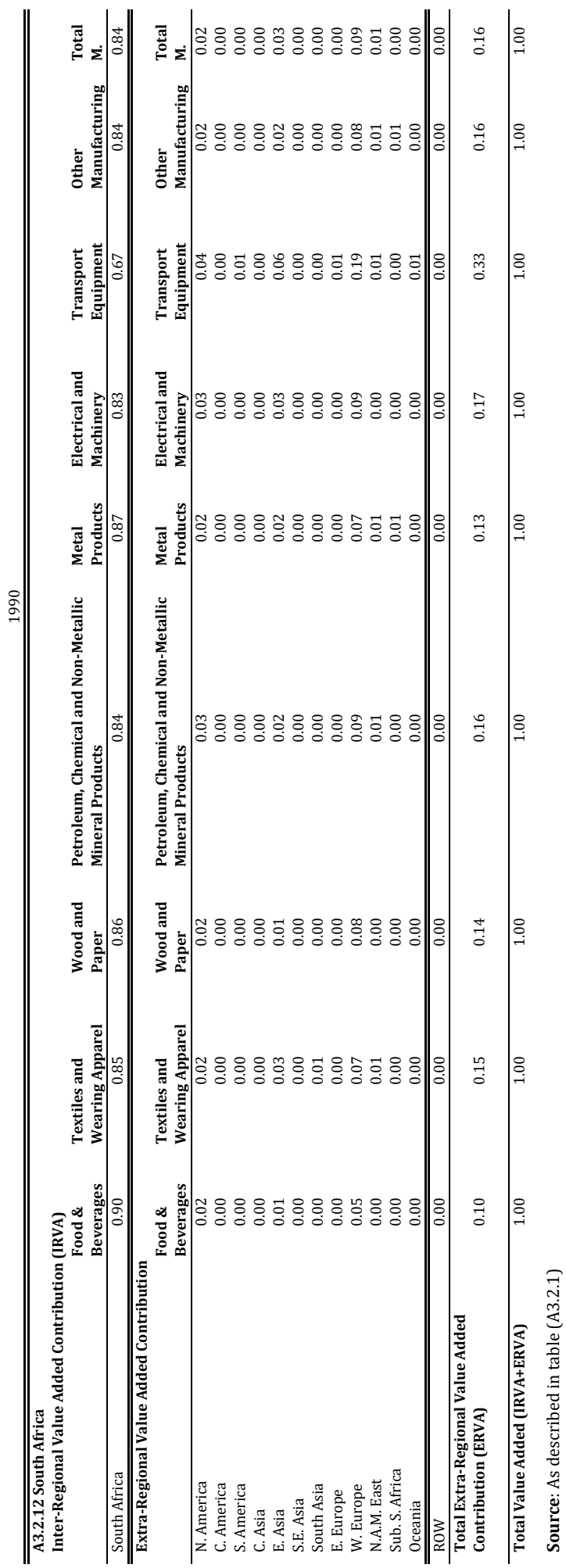




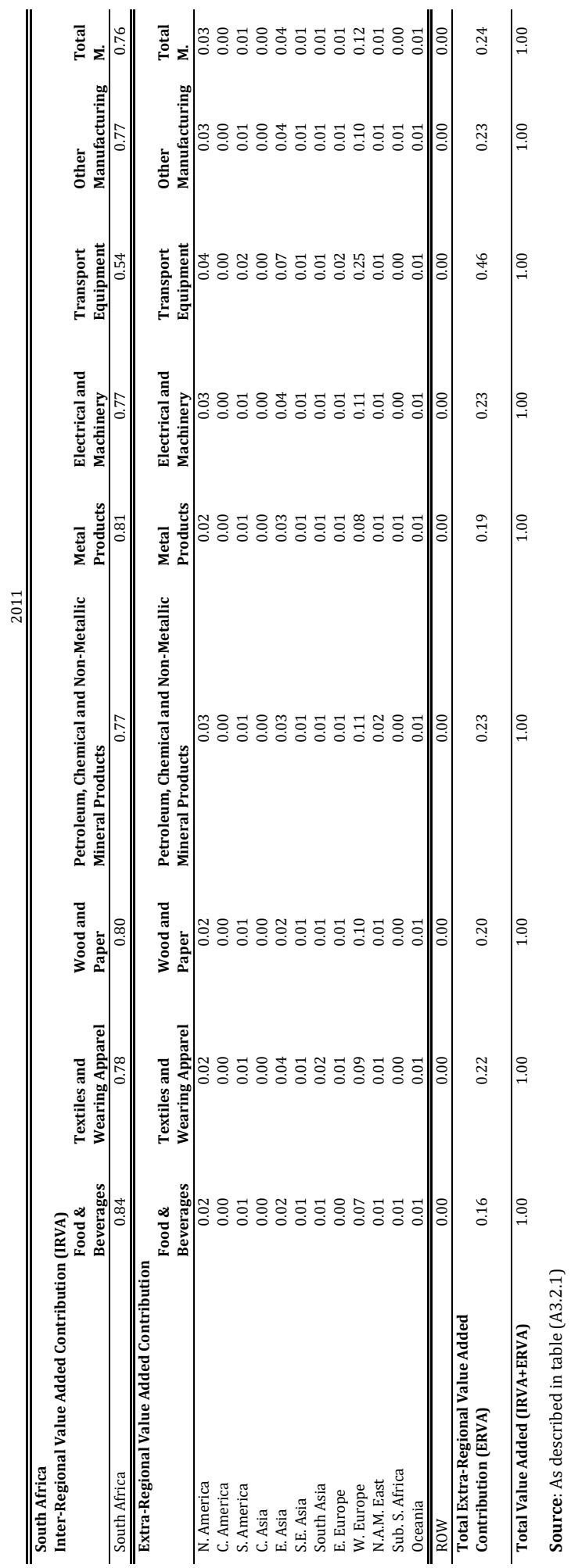




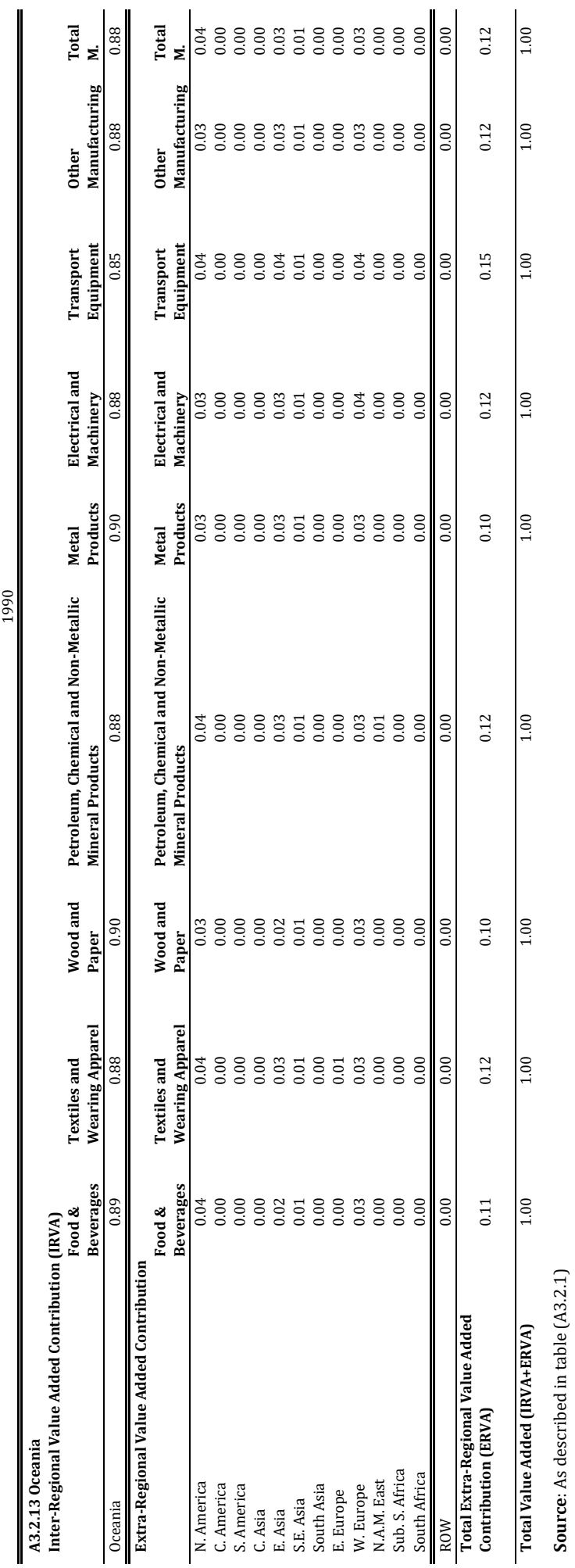




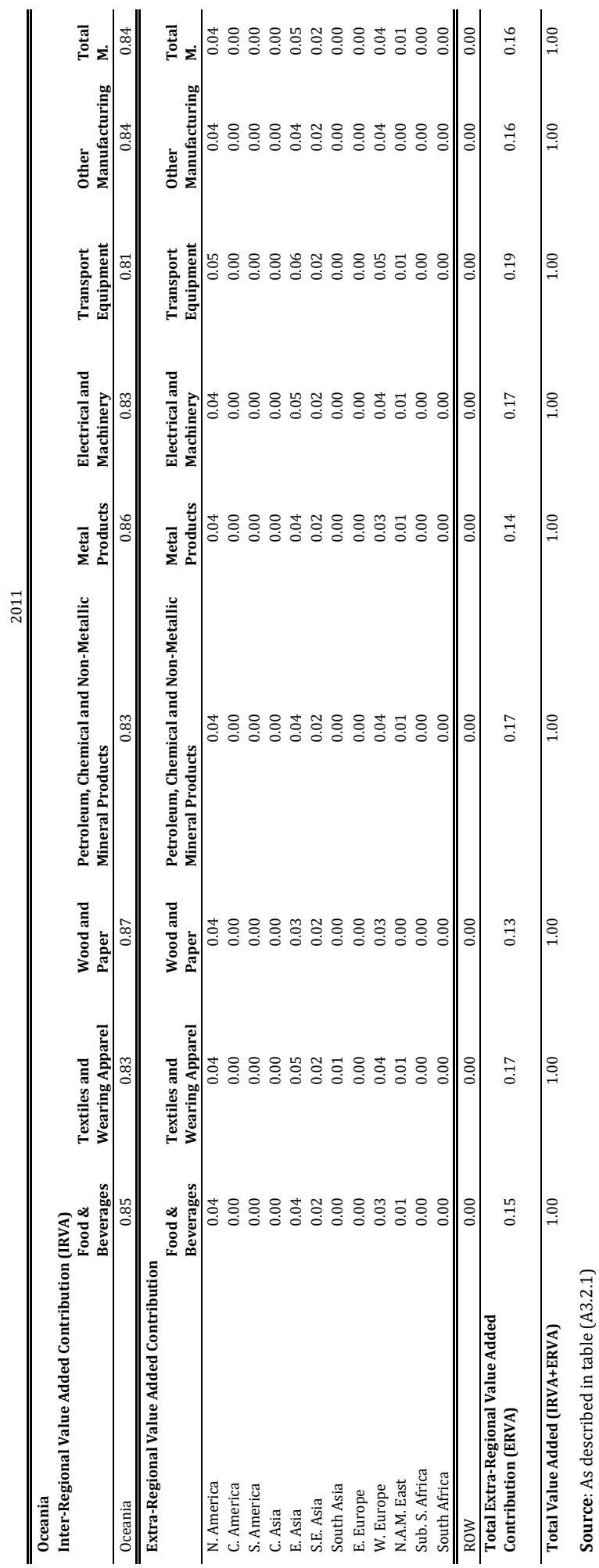




\title{
Chapter 4
}

\section{Industrial Policy and the Domestic Content of Mexico's Maquila Exports: A long-run Perspective ${ }^{+, * *}$}

\begin{abstract}
This chapter studies the domestic value added content of exports in a developing country, namely Mexico's maquiladoras (export-processing firms) during the period from 1981 to 2006. Initially the government viewed maquiladoras as mere providers of employment. This view and subsequent industrial policies shifted with the increasing outward orientation of Mexico in the late 1980s. The government started to promote the sourcing of intermediates from Mexican firms and technological upgrading within maquiladora firms. We combine a recently released input-output table for maquiladora industries with detailed longitudinal data to study whether observed patterns are related to changes in industrial policy. Over time, productivity and the share of skilled workers in maquiladoras increased only modestly. A long-run decline in aggregate domestic value added embodied in maquila exports, from 31 percent in 1981 to 21 percent in 2006, is largely explained by the falling domestic content within electronics manufacturing. Changes in the domestic content of exports appear mainly related to internal and external shocks and not to changes in the regulatory environment.
\end{abstract}

JEL Codes: C67, L6

Keywords: Domestic content, Industrial policy, Export processing, Mexico

\footnotetext{
† This chapter has been co-authored with Gaaitzen De Vries (University of Groningen). This chapter is also based on Castillo, J.C. and G.J. De Vries (2018), “The Domestic Content of Mexico's Maquiladora Exports: A Long-Run Perspective", Journal of International Trade and Economic Development, 27(2), 200-219. DOI: 10.1080/09638199.2017.1353125
}

**We thank Klaas de Vries for research assistance, Bart Los, Adam Szirmai, Bart Verspagen for many insightful comments and discussions. We would also like to thank UNIDO for financially supporting the $\mathrm{PhD}$ project of Juan Carlos Castillo. Comments and discussions based on presentations at a research seminar and a workshop at the University of Groningen, the International Input-Output Conference 2013 and 2014, and the Fifth Spanish Input-Output Conference helped to improve this paper 


\subsection{Introduction}

Mexico's export-processing firms belong to one of the oldest and largest international production networks in the world. The first export-processing firms (officially known as maquiladoras de exportación) were established during the 1960s. Maquiladoras were allowed to import material and equipment without paying tariffs. In combination with low wages, it was very attractive for multinational enterprises to set up an exportprocessing subsidiary in Mexico. Employment in maquiladoras increased from 0.12 million in 1980 to 1.2 million in 2006. Maquiladoras account for about 20 percent of Mexican manufacturing value added and about half of the country's exports in 2006 (Bergin et al. 2009).

In the 1960s and 70s, many developing countries pursued a development strategy termed import substitution industrialization, which aimed at building a domestic industry behind high tariff walls. The emergence of export-processing firms in Mexico was not in line with this import substitution industrialization. However, the government saw maquiladoras as necessary providers of employment along its Northern border with the United States due to the end of the bracero guest-worker program for temporary work of Mexicans in the U.S. (mainly seasonal work in agriculture). Over time, policy makers increasingly realized that maquiladoras not only provide jobs, but are also important for generating foreign currency and for the development of domestic firms that deliver inputs to these maquiladoras. As a result, various policies were put in place during the 1990s to stimulate the technological development of maquiladoras and to increase incentives for sourcing inputs locally (SECOFI, 1994; SECOFI, 1998). These policies aimed to increase the domestic content of maquila production and the creation of good (skilled) jobs. Basically, it is a policy that many developing countries with export processing zones pursue nowadays. Are these changes in industrial policy in Mexico related to changes in the domestic content of exports? Did productivity and the quality of jobs improve within maquiladoras over time?

This chapter is the first study to analyze long-term trends in the domestic content of Mexico's maquila exports. We combine a recently released input-output table for maquiladora industries with detailed longitudinal data on value added, gross exports, employment by skill type, and domestic and imported intermediate inputs to relate observed patterns to changes in industrial policy. Maquiladoras in Mexico predominantly export finished goods (Verhoogen, 2008). This contrasts to a 'typical' firm, which might produce intermediate inputs for use by other firms or sell goods in the local market (and sometimes also the foreign market). In contrast, a maquila firm assembles a good and sells it in the United States. ${ }^{10}$ We study whether these maquiladoras upgraded their activities (reflected in an increasing skill content and/or rise in productivity), and increasingly sourced intermediate inputs locally, which could signal the success of industrial policies in stimulating the development of the domestic economy.

${ }^{10}$ Most imports are from the U.S., and over 99.7 percent of sales were in the U.S (Utar and Torres Ruiz, 2013). 
Despite various industrial policies, we find that the share of domestic value added in aggregate maquila exports fell from about 31 percent in 1981 to about 21 percent in 2006. However, the domestic content share varies substantially over time. The 1982 debt crisis and the 1994 Tequila crisis together with the run-up and adoption of the North American Free Trade Agreement (NAFTA) during the early 1990s coincide with declines in the domestic content. The emergence of China, especially after its entry to the WTO in 2001, appears related to a gradual decline in the domestic value added of aggregate maquila exports. A decomposition analysis suggests that this is partly driven by the demise of textile manufacturing that has a relative high domestic value added content. However, the overall long-run decline in the aggregate domestic value added embodied in maquila exports, is largely accounted for by the falling domestic content within electrical machinery product manufacturing.

Research that studies the export composition of Mexico typically finds that the technology composition of Mexico's exports increased substantially, because it transformed from one based on raw materials to one dominated by medium- and hightechnology manufactured products during the past decades (Sturgeon and Gereffi, 2009). This suggests learning and industrial upgrading is taking place in Mexico. However, to assess whether the transformation is real and not just a shift towards other final assembly activities, one need know the value that is added in production by a country, rather than the gross output value of its exports, which is the approach taken in this paper. So far, most analysis of the domestic content embodied in exports and technology upgrading within maquiladoras has been limited to surveys and case studies. These studies provide a rich characterization of maquila firms, but it is unclear whether these findings can be generalized. We aim to provide a macro perspective to these case studies. A clear limitation in this approach, however, is that we are unable to causally link industrial policy to the domestic content of exports. We will relate industrial policies to changes in the domestic content, but more detailed and novel identification strategies are required to causally link policy and the domestic content.

Our chapter is most closely related to de la Cruz et al. $(2011,2013) .{ }^{11}$ De la Cruz et al. (2011, 2013) measure the domestic content of Mexico's exports for the period from 2000 to 2006. Similar to this paper, they use the 2003 input-output table that distinguishes processing and non-processing activities. Their results for the domestic content share in Maquiladora exports in 2003 are fairly similar. Compared to de la Cruz et al. $(2011$, 2013), changes during 2000-2006 in the domestic content are only due to variation in the export composition. In contrast, in this paper we do collect and use information on production and inputs. Hence we allow the domestic content to vary if input cost shares change over time, which is more accurate. The purpose of de la Cruz et al. $(2011,2013)$ is also different from ours. They aim to provide point estimates for the domestic content in Mexico's processing and non-processing exports and compare these to those for China. In comparison, this chapter aims to relate changes in the domestic content of maquiladora exports to changes in industrial policy. We take a much longer time perspective, from 1981 to 2006. Industrial policies changed in important ways

\footnotetext{
${ }^{11}$ See also Johnson and Noguera (2012) who separate the value added content of Mexico's maquila and non-maquila exports for the year 2004.
} 
during the 1980s and 90s (as we will discuss in section 4.2), so a long-run approach is necessary in order to relate changes in the domestic content of exports to changes in industrial policy. Changes in the domestic content of exports are one way to examine whether industrial upgrading is taking place. Typically, if activities shift to higher value adding stages of production (say from assembly to product development), we also expect these shifts to be accompanied by an increase in skills and capital. In contrast to de la Cruz $(2011,2013)$, we therefore also examine the productivity performance of maquiladoras and explore changes in the share of non-production workers over time.

The remainder of the paper is organized as follows. In the next section (4.2), we give an overview of industrial policies for the maquila industry from its inception in the 1960s until the merging of the program in a broader framework in 2006. We argue that industrial policy changed considerably as time progressed, but there is little evidence to guide us whether these policies had their intended effects. In section 4.3 , we discuss the data and provide a descriptive analysis of changes in the use of domestic intermediate inputs by maquiladoras, as well as productivity growth and the use of skilled workers within maquiladoras. We also examine changes in the industry composition from 1981 onwards. Section 4.4 discusses the estimation of time series input-output tables and describes the method to measure the domestic value added content of exports. Section 4.5 presents empirical results and it returns to a discussion of industrial policies related to changes in the share of domestic content in maquiladora exports. Section 4.6 provides concluding remarks.

\subsection{Industrial Policy and Mexican Maquiladoras: an Overview}

The maquiladora program was devised in the 1960s as an emergency program to cope with rising unemployment observed in the northern part of Mexico. Mexicans were pushed out of the United States due to end of the bracero guest-worker program in 1964. Initially, the maquila program was restrictive (Contreras and Munguía, 2007). For example, firms were supposed to be located within 20 kilometers of the Mexican border; have a minimum national ownership of 51 percent; and they had the obligation of reexporting their entire production. This restrictive legal framework was put in place, because the program was not in line with the Import Substitution Industrialization (ISI) policies prevailing in Mexico at the time. Providing tariff exemptions to manufacturing firms that are partly foreign owned was simply a policy contrary to the strategy of ISI. As a consequence of this ISI, the government of Mexico hardly implemented policies related to firms operating under the maquiladora program.

During the 1970s, several laws were passed that aimed to reduce unemployment, by permitting the creation of maquiladoras in coastal areas (in 1971), and soon thereafter for the entire Mexican territory (in 1972). Yet most maquiladoras remain along the Northern border of Mexico to avoid higher transport costs. In 1977 a law was passed that allowed maquiladoras to be completely foreign owned (Urias, 1978). Few attempts were made to promote technological upgrading within maquilas and to increase the domestic content of production however. To the contrary, regulations implemented by the Mexican general Law on Foreign Investment in 1973, allowed the government to review and control the implementation of technologies in maquiladoras. Also, the 
government was able to prohibit any foreign firm or new plant from entry if it could harm the national industry (González, 1990). These policies limited the possibility of industrial upgrading as it posed restrictions to the implementation of foreign technologies.

In the mid-1980s, as many Latin American countries (including Mexico) struggled with the debt crisis, Mexico's policies became more outward-oriented and various marketoriented reforms were implemented. A key policy change was Mexico joining the General Agreement on Tariffs and Trade (GATT) in 1985, which served as an initial push for domestic and international trade reforms during the upcoming years. Once this new economic model was established, major changes were seen in the legal framework for maquiladoras. The government recognized the potential of maquila firms as one of the drivers of the new export-led development in Mexico. According to new regulations that were passed in 1989 (see Government of Mexico, 1989), the maquiladora industry was now supposed to meet the following objectives: (1) to provide higher levels of employment; (2) to increase manufacturing exports and levels of foreign exchange; (3) to stimulate the development and transfer of knowledge and; (4) to promote investment in human capital through further integration with the local Mexican manufacturing industry.

Various researchers have studied the effects of these new government objectives, but so far this has been restricted to selected sectors. For example, Wilson (1992) and Carrillo and Hualde (1997) study changes in the technology used in automotive and electronic manufacturing during the 1980s. They find that new technologies were typically introduced to obtain more precision, control and quality at labor-intensive activities. Hence, old machinery was replaced by technologically more sophisticated instruments that still needed a low qualified workforce to operate (Carrillo and Hualde, 1997). Also, more autonomous decision making was observed, but this remained restricted to issues such as recruitment and human resource management. Hardly ever did local managers participate in the selection of inputs or in the decision process of goods to be produced as most of the technical specifications came from abroad. Along the same lines, local management had little influence on investment, finance or production technology decisions (Wilson, 1992).

Output and employment expanded fast during the 1990s. And as we will describe below, the composition of output increasingly shifted towards the production of electronic and transport equipment goods. This growth was underpinned by legal changes that were in line with the liberalization of the economy. For instance, the new Law on Foreign Investment of 1990 represented a major relaxation of policies towards foreign direct investment relative to that of 1973, because it reduced uncertainty and allowed for long term planning of operations. This new regulation was thought to induce a change in current corporate strategies of foreign firms under the maquila program so that they could develop progressively more technologically complex activities in the country, moving away from the labor intensive ones (Carrillo, 2007). Along the same lines, 
import licensing continued to decline in importance and easier and faster administrative procedures were implemented. ${ }^{12}$

In 1994, the removal of trade and investment barriers in the North American Free Trade Agreement (NAFTA) gave rise to another output boost for maquila industry. The NAFTA agreement increased the preferential access of maquiladoras to the US market relative to firms outside the NAFTA area due to the execution of the principles of national treatment and most-favored-nation (NAFTA Article 102). Non-NAFTA originated inputs had to pay Mexico's Most Favored Nation (MFN) tax, around 35 percent in 1994, while the intermediate goods originating in the NAFTA region could be imported free of duty. Hence, these new regulations created an important incentive for the production of parts and components in maquiladoras because the inputs eligible for the tariff exemption were not only those including pure NAFTA content, but also those from other regions that have been previously processed in Mexico. ${ }^{13}$ In addition, with the NAFTA agreement, the benefits to maquila firms were extended to companies that supplied them goods and services thereby increasing the incentive for domestic firms to supply maquiladoras.

As a result of this changing economic environment in Mexico, maquiladoras started to introduce more technologically complex procedures. Buitelaar and Padilla (2000) argue that modern management systems were more commonly seen in maquiladoras, such as total quality control, just in time delivery, elaborate operation manuals as well as norms regarding organizational culture and labor discipline. In addition, they find that more skilled workers were employed and they observe an increase in local R\&D centers. However, these results are based on a case study and it remains to be seen whether technological upgrading is a general pattern.

A large contraction of output and employment in the maquiladora industry occurred during the early 2000s. This was in part due to the 2001 recession of the US economy with the collapse of the dot-come bubble, and in part due to the industrial emergence of China and its entry to the WTO in 2001. China's emergence has had a profound negative effect on maquiladoras. The reason for this negative effect is often sought in the similarity of the composition of US imports from Chinese and Mexican producers (Dussel Peters, 2005; Gallagher et al., 2008).

In light of increasing competition, the government of Mexico implemented more changes in the legal framework that aimed to induce an increasing number of maquiladoras to

\footnotetext{
${ }^{12}$ At the same time, other export promoting programs for the manufacturing industry were implemented. In 1985, the "Programas de Importación Temporal para Producir Articulos de Exportación" (PITEX) came into effect with the intention of permitting exporting firms in domestic manufacturing to import intermediate inputs and machinery free of duty as long as 30\% of their total sales were exported. As discussed in chapter 2, one of the difference between the firms under PITEX and the maquiladora program lies in the fact that the industries under the latter program were exempted to a bigger amount of taxes. Similarly, unlike maquiladoras, PITEX firms were mainly located in the interior of Mexico as most of their production was destined for domestic consumption (de la Cruz et al., 2011).

13 As of 2001, only North American inputs were exempted from tariffs. In order not to lose competitiveness, policy makers implemented a new program called "Sectoral Programmes" (PROSECs) that provided tax exemption to the import of a specific percentage of inputs not produced in North America across selected industries.
} 
exit low-tech, labor intensive industries and evolve toward higher value added, technology intensive sectors (Sargent and Mathews, 2008). During the early 2000s, the government provided substantial tax incentives to maquiladora firms that engaged in research and development activities (R\&D) and created a fund to promote Mexico's software industry (Ruiz Durán et al., 2005). State governments, industry chambers, and universities were also involved in the upgrading efforts. The branch of Mexico's largest private university system in Guadalajara established institutes designed to accelerate the development of design engineering centers, software development firms, and technology intensive startups in the city's cluster of electronics firms. The government in Mexico was especially interested in attracting new companies engaged in applied research, product and process development, product testing, and high-tech manufacturing in five industries; biotechnology, mechatronics, information technology, health, and nanotechnology (Sargent and Mathews, 2008).

In a nutshell, Mexico's industrial policy towards maquiladoras gradually shifted from viewing them as mere providers of employment towards promoting the sourcing of intermediates from upstream domestic firms and technological upgrading within maquiladora firms. In the next section we discuss the dataset to that will be used to analyze whether these policy changes had their intended effects.

\subsection{Database Construction and Descriptive Statistics for Maquila Industries}

The dataset for detailed maquiladora manufacturing industries consists of longitudinal information on output (gross output and value added), gross exports, as well intermediate inputs and employment distinguished by production and non-production workers. This data is derived from various publications by the statistical office (INEGI 1991, 2001, 2005). The data presented in these publications are based on the monthly statistical surveys for the maquiladora industry as well as the five-yearly economic census. The monthly sample survey of the maquiladora industry collects detailed information on the business operations of maquilas. The setup of the survey has not changed much during the period analyzed, and the economic census is a full census of economic activity that underpins this monthly survey. Data from 1990 to 2006 can be readily obtained from the national statistical office's website (www.inegi.org.mx), but to trace the development further back and to obtain more industry detail, we collected and digitized hard copies of various reports (notably INEGI 1991, 2001). Detailed industry data following Mexico's industry classification is matched to two digit industries in the International Standard Industrial Classification 3.1.14

After 2006, the maquiladora program was merged with another program that offers duty relief for temporary imports, the PITEX program (Programas de Importación Temporal para Producir Articulos de Exportación). As a result, the statistical office no longer updates information for maquiladoras. Information that includes maquiladoras

14 Our analysis starts in 1981 as we were unable to obtain industry level data further back. The Maquiladora program started in the 1960s, but it only started to boom with the increasing outward orientation of Mexico during the late 1980s (Feenstra and Hanson, 1996). We believe the time period included in this chapter captures the most important periods in the history of the Maquiladora program. 
and other firms is reported in the monthly statistical report of the IMMEX program from 2006 onwards (Industria Manufacturera, Maquiladora, y de Servicio de Exportación). Our time series stop in 2006, because it is not possible to distinguish maquiladora firms in these reports. Also, policies specific to maquiladoras are no longer present from 2006 onwards. Thus we focus on the domestic content of maquila exports in the period from 1981 to 2006.

Columns (1) - (4) of table 4.1 show gross output shares by industry for 1981, 1990, 2000, and 2006. Note that gross output equals exports for maquiladoras since we assume that everything produced is subsequently exported (this is further discussed in section 4.4). Changes in gross output shares reflect changes in the industry composition. Textile products, electronics, and transport equipment account for the majority of gross output, with the assembly of electronic goods by itself accounting for over half of the gross production value. ${ }^{15}$

During the 1980s, transport equipment and miscellaneous manufacturing (including furniture, jewelry, musical instruments, sports goods and toy production) grew substantially faster as compared to other sectors such as textiles and electronics. The opposite pattern is observed for the 1990s. After 2000 we observe a sharp drop in the relative importance of textile manufacturing. This drop might be related to the entry of China to the WTO in 2001 and the end of the Multi-Fiber Agreement in 2004 that eliminated import quotas for textile products. Mexican textile firms faced relatively tough competition from Chinese firms thereafter. These import competition effects in the US market are likely to differ across industries, for example due to quality differences and transport costs, but also firm size within industries (Iacovone et al. 2013).

Changes in the relative size of sectors carry important implications for the composition of maquila exports and subsequently also for the domestic value added content of exports. In column (5) we report the share of domestic intermediate inputs in total intermediate inputs in 2006. The share of domestic intermediates varies substantially across industries. Food processing manufacturing is sourcing a lot of inputs domestically (37.9 percent in 2006) as fresh produce typically requires immediate processing. However, most inputs in the more technologically advanced electronics manufacturing sector are sourced from abroad. The domestic share is only 6.8 percent in 2006. The share of domestic inputs directly used in production reflects the direct domestic content of maquila exports. Hence, the relative decline of textile manufacturing with a high share of domestically produced intermediates and the relative expansion of electronics and transport equipment manufacturing with a low domestic content after 2000 suggests that the domestic content in aggregate exports declined. We will examine this more formally in section 4.5 .

\footnotetext{
15"Business services" includes activities such as "professional services", "leisure services" and "other services". These services are provided by some maquiladoras (INEGI, 2010).
} 
Table (4. 1): Descriptive Statistics, Size and Domestic Input use for Maquiladora Industries.

\begin{tabular}{|c|c|c|c|c|c|}
\hline & \multicolumn{4}{|c|}{ Gross output shares } & \multirow{2}{*}{$\begin{array}{l}\begin{array}{l}\text { Domestic } \\
\text { intermediate } \\
\text { use shares }\end{array} \\
\begin{array}{c}2006 \\
(5)\end{array}\end{array}$} \\
\hline & $\begin{array}{c}1981 \\
(1)\end{array}$ & $\begin{array}{c}1990 \\
(2)\end{array}$ & $\begin{array}{c}2000 \\
\text { (3) }\end{array}$ & $\begin{array}{c}2006 \\
(4)\end{array}$ & \\
\hline Food, Beverages and Tobacco & 1.9 & 1.1 & 0.4 & 0.8 & 37.9 \\
\hline Textiles and Textile Products & 15.5 & 7.4 & 12.0 & 7.4 & 16.0 \\
\hline Leather, Leather and Footwear & 1.0 & 1.0 & 0.6 & 0.3 & 16.0 \\
\hline Pulp, Paper, Printing and Publishing & 1.5 & 3.6 & 2.0 & 1.9 & 17.7 \\
\hline Chemicals and Chemical Products & - & 0.3 & 0.2 & 0.2 & 35.1 \\
\hline Rubber and Plastics & 2.3 & 1.6 & 2.2 & 3.1 & 22.9 \\
\hline Other Non-Metallic Minerals & 0.4 & 0.6 & 0.7 & 1.9 & 10.5 \\
\hline Basic Metals and Fabricated Metal & 2.4 & 3.1 & 3.1 & 3.2 & 21.4 \\
\hline Machinery & 1.8 & 2.0 & 1.8 & 2.3 & 17.3 \\
\hline Electronics & 55.3 & 45.9 & 52.9 & 53.0 & 6.8 \\
\hline Transport Equipment & 11.4 & 22.5 & 16.5 & 17.2 & 14.2 \\
\hline Miscellaneous manufacturing & 2.3 & 9.7 & 6.1 & 6.9 & 10.1 \\
\hline Business services & 4.2 & 1.3 & 1.5 & 1.8 & 24.5 \\
\hline Total & 100.0 & 100.0 & 100.0 & 100.0 & 10.9 \\
\hline
\end{tabular}

Notes: Columns (1) - (4) show gross output shares in current prices by industry. Column (5) shows the share of domestic intermediate inputs in total intermediate inputs. Total refers to total maquila industries. Wood and Products of Wood and Cork is included in Pulp, Paper, Printing and Publishing manufacturing. Sources: INEGI $(1991,2001,2005)$ and others, see text.

Figure 4.1 shows various indicators of technological development within maquila manufacturing industries. The top panel shows productivity growth for total manufacturing and the three largest sectors (textile, electronics, and transport equipment manufacturing). We divided real value added by hours worked to measure labor productivity. Based on growth rates of labor productivity an index is constructed, which equals 1 in 1981. The overall trend suggests that productivity hardly improved during the period considered. In 1997 there is a substantial drop in labor productivity, which arises from a substantial increase in hours worked between 1996 and 1997. In 1997, there is a substantial drop in labor productivity, which arises from a new tax regulation imposed on the profits earned by maquiladora firms. ${ }^{16}$ From the late $1990 \mathrm{~s}$ onwards, productivity modestly improved.

The dataset we constructed distinguishes between production workers and nonproduction workers. Production workers mainly undertake manual tasks, whereas nonproduction workers mainly undertake managerial and administrative tasks. The bottom panel of figure 4.1 shows the share of non-production workers in total persons engaged, which proxies for the quality of jobs. The figure reveals that more technology intensive

\footnotetext{
${ }^{16}$ As mentioned in Chapter 2,before 1995, maquila firms paid little (or any) income and asset taxes because they were not operating as profit centers, and often leased machinery and equipment (Rice, 1998). After 1995, as a result of the boom in production triggered by NAFTA, the Mexican government no longer regarded maquila firms as cost centers but as profit centers. Thus, in the following years, maquiladoras were required to report arm's-length profits or to meet a safe harbor for tax purposes (PWC, 2013). In general, the main implication behind this policy shift was that maquilas were now supposed to pay income taxes on the basis of their profits just like any other manufacturing firm in Mexico (Gambrill, 2002).
} 
sectors such as electronics and transport equipment manufacturing have a higher share of non-production workers compared to less technology intensive sectors such as textile manufacturing. A slightly upward trend, though from low initial levels, can be observed.

Figure (4. 1): Productivity Growth and Share of non-Production Workers, 1981-2006.
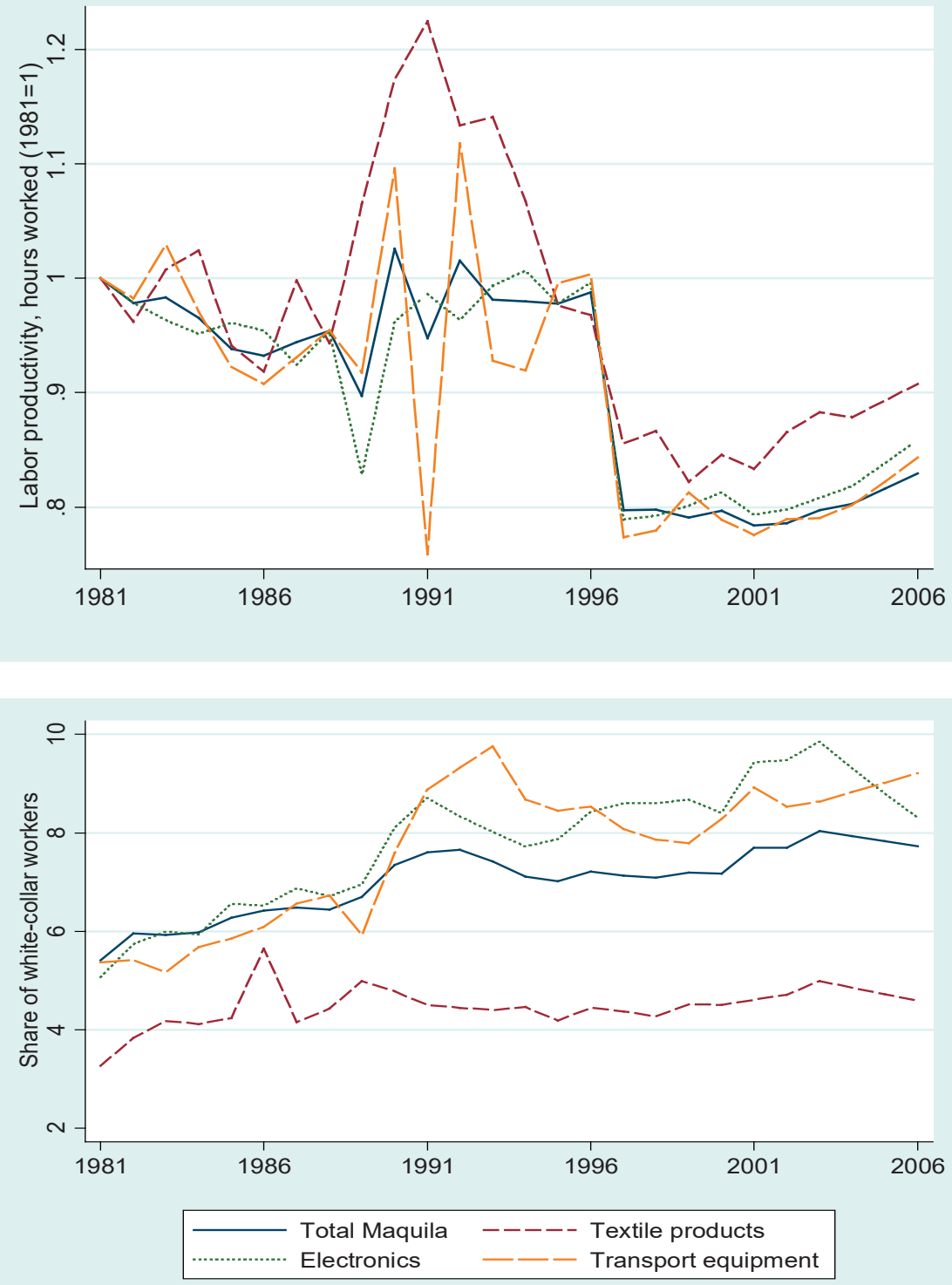

Notes: The first panel shows productivity growth, which is based on the growth in real value added divided by persons engaged (the index equals 1 in 1981). The second panel shows the percentage share of non-production (white-collar) workers in total persons engaged. Sources: INEGI $(1991,2001,2005)$ and others, see text. 
Overall, however, the modest positive trend in labor productivity and the small increase in non-production workers suggest that technological development in the maquiladora industry has not advanced at a fast pace. In the next sections we will study whether the domestic content of exports has increased. We first outline the input-output table and the method to measure the domestic content of exports before turning to the empirical analysis.

Our preferred method (explained in the next section) to measure the direct and indirect domestic input content embodied in maquila exports requires an input-output table. INEGI recently released such a table for the maquila industry for the year 2003 (INEGI, 2010). Although total economy input-output tables are available for Mexico as well, the use of such tables would introduce a bias in the measured domestic content if the sourcing structure differs across maquiladora and non-maquiladora exporting firms. Dietzenbacher et al. (2012) show how this sourcing structure differs between processing and non-processing firms in China.

The maquiladora input-output table is constructed on the basis of a Supply and Use Table (SUT) at basic prices and additional assumptions concerning technology. To transform the SUT in an industry by industry Input Output Table (IOT), we use the socalled "fixed product-sales structure" assumption stating that each product has its own specific sales structure irrespective of the industry where it is produced. The sales structure assumption refers to the proportions of the output of the product in which it is sold to the respective intermediate and final users. This assumption is most widely used to transform SUTs into IOTs, not only because it is more realistic than its alternatives, but also because it requires a relative simple mechanical procedure. Furthermore, it does not generate any negatives in the IOT that would require manual rebalancing (see Miller and Blair (2009) for further discussion).

In constructing the maquila SUT, INEGI relies on various internal and externally available statistical sources. The main source for production data is the Monthly Statistical Report for the Maquiladora Industry undertaken by INEGI. This information is combined with the Foreign Trade Database prepared by the Central Bank of Mexico, which contains information on imported intermediate consumption. Trade margins (the difference between products valued at producer and purchasers' prices) are estimated from the 2004 Commercial Census. Gross value-added is the sum of the wage bill, net taxes on subsidies from production and the gross operating surplus. The "National Survey of Employment for 2003" prepared by INEGI in conjunction with the Monthly Statistical Report was the underlying source of information for these data. For further details on the methods and sources, see INEGI (2010).

\subsection{Methodology to Measure the Domestic Content of Exports Over Time}

This section is divided in two parts. First, we outline the method to measure the domestic content of maquila exports. Second, we discuss the (G)RAS procedure to estimate time series input-output tables for Mexico. 


\subsubsection{Measuring the Domestic Content of Maquila Exports}

We use the approach from Los et al. (2016) to measure Mexican value added embodied in maquila exports. There is a big debate in the literature about how to measure domestic value added in gross exports in global or inter-regional input-output tables, and various methods are proposed (see e.g. Daudin et al. 2011; Johnson and Noguera, 2012; Foster-McGregor and Stehrer, 2013). In an influential article, Koopman, Wang, and Wei (2014) provide a complete decomposition of the gross exports value of a country into nine terms, based on an input-output representation of the world economy. However, their accounting approach is mathematically tedious. And a key issue in that paper concerns what to do with the so-called 'pure double counted' terms in measuring the domestic content of exports. When there is two-way trade in intermediates, meaning that country A needs inputs from country B to produce inputs for B, it is typically difficult to establish the origin of these pure double counted terms. Conceptually tables can be constructed that trace this two-way trade, but empirical input-output tables will never have the required level of detail and it is hard to imagine they ever will, given the amount of information that would be needed. It implies that all tasks in all supply chains in the world should be represented as separate industries.

Los et al. (2016) introduce an elegant and intuitive method to measure domestic value added in gross exports. They extract all export flows from a country and calculate how much value added would be generated in that hypothetical situation. Domestic value added in exports is defined as the difference between actual and hypothetical GDP in that country. They show their measure is equal to the first five terms in the key equation (36) of Koopman et al. (2014). These five terms in Koopman et al. (2014) do not include any pure double counted terms. In addition, Los et al. (2016) show that their and Koopman et al. (2014) measure of domestic value added in exports is equal to one minus Vertical Specialization (VS), with VS as originally suggested by Hummels, Ishii and Yi (2001). In what follows we write down formally how we measure Mexican value added in maquiladora exports.

Consider $n$ industries and let the matrix $\mathbf{Z}$ denote domestic inter-industry flows from industry $i$ to industry $j$. The vector of exports is denoted by $\mathbf{e}$, the final demand vector by $\mathbf{f}$, the vector of value added by $\mathbf{v}$, the vector of industry gross outputs by $\mathbf{x}$, and let $\mathbf{M}$ denote the import use matrix with a typical element $m_{i j}$ the imports of industry $i$ by industry $j$.

The domestic and imported intermediate input flows for both domestic and maquila industries can be depicted in an adaptation of the ordinary input-output table, see table 2. The framework is similar to an inter-regional input-output table, with two regions. In this table, the matrix $\mathbf{Z}^{\mathrm{DD}}$ gives domestic industry deliveries to other domestic industries, whereas $\mathbf{Z}^{\mathrm{DP}}$ gives domestic inter-industry flows to maquila industries. Likewise, the vector $\mathbf{v}^{\mathrm{D}}$ gives value added generated in domestic industries whereas $\mathbf{v}^{\mathrm{P}}$ gives value added in maquila (export-processing) industries.

Note that maquila firms in the final use block are assumed not to deliver output for final demand ( $f \mathrm{p}=0$, see table 4.2). INEGI (the national statistical office of Mexico) regularly carries out surveys, and consistently finds that maquiladoras sell less than $5 \%$ of their 
output domestically (Verhoogen, 2008). Some of these domestic sales of maquiladoras may end up as intermediate inputs for domestic firms (which would be in the matrix $\mathbf{Z}^{\mathrm{PD}}$, here set to zero). We are unable to take these intermediate transactions into account and this will result in a bias in our estimates. However, given the typically low value of these transactions we presume this bias will not be large. We also assume $\mathbf{Z}^{\mathrm{PP}}$ is zero, hence no intermediate deliveries amongst maquiladoras, but below discuss an approach to infer the bias from this assumption.

We assume that maquila output is exported, so gross output of maquila firms equals gross exports. This is consistent with procedures at the statistical office INEGI, who give the estimates for the maquiladora industries that are compatible with the Mexican Balance of Payments. In the Mexican BOP, gross output equals gross exports and imported intermediate inputs equals the total value of maquila imports such that the difference is the maquiladora trade balance.

Table (4. 2): Expanded Input-Output Table for Mexico.

\begin{tabular}{llllll}
\hline \multicolumn{5}{c}{} & \multicolumn{2}{l}{ Intermediate use } & Final use & & \\
$D$ & $D$ & $P$ & $F D$ & $E X P$ & $T O T$ \\
$P$ & $\mathbf{Z}^{\text {DD }}$ & $\mathbf{Z}^{\text {DP }}$ & $\mathbf{f}^{\mathrm{D}}$ & $\mathbf{e}^{\mathrm{D}}$ & $\mathbf{x}^{\mathrm{D}}$ \\
$I M P$ & 0 & 0 & 0 & $\mathbf{e}^{\mathrm{P}}$ & $\mathbf{x}^{\mathrm{P}}$ \\
$V A$ & $\mathbf{M}^{\mathrm{D}}$ & $\mathbf{M}^{\mathrm{P}}$ & $\mathbf{f}^{\mathrm{M}}$ & 0 & $\mathbf{x}^{\mathrm{M}}$ \\
$T O T$ & $\left(\mathbf{v}^{\mathrm{D}}\right)^{\prime}$ & $\left(\mathbf{v}^{\mathrm{P}}\right)^{\prime}$ & & & \\
\hline & $\left(\mathbf{x}^{\mathrm{D}}\right)^{\prime}$ & $\left(\mathbf{x}^{\mathrm{P}}\right)^{\prime}$ & & & \\
\hline
\end{tabular}

Notes: $\mathrm{D}=$ industries producing for domestic use; $\mathrm{P}=$ maquila industries (export processing); $\mathrm{FD}=$ final demand; $\mathrm{EXP}=$ exports; TOT = gross industry outputs (and total imports in the column TOT); IMP = imports; and VA = value added.

The direct requirements for domestic input $i$ per unit of output $j$ are given by $\mathbf{A}^{\mathbf{D D}}=\mathbf{Z}^{\mathbf{D D}}\left(\widehat{\boldsymbol{x}^{\boldsymbol{D}}}\right)^{-1}$ for domestic industries (with typical element $a_{i j}^{D D}=z_{i j}^{D D} / x_{j}^{D}$ ) and $\mathbf{A}^{\mathbf{D P}}=\mathbf{Z}^{\mathbf{D P}}\left(\widehat{\boldsymbol{x}^{\boldsymbol{P}}}\right)^{-1}$ for maquila industries. ${ }^{17}$

Production typically requires domestic and imported inputs. However, these inputs in turn also require domestic and imported inputs. The latter effects are indirect effects. The size of these indirect effects depends on the interrelatedness of production across industries and countries. To include both direct and indirect effects in an analysis of the domestic content of exports, we calculate the total effect using the Leontief inverse $\mathbf{L}=$ (I - A) ${ }^{-1}$, where I is the identity matrix, a diagonal matrix of ones.

The total domestic content of aggregate maquila exports is one minus VS as in Hummels et al. (2001), which is given by

$$
D C E=(\boldsymbol{v})^{\prime}(\boldsymbol{I}-\boldsymbol{A})^{-1} \boldsymbol{e}^{P} /\left(\boldsymbol{u}^{\prime} \boldsymbol{e}^{P}\right),
$$

\footnotetext{
17 The circumflex indicates a diagonal matrix, in this case with the vector $\mathbf{x}$ on the main diagonal.
} 
We will use equation (4.1) to calculate the Domestic Content of maquila Exports (DCE). By observing the variables included in equation (4.1), the reader should notice that our proposed measure of DCE includes the joint value added contribution from maquila and domestic producers; $\boldsymbol{v}$ is a row vector that contains information on the value added coefficients for maquila and for the domestic sector, respectively (as described in table 4.2); $\boldsymbol{A}$ is the full leontief matrix which separately includes all the available information for the direct requirements for domestic input $i$ per unit of output $j$ as suggested in table 4.2. This means that $\boldsymbol{A}$ separately includes $\mathbf{A}^{\mathbf{D D}}, \mathbf{A}^{\mathbf{D P}}$ as well as $\mathbf{A}^{\mathbf{P D}}$ and $\mathbf{A}^{\mathbf{P P}}$. Given that, by definition, maquiladora firms do not produce intermediate inputs, matrices $\mathbf{A}^{\mathbf{P D}}$ and $\mathbf{A}^{\mathbf{P P}}$ (included in $\mathbf{A}$ ) are only consistent of zeros. In addition, the information for column $\boldsymbol{e}^{D}$ in total column $\boldsymbol{e}$ (again in table 4.2) is set to zeros in order to only compute value added embodied in maquila exports. The entire latter column represents the information contained in $\boldsymbol{e}^{P}$ at equation (4.1). Finally, $\mathbf{u}$ is a summation vector consisting of ones, and a prime (e.g. $\mathbf{u}^{\prime}$ ) indicates transposition.

In order to measure DCE annually from 1981 to 2006 by means of equation (4.1), we need a time series of the expanded input-output table as shown in table 4.2. This objective will be met in the next sections.

\subsubsection{Construction of Time Series IOTs.}

For the purposes of this chapter, we will extrapolate the official intermediate use tables for maquiladora and for the domestic sector that were produced for 2003. Extrapolating these official tables (which are also available for domestic and imported intermediate use) would allow us to fill the different set of matrices shown in table 4.2 (namely $\mathbf{Z}^{\mathrm{DD}}$, $\mathbf{Z}^{\mathrm{DP}}, \mathbf{M}^{\mathrm{D}}, \mathbf{M}^{\mathrm{P}}$ ) for the period from 1981 to 2006 . To do so, the literature offers a wide pallet of methods to project IOTs for non-benchmark years. Temurshoev et al. (2011) provide an overview and asses the performance of various projection methods. They find that (G)RAS gives one of the most reliable projections of the data. We use the iterative algorithm of (G)RAS proposed by Lenzen et al. (2007). Basically, the G-RAS procedure requires a benchmark input-output table and row and columns sums for all years for which we would like to estimate IOTs. (G)RAS estimates new IO matrices for all years as close as possible to the benchmark table under the external constraints of the row and column sums.

Yearly data on domestic and imported intermediate consumption reported at the subsectoral level (as described in section 4.3) for maquila and domestic firms will act as our external constraint of the row and column sums as required by the (G) RAS procedure. Additional yearly official information on gross output, final demand, gross value added reported at the sub-sectoral level (also described in section 4.3) will be used to fill the vector cells required in table 4.2

While the (G)RAS approach allows us to project IOTs for non-benchmark years, an important limitation that we face is the absence of benchmark tables for earlier years. Our approach takes into account differences in the overall structure of the maquila and domestic industries, but if intermediates sourcing structures change substantially over time, these changes are not necessarily well accounted for. Temurshoev et al. (2011) asses the bias in projecting supply and use tables (the building blocks for IOTs) for Spain 
and the Netherlands. That is, they project a table to a particular year, say 2000 and compare the projected table with the officially published table from 2000. A five-year projection of the use table (projecting for 2000 using a 1995 benchmark table) results on average in about a 9 percent margin of error for any particular element in the use table. ${ }^{18} \mathrm{~A}$ ten-year projection of the use table gives an almost 18 percent margin of error, almost twice as large. If this carries over to our context, our projection for the earliest year in our sample - 1981 - based on the 2003 benchmark table may have a 40 percent margin of error. This is a substantial error margin and it might be even larger in our projections considering the more volatile development path in Mexico compared to Spain and the Netherlands on which the estimates by Temurshoev et al. (2011) are based. It is a serious limitation of the analysis presented here, and we will get back to this when discussing the results, in particular for the early 1980s. However, our approach is not uncommon in the literature. See e.g. Johnson and Noguera (2014) who estimate global input-output tables backwards for four decades. Also, one reason why we presented measures of upgrading such as productivity growth rates and the share of non-production workers in section 4.3 was to back up our key finding, namely that the domestic content of maquiladora exports has been in a long term decline. In addition, in the next section we seek to relate several sector-specific findings to sector-specific policies to be more certain that we are capturing something real and not just measurement error.

\subsection{The Domestic Content of Maquila Exports}

In this section we describe the evolution of Mexico's value added share in maquila exports for the period from 1981 to 2006. In section 5.1 we document aggregate and industry trends. Subsequently we examine whether changes in the aggregate trend are driven by changes within industries or by changes in the industry composition in section 5.2.

\subsubsection{The Domestic Content of Maquila Exports: Aggregate and Industry Trends}

The share of domestic content in aggregate exports is shown in figure 4.2. We use the extended input-output tables and equation (4.1) to calculate domestic content for the period from 1981 to 2006. The figure reports the total domestic content, which incorporates indirect effects, because for the production of domestic intermediates also imported inputs are used. In 1981, the domestic content share in Mexico's maquila exports is about 31 percent. In 2006 this share has fallen to about 21 percent. Even if we ignore the turbulent early 1980s, our findings suggest that the domestic content was between 25 and 20 percent. This suggests the domestic content of maquila exports has declined substantially.

Buitelaar and Perez (2000) use detailed firm-level studies to explain why local firms supply so few inputs to maquiladoras. They argue that part of the low domestic content embodied in maquila exports relates to the regulatory environment that did not

\footnotetext{
18 This is based on a weighted absolute percentage error, which weights each percentage deviation of a cell element in the use table from the true element by the relative size of the corresponding true element in the overall sum of the actual elements. We discuss the weighted absolute percentage error for its simplicity in interpretation but note that a more sophisticated measure, the psi statistic, produces essentially the same results.
} 
stimulate the development of a local supplier network until the increasing outward orientation in the late 1980s. Other factors are at work that relate to persistent low domestic content, even after the policy changes that started to stimulate local sourcing. These other factors include transnational corporate strategies that do not consider local procurement to be important, and U.S. import tariffs on Mexican intermediates embodied in maquila exports. Supply side constraints also affect the domestic content of exports. For example, local firms have to pass very strict and time-consuming processes of certification and quality control before they can provide multi-national firms with inputs, which appears in particular an obstacle to potential suppliers to electronics maquiladoras. In addition, the quality and technology of inputs demanded by maquiladoras is typically quite high and often subject to change. Maquiladoras demand low prices for their inputs, and they demand predictable delivery times.

The domestic content varied substantially over time. In particular, the 1982 debt crisis and the 1994 Tequila crisis coincide with a substantial drop in domestic value added embodied in maquila output. ${ }^{19}$ After the 1982 debt crisis there does not seem to be a recovery, but after the 1994 crisis the domestic content recovered to levels observed before the crisis. The increasing value added content during the second half of the 1990s is consistent with case study findings presented by Buitelaar and Perez (2000). Indeed, the abolition of U.S. duties on Mexican intermediate inputs with the 1994 NAFTA agreements might have had a positive effect on domestic sourcing by maquiladoras, although the 1985 GATT agreement appears unrelated to a substantial change in domestic value added. After 2001 we observe that the domestic content share decreases again. These results suggest that aggregate patterns appear mainly related to internal and external shocks, such as the 1982 and 1994 crisis, and not so much to changes in the regulatory environment.

In table 4.3 we further explore the domestic content of exports at the industry level. These results are obtained by replacing the export vector $\mathbf{e}^{\mathrm{P}}$ in equation (4.1) by a diagonal matrix with the vector $\mathbf{e}^{\mathrm{P}}$ on the main diagonal. The findings suggest that the domestic content differs substantially across sectors. In particular, the domestic content is low in electronics manufacturing (14 percent in 2006) as compared to textiles manufacturing (31 percent). The findings tend to suggest that the domestic content is lower in technology-intensive sectors. ${ }^{20}$

\footnotetext{
19 These findings seem at odds with currency devaluation, which one would expect to result in a decrease of imported intermediates. However, other effects may dominate. For example, credit constraints or increased uncertainty may affect domestic sources, and changes in industry composition of exports may also affect these outcomes. If industries with lower domestic value added content expand, the overall effect is a decrease in domestic content of aggregate maquila exports, further discussed in section 4.5.2. ${ }^{20}$ de la Cruz et al. $(2011,2013)$ find similar differences across sectors.
} 
Figure (4. 2): The Domestic Content of Aggregate Maquila Exports.

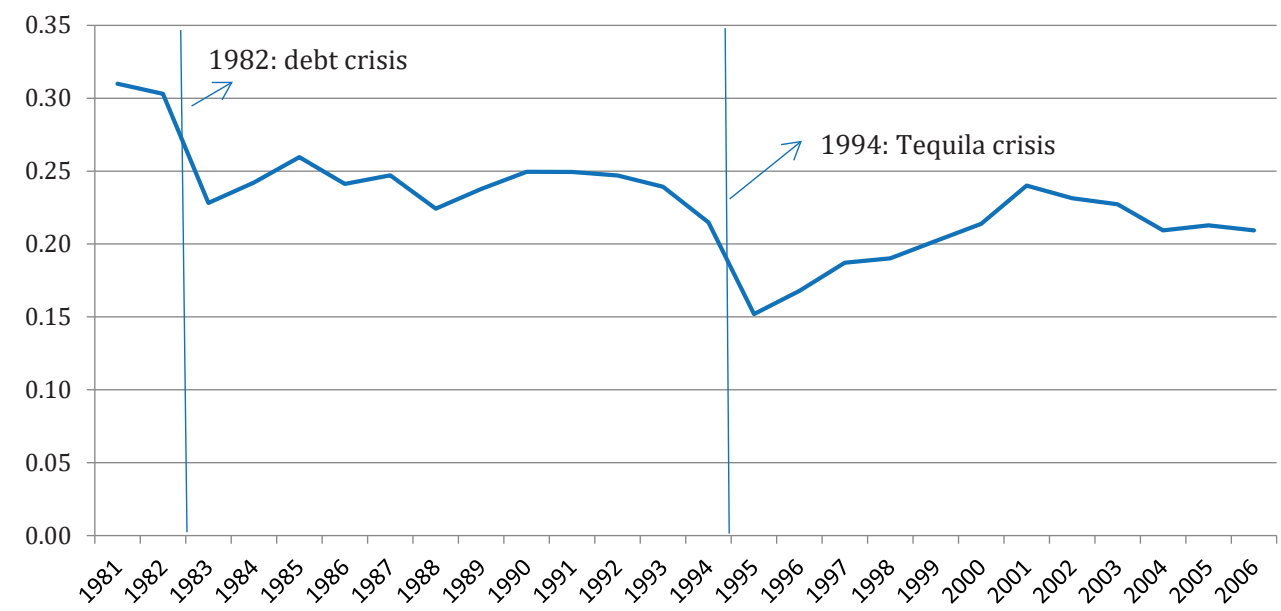

Notes: Domestic content as a share in aggregate maquila exports.

Source: Author's calculations using time series estimates and equation (4.1).

Table (4. 3): Domestic Content of Maquila Exports, Industry Results.

\begin{tabular}{lcccc}
\hline & 1981 & 1990 & 2000 & 2006 \\
\hline Food, Beverages and Tobacco & 0.27 & 0.64 & 0.62 & 0.44 \\
Textiles and Textile Products & 0.28 & 0.27 & 0.31 & 0.31 \\
Leather, Leather and Footwear & 0.44 & 0.38 & 0.27 & 0.28 \\
Pulp, Paper, Printing and Publishing & 0.56 & 0.28 & 0.36 & 0.31 \\
Chemicals and Chemical Products & - & 0.47 & 0.43 & 0.46 \\
Rubber and Plastics & 0.37 & 0.37 & 0.36 & 0.35 \\
Other Non-Metallic Minerals & 0.48 & 0.44 & 0.33 & 0.18 \\
Basic Metals and Fabricated Metal & 0.31 & 0.27 & 0.31 & 0.30 \\
Machinery & 0.37 & 0.26 & 0.25 & 0.26 \\
Electronics & 0.25 & 0.20 & 0.16 & 0.14 \\
Transport Equipment & 0.33 & 0.27 & 0.21 & 0.27 \\
Miscellaneous manufacturing & 0.35 & 0.28 & 0.24 & 0.25 \\
Business services & 0.91 & 0.52 & 0.42 & 0.41 \\
\hline
\end{tabular}

Notes: author's calculations using time series estimates and equation (4.1) where $\mathbf{e}^{\mathrm{P}}$ is put on the main diagonal of a matrix of equal dimension as the number of industries.

The time series results from 1981 to 2006 suggest that in some industries the domestic content was relatively stable, for example in textiles at about 30 percent. However, in most industries the share fell, even if we ignore the results for the early 1980s, although the decline then becomes less pronounced. For example, in the non-metallic minerals sector, the domestic content declined substantially from 48\% in 1981 to 18\% in 2006 . This sector experienced a considerable change in its sourcing pattern, in particular after the implementation of NAFTA, which removed tariff imports of glass, gypsum, and cement. The domestic content of leather and footwear maquila manufacturing declined 
during the 1990s. It came after the opening up of the market in 1988, when tariffs on imports were cut and all import licenses were eliminated. Mexican shoe manufacturers were initially ill-equipped to compete with imports on price, quality and fashion content (Rabellotti, 1999). It also brought more pressures to domestic suppliers in the footwear industry since there were great difficulties in the supply of raw materials and particularly in the supply of bovine leather (Ortiz and Martinez, 2000). Thus, many producers substituted domestic supplies with cheaper and higher quality imported supplies (Woodruff, 1998).

The pulp, paper, printing and publishing sector experienced a gradual decline in domestic content after 2000. Here Mexican firms face stiff competition from forestry firms in Canada and the United States who leverage their technology and scale of production to supply forestry products of high quality and low price. The biggest change for machinery manufacturing appears to have happened in the 1980s. In its "Plan Nacional de Desarrollo Industrial: 1979-1982" the government started to promote the production of capital goods. The government was expected to purchase $40 \%$ from the total production of machinery and equipment. Furthermore, the domestic production of machinery and equipment was to be purchased by the government with a price $15 \%$ higher than the one established by the market. The government also offered to pay the transportation costs. Following the same stream of ideas, the government also offered fiscal credits (25\% for new investments) and preferential prices for electricity, fuel oil, natural gas, and basic petrochemical goods (Bancomext, 1979). Nonetheless, the government decided to stop this whole program due to the debt crisis faced by Mexico in 1982. After that, imports of machinery products became increasingly important. In business services the domestic content also fell, especially during the 1990s from $52 \%$ in 1990 to $42 \%$ in 2000 . The maquiladora business services sector mainly consists of the provision of specific services to maquiladoras such as renting of industrial units, transportation, customs tariff advice, legal advice, services for the hiring and provision of labor and they supply services aimed at facilitating maquiladora exports. A Maquiladora decree in 1989 (and a follow up in 1998) gave services firms much more freedom in importing equipment and other inputs free of duty (González-Aréchiga et al. 1991, which might be related to the drop in domestic content after 1990.

The food sector experienced an increase in domestic content during the 1980s and a decline after the 1990s. Initially, in the early 1980s, the food sector was characterized by a high level of foreign content. Most of the multinationals in the food industry were of US origin. These firms used abundant and cheap agricultural products from the US, such as wheat, soy, sorghum and milk, because they were highly subsidized by the US government. In contrast the multinational firms did not process much of Mexico's main food staples such as corn, beans, and rice (Rama, 1984). In order to increase the domestic content in the food industry, the Mexican government imposed several restrictions on agricultural imports when the GATT was signed (GATT, 1986). Amongst others, these import restrictions included a $45 \%$ tariff on imports of condensed milk, $50 \%$ on butter, $10 \%$ on sorghum, $40 \%$ on corn, wheat, soy, beer, wine (GATT, 1986). Our findings suggest that these restrictions are related to an increase in domestic content during the 1980s, suggesting a switch to more domestic inputs following the GATT 
provisions. However, in line with the implementation of NAFTA, the restrictions for the imports of sorghum were removed in 1994, those for wheat, milk and soy in 2003 and those for corn in 2008 (Schwentesius Rindermann and Gómez-Cruz, 2001). The maquiladora decree of 2002 also allowed tariff exemptions on the imports from milk (powder), eggs, corn (powder), and sugar. After 1990 we again observe a decline in the domestic content of the food industry.

For the largest maquiladora sector, 'maquiladora electrónica' or electronics maquiladoras, we also find a decline in the domestic content, from 25 percent in 1981 to 14 percent in 2006. During the 1980s, as electronic production expanded, more complex technologies were introduced such as microelectronic machinery (Brown and Dominguez, 1989). These technologies were intended to better control the productive process and reduce labor costs. Besides reducing on direct labor inputs, local suppliers also faced difficulties in expanding their supply of intermediates. For example, local suppliers experienced difficulties in obtaining quality certificates; had continuous changes in the design of electronic products; and faced formidable foreign competition. In 2001, a critical year for the electronic industry with the dot.com crisis in the US and the entry of China to the WTO, the Mexican government unilaterally implemented the 'Information Technology Agreement (ITA)' (Olliver-Fiero, 2007). The ITA eliminated tariffs on electronics imported into Mexico, including tariffs on subassemblies and raw materials used for electronics production. These policies helped to strengthen the position of maquiladora producers in the electronics industry, but they did not promote the production of subassemblies and components by Mexican firms. Most inputs provided by local suppliers are those used in the last stage of manufacturing production, such as corrugated fiberboard, accessories for metal casting, instruction manuals, wooden pallets, polyethylene, foam, uniforms, packaging and so forth (Carrillo and Zarate-Cornejo 2003).

\subsubsection{The Domestic Content of Maquila Exports: a Disaggregation Analysis}

To disaggregate the aggregate change in domestic export content, we apply a 'within' and 'between' analysis, which can be written in the current context as follows

$$
D C E_{t+1}-D C E_{t}=\sum_{i}\left(\left(\left(D C E_{i, t+1}-D C E_{i, t}\right)\left(\frac{\omega_{i, t+1}+\omega_{i, t}}{2}\right)\right)+\left(\left(\omega_{i, t+1}-\omega_{i, t}\right)\left(\frac{D C E_{i, t+1}+D C E_{i, t}}{2}\right)\right)\right),(4
$$

where $\mathrm{DCE}_{\mathrm{i}, \mathrm{t}}$ is the domestic content of exports by industry $i$ in year $t$, and $\omega_{i, t}$ is industry $i$ 's share in total exports at time $t$. The industry contribution in equation (4.2) is split into two terms. The first term gives the industry contribution due to changes in the industry level DCE share (within), and the second term gives the contribution due to changes in the industry-level export share (between).

The results from this decomposition are given in table 4.4 for the period from 1981 to 2006. Contribution from the three most important maquila sectors (based on export shares) are shown, namely textiles and textile products, electronics, and transport equipment. The other sectors are grouped. The decomposition suggests that 
changes in the aggregate domestic content are mainly accounted for by changes within industries. The substantial drop in the domestic content of electronics manufacturing accounts for almost two thirds of the aggregate change in domestic content.

Table (4. 4): Sources of Change in Domestic Value Added of Maquila Exports, 1981 to 2006

\begin{tabular}{|c|c|c|c|c|c|}
\hline & \multicolumn{2}{|c|}{$\begin{array}{l}\text { Share of domestic content } \\
\text { in exports }\end{array}$} & \multicolumn{3}{|c|}{ Contribution of (in percent): } \\
\hline & 1981 & 2006 & $\begin{array}{l}\text { Change in } \\
\text { industry } \\
\text { DCE } \\
\text { intensity }\end{array}$ & $\begin{array}{l}\text { Change in } \\
\text { industry } \\
\text { share in } \\
\text { overall } \\
\text { exports }\end{array}$ & Total \\
\hline Total maquiladora & 0.31 & 0.21 & & & \\
\hline Textiles and Textile Products & 0.28 & 0.31 & -2.6 & 23.8 & \\
\hline Electronics & 0.25 & 0.14 & 61.7 & 4.4 & \\
\hline Transport Equipment & 0.33 & 0.27 & 8.0 & -17.1 & \\
\hline \multirow[t]{2}{*}{ Other } & & & 27.7 & -6.0 & \\
\hline & & & 94.8 & 5.2 & 100 \\
\hline
\end{tabular}

Notes: author's calculations using equation (4.2).

The dominance of within-industry effects is confirmed from decompositions using different time periods. In table 4.5 we do the same decomposition, but for the period from 2001 to 2006. This period coincides with the demise of textile maquiladora activities due to the strong competition from China after its entry to the WTO in 2001 and the end of the Multi-Fibre Arrangements in 2004 (Utar, 2013). The effect of the shrinking share of textile manufacturing output (it fell from 13 percent in 2001 to 7 percent of gross output in 2006) is clearly borne out by the decomposition results. About half of the fall in the domestic content between 2001 and 2006 is accounted for by textile manufacturing. Interestingly, changes within industry still explain most of the change in the domestic content of exports. The 'within' explanation of changes in the aggregate content is the dominant explanation, also if we consider different time periods. Again, electronic manufacturing accounts for the majority of the withinindustry decline in the domestic content of exports. 
Table (4. 5): Sources of Change in Domestic Value Added of Maquila Exports, 2001 to 2006.

\begin{tabular}{|c|c|c|c|c|c|}
\hline & \multicolumn{2}{|c|}{$\begin{array}{l}\text { Share of domestic content } \\
\text { in exports }\end{array}$} & \multicolumn{3}{|c|}{ Contribution of (in percent): } \\
\hline & 2001 & 2006 & $\begin{array}{l}\text { Change in } \\
\text { industry DCE } \\
\text { intensity }\end{array}$ & $\begin{array}{l}\text { Change in } \\
\text { industry } \\
\text { share in } \\
\text { overall } \\
\text { exports }\end{array}$ & Total \\
\hline Total maquiladora & 0.24 & 0.21 & & & \\
\hline Textiles and Textile Products & 0.35 & 0.31 & 13.2 & 51.3 & \\
\hline Electronics & 0.18 & 0.14 & 68.7 & -8.2 & \\
\hline Transport Equipment & 0.24 & 0.27 & -18.9 & -3.3 & \\
\hline \multirow[t]{2}{*}{ Other } & & & 26.6 & -29.4 & \\
\hline & & & 89.6 & 10.4 & 100 \\
\hline
\end{tabular}

Notes: author's calculations using equation (4.2).

\subsection{Concluding Remarks.}

This chapter studied the domestic content of maquila industries. It took a long-run macro perspective in order to relate changes in industrial policies to changes in the domestic content of maquila exports. Initially the government viewed maquiladoras as mere providers of jobs. This view and subsequent industrial policies shifted with the increasing outward orientation of Mexico in the late 1980s. We combined a recently released input-output table for maquiladora industries with detailed longitudinal data on output and inputs to study whether observed patterns are related to changes in industrial policy. We find substantial differences in the domestic value added content of exports across industries and over time. The domestic content is typically higher in labor-intensive goods manufacturers, such as textiles, compared to more capitalintensive industries such as transport and electronic goods manufacturing. Over time, productivity and the share of skilled workers in maquiladoras improved only modestly. A long-run decline in aggregate domestic value added embodied in maquila exports, from 31 percent in 1981 to 20 percent in 2006, is largely accounted for by the falling domestic content in electrical machinery product manufacturing. Overall, our findings suggest that even if industrial policies had their intended effects for specific sectors at specific moments in time, these effects are not observed in the aggregate as the domestic content fell.

This paper is the first to study long-term trends in the domestic content of Mexico's maquila exports. So far, most analysis of domestic content and technology upgrading within maquiladoras are limited to case studies. We provide a macro perspective to these case studies. A clear limitation in this approach is that we are unable to causally link industrial policy to the domestic content of exports. Typically, detailed micro studies are better able to isolate effects of particular policies. However, our findings show the overall picture, which suggests that even if some detailed micro studies may find that industry-specific policies have been successful (Jordaan, 2011), overall these policies are not visible as productivity levels and the use of skilled workers in maquila 
industries hardly improved. Also, we do not find a systematic tendency of increased domestic sourcing of inputs.

This carries important implications for other developing countries that try to start a process of technological upgrading after entering global value chains via final assembly activities.

Various policy measures might be considered to increase the local content of maquiladoras production. We discuss some here, but refer the interested reader to Brannon et al. (1994) and Verhoogen (2012) for further discussion. In particular, the government might seek to strengthen engineering and design capacities by means of active education and technology acquisition policies. Typically these high-skilled activities generate much higher value added compared to the provision of standard inputs such as boxes and packaging materials. Also, the Mexican government might stimulate decentralized decision making at maquiladora establishments and engaging them with local suppliers. If maquiladoras source inputs locally, they have a strong incentive to improve the quality of these goods sourced, which stimulates productivity growth of suppliers (Brannon et al., 1994). Also, government officials might actively encourage joint ventures to increase technology spillovers. Although our analysis is for Mexico's maquiladoras, we belief the analysis presented here has wider appeal. In particular the analysis has wider relevance for other developing countries that are characterized by low domestic value added content of exports as our analysis seeks to relate industrial policies to changes in the domestic content of exports. Many other Central-American countries, but also developing Asian and African countries have export processing firms and low domestic content (Koopman et al. 2014). Which nations and firms have been successful and why? Future research may seek to extent this type of long-term analysis of industrial upgrading to other developing countries to get a tighter grip on policies that kick start technological upgrading. 


\title{
Chapter 5.
}

\section{Mexican Manufacturing and its Integration into Global Value Chains ${ }^{\dagger}, * *$}

\begin{abstract}
This paper studies the value added contributions to final manufacturing output produced in Mexico. It distinguishes between contributions originating from foreign producers located in different major regions of the world economy and contributions made by domestic producers. The analysis is performed for the main two components of Mexican manufacturing: assembly plants producing for export markets (Maquiladora industry) and manufacturing firms mainly producing for the domestic market (Domestic Manufacturing). To this end, Mexico (Maquiladora) and Mexico (Domestic Manufacturing) are separately included into World Input-output Tables (WIOT) from 1998 to 2011. The empirical analysis shows that the structure of value added contributions with regard to the final output of the Mexican domestic sector has remained unaltered, while the structure of value added contributions to the final output of the Maquiladora sector has drastically changed over time.

For its own final output, Mexico (Domestic) has the largest share of value added contributions with some increase in the value added contributions of producers in foreign countries (notably, the USA). With regard to the final output of Mexico (Maquiladora) there was a shift from a dominance of US value added in all the manufacturing sectors (70\% in 1998) to a much more diversified structure of value added contributions. By 2011, the East Asian share in value added was the largest in the Electrical and Optical equipment sector. Mexico (Domestic Manufacturing) and Mexico (Maquiladora) had the largest value added contributions in the Transport Equipment sector, while the US continued to account for the lion's share of value added in the textile industry.

In my view, those changes in the structure of value added contributions have to do with decisions by US firms to reallocate production to low-cost countries in Asia. They reflect changing patterns of the integration of Mexico in global value chains.
\end{abstract}

JEL Codes: C67, L6. F2

Keywords: Global Value Chains, Export processing, World Input-output Tables, Manufacturing, Mexico

†This chapter has been co-authored with Adam Szirmai (UNU-MERIT) and is based on Castillo, J.C. and A. Szirmai (2016), "Mexican Manufacturing and its Integration into Global Value Chains", UNIDO-Inclusive and Sustainable Development Working Paper Series, WP 3/2016.

** The authors gratefully acknowledge financial support from UNIDO for the PhD project of Juan Carlos Castillo (UNIDO Specialization on Structural Change and Industrialization). We thank Bart Verspagen for advice, comments and criticisms. Comments and discussion based on the International Input-Output Conference 2015 and, research seminars at UNIDO and the Faculty of Economics from the National Autonomous University of Mexico. 


\subsection{Introduction}

In the last two decades, Mexico's manufacturing production has increased substantially. According to De La Cruz et al. (2011), Mexico's international trade (exports plus imports of goods) grew from $\$ 82.3$ billion in 1990 to $\$ 553.8$ billion in 2007 , representing $56 \%$ of the GDP during that same year. Moreover, this remarkable performance is further confirmed by the current position of Mexican manufacturing. According to the Mexican Ministry of Economic Affairs, by 2014 Mexico was producing more manufacturing goods than all other Latin American countries put together; it is the World's largest provider of flat screen televisions and the largest recipient of FDI in the Aerospace sector (Secretaría de Economía, 2016).

Assessing the domestic and foreign value added content of Mexican manufacturing production has been a major concern of scholars. However, they have reached very different conclusions depending on the different components of Mexican industry that they studied. For instance, when considering the production from the whole universe of manufacturing firms in Mexico, the conclusion has been that domestic value added content is substantially higher than the foreign one. According to the Trade in Value Added initiative (OECD-WTO, 2015) Mexico's domestic value added content of its exports in 2011 was $70 \%$ and had remained relatively stable since the 2000 's. A similar conclusion is reached when the manufacturing firms that produce both for the domestic and for the foreign market (i.e. the Domestic economy of Mexico) are analyzed. According to the estimates of De La Cruz et al. (2011) and Koopman et al. (2014), the domestic share of value added content in the exports of Mexico-Domestic is more than $70 \%$ in 2004 . On the other hand, when analyzing the firms that solely produce for the foreign market (Maquiladora industry) very different conclusions are reached. In this case, it is found that the firms in the Maquiladora sector have been unable to steadily increase the domestic value added content of their exports (less than $25 \%$ of total value added content) (De La Cruz et al., 2011; Koopman et al.,2014; Castillo and De Vries, 2018).

This research studies the value added trends observed in the final output produced by Maquiladora and by the Domestic economy of Mexico in a single unified framework. It is the Global Value Chain perspective that provides such a unified framework. This means that we will quantify the value added contributions from domestic and foreign producers (by country of origin) that participate in the production for exports (Maquiladora), as well as the value added contribution in the production that supplies both domestic and foreign markets (Domestic Economy of Mexico). We examine two main research questions:

(1) Which regions and countries capture most of the value added embodied in Mexico's final output as a result of the increasing globalization of production?;

(2) To what extent does Mexico itself benefit from such final output?

With regard to the first research question, our aim is to understand to what extent foreign producers in major regions (US/Canada, East Asia and Europe) interact with each component from the Mexican manufacturing production (Domestic Economy and 
Maquiladora), as well as the extent to which such regional interaction within each manufacturing component drives the foreign value added content for the total manufacturing production in Mexico. With regard to the second research question we want to analyze how local producers in the Maquiladora and in the Domestic Economy of Mexico interact in order to produce their own manufacturing goods and the extent to which their own value added content drives the results for the total domestic value added content in the total manufacturing production of Mexico.

In order to meet those objectives, we have constructed a novel data set where the Maquiladora and the Domestic Economy of Mexico are included into the World Inputoutput Tables (WIOT) from 1998 to 2011. With help of such tables, and by implementing a new measure of fragmentation that is extended to a multi-country setting (Los et al., 2013), our research will show that each component of Mexican manufacturing production has had a different pattern of integration into Global Value Chains.

On the one hand, the value chains of manufacturing production in the Domestic Economy of Mexico are still predominantly local and regional. Such production only experienced minor changes in terms of the local/ regional value added content embodied on its final output. Between 1998 and 2011, local producers in the Domestic economy of Mexico accounted for the largest value added share $(74 \%$ of the value added content of total final output in 2011), while there were only minor increases in the share of firms from US/Canada and East Asia in the value added content of final output (16\% and $3 \%$ respectively by 2011). This pattern where local producers in the Domestic Economy of Mexico have the largest share in the value added content embodied on its own final manufacturing output was observed in every single manufacturing sector with very few changes over time.

On the other hand, value chains in the Maquiladora sector are both regional and global. Over time, Maquiladora presents major changes on its country/ regional value added content. The US/Canada share in value added content embodied in the total maquiladora final output dramatically decreased from 68\% in 1998 to 29\% in 2011. During the same period, the corresponding East Asian and Mexican value added in final maquiladora output increased from $6 \%$ to $23 \%$ and from $20 \%$ to $33 \%$, respectively. This trend, however, shows substantial variation across key maquiladora manufacturing sectors. While US/Canada had the largest share of value added content in every single manufacturing sector in 1998, by 2011 East Asia had the largest share in Electronic Equipment (40\%), and local Mexican producers had the largest share in Transport Equipment (49\%) and US/Canada in Textiles and Textile products (39\%).

Thus, on the basis of the empirical evidence, our research reaches four major conclusions.

First of all, we identify a decline in the dependence of Maquiladora production on US inputs. This decline is counterbalanced by an increasing use of East Asian inputs (mostly sourced from China). 
Second, we provide new empirical evidence for the debate between regionalization and globalization of the sourcing of inputs for manufacturing production. ${ }^{21}$ Much current research argues that global value chains in manufacturing is still primarily operate at the local and regional level despite dramatic decreases in transport and communication costs. Our research, on the other hand, indicates that countries with maquiladora-like production (export processing zones) can experience both regionalization and globalization of manufacturing production ${ }^{22}$. The relative importance of localization, regionalization or globalization of manufacturing will depend on certain conditions related to the type of final good being produced (its modularity), trade and policy incentives, the competitive advantages offered by the country and so forth.

The third finding is the complex scenario that policy makers face nowadays, if they wish to increase the use of domestic inputs in the context of global value chains. Our results for the automotive industry in maquiladora production indicate that incentives provided under industrial policies and trade agreements (such as NAFTA) are not sufficient to increase the use of domestic inputs. Maquiladora production in this particular manufacturing sector further required bilateral industrial cooperation between the governments of Mexico and the United States. This bilateral cooperation, effectively combined with Mexican tax incentives and NAFTA benefits, seems to have been the key factor behind the increasing domestic value added content in the transport sector.

The last finding from our research is the relative contribution of domestic inputs in creating value added in the domestic sector and in the Maquiladora. Our research indicates that over time the domestic sector has had much stronger domestic linkages than Maquiladora. Moreover, we show that the aggregate trends in domestic value added content for the whole universe of producers in Mexico is largely driven by the producers in the Domestic economy of Mexico. Therefore, the role of maquiladora production in inducing a higher use of domestic inputs remains limited.

This chapter is structured as follows. Section 5.2 describes the main characteristics in the production of Maquiladora and in the Domestic Economy of Mexico, as well as some considerations about the key features of manufacturing production in Mexico. Moreover, this section describes the new concept of "Manufactura Global". This concept, introduced by the Mexican statistical office, represents the new official statistical tool to study maquiladora-like production within the national accounting system from Mexico. Section 5.3 describes our methods. Section 5.4 presents our data construction strategy to divide Mexico (as presented by WIOD) into Mexico (Maquiladora/Manufactura Global) and Mexico (Domestic Economy) from 1998 to 2011. Section 5.5 presents our data requirements. Section 5.6 introduces information with regard to sectoral gross output shares and sources of intermediate inputs (by country and region of origin). Section 5.7 presents our main empirical results. Finally, section 5.8 provides conclusions and some ideas about the future of manufacturing in Mexico.

\footnotetext{
${ }^{21}$ Regionalization refers to the sourcing of inputs from Mexico's NAFTA neighbors Canada and the USA. Globalization refers to the sourcing of inputs from Asia. Local value chains refer to the sourcing of inputs within the domestic economy of Mexico.

22 Globalization of manufacturing production should be understood as the increasing participation of countries outside the region in the final output produced by a given country.
} 


\subsection{An Overview of Mexican Manufacturing}

The firms in the Mexican manufacturing industry can be classified into two categories. On the one hand, there are the manufacturing firms that participate in Mexico's export promoting program. Here, we observe firms that participate in the maquiladora program (that export their entire production to foreign markets) and, as of 2007, firms that participate in the IMMEX program (which include maquiladora plants and, a broader set of firms that produce both for domestic and foreign markets. The second category are all those firms that do not participate in the previously mentioned export promoting programs and that also produced for domestic and foreign markets (i.e. the domestic manufacturing of Mexico). In the forthcoming paragraphs, we discuss each of these categories in more detail.

\subsubsection{Export Promoting Programs and the Production for Global Production Networks.}

The Maquila industry, officially known as "Industria Maquiladora de Exportación", mainly consists of foreign firms located in the North of Mexico close to the border with the United States. The Maquiladora export promoting program allows for the temporary imports of intermediate imports (and of capital goods) for the production of manufacturing goods in Mexico. Provided that such production is exported, Maquiladora firms receive significant tariff incentives. Those tariff incentives include exemptions from general import taxes, value added taxes and countervailing duties, when applicable. Most of the intermediate inputs used by the Maquila industry come from the United States (though progressively more from East Asia), and its entire final output is exported, mainly to the United States.

According to official statistics, Maquiladora firms do not produce any intermediate goods. The domestic intermediate goods used by the Maquiladora are completely sourced by local manufacturing producers in the rest of the economy (i.e. local producers in the Domestic Economy of Mexico). Historically, and as described in chapter 2 , the Mexican government has made some attempts to promote increasing domestic sourcing of intermediate inputs from local producers by Maquiladora firms. These attempts include programs for the development of domestic suppliers, support for research and development activities (Durán, 2005) and, more recently, the establishment of meetings between maquiladora producers and domestic suppliers in order to negotiate input sales. Nevertheless, as documented in chapter 4 of this dissertation, the Maquiladora industry has not increased its domestic intermediate consumption over time. Furthermore, chapter 4 documented a long-run decline in the domestic value added content of maquiladora exports (from 30\% in 1981 to $20 \%$ in 2006), which appears mainly related to external and internal shocks to the Mexican economy (debt crisis, signing of NAFTA, industrial emergence of China) rather than changes in the regulatory environment.

The maquiladora firms do not have much incentive to increase domestic sourcing of intermediate inputs. The reasons for this, however, are not limited to the tariff exemptions provided on the imports of intermediate goods. Other reasons include the high standards imposed by Maquiladora firms on domestic producers. For example, domestic producers have to meet very strict and time-consuming processes of 
certification and quality control before they can supply inputs to multi-national firms in the Maquiladora sector. In addition, the quality and technology of inputs demanded by maquiladoras is typically quite high and often subject to change.

Given the success of the Maquiladora program in increasing the size and export orientation of Mexican manufacturing ${ }^{23}$, the Mexican government has implemented similar other export promoting programs. As discussed in chapter 2, by 1985, the "Programas de Importación Temporal para Producir Articulos de Exportación" (PITEX) came into effect with the intention of permitting firms to import intermediate inputs and machinery free of duty as long as $30 \%$ of their total sales were exported. The difference between the PITEX and the maquiladora program lies in the fact that under the latter program firms were exempted from taxes to an even higher degree. Similarly, unlike maquiladoras, PITEX firms were mainly located in the interior of Mexico, as most of their production was destined for domestic consumption (De la Cruz et al., 2011).

In 2007, the "Manufacturing, Maquila and Export Service Industry" (IMMEX) program was implemented. This program combined Maquiladora and PITEX firms into a single export promoting program. Acknowledging new ways to organize manufacturing production, the IMMEX framework also allowed for the creation of new types of export promoting firms that were different to the concept of Maquiladora and PITEX firms (IMMEX Controladora and IMMEX Terciarizacion according to chapter 2). The main idea behind the IMMEX program was to integrate in a single framework all the manufacturing firms in Mexico that together represent $85 \%$ of the country's final manufacturing exports ${ }^{24}$ (Secretaría de Economía, 2010). Likewise, this program aimed at simplifying tariff procedures for Maquila and PITEX firms that were to be exempted from the payment of general import tax, value added tax and, where appropriate, countervailing duties.

Acknowledging the increasing opportunities for participation of manufacturing firms in global value chains, in 2014 the Mexican Statistical Office (INEGI) released a new statistical tool named "Manufactura Global". This new statistical was designed to coexist with the information provided for the IMMEX program and with the old data for Maquiladora firms. The main objective behind the concept of Manufactura Global was to more thoroughly measure the participation of Mexican manufacturing firms in global production networks. To that end, INEGI identifies from the whole universe of manufacturing firms located in Mexico those that were highly engaged in global production networks. Conceptually, those Mexican firms highly engaged in global production networks are the ones that meet one of the following three criteria: (1) their production should be for exports and most of their intermediate goods should be

\footnotetext{
23 The Maquiladora Program was initially set up during the 1960s as an emergency program to cope with rising unemployment in North Mexico. It only started to boom during the late 1980s with the increasing outward orientation of the Mexican economy.

${ }^{24}$ According to chapter 2 of this dissertation, in order to receive benefits from the IMMEX program, manufacturing firms are required to report annual sales of more than US\$500,000 dollars or to export at least $10 \%$ of their total final output. Therefore, the remaining 15\% of Mexico's total manufacturing exports might include firms that do not meet this sales criterion, that are not registered as IMMEX firms and that solely benefit from other incentives (trade benefits under NAFTA, competitive advantages from Mexico, etc.).
} 
imported (a ratio of at least $2 / 3$ of their imported intermediate goods with respect to their exports); (2) they should be mostly foreign owned or, (3) produce intermediate goods that are exported for the production of other global production networks not located in Mexico. If a manufacturing firm meets one these criteria, it is classified then as Manufactura Global. As can be seen, this concept takes into account both firms that import a significant amount of intermediate inputs, to re-export them back as final goods, as well as firms that export domestically produced intermediate goods for other manufacturing firms not located in Mexico.

By definition, firms under the concept of Manufactura Global include IMMEX firms (maquiladora and PITEX), as well as manufacturing firms not belonging to IMMEX but located in the domestic economy of Mexico and that meet the aforementioned criteria of being highly engaged in global production networks. According to the first estimates provided by INEGI (2014), the gross production from Manufactura Global represented $25.8 \%$ of the total manufacturing production in Mexico by 2012. This means that $1 / 4$ of the total production in Mexico participates in global production networks by either assembling/transforming domestic and foreign intermediate inputs and/or exporting final and intermediate goods.

\subsubsection{The Domestic Economy of Mexico}

As can be seen, the rest of manufacturing firms in Mexico that do not belong to the IMMEX program or that are not highly engaged in global production networks can be regarded as firms under the domestic economy of Mexico. The manufacturing firms under the Domestic economy of Mexico produce both for the foreign and the domestic market but most of their production is oriented to the Mexican market. According to the latest estimates, by 2012 the Domestic Economy of Mexico accounted for $74 \%$ of the total manufacturing production in Mexico and for $29 \%$ of the total manufacturing exports. In the same year, producers in the domestic economy accounted for $90 \%$ of total domestic intermediate goods in Mexico and 45\% of the total supply of imported intermediate inputs (INEGI, 2014)

Data for the manufacturing firms under the domestic economy can be found in the monthly industrial survey (Encuesta Industrial Mensual) from INEGI and, as of 2014, they can be also found under the concept of "Rest of Manufacturing Production" in Mexico or "Manufactura No Global” (INEGI, 2014).

\subsubsection{Competitive Advantages of Manufacturing Production in Mexico.}

Manufacturing production in Mexico enjoys some significant advantages compared to other major emerging economies. Manufacturing producers in Mexico have benefited substantially from the proximity to the United States, from the tariff exemptions under NAFTA and from the existence of different export promoting programs (Maquiladora, PITEX and, currently, the IMMEX program). Nevertheless, some new features of the Mexican economy are expected to further boost manufacturing production. On the one hand, Mexico provides new opportunities for manufacturing producers given China's recently soaring wages. According to the Economist (2014), Mexican wages have grown less than $50 \%$ in dollar terms over a decade, leaving them 13\% cheaper (adjusted for 
productivity) than China's. On the other hand, there is Mexico's new energy reform. The country's opening up to foreign investors in the oil industry, along with the discovery of new gas resources, is expected to boost production in the petro-chemical sector and, more importantly, to provide cheaper domestic energy. In this context, lower energy and labor costs will be the new advantages offered by Mexico that are complemented with its huge domestic market (120 million people by 2013) and its 44 free trade agreements.

Similarly, Mexico has a competitive advantage in four areas that allow the country to compete effectively with low-cost producers in East Asia. According to Watkins (2007), Mexico has competitive advantages in the following four lines of production; (1) manufacturing production with a high weight to value ratio (the production of cars, flat screens and appliances of large size); (2) production of firms that implement just-intime procedures and whose production is subject to frequent changes in design (auto parts); (3) goods that require strong managerial involvement in order to meet high quality standards (aerospace industry and medical instruments) and; (4) manufacturing goods where the protection of property rights is important.

Products with a high weight to value ratio are those bulky manufacturing goods for which shipping represents a sizeable share of the cost structure. They include vehicles, non-collapsible furniture, electrical machinery, and appliances of large size. The lower costs of shipping these products from Mexico to the United States implies a benefit for firms that is sufficient to compensate for the large labor cost advantages offered by East Asian countries. Let us consider the case of a refrigerator proposed by The Boston Consulting Group (2008). According to their calculations, the typical U.S. retail price of this product is around $\$ 500$ dollars. If it were manufactured in a low-cost East Asian country and sold in the United States the cost of shipping would represent $\$ 100$ dollars ( $20 \%$ of the price tag), while producing it and shipping from Mexico would cost around $\$ 49$ dollars (10\% of the price tag). In this context, difference in freight costs is a major source of competitive advantage for Mexico ${ }^{25}$.

Manufacturing firms that need minimize response times, tend to favor Mexico as a production site when they seek to produce for the North American market. Firms located in Mexico are able to offer just-in-time shipping to their counterparts in the US, with a distance short enough to make production in East Asia impractical. Door-to-door time for products sourced from China's east coast and continuing into the interior of the United States average three to four weeks via the West Coast of the United States and four to six weeks via the East Coast. In contrast, door-to-door time is less than a week for products sourced from Mexico (Boston Consulting Group, 2008). This advantage in delivery is critical for manufacturing products for which demand is volatile or for perishable, bulky and seasonal products for which carrying costs are high ${ }^{26}$.

\footnotetext{
${ }^{25}$ In order to further understand the magnitude of the differences in shipping costs, the Boston Consulting Group (2008) also compares freight costs for shipping containers to Pittsburgh, from Mexico, Brazil and China. From Mexico, the shipping cost would be $\$ 2,679$; from São Paulo, $\$ 4,637$ and from Shanghai, $\$ 5,437$.

${ }^{26}$ The shipping times in Mexico have been further reduced. In the past, trucks from Mexico were not permitted to cross the US border, so all shipments were unloaded and reloaded onto U.S. trucks (a process that delayed shipments for about eight hours). Nonetheless, as of September 2007, Mexican carriers have
} 
Strong managerial involvement is required in the production of those goods that need to meet strict quality requirements. This is the case of the aerospace industry, the production of which also places a high premium on property rights. Both in terms of strong managerial involvement and protection of property rights, Mexico has a significant competitive advantage compared to East Asia. On the one hand, face-to-face meetings are more feasible given that Mexico does not have important time zone differences with major cities in the United States, as well the fact that flights between the two countries only take a few hours. Similarly, managerial involvement is enhanced by the fact that Mexico provides a sizeable pool of US-educated managers with Western ways of thinking and doing business (Boston Consulting Group, 2008). Next, as regards protection of property rights Mexico has advantages over most low country locations. This country has signed an important number of agreements with major advanced and emerging economies on reciprocal promotion and protection of investments (RIPPA) ${ }^{27}$. Such agreements are established by the Mexican Government to provide national and foreign investors with a legal framework that offers stronger protection for foreign investment and Mexican investment abroad.

We can mention some other competitive advantages of manufacturing production in Mexico. The production of components in Mexico's aerospace industry has received significant incentives in the last years. For instance, in 2007 Mexico and the United States signed the Bilateral Aviation Safety Agreement (BASA). This agreement recognizes the technical capabilities of Mexico's Directorate of Civil Aeronautics to certify the safety of components made in the country. The recognition provided by this agreement makes re-certification by the US Federal Administration unnecessary. This situation is extremely important for the aeronautic industry in Mexico. The agreement eliminates a step in the supply-chain since products no longer need to be examined internationally before being shipped off to consumers to undergo further assembly operations.

Mexican producers also enjoy the benefits provided by NAFTA. For instance, in the textile industry NAFTA rules are particularly demanding for non-NAFTA producers. This is the case of the NAFTA rules of origin "yarn forward" and "fiber forward". Yarn forward means that the yarn used to produce a fabric must originate in a NAFTA member country. Exemptions from those rules are granted in the cases where the imported textile yarns are not widely produced in North America (the case of silk), provided that the fabric is cut and sewn in one or more NAFTA countries. More demanding rules of origin obtain for textile goods which are widely produced in NAFTA. For example, cotton yarn and cotton knitted fabrics are subject to a fiber forward rule for goods traded between the three countries, while man-made fiber sweaters are subject to a "fiber-forward" rule as to trade between the United States and Mexico.

\footnotetext{
been granted "hosted carrier" status, which allows them free movement within the United States, thus reducing shipping times (Boston Consulting Group, 2008).

27 In general, those RIPPAs cover disciplines such as investment definition, scope of application, promotion and admission, investment treatment, expropriation, transfers and resolution of investor-State and State-State controversies.
} 
NAFTA rules of origin in the automotive industry are also an important factor encouraging foreign investors to allocate their production to Mexico, rather than to East Asia. The North American regional value content requirement for autos and light vehicles, their engines and transmissions as well as for other vehicles was initially set at $50 \%$. As of 2002 it was increased to $62 \%$. As for production of televisions, under NAFTA regulations, flat screens assembled in Mexico enjoy duty free access to the US market even if they contain components originating from non-NAFTA countries.

Finally, it is also worth mentioning some other areas of production where Mexico has less competitive advantages. This is the case with manufacturing goods with light weight and high volume and the ones with a high value-to-weight ratios. The manufacturing goods with light weight and high volume include the textile industry in general as well as "other manufacturing goods" (umbrellas, toothbrushes, toys, bikes collapsible furniture and so forth). The goods with a high value to weight ratio are the ones produced by the electronic industry. Compared to Mexico, Chinese producers in those industries benefit from a well-developed chain of suppliers, abundant labor and a larger domestic market. Furthermore, the fact that the textile industry, other manufacturing goods and the electronic industry are not subject to frequent changes in style allows producers to plan the production well in advance. This characteristic, along with its light output weight, permits shipping the production further lowering transport and total costs. Similarly, many of those goods are mainly sold in North America by huge retailers such as Wal-Mart and its counterpart for the Mexican domestic market Wal-Mexico. Therefore, Mexican producers in those sectors will continuously face difficulties in increasing their market share in the US.

In a nutshell, the next decade will offer many significant advantages to manufacturing producers in Mexico compared to major producers in other emerging economies. Along with the proximity to the United States and tariff incentives under NAFTA and IMMEX rules, producers in Mexico will also benefit from lower labor and energy costs. Nevertheless, success in manufacturing will be greater if production is concentrated in activities where Mexico has the greatest competitive (or comparative) advantages. Manufacturing goods with a high weight to value ratio, whose quality is more important than their prices, that are specially protected under NAFTA rules and whose production is mainly oriented towards foreign markets will continue to be the key drivers of Mexican manufacturing production. These goods include flat screens, appliances of large size (fridges, electric ovens and so forth), medical instruments and automotive products. Following the same reasoning, the manufacturing goods that imply low weight and high volume but whose production is abundant in North America (and that are therefore protected under NAFTA considerations) will also be among the key drivers of Mexican manufacturing production. In this case, we are referring to the manufacture in cotton.

Manufacturing producers will face significant difficulties in increasing their production for exports in the manufacturing sectors where Mexico has less competitive advantages and, where production is less protected under NAFTA regulations. This will be the case for many textile products (clothing, footwear, leather, sportswear, etc.), electronic products (appliances of small size, mobile phones, computers, microwaves, and so forth) and other manufacturing goods. 


\subsection{Methodology}

In assessing the value added contributions from the different countries and regions involved in the production of Mexico's final manufacturing output, our research will closely follow the approach proposed by Los et al. (2015). By generalizing a measure of fragmentation proposed by Feenstra and Hanson (1999), these authors introduce a metric that uses information from World Input-output Tables to describe the international fragmentation of specific global production networks. Specifically, Los et al. (2015) decompose the value of a final product in the last stage (country) where the final manufacturing production took place. This decomposition includes the value added generated in all the countries that contribute to that final product. Therefore, this measure does not only take into account the value added by the immediate suppliers of intermediates, but also the value added by suppliers further upstream

Formally, consider a particular industry $i$ located in a specific country $j$, denoted by $(i, j)$. For a good to be produced in an industry $(\mathrm{i}, \mathrm{j})$ activities in industries $s=1, \ldots, \mathrm{S}$ in each of the countries $n=1, \ldots, N$ are needed. To decompose the total final value of this good into the value added contributions from different industries and countries, the first step to take is to find the levels of gross output associated with the production of $(\mathrm{i}, \mathrm{j})$. Those can be estimated by applying standard input-output methods to global input-output tables. Global input-output tables contain information on the values of intermediate input flows among all country industries in the world, as well as on the values of flows from each of these country-industries to final use in each of the countries.

These tables also contain information on value added generated in each of the country industries. Combining information on value of sales and value added per dollar of sales leads to estimates of value added in each of the $S^{*} N$ industries as a consequence of final demand for product $(\mathrm{i}, \mathrm{j})$. For this, we use an equation that has been a standard tool in input-output analysis for over decades (Miller and Blair, 2009);

$$
\mathbf{g}=\hat{\mathbf{v}}(\mathbf{I}-\mathbf{A})^{-\mathbf{1}}(\mathbf{F e})(5.1)
$$

In this equation ${ }^{28}, \mathbf{g}$ is the vector of value added created in each of the SN countryindustries involved in a value chain. The choice for a specific final output matrix $\mathbf{F}$ determines which value chain is considered. Final output is output delivered for household consumption and investment demand (both including domestic and final foreign demand). $\mathbf{e}$ is a summation vector. $(\mathbf{I}-\mathbf{A})^{\mathbf{- 1}}$ is the well-known Leontief inverse, the use of which ensures that value added contributions in all tiers of suppliers are taken into account. $\mathbf{v}$ is a vector with value added to gross output ratios, for each of the country-industries ${ }^{29}$

The $(S N x S N)$-matrix $\mathbf{A}$ and the $(S N)$-vector $\mathbf{v}$ are obtained as $\mathbf{A}=\mathbf{Z}(\hat{\mathbf{x}})^{-\mathbf{1}}$ and $\mathbf{v}^{\prime}=\mathbf{w}^{\prime}(\widehat{\mathbf{x}})^{-\mathbf{1}}$, respectively. A gives the intermediate inputs per unit of output of gross output (x), while $\mathbf{v}$ represents the value added generated per unit of gross output. $\mathrm{F}$ stand for a final demand matrix of dimensions SNXCN (where C is the number of final

\footnotetext{
28 This equation has been already introduced in Chapter (3) as equation (3.1).

${ }^{29}$ Matrices are indicated by bold capital symbols and (column) vectors by bold lowercases. Hats denote diagonal matrices with the corresponding vector on the main diagonal.
} 
demand categories per country). This implies that Fe is an (SN) vector with a single positive element, which is obtained by adding foreign and final demand for $(\mathrm{I}, \mathrm{j})$ 's product.

As can be observed, implementing the aforementioned methodology will allow us to decompose $\mathbf{g}$ which contains the value added generated in each of the industries in each of the countries that can be attributed to the global value chains of final manufacturing production in the domestic economy of Mexico (Domestic) and the Mexican Maquiladora sector (Maquiladora/Manufactura Global). Implementing this methodology in our research requires World Input-Output Tables that include separate input-output tables for Mexico (Domestic) and Mexico (Maquiladora/Manufactura Global).

\subsection{Data Construction Methods: How to Include Mexico (Domestic) and Mexico (Maquiladora/Manufactura Global) in WIOT?}

A World Input-Output Table (WIOT) is an extension of a national input-output table. A WIOT explicitly indicates the imports by country of origin of goods for intermediate and final use, received by countries. In this paper, the analysis is based on the World InputOutput Database (WIOD) of the Groningen Growth and Development Centre (GGDC, 2015). A WIOT also indicates the domestic consumption of goods for intermediate and final use and the delivery of those goods domestically produced by county of destination. The novelty of the present paper is that we break down the input-output data for Mexican manufacturing into a maquila sector and a Domestic sector. Referring to our discussion in section 5.2, figure 5.1 indicates the set-up for a WIOT that divides Mexican Manufacturing into its Domestic economy and Maquiladora/Manufactura Global components. This figure has been divided into three sets. Set (A) indicates the industry by industry intermediate use of goods from WIOD countries according to their origin (imported or domestic). Set (B) indicates the final use of goods from WIOD countries according to their origin. Finally, set (C) indicates the total output in each WIOD country.

As can be seen in set (A), Mexico (Domestic) and Mexico (Maquiladora/Manufactura Global) report their industry by industry intermediate use of goods delivered by Country A and the rest of the World respectively (imported intermediate goods). At the same time, Mexico (Domestic) and Mexico (Maquiladora/M. Global) report their industry by industry intermediate use of goods that are both delivered by the Mexico (Domestic) (domestic intermediate goods). Similarly, given that the maquiladora does not deliver any intermediate goods to country (A), Mexico (Domestic), Mexico (Maquiladora/M. Global) and the rest of the world all the squares designed to indicate those deliveries are left in blank (they are equal to zero).

On the other hand, in set (B), Mexico (Domestic) and Mexico (Maquiladora/M. Global) report their final use consumption according to domestic or imported origin. Mexico (Domestic) indicates the final use of goods delivered by Country (A,) by Mexico (Domestic) and by the rest of the World. Following our definition of maquiladora, Mexico (Maquiladora/M. Global) only indicates the final use of capital goods delivered by Country (A) and by the rest of the World. Country (A) in set B reports the final use of goods delivered by Country (A), by Mexico (Domestic), by Mexico (Maquiladora/M. Global) and by the rest of the World. The same description for Country (A) applies for 
the rest of the world. Finally, set (C) indicates the total output by each industry in each WIOD country.

\section{Figure (5. 1): WIOT Set up with Mexico (Domestic) and Mexico (Maquiladora)}

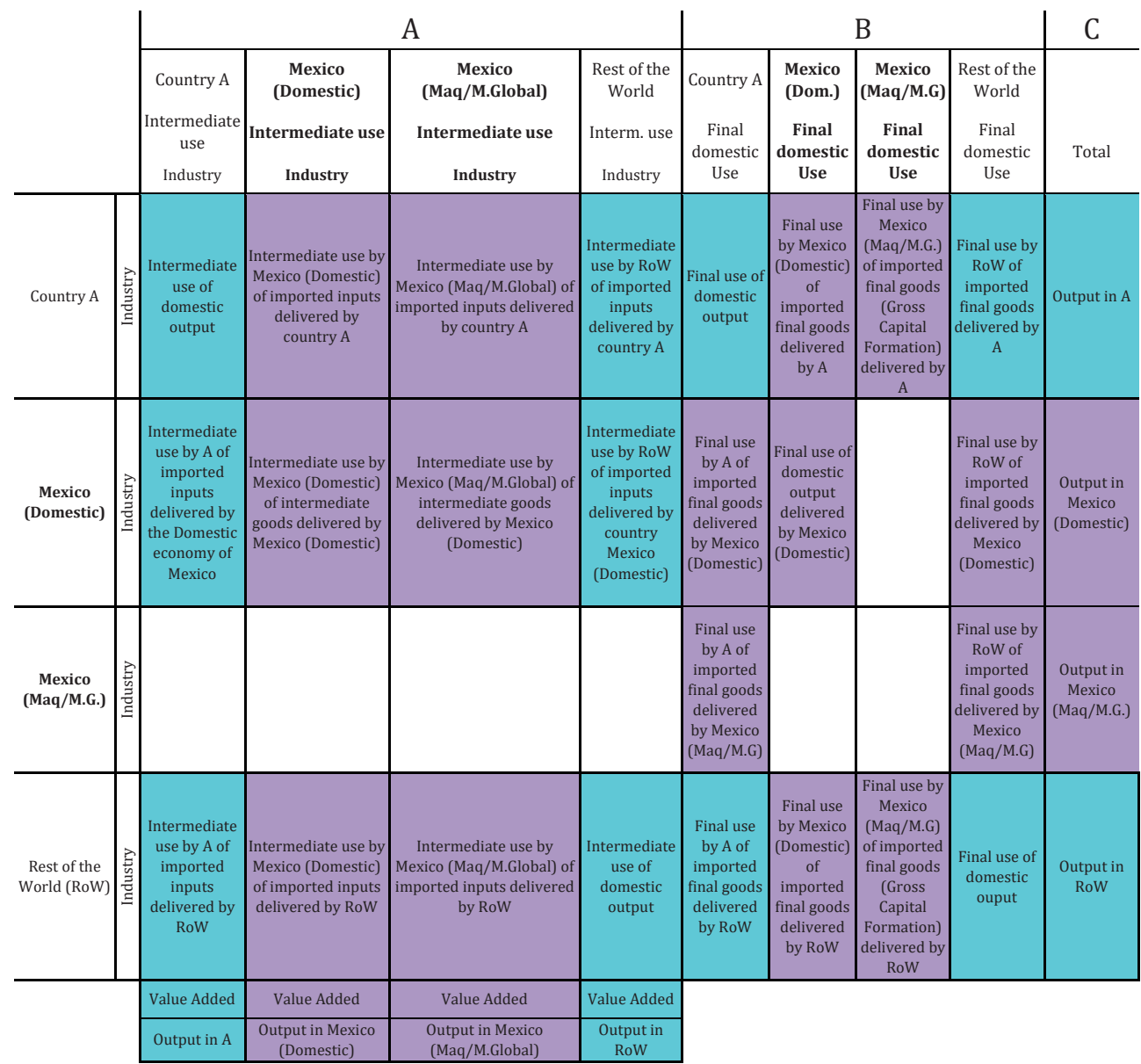

In order to implement these ideas, several adaptations have to be made to the input tables (supply and use tables) originally used by WIOD that allow us to include Mexico (Domestic) and Mexico (Maquiladora/M. Global) into the structure of the World InputOutput Tables. So as to better understand how our research needs to proceed, the left hand side of Figure 5.2 presents an overview of the supply and use tables used by WIOD to include Mexico (Total Economy) in the World Input-Output Tables As can be seen, WIOD first created national (i.e. total economy) supply and use tables which were then used to create national input-output tables. Afterwards, those supply and use tables were linked across countries (by means of bilateral trade data) to create international supply and use tables for Mexico. Finally, the international supply and use tables of 
Mexico, and that of the rest of WIOD countries, were used to create the world inputoutput tables. Considering this situation, the right hand side of figure 5.2 also presents the supply and use tables that are required to include Mexico (Domestic) and Mexico (Maquiladora/M. Global) in WIOT.

\section{Figure (5. 2): Supply and Use Tables Required for Constructing WIOT.}

Supply and Use tables used by WIOD to
include Mexico in WIOT
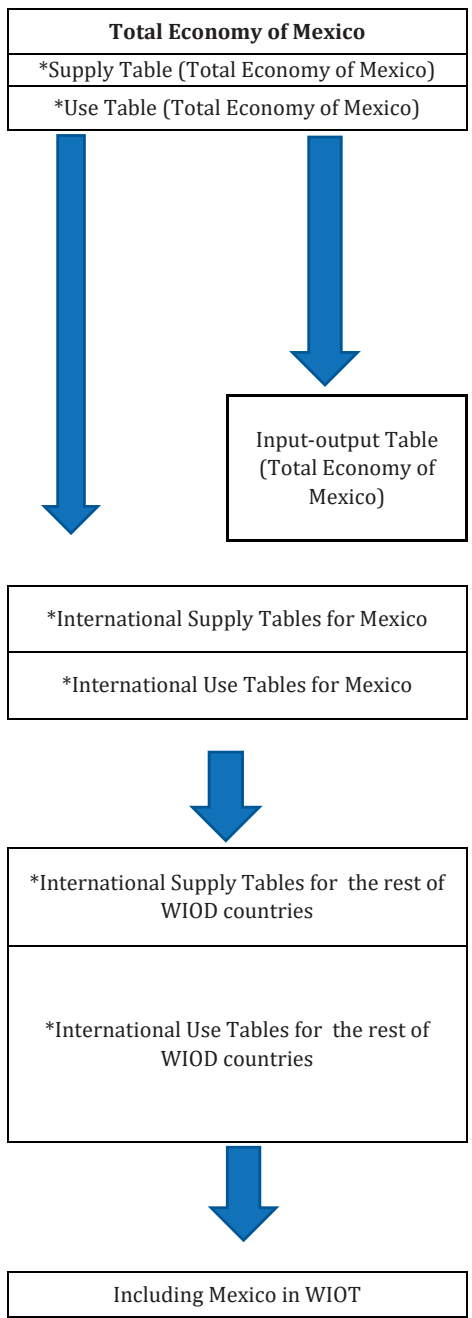

Supply and Use tables used by our research to include Mexico (Domestic) Mexico (Maquiladora/M. Global) in WIOT

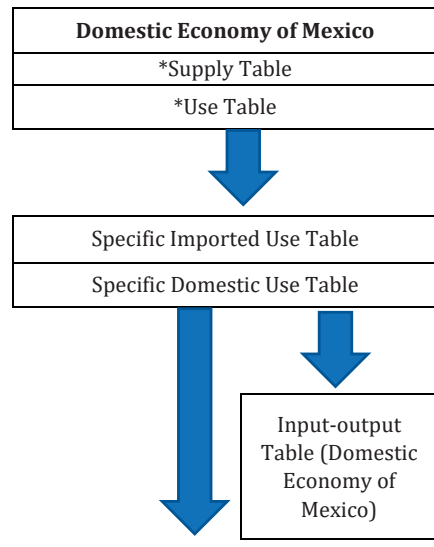

\begin{tabular}{|c|}
\hline Maquiladora/M. Global \\
\hline *Supply Table \\
\hline *Use Table \\
\hline
\end{tabular}

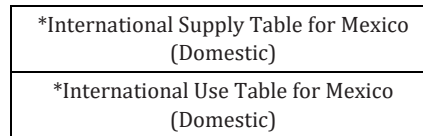

*International Supply Table for Mexico (Maq/M. Global)

*International Use Table for Mexico (Maq/M. Global)

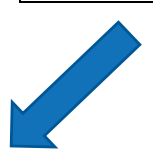

*International Supply Tables for the rest of WIOD countries

*International Use tables for the rest of WIOD countries (modified to include Maquiladora/M. Global and domestic economy of Mexico)
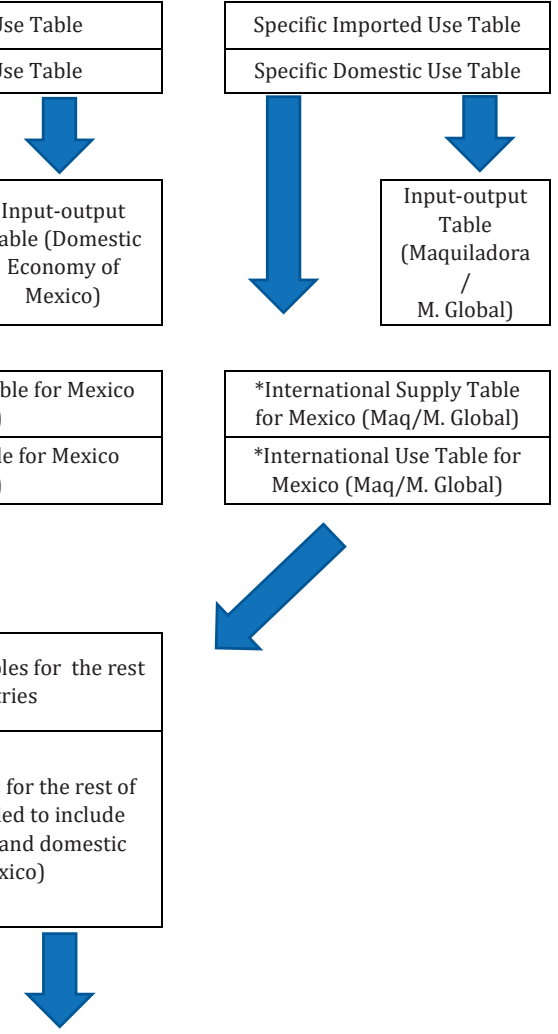

Including Mexico (Domestic) and Mexico (Maq/M. Global) in WIOT 
We require specific supply and use tables (imported and domestic use) for the domestic economy of Mexico and for the maquiladora industry to create input-output tables and international use tables for each of these two concepts. Furthermore, we need to modify the original set up from all the international use tables from WIOD countries to include Mexico (Maquiladora/ M. Global) and Mexico (Domestic) in their original set up. The appendix A5.1 to this chapter provides a detailed methodological discussion of the steps taken to build the national and international supply and use tables for the two components of the Mexican economy, as well as our final set up of WIOTs with those included.

\subsection{Data Requirements}

As discussed in the previous section, including Mexico (Domestic) and Mexico (Maquiladora/Manufactura Global) into the WIOT implies creating supply and use tables - imported and domestic use tables as well as international supply and use tables - for each of the two components of the Mexican economy. Furthermore, it requires including Mexico (Domestic) and Mexico (Maquiladora/Manufactura Global) into the structure of the international use tables from each of the WIOD countries.

In order to meet these objectives, our research requires three type of data; (a) official supply and use tables (domestic and imported use) for Mexico (Domestic) and Mexico (Maquiladora/Manufactura Global) respectively, and; (b) yearly time series from the national accounting system classified according to gross production, gross value added, imported and domestic intermediate consumption, final use and, so forth. (a) and (b) will be the basis for calculating the time series SUTs for each component of the Mexican economy. Finally, the last type of data is (c) bilateral trade data by country of origin (imports) for Mexico (Domestic and Maquiladora/Manufactura Global, respectively) and by country of destination (exports) for Mexico (Maquiladora/Manufactura Global). The latter will be the input data to calculate the international use tables from Mexico (Domestic and Maquiladora/Manufactura Global) and to modify the structure of the international use table from the rest of WIOD countries. In the next lines, we will further describe the main features behind these three types of data.

\subsubsection{Data for SUTs from Mexico (Domestic) and Mexico (Maquiladora/Manufactura Global).}

Our research plans to create time series of extrapolated SUTs for the two components of the Mexican economy by means of the well known SUT-RAS procedure (Temurshoev and Timmer (2011). The SUT-RAS procedure requires a base matrix which is to be extrapolated with yearly data on industrial output. INEGI (the Mexican Statistical Office) provides specific data for each component of the Mexican economy to carry out this endeavor.

As mentioned already, official SUTs for the total economy of Mexico (2003) were the ones used by WIOD to include Mexico into the WIOT. In order to construct those official SUTs for 2003, INEGI first created specific SUTs for Mexico (Domestic Economy) and for Mexico (Maquiladora). This means that the sum of the SUT for Mexico (Domestic) and the ones for Mexico (Maquiladora) equal the SUT for the total economy of Mexico. Moreover, the available official use tables are further decomposed in specific imported and domestic use tables, per each component of the Mexican economy, respectively. 
INEGI also separately reports yearly national accounts data for Mexico (Domestic), Mexico (Maquiladora) and Mexico (Manufactura Global). Such data is similar to the data used by WIOD in order to include Mexico in their dataset. It includes data for gross production, gross value added, imported and domestic intermediate consumption, total imports and exports and for the case of Domestic Economy final demand (note that Maquiladora/Manufactura Global do not consume final goods). All the information for the Domestic Economy of Mexico is readily available on INEGI's website (www.inegi.org.mx). The information for Maquiladora is also available from 1990 to 2006. From 2007 onwards, data for the IMMEX program is available but it is not reported in terms of the national accounting system ${ }^{30}$. Nevertheless, in 2014 INEGI released data for the Manufactura Global that is published in terms of the national accounts from 2003 to 2012.

With this background information in mind, we proceed to construct our own dataset as follows. The starting point was to extrapolate the official 2003 domestic (imported) intermediate use table for the Domestic economy of Mexico with yearly data of domestic (imported) intermediate consumption for that same component of the Mexican economy ${ }^{31}$. With this first step, we obtained time series of extrapolated domestic and imported intermediate use tables for Mexico (Domestic) from 1998 to 2011. Those domestic and imported intermediate use tables were then added up to obtain the total intermediate use table in Mexico (Domestic). Finally, once we had the total intermediate use tables for Mexico (Domestic), yearly information for the final use of Mexico (Domestic) was included in order to obtain the total use table for the Domestic economy as proposed in figure 5.2. With the corresponding specific information for Maquiladora and for Manufactura Global, our research followed the same procedure in order to create time series of extrapolated total use tables for Mexico (Maquiladora) from 1998 to 2006 and, for Mexico (Manufactura Global) from 2007 to 2011.

The same approach was followed when creating the times series of extrapolated supply tables for Mexico (Domestic) and Mexico (Maquiladora/Manufactura Global). We used the SUT-RAS procedure to extrapolate the corresponding 2003 supply table with annual data on gross output according to the respective component of the Mexican economy. Once we had the time series of supply tables, we added them their corresponding information for total imports. In that way, we finally obtained time series of total supply tables for Mexico (Domestic) and Mexico (Maquiladora/Manufactura Global), respectively for the same period of time from the total use tables. Finally, with all those tables we ensure that basic accounting identity (total supply equals total use) was met for each component of the Mexican economy.

\footnotetext{
${ }^{30}$ During the last years, INEGI has continuously updated the data for the IMMEX program. At the early stages of this research, IMMEX data for the total imported and domestic intermediate consumption were only reported. By 2015, such data reported per manufacturing sector has become available. Nevertheless, our research cannot use IMMEX data because official data for gross value added and gross output is still not available.

${ }^{31}$ From 1998 to 2006, yearly times series data for the Domestic Economy of Mexico and Maquiladora are available in current and constant prices of 2003. From 2007 to 2011, yearly times series data for Manufactura No Global and Manufactura Global are available in current and constant prices of 2008.
} 


\subsubsection{Data for the International SUTs from Mexico (Domestic) and Mexico (Maquiladora) Manufactura Global).}

In order to move from SUTs to international SUTs, Timmer et al. (2014) relied in the bilateral import data reported by each WIOD country in the UN COMTRADE database. The bilateral import data, reported at the 6 digit level from the Harmonized System (HS), was then allocated to three use categories (intermediate, final consumption and, investment) according to the Broad Economic Categories Classification (BEC). Given the lack of standardized bilateral service trade data, WIOD constructed their own database for services relying on different data sources (including OECD, Eurostat, IMF and WTO). Similarly, since there is not a service data classification for breaking services down according to the aforementioned use categories, WIOD relied on the information provided in existing import use or symmetric import IO tables.

Once all the information from international trade statistics was gathered, WIOD calculated for each use category the share of imports of product $\boldsymbol{i}$ delivered by country A in the total imports of product $\boldsymbol{i}$ received by country B in that same use category. For instance, with the international trade data, they determined for the intermediate use category the share of the imports of chemical products delivered by Canada in the total intermediate imports of chemical products received by Mexico. Finally, those shares of use categories were applied to the total imports of product $\boldsymbol{i}$ as given in the SUT time series to derive imported use values. The shares (and not the actual values) from international trade statistics were used in order to ensure consistency between the data reported in the time series of extrapolated SUT and the international SUTs.

With this background information in mind, we can indicate all the necessary data to create international SUTs for Mexico (Domestic) and Mexico (Maquiladora/Manufactura Global). Transforming SUTs into international SUTs requires bilateral trade data. INEGI reports official bilateral trade data for Mexico (Domestic) and for Mexico (Maquiladora) from 1998 to 2006. Each product category at a 8 digit level from the Harmonized System is reported in three columns; one column reporting the imports (exports) made by Maquiladora firms, a second column with the imports (exports) made by non-maquila firms and, a third column (the sum of maquila and non maquila firms) indicating the total imports (exports) made by Mexico under that 8 digit level product category. As of 2007, bilateral trade data for the total economy of Mexico is only available.

In order to further extend our analysis to more recent years and to include the Manufactura Global our research did the following. Given that Manufactura Global by definition includes all the foreign firms that mainly import intermediate goods (at least $70 \%$ of their total imports) to process them and eventually export them as a final manufacturing good, we decided to implement the same criteria in our available bilateral data. This means that within each product category at the 8 digit level from the previous data base, we identified those products whose ratio of maquiladora imports (exports) to total imports (exports) was higher than 70\%. In that way, we were able to obtain a list of 8 digit level codes from the Harmonized system that were the basis to distinguish trade data for Manufactura Global within the bilateral trade data from 2007 onwards. Similarly, those 8 digit level products that did not meet our criteria for Manufactura Global trade were treated as the bilateral data for Domestic Economy from 2007 onwards. 
As for the case of services, we faced the same problem as WIOD of not having a standardized service bilateral trade data base. Therefore, we decided to use the bilateral service data for Mexico provided by WIOD in their international SUTs. Given that "Other Business services" (the only service sector within Maquiladora) accounts for less than $2 \%$ of the total gross production of Maquiladora, we assumed that all the bilateral service data reported for Mexico by WIOD refer to bilateral service data of the Domestic Economy of Mexico. Nevertheless, in order to have bilateral service trade data for the maquiladora sector of "Other Business Services" we assumed that its import structure by country of origin was the same as the one reported for that same service sector in WIOD's bilateral import data for Mexico.

Following the same reasoning, once we gathered all the necessary bilateral import data for each component of the Mexican economy, we only implemented the BEC intermediate use category to identify the intermediate goods in the Domestic Economy of Mexico. This means that we did not classify our bilateral import data in terms of the other two BEC use categories of final consumption and investment. There are several reasons for this. First of all, in my view, the bilateral import data for the Maquiladora and the Manufactura Global do not require any additional classification as their import data (by definition) belongs to their imported intermediate consumption. Second of all, our research decided not to modify the bilateral import data for final consumption and investment initially reported for Mexico in WIOD given that also, by definition, that data corresponds to the Domestic Economy of Mexico. Just remember that neither the Maquiladora nor the Manufactura Global import goods for final consumption. In addition, Maquiladora and Manufactura Global do not report any official information on their imports of capita equipment. Therefore, the structure of the international use tables from Mexico in the section of final demand and gross capital formation as initially reported by WIOD will remain completely unaltered and simply relabeled as final demand and gross capital formation for Mexico (Domestic).

The next step was to identify the imported intermediate use share of product i delivered by country A in the total intermediate imports of product i from each component of the Mexican economy. Once we obtained those shares, we applied them to their corresponding total imports of product $\boldsymbol{i}$ as given in our imported use time series to derive imported use categories. Finally, the information for gross value added, gross production and total exports was included in order to have international use tables for Mexico (Domestic) and Mexico (Maquiladora/Manufactura Global) from 1998 to 2011 as proposed in figure 5.2 .

The last step before including Mexico (Domestic) and Mexico (Maquiladora/ Manufactura Global) into the WIOTs was to include those components of the Mexican economy into the structure of the international SUT from the rest of WIOD countries. In that context, we decided that the information for Mexico initially reported by WIOD in the structure of the international SUTs from the rest of WIOD countries corresponded to that of the Domestic Economy of Mexico. The main reason for this is that the Maquiladora industry only exports final manufacturing goods and by definition does not supply intermediate goods to other markets. Furthermore, exporting intermediate and final goods as well as capital goods (investment) is a role solely taken by the Domestic 
Economy of Mexico. Therefore, just as in the previous case, all the data for Mexico initially contained in the international SUTs from the rest of WIOD countries will be unaltered and simply relabeled as the one for Mexico (Domestic).

Nonetheless, bilateral data for the exports of Maquiladora and of Manufactura Global is still required in order to have complete international use tables for the rest of WIOD countries. So as to meet the aforementioned objective, our research also retrieved Maquiladora bilateral export data (by country of destination) from 1998 to 2006. Data for the bilateral exports of Manufactura Global was obtained with the same criteria we followed to identify its bilateral imports. This means obtaining codes at the 8 digit level of the HS whose ratio of maquila exports to total economy exports was higher than $70 \%$ and using those codes to retrieve Manufactura Global exports by country of destination from 2007 to 2011. Afterwards, we obtain the exports share by country of origin and applied them to their corresponding total exports of product $\boldsymbol{i}$ as given in our use tables from Maquila/Manufactura Global. Finally, that information of Maquila/Manufactura Global exports by country of origin and by product category was benchmarked with the corresponding information for final use reported in each WIOD country.

Finally, with all the required international SUTs for Mexico (Domestic), Mexico (Maquiladora/ Manufactura Global) and for the rest of WIOD countries, we proceeded to construct the WIOTs from 1998 to 2011. Following WIOD, we transformed all the international SUT into a world input-output structure by means of the "fixed productsales structure" assumption. This assumption states that each product has its own specific sales structure irrespective of the industry where it is produced. Sale structure here refers to the proportions of the output of the product in which it is sold to the respective intermediate and final demand users (Timmer et al., 2014).

Before presenting our main results, some considerations about the main methodological differences between Maquiladora and Manufactura Global should be addressed. According to INEGI (2014), Manufactura Global also includes some firms in the domestic economy of Mexico that mainly export intermediate goods to other countries to explicitly participate in global production networks. This becomes an issue because then the data for total exports in Manufactura Global does not solely include final manufactured goods (as in the case of Maquiladora exports) but also intermediate goods. In order to maintain the consistency between the data reported for the Maquiladora and that for the Manufactura Global we made the simplifying assumption that in both cases total exports consist only of final manufactured goods.

Two important factors support the assumption that intermediate exports are so modest they can be neglected. On the one hand, given that official data for the Maquiladora and for the Manufactura Global overlap from 2003 to 2006, our research can directly identify the share of Maquiladora production within Manufactura Global for those 3 years. The Maquiladora share is $71 \%$ for those years. The remaining $29 \%$ corresponds to the sum of final manufacturing exports from PITEX firms, the final goods from firms in the Domestic Economy whose production is mostly for exports ${ }^{32}$ and, the intermediate

\footnotetext{
32 The reader should note that Manufactura Global does not take into account the total production for exports from the Domestic Economy of Mexico. In this case, final goods from firms in the Domestic
} 
goods produced by firms in the Domestic Economy that are exported for the production of a final good in a foreign market ${ }^{33}$. Unfortunately, there is no available data to find the share in Manufactura Global for the aforementioned firms. However, according to De la Cruz et al. (2011), exports of manufactured goods under the Maquiladora and PITEX programs accounted for 85.4 percent of total manufactured exports of $\$ 195.6$ billion US dollars in 2006. Therefore, with those arguments in mind, we are confident that bulk of exports contained in the data for Manufactura Global refers to final manufacturing goods and that the share of exported intermediates is modest.

An alternative way to further confirm our assumption is to look at the intermediate goods delivered by Mexico to the United States, its largest trading partner that receives around $90 \%$ of its total manufacturing exports (De la Cruz et al., 2011). According to data from OECD.Stat (Trade in Value Added) recently available online, the share of Mexican intermediate goods in total intermediate imports received by the US is only $10 \%$. This modest share can be observed from 2008 to 2011 and in all the years where data is available. Note that this $10 \%$ includes intermediate imports delivered to the US by firms in the domestic economy of Mexico. Therefore, the share of intermediate exports from Manufactura Global is substantially lower than $10 \%$.

\subsection{Sectoral Shares and Sources of Intermediate Inputs}

This section presents sectoral gross output shares for the final manufacturing production from Mexico (Domestic) and Mexico (Maquiladora/M. Global), as well as their domestic and imported intermediate consumption (by country and region of origin).

Table 5.1 indicates the sectoral shares in gross manufacturing output for each of the two components of Mexican manufacturing distinguished in this paper. As can be seen, the sectoral structure of Mexico (Domestic) is more diversified than that of Mexico (Maquiladora/M. Global). The production of Mexico (Maquila/M. Global) is mainly concentrated in four manufacturing sectors namely, Electrical and Optical Equipment, Transport Equipment, Textiles and Other Manufacturing. In Mexico (Domestic) sectors with important shares in gross manufacturing output include sectors such as the Food sector, Coke and Petroleum, Chemical products, Basic Metals, Transport Equipment and so forth. A special case is that of textiles which seems to be experiencing progressively

Economy whose production is mostly for exports refers to the following; firms that are mostly foreign owned located in the domestic economy of Mexico and that import most of their intermediate goods to produce a final good to be exported. This means those firms in the domestic economy of Mexico that are meeting two of the conditions established by INEGI to be considered a firm under Manufactura Global (being mostly foreign owned and have a ratio of at least $2 / 3$ of their imported intermediate consumption with respect to their exports). For instance, the final goods exported by firm under the domestic economy that is not foreign owned Mexico and that use mainly domestic inputs for its final good are not considered as part of Manufactura Global.

33 Manufactura Global does not include as well the total intermediate goods exported by the Domestic Economy of Mexico. In this particular case, the intermediate goods produced by firms in the Domestic Economy that are exported for the production of a final good in a foreign market refers to the following; subsidiaries of a foreign company that were located in the domestic economy of Mexico in order to produce intermediate goods that have to be exported for the production of a final good in a foreign market. For instance, if a firm in the domestic economy produces intermediate goods to be exported but such firm is not a subsidiary from foreign company (mostly of foreign owned), then its intermediate production will not be considered as part of Manufactura Global. 
declining shares in the total production within each component of Mexican manufacturing. Finally, it is worth mentioning that most of the gross output from Mexico (Domestic) is supplied to the domestic market and to the United States, while almost the entire production from Mexico (Maquiladora/M. Global) is exported to the United States.

Table (5. 1): Gross Output Shares per Manufacturing Sector: Domestic, Maquiladora and Manufactura Global.

\begin{tabular}{|c|c|c|c|c|c|c|c|c|}
\hline & \multicolumn{4}{|c|}{$\begin{array}{c}\text { Mexico } \\
\text { (Domestic) }\end{array}$} & \multicolumn{2}{|c|}{$\begin{array}{c}\text { Mexico } \\
\text { (Maquiladora) }\end{array}$} & \multicolumn{2}{|c|}{$\begin{array}{c}\text { Mexico } \\
\text { (M. Global) }\end{array}$} \\
\hline & 1998 & 2006 & 2007 & 2011 & 1998 & 2006 & 2007 & 2011 \\
\hline Food, Beverages and Tobacco & 21.1 & 26.6 & 27.2 & 28.9 & 0.5 & 0.9 & 0.9 & 0.6 \\
\hline Textiles and Textile Products & 5.2 & 3.6 & 3.4 & 3.0 & 11.8 & 7.5 & 2.9 & 2.3 \\
\hline Leather, Leather and Footwear & 1.5 & 1.0 & 0.9 & 0.8 & 0.6 & 0.3 & 0.2 & 0.2 \\
\hline $\begin{array}{l}\text { Wood and Products of Wood and } \\
\text { Cork }\end{array}$ & 1.2 & 1.0 & 1.0 & 0.9 & 0 & 0 & 0 & 0 \\
\hline $\begin{array}{l}\text { Pulp, Paper, Printing and } \\
\text { Publishing }\end{array}$ & 3.9 & 3.4 & 3.4 & 3.2 & 2.5 & 2 & 0.7 & 0.6 \\
\hline $\begin{array}{l}\text { Coke, Petroleum and Nuclear } \\
\text { Fuel }\end{array}$ & 5.2 & 12.1 & 12.4 & 15.0 & 0 & 0 & 0 & 0 \\
\hline $\begin{array}{l}\text { Chemicals and Chemical } \\
\text { Products }\end{array}$ & 10.5 & 14.8 & 15.1 & 12.5 & 0.2 & 0.2 & 1.8 & 1.9 \\
\hline Rubber and Plastics & 2.8 & 3.6 & 3.5 & 3.5 & 2.2 & 3.1 & 1.8 & 1.7 \\
\hline Other Non-Metallic Mineral & 3.8 & 4.4 & 4.4 & 3.7 & 0.6 & 1.9 & 0.7 & 0.5 \\
\hline $\begin{array}{l}\text { Basic Metals and Fabricated } \\
\text { Metal }\end{array}$ & 9.2 & 11.3 & 11.0 & 10.8 & 3.3 & 3.3 & 4.4 & 4.4 \\
\hline Machinery, Nec & 1.8 & 2.6 & 2.5 & 3.3 & 2 & 2.3 & 2.1 & 3.6 \\
\hline Electrical and Optical Equipment & 14.8 & 5.1 & 4.9 & 4.0 & 51.6 & 54 & 46.4 & 38.4 \\
\hline Transport Equipment & 16 & 8.3 & 8.2 & 8.2 & 17.8 & 17.5 & 32.3 & 38.5 \\
\hline Manufacturing, Nec; Recycling & 3 & 2.3 & 2.2 & 2.2 & 6.9 & 7.1 & 5.9 & 7.3 \\
\hline Total & 100 & 100 & 100 & 100 & 100 & 100 & 100 & 100 \\
\hline
\end{tabular}

Source: as described in section 5.5

The data in table 5.1 reveal the pattern of specialization of the maquiladora industry during the last decade. The fact that the production of maquiladora is only concentrated in four manufacturing sectors suggests that producers supplying foreign markets have specialized in the sectors where Mexico has the greatest competitive advantages, Here, we are referring to the production of goods with a high weight-to-value ratio (fridges, non-collapsible furniture, etc), those that involve just-in-time procedures (transport equipment) , those that benefit from NAFTA regulations (the production of flat-screens) and so forth.

The steady decline in the textile production for exports is associated with the emergence of more efficient producers in East Asia, which are strongly specialized in textiles and represent fierce competition for maquiladora producers. The response of maquiladora firms was to specialize in the manufacture of other textile goods, such as cotton products. These are the goods for which NAFTA offers the greatest protection for maquila producers. Finally, the diversified structure of Mexico (Domestic) indicates that this segment of the Mexican manufacturing sector is not practicing the pattern of specialization observed in Mexico (Maquiladora/M.Global). This is because the 
production of Mexico (Domestic) is mainly supplied to the domestic market and does not face significant pressures from foreign low-cost producers.

Table 5.2 presents the intermediate consumption for the total manufacturing production of Mexico (Domestic) and for three important sectors within that segment of the economy ${ }^{34}$.This table explicitly indicates the origin of the intermediate inputs (domestic or specific country or region of origin).

Table (5. 2): Intermediate Inputs used in manufacturing in Mexico (Domestic), by Region of Origin (\%)

\begin{tabular}{|c|c|c|c|c|c|c|c|c|}
\hline & \multicolumn{2}{|c|}{$\begin{array}{c}\text { Total Manufacturing } \\
\text { production }\end{array}$} & \multicolumn{2}{|c|}{$\begin{array}{c}\text { Textile and Textiles } \\
\text { products }\end{array}$} & \multicolumn{2}{|c|}{$\begin{array}{c}\text { Electrical and Optical } \\
\text { Equipment }\end{array}$} & \multicolumn{2}{|c|}{$\begin{array}{c}\text { Transport } \\
\text { Equipment }\end{array}$} \\
\hline & 1998 & 2011 & 1998 & 2011 & 1998 & 2011 & 1998 & 2011 \\
\hline Mexico (Domestic) & 70.6 & 67.0 & 76.3 & 69.9 & 40.8 & 31.5 & 53.8 & 54.8 \\
\hline \multicolumn{9}{|l|}{ NAFTA } \\
\hline United States & 20.0 & 19.9 & 15.7 & 18.7 & 38.4 & 36.0 & 36.6 & 26.2 \\
\hline Canada & 0.6 & 1.1 & 0.2 & 0.2 & 1.0 & 1.0 & 1.1 & 1.6 \\
\hline \multicolumn{9}{|l|}{ East Asia } \\
\hline China & 0.3 & 2.2 & 0.1 & 4.3 & 1.5 & 9.6 & 0.1 & 2.7 \\
\hline Japan & 1.1 & 1.5 & 0.2 & 0.1 & 4.0 & 5.5 & 1.4 & 6.3 \\
\hline South Korea & 0.3 & 0.6 & 1.7 & 0.6 & 0.3 & 1.6 & 0.0 & 0.8 \\
\hline Taiwan & 0.3 & 0.3 & 0.7 & 0.6 & 1.2 & 1.2 & 0.3 & 0.3 \\
\hline \multicolumn{9}{|l|}{ Europe } \\
\hline Germany & 1.9 & 1.6 & 0.5 & 0.5 & 4.3 & 3.7 & 5.2 & 3.1 \\
\hline France & 0.5 & 0.4 & 0.1 & 0.1 & 1.7 & 1.3 & 0.2 & 0.3 \\
\hline United Kingdom & 0.3 & 0.2 & 0.1 & 0.1 & 0.6 & 0.4 & 0.1 & 0.1 \\
\hline Rest of Europe & 1.8 & 2.3 & 1.2 & 1.7 & 4.0 & 3.3 & 0.6 & 1.9 \\
\hline Rest of the World & 2.2 & 2.9 & 3.0 & 3.1 & 2.2 & 5.0 & 0.6 & 1.9 \\
\hline $\begin{array}{l}\text { Total intermediate } \\
\text { inputs }\end{array}$ & 100.0 & 100.0 & 100.0 & 100.0 & 100.0 & 100.0 & 100.0 & 100.0 \\
\hline
\end{tabular}

Sources: as described in section 5.5 .

In this table 5.2, we observe that from 1998 to 2011, Mexico (Domestic) itself is the main source of intermediate goods used by the manufacturing firms in Mexico (Domestic). During those years, the share of Mexico (Domestic) in the total intermediate goods used by Mexico (Domestic) is more than $70 \%$ with little variation over time. The share of the US is $20 \%$, while the other countries account for the remaining $10 \%$.

The aggregate pattern in which Mexico (Domestic) supplies most of the intermediate inputs used by Mexico (Domestic), can also be observed for two of the three subsectors included in the table. During the years under consideration, the Transport sector sourced more than $54 \%$ of its intermediate inputs from Mexico (Domestic), The corresponding figure for textiles was more than $70 \%$. Electrical and Optical equipment is the only exception. In 1998, this sector was primarily using intermediate goods produced by Mexico (Domestic) producers. By 2011 US accounted for the highest share

\footnotetext{
34 We decided to focus on the trends observed in the Electrical and Optical Equipment sector, Transport Equipment and Textiles and Textiles products both for the case of Mexico (Domestic) and Mexico (Maquiladora/M. Global). In my view point, analyzing those sectors allows us to better understand the new pattern of manufacturing specialization at the Maquiladora industry. According to table 5.1, since 1998, Electrical and Optical Equipment and Transport Equipment represent more than 70\% of the total manufacturing production in Maquiladora. The textile industry also provides an interesting case, given the dramatic decline of its share in total maquiladora output (from 11\% in 1998 to 2.3\% in 2011). Finally, we extend the analysis of those sectors for the case of Mexico (Domestic) to allow for comparison between the two segments of Mexican manufacturing.
} 
of intermediates, while there had been dramatic increases in the share of China. Japan and South Korea also increased their intermediate input shares between 1998 and 2011.

Table 5.3 presents the origin of intermediate inputs for Maquiladora (upper panel) and Manufactura Global (lower panel). There are substantial differences compared to the figures for Mexico (Domestic) in table 2. In 1998, US producers provided more than $84 \%$ of the total intermediate inputs used by Maquiladora firms. Only 8.5\% was sourced from Mexico (Domestic). The remaining 12\% consisted of intermediate goods from the rest of the world. By 2006, the US share had dropped to 42.5 per cent, while the shares of East Asia and the rest of the world increased dramatically. By 2011 a dramatic diversification had taken place, as can be observed in the figures for the intermediate input structure of Manufactura Global. In that year, US producers provided $32 \%$ of the total intermediate goods, East Asian countries 30\%, Mexico (Domestic) 22.5\% and Europe 7.1\% with the remaining share coming from the rest of the World.

The steady and sharp decline of the US share in intermediate goods in Maquiladora/M. Global can be observed in every single manufacturing sector. In the case of the textile industry, the decline in US shares was accompanied by a slight increase in the intermediate inputs supplied by Mexico (Domestic) and a steady (but still modest) increase of East Asian inputs. In the case of Transport Equipment, the decline in US inputs is mainly associated with a continuous increase in the inputs supplied by Mexico (Domestic) and, to a lesser extent, to the inputs produced in Europe and East Asia. The most interesting case is the Electrical and Optical Equipment sector, which is the largest sector within Maquiladora/M. Global. As of 2006 East Asia became the most important supplier of intermediate inputs. In 1998, the share of East Asian countries in the intermediate inputs of this sector was only $8 \%$. By 2011, it had increased to $50 \%$. The share of US inputs declined from $84 \%$ to $27 \%$, while the share of Mexico (Domestic) nearly doubled (from $5 \%$ to $10 \%$ ) during the period under consideration

Our data indicate that the increasing globalization of production has had different effects on the domestic and imported origin from the inputs used by each segment of the Mexican manufacturing production. First of all, over the last decade, firms in Mexico (Domestic) have remained highly dependent on the intermediate inputs also produced by Mexico (Domestic). Drastic reductions in transport and communications costs have only altered the intermediate input structure in the Electrical and Optical equipment sector that receives more of its intermediate inputs from US and from East Asia than from Mexico (Domestic). Nevertheless, that change is compensated by the relatively unchanged intermediate input structure of the rest of the manufacturing sectors. 
Table (5. 3): Share of Intermediate Inputs used in the Manufacturing Production from Mexico (Maquila) and Mexico (Manufactura Global).

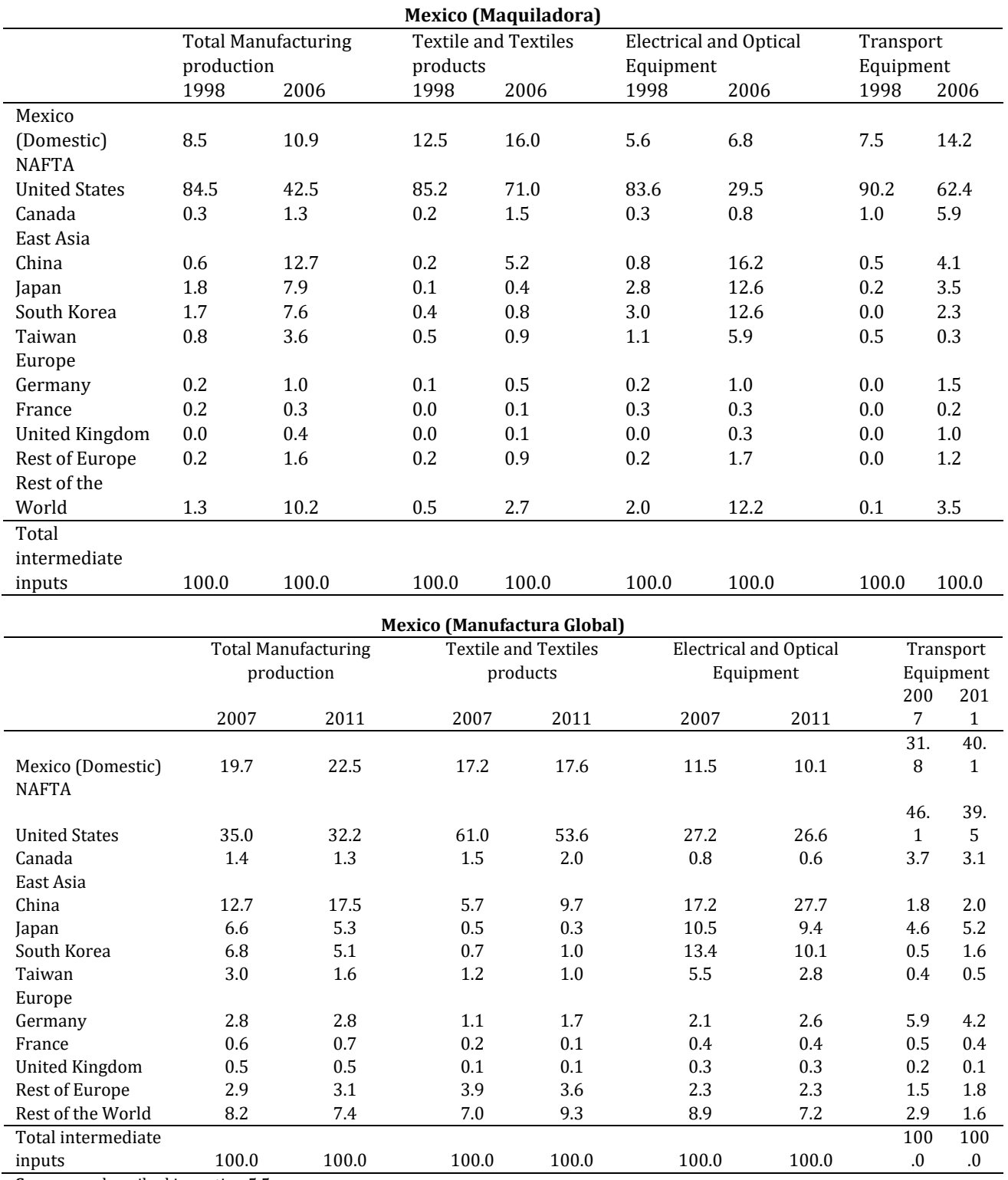

Source: as described in section 5.5

On the other hand, firms in Mexico (Maquiladora/M. Global) faced major changes in the domestic and foreign origin of their intermediate consumption. In my view, these changes are a response of maquiladora to its new pattern of specialization. In order to properly take advantage of the benefits offered by NAFTA, by the Maquiladora/IMMEX program and by the areas where Mexico offers a competitive advantage, the export producers had to drastically modify the sourcing of their intermediate inputs. 
At the aggregate level, Maquiladora substantially reduced its dependence on US intermediate inputs in favor of progressively more inputs from East Asia (China). At the sectoral level, however, a more diversified structure of intermediate sourcing is observed with some sectors using more inputs from China, other sectors using more inputs from the US and, some others more from Mexico.

In sum, we may draw the following conclusions with regard to the manner in which Mexican manufacturing industry responds to the increasing globalization of production. Firms mostly producing for the domestic market (those in Mexico-Domestic) operate in the context of local value chains with most of the value being added by Mexico-Domestic. The firms producing for exports (those in Mexico-Maquiladora) are part of local, regional and global value chains. Whether firms in Maquiladora belong to local, regional or global value chains depends on the types of goods being produced, trade and tariff incentives, as well as the competitive advantages offered by Mexico. This will be further examined in our value added calculations in the next section.

\subsection{Results: the Structure of Value Added Contributions}

This section describes the structure of value added contributions embodied in the final manufacturing output (at industry and sector level) of the different segments of the Mexican manufacturing sector: Mexico (Domestic), Mexico (Maquiladora/M. Global) and Mexico (Total economy). The question here is which countries and regions capture most of the value added embodied in Mexican manufacturing production and to what extent Mexico itself profits from its manufacturing production. The value added contributions have been derived using equation (5.1) and distinguish both domestic and foreign value added content (by country and region of origin). Particular attention is paid to the value added contributions of Mexico and the different patterns found for Mexico (Maquiladora/M. Global) and Mexico (total economy).

\subsubsection{The Domestic Economy of Mexico}

Figure 5.3 indicates the structure of value added contributions by region of origin in the aggregate final manufacturing output of the Mexican Domestic sector (Mexico Domestic) from 1998 to 2011. The figure shows that the value added contribution from Mexico (Domestic) and from different regions did not change much over time. The value added contribution from Mexico (Domestic) was always above 74\%. US/Canada and Europe saw their contribution decrease at the expense of an increase in the East Asian contribution. East Asian countries more than doubled their combined value added contribution in the final output from Mexico (Domestic). By 2009 their share is higher than that of Europe. Nevertheless, the value added from both East Asia and Europe remains significantly lower than that of US/Canada. 
Figure (5. 3): Share of value added content of total final manufacturing output in Mexico (Domestic), by region of origin.

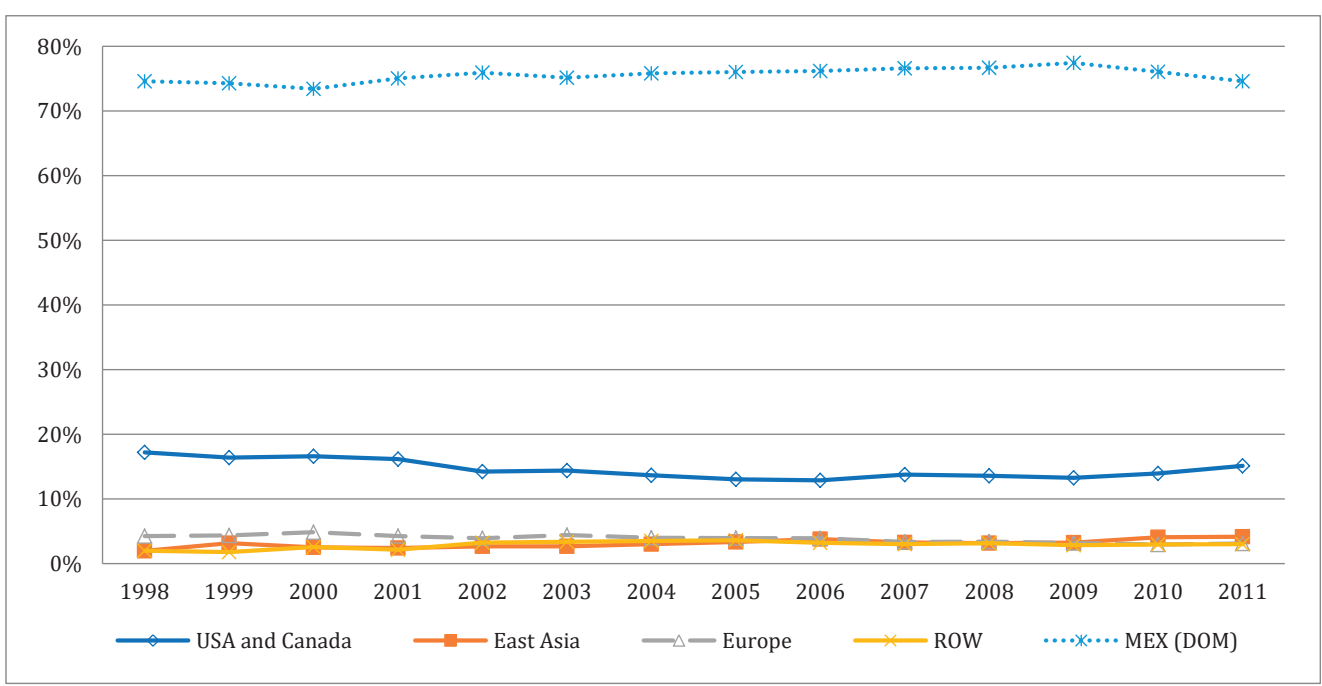

Source: Author's calculation based on WIOT including Mexico (Maq/M.Global) and Mexico (Domestic) and using equation (5.1).

Notes: ROW stands for Rest of the World.

Table 5.4 presents the evolution of the structure of value added contributions for three manufacturing sectors in Mexico (Domestic) for selected years ${ }^{35}$.

As at the aggregate level, the three sectors have remarkably high and stable domestic contributions to value added. Electrical and Optical equipment is the only exception. This is the manufacturing sector in Mexico (Domestic) with the lowest domestic value added contribution, which has also been declining over time (45\% in 1998 and 39\% by 2011). The increase of the contributions of East Asian countries is responsible for this decline as well as for the decline of the shares of US/Canada and Europe within the same sector. The East Asian share doubled from $6.7 \%$ in 1998 to $14.7 \%$ in 2011. According to our data, China drives this increase, in the light of its tenfold increase in value added share in this short period.

In sum we may infer that the increasing value added contribution from East Asian countries (notably China) in the Electronic and Optical equipment produced by Mexico (Domestic) is the factor driving the increase in the value added contribution of this region in the aggregate output of Mexico (Domestic). Nevertheless, the East Asian share in total industry still remains modest, given the remarkably shares of high value added originating in Mexico (Domestic) and the importance of NAFTA neighbors (US/Canada) in most of the other manufacturing sectors.

35 In section 5.5.1, we mentioned the reasons why this research decided to focus only on three manufacturing sectors. Nevertheless, the appendix A5.2 to this research provides the evolution of the structure of the value added contribution for all manufacturing sectors from 1998 to 2011. Such information is provided both for Mexico (Domestic) and Mexico (Maquila/M. Global). 
Table (5. 4): Share of Regional Value Added Content Embodied in Final Manufacturing Output Produced by Mexico (Domestic). Selected Manufacturing Sectors.

\begin{tabular}{l|c|c|c|c|}
\hline \multirow{2}{*}{ Textiles and Textile Products } & \multicolumn{4}{c}{ Domestic Economy of Mexico } \\
\cline { 2 - 5 } Region & $\mathbf{1 9 9 8}$ & $\mathbf{2 0 0 0}$ & $\mathbf{2 0 0 5}$ & $\mathbf{2 0 1 1}$ \\
\cline { 2 - 5 } USA and Canada & 17.0 & 18.6 & 13.9 & 12.4 \\
East Asia & 2.8 & 3.8 & 4.5 & 4.0 \\
Europe & 2.9 & 2.7 & 3.4 & 2.2 \\
ROW & 3.2 & 2.9 & 3.7 & 3.0 \\
MEX (DOM) & 74.1 & 71.9 & 74.6 & 78.5 \\
\hline Total final output & 100 & 100 & 100 & 100
\end{tabular}

Transport Equipment

\begin{tabular}{l|c|c|c|c|}
\cline { 2 - 5 } Region & \multicolumn{4}{|c|}{ Domestic Economy of Mexico } \\
\cline { 2 - 5 } & $\mathbf{1 9 9 8}$ & $\mathbf{2 0 0 0}$ & $\mathbf{2 0 0 5}$ & $\mathbf{2 0 1 1}$ \\
\hline USA and Canada & 27.0 & 26.7 & 22.2 & 19.0 \\
East Asia & 2.0 & 2.9 & 3.6 & 7.8 \\
Europe & 5.1 & 5.4 & 6.0 & 4.5 \\
ROW & 1.2 & 1.8 & 3.2 & 3.0 \\
MEX (DOM) & 64.7 & 63.2 & 65.0 & 65.7 \\
\hline Total final output & 100 & 100 & 100 & 100
\end{tabular}

Electrical and Optical Equipment

\begin{tabular}{l|c|c|c|c|}
\cline { 2 - 5 } Region & \multicolumn{4}{|c|}{ Domestic Economy of Mexico } \\
\cline { 2 - 5 } & $\mathbf{1 9 9 8}$ & $\mathbf{2 0 0 0}$ & $\mathbf{2 0 0 5}$ & $\mathbf{2 0 1 1}$ \\
\hline USA and Canada & 35.3 & 32.5 & 23.8 & 31.0 \\
East Asia & 6.6 & 7.8 & 15.7 & 14.7 \\
Europe & 10.0 & 11.5 & 11.9 & 8.3 \\
ROW & 3.0 & 6.0 & 8.0 & 6.7 \\
MEX (DOM) & 45.2 & 42.2 & 40.7 & 39.3 \\
\hline Total final output & 100 & 100 & 100 & 100 \\
\hline Source: as described in figure (5.3). & \multicolumn{4}{|l}{} \\
\hline
\end{tabular}




\subsubsection{Maquiladora Industry (1998-2006) and Manufactura Global (2007-2011)}

Compared to Mexico (Domestic), a completely different story can be observed in the case of structure of value added shares in Mexico (Maquiladora/M. Global). Figure 5.4 presents the value added contribution by country of origin in the aggregate final manufacturing output produced by Mexico (Maquiladora/M. Global). Given the difference in coverage of the firms included in the Maquiladora industry and those included in Manufactura Global, figure 5.4 is divided into two panels, the first referring to Maquiladora, the second to Manufactura Global.

Figure (5. 4): Value Added Contribution (by Country of Origin) in Mexico (Maquiladora/M. Global). Total Final Manufacturing Output.

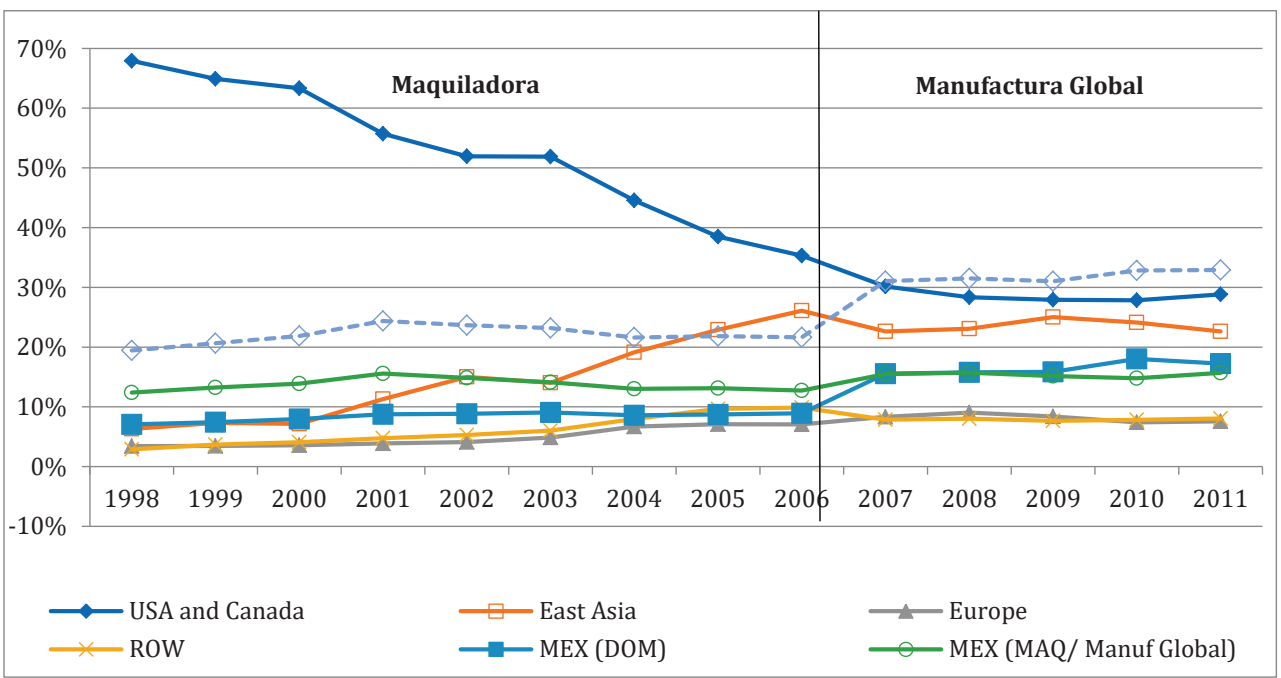

Source: as described in figure (5.3).

As mentioned previously, the domestic value added contributions from Mexico (Maq./M. Global) and from Mexico (Domestic) are considered separately for the case of final manufacturing output produced by Mexican Maquiladora/Manufactura Global sector. The sum of the value added contribution from Mexico (Maq./M.Global) and from Mexico (Domestic) is equal to the total domestic value added embodied in the Maquiladora/M. Global final manufacturing production. This total domestic value added contribution is also represented in figure 5.4 as Mexico (Total). For all years in figure 5.4 for which data for the Maquiladora were available, we observed that value added share of Mexico (Maquiladora) was higher than that of Mexico (Domestic) with $12.4 \%$ versus $7.1 \%$ in 1998 and $12.7 \%$ versus $8.9 \%$ by 2006, respectively. When considering the joint contribution from Mexico (Maquiladora) and Mexico (Domestic), i.e. the total domestic value added contribution in Maquiladora production represented by Mexico (Total), we observed the same cyclical behavior - increases till 2001, decreases thereafter - as described in chapter 4 .

In my view, this cyclical behavior is mainly related to external shocks and changes in the international trade environment and not to changes in the domestic regulatory 
environment. Our detailed data allow us to conclude that those external shocks have mainly affected the value added contributions from Mexico (Maquiladora), with the contributions from Mexico (Domestic) remaining unaltered. The US crisis and China's entrance to the World Trade Organization (WTO) in 2001 (the first external shock considered in our research) induced a steady decline in the value added contribution from Mexico (Maquiladora) from a peak $15.6 \%$ in 2001 to $12.7 \%$ in 2006. This went hand in hand with a loss in employment experienced by maquila producers after 2001.

We see that the value added contribution from Mexico (Domestic) in Maquiladora production did not significantly change over time. It even showed a marginal increase from $7 \%$ in 1998 to $9 \%$ in 2006. The value added contribution from Mexico (Domestic) is perhaps the most relevant one, given that it reflects the degree to which Mexican manufacturing suppliers succeed in interacting more effectively with foreign producers in order to trigger more benefits of exports for the rest of the economy (inducing for instance a process technological learning). The fact that the value added contribution in Maquiladora production remained below 9\%, indicates that Mexican suppliers were unable to meet the input requirements of foreign firms producing for export in Mexico.

From 2007 onwards. we see that the value added contribution from Mexico (Domestic) in the total final manufacturing output from Mexico (Manufactura Global) is higher than the one from Mexico (Domestic) in Mexico (Maquiladora). This is linked to the increase in the value added contribution from Mexico (Domestic) between 2006 and 2007, when the analysis shifts from Mexico (Maquiladora) to Mexico (Manufactura Global) in figure 5.4. The main factor behind the higher value added from Mexico (Domestic) embodied in Mexico (Manufactura Global) is that the corresponding data for Manufactura Global include not only the Maquiladora firms, but also those in the PITEX program, new IMMEX firms, as well as firms in the Domestic Economy that are highly engaged in global production networks. Therefore, the figures from 2007 to 2011 are not strictly comparable to those from 1998 to 2006.

Despite its higher value from 2007 to 2011, the trend in the value added contributions from Mexico (Domestic) in the total final manufacturing output of Mexico (Manufactura Global) is similar to that from 1998 to 2006 . There is a modest net increase in its share (from 15.5\% in 2007 to $17.2 \%$ in 2011) and just as in the case of Maquiladora, the share does not seem to have been severely affected by external shocks (in this case the financial crisis in 2008).

The value added contribution of Manufactura Global to its own final output shows more volatility. During the transition from Mexico (Maquila) to Mexico (M. Global), the value added contribution from Maquiladora increases from $12.7 \%$ in 2006 to $15.6 \%$ by 2007. As in the case of Maquiladora, Mexico (Manufactura Global) seems to be sensitive to external shocks. As a result of the financial crisis in 2008, the value added contribution from Mexico (Manufactura Global) decreased from 15.7\% in 2008 to $14.8 \%$ in 2010, with some recovery by 2011 . The value added decrease after 2008 reflects the hiring of less workers as a result of firms under Manufactura Global reducing their output or shutting down. 
In my view, the value added contributions from Mexico (Manufactura Global) and Mexico (Domestic) in the total final manufacturing output of Mexico (M. Global) from 2007 to 2011 follow patterns similar to those observed for Mexico (Maquiladora) between 1998 and 2006. On the one hand, given the lack of variation and lack of substantial increase observed in the contribution from Mexico (Domestic), we may conclude that manufacturing firms in Mexico supplying domestic inputs to IMMEX firms (and to those other firms highly engaged in global production networks) are still far from meeting the requirements of foreign producers. These producers seek to export to one of the major markets in the World (the United States) and Mexican suppliers to Manufactura Global have not been able to meet their competitive standards. When comparing the contribution from Mexico (Domestic) and Mexico (Manufactura Global) in the total output from Manufactura Global, we can see that contribution from Mexico (Domestic) has become slightly higher than that of Mexico (M. Global). Nevertheless, just as in case of Maquiladora, the fluctuations in the total domestic value added embodied in M. Global can still be attributed to the changes in the value added contributions from Manufactura Global.

Figure 5.4 also indicates the value added contribution from non-Mexican countries in the final manufacturing production of Mexico (Maquiladora) and Mexico (Manufactura Global). We observe a dramatic decline in the value added contribution from US/Canada producers over time. In 1998, the value added contribution from US/Canada producers to the total final manufacturing output from Mexico (Maquiladora) was 68\%. By 2006, the last year for which Maquiladora data was available, the US/Canada value added contribution had declined to 35\%. This decline continues from 2007 to 2011. By 2011 the share of US/Canada was $29 \%$. Given the small increases and minor variations in the total domestic value added embodied in the final manufacturing output of Maquiladora and M. Global, we can indicate that an increase in the value added contribution from East Asian producers was mainly achieved at the expense of the US/Canada value added contributions to final output

In 1998, the joint value added contribution from East Asian producers in the final manufacturing output from Mexico (Maquiladora) was 6.3\%. At that time, it was already larger than the share of Europe (3.4\%) and that of the rest of the world $(2.7 \%)$, but it was ten times smaller than the joint contribution from US/Canada. In 2006, the joint contribution from East Asia in Maquiladora production was of 26\%. In 2011 its contribution was 23\% of the final output in Manufactura Global. During those years, the country that was mainly driving the increasing East Asian value added content was, of course, China. By 2005, the individual contribution from China in Maquiladora production surpassed that of Japan and by 2011, Chinese producers accounted for half of the total East Asian value added embodied in Manufactura Global final manufacturing output.

We find that during the last decade (the 2000s) the increasing globalization of production induced two effects in the value added structure embodied in the Mexican production of final manufactured goods that are mainly exported to the US. On the one hand, it induced dramatic shifts in the value added contributions from foreign producers participating in the production of Mexico (Maquila/Manufactura Global), with NAFTA 
neighbors adding progressively less value added in the total final manufacturing output and East Asia steadily adding more and more. This is the consequence of US producers outsourcing increasing parts of production for intermediate use to Asia. Thus global value chains become more complicated. In the earlier period, producers in the USA provide inputs to Mexican producers, producing final goods for the US market. Later, American producers relocated their activities to Asia and provide inputs for Mexican exporters via Asia.

On the other hand, the increasing globalization of production did not significantly alter the structure of domestic value added contributions to Mexico (Maquiladora/M. Global). From 1998 to 2006, the value added contribution from the firms in the Domestic Economy of Mexico did not show any signs of dramatic increase or decline due to the increasing globalization of production faced by Maquila producers. Similarly, the corresponding value added of Mexico (Domestic) embodied in Manufactura Global from 2007 to 2011 does not seem to have changed drastically. In this context, the variations in the total domestic value added of Mexico (Maquiladora/M. Global) mainly reflect the response (expansion/contraction) of the volume of low qualified employment to the external shocks in 2001 and 2008.

In the end, the main outcome induced by the increasing globalization of production during the 2000s has been a drastic diversification in the value added contributions by country of origin to the final manufacturing output in Mexico (Maquiladora/M. Global). According to figure 5.4, this process of value added diversification has become more pronounced since 2005 and it has become deeper over time. For instance, by 2010 the domestic value added contribution of Mexico (Total) in Manufactura Global production was 33\%, that of US/Canada was 28\%, the of East Asia 24\%, that of Europe $8.4 \%$ and that of the rest of the World $7.7 \%$.

Table 5.5 presents the structure of value added contributions per manufacturing subsector for selected years for Mexico (Maquiladora) and Mexico (M. Global) respectively. As can be seen, the decline in the shares of US/Canada producers and, the corresponding diversification of the value added structure observed at the aggregate level can also be observed at the sectoral level. In the case of the textile industry, we see that loss in US/Canada value added contributions went hand in hand with gains of textile producers in East Asia (notably China), but also of those in Europe and the rest of the World. The joint contribution from Mexico (Domestic) and Mexico (Maquiladora/Global), i.e. the total domestic value added embodied in the final manufacturing output remained between 28 and $33 \%$ and thus it was not drastically modified. Once more, we can see that firms in Mexico (Domestic) supplying inputs to Maquiladora/M. Global were unable to profit from the decline in US/Canada value added and did not increase their share in value added contributions. The value added from Maquiladora/M. Global suffered minor variations related to the sensitivity to the external shocks in 2001 and 2008.

The most drastic change can be observed in the case of the Electric and Optical equipment. In Mexico (Maquiladora) from 1998 to 2006, the US/Canada share in value added embodied in final manufacturing output declined from $70 \%$ to $28 \%$, while East 
Asia increased its share from $9 \%$ to 38\%. Such trends continued in the years for which data for Mexico (Manufactura Global) were available. By 2011, the corresponding share for East Asia was 39\% while that of US/Canada was 26\%. Just as in the case of the textile industry, the contribution of Mexico (Domestic) and Mexico (Maquiladora/M. Global) remained low and did not change substantially.

Transport equipment shows a somewhat different trend in its value added structure. Here, we can also see that the value added contribution of US/Canada has substantially declined both in the case of the final output in Mexico (Maquiladora) and in Mexico (Manufactura Global). But in this industry, these declines go hand in hand with increasing value added contributions from Mexico (Domestic) and Mexico (Maquiladora/M. Global). From 1998 to 2006, it can be seen that firms in Mexico (Domestic) nearly doubled their value contribution in the final output of the transport sector from Mexico (Maquiladora). The value added from Mexico (Maquiladora) also steadily increased, despite a temporary contraction as a result of the external shock in 2001. The joint value added contribution from firms Mexico to the final transport production in Mexico (Maquiladora) increased from 20\% in 1998 to 29\% by 2006.

In the years after 2007 when the data for Mexico (Maquiladora) are replaced by data for Mexico (Manufactura Global), we see that the corresponding value added for Mexico (Domestic) nearly doubles from 2006 to 2007. This situation is mainly because of the larger population of firms included under the concept of Manufactura Global. Nevertheless, between 2007 and 2011 we also see that general upward trend for the automotive sector in the Maquiladora also continues in the case of the Manufactura Global. There is a continuous decline in US/Canada value added contributions, while the value added share of Mexican firms increases. By 2011, the value added contribution from Mexico (total economy) in the transport equipment sector from Manufactura Global was $50 \%$, the one from US/Canada 31\%, East Asia 8.6\%, Europe $6.1 \%$ and the rest of the world $4 \%$. 
Table (5. 5): Share of Regional Value Added Embodied in Final Manufacturing Output Produced by Mexico (Maquiladora/M. Global). Selected Manufacturing Sectors.

\begin{tabular}{l|c|c|c|c|}
\hline \multirow{2}{*}{ Textiles and Textile Products } & \multicolumn{2}{|c}{ Maquiladora } & \multicolumn{2}{c}{ M. Global } \\
\cline { 2 - 5 } Region & $\mathbf{1 9 9 8}$ & $\mathbf{2 0 0 0}$ & $\mathbf{2 0 0 5}$ & $\mathbf{2 0 1 1}$ \\
\hline USA and Canada & 64.4 & 51.6 & 46.8 & 39.0 \\
East Asia & 2.7 & 7.7 & 8.5 & 12.3 \\
Europe & 3.0 & 4.3 & 6.6 & 6.3 \\
ROW & 1.9 & 4.6 & 6.8 & 8.8 \\
MEX (DOM) & 9.4 & 11.7 & 12.5 & 12.3 \\
MEX (MAQ/ Manuf Global) & 18.7 & 20.2 & 18.9 & 21.3 \\
\hline Total final output & 100 & 100 & 100 & 100
\end{tabular}

\begin{tabular}{l|c|c|c|c|}
\hline \multirow{2}{*}{ Transport Equipment } & \multicolumn{2}{|c|}{ Maquiladora } & \multicolumn{2}{c|}{ M. Global } \\
\cline { 2 - 5 } Region & $\mathbf{1 9 9 8}$ & $\mathbf{2 0 0 0}$ & $\mathbf{2 0 0 5}$ & $\mathbf{2 0 1 1}$ \\
\hline USA and Canada & 71.7 & 49.6 & 35.4 & 31.3 \\
East Asia & 3.5 & 10.1 & 7.4 & 8.6 \\
Europe & 3.2 & 6.1 & 7.6 & 6.1 \\
ROW & 2.1 & 5.9 & 4.5 & 3.9 \\
MEX (DOM) & 6.5 & 11.4 & 22.8 & 28.1 \\
MEX (MAQ/ Manuf Global) & 13.0 & 17.0 & 22.2 & 22.1 \\
\hline Total final output & 100 & 100 & 100 & 100
\end{tabular}

Electrical and Optical Equipment

\begin{tabular}{l|c|c|c|c|}
\hline \multirow{2}{*}{ Region } & \multicolumn{2}{|c|}{ Maquiladora } & \multicolumn{2}{c|}{ M. Global } \\
\cline { 2 - 5 } USA and Canada & $\mathbf{1 9 9 8}$ & $\mathbf{2 0 0 0}$ & $\mathbf{2 0 0 5}$ & $\mathbf{2 0 1 1}$ \\
East Asia & 69.6 & 28.1 & 26.1 & 25.7 \\
Europe & 8.7 & 37.9 & 36.3 & 39.2 \\
ROW & 3.8 & 7.8 & 8.6 & 7.8 \\
MEX (DOM) & 3.6 & 11.4 & 9.8 & 10.6 \\
MEX (MAQ/ Manuf Global) & 5.0 & 6.0 & 9.9 & 8.6 \\
\hline Total final output & 9.3 & 8.8 & 9.4 & 8.2 \\
\hline
\end{tabular}

Source: as described in figure (5.3) 


\subsubsection{Total Economy of Mexico (1998-2011)}

Figure 5.5 presents the evolution from the structure of value added contributions embodied in the final manufacturing output produced by the total economy of Mexico. The figures were obtained by adding the value added structure from Mexico (Domestic) and the one from Mexico (Maquiladora/M. Global).

Figure (5. 5): Value Added Contribution (by Country of Origin) in Mexico (Total Economy) Final Manufacturing Output.

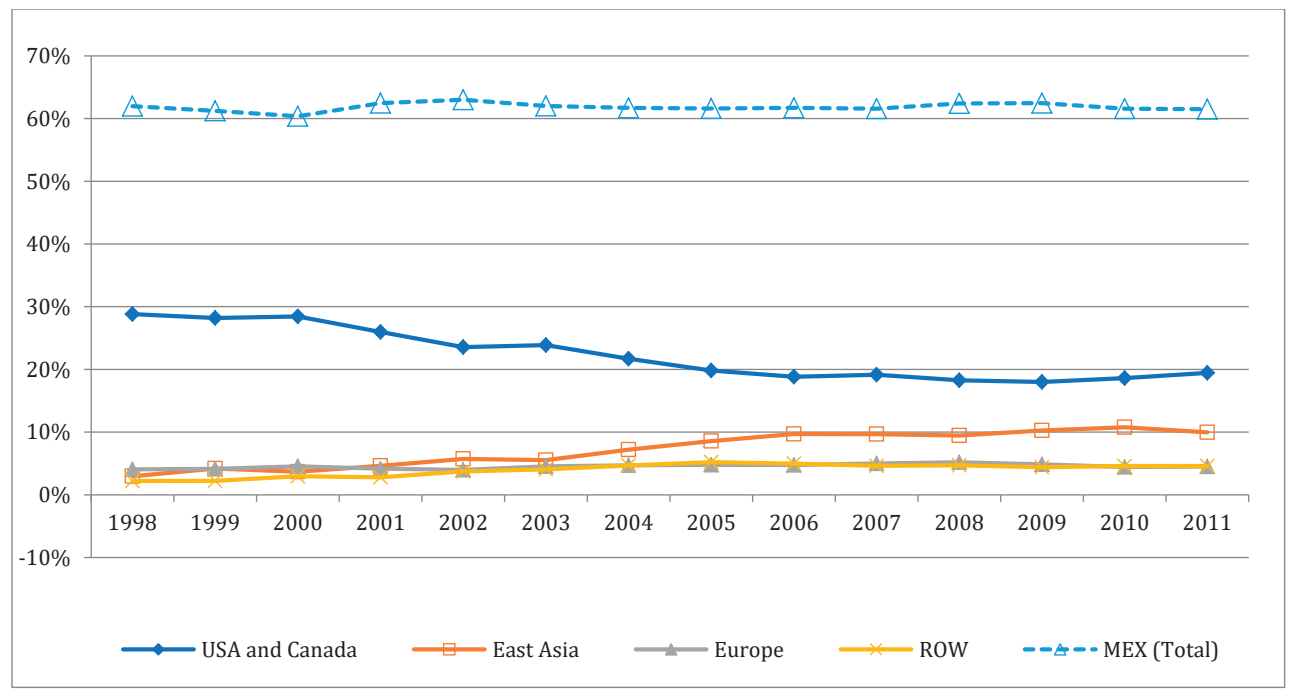

Source: as described in figure (5.3).

The figure shows that the value added structure of Mexico (total economy) resembles the value added structure of Mexico (Domestic). As before, we observe that the substantial decline in the US/Canada value added embodied in Maquiladora/M. Global production is largely dampened by the value added contribution from US/Canada in the final output from Mexico (Domestic). As a result the decline of the value added contribution of US/Canada in the total manufacturing sector in figure 5.5 is less dramatic than in figure 5.4 .

Figure 5.5 also indicates an increasing contribution from East Asia in the total final manufacturing output produced in the total economy of Mexico. According to our data, the main source of this increase is the higher levels of value added from East Asian producers identified in the production of Electrical and Optical Equipment by Mexico (Domestic) and, to a much greater extent, in the production of Electrical and Optical Equipment by Mexico (Maquiladora/M. Global).

Our data also allow us to break down each country's value added contributions in the total final manufacturing output of Mexico (total economy), according to whether these contributions are made in the domestic sector or in the Maquiladora/Manufactura General sector. The data are reproduced in table 5.6. 
Table (5. 6): Share in Value Added Content of Final Manufacturing Output by Region/Country of Origin in Mexico (Total Economy).

\begin{tabular}{|c|c|c|c|c|c|c|c|c|c|}
\hline & & \multicolumn{2}{|c|}{$\begin{array}{c}\text { Total } \\
\text { Manufacturing } \\
\text { production }\end{array}$} & \multicolumn{2}{|c|}{$\begin{array}{c}\text { Textile and } \\
\text { Textiles products }\end{array}$} & \multicolumn{2}{|c|}{$\begin{array}{c}\text { Electrical and } \\
\text { Optical Equipment }\end{array}$} & \multicolumn{2}{|c|}{$\begin{array}{l}\text { Transport } \\
\text { Equipment }\end{array}$} \\
\hline & & 1998 & 2011 & 1998 & 2011 & 1998 & 2011 & 1998 & 2011 \\
\hline \multirow{5}{*}{ Mexico } & (Domestic Mx) & 57.5 & 51.1 & 44.1 & 58.4 & 23.1 & 16.0 & 50.9 & 34.2 \\
\hline & (Domestic to & & & & & & & & \\
\hline & MAQ/M.G.) & 1.6 & 5.4 & 3.8 & 3.1 & 2.5 & 5.1 & 1.4 & 13.5 \\
\hline & (MAQ/M.G.) & 2.8 & 4.9 & 7.6 & 5.4 & 4.5 & 4.9 & 2.8 & 10.6 \\
\hline & Total Mexico & 62.0 & 61.5 & 55.4 & 67.0 & 30.1 & 25.9 & 55.1 & 58.3 \\
\hline \multirow{2}{*}{$\begin{array}{l}\text { United } \\
\text { States }\end{array}$} & (Domestic Mx) & 12.7 & 9.7 & 9.9 & 8.9 & 17.5 & 12.1 & 20.5 & 9.2 \\
\hline & (MAQ/M.G.) & 15.2 & 8.5 & 25.7 & 9.5 & 33.4 & 14.7 & 14.9 & 13.8 \\
\hline \multirow{3}{*}{ Canada } & (Domestic) & 0.6 & 0.6 & 0.3 & 0.3 & 0.6 & 0.6 & 0.8 & 0.7 \\
\hline & (MAQ/M.G.) & 0.3 & 0.6 & 0.5 & 0.5 & 0.6 & 0.6 & 0.4 & 1.2 \\
\hline & Total US and Canada & 28.8 & 19.4 & 36.3 & 19.2 & 52.0 & 27.9 & 36.5 & 24.9 \\
\hline \multirow{2}{*}{ China } & (Domestic Mx) & 0.3 & 1.4 & 0.2 & 2.2 & 0.7 & 3.2 & 0.1 & 1.3 \\
\hline & (MAQ/M.G.) & 0.2 & 3.8 & 0.3 & 2.4 & 0.6 & 12.6 & 0.2 & 1.5 \\
\hline \multirow{2}{*}{ Japan } & (Domestic Mx) & 0.9 & 1.1 & 0.3 & 0.2 & 2.0 & 1.9 & 1.1 & 2.3 \\
\hline & (MAQ/M.G.) & 0.7 & 1.9 & 0.4 & 0.3 & 2.1 & 5.5 & 0.3 & 2.0 \\
\hline \multirow{2}{*}{$\begin{array}{l}\text { South } \\
\text { Korea }\end{array}$} & (Domestic Mx) & 0.2 & 0.2 & 0.8 & 0.3 & 0.2 & 0.5 & 0.1 & 0.3 \\
\hline & (MAQ/M.G.) & 0.3 & 1.1 & 0.2 & 0.2 & 1.1 & 3.8 & 0.1 & 0.5 \\
\hline \multirow{3}{*}{ Taiwan } & (Domestic Mx) & 0.2 & 0.1 & 0.3 & 0.2 & 0.5 & 0.4 & 0.2 & 0.1 \\
\hline & (MAQ/M.G.) & 0.2 & 0.4 & 0.2 & 0.2 & 0.6 & 1.3 & 0.1 & 0.2 \\
\hline & Total East Asia & 3.0 & 10.0 & 2.7 & 6.1 & 7.6 & 29.2 & 2.3 & 8.2 \\
\hline \multirow{2}{*}{ Germany } & (Domestic Mx) & 1.3 & 0.7 & 0.4 & 0.4 & 1.9 & 1.2 & 2.6 & 1.0 \\
\hline & (MAQ/M.G.) & 0.2 & 0.8 & 0.2 & 0.4 & 0.4 & 1.6 & 0.1 & 1.3 \\
\hline \multirow{2}{*}{ France } & (Domestic Mx) & 0.4 & 0.2 & 0.2 & 0.1 & 0.8 & 0.4 & 0.2 & 0.2 \\
\hline & (MAQ/M.G.) & 0.1 & 0.2 & 0.2 & 0.1 & 0.3 & 0.4 & 0.1 & 0.2 \\
\hline \multirow{6}{*}{$\begin{array}{l}\text { United } \\
\text { Kingdom }\end{array}$} & (Domestic Mx) & 0.3 & 0.2 & 0.2 & 0.1 & 0.5 & 0.2 & 0.3 & 0.1 \\
\hline & (MAQ/M.G.) & 0.2 & 0.2 & 0.2 & 0.1 & 0.3 & 0.4 & 0.1 & 0.2 \\
\hline & Rest of Europe & 1.6 & 2.2 & 1.5 & 2.1 & 2.7 & 3.7 & 1.2 & 2.2 \\
\hline & Total Europe & 4.1 & 4.5 & 2.9 & 3.2 & 6.9 & 8.0 & 4.7 & 5.3 \\
\hline & Rest of the World & 2.2 & 4.6 & 2.7 & 4.5 & 3.3 & 9.0 & 1.4 & 3.4 \\
\hline & $\begin{array}{l}\text { Total final } \\
\text { manufacturing } \\
\text { production }\end{array}$ & 100.0 & 100.0 & 100.0 & 100.0 & 100.0 & 100.0 & 100.0 & 100.0 \\
\hline
\end{tabular}


First of all, firms in Mexico (Domestic) account for the largest share in the total value added structure of Mexico (total economy). The contribution of the domestic component decreased during the years studied here (from 57.5\% in 1998 to 51.1\% in 2011). Second, the value added contribution from the firms in Mexico (Domestic) sourcing intermediate inputs to firms in Mexico (Maquiladora/M. Global) increased from 1.6 to 5.4\%. Finally, the value added contribution from the firms in Mexico (Maquiladora/M. Global) was less than 5\% with some decline due to the external shocks of 2001 and 2008.

Of the three key manufacturing sectors considered in this paper, Transport Equipment and Textile products are the sectors that contribute the most to the total domestic value added in Mexico (Total). Nonetheless, in my view, the value added contribution from the Transport Equipment sector is the most important for total manufacturing in Mexico. This is mainly because of changes in the shares of textiles and transport equipment in the gross production of Mexico (Domestic) and Mexico (Maquila/M. Global), as described in table 5.1. In spite of the fact that the textile industry has a higher level of domestic value added in its total output than the transport sector, the textile industry has been experiencing a continuous decline in its share in the total output in each segment of the Mexican industry over time. Therefore, the opportunities for Mexico to pursue a process of upgrading (a higher level of domestic value added content) are primarily to be found in the transport sector.

We can now indicate how the effects from the increasing globalization of production express themselves in the structure of value added contributions for Mexico (total economy). On the one hand, the steady decline in the sourcing of intermediate inputs from US/Canada producers in the three most important manufacturing sectors in Mexico (i.e. Textiles, electrical and optical equipment and transport) resulted in a decline of the US/Canada value added share that can be observed at all three levels of analysis (Domestic, Maq./M.Global and, total). This decline offered opportunities for an increase in the value added share of foreign and domestic producers, that were differently exploited, depending on the sector in question. East Asian producers gained significant value added shares in the Electronic and optical equipment production in Mexico (Domestic) and even more so in Mexico (Maq./M. Global), where they now account for the largest share. ${ }^{36}$ This increase in electronics is the main source of the increasing East Asian value added share observed at the aggregate level in the total production of Mexico (total economy). On the other hand, firms in Mexico (Domestic) and Mexico (Maq./M. Global) have succeeded in increasing their value added share in the transport equipment and textile sectors. The increases in those two manufacturing sectors, however, have not been sufficient to achieve higher levels of domestic value added shares in the final manufacturing output of Mexico (Total). In the period studied, the total domestic value added share in Mexico (Total) has not changed much. There has been a minor decrease from $62 \%$ in 1998 to $61.5 \%$ in 2011.

\footnotetext{
36 The manufacturing subsectors within the Electrical and Optical equipment sector that do not enjoy an important modularity in their production (ovens, fridges, heaters) were less likely to reallocate their production in East Asian and opted for Mexico instead. But, the sector as a whole did increase its share in value added contributions.
} 


\subsection{Concluding Remarks.}

Mexican manufacturing is composed of two sets of firms: firms primarily producing for foreign markets (Maquiladora/ M. Global) and firms primarily producing for the domestic market (Domestic manufacturing of Mexico). This chapter tries to analyze how each component of the Mexican manufacturing was affected by the increasing globalization of manufacturing production. Moreover, our research tries to identify which countries and regions from the World economy succeed in capturing most of the value added embodied in Mexican exports, as well as the extent to which Mexico itself profits from its exports.

Our value added calculations confirm that in the context of increasing globalization of production, manufacturing firms in Mexico operate under local, regional and global value chains. Firms mostly producing for the domestic market (those in MexicoDomestic) operate in the context of local value chains with most of the value being added by Mexico (Domestic). Firms that produce for foreign markets (those in the Maquiladora industry) participate in local, regional and global value chains depending on the manufacturing sector. Thus, in order to identify the country or region that captures the highest value added contribution in the final output produced by Maquiladora/M. Global we need to analyze the conditions and factors that affect the nature of value added contributions. Those conditions include the type of good being produced, trade and tariff incentives, as well as the competitive advantages of the Mexican economy.

The pattern where firms in Mexico (Domestic) participate in local value chains and, firms in Mexico (Maquiladora/M. Global) participate in both local and regional or global value chains is the result of the new pattern of specialization of export producers since the beginning of the new millennium. Our results indicate that during the 1990s the total manufacturing production in Mexico was only local and regional. Mexico (Domestic) captured most of the value added embodied in its own final output, while the US captured most of the value added embodied in Maquiladora final output. The implementation of NAFTA, significant decreases in transport and communication costs and the emergence of more efficient producers in East Asia induced Maquiladora firms to specialize in manufacturing activities where Mexico offered the greatest competitive advantages, scaling down production of goods in which Mexico could not withstand the fierce international competition (textiles). The increasing globalization of production did not induce a new pattern of specialization for the firms in Mexico (Domestic), because those firms were not subject to significant competitive pressures (price, high quality standards, etc.) from low cost producers in supplying the domestic market.

In order to achieve success in the new patterns of specialization, maquiladora firms had to modify their sourcing behavior drastically. This resulted in a dramatic decline of imports of intermediate goods from the US. By 2005, maquiladora firms sourced most of their intermediate goods in the electronic industry from East Asia (China) and in the case of the transport equipment sector from Mexico. In some other manufacturing sectors, they continue to source their inputs from the US. Thus, Maquiladora firms now 
belong to local, regional as well as global value chains depending on the type of good being produced.

In my view, this pattern where maquiladora firms opt for global value chains in the electronic industry and for regional value chains in the transport industry (and in other manufacturing sectors) is a reflection of reallocation decisions by foreign (US) producers supplying intermediate inputs to the maquiladora industry. US producers who used to supply intermediate goods to maquiladora firms during the 1990s, reallocated their production either to East Asia (China) or to Mexico during the 2000s, in order to continue supplying intermediate goods to maquiladora firms. Those reallocation decisions were made considering trade and tariff incentives as well as the competitive advantages offered by each country in a particular manufacturing sector.

Our research also indicates that the pursuit of industrial upgrading in the context of this new pattern of specialization will remain a challenging task. The case of the transport equipment sector highlights to the fact that trade and tax incentives are only a necessary condition for higher levels of domestic value added content, not a sufficient one. Further regional cooperation and regulation is required between the neighboring countries that participate in the production of the final goods. Here, we are referring to the regional cooperation between the governments of Mexico and the United States, when signing the Bilateral Aviation Safety Agreement in 2007. This agreement recognizes the existence of North American production in the aerospace industry and was signed both in the interest of American firms producing in Mexico and in the interest of Mexico in acquiring technological capabilities from its neighbor. In my view, this agreement combined with tax incentives and NAFTA benefits is one of the main reasons behind the increase in the domestic value added contribution from Mexico in the transport equipment sector. This kind of regional value chain cooperation should be taken into account as a policy option for less developed economies to benefit from the increasing globalization of production.

Finally, it is important to note that in terms of value added creation manufacturing production in Mexico still benefiting more from the production for its domestic market, production for export markets. This is the case in spite of the increasing globalization of production, the new patterns of specialization in the production of Mexican exports and the drastic changes in the sourcing behavior of maquiladora firms that participate in local, regional and global value chains. During the period studied in this paper, the contribution of domestic inputs in creating value added in Mexico (Domestic) was much larger than that in Mexico (Maquiladora). This is true even if we consider the increasing domestic value added content of from maquiladora firms in the transport sector. As long as, Mexico (Domestic) has much stronger linkages with the rest of the domestic economy, the scope for maquiladora to induce industrial upgrading remains limited. 


\section{Appendix A5.1.}

\section{A5.1.1 Supply and Use tables for Mexico (Domestic) and Mexico (Maquiladora/ Manufactura Global).}

The first step taken by our research was to define the set-up for the supply and use tables of maquiladora/manufactura global and domestic economy of Mexico. This set up is presented in figure A5.1.

Figure A5.1: Supply and Use Tables for Mexico (Domestic Economy) and Mexico (Maquiladora/M. Global).
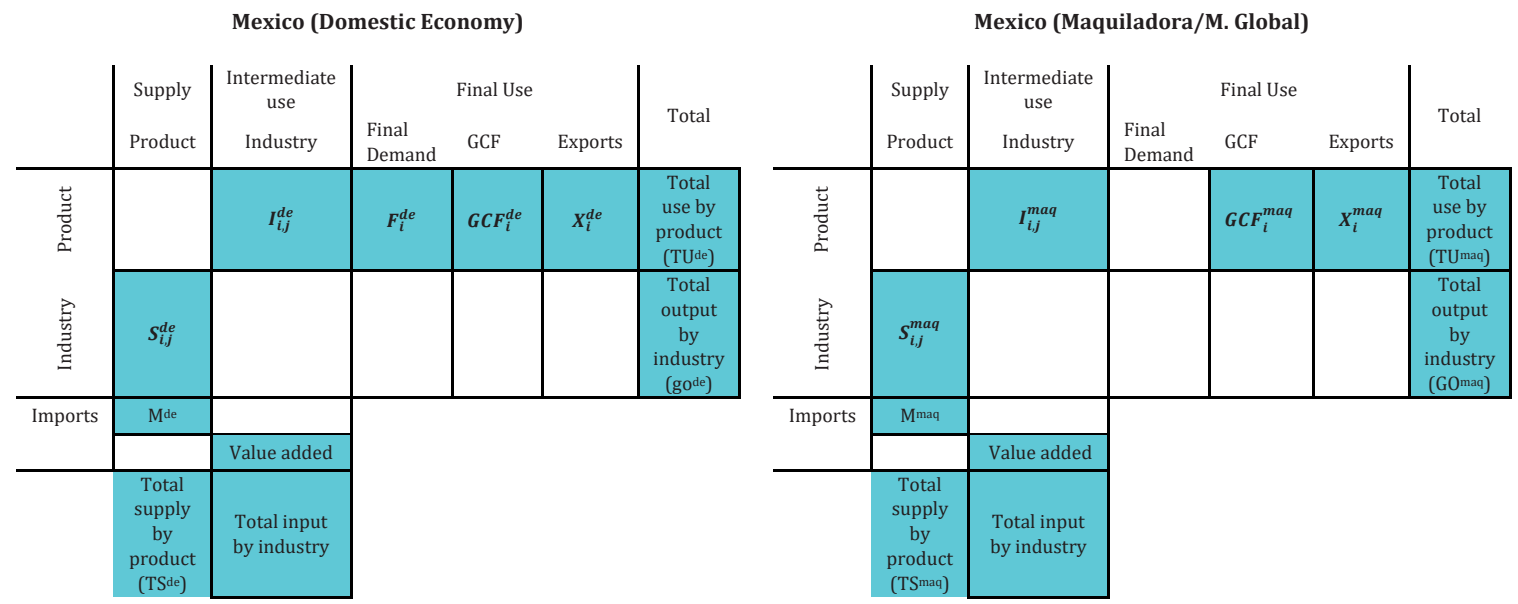

Notes: (de) refers to Domestic Economy and (maq) refers to Maquilladora/M. Global

Let $\mathrm{S}$ denote supply and $\mathrm{M}$ imports, subscripts $\mathrm{i}$ and $\mathrm{j}$ denote products and industries respectively. Superscript (de) stands for domestic economy of Mexico and (maq) indicate maquiladora/manufactura global. Then, total supply (TS) for each product (i) will be given by the summation of supply and imports as follows;

$$
\begin{aligned}
T S_{i}^{d e} & =\sum_{j} S_{i, j}^{d e}+M_{i}^{d e} \\
T S_{i}^{m a q} & =\sum_{j} S_{i, j}^{m a q}+M_{i}^{m a q}
\end{aligned}
$$

Total use (TU) should be determined by the summation of final demand (F), gross capital formation (GCF), exports (X) and intermediate use (I). This identity will only hold for the domestic economy of Mexico. In the case of the maquiladora, total use will not consider the concept of final demand given that this industry does not consume final goods. Therefore;

$$
\begin{aligned}
& T U_{i}^{d e}=\sum_{j} I_{i, j}^{d e}+F_{i}^{d e}+G C F_{i}^{d e}+X_{i}^{d e} \\
& T U_{i}^{m a q}=\sum_{j} I_{i, j}^{m a q}+G C F_{i}^{m a q}+X_{i}^{m a q}
\end{aligned}
$$

Then, the identity of supply and use for each concept will be given for the domestic economy as follows

$$
\sum_{j} S_{i, j}^{d e}+M_{i}^{d e}=\sum_{j} I_{i, j}^{d e}+F_{i}^{d e}+G C F_{i}^{d e}+X_{i}^{d e}
$$

And for the maquiladora; 


$$
\sum_{j} S_{i, j}^{m a q}+M_{i}^{m a q}=\sum_{j} I_{i, j}^{m a q}+G C F_{i}^{m a q}+X_{i}^{m a q}
$$

The second accounting identity will be written as follows:

$$
\begin{array}{ccc}
\sum_{j} T S_{i, j}^{d e}=V A_{j}^{d e}+\sum I_{i, j}^{d e} & \forall j & \text { (5.4.1) for the domestic economy } \\
\sum_{j} T S_{i, j}^{m a q}=V A_{j}^{m a q}+\sum I_{i, j}^{m a q} & \forall j & \text { (5.4.2) for the maquiladora/m. global }
\end{array}
$$

This identity indicates that for each industry the total value of output (at the left hand side) is equal to the total value of inputs (right hand side). The latter is given by the sum of value added (VA) and intermediate use of products.

\section{A5.1.2. International Supply and Use tables for Mexico (Domestic) Mexico (Maquiladora/M. Global)}

With this information in mind, we proceed to calculate the international supply and use tables. An international use table is an extension of the national use table. The main difference with respect to the national use table is that the international use table explicitly indicates the use of each product by country of origin. Therefore, in order to continue a split must be made between the products that were imported and those that were domestically produced. Equations (5.5.1), (5.5.2) (5.6.1) and (5.7.1) indicate the intermediate consumption, final demand and gross capital formation for each of the two components of the Mexican economy respectively. The first superscript (de/maq) indicates the component of the Mexican economy, while the second superscript $(\mathrm{dom} / \mathrm{m})$ indicates domestic or imported origin respectively. For instance, $I_{i}^{\text {de dom }}$ indicates the domestic intermediate consumption by the domestic economy of Mexico, and $I_{i}^{d e} m$ stands for the imported intermediate consumption by the domestic economy of Mexico. Thus;

$$
\begin{array}{ll}
I_{i, j}^{d e}=I_{i, j}^{d e d o m}+I_{i, j}^{d e m} & \forall i, j \\
I_{i, j}^{\text {maq }}=I_{i, j}^{\text {maq dom }}+I_{i, j}^{\text {maq }} m & \forall i, j \\
F_{i}^{d e}=F_{i}^{\text {de dom }}+F_{i}^{\text {de } m} & \forall i \\
G C F_{i}^{\text {de }}=G C F_{i}^{\text {de dom }}+G C F_{i}^{\text {de } m} & \forall i \\
G C F_{i}^{\text {maq }}=G C F_{i}^{\text {maq } m} & \forall i
\end{array}
$$

In this context, equation (5.81 and 5.8.2) show the supply for the domestic economy and for the maquiladora industry, respectively. As can be seen, the supply of the domestic economy contains the domestic intermediate goods produced by the domestic economy and delivered to the maquiladora $\left(I_{i, j}^{\text {maq dom }}\right)$. Similarly, the supply of the maquiladora equals the total exports from this industry as all the production is to be exported.

$$
\begin{aligned}
& \sum_{j} S_{i, j}^{d e}=\sum_{j} I_{i, j}^{\text {de dom }}+\sum_{j} I_{i, j}^{\text {maq dom }}+F_{i}^{d e d o m}+G C F_{i}^{d e d o m}+X_{i}^{d e} \forall i, j \\
& \sum_{j} S_{i, j}^{\text {maq }}=X_{i, j}^{\text {maq }} \quad \forall i, j
\end{aligned}
$$

Finally, we also split the total imports from each component of the Mexican economy as follows:

$$
\begin{array}{ll}
M_{i, j}^{d e}=I_{i, j}^{d e m}+F_{i}^{d e m}+G C F_{i}^{d e m} & \forall i, j \\
M_{i, j}^{\text {maq }}=I_{i, j}^{\text {maq } m}+G C F_{i}^{\text {maq } m} & \forall i, j
\end{array}
$$


On the basis of this information, figure A5.2 presents a set up for the international supply and use tables for Mexico (Domestic), Mexico (Maquiladora/M. Global). Here, all the information presented in previous equation is allocated according to their use (intermediate or final) and according to their origin (domestic or imported by country of origin).

Figure A5.2: International SUT for Mexico (Domestic), Mexico (Maquiladora/M. Global).

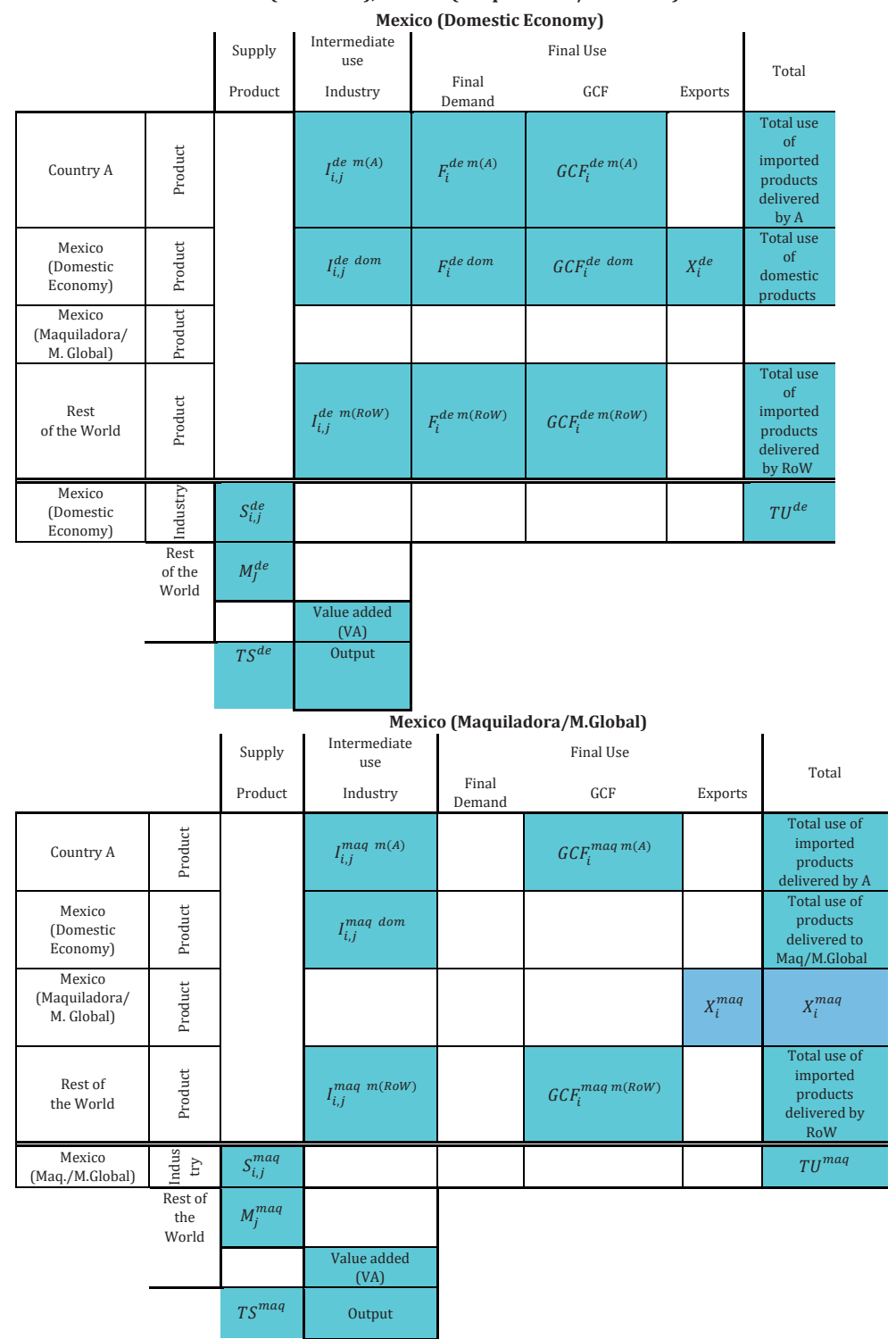

Notes: the first superscript indicates the main component being studied (Domestic Economy or Maq/M. Global) and the second superscript indicates origin from goods (domestic or imported). For instance $I_{i, j}^{m q q} m(\mathrm{RoW})$ indicates intermediate imports delivered by the Rest of the World to the maquiladora/m. global.

In order to construct those international use tables, we need to break down imports by country of origin and by use category. Following Timmer et al. (2014), this step requires 
international trade statistics that are to be benchmarked with the official data from the national accounting system by which the national SUTS were built. That step was followed in order to ensure consistency between the data in the national and international use tables.

Formally, let $m_{i, k}^{l}$ indicate the share of use categories $\boldsymbol{I}$ (intermediate, final consumption or investment) in imports of product $\boldsymbol{I}$ delivered by a particular country $\boldsymbol{k}$ to a component of the Mexican economy $\boldsymbol{\alpha}$ (domestic economy or maquiladora/m.global) defined as follows.

$$
m_{i, k}^{\alpha l}=\frac{\widetilde{M}_{i, k}^{\alpha l}}{\widetilde{M}_{i}^{\alpha}} \text { such that } \sum_{k} \sum_{l} m_{i, k}^{\alpha l}=1
$$

where $\widetilde{M}_{i, k}^{\alpha l}$ is the total value from all 6-digit products that are classified by use category $\mathbf{I}$ and WIOD product group $\boldsymbol{i}$ imported from country $\boldsymbol{k}$ (and delivered to component $\boldsymbol{\alpha}$ ), and $\widetilde{M}_{i}^{\alpha}$ the total value of WIOD product group $\boldsymbol{i}$ imported by component $\boldsymbol{\alpha}$ of the Mexican economy. These shares have to be derived from the bilateral trade statistics and applied to the total imports of product $\boldsymbol{I}$ by component $\boldsymbol{\alpha}$ of the Mexican economy as given in the SUT time series to derive their imported use categories. In this context $I_{i, k}^{\alpha m}$ is the amount of product group $\boldsymbol{i}$ imported from country $\boldsymbol{k}$ and used as intermediate by industry $\boldsymbol{j}$ in component $\boldsymbol{\alpha}$ of the Mexican economy.

$$
I_{i, k}^{\alpha m}=m_{i, k}^{\alpha I} M_{i}^{\alpha} \frac{I_{i, j}^{\alpha}}{I_{i}^{\alpha}} \quad \forall j
$$

Where $I_{i}^{\alpha}=\sum_{j} I_{i, j}^{\alpha} \quad \forall i$ such that $\frac{I_{i, j}^{\alpha}}{I_{i}^{\alpha}}$ is the share of intermediates of product $\boldsymbol{i}$ used by industry $\boldsymbol{j}$ in each component $\boldsymbol{\alpha}$ of the Mexican economy.

By definition, it is only the domestic economy of Mexico that demands goods for final demand and for gross capital formation. Therefore, our research did not modify that data original reported by WIOD on their international use tables for the total economy of Mexico. We simply transfer them to our international use tables and relabeled them as the final demand and gross capital formation for the Domestic economy of Mexico. Finally, in the case of the imported gross capital formation for the Maquiladora and M. Global, we obtained that data from our trade data statistics after classifying its bilateral import by its corresponding BEC category. Afterwards, we simply allocate those gross capital imports classified by product category in the columns for gross capital formation (there will be no changes in inventories for the Maquiladora/M. Global). This is because of the fact that official imported use table for the maquiladora does not provide gross capital categories so we cannot benchmarked them. 


\section{A5.1.3 .International SUT for the Rest of WIOD Countries Including Mexico (Domestic) and Mexico (Maquiladora/Manufactura Global).}

Figure A5.3 presents the set up for an international use table for the rest of WIOD countries where Mexico (Domestic) and Mexico (Maquiladora/M. Global) are included. Here, we assume that the domestic economy of Mexico delivers goods for intermediate use, final demand and gross capital formation. On the other hand, it is assumed that the maquiladora/m. global only delivers goods for final demand. Therefore, our research decided that we only needed to calculate the columns for final demand delivered by the domestic economy of Mexico $\left(F_{i}^{a} m(d e)\right.$ ) and by Maquiladora/M. Global $\left(F_{i}^{a m(m a q)}\right)$. This means that the data for intermediate goods and gross capital formation demanded by WIOD countries and delivered by Mexico (as initially reported by WIOD) will remain unaltered. We will simply re-label them as the intermediate goods and gross capital formation delivered by the domestic economy of Mexico.

Figure A5.3: International SUT for WIOD countries including Mexico (Domestic), Mexico (Maquiladora/M. Global).

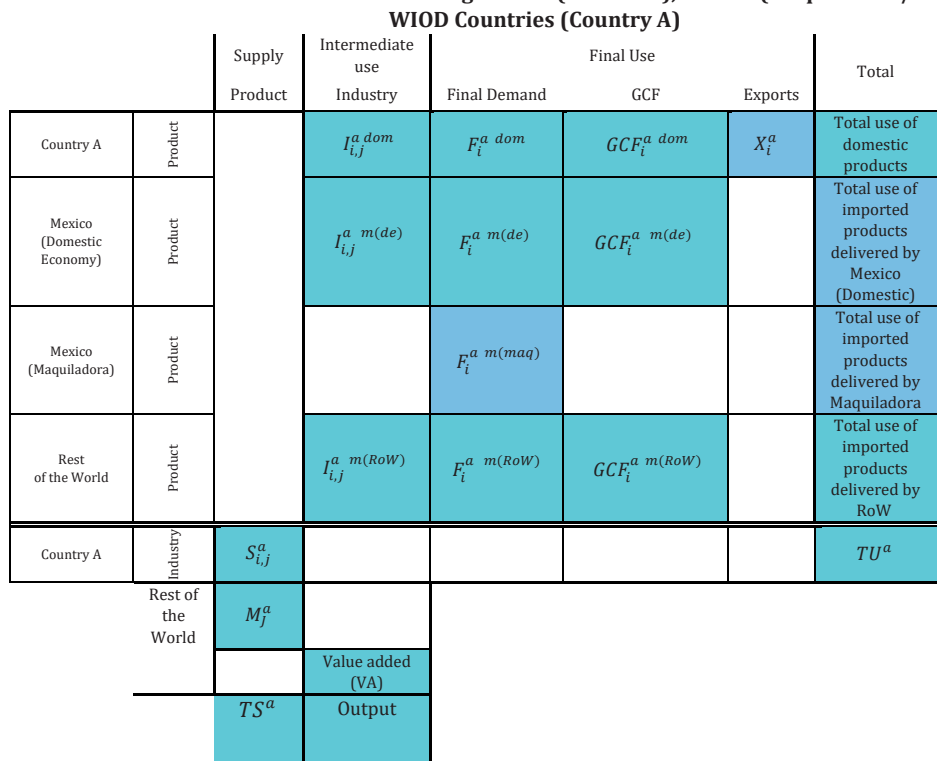

Notes: the first superscript indicates the main country being studied and the second superscript indicates origin from goods (domestic or imported). For instance $I_{i, j}^{a} m(R o W)$ indicates intermediate imports delivered by the Rest of the World to country A.

In calculating the final demand deliveries by Mexico (Domestic) to the rest of WIOD countries, ideally we would have to find the difference between the data originally provided by WIOD and our specific data for Mexico (Maq/M. Global). This is because, in principle, the data originally provided by WIOD in the international use tables for the rest of WIOD countries contains both Maquila and Domestic economy deliveries. In doing that, however, we found that our Maq/M. Global export data was in many case much larger than the one originally provided in WIOD for the case of Mexico. This issue is explained by the fact that (when constructing those tables) WIOD relied on the imports reported by each country and that our data for Maq/M. Global in this specific international use tables needs to rely on the data for exports. Therefore, in order to exclude negative values and ensure the consistency of our results, our research will also assume that the final demand deliveries originally reported by WIOD for the case of the total economy of Mexico correspond to the those deliveries by the Domestic Economy of Mexico. 
Relying in Maq/M. Global bilateral exports is a crucial step in constructing international SUTs like the one in figure A5.3. This is because there is no other alternative way by which we can indicate how the Maq/M. Global gross production in each of the WIOD countries. Furthermore, we are confident that aforementioned assumption will not severely bias our results given that the bulk of manufacturing exports from Maq/M. Global go to the United States.

Formally, let $x_{i, k}^{\text {maq }}$ indicate the share of final demand use in exports of product $\boldsymbol{i}$ delivered by Maq/M. Global to particular country $\boldsymbol{k}$ defined as follows.

$$
x_{i, k}^{m a q}=\frac{\tilde{x}_{i, k}^{m a q}}{\tilde{X}_{i}^{\text {maq }}} \text { such that } \sum_{k} x_{i, k}^{m a q}=1
$$

where $\tilde{X}_{i, k}^{\text {maq }}$ is the total value from all 6-digit products that are classified by product group $\boldsymbol{i}$ exported by Maq/M. Global and delivered to country $\boldsymbol{k}$, and $\tilde{X}_{i}^{\text {maq }}$ the total value of WIOD product group $\boldsymbol{i}$ exported by Maq/M Global. These shares have to be derived from the bilateral trade statistics and applied to the total exports of product $\boldsymbol{i}$ from Maq/M. Global. Finally, that value is applied to the final demand share of use category from the rest of WIOD countries (as given in their SUT time series) to derive the necessary imported final use categories. In this context $F_{i}^{k m(m a q)}$ is the amount of product group $\boldsymbol{i}$ imported from Maq/M. Global and used as final demand in country $\mathrm{k}$

$$
F_{i}^{k m(m a q)}=x_{i, k}^{m a q} X_{i}^{m a q} \frac{F C_{i, f}^{k}}{F C_{i}^{k}}
$$

Where $\frac{F C_{i, f}^{k}}{F C_{i}^{k}}$ is the share of final demand goods by use categories in country $\mathrm{k}$.

Once we had all the international SUT for Mexico (Domestic), Mexico (Maquiladora/Manufactura Global) and the rest of WIOD countries, we proceeded to calculate the WIOT which is presented in Figure A.1.4. Following WIOD, we transformed all the international SUT into world inputoutput structure by means of the "fixed product-sales structure" assumption. This assumption states that each product has its own specific sales structure irrespective of the industry where it is produced. Sales structure here refers to the proportions of the output of the product in which it is sold to the respective intermediate and final users. 


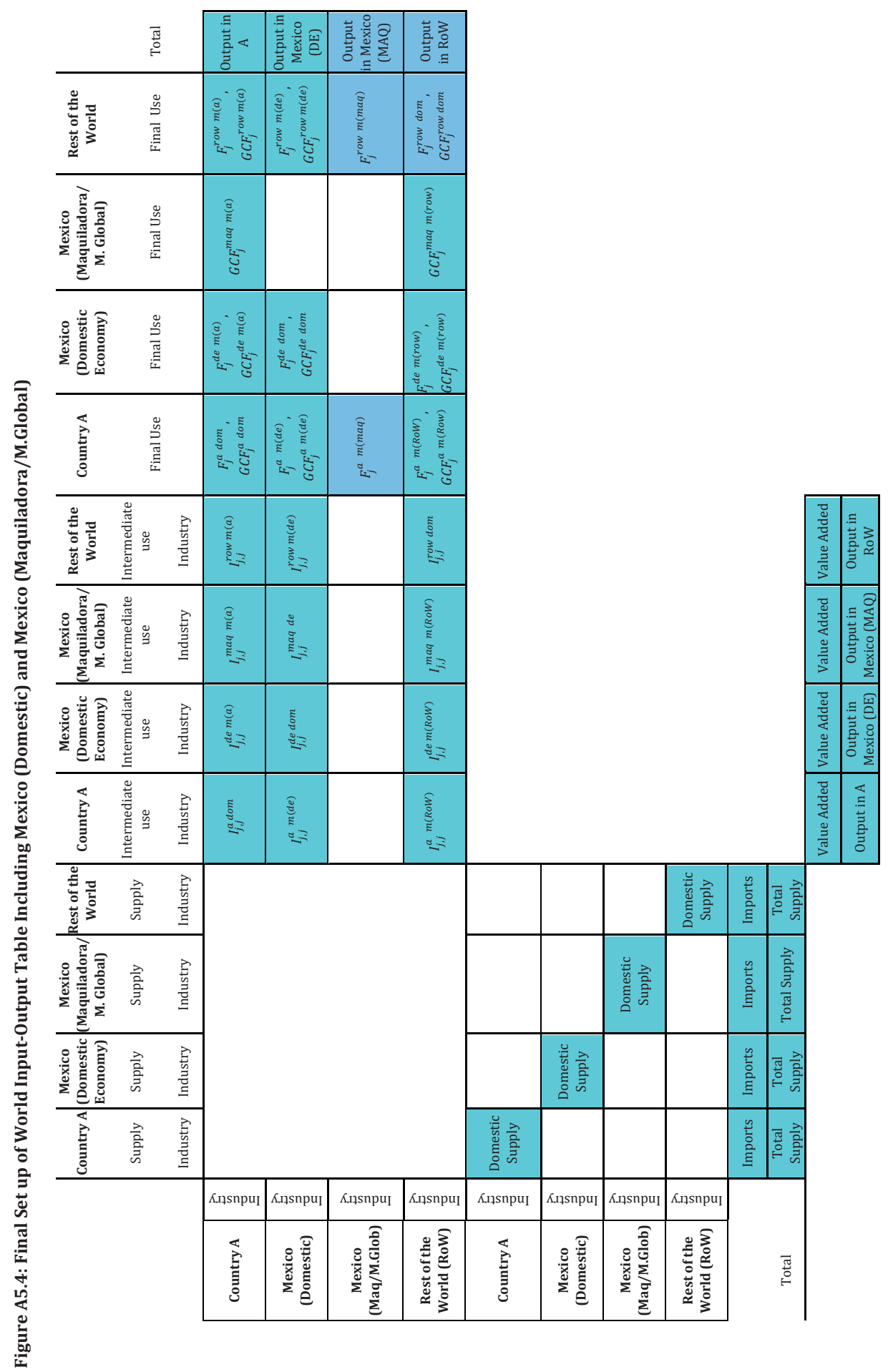




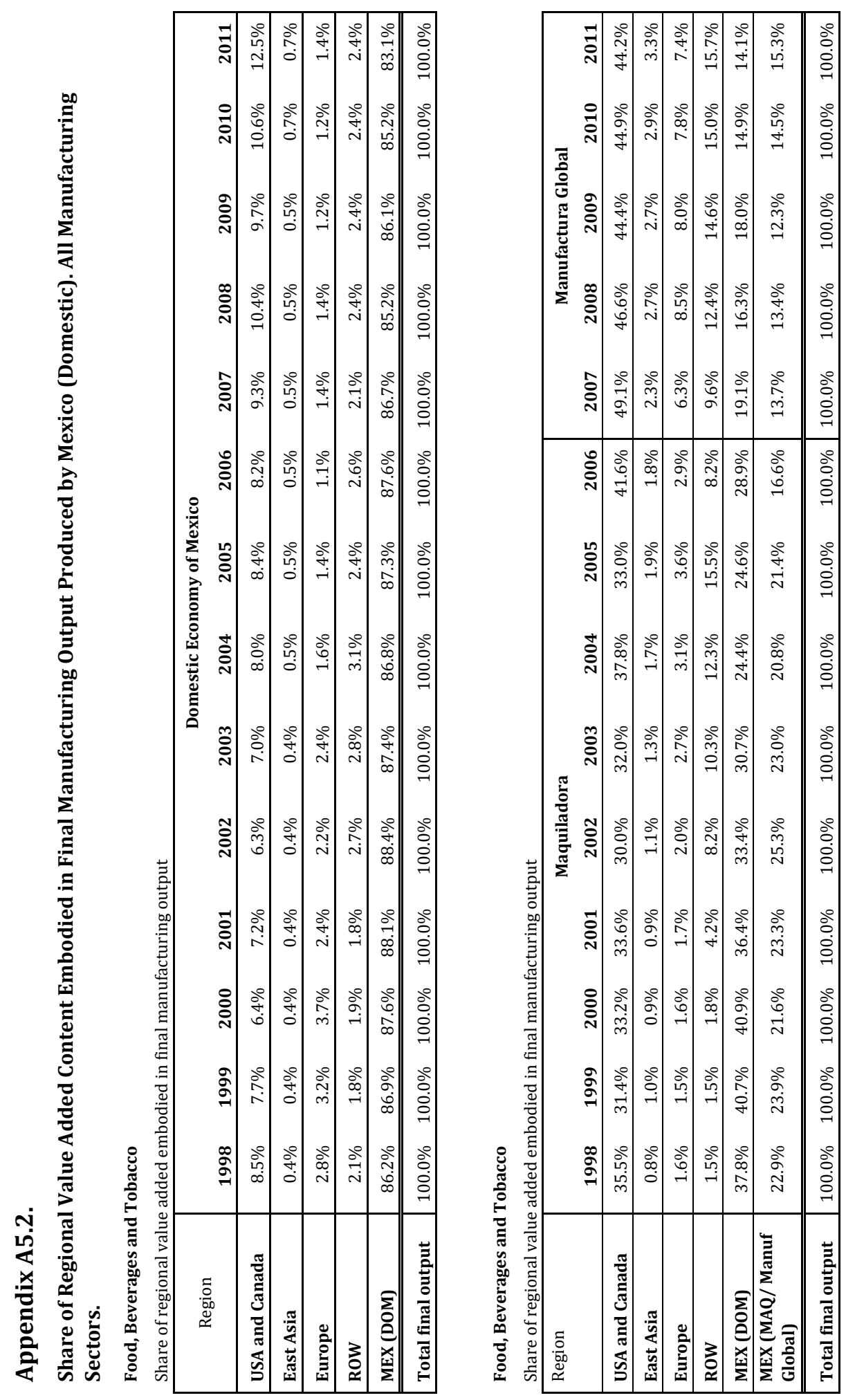



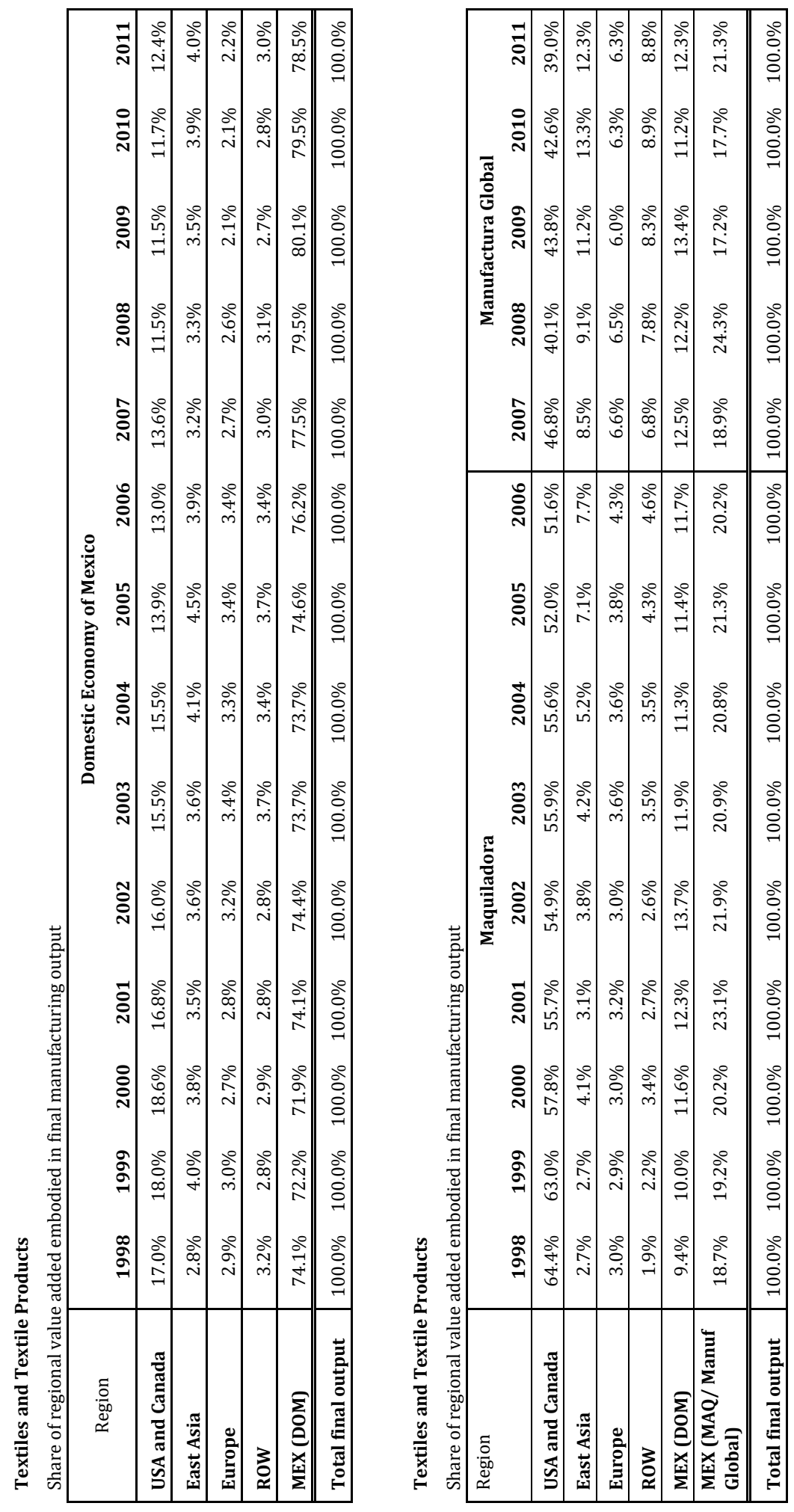


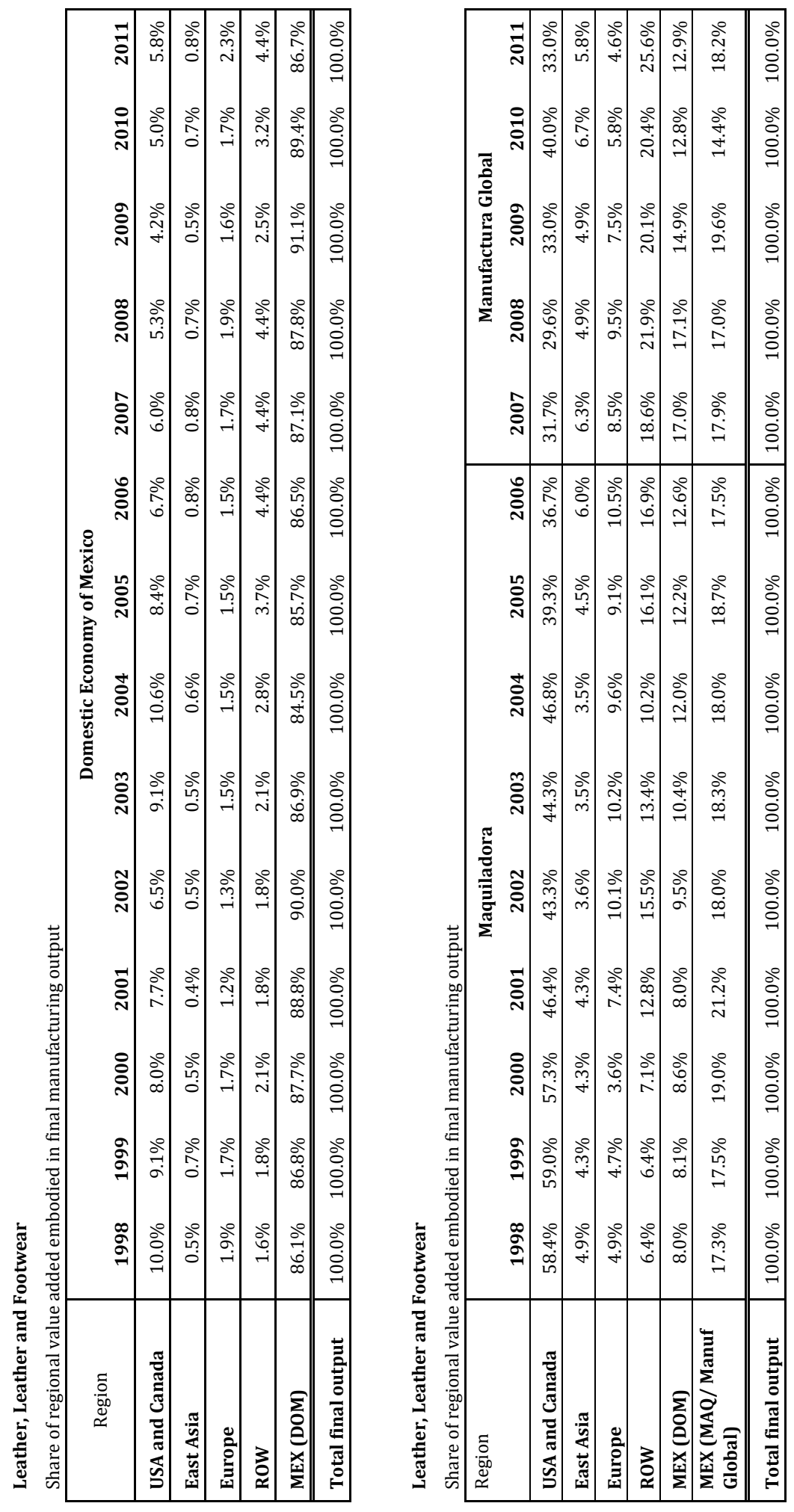




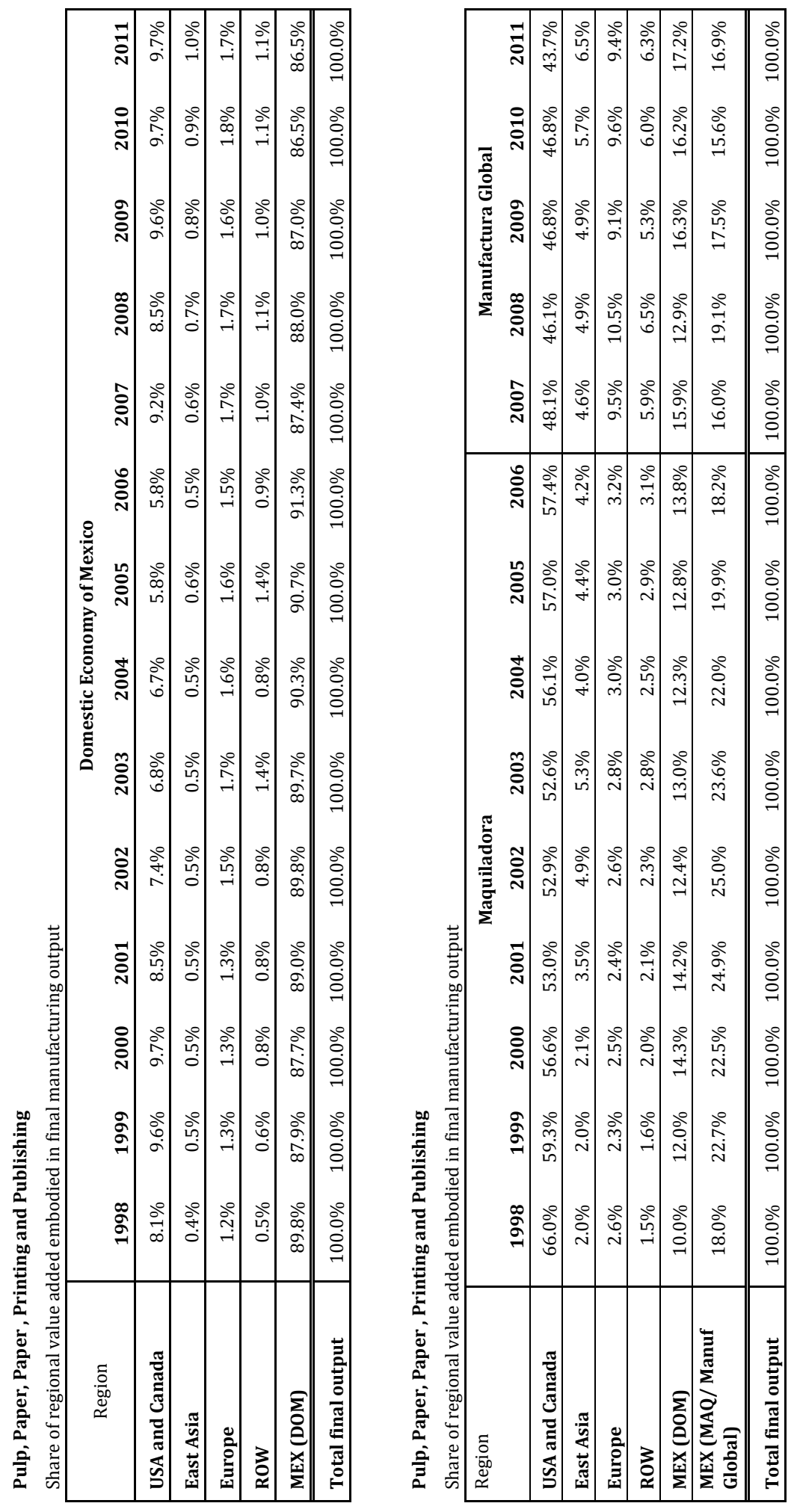




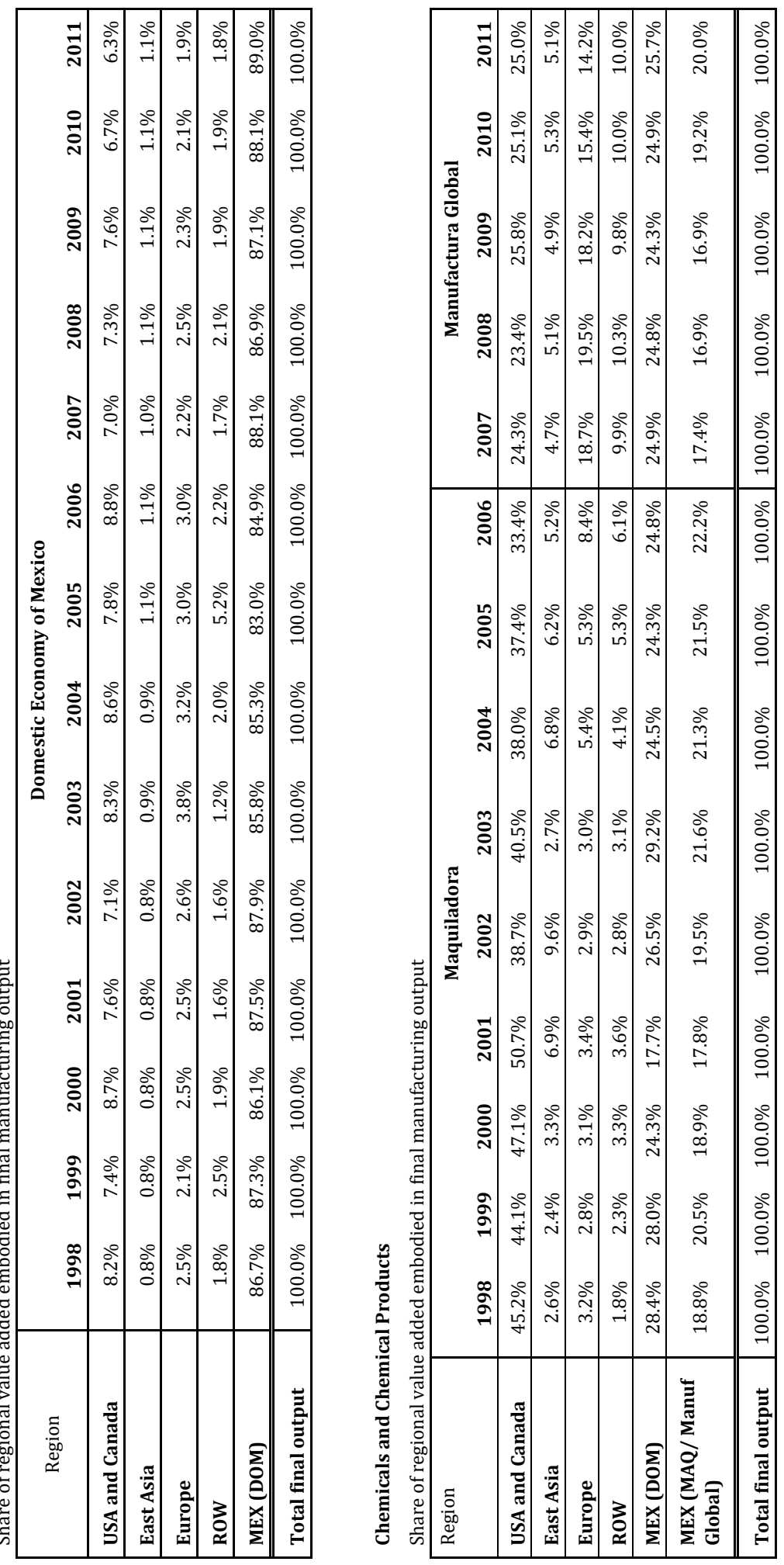



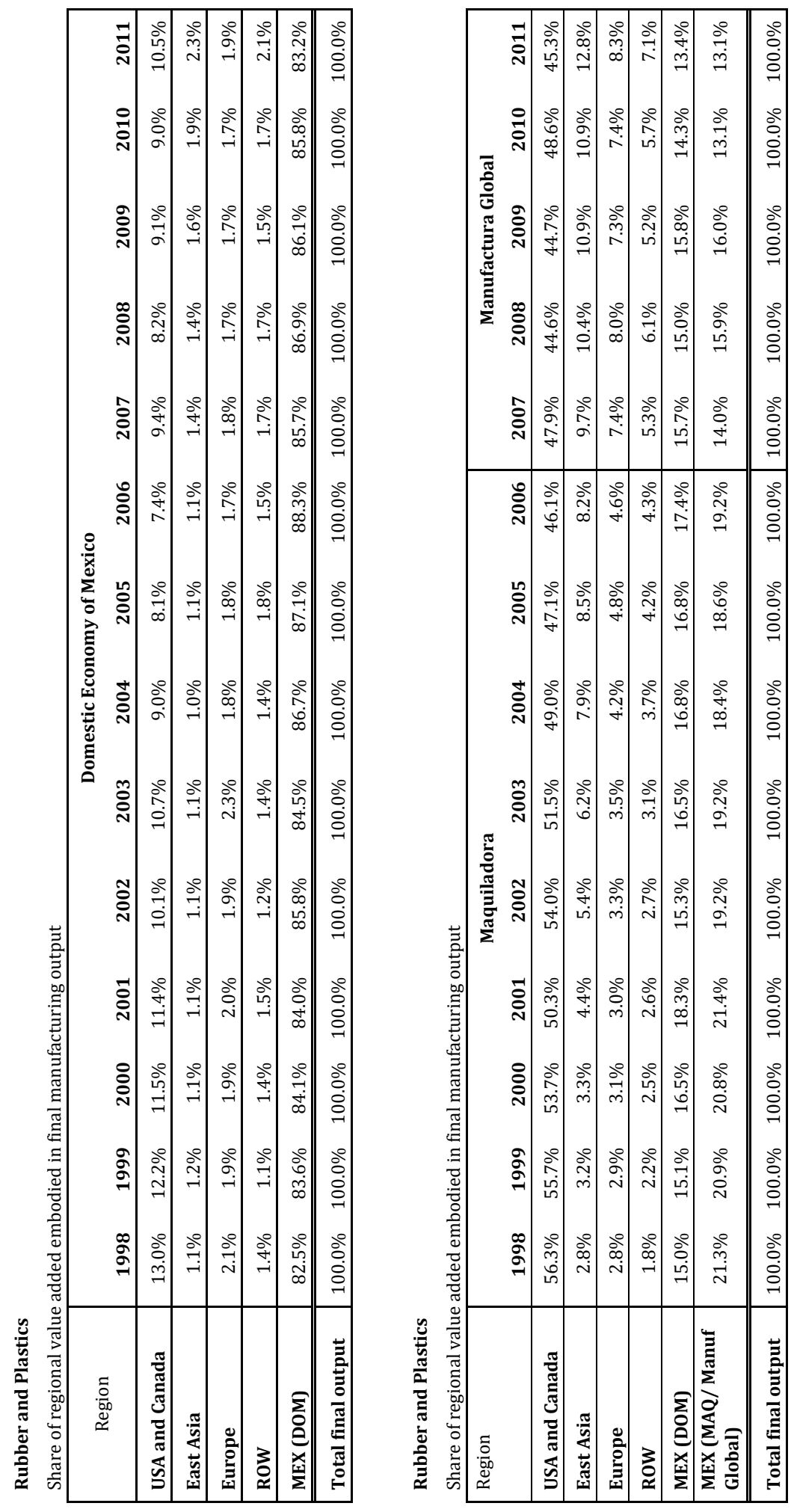


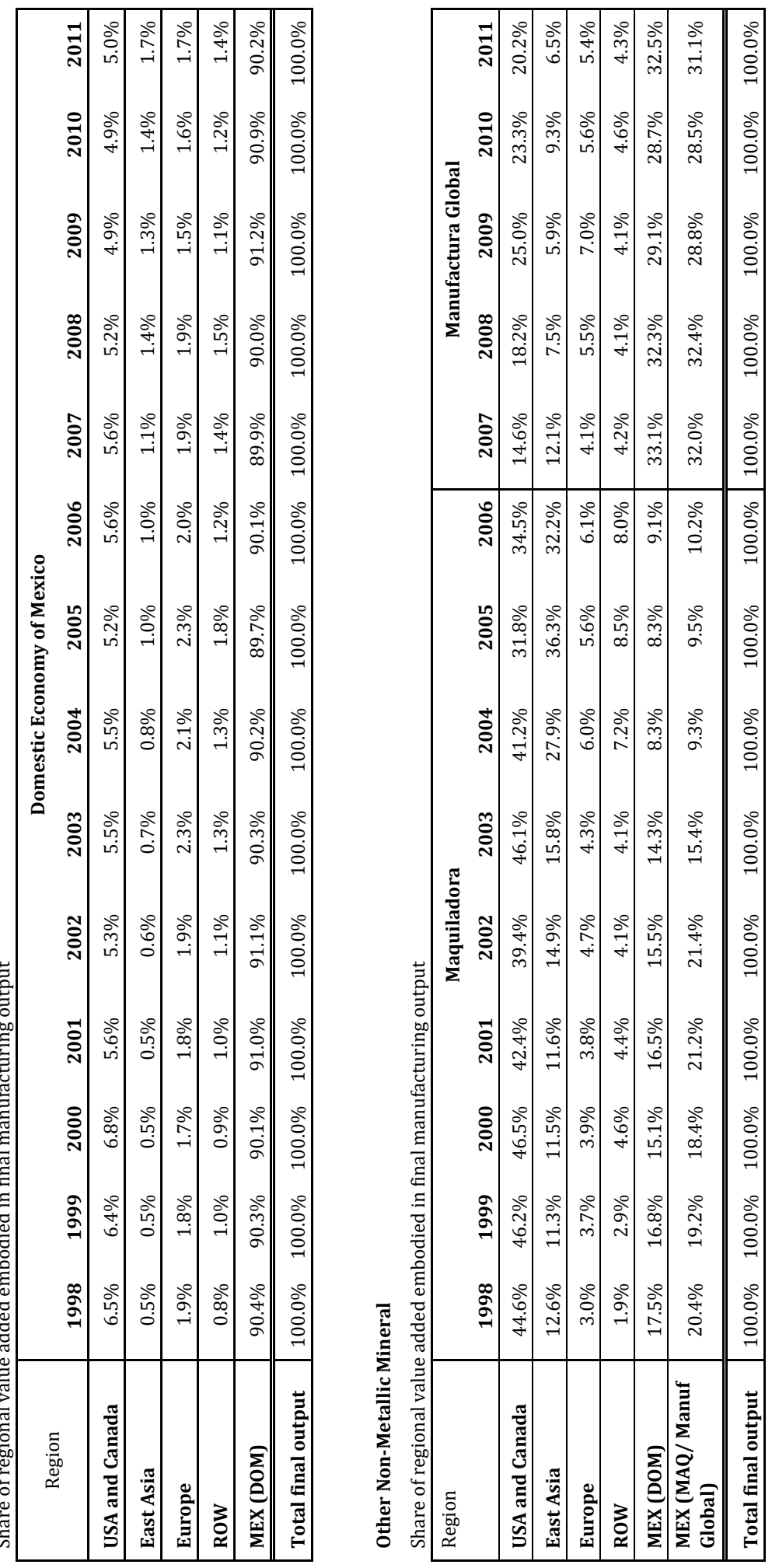



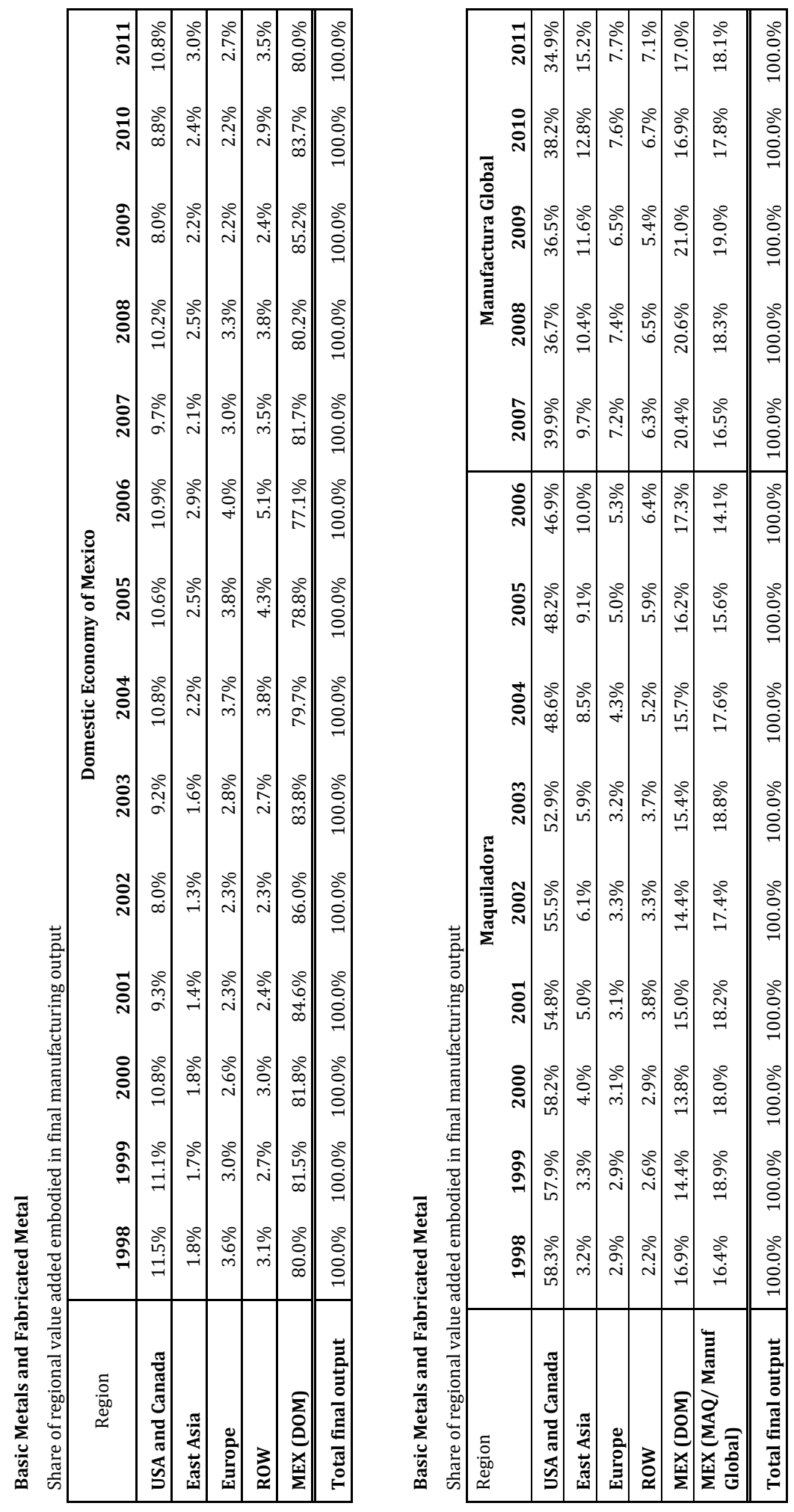


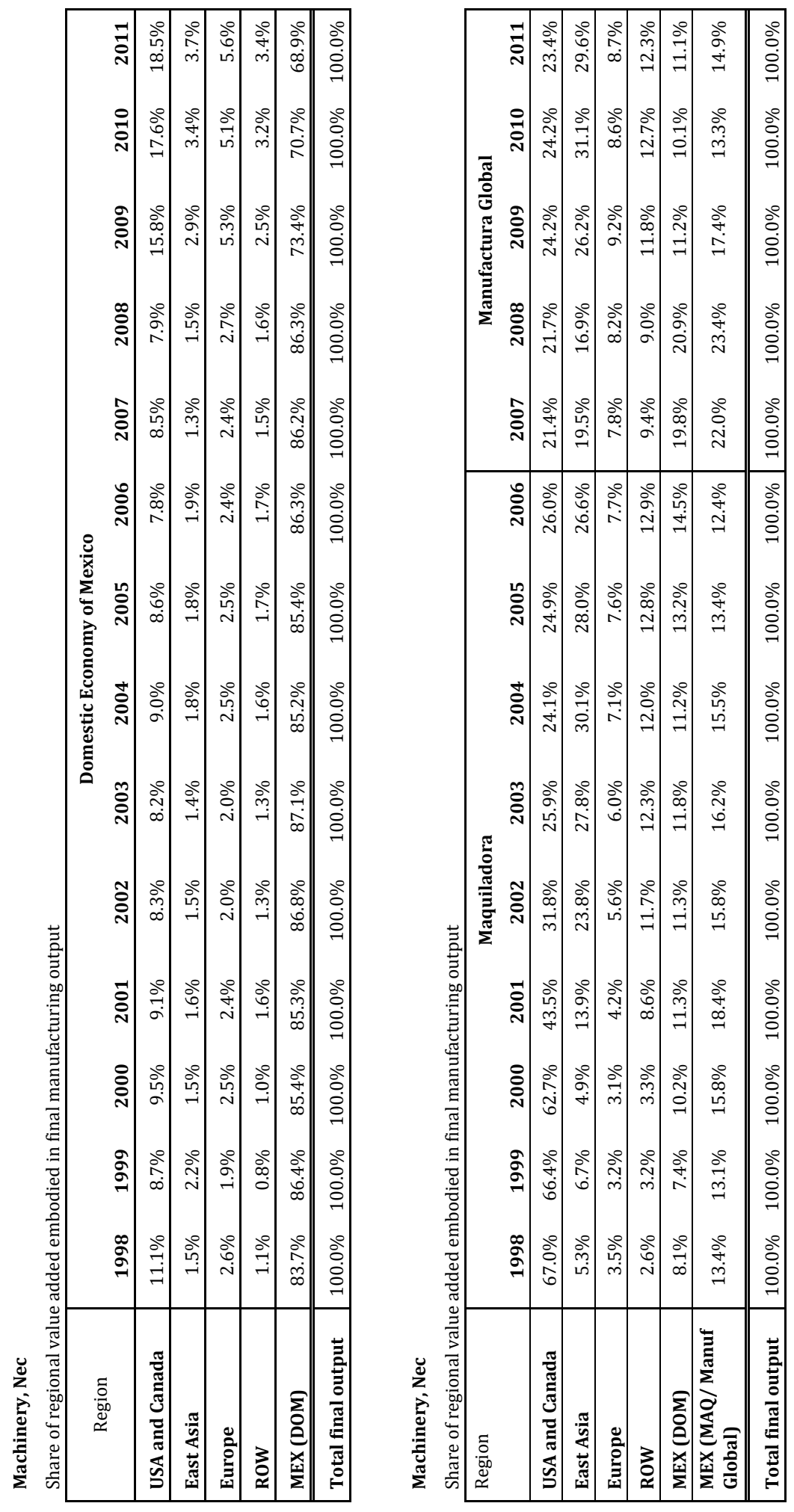




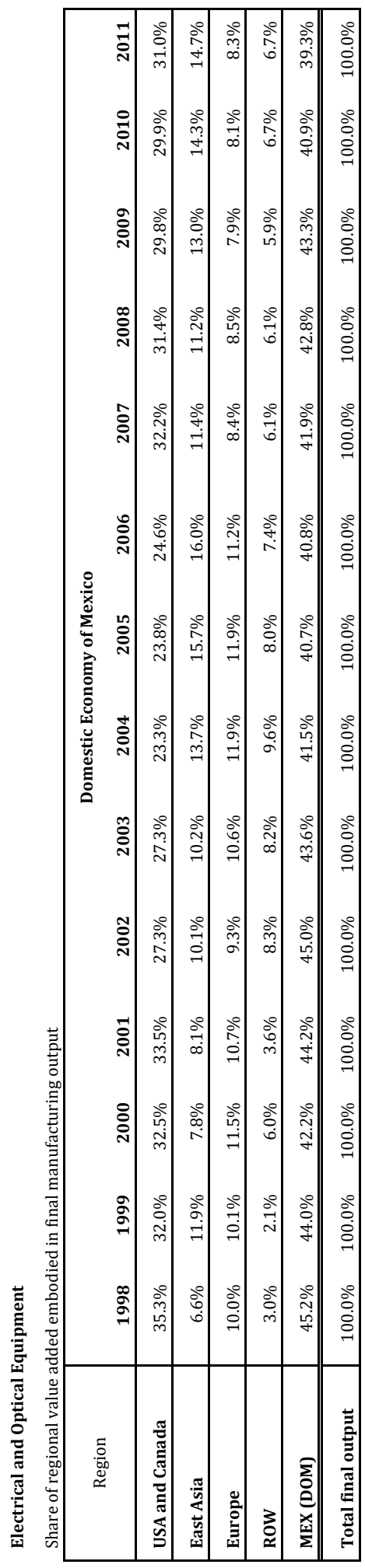

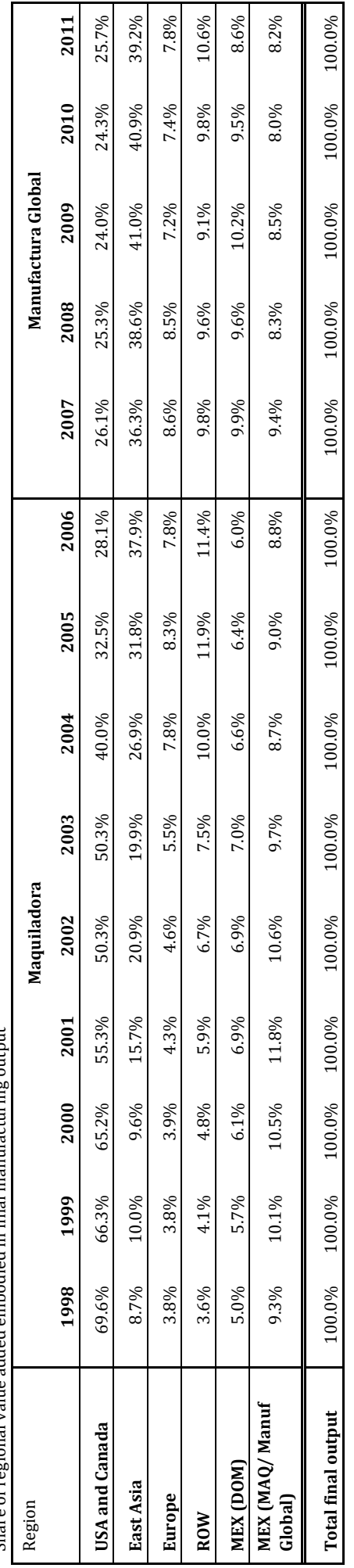




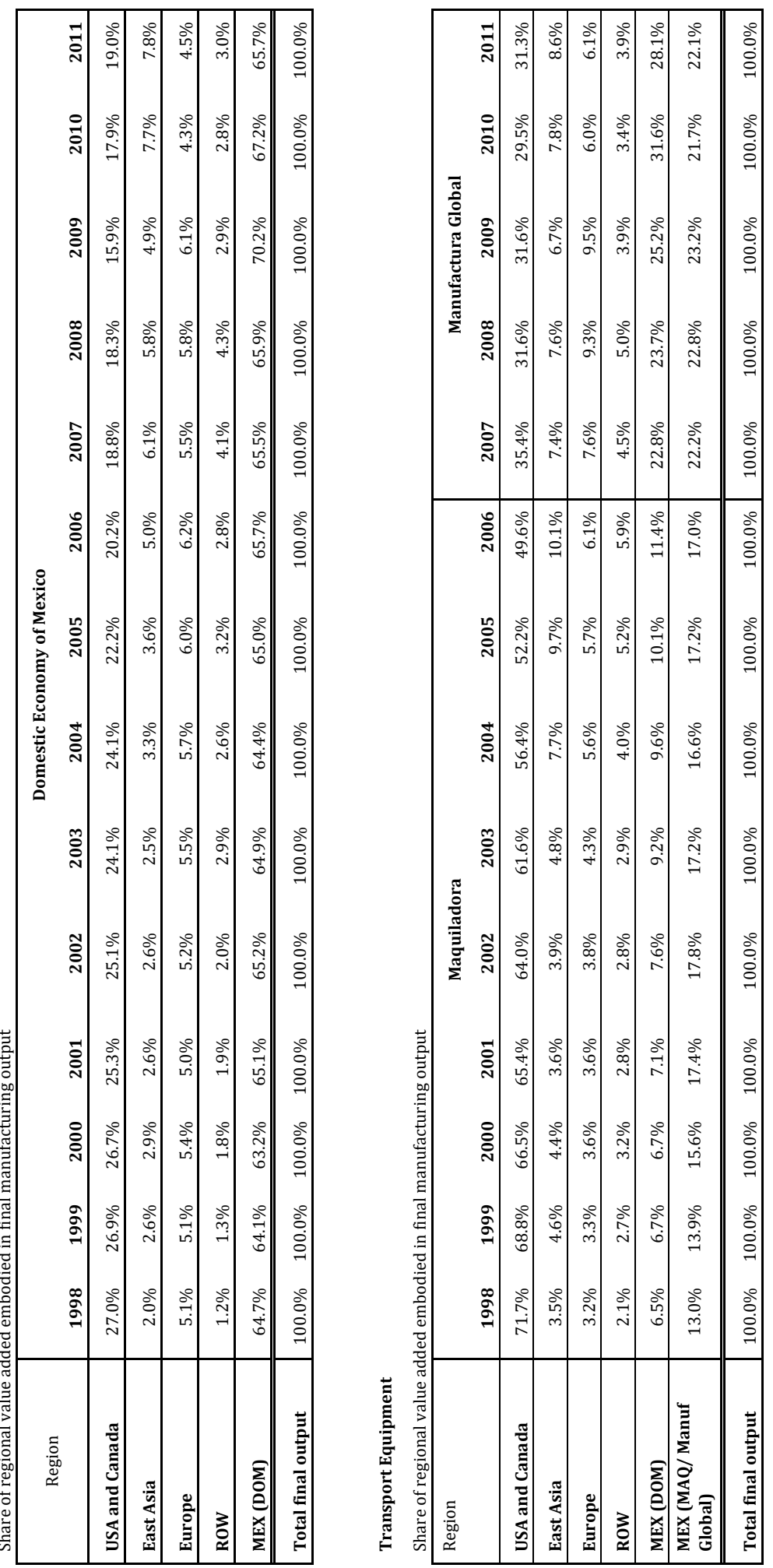



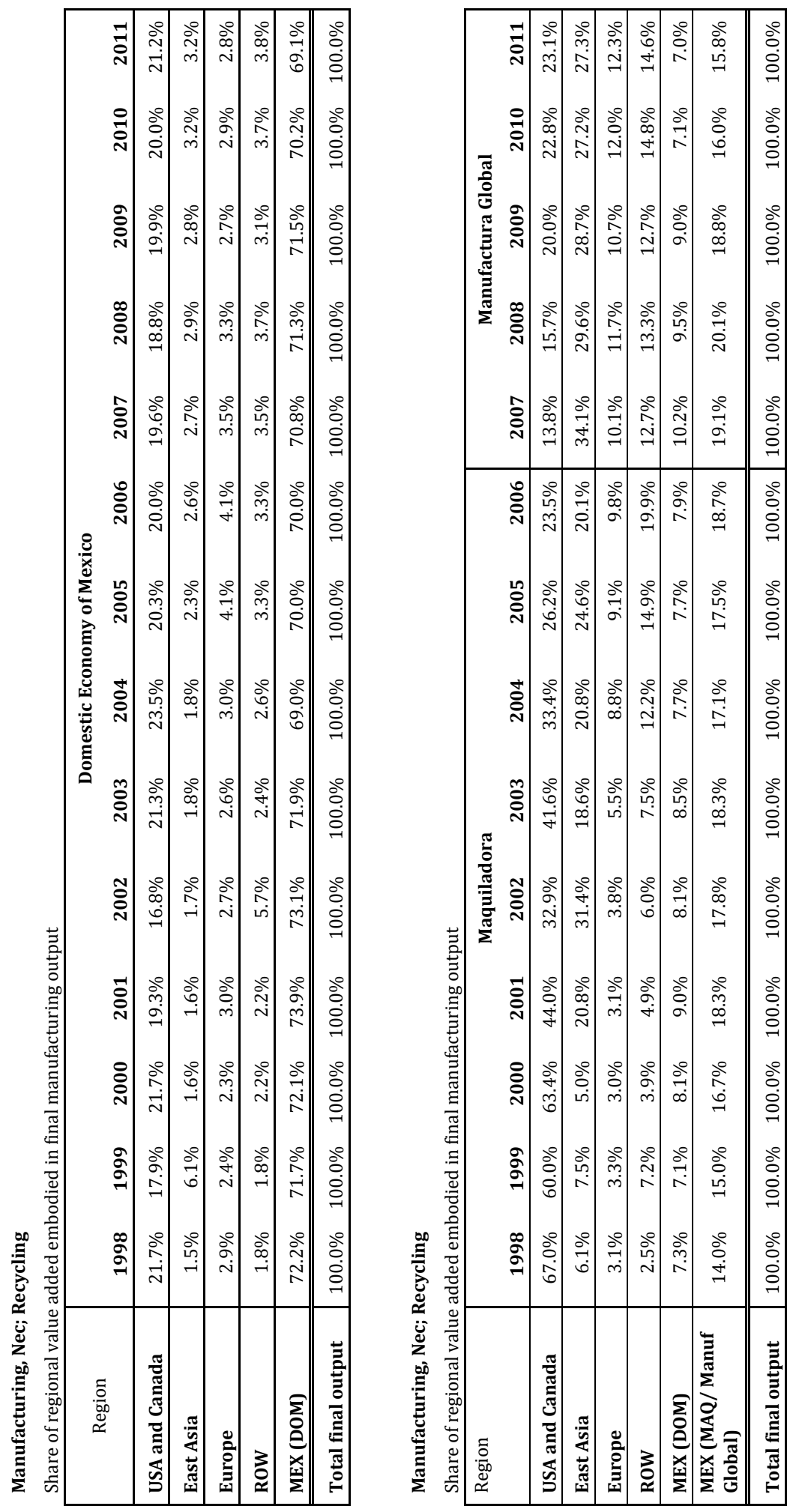



\title{
Chapter 6
}

\section{The Micro-foundations of Productivity and of Productivity Growth in Mexico's Exporting sector: 1990-2014**}

\begin{abstract}
This chapter studies labor productivity (and labor productivity growth) in Mexico's export promoting programs, both at the aggregate level and the firm level. To this end, we rely on official firm-level information for the Maquiladora industry (1990-2006) and on data for Mexico's new exporting program known as IMMEX (2007-2014). At the aggregate level, our findings indicate that the exporting sector does not contribute much to increases in aggregate labor productivity. Changes in labor productivity in domestic manufacturing drive productivity trends in total Mexican manufacturing. Upgrading (increases in value added output ratios) by exporting firms appears to have no role in productivity growth, and we even find that there is a negative but small contribution to productivity from changes in the value added to output ratio. At the micro-level, we find that the firms in the maquiladora dataset (up to 2007) are rather different from firms in the IMMEX dataset (from 2007). We identify GVC-intensive and non-GVC intensive firms in the IMMEX dataset, and find differences between them, and relative to the maquiladora firms, in terms of the microeconomic determinants of labour productivity.
\end{abstract}

JEL Codes: F14, L6.

Keywords: Firm-level, Maquiladora, IMMEX, Global Value Chains, Mexico.

\footnotetext{
**This chapter has been co-authored with Bart Verspagen and Adam Szirmai (UNU-MERIT). The authors would like to thank Dirección General de Acceso a Microdatos from Instituto Nacional de Estadística e Informática (INEGI) for their help and kind support during the remote processing of numerous do-files. In particular, we would like to thank Natalia Volkow, Liliana Martínez, Carmen Márquez, Lourdes Garrido and all staff from Área Enláce at INEGI.
} 


\subsection{Introduction.}

This chapter studies labor productivity (and labor productivity growth) in Mexico's exporting sector, both at the aggregate and the firm level. At the aggregate level, we seek to explain how Mexico's exporting sector contributes to changes in the aggregate labor productivity levels of Mexican manufacturing. At the micro-level, our objective is to understand variations in labor productivity in exporting firms, and to identify the factors that determine variations in productivity levels and productivity growth.

It is often the Maquiladora firms that attract attention as the exporting sector of Mexican manufacturing. However, there are also Mexican exporting manufacturing firms that do not work according the maquiladora model. Maquiladora firms are the assembly firms that export their entire output to the US. Firms belonging to the maquiladora program enjoy tariff exemptions for imported inputs and capital goods, provided by the Mexican government, and trade incentives within the NAFTA framework. In general, those firms mostly or even exclusively rely on imported intermediate inputs with a very limited use of domestic inputs.

Our analysis will attempt to shed some light on the role of the exporting sector in the development of labor productivity, relative to the domestic sector, and in terms of the distinction between maquiladora firms and other exporting firms. Following the available data, during the period up to 2006, we define the exporting sector exclusively as firms in the so-called Maquiladora export promoting program. Since 2007, we not only include Maquiladora firms in the export sector, but also a broader set of exportoriented firms that produce both for the domestic market and for export markets and meet certain minimum export criteria to qualify for the so-called IMMEX program. The manufacturing firms that do not belong to the Maquiladora program (before 2006) or to the IMMEX program (after 2007) are considered as the domestic manufacturing sector of Mexico. These firms produce both for the domestic and the foreign market.

Previous studies of labor productivity for Mexican manufacturing have only considered the evidence from the exporting sector and from domestic manufacturing separately, and they have also focused exclusively on the maquiladora firms in analyzing the exporting sector. Little is known about the micro foundations of productivity performance and the ways in which they affect the comparative contributions of the domestic and export sectors to total productivity. Our research aims to cope with these limitations. We will first study how Maquiladora and IMMEX firms contribute to aggregate changes in the labor productivity trends of Mexican manufacturing. We will compare maquiladora and IMMEX firms to the domestic part of Mexican manufacturing, and also implement a comparison of the maquiladora and IMMEX definitions of the exporting sector. The latter comparison is difficult because the time periods for which both datasets (or definitions) are available do not overlap. However, we will still be able to present some indirect evidence on the role of maquiladora firms versus other exporting firms.

Subsequently, we will study the firm-level variation of labor productivity in the maquiladora and IMMEX datasets. We are unable to directly observe maquiladora firms in the IMMEX dataset, but will attempt to identify them based on the fraction of exports 
to total production, and import of intermediates to total intermediate use. In this way, we will be able to compare maquiladora firms and other exporting firms for the IMMEX period. Although our macro-analysis also includes the aggregate labor productivity performance of domestic manufacturing and its role in explaining changes in aggregate labor productivity levels and trends in Mexican manufacturing, there are no micro data for domestic manufacturing. Therefore, our research cannot empirically extend the analysis to the micro foundations of firms in the domestic manufacturing sector.

Our general research question is the following: which variables within the exporting sector can explain the trends in labor productivity in Mexican manufacturing, and the differences between firms in terms of labor productivity? We propose several subquestions that further elaborate these issues both at the aggregate and the micro level. At the aggregate level, the main question concerns the contribution of the exporting sector and of domestic manufacturing to changes in aggregate labor productivity of Mexican manufacturing.

At the micro level, we seek to explain how and why firms differ with regard to the key factors that induced changes in labor productivity performance at the aggregate level. Which are the firm-level sources of variation in levels and growth rates for those elements within the exporting sector? In this part of the analysis, we will not only explain how different firm-level variables affect variations in plant-level productivity in the export sector, but also, and more importantly, we will also explain how those firmlevel variables can trigger changes in aggregate labor productivity levels in the export sector and changes in the aggregate productivity levels of Mexican manufacturing.

This research has several novel elements. Not only do we propose a framework to understand the micro and macro foundations for the contribution of firms engaged in Global Value Chains (GVCs) to changes in the total manufacturing productivity of a given country, our research will also provide a temporal perspective. This is because we will utilize two official firm-level datasets that permit the analysis of firms in global value chains (GVCs): the Maquiladora firm-level dataset (1990-2006), and its latest update, the IMMEX firm-level dataset (2007-2014). This will provide insights into the role of maquiladora firms compared to other exporting firms.

Our main findings are the following. At the aggregate level, we observe that the export sector in Mexico plays a limited role in labor productivity growth in total Mexican manufacturing. Domestic manufacturing is the sector driving most of the changes. Similarly, upgrading (defined as increases in the value added to output ratio) in exporting firms is also found to be relatively unimportant for aggregate changes in labor productivity ${ }^{37}$.

At the micro-level, capital per worker, gross output, the ratio of highly skilled workers to low skilled workers, as well as changes in the composition of labor are positively

\footnotetext{
37 These ideas further confirm that the export sector is more attuned to Mexican factor proportions with abundant cheap labor. Along the same lines, the higher productivity of the domestic sector is probably the result of a misallocation of resources and a capital bias.
} 
associated with higher plant-level labor productivity at exporting firms. Conversely, a higher consumption of imported intermediate inputs is found to have a negative impact on firm-level productivity. An error correction model specification indicates convergence to the long-run equilibrium in labor productivity levels for maquiladora and GVC-intensive firms.

This chapter is structured as follows. Section (6.2) reviews the literature. Here, we discuss previous studies that deal with the evolution of productivity in Mexican manufacturing. Section (6.3) presents our aggregate information and introduces a technique to decompose changes in labor productivity. This section also presents labor productivity decomposition results at the sectoral level and for different time periods. Section (6.4) indicates our firm-level evidence for maquila and IMMEX firms. Here, we also identify sub-groups of firms within the IMMEX dataset (GVC intensive and non-GVC intensive). Section (6.5) presents our econometric specification (the Error Correction Model) and explains the selection of independent variables for the micro-economic analysis. In this same section, we present our econometric results for maquiladora and for the sub-groups of firms within IMMEX. Conclusions and points for further discussion are provided in section (6.6).

\subsection{Literature Review: The Evolution of Productivity in Mexican Manufacturing.}

The main objective of this literature review is to understand the evolution of productivity of Mexican manufacturing firms since the mid 1980s, when the country decided to open its economy to foreign markets. To this end, we will rely on the information provided in table 6.1, which summarizes the main findings from different scholars that analyzed productivity in Mexican manufacturing, considering different time periods, different measures (total factor productivity or labor productivity), as well as different datasets. The use of different datasets (the last column of table 6.1) was our main criteria to determine which component of Mexican manufacturing was being analyzed. Studies relying on information from the National Accounting System were regarded as studies for the productivity of the total manufacturing sector in Mexico. Those relying on the Encuesta Industrial Anual were considered to refer to the domestic manufacturing sector and those using the EMIME dataset were regarded as part of Maquiladora $^{38}$ (exporting sector). In the forthcoming paragraphs, we will indicate that the productivity growth for domestic manufacturing has been generally larger than for Maquiladora and/or the total economy of Mexico considering different methodologies and different periods of time.

\subsubsection{Productivity within Total Manufacturing.}

The first panel of table 6.1 indicates results for the average productivity growth in the total economy of Mexico. By observing the results for total factor productivity (TFP), we can see that the average growth of productivity in Mexican manufacturing seems to be positive and more stable in the decades prior to the opening up of the country (19501974 and 1960-1980) than in the first years of trade liberalization (1983-1989).

\footnotetext{
${ }^{38}$ Prior to the present study, there are no studies that analyze the labor productivity of IMMEX firms.
} 
According to Mollick and Cabral (2009), TFP appears to be negative in the NAFTA period (1994-2000). Those negative TFP results seem to be confirmed by Loayza et al. (2004). As for the calculations of labor productivity, we see that its average growth rate falls in the years that followed the liberalization of economy (1983-1989 and 1980-1993), compared to the earlier decades. In the NAFTA period, labor productivity only shows small positive average growth. Given the negative TFP growth during the same period, the latter would suggest that capital intensity increased.

\subsubsection{Productivity within Domestic Manufacturing.}

Results for the productivity of firms belonging to the domestic manufacturing sector of Mexico are presented in the second panel of table 6.1. Firms in the domestic manufacturing of Mexico have been analyzed by relying on the information contained in the Encuesta Industrial Annual (EIA). This is an official firm-level data-set collected and compiled by Mexico's statistical office (INEGI). The data-set provides plant-level information on the number of employees, hours worked, wages, value of production and sales, exports, value of intermediate inputs, inventories, investment, etc. (De Hoyos and Iacovone, 2013). It is important to note that EIA explicitly excludes the informal sector (i.e. unregistered firms) and maquiladora firms (Montes-Rojas and Santamarina, 2007). The reason for the exclusion of maquiladora firms from EIA is the fact that there is a separate industrial survey for exporting firms (EMIME and, since 2007, the IMMEX program). Various authors have studied the productivity of domestic manufacturing relying on different updates and data from the EIA. 
Chapter 6.

Table (6. 1): Summary of Estimates of TFP and of Labor Productivity Annual Average Growth. Mexican Manufacturing.

Total Economy of Mexico

\begin{tabular}{|c|c|c|c|c|}
\hline Author & Period & $\begin{array}{l}\text { Total Factor Productivity } \\
(\%)\end{array}$ & $\begin{array}{l}\begin{array}{l}\text { Labor Productivity } \\
(\%)\end{array} \\
\end{array}$ & Data source \\
\hline Chenery (1986)* & $1950-1974$ & 2 & 3 & \multirow{5}{*}{ National Accounts } \\
\hline Hernández Laos and Velasco (1990)* & $1960-1980$ & 1.1 & 3.4 & \\
\hline Hernández Laos (1991)* & 1983-1989 & 5.3 & 2.1 & \\
\hline $\begin{array}{l}\text { Loayza, Fajnzylber \& Calderon } \\
(2004)^{* *, a}\end{array}$ & $1981-1990$ & 6.9 & & \\
\hline Loayza et al. (2004)**,a & $1991-2000$ & -19.2 & & \\
\hline \multirow{2}{*}{ Mollick and Cabral (2009)*** } & $1980-1993$ & -3.37 & 2.4 & \multirow{2}{*}{$\begin{array}{l}\text { Data from Nicita and } \\
\text { Olarreaga (2006). }\end{array}$} \\
\hline & $1994-2000$ & -1.26 & 1.31 & \\
\hline \multicolumn{5}{|l|}{ Domestic Economy of Mexico } \\
\hline Author & Period & $\begin{array}{l}\text { Total Factor Productivity } \\
(\%)\end{array}$ & $\begin{array}{l}\text { Labor Productivity } \\
(\%)\end{array}$ & Source \\
\hline Samaniego (1984)* & $1963-1981$ & 3.6 & 6 & \multirow{11}{*}{$\begin{array}{c}\text { Encuesta Industrial } \\
\text { Anual }\end{array}$} \\
\hline \multirow{4}{*}{ Fragoso $(2002)^{* * *}$} & $1970-1979$ & 0.3 & 1.8 & \\
\hline & $1980-1989$ & 1.9 & 2.7 & \\
\hline & $1980-1983$ & -3.5 & -0.9 & \\
\hline & 1984-1989 & 4.1 & 3.1 & \\
\hline Brown and Dominguez (1999)* & $1984-1990$ & 4.8 & 3.3 & \\
\hline \multirow{3}{*}{ Fragoso $(2002)^{* * *}$} & $1990-1998$ & 2.9 & 4.2 & \\
\hline & 1990-1994 & 5 & 6.7 & \\
\hline & $1995-1998$ & 0.8 & 1.7 & \\
\hline \multirow{2}{*}{ Montes-Rojas \& Santamaria (2007)** } & 1994-2002 & -0.6 & 3.24 & \\
\hline & $1995-2002$ & 0.31 & 4.27 & \\
\hline \multicolumn{5}{|l|}{ Maquiladora } \\
\hline Author & Period & $\begin{array}{l}\text { Total Factor Productivity } \\
(\%)\end{array}$ & $\begin{array}{l}\text { Labor Productivity } \\
(\%)\end{array}$ & Source \\
\hline González-Arechiga \& Ramirez (1989)*** & $1980-1986$ & & -4.26 & \multirow{6}{*}{ EMIME } \\
\hline Cortez $(1999)^{* * *}$ & $1990-1996$ & & 1 & \\
\hline Mendoza $(2004)^{* * *, a}$ & 1990-1999 & & -0.36 & \\
\hline Díaz González (2006)***,a & 1991-2004 & -0.7 & & \\
\hline Utar \& Ruiz (2013) ${ }^{* * *}$ & 1999-2006 & 0.078 & & \\
\hline Castillo \& De Vries (2018) $)^{* * *, a}$ & $1981-2006$ & & -0.8 & \\
\hline
\end{tabular}

Source: * Brown and Dominguez (1999), ${ }^{* *}$ Montes-Rojas \& Santamaria (2007) and, ${ }^{* * *}$ this research.

${ }^{\text {a }}$ Growth rates were here calculated with the information provided by the respective authors.

Fragoso (2002) analyzed the evolution of TFP in domestic manufacturing from the 1970 s to the end of the 1990s. The author relied on three versions of EIA that differ in terms of the period covered (1970-1983, 1984-1994, and 1994-1998). According to Fragoso (2002), the largest increase of TFP took place between 1990 and 1994 (an average TFP growth rate of 5\% during those years). In addition, the results from Fragoso (2002) also indicate that the average growth rate of labor productivity seems to have declined by the end of the 1990s (1995-1998).

Montes-Rojas and Santamaria (2007) relied on the information contained in EIA to analyze the evolution of labor productivity and TFP from 1994 to 2002. According to those authors, labor productivity increased significantly during this period (an average annual growth rate of 3\% for 1994-2002 and, 4\% for 1995-2002). In their calculations, 
the crisis of 1994-1995 initially resulted in a decline of labor productivity of $7 \%$. But there was a rapid recovery in productivity in the subsequent years. Montes-Rojas and Santamaria (2007) also indicate that their findings for TFP are very different from those for labor productivity. Their estimates yield negative or small increments in TFP with a maximum decline of $5 \%$ and a minimum decline of $0.6 \%$. In their view, the observed stagnation or decline in TFP can be explained by the important increase in investment, which was not mirrored by a similar increase in output. Therefore, the differences between labor productivity and TFP can be attributed to the acquisition of capital goods, which significantly increased output per worker although it did not increase output enough to increase total factor productivity. Finally, their findings also indicate that productivity growth was higher in sectors with medium-size firms and relatively abundant low-skilled labor. This result is in line with the idea that NAFTA favored sectors relatively abundant in non-skilled labor.

De Hoyos and Iacovone (2013) studied the impact of NAFTA on firm-level productivity. They also relied on the EIA data-set from 1993 to 2002. Their findings indicate that NAFTA stimulated the productivity of Mexican plants via an increase in import competition and easier access to imported intermediate inputs. Nevertheless, they also argue that the impact of trade reforms was not identical for all firms, because only fully integrated firms (firms simultaneously exporting and importing) could benefit more from the incentives provided by NAFTA and achieve higher levels of productivity than the rest of firms within Mexican domestic manufacturing.

\subsubsection{Productivity within the Maquiladora Industry.}

Studies dealing with the evolution of productivity in maquiladora industry are presented in the last panel of table 6.1. These studies can be divided into those that have relied on the official maquiladora firm-level and aggregate data-sets, and those that have collected their own non-official plant-level information. The official source of information for the maquiladora program is contained in the Encuesta Mensual de la Industrial Maquiladora de Exportación (EMIME). Both at the aggregate level and firmlevel, EMIME offers information similar to that contained in EIA in terms of gross output, value added, imported and domestic intermediate good, labor qualification, and so forth (for specific details about the EMIME dataset, please refer to section 6.4). The aggregate maquiladora information is available from 1980 to 2006, while the firm-level data-set can be obtained from 1990 to $2006 .{ }^{39}$ The studies based on non-official plant level data on maquiladora firms have focused on the dynamics of major industrial centers (such as the Mexican municipalities of Tijuana, Reynosa, Monterrey, etc.), considering key manufacturing sectors (mostly electronic and textiles) for a limited number of years.

González-Arechiga and Ramírez (1989) performed one of the first studies to analyze the evolution of productivity in maquiladora firms, by combining both aggregate and nonofficial plant level information. According to their findings, during the period from 1980 to 1986, gross output per worker in the maquiladora industry grew considerably (an average growth rate of $12 \%$ ). Nevertheless, labour productivity levels in maquiladora

392006 is the last year of observation for those two aggregate and micro data-sets due to the fact as of 2007 maquiladora data is now reported within the framework of the IMMEX program. 
declined when productivity was measured as value added per worker (an average growth rate of $-4 \%$ during 1980-1986). Cortez (1999) indicates low labor productivity growth from 1990 to 1996 in major Maquiladora northern states (Sonora and Baja California). In his view, the reasons for low labor productivity growth are the lack of technological learning due to continuous rotation of low-skilled labor in maquiladora firms and, the lack of a linkage between higher investment rates and higher labor productivity growth rates. At the sectoral level, Cortez (1999) indicates that the increasing use of better technologies during those years in major sectors such as machinery and equipment did not necessarily imply higher labor productivity growth for maquila firms, because the the new technologies (embodied in machinery) needed considerable amounts of low qualified workers to operate it (Carrillo and Hualde, 1997).

Likewise, Mendoza (2004) studies the labor productivity performance in maquiladora industry at the aggregate level by considering different manufacturing sectors and regions in Mexico from 1990 to 1999. In this case, it is argued that different maquiladora sectors show different levels of sectoral productivity due to the existence of different levels of technology across sectors, differences in firm size, different labor qualification and different capital endowments. The author's calculations for labor productivity show no drastic changes when comparing the levels in 1990 (21.9) and the ones for 1999 (21.2), i.e., an average negative productivity growth of $-0.36 \%$ (presented in table 6.1 ). Mendoza (2004) also indicates that machinery and equipment and chemical products were the sectors with the highest labor productivity levels during those years.

As for the case of electronic production (another key maquiladora sector), the TFP calculations of Díaz González (2006) indicate that the TFP growth of those firms (and that of the maquila industry as a whole) remained low from 1991 to 2004, with some signs of recovery by 2001. According to this author, the recovery in TFP can be explained by the exit of the least productive firms after 2000 (although the author is unable to provide empirical evidence for this specific issue). In our calculations of productivity growth, using TFP data from Díaz González (2006) for the first and final year of observation, average productivity growth is $-0.7 \%$.

An increase in maquiladora TFP growth levels after 2000 is confirmed at the firm-level by Utar and Torres-Ruiz (2013). Relying on the official EMIME micro dataset, those authors analyze impacts of the industrial emergence of China on maquiladora producers at firm level. Their findings indicate that increasing competition induced maquiladora firms to achieve higher productivity levels. However, their calculations for the average growth rate of TFP are very small $(0.078 \%$ for 1999-2006). Following the same micro approach, Sargent and Mathews (2008) collect non-official plant-level information to determine which type of maquiladora firms were more likely to survive competition from Chinese producers. During the 1990s and early 2000s, they observe that the firms that survived were large (as measured by the number of employees). Furthermore, auto parts producers were much more likely to survive than maquiladoras in the electronic/electrical sector. Finally, Castillo \& De Vries (2018) consider a long time span of 25 years. They divided real value added by hours worked, and constructed an index that equals 1 in 1981, finding that Maquiladora labor productivity had declined to 0.82 by 2006 . Thus, Considering the whole period, an average annual negative productivity 
growth of $-0.8 \%$ is observed ${ }^{40}$ (table 6.1). Modest changes in labor productivity are also observed by those authors in key maquiladora sectors such as Textiles, Electronics and Transport equipment for the same period.

Concluding, we observe that maquiladora and domestic firms (and thus, total manufacturing in Mexico) have mostly followed a similar productivity trend over time. For instance, according to the TFP and labor productivity results described in table 6.1, productivity growth for total manufacturing and for domestic manufacturing was found to be low by the late 1980s, early 1990s and by the end of 1990 s. After that decline, firms in domestic manufacturing once again show positive but limited productivity growth (in the early 2000s). Likewise, firms in maquiladora production had negative labour productivity rates during most of the 1990s and positive (but limited) growth in the early and mid-2000s. Even though we see a common pattern for all Mexican manufacturing firms, it is also worth observing that the productivity growth of domestic manufacturing firms seems to be higher most of the time than that of maquiladora and total manufacturing. The relative importance of domestic manufacturing is especially observed in the column for the results of labor productivity in table 6.1 and seems to become deeper as of the late 1980s. This indicates that, at least at the aggregate level, domestic manufacturing plays a more important role than maquiladora in determining productivity levels for Mexican manufacturing.

Despite the existence of all this useful information about the evolution of productivity in Mexican manufacturing, some other important conclusions are in order. One important issue is the lack of studies that deal with the evolution of Mexican manufacturing since the end of the 2000s. Those are necessary to understand the impact of events such as the 2008 crisis in maquiladora and domestic manufacturing firms. Similarly, there are no studies that take into consideration the evolution of productivity of firms in the IMMEX program from 2007 onwards. Analyzing the IMMEX program is very important given that it constitutes the only up-to-date source of information to analyze the current evolution of exporting firms in Mexico (Maquiladora firms and firms belonging to the PITEX program). More importantly, one key issue in the study of the evolution of productivity levels in Mexican manufacturing is that exporting and domestic manufacturing firms have only been analyzed separately. Little is known as to how each component contributes to aggregate productivity levels in total Mexican manufacturing. The next sections of this chapter will try to cope with all these limitations.

\subsection{The Productivity Contribution of the Exporting Sector: an Aggregate Perspective.}

The main objective of this section is to assess the contribution of the exporting sector to aggregate manufacturing labor productivity in Mexico. We will provide descriptive evidence in terms of the construction of time series for labor productivity and underlying variables, and also decompose changes in aggregate labor productivity in

\footnotetext{
${ }^{40}$ According to our calculations in section 6.3.2, annual labor productivity growth for Maquiladora firms is of $1.1 \%$ between 1990-2006. By comparing these results to the estimates fron Castillo \& De Vries (2018) for 1980-2006 (-0.8\%), we can infer that Maquiladora firms experienced rather negative growth during the years between 1980 and 1990 .
} 
Mexican manufacturing over time. Our level of analysis will either be total manufacturing, or a subsector of manufacturing, but never the individual firm. The analysis of firm level micro data is left for the next section.

We use three sources of aggregate data (all available at www.inegi.gob.mx). The first source of information is data from Mexico's National Accounting System (NAS). These data refer to Mexico's total manufacturing (1990-2014). The second source is data for Maquiladora retrieved from EMIME (1990-2006) and, the third one is information for the IMMEX program (available from July 2007 to 2014). Our estimates for domestic manufacturing were always obtained as the difference between the data for total manufacturing and the data for exporting firms (either Maquiladora or IMMEX program). ${ }^{41}$

The Maquiladora (EMIME) and IMMEX datasets not only cover different time periods, they also cover different types of firms. Firms in the maquiladora dataset are all participants in international value chains, more specifically they are assembly firms which import intermediate goods from the US and export their total final output to the US. The IMMEX dataset not only includes these Maquiladora firms, but also a broader set of export-oriented firms that produce both for the domestic market and for export markets and meet certain minimum export criteria to qualify for the so-called IMMEX program. ${ }^{42}$ Thus, using IMMEX, we apply a broader definition of the exporting sector than just the maquiladora.On the one hand, the discontinuity between the maquiladora and IMMEX datasets provides a problem for assessing the contribution of the exporting sector to the development of labour productivity, because the definition of the exporting sector changes over time. On the other hand, this provides an opportunity to compare the impact of the pure maquiladora firms to the other exporting firms in Mexican manufacturing. In this section, we will implement this comparison by comparing the time periods covered by our two datasets, maquiladora and IMMEX. In the next section, we will provide a sharper analysis by trying to identify the maquiladora firms in the micro-level IMMEX dataset.

Let us explain in detail the data and variables related to total manufacturing, Maquiladora and IMMEX program. Information on gross output and value added was directly available for total manufacturing. However, in the case of Maquiladora and IMMEX additional calculations had to be made. For maquiladora firms, gross value added was computed as the sum of labor remuneration, utilities and the rental cost of machinery and equipment. For the same set of firms, intermediate consumption was

\footnotetext{
${ }^{41}$ Data for the Domestic Manufacturing of Mexico is the same as has been already been used in Chapter 5 of this dissertation (Mexican Manufacturing and its integration into Global Value Chains). Differences in the period being analyzed in Chapter 5 and in this one, as well as the compatibility of information are the main reason for us not to rely here in Chapter 6 on the direct information for domestic manufacturing. Our research could access aggregate and micro information for EMIME and IMMEX from 1990 to 2014. Aggregate information for domestic manufacturing (as presented in EIA) was only available from 1994 onwards. Thus, since our research wanted to analyze the pre-NAFTA period for maquiladora, we decided to rely on the complete time-series information offered by the NAS and compute domestic manufacturing as a residual.

42 Prior to 2007, there was also an export programme called PITEX which supported firms that exported at least 10 percent of their output. In our analysis however, these non-Maquila firms were included in the domestic sector. After 2007, these PITEX firms would be included in the IMMEX category.
} 
regarded as the sum of imported and domestic intermediate goods and total intermediate expenses. The sum of gross value added and of intermediate consumption provides our estimate of maquiladora gross output.

On the other hand, information for IMMEX was more difficult to compute. Unlike EMIME, IMMEX does not publish data entirely in line with the NAS. In this context, following the concepts from INEGI (2012) and the information provided in the official IMMEX industrial surveys, gross value added had to be computed as a residual. From the IMMEX variable named "Ingresos por Maquila, Submaquila and Remanufactura" (i.e., income obtained as a result of maquiladora-related operations) we subtract the value of domestic intermediate inputs. ${ }^{43}$ The residual of this computation is our measure of gross value added for IMMEX firms. Gross output for IMMEX firms is regarded as the sum of the variable named "income obtained as a result of maquiladora related operations" and the variable accounting for imported intermediate consumption. Total intermediate consumption for IMMEX was computed following the same procedure as for maquiladora firms. Once we obtained all this information for total manufacturing, Maquiladora and IMMEX, value added and output deflators were utilized to convert the data to constant Mexican pesos of 2008. Finally, for the case of variables measuring employment, we faced no major difficulties since INEGI directly publishes such information for total manufacturing, Maquiladora firms and firms under the IMMEX program.

\subsubsection{A Decomposition Method.}

In this section, we discuss the methodology used to identify how exporting firms (Maquiladora and IMMEX firms) and domestic manufacturing firms contribute to changes in total manufacturing productivity. Before illustrating the mathematical steps we follow, some definitions are in order. We define manufacturing productivity as the ratio of gross value added to manufacturing employment. Gross value added is the sum of labor remuneration (which consists of wages but also of all other labor related expenditures), profits and the rental cost of capital. In the case of the total manufacturing sector, value added $(Y)$ is the sum of the value added created by exporting firms $\left(Y^{M}\right)$ and the that created by producers in the domestic economy of Mexico $\left(Y^{D}\right)$. Also, total manufacturing employment $(L)$ is the sum of workers employed in the exporting sector $\left(L^{M}\right)$ and, those workers in domestic manufacturing $\left(L^{D}\right)$. In this context, total manufacturing productivity in Mexico can be defined as follows: ${ }^{44}$

$\frac{Y}{L}=\frac{Y^{M}+Y^{D}}{L^{M}+L^{D}}$

We can expand equation (6.1) to include the share of labor in the export sector (and of labor in domestic manufacturing) in total manufacturing labor in Mexico:

\footnotetext{
43 In line with "Cuestionario Mensual para Establecimientos Manufactureros-Programa IMMEX", the variable named "Ingresos por Maquila, Submaquila y Remanufactura" is computed considering the sum of production costs (labor, depreciation of capital, domestic inputs, etc.) plus total expenses and utility.

44 From 2007 onwards, the superscript M in our equations (and in our calculations) no longer refers to Maquiladora but to the IMMEX sector (Maquiladora, PITEX plus new type of IMMEX firms).
} 
$\frac{Y}{L}=\frac{Y^{M}+Y^{D}}{L^{M}+L^{D}}=\frac{Y^{M}}{L^{M}} \frac{L^{M}}{L^{M}+L^{D}}+\frac{Y^{D}}{L^{D}} \frac{L^{D}}{L^{M}+L^{D}}=\frac{Y^{M}}{L^{M}} \sigma^{M}+\frac{Y^{D}}{L^{D}}\left(1-\sigma^{M}\right)$

In this case $\sigma^{M}=\frac{L^{M}}{L^{M}+L^{D}}$ refers to the share of labor employed in the export sector in total manufacturing employment, while $\left(1-\sigma^{M}\right)$ refers to the share of domestic manufacturing employment in total manufacturing employment. Now, given that our objective is to study changes in manufacturing labour productivity over time, we write equation (6.2) as a change in the level of productivity (with subscript 0 referring to the begin of a period and 1 to the end, and the delta indicates a change between periods 0 and 1):

$\Delta \frac{Y}{L} \equiv \frac{Y_{1}}{L_{1}}-\frac{Y_{0}}{L_{0}}=\Delta\left(\frac{Y^{M}}{L^{M}} \sigma^{M}\right)+\Delta\left[\frac{Y^{D}}{L^{D}}\left(1-\sigma^{M}\right)\right]=$

$\left(\frac{v_{1} X_{1}^{M}}{L_{1}^{M}} \sigma_{1}^{M}-\frac{v_{0} X_{0}^{M}}{L_{0}^{M}} \sigma_{0}^{M}\right)+\left[\frac{Y_{1}^{D}}{L_{1}^{D}}\left(1-\sigma_{1}^{M}\right)-\frac{Y_{0}^{D}}{L_{0}^{D}}\left(1-\sigma_{0}^{M}\right)\right]$

Note that in this equation we also made the substitution $Y^{M}=v X^{M}$, where $X^{M}$ refers to gross output produced by the exporting firms, and $v$ is the value added-to-gross-output ratio (which is also the upgrading variables). For Maquiladora firms, by definition, gross output equals gross exports, which is why in this case we use the symbol $X$ for gross output. This is because, as mentioned in previous chapters, firms within Maquiladora receive tariff exemptions provided that all their gross output is exported. However, the IMMEX program includes both Maquiladora and PITEX firms, and firms in the unified framework of IMMEX (either Maquiladora or PITEX firms) receive tariff exemptions provided that at least $10 \%$ of their gross output is exported. Hence, for the case of IMMEX, gross output is no longer equal to gross exports. We nevertheless use the symbol $X$ for gross output of firms in the exporting sector. Through a series of intermediate steps, equation (6.3) can be re-written to obtain a decomposition of the change of aggregate labor productivity into four terms, each of which includes a weighted change (delta term) of one of the main variables in the analysis. However, the weights in this procedure are not unique, there various possible weighting schemes in terms of whether values from either the 0 or 1 period are used. As is common in the literature (Dietzenbacher et al., 2000), we use two of these possible decompositions, as follows:

$\Delta \frac{Y}{L}=v_{0} \sigma_{0}^{M} \Delta \frac{X^{M}}{L^{M}}+\frac{X_{1}^{M}}{L_{1}^{M}} \sigma_{0}^{M} \Delta v+\left(v_{1} \frac{X_{1}^{M}}{L_{1}^{M}}-\frac{Y_{1}^{D}}{L_{1}^{D}}\right) \Delta \sigma^{M}+\left(1-\sigma_{0}^{M}\right) \Delta \frac{Y^{D}}{L^{D}}$

$\Delta \frac{Y}{L}=v_{1} \sigma_{1}^{M} \Delta \frac{X^{M}}{L^{M}}+\frac{X_{0}^{M}}{L_{0}^{M}} \sigma_{1}^{M} \Delta v+\left(v_{0} \frac{X_{0}^{M}}{L_{0}^{M}}-\frac{Y_{0}^{D}}{L_{0}^{D}}\right) \Delta \sigma^{M}+\left(1-\sigma_{1}^{M}\right) \Delta \frac{Y^{D}}{L^{D}}$

As can be noted, the timing of the weights in equations (6.4) and (6.5) is exactly 'polar' to each other, i.e., where a value from period 0 appears in one equation, a period 1 value appears in the other equation, and vice versa. We then define a decomposition with 'average polar' weights as:

$\Delta \frac{Y}{L}=\frac{1}{2}\left[v_{0} \sigma_{0}^{M}+v_{1} \sigma_{1}^{M}\right] \Delta \frac{X^{M}}{L^{M}}+\frac{1}{2}\left[\frac{X_{1}^{M}}{L_{1}^{M}} \sigma_{0}^{M}+\frac{X_{0}^{M}}{L_{0}^{M}} \sigma_{1}^{M}\right] \Delta v+\frac{1}{2}\left[\left(v_{1} \frac{X_{1}^{M}}{L_{1}^{M}}-\frac{Y_{1}^{D}}{L_{1}^{D}}\right)+\left(v_{0} \frac{X_{0}^{M}}{L_{0}^{M}}-\right.\right.$

$\left.\left.\frac{Y_{0}^{D}}{L_{0}^{D}}\right)\right] \Delta \sigma^{M}+\frac{1}{2}\left[\left(1-\sigma_{0}^{M}\right)+\left(1-\sigma_{1}^{M}\right)\right] \Delta \frac{Y^{D}}{L^{D}}$ 
This is the formula that we will use for the decomposition of aggregate Mexican manufacturing labor productivity. It indicates that labor productivity in Mexican manufacturing can change a result of the following factors: (1) a change of gross exports per worker in the export sector, $\Delta \frac{X^{M}}{X^{L}},(2)$ a change of the value added to output ratio in the export sector (or upgrading), $\Delta v$, (3) a change of the share of manufacturing employment in the export sector, $\Delta \sigma_{M}$, and, (4) a change of labor productivity in domestic manufacturing firms $\Delta \frac{Y^{D}}{L^{D}}$. We will apply this decomposition to the period from 1990 to 2014 in the next section.

\subsubsection{Decomposition of Aggregate Manufacturing Labour Productivity}

Table 6.2 presents our estimates for aggregate labor productivity in Mexican manufacturing from 1990 to 2014. Here, we observe labor productivity levels (thousands of constant Mexican pesos of 2008) for the export sector, domestic manufacturing and total manufacturing, considering all manufacturing sectors 45 .

In order to better understand the information contained in table 6.2, we refer to figure (6.1). Such figure is divided into two panels. The first panel (figure 6.1.1) indicates labor productivity levels (the same as in table 6.1), while the second panel (figure 6.1.2) studies labor productivity growth rates. In each of those two panels, we observe the evolution of labor productivity (in terms levels or in terms growth, respectively) for the export sector, domestic manufacturing and total manufacturing. Let us now describe the tendency observed in each panel. The most striking element in the top panel of the figure is the watershed difference between the two definitions of the exporting sector. Up to 2006, the maquiladora sector shows a much lower level of labour productivity than the domestic sector, resulting in labor productivity levels for the exporting sector being very much lower than the aggregate. From 2008 onwards, however, with the new (IMMEX) definition of the exporting sector, the labour productivity level of exporting firms are above the domestic sector, and hence also above the average level in manufacturing. This clearly illustrates that we must look at the maquiladora and IMMEX definitions of the exporting sector as very much different from each other, and it points to the importance of comparing maquiladora and other exporting firms, something we will attempt to do below.

\footnotetext{
${ }^{45}$ Appendix A6.1 presents the raw data (total and per manufacturing sector) for gross value added and labor that were used in the calculation of labor productivity in table 6.1. Furthermore, it also presents calculations for labor productivity levels (total and per manufacturing) for the export sector, domestic manufacturing and total manufacturing.
} 
Table (6. 2). Labor Productivity in Maquiladora, IMMEX, Domestic and Total Economy. All Manufacturing Sectors. Thousands of Mexican pesos (constant prices of 2008).

\begin{tabular}{|c|c|c|c|}
\hline Year & Maquiladora & Domestic Manufacturing & $\begin{array}{l}\text { Total Mexican } \\
\text { Manufacturing }\end{array}$ \\
\hline 1990 & 154 & 564 & 519 \\
\hline 1991 & 155 & 627 & 571 \\
\hline 1992 & 147 & 596 & 541 \\
\hline 1993 & 126 & 540 & 486 \\
\hline 1994 & 126 & 555 & 495 \\
\hline 1995 & 158 & 740 & 647 \\
\hline 1996 & 187 & 858 & 744 \\
\hline 1997 & 151 & 655 & 562 \\
\hline 1998 & 149 & 597 & 512 \\
\hline 1999 & 154 & 585 & 498 \\
\hline 2000 & 152 & 543 & 462 \\
\hline 2001 & 177 & 527 & 461 \\
\hline 2002 & 163 & 540 & 464 \\
\hline 2003 & 176 & 563 & 485 \\
\hline 2004 & 167 & 583 & 492 \\
\hline 2005 & 172 & 666 & 557 \\
\hline 2006 & 182 & 726 & 606 \\
\hline Year & IMMEX & Domestic Manufacturing & $\begin{array}{l}\text { Total Mexican } \\
\text { Manufacturing }\end{array}$ \\
\hline 2008 & 896 & 478 & 624 \\
\hline 2009 & 885 & 537 & 660 \\
\hline 2010 & 865 & 488 & 625 \\
\hline 2011 & 903 & 501 & 649 \\
\hline 2012 & 856 & 495 & 630 \\
\hline 2013 & 941 & 510 & 675 \\
\hline 2014 & 860 & 471 & 621 \\
\hline
\end{tabular}

Source: Source: Author's calculation using data from INEGI's National Accounting System (1990-2014), EMIME (1990-2006) and, IMMEX (2008-2014).

Apart from the differences in levels, figure (6.1) confirms the finding from our literature review that the export sector, domestic manufacturing and total manufacturing have followed (in general) the same tendency in labor productivity over time. Exporting firms, firms in domestic manufacturing and the total manufacturing of Mexico experienced an important increase in their labor productivity levels after 1994 and also faced a major decline in those levels by 1998. The signing of NAFTA and the currency crisis in Mexico (both taking place in 1994) implied higher productivity levels both for exporting and domestic firms. Booming labor productivity levels lasted for about three years (1994-1997). Once the initial effervescence from NAFTA finished and the Mexican economy reached some stability (after having faced a major currency crisis), a decline in labor productivity levels is observed (1998). For Maquiladora firms, this decline in labor productivity levels coincides with a new tax regulation imposed on the profits generated 
by these firms (see Chapter 2 for details). Finally, we also observe a steady increase in productivity levels after 2001 and up to 2006 (both for exporting and domestic firms, as well as for total manufacturing). But from 2008 onwards, which is the period of the new IMMEX dataset, labor productivity no longer grows.

On the other hand, the finding from our literature review that labor productivity growth in domestic manufacturing is higher than that of the export sector is only partially supported by figure (6.1.1). At least for some year intervals, annual labor productivity growth has been higher for the export sector than for domestic manufacturing. These year intervals are 1998-2003 for Maquiladora firms, and the years 2011 and 2013 for IMMEX. For Maquiladora, higher productivity levels from 1998-2003 are associated with the recuperation of the export promoting sector after drastic decreases in labor productivity. More importantly, such higher productivity for maquila firms is reflecting the competitive pressures that the export sector faced in light of the industrial emergence of China and its accession to the WTO (2001). For the case of IMMEX, higher labor productivity levels than domestic or total manufacturing can be also be explained by the recuperation of the export sectors after the 2008 financial crisis and, also, as result of the change in dataset. Finally, let us discuss the overall growth rates for the export and domestic sector during the two periods here considered (1990-2006 and, 2008-2014). As for the export sector, we observe that Maquiladora presents annual productivity growth of $1.1 \%$ between 1990 and 2006, while the one for the IMMEX program is of $-0.7 \%$ between 2008 and 2014. Regarding the domestic sector, we observe annual productivity growth of $1.8 \%$ between 1990 and 2006 and of $-0.3 \%$ between 2008 and 2014. In this context, we can infer that the annual productivity growth at the export sector is generally slower and less positive than that of the domestic sector when considering the years between 1990-2006 and 2008-2014. 
Figure (6.1. 1): Aggregate Labor Productivity in Mexican Manufacturing: 1990-2014. All Sectors. Thousands of Mexican pesos (Constant Prices of 2008).

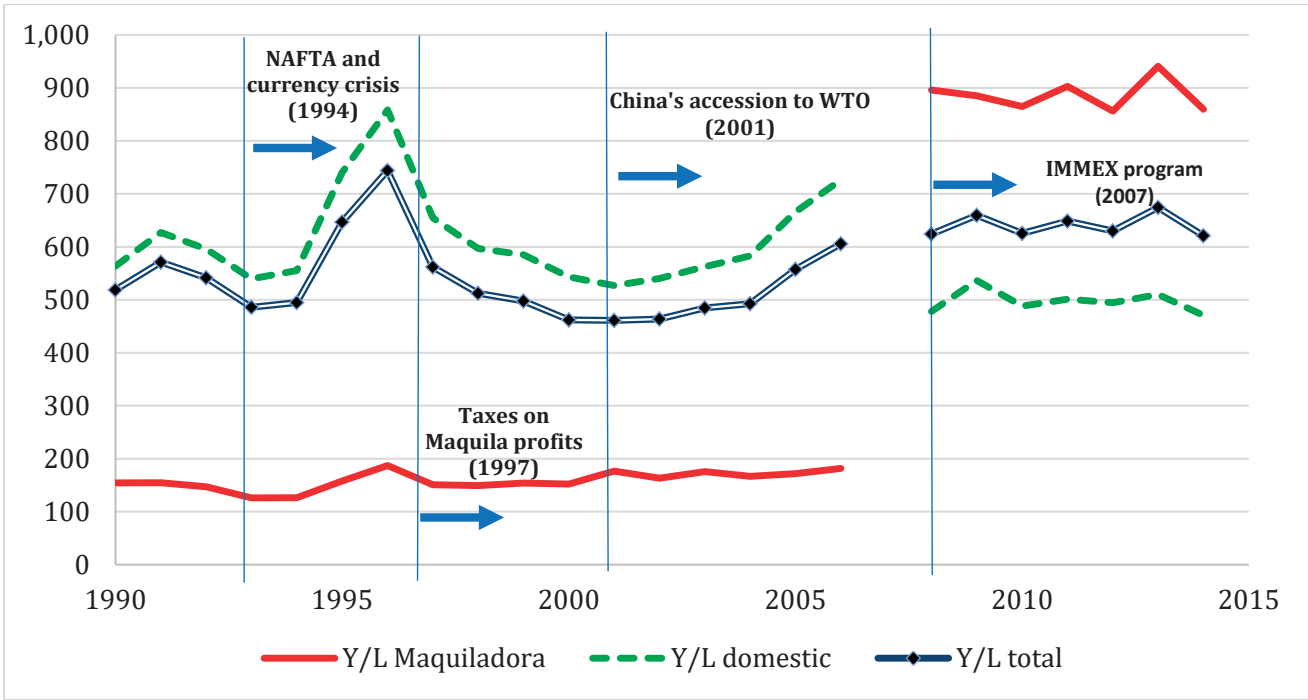

Figure (6.1. 2): Aggregate Labor Productivity Growth (\%) in Mexican Manufacturing: All Sectors. Maquiladora (1990-2006) and IMMEX (2008-2014).

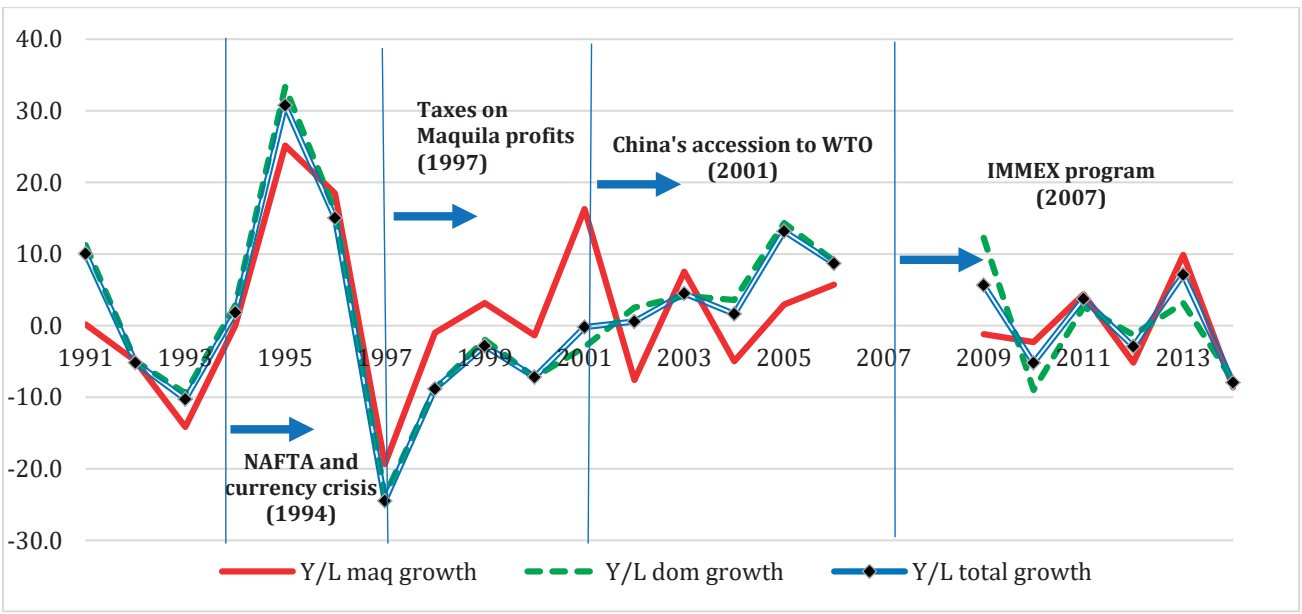

Notes: For IMMEX, the productivity growth rate in 2006-2007 is here excluded due to incompatibility of information between EMIME and IMMEX Source: Author's calculation using data from INEGI's National Accounting System (1990-2014), EMIME (1990-2006) and, IMMEX (July 2007-2014). 
We now proceed to study the contributions to changes in the aggregate labor productivity levels of Mexican manufacturing, according to the four factors described in equation (6.6). We present decomposition results for different time periods that are relevant in the evolution of Maquiladora/IMMEX firms or the Mexican economy at large. For instance, we include the signing of NAFTA and the currency crisis (1994), the industrial emergence of China and the US crisis (2001), the positive expansion of Maquiladora after a major drop of productivity in 1997 (1998-2003 according to figure 6.1), the available years to study IMMEX firms (2008-2014) as well as the first and final years of observation in the Maquiladora. Table 6.3 presents the decomposition results, and is divided into four main panels that present our productivity decomposition results for the total manufacturing sector, and three key exporting sectors (Textiles, Transport equipment and Electrical equipment) ${ }^{46}$.

If we focus on the entire period (1990 - 2006) for the maquiladora definition of the exporting sector, we see a negative contribution (sum of $\mathrm{A}-\mathrm{C}$ ) of the exporting sector to labor productivity growth in Mexican manufacturing. Labor productivity grows by almost $17 \%$ over this entire period, or which $26 \%$-points (factor D) are attributed to the productivity growth bonus that the domestic sector enjoys over the exporting sector. Hence a $-9 \%$-points contribution is seen for the exporting sector. When we further divide this into the factors $\mathrm{A}-\mathrm{C}$, we see that it is mainly factor $\mathrm{C}$ that is responsible for this. Factor $C$ represents the increase in employment share of the maquiladora sector, which has a negative effect on aggregate productivity because the sector's labor productivity level is below that of the domestic sector. In addition to this, the upgrading factor (B) also has a negative, but much smaller, impact, due to the fact that the value added to output ratio goes down in the maquiladora sector over this period. Gross output per worker increases somewhat, which has a (small) positive effect.

Interestingly, this aggregate picture can be much different at the sectoral level. In textiles, we observe modestly negative labor productivity growth over the entire period, but with all the signs of the effects $\mathrm{A}-\mathrm{C}$ the same as in the aggregate manufacturing case. In Transport equipment, all effects have the same sign as in the aggregate manufacturing case, except for the upgrading factor B, which has a modestly positive effect. In Electrical equipment, the maquiladora sector has a positive overall effect on labor productivity growth (sum of A - C). Here, the only maquiladora factor with a negative sign is the upgrading factor $B$, which is very strongly negative at $-37.5 \%$, but this is "compensated" by a strong increase in gross output per worker (factor A).

The shorter time periods within the long 1990-2006 time stretch show fluctuating results, both at the level of aggregate manufacturing, and at the sectoral level. The 20012006 period appears as particular influential, representing the strong rise of China as an industrial power. During this period, the upgrading factor (B) is particularly strong and negative in all cases except transport equipment. Interestingly, the upgrading factor has a negative impact only in one other sub-period, i.e., 1990-1994.

\footnotetext{
${ }^{46}$ Appendix A6.2 presents similar decomposition results for the rest of manufacturing sectors not included in table 6.3.
} 
Table (6. 3): Contribution to Changes in Aggregate Labor productivity (\%)

\begin{tabular}{|c|c|c|c|c|c|}
\hline \multicolumn{6}{|c|}{ Total } \\
\hline Years & $\begin{array}{l}\text { A (gross output / } \\
\text { labor export } \\
\text { sector) }\end{array}$ & $\begin{array}{l}\text { B (upgrading export } \\
\text { sector) }\end{array}$ & $\begin{array}{l}\text { C (employment } \\
\text { share export } \\
\text { sector) }\end{array}$ & $\begin{array}{c}\mathrm{D} \\
\text { (domestic } \\
\text { sector) }\end{array}$ & $\% \Delta(\mathrm{Y} / \mathrm{L})=\mathrm{A}+\mathrm{B}+\mathrm{C}+\mathrm{D}$ \\
\hline 1990-1994 & 0.2 & -0.9 & -2.5 & -1.4 & -4.6 \\
\hline 1994-1998 & 0.7 & 0.1 & -4.3 & 7.0 & 3.6 \\
\hline 1998-2001 & 0.8 & 0.2 & 0.1 & -11.1 & -10.0 \\
\hline $2001-2006$ & 2.1 & -1.9 & -3.3 & 34.4 & 31.4 \\
\hline 1994-2001 & 1.5 & 0.2 & -3.7 & -4.8 & -6.8 \\
\hline 1990-2006 & 3.2 & -2.3 & -10.3 & 26.2 & 16.7 \\
\hline 2008-2014 & 0.9 & -3.0 & 2.4 & -0.7 & -0.5 \\
\hline \multicolumn{6}{|c|}{ Textiles } \\
\hline Years & $\begin{array}{l}\text { A (gross output / } \\
\text { labor export } \\
\text { sector) }\end{array}$ & $\begin{array}{l}\text { B (upgrading export } \\
\text { sector) }\end{array}$ & $\begin{array}{c}\text { C (employment } \\
\text { share export } \\
\text { sector) }\end{array}$ & $\begin{array}{c}\text { D } \\
\text { (domestic } \\
\text { sector) }\end{array}$ & $\% \Delta(\mathrm{Y} / \mathrm{L})=\mathrm{A}+\mathrm{B}+\mathrm{C}+\mathrm{D}$ \\
\hline 1990-1994 & -0.1 & -0.6 & -3.3 & -11.2 & -15.2 \\
\hline 1994-1998 & 2.9 & 1.1 & -4.4 & -3.9 & -4.2 \\
\hline 1998-2001 & 3.6 & 0.7 & 0.0 & -26.1 & -21.8 \\
\hline 2001-2006 & 7.0 & -4.4 & 0.0 & 49.9 & 52.5 \\
\hline 1994-2001 & 5.6 & 1.7 & -1.7 & -30.7 & -25.1 \\
\hline 1990-2006 & 6.2 & -1.1 & -5.8 & -2.5 & -3.1 \\
\hline 2008-2014 & -1.4 & 0.5 & 1.1 & 20.5 & 20.8 \\
\hline \multicolumn{6}{|c|}{ Transport Equipment } \\
\hline Years & $\begin{array}{l}\text { A (gross output / } \\
\text { labor export } \\
\text { sector) }\end{array}$ & $\begin{array}{l}\text { B (upgrading export } \\
\text { sector) }\end{array}$ & $\begin{array}{c}\text { C (employment } \\
\text { share export } \\
\text { sector) }\end{array}$ & $\begin{array}{c}\text { D } \\
\text { (domestic } \\
\text { sector) }\end{array}$ & $\% \Delta(\mathrm{Y} / \mathrm{L})=\mathrm{A}+\mathrm{B}+\mathrm{C}+\mathrm{D}$ \\
\hline 1990-1994 & 0.2 & -1.0 & -2.5 & 9.4 & 6.1 \\
\hline 1994-1998 & -2.3 & 0.6 & -2.5 & 13.3 & 9.0 \\
\hline 1998-2001 & 2.9 & -0.2 & 0.0 & -11.0 & -8.2 \\
\hline 2001-2006 & 2.9 & 3.0 & -4.1 & 43.3 & 45.2 \\
\hline 1994-2001 & 0.7 & 0.4 & -2.1 & 1.1 & 0.0 \\
\hline 1990-2006 & 3.9 & 2.0 & -10.2 & 58.4 & 54.1 \\
\hline 2008-2014 & 0.3 & -8.5 & 4.1 & 5.2 & 1.1 \\
\hline \multicolumn{6}{|c|}{ Electrical Equipment } \\
\hline Years & $\begin{array}{l}\text { A (gross output / } \\
\text { labor export } \\
\text { sector) }\end{array}$ & $\begin{array}{l}\text { B (upgrading export } \\
\text { sector) }\end{array}$ & $\begin{array}{l}\text { C (employment } \\
\text { share export } \\
\text { sector) }\end{array}$ & $\begin{array}{c}\text { D } \\
\text { (domestic } \\
\text { sector) }\end{array}$ & $\% \Delta(\mathrm{Y} / \mathrm{L})=\mathrm{A}+\mathrm{B}+\mathrm{C}+\mathrm{D}$ \\
\hline 1990-1994 & 6.3 & -14.3 & 3.6 & -5.3 & -9.7 \\
\hline 1994-1998 & 18.4 & 0.0 & -2.9 & 10.0 & 25.6 \\
\hline 1998-2001 & 12.9 & -1.6 & -4.3 & -20.7 & -13.7 \\
\hline 2001-2006 & -0.9 & -19.4 & 17.0 & 77.5 & 74.2 \\
\hline 1994-2001 & 34.2 & -1.8 & -8.4 & -15.6 & 8.4 \\
\hline 1990-2006 & 42.1 & -37.5 & 9.3 & 56.7 & 70.6 \\
\hline $2008-2014$ & -1.7 & -4.1 & -1.1 & 12.1 & 5.3 \\
\hline
\end{tabular}

Notes: $\Delta$ indicates changes with respect to the previous year of observation.

Source: Author's calculation based on equation (6.6) using data from INEGI's National Accounting System (1990-2014), EMIME (1990-2006) and, IMMEX (2008-2014). 
Focusing next on the IMMEX period, we see a different picture. For the case of all manufacturing sectors, the IMMEX years (2008-2014) show the an overall positive (but small) effect of the exporting sector, with factor $C$ (increase of the share of the exporting sector) as the largest effect. This is now positive because the level of labor productivity in the exporting sector, in the IMMEX definition, is larger than that of the domestic sector. Upgrading (factor B) still has a negative, and comparatively strong impact.

Concluding, it makes a big difference whether we look at the Mexican exporting sector from the point of view of the maquiladora, or using the IMMEX dataset. The maquiladora dataset shows a sector that has comparatively low labor productivity, but grows rapidly, especially so in terms of employment. In roughly 25 years, Maquiladora increase from rather low shares in output to almost half of manufacturing production and half of manufacturing gross value added in Mexico, with an important and increasing share of total manufacturing employment. On the other hand, in the IMMEX dataset, the exporting sector appears as more productive than the domestic sector.

This suggests that the Mexican exporting manufacturing sector is in fact a heterogeneous sector. One part of it, the maquiladora, derives its dynamic impact on the Mexican economy by its ability to absorb large amounts of labor, while the other part also has a dynamic influence by higher productivity levels and growth rates. Thus, the impact of the maquiladoras in terms of raising living standards is mainly in terms of transferring labour from lower-productivity activities into manufacturing, and not so much in terms of upgrading labor productivity in manufacturing. Upgrading has never been strong in maquiladoras and this is a major brake on productivity growth. The sector has rapidly increased its contributions to output and employment, but could have made a much larger contribution to productivity if it had experienced more upgrading. The non-maquiladoras part of the Mexican economy (i.e. domestic manufacturing) is at an advantage in terms of labor productivity growth, but has not been able to absorb large amounts of workers.

\subsection{Firm-Level Analysis}

\subsubsection{Data.}

We now proceed to analyze the differences between the maquiladora and other part of the exporting sector at the microeconomic level. Our micro analysis will rely on two official unbalanced firm level panel data sets collected and compiled by INEGI; the first one is the EMIME (maquiladora) firm level dataset from 1990 to 2006 and, the second one is the IMMEX firm level dataset (July 2007-2014). These firm-level datasets were used as raw data by INEGI to construct aggregate information. Both EMIME and IMMEX report their own official variables at the aggregate and firm-level.

Let us first focus on the different information presented by the Maquiladora and the IMMEX datasets. As can be seen from appendix tables A6.1, when compared to Maquiladora, IMMEX has a higher share in total manufacturing for all relevant variables such as employment, gross output and value added. Focusing on the last year of observation for Maquiladora firms (2006) and, the first full year for IMMEX firms 
(2008) 47 , the difference is usually quite large. These differences are related to the number of firms included in the two datasets. According to INEGI (2011a), by December 2006, EMIME had collected information for 2,600 maquiladora firms while, by July 2011, the IMMEX dataset had collected data for 6,400 firms. Moreover, according to estimates provided by De La Cruz et al. (2001) from the total set of firms that were going to be considered part of the IMMEX program, by the end of 2006, 56\% were PITEX firms and $44 \%$ Maquiladora firms. This would suggest that of the 6,400 IMMEX firms, about 2,800 could be considered maquiladora, which is slightly more than the 2,600 in the EMIME dataset. We will come back to these numbers when we present detailed information on the IMMEX dataset below.

The EMIME firm-level dataset consists of 34,728 plant-year observations (1990-2006). For each plant, there is information on hours worked, number of employees and wages all of them reported by gender and by job category (administrators, technicians and workers), as well as plant expenditures (energy consumption, telephone, services provided by third parties, custom procedures, freight, maintenance of buildings, fuels water consumption and other expenditures), domestic and imported intermediate consumption, value added and profits. The EMIME dataset also contains one variable related to capital expenditures named "expenditures on machinery and equipment". According to Utar and Ruiz (2013), this variable refers to firm-level domestic expenditures on precision and resistance instruments, rotation bands, forklifts and, trucks with special containers (toxic waste). EMIME does not report plant-level expenditures on imported capital equipment.

The IMMEX dataset consists of 41,500 observations (July 2007 to December 2014). Plant level data for wages, number of employees, hours worked are also reported by job category. Nevertheless, unlike EMIME, IMMEX only reports data for two job categories, namely technicians and workers (lumped into a single category) and, administrative staff. In addition, IMMEX reports two different revenue categories that a firm might obtain from domestic or foreign market operations respectively. This refers to the categories of revenue obtained as a result of maquiladora related operations (ingresos por maquila, submaquila y re-manufactura) versus other revenues. IMMEX data for plant expenditures is less detailed than for EMIME. For instance, there is no IMMEX variable that directly quantifies firm-level expenditures on capital equipment. In this regard, the only available variable that approximates to capital equipment is "payments for the rent of movable assets". IMMEX micro data for domestic and imported intermediates are reported in the same ways as for EMIME.

Table 6.4 presents basic firm-level statistics for four relevant Maquiladora and IMMEX variables included in equation (6.6). These are the value added to output ratio $(v)$, the value added to employment ratio $\left(\frac{v X^{M}}{L^{M}}\right)$, the output to employment ratio $\left(\frac{X^{M}}{L^{M}}\right)$ and, the share of employment from the exporting sectors in total manufacturing employment in Mexico $\left(\sigma^{M}\right)$. As mentioned in previous paragraphs, these firm-level variables were constructed following the same concepts and methodology as used at the aggregate level.

${ }^{47}$ For IMMEX firms, the information for 2007 only goes from July to December. 
Table 6.4 confirms the mean higher value of productivity in IMMEX as compared to EMIME (maquiladora), both in terms of gross output per worker, and value added per worker. Also value added to gross output is higher (on the average) in IMMEX. We also note from table 6.4 that the degree of heterogeneity, as measured by the coefficient of variation, i.e., the standard deviation divided by the mean, is higher for the productivity measures than it is for the value added to output ratio. In both datasets, the standard deviation for the latter variable is smaller than the mean, while it is larger than the mean for the output or value added per worker measures. This is why we will focus on productivity rather than value added to output (upgrading) in the regression analysis. We also note that most measures have positive skewness, which indicates that a relatively large part of the observations is found to the right of the mean value. Only value added to output in the IMMEX dataset has negative skewness.

Table (6. 4): Basic Statistics for the Entire Sample (between Firms and Over Time), Maquiladora (1990-2006) and IMMEX (2008-2014) Firm-Level Datasets, All Years and All Manufacturing Sectors (Shares and Constant Mexican Pesos of 2008).

\begin{tabular}{|c|c|c|c|c|c|c|c|c|}
\hline Maquiladora & Mean & $\begin{array}{c}\text { Std. } \\
\text { Deviation }\end{array}$ & Variance & Skewness & Kurtosis & Min. & Max. & Obs. \\
\hline Value added to output ratio & 0.4 & 0.3 & 0.1 & 1 & 4.7 & 0.0 & 2.2 & 34,728 \\
\hline Value added per worker & 137 & 175 & 30,646 & 16 & 488 & -10 & 9,090 & 34,728 \\
\hline Output per worker & 624 & 1,491 & $2,222,947$ & 25 & 1,109 & 2 & 96,849 & 34,728 \\
\hline IMMEX & Mean & $\begin{array}{c}\text { Std. } \\
\text { Deviation }\end{array}$ & Variance & Skewness & Kurtosis & Min. & Max. & Obs. \\
\hline Value added to Output ratio & 0.8 & 0.3 & 0.1 & -0.5 & 2.5 & 0.0 & 1.3 & 34,948 \\
\hline Value added per worker & 776 & 1,852 & $3,430,753$ & 10 & 164 & 0.0 & 52,851 & 34,948 \\
\hline Output per worker & 1,226 & 2,889 & $8,343,702$ & 10 & 180 & 0.0 & 89,488 & 34,948 \\
\hline
\end{tabular}

Source: Author's calculation based on INEGI's EMIME and IMMEX firm-level datasets.

Notes: for the case of IMMEX the observations corresponding to 2007 (July 2007 to December 207) have been here dropped. Similarly, IMMEX firms reporting negative gross value added for at least one year of observation have been here dropped.

One important thing to mention is the fact that there were some firms with negative gross value added, both in the Maquiladora and the IMMEX dataset. For the case of the Maquiladora firm-level dataset, only 2 firms (3 observations) presented negative gross value added (one firm in the textile sector for two consecutive years and, other firm in the chemical sector for only year). We decided to keep these in all of our calculations. However, in the IMMEX dataset, 404 firms presented negative gross value added in at least one year of observation. In total, there were 638 observations with negative value added (out of 2,357 total observations for 404 firms).

In line with our methodology described above, gross value added for IMMEX firms was calculated by subtracting its total domestic intermediate consumption from the total income obtained by a given firm. Thus, at the firm-level, negative gross value added could be obtained in a given year because (1) a given IMMEX firm reported a higher level of domestic intermediate inputs than its corresponding level for total income or, (2) a given IMMEX firm reported domestic intermediate consumption but without providing information for total income.

Since the presence of negative gross value added observations is mostly seen in the IMMEX dataset, and very rarely in the EMIME dataset, we infer that the reason for these 
negative observations is related to the new type of exporting firms included in the IMMEX framework and IMMEX dataset since 2007. In this regard, we are referring to a type of firm named IMMEX Controladora. In line with Chapter 2, IMMEX Controladora refers to firms that control and administrate temporary imports from several other firms belonging to the same organization or hierarchical structure. IMMEX Controladora is the main representative of these other firms with regard to customs authorities in Mexico. Therefore, a given IMMEX Controladora firm could be reporting higher domestic intermediate consumption than total income, because it is jointly reporting the value of domestic inputs used and total income obtained by a variety of firms that belong to its organization. For instance, an indirect exporter in Mexico (belonging to the organization of a IMMEX Controladora) might process domestic and imported intermediate inputs which are later sent to other firms within the same organization for further processing. Such an indirect exporter reports no total income to the IMMEX Controladora because its processing operations took place within one and the same organization (no third parties were involved). Alternatively, other indirect exporters in Mexico, registered as IMMEX firms, rather than as part of an IMMEX Controladora, might report no income given that their processing of domestic and imported inputs only took place within the same organization.

Therefore, we decided to drop from the IMMEX dataset all those firms that reported at least one year of negative value added. In addition, for the IMMEX dataset, we also dropped all observations for 2007, because for that year information was only reported from July to December of such year. The final IMMEX dataset that we use consists of 34,948 observations, as described in the bottom panel of table 6.4 .

\subsubsection{Identifying sub-Groups of Firms in the IMMEX Dataset.}

The aggregate productivity data of figure 6.1 clearly show that, up to 2007, maquiladora firms are less productive than average Mexican manufacturing. However, the entire IMMEX sample, which includes the maquiladora as well as a broader set of exporting firms, appears as more productive than average manufacturing after 2008. We will investigate this phenomenon by a set of micro-level regressions aimed at explaining labour productivity at the firm level. To obtain insight into the differential performance between maquiladora firms and other exporting firms, it is crucial that we are able to distinguish these two types of firms in the IMMEX dataset.

Our attempt to do this is based on descriptive statistics with regard to imported intermediates and exported production. Table 6.5 provides these descriptives. The two top lines document results for the entire sample. The share of exports in total output is just above $60 \%$. We notice that there are also observations that have zero exports. Since IMMEX firms, by definition, are exporting firms, we must conclude that these are observations that refer to individual years in which the firm does not export, while it exports in other years. This is not completely uncommon, as the $5 \%$ percentile value is still at 0 for the entire sample. On the other hand, we also have observations where the entire output is exported, for example at the $90 \%$ percentile and up for the total sample. The median for exports is about $10 \%$-points above the mean, indicating a skew towards larger values of this variable. The share of imported intermediates (to total 
intermediates) is significantly smaller, at about $18 \%$ in the total sample. The median value is much lower than this, at only about $2 \%$, indicating a clear skew towards smaller values.

Table (6. 5): Basic Statistics for Exports and Imported Intermediates (between Firms and Over Time), IMMEX (20082014), All Years and All Manufacturing Sectors (Shares and Constant Mexican Pesos of 2008)

\begin{tabular}{|c|c|c|c|c|c|c|c|c|}
\hline & Mean & $\begin{array}{c}\text { Std. } \\
\text { Deviation }\end{array}$ & $\begin{array}{c}5 \% \\
\text { percentile }\end{array}$ & $\begin{array}{c}10 \% \\
\text { percentile }\end{array}$ & Median & $\begin{array}{c}90 \% \\
\text { percentile }\end{array}$ & $\begin{array}{c}95 \% \\
\text { percentile }\end{array}$ & Obs. \\
\hline \multicolumn{9}{|l|}{ IMMEX - total } \\
\hline Exports to gross output & 0.619 & 0.375 & 0 & 0.005 & 0.723 & 1 & 1 & 34,837 \\
\hline Share imported intermediates & 0.179 & 0.257 & 0 & 0 & 0.022 & 0.611 & 0.760 & 34,516 \\
\hline \multicolumn{9}{|c|}{$\begin{array}{l}\text { IMMEX - only firms defined as GVC- } \\
\text { intensive }\end{array}$} \\
\hline Exports to gross output & 0.893 & 0.167 & 0.566 & 0.710 & 0.962 & 1 & 1 & 8,348 \\
\hline Share imported intermediates & 0.156 & 0.218 & 0 & 0 & 0.059 & 0.482 & 0.657 & 8,253 \\
\hline \multicolumn{9}{|c|}{$\begin{array}{l}\text { IMMEX - only firms defined as non- } \\
\text { GVC intensive }\end{array}$} \\
\hline Exports to gross output & 0.518 & 0.380 & 0 & 0 & 0.508 & 1 & 1 & 22,146 \\
\hline Share imported intermediates & 0.182 & 0.269 & 0 & 0 & $0.7 \mathrm{E}-4$ & 0.646 & 0.780 & 22,000 \\
\hline
\end{tabular}

Source and notes as described in table 6.4

The traditional image of the maquiladora is a firm that imports (almost) all of intermediates and exports (almost) all of its output. Clearly, the descriptive statistics in table 6.5 show that we have very few observations that adhere to this image. It is especially the import variable that is responsible for this. Only $5 \%$ (i.e., about 1,700 ) of all observations have a larger than $76 \%$ share of imported intermediates, and a fair amount of observations (slightly more than $40 \%$ ) have zero imported intermediates.

Given that we can only find few typical maquiladora firms in the IMMEX dataset, we opt for a slightly different rule for splitting the IMMEX firms. We define one group of firms, which we call GVC intensive IMMEX firms as those firms that export more than $70 \%$ of their total output, and import at least some $(>0 \%)$ of their intermediate goods. We use the first year of observation for each firm to measure this. Firms that do not meet these two criteria in the first year of their existence in the dataset are defined as non-GVC intensive IMMEX firms.

The bottom parts of table 6.5 document descriptive statistics for the GVC-intensive and non-GVC-intensive firms, defined in this way. Clearly, GVC intensive firms score higher on both variables (by definition), but the average for the share of imported intermediates is only about $16 \%$ for these firms. Somewhat paradoxically, this share is a bit larger for non-GVC-intensive firms. Obviously, this is caused by the fact that only the first observation of each firm defines its status as either GVC-intensive or non-GVCintensive. What this ultimately shows, is that this categorization of firms is not static over time, at least not in the IMMEX dataset that we are using. Nevertheless, we proceed to estimate our regression models with this definition in mind. We also experimented with alternative definitions, but we do not document those results. 


\subsection{Econometric Analysis}

\subsubsection{Econometric Specification}

The econometric specification that will be used starts from two main ideas, which are (1) that the level of productivity depends on the level of a set of explanatory variables, and (2) that productivity growth depends on the level of that same set of explanatory variables. These are alternative but complementary interpretations of the relationship between productivity and its determinants. As an example, think about skills (or educational level) of the workers. On the one hand (our first idea above), a higher skilled worker is likely to be more productive, but we may also expect (our second idea) that a higher skilled worker will be able to learn more efficiently and hence generate a higher amount of productivity growth.

In the econometric specification, both ideas are combined in the form of a so-called Error Correction Model (ECM). ECMs were first proposed by Engle and Granger (1987) and include first differences specifications for the set of independent variables included in the regression, as well as lagged specifications for all dependent and independent regressors. Let us now explain in detail the reasoning behind the ECM.

The first of the two above ideas may be formalized as follows:

$$
\ln (Y)=c+a * \ln (X),
$$

where $Y$ is the level of labor productivity, and $X$ is the set of independent variables, also specified in levels (as opposed to growth rates). Note that this equation may readily be transformed to first differences, yielding

$$
\ln \left(Y_{t}\right)-\ln \left(Y_{t-1}\right)=\Delta \ln (Y)=a *\left[\ln \left(X_{t}\right)-\ln \left(X_{t-1}\right)\right]=a \Delta \ln (X)
$$

On the other hand, the second idea above can be formalized as follows:

$$
\ln \left(Y_{t}\right)-\ln \left(Y_{t-1}\right)=\Delta \ln (Y)=d+b *\left[\ln \left(X_{t-2}\right)\right]
$$

Note the crucial difference between equations (6.8) and (6.9): (6.8) is specified completely in first differences, while (6.9) only has first differences on the left hand side.

The ECM combines all these approaches in a single estimation. ECMs assume that the first-level specification (equation 6.7) can be regarded as a long run equilibrium. Therefore, the following expected to hold in the long-run:

$$
E C \equiv \ln (Y)-c-a * \ln (X)=0
$$

Equation (6.10) states that equation (6.8) holds exactly in the long run, i.e., that any residuals (or error terms) in equation (6.8) would be zero in the long run. The full ECM specifies that all deviations from equation (6.10) (i.e., from $E C=0$ ) will induce "adjustments" (or "corrections") that will bring the firm back to the equilibrium $(\mathrm{EC}=0$ ). This is captured in the following specification:

$\ln \left(Y_{t}\right)-\ln \left(Y_{t-1}\right)=c_{0}+a_{0} *\left(\ln \left(X_{t}\right)-\ln \left(X_{t-1}\right)\right)+k * E C_{t-1}$, 
with $k<0$. Note that when the dependent variable is above its equilibrium level, $E C>0$ will hold. With negative $k$, this will induce the dependent variable to fall, because then $k$ * $E C<0$, and the left hand side of equation (6.11) is the change in the dependent variable.

To arrive at a version of the DCM that can easily be estimated, we substitute the definition of EC into equation (6.11) to arrive at

$$
\begin{aligned}
& \Delta \ln \left(Y_{t}\right)=\ln \left(Y_{t}\right)-\ln \left(Y_{t-1}\right)=c_{0}+a_{0} * \Delta \ln \left(X_{t}\right)+k *\left[\ln \left(Y_{t-2}\right)-c-a * \ln \left(X_{t-2}\right)\right]= \\
& c_{0}-k c+a_{0} * \Delta \ln \left(X_{t}\right)+k \ln \left(Y_{t-2}\right)-a k * \ln \left(X_{t-2}\right)
\end{aligned}
$$

In this equation, the change of labor productivity depends on the change in the independent variables (first idea above), but also on the level of the independent variables (second idea above), and in addition it depends on the lagged value of itself ${ }^{48}$. Econometric estimation of the model can be implemented as follows

$$
\Delta \ln \left(Y_{t}\right)=c_{1}+a_{0} * \Delta \ln \left(X_{t}\right)+k \ln \left(Y_{t-2}\right)+a_{1} * \ln \left(X_{t-2}\right)
$$

This will directly provide an estimate of the error correction parameter $k$, whereas the long-run elasticities $a$ can readily be obtained from the estimated parameters $k$ and $a_{1}$ $\left(a=-a_{1} / k\right)$. Hence, the estimation of equation (6.13) both yields information on short run adjustments (parameters $k$ and $a_{0}$ ) and long-run equilibrium (parameters $a$ ).

\subsubsection{Selection of Explanatory Variables}

Our main interest is to find indications of the micro-level variables that may explain the strikingly different labour productivity performance between maquiladora firms and non-maquiladora firms that still export. Our aggregate analysis suggests that the differences between these two groups of firms are large. Firm-level variations in our preferred measure of labor productivity for Maquiladora/IMMEX firms, i.e. value added per worker will be the dependent variable in the analysis. This section will present the operationalization of the independent variables, their expected sign and impact on labor productivity, as well as the specific data we use both for the case of EMIME and IMMEX. Table A6.3 in the appendix indicates specific details about the operationalization of each variable. Also, table A6.4 in the appendix presents basic statistics for our set of dependent and independent variables.

The explanatory variables that will be used in the regressions are as follows: (1) economies of scale; (2) capital deepening; (3) use of imported intermediates; (4) the quality of labor force, and; (5) export intensity. Let us now discuss each factor in detail.

Regarding the first factor, according to Verdoorn (1949) higher gross output can lead to higher productivity in a given firm due to the existence of dynamic economies of scale. To capture this effect, we include the logarithm of firm-level output produced by a given exporting firm (In_output). The traditional Verdoorn effect is a dynamic effect, i.e., we

\footnotetext{
$48 \mathrm{t}-2$ is included in formula 6.12 as it indicates the lagged value of the initial lagged value (t-1) from the independent variables that were included in the first set of regressions. A second lagged of the initial lagged value is here included to further assess the existence of a long run relationship between the dependent and independent variables
} 
can expect growth of output to lead to growth of productivity. But note that the ECM also includes a static scale effect, in which the level of output may lead to growth of productivity. We also include the size of the firm in terms of employees as an explanatory variable related to scale. Note that this is the variable that appears in the denominator of the dependent variable (which is value added divided by number of employees). We include this variable mainly as a control to account for the negative effect that firm size may have through this channel.

As for the second variable, an increase in the amount of capital per worker (i.e., capital deepening) will lead to rising firm-level productivity. According to McEachern (2014), as capital per worker increases, output per worker will also increase but, at a diminishing rate given the law of diminishing returns to capital. As mentioned in previous sections, in the case of Maquiladora and IMMEX firms, there is no available information on the firm-level imports of machinery and equipment. However, variables related to firm-level investment are available for both datasets (domestic purchases of machinery and equipment for Maquiladora and, payments for the rent of movable assets in the case of IMMEX). Thus, to account for the impact of capital deepening in labor productivity, we will rely on the investment variables to construct our own proxy for capital deepening. We constructed a capital stock following the Perpetual Inventory Method (PIM). Initial capital stocks (which are required for computing PIM) were constructed following Timmer (1999) (see table A6.3 for details). With this information, we constructed the firm-level ratio of capital stock to labor (capital_labor). Labor working with higher capital levels should induce higher gross value added per worker. So, we expect the variable capital_labor to have a positive impact on labor productivity.

Regarding the impact of foreign intermediate inputs on firm level productivity, we identified mixed empirical evidence. On the one hand, by using firm-level data for Chilean manufacturing, Kasahara and Rodrigue (2008) find evidence that imported intermediates improve productivity. In their view, a firm can immediately increase productivity by switching from being a non-importer to an importer of foreign intermediates. In general, the argument here is that a high ratio of imported inputs could provide opportunities for learning especially if combined with a highly educated working force. On the other hand, other studies indicate that imported inputs do not necessarily lead to rising productivity. For instance, on his study of Colombian firms, Van Biesebroeck (2003) finds that importing inputs has a negative effect on productivity growth. According to this author, many technologies used in developing economies (that are created in advanced countries) are inappropriate for the local mix of skills. Thus, having access to new technologies (or highly complex intermediate inputs) will not suffice to increase productivity. We therefore do not formulate exact expectations for the variable on foreign inputs, which we define as the ratio of imported intermediate inputs to total intermediate consumption (imp_interm). Either a positive or a negative sign is possible on this variable.

As for the fourth factor, it can be argued that a well-educated work force contributes to a better use of available technologies. We will construct three different proxies to account for the impact of the quality of labor force in firm-level labor productivity. In line with Montes-Rojas and Santamaria (2007), our first proxy for the quality of labor will be a 
ratio of the blue collar to white collar working hours (blue_white_hours). If a given firm decides to increase its use of low-qualified labor and reduce the share of its highlyqualified labor, labor productivity level should decrease. Therefore, for this variable (blue_white_hours), we expect a negative impact on labor productivity. Following the same stream of ideas, Haltiwanger et al. (1999) states that firms that with higher fractions of educated workforce are prone to higher productivity levels. Also, these authors empirically confirm the need to add workforce composition variables in to firmlevel productivity regressions given that those variables add significant explanatory power. Considering these arguments from Haltiwanger et al. (1999), the second proxy for the quality of labor will be the share of technicians in total employment (tech_empleo). The reasoning here is that a higher use of technicians with respect to total labor in the firm should be reflected in rising productivity. Finally, also considering the arguments from the latter authors, our third proxy for the quality of labor is a workforce composition variable which is the ratio of average firm-level remuneration to total firmlevel labor (labor_comp). A higher quality of labor in an exporting firm should be reflected in higher wages, which is why this variable may be interpreted as an indicator for the quality of labor. In our expectation, higher values of the labor compensation variable will be associated with higher productivity levels.

With regard to our fifth independent variable, Castellaci (2002) finds that productivity growth is positively influenced by firm's export intensity in his econometric analysis of Italian manufacturing firms from 1989 to 1994. Following Castellaci (2002), we will measure export intensity as the share of foreign sales on total sales (export_int). Nevertheless, a distinction between foreign sales and total sales is only available for the case of the IMMEX and not for the Maquiladora panel dataset. Thus, our econometric analysis can only include the export intensity variable for the analysis of productivity of IMMEX.

Finally, as further control variables, we also include the firm's age (in years, and also including a squared version).

\subsubsection{Econometric Results}

Before estimating the full ECM, we attempt to estimate the long-run relation directly by adding an error term to equation (6.7). This equation is estimated by using fixed effects. ${ }^{49}$ Results are presented in table 6.6, both for EMIME (Maquiladora) and IMMEX. For IMMEX, we present results for the sample of firms that is defined as GVC-intensive, and those defined as non-GVC-intensive. In general, our econometric results in this table differ more between the two datasets than between the GVC-intensive and non-GVCintensive firms within IMMEX.

We start with scale effects, which are captured by the size variable (incl. the square) and the ln_output variable. Both size variables are significant in the EMIME dataset and in IMMEX-GVC-intensive regressions. The quadratic term is not significant in the IMMEXnon-GVC-intensive regression. The positive sign on the squared size term indicates a

\footnotetext{
${ }^{49}$ For every specification, Hausman tests (not reported here) prefer fixed effects over a random effects specification.
} 
minimum efficient size, but this minimum lies far outside the relevant range of employee size. Thus, the regressions all show a negative effect of size in terms of employees on labour productivity. This seems mainly the result of the fact that the number of employees occurs in the denominator of the dependent variable.

Table (6. 6): Econometric Results for IMMEX, Fixed effects Dependent variable: Logarithm of FirmLevel Labor Productivity.

\begin{tabular}{|c|c|c|c|}
\hline & $\begin{array}{c}\text { EMIME } \\
\text { (maquiladora) }\end{array}$ & $\begin{array}{c}\text { IMMEX } \\
\text { (GVC-intensive) }\end{array}$ & $\begin{array}{l}\text { IMMEX (non-GVC- } \\
\text { intensive) }\end{array}$ \\
\hline \multirow[t]{2}{*}{ ln_size } & $-0.028^{* * *}$ & $-1.050^{* * *}$ & $-1.010^{* * *}$ \\
\hline & $(0.07)$ & $(0.11)$ & $(0.06)$ \\
\hline \multirow[t]{2}{*}{ ln_size_squared } & $4.47 \mathrm{E}-4^{* * *}$ & $7.37 \mathrm{E}-3^{* *}$ & $7.38 \mathrm{E}-4$ \\
\hline & $(0.00)$ & $(0.00)$ & $(0.01)$ \\
\hline \multirow[t]{2}{*}{ ln_age } & $0.021^{*}$ & $0.118^{* * *}$ & $0.173^{* * *}$ \\
\hline & $(0.01)$ & $(0.02)$ & $(0.02)$ \\
\hline \multirow[t]{2}{*}{ ln_age_squared } & $-0.082^{* * *}$ & $-0.077^{* * *}$ & $-0.082^{* * *}$ \\
\hline & $(0.00)$ & $(0.01)$ & $(0.01)$ \\
\hline \multirow[t]{2}{*}{ ln_imp_interm } & $-0.044^{* * *}$ & $-0.016^{* * *}$ & $-0.019^{* * *}$ \\
\hline & $(0.00)$ & $(0.00)$ & $(0.00)$ \\
\hline \multirow[t]{2}{*}{ ln_export_int } & & $0.251^{* * *}$ & $0.078^{* * *}$ \\
\hline & & $(0.01)$ & $(0.01)$ \\
\hline \multirow[t]{2}{*}{ ln_output } & $0.261^{* * *}$ & $0.972^{* * *}$ & $0.981^{* * *}$ \\
\hline & $(0.01)$ & $(0.01)$ & $(0.01)$ \\
\hline \multirow[t]{2}{*}{ ln_capital_labor } & $0.302^{* * *}$ & -0.008 & -0.015 \\
\hline & $(0.07)$ & $(0.10)$ & $(0.03)$ \\
\hline \multirow[t]{2}{*}{ ln_blue_white_hours } & -0.013 & -0.023 & -0.013 \\
\hline & $(0.01)$ & $(0.01)$ & $(0.02)$ \\
\hline \multirow[t]{2}{*}{ ln_tech_empleo } & $0.024^{* *}$ & -0.016 & 0.018 \\
\hline & $(0.01)$ & $(0.01)$ & $(0.02)$ \\
\hline \multirow[t]{2}{*}{ In_labor_comp } & $0.617^{* * *}$ & $0.044^{* *}$ & 0.012 \\
\hline & $(0.01)$ & $(0.01)$ & $(0.01)$ \\
\hline \multirow[t]{2}{*}{ ln_constant } & $-3.409^{* * *}$ & 0.087 & -0.019 \\
\hline & $(1.03)$ & $(1.83)$ & $(0.57)$ \\
\hline r-sqr & 0.659 & 0.834 & 0.628 \\
\hline dfres & 13,784 & 2,756 & 4,015 \\
\hline bic & $-9,823.7$ & $-3,771.8$ & $-1,797.9$ \\
\hline obs & 17,494 & 3,824 & 5,668 \\
\hline No. firms & 3,700 & 1,057 & 1,642 \\
\hline
\end{tabular}

Notes: ${ }^{*} \mathrm{p}<0.05,{ }^{* *} \mathrm{p}<0.01,{ }^{* * *} \mathrm{p}<0.001$. Robust standard errors are shown in parentheses.

On the other hand, our proxy for the impact of economies of scale (In_output) has a positive and statistically significant impact on labor productivity. This effect is stronger in IMMEX than in EMIME, and it does not differ much between the two types of IMMEX firms. Higher output in Maquiladora and IMMEX firm will induce higher productivity levels as expected. Note that in this specification, the scale effect is purely static. 
With respect to capital deepening (higher capital per worker, capital_labor variable), we find a positive and significant effect only in EMIME, indicating that here more capital per worker in exporting firms is positively associated with productivity levels. The variable is not significant in the IMMEX regressions.

For imported intermediates, we observe that a higher value leads to lower labor productivity levels for all exporting firms in Mexico (a significant and negative sign). This negative coefficient supports the idea that exporting firms usually import inputs with high technological content produced by more efficient suppliers located elsewhere, and that such imports lower their own productivity, supporting the earlier finding by Van Biesebroeck (2003). This effect is weaker in the IMMEX dataset, where it does not differ much between the two groups of firms.

Of the three proxies for the quality of labor, two are significant for EMIME, and only one for IMMEX. We also ran regressions with just one of these proxies included the time, and the results do not differ much from what is documented here. The blue to white collar ratio is not significant. For the second proxy for the quality of labor (tech_empleo), we observe that increasing the share of highly skilled labor in total labor will be positively associated with higher productivity levels at exporting firms, but only in the EMIME dataset. The third proxy for the quality of labor (labor_comp) is positive and significant, i.e., higher expenditures on labor are associated with higher productivity. This positive effect is found for the EMIME dataset, where it is strong, and also for the IMMEX group of firms defined as GVC-intensive. It is not significant for IMMEX-non-GVCintensive firms. Finally, for the specific case of IMMEX firms (we do not have this variable for EMIME firms), we find a positive and statistically significant coefficient of the variable export_int, indicating that the higher exports, the higher productivity. This effect is much stronger for the GVC-intensive firms.

For our control variable age and age squared, both variables are significant in all three regressions. The negative sign on age squared indicates a maximum in the age productivity relationship. This maximum lies just beyond one (to be precise at 1.14) year for EMIME, which indicates that the effect of age is really negative. For IMMEX-GVCintensive, the maximum lies at 2.2 years, and for IMMEX-non-GVC-itensive, it lies at 2.9 years, also indicating mostly a negative relationship between age and productivity.

We now proceed to present results for the full ECM specification. Table 6.7 presents our error correction model estimation for Maquiladora and IMMEX. We find a significant and negative sign of the error correction term (this is the coefficient on the lagged dependent variable, labeled In_labour_prod in the table) for EMIME and IMMEX-GVCintensive firms. This confirms the relevance of the error-correction model for these datasets. However, the error correction coefficient is not significant (and positive) for the non-GVC-intensive group in IMMEX. This points to a first and fundamental difference between the two groups of IMMEX firms. One group, the GVC-intensive group, has a long-run equilibrium productivity level to which it adjusts, while the productivity dynamics in the non-GVC-intensive group are influenced mostly by shorter-run dynamics. In EMIME, the adjustment speed is about twice $(20 \%)$ that of the GVCintensive IMMEX firms (11\%). 
Table (6. 7): Error Correction Model Estimation for Maquiladora and IMMEX

\begin{tabular}{|c|c|c|c|}
\hline & EMIME (maquiladora) & IMMEX (GVC-intensive) & IMMEX (non-GVC-intensive) \\
\hline \multirow[t]{2}{*}{$\Delta \ln \_$size } & $-0.962^{* *}$ & 20.466 & $-1.043^{* *}$ \\
\hline & $(0.30)$ & $(32.87)$ & $(0.36)$ \\
\hline \multirow[t]{2}{*}{$\Delta l n \_s i z e \_s q u a r e d$} & -0.004 & -0.008 & -0.020 \\
\hline & $(0.00)$ & $(0.01)$ & $(0.01)$ \\
\hline \multirow[t]{2}{*}{$\Delta \ln \_$age } & 0.122 & $92.836^{* *}$ & $173.447^{* * *}$ \\
\hline & $(2.47)$ & $(34.50)$ & (29.27) \\
\hline \multirow[t]{2}{*}{$\Delta \ln \_$age_squared } & -0.437 & -101.329 & $-165.751^{* * *}$ \\
\hline & $(0.65)$ & (30.68) & (24.95) \\
\hline \multirow[t]{2}{*}{$\Delta l n \_i m p \_i n t e r m$} & $-0.040^{* * *}$ & -0.007 & $-0.026^{* *}$ \\
\hline & $(0.01)$ & $(0.01)$ & $(0.01)$ \\
\hline \multirow{2}{*}{$\Delta l n \_$export_int } & & $0.84^{* * *}$ & $0.066^{* * *}$ \\
\hline & & $(0.04)$ & $(0.01)$ \\
\hline \multirow[t]{2}{*}{$\Delta \ln \_$output } & $0.203^{* * *}$ & $1.043^{* * *}$ & $1.020^{* * *}$ \\
\hline & $(0.01)$ & $(0.02)$ & $(0.02)$ \\
\hline \multirow[t]{2}{*}{$\Delta \ln \_$capital_labor } & $0.705^{*}$ & 21.349 & 0.224 \\
\hline & $(0.30)$ & $(32.87)$ & $(0.34)$ \\
\hline \multirow[t]{2}{*}{$\Delta \ln$ blue_white_collar } & 0.004 & 0.012 & 0.033 \\
\hline & $(0.01)$ & $(0.03)$ & $(0.03)$ \\
\hline \multirow[t]{2}{*}{$\Delta \mathrm{ln} \_t e c h \_$empleo } & 0.009 & -0.012 & 0.015 \\
\hline & $(0.01)$ & $(0.03)$ & $(0.03)$ \\
\hline \multirow[t]{2}{*}{ 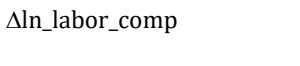 } & $0.719^{* * *}$ & 0.019 & 0.025 \\
\hline & $(0.01)$ & $(0.04)$ & $(0.02)$ \\
\hline \multirow[t]{2}{*}{ ln_labour_prod $(t-2)$} & $-0.202^{* * *}$ & $-0.111^{*}$ & 0.030 \\
\hline & $(0.01)$ & $(0.04)$ & $(0.03)$ \\
\hline \multirow[t]{2}{*}{ ln_size $(t-2)$} & -0.182 & -15.386 & -0.288 \\
\hline & $(0.13)$ & $(15.02)$ & $(0.16)$ \\
\hline \multirow[t]{2}{*}{ ln_size_squared $(t-2)$} & 0.001 & 0.006 & 0.023 \\
\hline & $(0.00)$ & $(0.01)$ & $(0.16)$ \\
\hline \multirow[t]{2}{*}{ ln_age $(t-2)$} & 0.038 & $20.493^{* *}$ & $38.243^{* * *}$ \\
\hline & $(0.48)$ & (7.05) & (6.29) \\
\hline \multirow[t]{2}{*}{ ln_age_squared $(t-2)$} & 0.009 & $-11.014^{* *}$ & $-16.570^{* * *}$ \\
\hline & $(0.10)$ & (3.38) & (2.52) \\
\hline \multirow[t]{2}{*}{ ln_imp_interm $(t-2)$} & -0.008 & -0.016 & 0.000 \\
\hline & $(0.01)$ & $(0.01)$ & $(0.01)$ \\
\hline \multirow[t]{2}{*}{ In_output $(t-2)$} & $0.058^{* * *}$ & $0.155^{* *}$ & 0.051 \\
\hline & $(0.01)$ & $(0.05)$ & $(0.04)$ \\
\hline \multirow[t]{2}{*}{ ln_capital_labor $(t-2)$} & -0.086 & -15.144 & 0.036 \\
\hline & $(0.13)$ & $(15.03)$ & $(0.11)$ \\
\hline \multirow[t]{2}{*}{ In_blue_white_collars $(t-2)$} & -0.007 & 0.002 & 0.014 \\
\hline & $(0.01)$ & $(0.03)$ & $(0.03)$ \\
\hline \multirow[t]{2}{*}{ In_tech_empleo $(t-2)$} & -0.010 & -0.044 & -0.032 \\
\hline & $(0.01)$ & $(0.03)$ & $(0.04)$ \\
\hline In_labor_comp $(t-2)$ & $0.127^{* * *}$ & -0.002 & -0.059 \\
\hline & $(0.01)$ & $(0.04$ & $(0.03)$ \\
\hline constant & 1.138 & 315.891 & $49.819^{* * *}$ \\
\hline & $(2.31)$ & $(297.31)$ & (7.48) \\
\hline r-sqr & 0.788 & 0.777 & 0.592 \\
\hline dfres & 8,012 & 1,209 & 1,861 \\
\hline bic & $-8,012.6$ & -782.2 & 148.9 \\
\hline obs & 10,530 & 1,767 & 2,686 \\
\hline No. firms & 2,497 & 535 & 802 \\
\hline
\end{tabular}

Notes: ${ }^{*} \mathrm{p}<0.05,{ }^{* *} \mathrm{p}<0.01,{ }^{* * *} \mathrm{p}<0.001$. Robust standard errors are shown in parentheses

In the EMIME dataset, the scale (ln_output) and labour composition have positive and significant long-run elasticities for the dependent variable labour productivity. In the 
GVC-intensive IMMEX group, scale (ln_output) also has a long-run positive elasticity, and the effect is stronger than in EMIME. For GVC-intensive IMMEX firms, age also has a significant long-run elasticity. With the squared age term negative, this long-run relationship has a maximum, which lies at about 2.5 years.

Scale effects (ln_output) also have a significant and positive short-run effect in all three regressions. This effect if stronger in both IMMEX regressions. Export intensity never has a significant long-run effect, but has a positive short-run effect for the IMMEX firms. This effect is much stronger for GVC-intensive IMMEX firms. GVC-intensive IMMEX firms do not have a significant short-run effect of imported intermediate, but this effect is negative for EMIME and non-GVC intensive IMMEX firms.

\subsection{Conclusions.}

This chapter studied the micro and macro foundations of labor productivity performance in the export sector in Mexico. We also aimed to compare the aggregate performance of the export sector and that of domestic manufacturing and the ways in which they affect total manufacturing productivity. To this end, this research relied on different sources of information that included aggregate and firm-level information for roughly 24 years. It remains to summarize our general findings.

Dictated by the available data, we use a number of different definitions of the exporting sector in Mexican manufacturing. Up to 2007, the available data on exporting firms are for the so-called maquiladora firms, which are firms that export (almost) all of their output and import (almost) all of their intermediates. They are assembly firms working mostly for the U.S. market. From 2008 to 2014, we have data on a broader set of exporting firms, many of which were not in the maquiladora dataset before 2007. As we show, many of these firms do not import any intermediate goods at all. Within this post2007 sample, we define two types of firms: those that are GVC-intensive and those that are not GVC-intensive. Note that the pre-2007 maquiladora firms and the post-2007 GVC-intensive firms are not identical. Ideally, we would have liked to define these groups in a much more similar way, but the data do not permit this.

Our results on aggregate and sectoral data break total productivity growth in Mexican manufacturing down into 4 factors: (1) changes of gross export per worker in the export sector; (2) changes of the value added to output ratio at the export sector; (3) changes in the share of employment in the export sector, and; (4) change of labor productivity in domestic manufacturing. Here, we empirically observe that labor productivity in domestic manufacturing (i.e., the fourth factor) drives most of the change in productivity for total manufacturing. Maquiladora firms (pre-2007) have lower labour productivity levels than domestic manufacturing firms, which implies that their rise in terms of employment share has a negative effect on overall productivity (factor 3 ). We also find that changes in the value added to gross output ratio (which we can consider as upgrading) are mostly negative in the maquiladora sector, and hence influence productivity negatively (factor 2). The positive impact of maquiladora on overall productivity comes from factor 1 , the intrinsic productivity growth of these firms, which is positive. After 2007, productivity growth does not differ much between exporting firms (now defined in a different way) and domestic firms. 
This part of our analysis leads to the conclusion that the impact of the Mexican maquiladora sector is mostly in terms of absorbing large amounts of workers that would otherwise be employed in sectors with lower productivity (e.g., agriculture). The maquiladora is not a particularly dynamic sector, and is not even highly productive when compared to domestic manufacturing. But it still had an impact on poverty and income of a large amount of workers, by the sheer increase in its size over a few decades.

Given the positive (but still limited) contribution of labor productivity growth in the export sector at the aggregate level, and the relatively large variation of labour productivity levels between firms in the exporting sector, our research then proceeded to econometrically explain the sources of firm-level variation in productivity levels and productivity growth. Capital deepening, economies of scale, higher shares of highlyskilled workers in total employment, as well as changes in the composition of labor (reflecting lower use of low-skilled workers), export orientation of firms, and the share of imported intermediates were used as explanatory variables. We estimated a fixed effects model for the level of labour productivity, and an error correction model for the change of the labour productivity.

We find differences in the results between different groups of firms. The error correction model applies to the maquiladora firms of the EMIME database (which runs up to 2007) and to GVC-intensive firms from the IMMEX data database (which starts in 2008). Non-GVC intensive firms in the IMMEX database do not show an error correction mechanism in which productivity adjusts to a long-run level determined by the explanatory variables. In general, we find that the export-orientation variable and the scale variable show the strongest productivity effects. The share of imported intermediates has a negative correlation to productivity and productivity growth, but not so in the GVC-intensive firms of the IMMEX database.

Overall, we see strong evidence that there are differences between GVC-intensive and non-GVC-intensive firms in terms of what determines productivity and its growth rate. But we cannot trace this to the extent we would like, because the microeconomic databases that are available do not allow us to identify the pure maquiladora firms in the period after 2007, and we do not have any information on exporting firms that are not maquiladora before 2007. Even better databases with a larger variety of firms would enable further research that can enlighten the recent role of the maquiladora in Mexican manufacturing. 


\section{Appendix A6.1}

Table. A61.1. Gross Output: Maquiladora (1990-2006) and IMMEX (2007-2014). Millions of Mexican Pesos (Constant Prices of 2008)

\begin{tabular}{|c|c|c|c|c|c|c|c|c|c|c|c|}
\hline Year & Food & Textiles & $\begin{array}{l}\text { Shoes/ } \\
\text { Leather }\end{array}$ & Wood & Chemicals & Transport & Machinery & $\begin{array}{c}\text { Electrical } \\
\text { E. }\end{array}$ & Other M. & Services & Total \\
\hline 1990 & 4 & 11 & 2 & 11 & 3 & 73 & 43 & 57 & 30 & 5 & 239 \\
\hline 1991 & 4 & 13 & 2 & 14 & 4 & 63 & 45 & 58 & 34 & 5 & 241 \\
\hline 1992 & 4 & 14 & 2 & 14 & 5 & 72 & 48 & 63 & 30 & 6 & 259 \\
\hline 1993 & 4 & 18 & 2 & 17 & 7 & 86 & 52 & 77 & 31 & 7 & 301 \\
\hline 1994 & 3 & 22 & 3 & 20 & 7 & 90 & 62 & 94 & 37 & 7 & 344 \\
\hline 1995 & 4 & 36 & 3 & 27 & 8 & 79 & 78 & 126 & 48 & 9 & 417 \\
\hline 1996 & 5 & 48 & 4 & 28 & 9 & 101 & 104 & 147 & 59 & 10 & 517 \\
\hline 1997 & 5 & 59 & 4 & 27 & 11 & 112 & 133 & 168 & 75 & 19 & 613 \\
\hline 1998 & 5 & 72 & 4 & 31 & 14 & 116 & 144 & 192 & 80 & 23 & 681 \\
\hline 1999 & 5 & 81 & 5 & 34 & 15 & 133 & 145 & 225 & 92 & 28 & 763 \\
\hline 2000 & 5 & 89 & 5 & 38 & 18 & 155 & 143 & 280 & 102 & 27 & 863 \\
\hline 2001 & 5 & 90 & 5 & 38 & 17 & 157 & 123 & 247 & 102 & 28 & 813 \\
\hline 2002 & 5 & 84 & 4 & 39 & 19 & 176 & 140 & 229 & 107 & 28 & 833 \\
\hline 2003 & 8 & 88 & 4 & 39 & 17 & 182 & 168 & 247 & 112 & 30 & 896 \\
\hline 2004 & 8 & 91 & 4 & 44 & 18 & 193 & 185 & 300 & 129 & 34 & 1,006 \\
\hline 2005 & 9 & 84 & 3 & 45 & 21 & 201 & 245 & 304 & 145 & 31 & 1,089 \\
\hline 2006 & 12 & 77 & 3 & 51 & 28 & 223 & 284 & 353 & 152 & 36 & 1,218 \\
\hline Year & Food & Textiles & $\begin{array}{l}\text { Shoes/ } \\
\text { Leather }\end{array}$ & Wood & Chemicals & Transport & Machinery & $\begin{array}{c}\text { Electrical } \\
\text { E. }\end{array}$ & Other M. & Services* & Total \\
\hline $2007 a$ & 150 & 52 & 7 & 22 & 222 & 604 & 237 & 424 & 63 & n.a. & 1,780 \\
\hline 2008 & 294 & 101 & 12 & 44 & 401 & 1,159 & 527 & 841 & 121 & n.a. & 3,500 \\
\hline 2009 & 293 & 96 & 13 & 47 & 501 & 947 & 369 & 672 & 115 & n.a. & 3,052 \\
\hline 2010 & 277 & 95 & 13 & 55 & 434 & 1,187 & 469 & 804 & 119 & n.a. & 3,453 \\
\hline 2011 & 276 & 95 & 17 & 56 & 372 & 1,385 & 531 & 823 & 127 & n.a. & 3,681 \\
\hline 2012 & 301 & 92 & 19 & 61 & 379 & 1,621 & 573 & 744 & 128 & n.a. & 3,918 \\
\hline 2013 & 294 & 88 & 19 & 67 & 432 & 1,663 & 599 & 759 & 135 & n.a. & 4,058 \\
\hline 2014 & 309 & 87 & 20 & 71 & 452 & 1,988 & 642 & 857 & 169 & n.a. & 4,595 \\
\hline
\end{tabular}

Source: Author's calculation using data from INEGI's National Accounting System (1990-2014), EMIME (1990-2006) and, IMMEX (July 2007-2014). For 2007, information was only available from July to December.

* Aggregate data for IMMEX services can be found under the category of "non-manufacturing establishments". Nonetheless, such information was not available at the firm level, Thus, for the sake of consistency, we decided to omit that information at the aggregate level. 
Chapter 6.

Table. A6.1.2. Gross Output: Domestic Economy of Mexico. Millions of Mexican Pesos (Constant Prices of 2008)

\begin{tabular}{|c|c|c|c|c|c|c|c|c|c|c|c|}
\hline Year & Food & Textiles & $\begin{array}{l}\text { Shoes/ } \\
\text { Leather }\end{array}$ & Wood & Chemicals & Transport & Machinery & Electrical E. & Other M. & Services & Total \\
\hline 1990 & 986 & 153 & 37 & 192 & 523 & 248 & 443 & 86 & 167 & 488 & 3,324 \\
\hline 1991 & 982 & 158 & 41 & 193 & 517 & 252 & 410 & 82 & 173 & 545 & 3,353 \\
\hline 1992 & 987 & 154 & 40 & 201 & 513 & 277 & 358 & 80 & 203 & 609 & 3,423 \\
\hline 1993 & 1,012 & 152 & 39 & 195 & 520 & 256 & 324 & 82 & 205 & 658 & 3,444 \\
\hline 1994 & 1,030 & 151 & 38 & 207 & 552 & 279 & 339 & 93 & 200 & 683 & 3,572 \\
\hline 1995 & 1,025 & 149 & 35 & 218 & 541 & 230 & 366 & 126 & 164 & 622 & 3,476 \\
\hline 1996 & 1,075 & 170 & 40 & 220 & 588 & 303 & 396 & 139 & 185 & 653 & 3,769 \\
\hline 1997 & 1,089 & 176 & 42 & 219 & 638 & 343 & 433 & 172 & 197 & 719 & 4,028 \\
\hline 1998 & 1,142 & 182 & 42 & 222 & 667 & 384 & 474 & 199 & 207 & 728 & 4,247 \\
\hline 1999 & 1,134 & 185 & 42 & 222 & 658 & 422 & 426 & 212 & 218 & 768 & 4,287 \\
\hline 2000 & 1,152 & 200 & 40 & 227 & 712 & 534 & 483 & 255 & 221 & 791 & 4,615 \\
\hline 2001 & 1,149 & 166 & 37 & 205 & 667 & 527 & 436 & 207 & 214 & 839 & 4,448 \\
\hline 2002 & 1,151 & 158 & 35 & 194 & 655 & 533 & 392 & 217 & 204 & 828 & 4,367 \\
\hline 2003 & 1,173 & 144 & 34 & 191 & 680 & 502 & 385 & 211 & 197 & 824 & 4,339 \\
\hline 2004 & 1,192 & 145 & 33 & 200 & 675 & 518 & 483 & 231 & 194 & 832 & 4,503 \\
\hline 2005 & 1,382 & 145 & 44 & 170 & 976 & 627 & 505 & 988 & 279 & 882 & 5,997 \\
\hline 2006 & 1,410 & 153 & 46 & 176 & 1,033 & 720 & 555 & 1,236 & 291 & 921 & 6,540 \\
\hline Year & Food & Textiles & $\begin{array}{l}\text { Shoes/ } \\
\text { Leather }\end{array}$ & Wood & Chemicals & Transport & Machinery & Electrical E. & Other M. & Services* & Total \\
\hline $2007 \mathrm{a}$ & 1,361 & 173 & 43 & 212 & 987 & 616 & 696 & 1,331 & 377 & n.a. & 5,795 \\
\hline 2008 & 1,290 & 120 & 36 & 198 & 850 & 278 & 569 & 902 & 289 & n.a. & 4,532 \\
\hline 2009 & 1,290 & 118 & 35 & 192 & 958 & 183 & 502 & 656 & 240 & n.a. & 4,173 \\
\hline 2010 & 1,320 & 130 & 38 & 201 & 734 & 296 & 602 & 884 & 271 & n.a. & 4,476 \\
\hline 2011 & 1,347 & 118 & 34 & 199 & 591 & 333 & 599 & 1,053 & 280 & n.a. & 4,553 \\
\hline 2012 & 1,353 & 122 & 32 & 205 & 519 & 321 & 588 & 1,295 & 285 & n.a. & 4,722 \\
\hline 2013 & 1,385 & 125 & 33 & 202 & 663 & 458 & 598 & 1,492 & 274 & n.a. & 5,230 \\
\hline 2014 & 1,384 & 123 & 31 & 204 & 624 & 343 & 612 & 1,584 & 261 & n.a. & 5,167 \\
\hline
\end{tabular}

Source and notes as described in table A61.1. 
Table.A6.1.3. Gross Output: Total Economy of Mexico. Millions of Mexican Pesos (Constant prices of 2008)

\begin{tabular}{|c|c|c|c|c|c|c|c|c|c|c|c|}
\hline \multirow{2}{*}{$\begin{array}{c}\text { Year } \\
1990\end{array}$} & \multirow{2}{*}{ 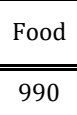 } & \multirow{2}{*}{$\begin{array}{c}\text { Textiles } \\
165\end{array}$} & \multirow{2}{*}{$\begin{array}{c}\text { Shoes/ } \\
\text { Leather }\end{array}$} & \multicolumn{7}{|c|}{ Wood Chemicals Transport MachineryElectrical E.Other M. Services } & \multirow{2}{*}{$\begin{array}{l}\text { Total } \\
3,564\end{array}$} \\
\hline & & & & 202 & 527 & 320 & 487 & 143 & 197 & 493 & \\
\hline 1991 & 986 & 170 & 43 & 207 & 521 & 315 & 455 & 139 & 208 & 550 & 3,594 \\
\hline 1992 & 991 & 168 & 43 & 216 & 517 & 349 & 406 & 143 & 233 & 615 & 3,681 \\
\hline 1993 & 1,016 & 170 & 42 & 212 & 527 & 342 & 376 & 159 & 236 & 666 & 3,745 \\
\hline 1994 & 1,033 & 173 & 41 & 227 & 559 & 369 & 401 & 187 & 236 & 689 & 3,916 \\
\hline 1995 & 1,029 & 185 & 38 & 245 & 548 & 309 & 444 & 252 & 213 & 630 & 3,893 \\
\hline 1996 & 1,079 & 218 & 44 & 249 & 598 & 404 & 500 & 286 & 245 & 664 & 4,286 \\
\hline 1997 & 1,093 & 235 & 46 & 247 & 649 & 455 & 566 & 340 & 272 & 738 & 4,641 \\
\hline 1998 & 1,147 & 254 & 46 & 253 & 680 & 500 & 618 & 391 & 287 & 751 & 4,928 \\
\hline 1999 & 1,139 & 267 & 47 & 255 & 673 & 555 & 571 & 437 & 310 & 796 & 5,050 \\
\hline 2000 & 1,157 & 289 & 45 & 266 & 729 & 689 & 626 & 535 & 323 & 818 & 5,478 \\
\hline 2001 & 1,154 & 256 & 42 & 244 & 685 & 685 & 559 & 454 & 316 & 867 & 5,261 \\
\hline 2002 & 1,156 & 242 & 39 & 233 & 675 & 709 & 532 & 446 & 312 & 856 & 5,200 \\
\hline 2003 & 1,181 & 232 & 38 & 230 & 697 & 684 & 553 & 458 & 309 & 854 & 5,235 \\
\hline 2004 & 1,200 & 236 & 37 & 243 & 694 & 711 & 669 & 530 & 323 & 866 & 5,508 \\
\hline 2005 & 1,391 & 229 & 47 & 216 & 997 & 828 & 749 & 1,292 & 424 & 913 & 7,086 \\
\hline 2006 & 1,422 & 230 & 49 & 227 & 1,060 & 943 & 839 & 1,589 & 443 & 957 & 7,758 \\
\hline Year & Food & \multicolumn{9}{|c|}{ TextilesShoes/Leather Wood Chemicals TransportMachineryElectrical E.Other M.Services* } & Total \\
\hline $2007 \mathrm{a}$ & 1,511 & 225 & 50 & 233 & 1,209 & 1,220 & 933 & 1,755 & 439 & n.a. & 7,575 \\
\hline 2008 & 1,584 & 221 & 49 & 242 & 1,251 & 1,437 & 1,095 & 1,743 & 409 & n.a. & 8,032 \\
\hline 2009 & 1,582 & 213 & 48 & 239 & 1,459 & 1,129 & 872 & 1,328 & 355 & n.a. & 7,225 \\
\hline 2010 & 1,597 & 225 & 52 & 255 & 1,168 & 1,483 & 1,071 & 1,687 & 390 & n.a. & 7,929 \\
\hline 2011 & 1,623 & 212 & 51 & 255 & 962 & 1,718 & 1,130 & 1,877 & 407 & n.a. & 8,234 \\
\hline 2012 & 1,654 & 214 & 52 & 266 & 899 & 1,942 & 1,161 & 2,039 & 414 & n.a. & 8,640 \\
\hline 2013 & 1,680 & 213 & 51 & 270 & 1,095 & 2,121 & 1,197 & 2,251 & 410 & n.a. & 9,288 \\
\hline 2014 & 1,693 & 210 & 51 & 275 & 1,076 & 2,331 & 1,254 & 2,441 & 430 & n.a. & 9,763 \\
\hline
\end{tabular}

Source and notes as described in table A61.1. 
Chapter 6.

Table A6.1.4. Gross Value Added: Maquiladora (1990-2006) and IMMEX (2007 -2014). Millions of Mexican Pesos (Constant Prices of 2008)

\begin{tabular}{|c|c|c|c|c|c|c|c|c|c|c|c|}
\hline Year & Food & Textiles & $\begin{array}{l}\text { Shoes/ } \\
\text { Leather }\end{array}$ & Wood & Chemicals & Transport & Machinery & $\begin{array}{c}\text { Electrical } \\
\text { E. }\end{array}$ & $\begin{array}{c}\text { Other } \\
\text { M. }\end{array}$ & Services & Total \\
\hline 1990 & 1 & 3 & 1 & 3 & 1 & 12 & 9 & 19 & 8 & 2 & 58 \\
\hline 1991 & 1 & 3 & 1 & 3 & 1 & 15 & 9 & 21 & 8 & 2 & 65 \\
\hline 1992 & 1 & 4 & 1 & 3 & 1 & 16 & 9 & 20 & 7 & 2 & 65 \\
\hline 1993 & 1 & 4 & 1 & 3 & 1 & 13 & 8 & 19 & 7 & 2 & 60 \\
\hline 1994 & 1 & 5 & 1 & 4 & 1 & 14 & 9 & 21 & 7 & 2 & 64 \\
\hline 1995 & 1 & 9 & 1 & 5 & 2 & 17 & 13 & 30 & 11 & 3 & 91 \\
\hline 1996 & 2 & 14 & 1 & 7 & 3 & 24 & 17 & 42 & 13 & 4 & 124 \\
\hline 1997 & 2 & 16 & 1 & 7 & 2 & 16 & 18 & 39 & 14 & 4 & 120 \\
\hline 1998 & 1 & 18 & 1 & 8 & 3 & 18 & 17 & 43 & 16 & 4 & 130 \\
\hline 1999 & 1 & 21 & 1 & 9 & 4 & 22 & 19 & 51 & 19 & 5 & 153 \\
\hline 2000 & 1 & 22 & 1 & 10 & 4 & 24 & 20 & 56 & 19 & 5 & 162 \\
\hline 2001 & 1 & 23 & 1 & 10 & 3 & 24 & 18 & 54 & 20 & 5 & 159 \\
\hline 2002 & 1 & 22 & 1 & 9 & 3 & 29 & 18 & 46 & 19 & 4 & 153 \\
\hline 2003 & 2 & 20 & 1 & 9 & 3 & 34 & 19 & 47 & 20 & 5 & 160 \\
\hline 2004 & 2 & 20 & 1 & 9 & 3 & 37 & 20 & 48 & 21 & 6 & 167 \\
\hline 2005 & 2 & 19 & 1 & 8 & 4 & 38 & 24 & 50 & 23 & 6 & 176 \\
\hline 2006 & 2 & 17 & 1 & 9 & 5 & 40 & 28 & 55 & 25 & 7 & 189 \\
\hline Year & Food & Textiles & $\begin{array}{l}\text { Shoes/ } \\
\text { Leather }\end{array}$ & Wood & Chemicals & Transport & Machinery & $\begin{array}{c}\text { Electrical } \\
\text { E. }\end{array}$ & $\begin{array}{c}\text { Other } \\
\text { M. }\end{array}$ & Services* & Total \\
\hline $2007 a$ & 83 & 25 & 3 & 10 & 109 & 309 & 123 & 82 & 22 & n.a. & 768 \\
\hline 2008 & 161 & 47 & 5 & 21 & 213 & 597 & 311 & 162 & 40 & n.a. & 1,557 \\
\hline 2009 & 169 & 46 & 6 & 23 & 330 & 477 & 218 & 146 & 42 & n.a. & 1,457 \\
\hline 2010 & 165 & 48 & 7 & 26 & 209 & 622 & 279 & 164 & 46 & n.a. & 1,566 \\
\hline 2011 & 160 & 45 & 7 & 25 & 230 & 721 & 305 & 158 & 45 & n.a. & 1,697 \\
\hline 2012 & 159 & 42 & 7 & 27 & 177 & 815 & 295 & 141 & 44 & n.a. & 1,705 \\
\hline 2013 & 178 & 41 & 7 & 30 & 325 & 876 & 341 & 148 & 44 & n.a. & 1,991 \\
\hline 2014 & 177 & 41 & 8 & 32 & 205 & 921 & 340 & 157 & 47 & n.a. & 1,928 \\
\hline
\end{tabular}

Source and notes as described in table A61.1. 
Table. A6.1.5. Gross Value Added: Domestic Economy of Mexico. Millions of Mexican Pesos (Constant Prices of 2008)

\begin{tabular}{|c|c|c|c|c|c|c|c|c|c|c|c|}
\hline Year & Food & Textiles & $\begin{array}{l}\text { Shoes/ } \\
\text { Leather }\end{array}$ & Wood & Chemicals & Transport & Machinery & $\begin{array}{c}\text { Electrical } \\
\text { E. }\end{array}$ & $\begin{array}{c}\text { Other } \\
\text { M. }\end{array}$ & Services & Total \\
\hline 1990 & 390 & 72 & 16 & 98 & 190 & 73 & 178 & 36 & 113 & 563 & 1,729 \\
\hline 1991 & 468 & 75 & 18 & 97 & 212 & 114 & 182 & 37 & 118 & 631 & 1,951 \\
\hline 1992 & 428 & 73 & 17 & 95 & 202 & 126 & 164 & 36 & 122 & 646 & 1,908 \\
\hline 1993 & 359 & 63 & 15 & 84 & 175 & 82 & 137 & 34 & 113 & 640 & 1,703 \\
\hline 1994 & 353 & 59 & 14 & 84 & 171 & 85 & 137 & 37 & 113 & 675 & 1,727 \\
\hline 1995 & 450 & 69 & 17 & 104 & 259 & 132 & 196 & 48 & 122 & 829 & 2,225 \\
\hline 1996 & 574 & 94 & 22 & 123 & 323 & 192 & 272 & 72 & 154 & 951 & 2,777 \\
\hline 1997 & 503 & 84 & 19 & 115 & 242 & 122 & 243 & 69 & 122 & 786 & 2,305 \\
\hline 1998 & 446 & 75 & 17 & 110 & 227 & 131 & 231 & 64 & 125 & 795 & 2,221 \\
\hline 1999 & 483 & 68 & 17 & 103 & 236 & 143 & 224 & 55 & 129 & 824 & 2,282 \\
\hline 2000 & 494 & 65 & 15 & 94 & 240 & 146 & 208 & 58 & 125 & 774 & 2,220 \\
\hline 2001 & 457 & 54 & 13 & 84 & 218 & 126 & 167 & 47 & 115 & 772 & 2,051 \\
\hline 2002 & 448 & 51 & 13 & 76 & 211 & 135 & 156 & 43 & 109 & 746 & 1,986 \\
\hline 2003 & 444 & 43 & 12 & 71 & 212 & 140 & 151 & 40 & 114 & 799 & 2,026 \\
\hline 2004 & 458 & 46 & 13 & 73 & 209 & 158 & 194 & 44 & 110 & 797 & 2,101 \\
\hline 2005 & 529 & 60 & 17 & 58 & 300 & 174 & 222 & 95 & 144 & 811 & 2,411 \\
\hline 2006 & 541 & 65 & 18 & 60 & 423 & 198 & 244 & 109 & 151 & 844 & 2,653 \\
\hline Year & Food & Textiles & $\begin{array}{l}\text { Shoes/ } \\
\text { Leather }\end{array}$ & Wood & Chemicals & Transport & Machinery & $\begin{array}{c}\text { Electrical } \\
\text { E. }\end{array}$ & $\begin{array}{c}\text { Other } \\
\text { M. }\end{array}$ & Services* & Total \\
\hline $2007 a$ & 541 & 70 & 16 & 70 & 373 & 193 & 239 & 97 & 165 & n.a. & 1,764 \\
\hline 2008 & 536 & 51 & 14 & 67 & 373 & 128 & 220 & 17 & 135 & n.a. & 1,542 \\
\hline 2009 & 534 & 47 & 13 & 66 & 561 & 91 & 154 & 20 & 134 & n.a. & 1,621 \\
\hline 2010 & 542 & 54 & 14 & 69 & 364 & 145 & 198 & 20 & 138 & n.a. & 1,545 \\
\hline 2011 & 555 & 57 & 14 & 70 & 353 & 180 & 218 & 29 & 144 & n.a. & 1,620 \\
\hline 2012 & 566 & 60 & 14 & 74 & 306 & 213 & 230 & 40 & 147 & n.a. & 1,650 \\
\hline 2013 & 567 & 59 & 13 & 73 & 436 & 220 & 217 & 33 & 131 & n.a. & 1,748 \\
\hline 2014 & 573 & 59 & 12 & 75 & 287 & 256 & 236 & 42 & 135 & n.a. & 1,675 \\
\hline
\end{tabular}

Source and notes as described in table A61.1. 
Chapter 6.

Table A6.1.6. Gross Value Added: Total Economy of Mexico. Millions of Mexican Pesos (Constant prices of 2008)

\begin{tabular}{|c|c|c|c|c|c|c|c|c|c|c|c|}
\hline Year & Food & Textiles & $\begin{array}{l}\text { Shoes/ } \\
\text { Leather }\end{array}$ & Wood & Chemicals & Transport & Machinery & $\begin{array}{c}\text { Electrical } \\
\text { E. }\end{array}$ & Other M. & Services & Total \\
\hline 1990 & 392 & 75 & 17 & 101 & 190 & 85 & 186 & 55 & 120 & 565 & 1,787 \\
\hline 1991 & 469 & 79 & 18 & 100 & 213 & 129 & 191 & 58 & 126 & 633 & 2,016 \\
\hline 1992 & 429 & 77 & 18 & 98 & 203 & 142 & 173 & 56 & 129 & 648 & 1,973 \\
\hline 1993 & 360 & 68 & 16 & 87 & 176 & 96 & 145 & 53 & 120 & 643 & 1,763 \\
\hline 1994 & 354 & 64 & 14 & 88 & 172 & 98 & 146 & 58 & 120 & 677 & 1,791 \\
\hline 1995 & 451 & 78 & 18 & 109 & 261 & 148 & 209 & 78 & 132 & 831 & 2,315 \\
\hline 1996 & 576 & 107 & 23 & 130 & 325 & 216 & 288 & 114 & 168 & 955 & 2,902 \\
\hline 1997 & 504 & 101 & 20 & 122 & 244 & 139 & 260 & 108 & 136 & 790 & 2,425 \\
\hline 1998 & 448 & 93 & 18 & 117 & 230 & 150 & 248 & 107 & 141 & 799 & 2,351 \\
\hline 1999 & 485 & 89 & 17 & 113 & 240 & 164 & 243 & 107 & 148 & 830 & 2,435 \\
\hline 2000 & 496 & 87 & 16 & 105 & 244 & 170 & 228 & 114 & 144 & 779 & 2,382 \\
\hline 2001 & 458 & 77 & 14 & 93 & 221 & 150 & 185 & 100 & 135 & 778 & 2,210 \\
\hline 2002 & 450 & 72 & 14 & 85 & 214 & 164 & 175 & 89 & 127 & 750 & 2,139 \\
\hline 2003 & 446 & 64 & 13 & 80 & 215 & 174 & 170 & 87 & 134 & 804 & 2,186 \\
\hline 2004 & 459 & 66 & 13 & 82 & 212 & 195 & 214 & 92 & 131 & 803 & 2,268 \\
\hline 2005 & 531 & 79 & 18 & 66 & 305 & 212 & 246 & 146 & 167 & 817 & 2,586 \\
\hline 2006 & 543 & 83 & 18 & 69 & 429 & 238 & 272 & 163 & 176 & 851 & 2,842 \\
\hline Year & Food & Textiles & $\begin{array}{l}\text { Shoes/ } \\
\text { Leather }\end{array}$ & Wood & Chemicals & Transport & Machinery & $\begin{array}{c}\text { Electrical } \\
\text { E. }\end{array}$ & Other M. & Services* & Total \\
\hline $2007^{a}$ & 624 & 95 & 20 & 80 & 482 & 502 & 362 & 179 & 188 & n.a. & 2,531 \\
\hline 2008 & 697 & 99 & 20 & 88 & 586 & 725 & 530 & 179 & 175 & n.a. & 3,099 \\
\hline 2009 & 703 & 94 & 20 & 90 & 891 & 568 & 371 & 165 & 177 & n.a. & 3,077 \\
\hline 2010 & 706 & 102 & 21 & 96 & 574 & 767 & 478 & 185 & 184 & n.a. & 3,111 \\
\hline 2011 & 714 & 102 & 21 & 96 & 583 & 902 & 524 & 187 & 189 & n.a. & 3,317 \\
\hline 2012 & 724 & 101 & 20 & 101 & 483 & 1,029 & 525 & 182 & 191 & n.a. & 3,355 \\
\hline 2013 & 745 & 101 & 20 & 104 & 760 & 1,096 & 557 & 181 & 175 & n.a. & 3,738 \\
\hline 2014 & 751 & 100 & 20 & 107 & 491 & 1,178 & 576 & 199 & 182 & n.a. & 3,604 \\
\hline
\end{tabular}

Source and notes as described in table A61.1 
Table. A6.1.7. Total Employment: Maquiladora (1990-2006) and IMMEX (2007-2014).

\begin{tabular}{|c|c|c|c|c|c|c|c|c|c|c|c|}
\hline Year & Food & Textiles & $\begin{array}{l}\text { Shoes/ } \\
\text { Leather }\end{array}$ & Wood C & Chemicals' & & MachineryE & 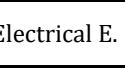 & $\begin{array}{c}\text { Other } \\
\text { M. }\end{array}$ & Services & Total \\
\hline 1990 & & & & & & & & & & & \\
\hline 1991 & 9,516 & 48,759 & 7,638 & & 7,943 & & & & 61,323 & & \\
\hline 1992 & 10,054 & & 7,666 & & 9,590 & & & & 61,015 & & 442,735 \\
\hline 1993 & 11,836 & 65,973 & 7,217 & 34,739 & 12,456 & 124,623 & 62,791 & 57,455 & 69,772 & 26,522 & 473,384 \\
\hline 1994 & 7,806 & 82,513 & 7,315 & 33,891 & 11,718 & 130,530 & 72,525 & 66,554 & 72,345 & 25,113 & 510,310 \\
\hline 1995 & 9,164 & 107,015 & 7,460 & 37,845 & 13,120 & 150,327 & 73,941 & & 78,469 & 30,054 & 573,878 \\
\hline 1996 & 11,255 & 147,196 & 7,493 & 41,343 & 14,439 & 161,141 & & & 96,288 & 32,324 & 664,954 \\
\hline 1997 & 12,565 & 183,241 & 8,786 & 45,383 & 17,453 & & & & 116,763 & & \\
\hline 1998 & 11,941 & & 9,309 & & & & & & 125,441 & & \\
\hline 1999 & 11,038 & & 8,623 & 60,017 & & & & & 154,115 & & \\
\hline 2000 & 10,183 & & 8,770 & & & & & & 157,320 & & \\
\hline 2001 & 9,798 & & 6,502 & 52,238 & 21,059 & & & & 138,263 & & 901,358 \\
\hline 2002 & 9,826 & 223,2 & 6,056 & & & & & & 140,059 & & 820 \\
\hline 2003 & 9,179 & 195,577 & 5,741 & & 21,176 & & & & 146,277 & & 909,624 \\
\hline 2004 & 10,533 & 200,645 & 4,673 & 53,329 & 27,084 & 249,528 & 132,523 & & 163,265 & & 999,663 \\
\hline 2005 & 10,463 & 169,677 & 5,292 & & 31,051 & 263,804 & & & 177,219 & & | \\
\hline 2006 & 11,008 & 158,286 & 5,727 & 57,540 & 37,054 & 268,032 & & & 182,148 & & $1,039,707$ \\
\hline Year & Food & lexules & & H & & & & & & & Total \\
\hline $2007 \mathrm{a}$ & 144,350 & & 17,412 & & & & & & 159,178 & & \\
\hline 2008 & 145,758 & & 15,356 & & 186,326 & 429,664 & & & 147,692 & & \\
\hline 2009 & 140,473 & & 16,746 & & 181,479 & & & & 140,342 & n.a. & $1,645,29$ \\
\hline 2010 & 138,818 & & 18,958 & & & & & & 148,168 & & \\
\hline 2011 & 146,108 & & 24,120 & & & & & & & n.a. & $1,879,114$ \\
\hline 2012 & 147,813 & & 25,596 & 41,203 & 233,996 & 605,565 & & 381,796 & 166,011 & n.a. & {$[1,991, / 6$} \\
\hline 2013 & 154,280 & 160,804 & 26,725 & 44,326 & 241,073 & 674,023 & 250,718 & 389,286 & 174,787 & n.a. & $2,116,022$ \\
\hline 2014 & 156,300 & 155,605 & 25,302 & 46,154 & 255,810 & 733,900 & 268,893 & 414,561 & 186,340 & n.a. & $2,242,865$ \\
\hline
\end{tabular}

Source and notes as described in table A61.1. 
Table. A6.1.8. Total Employment: Domestic Economy of Mexico.

\begin{tabular}{|c|c|c|c|c|c|c|c|c|c|c|}
\hline Year & Food Textiles & $\begin{array}{l}\text { Shoes/ } \\
\text { Leather }\end{array}$ & Wood C & Chemicals & Transport & Machinery & lectrical $\mathrm{F}$ & Other M. S & Services & Total \\
\hline 1990 & $641,193527,607$ & 108,353 & 164,274 & 393,831 & 295,150 & 299,392 & 269,938 & 105,0122 & 262,119 & $3,066,869$ \\
\hline 1991 & $655,002531,034$ & 112,292 & 163,450 & 401,902 & 286,240 & 303,964 & 277,555 & 103,4272 & 276,530 & $3,111,396$ \\
\hline 1992 & $672,345518,280$ & 107,886 & 165,263 & 395,282 & 345,373 & 309,747 & 282,289 & 117,0652 & 288,452 & $3,201,982$ \\
\hline 1993 & $679,253515,872$ & 101,163 & 154,367 & 383,933 & 313,157 & 298,940 & 292,379 & 116,1483 & 300,699 & $3,155,911$ \\
\hline 1994 & $667,973497,454$ & 92,557 & 151,584 & 370,978 & 305,242 & 290,327 & 304,284 & 116,0333 & 314,031 & $3,110,463$ \\
\hline 1995 & $651,170481,971$ & 83,409 & 136,668 & 348,688 & 294,900 & 265,478 & 305,199 & 112,9533 & 325,229 & $3,005,665$ \\
\hline 1996 & $661,413548,010$ & 88,708 & 146,700 & 365,489 & 324,289 & 287,153 & 348,903 & 125,5573 & 339,106 & $3,235,328$ \\
\hline 1997 & $667,849620,088$ & 93,083 & 156,410 & 384,328 & 368,915 & 325,800 & 412,902 & 142,2623 & 349,693 & $3,521,330$ \\
\hline 1998 & $685,584657,228$ & 90,157 & 164,165 & 396,147 & 409,945 & 348,241 & 457,263 & 150,1663 & 362,446 & $3,721,342$ \\
\hline 1999 & $703,465704,228$ & 90,313 & 163,244 & 400,517 & 433,794 & 351,673 & 492,751 & 180,0003 & 379,453 & $3,899,438$ \\
\hline 2000 & $701,512747,547$ & 91,466 & 168,401 & 406,227 & 473,453 & 354,104 & 565,180 & 184,3213 & 395,807 & $4,088,018$ \\
\hline 2001 & $702,600695,336$ & 82,336 & 155,406 & 394,108 & 447,938 & 330,890 & 506,783 & 166,3214 & 411,302 & $3,893,020$ \\
\hline 2002 & $700,710616,124$ & 76,063 & 137,999 & 378,536 & 437,731 & 308,924 & 427,573 & 169,0264 & 424,636 & $3,677,322$ \\
\hline 2003 & $700,355574,582$ & 71,580 & 133,861 & 363,082 & 433,414 & 291,073 & 413,958 & 176,5074 & 443,141 & $3,601,553$ \\
\hline 2004 & $688,085545,603$ & 69,021 & 137,417 & 357,572 & 436,816 & 294,772 & 421,583 & 194,6274 & 459,740 & $3,605,236$ \\
\hline 2005 & $689,375522,039$ & 70,754 & 132,373 & 348,792 & 452,265 & 299,118 & 425,788 & 208,1574 & 469,882 & $3,618,543$ \\
\hline 2006 & $698,420494,193$ & 71,286 & 132,945 & 338,216 & 458,976 & 312,842 & 431,272 & 213,6245 & 500,983 & $3,652,757$ \\
\hline Year & Food Textiles $S$ & oes/Leathe & Wood C & Chemicals & Transport & Machinery & lectrical $\mathrm{E}$ & Other M.S & Services* & Total \\
\hline $2007 \mathrm{a}$ & $685,015460,594$ & 67,799 & 136,793 & 330,370 & 688,303 & 255,132 & 622,654 & 191,748 & n.a. & $3,438,408$ \\
\hline 2008 & $680,465412,985$ & 62,900 & 123,341 & 319,660 & 603,483 & 261,367 & 580,758 & 181,416 & n.a. & $3,226,375$ \\
\hline 2009 & $677,981370,092$ & 60,061 & 119,275 & 294,002 & 539,117 & 230,130 & 557,312 & 172,704 & n.a. & $3,020,674$ \\
\hline 2010 & $671,922370,893$ & 62,215 & 121,957 & 297,724 & 612,158 & 256,411 & 590,309 & 180,531 & n.a. & $3,164,120$ \\
\hline 2011 & $680,815347,434$ & 61,752 & 119,013 & 299,754 & 685,311 & 275,841 & 568,978 & 195,256 & n.a. & $3,234,154$ \\
\hline 2012 & $688,026337,135$ & 64,060 & 116,814 & 298,990 & 766,918 & 282,275 & 580,217 & 201,708 & n.a. & $3,336,143$ \\
\hline 2013 & $688,786341,041$ & 63,794 & 115,148 & 289,684 & 851,831 & 277,920 & 586,694 & 211,149 & n.a. & $3,426,047$ \\
\hline 2014 & $697,855339,391$ & 63,931 & 108,854 & 288,684 & 925,325 & 294,577 & 618,491 & 222,706 & n.a. & $3,559,814$ \\
\hline
\end{tabular}

Source and notes as described in table A61.1. 
Table A6.1.9. Total Employment: Total Economy of Mexico.

\begin{tabular}{|c|c|c|c|c|c|c|c|c|c|c|c|}
\hline Year & Food & Textiles & $\begin{array}{l}\text { Shoes/ } \\
\text { Leather }\end{array}$ & Wood & Chemicals & Transport & Machinery & Electrical E. & Other M. & Services & Total \\
\hline 1990 & 648,621 & 570,284 & 115,662 & 188,482 & 400,525 & 402,042 & 352,660 & 318,469 & 163,517 & 283,791 & $3,444,053$ \\
\hline 1991 & 664,518 & 579,793 & 119,930 & 191,401 & 409,845 & 412,778 & 358,583 & 327,028 & 164,750 & 301,968 & $3,530,594$ \\
\hline 1992 & 682,399 & 576,252 & 115,552 & 194,168 & 404,872 & 467,916 & 371,545 & 338,900 & 178,080 & 315,033 & $3,644,717$ \\
\hline 1993 & 691,089 & 581,845 & 108,380 & 189,106 & 396,389 & 437,780 & 361,731 & 349,834 & 185,920 & 327,221 & $3,629,295$ \\
\hline 1994 & 675,779 & 579,967 & 99,872 & 185,475 & 382,696 & 435,772 & 362,852 & 370,838 & 188,378 & 339,144 & $3,620,773$ \\
\hline 1995 & 660,334 & 588,986 & 90,869 & 174,513 & 361,808 & 445,227 & 339,419 & 371,682 & 191,422 & 355,283 & $3,579,543$ \\
\hline 1996 & 672,668 & 695,206 & 96,201 & 188,043 & 379,928 & 485,430 & 368,109 & 421,422 & 221,845 & 371,430 & $3,900,282$ \\
\hline 1997 & 680,414 & 803,329 & 101,869 & 201,793 & 401,781 & 555,094 & 423,597 & 501,472 & 259,025 & 386,583 & $4,314,957$ \\
\hline 1998 & 697,525 & 876,307 & 99,466 & 215,391 & 416,654 & 609,855 & 447,553 & 546,161 & 275,607 & 404,814 & $4,589,333$ \\
\hline 1999 & 714,503 & 967,222 & 98,936 & 223,261 & 423,290 & 650,647 & 462,892 & 591,473 & 334,115 & 424,539 & $4,890,878$ \\
\hline 2000 & 711,695 & $1,036,513$ & 100,236 & 230,850 & 431,592 & 719,264 & 471,771 & 667,990 & 341,641 & 445,217 & $5,156,769$ \\
\hline 2001 & 712,398 & 926,527 & 88,838 & 207,644 & 415,167 & 666,229 & 432,511 & 591,884 & 304,584 & 448,596 & $4,794,378$ \\
\hline 2002 & 710,536 & 839,334 & 82,119 & 190,396 & 400,267 & 679,318 & 420,428 & 521,109 & 309,085 & 461,550 & $4,614,142$ \\
\hline 2003 & 709,534 & 770,159 & 77,321 & 184,566 & 384,258 & 671,991 & 402,968 & 508,854 & 322,784 & 478,742 & $4,511,177$ \\
\hline 2004 & 698,618 & 746,248 & 73,694 & 190,746 & 384,656 & 686,344 & 427,295 & 534,289 & 357,892 & 505,117 & $4,604,899$ \\
\hline 2005 & 699,838 & 691,716 & 76,046 & 188,514 & 379,843 & 716,069 & 439,586 & 546,559 & 385,376 & 517,332 & $4,640,879$ \\
\hline 2006 & 709,428 & 652,479 & 77,013 & 190,485 & 375,270 & 727,008 & 456,133 & 554,904 & 395,772 & 553,972 & $4,692,464$ \\
\hline Year & Food & Textiles & $\begin{array}{l}\text { Shoes/ } \\
\text { Leather }\end{array}$ & Wood & Chemicals & Transport & Machinery & Electrical E. & Other M. & Services* & Total \\
\hline $2007^{a}$ & 829,365 & 650,708 & 85,211 & 173,640 & 529,067 & $1,187,017$ & 460,324 & $1,074,271$ & 350,926 & n.a. & $5,340,529$ \\
\hline 2008 & 826,223 & 588,763 & 78,256 & 157,738 & 505,986 & $1,033,147$ & 465,714 & 979,622 & 329,108 & n.a. & $4,964,557$ \\
\hline 2009 & 818,454 & 537,558 & 76,807 & 153,871 & 475,481 & 951,746 & 411,781 & 927,221 & 313,046 & n.a. & $4,665,965$ \\
\hline 2010 & 810,740 & 537,819 & 81,173 & 162,481 & 506,708 & $1,091,469$ & 468,755 & 986,758 & 328,699 & n.a. & $4,974,602$ \\
\hline 2011 & 826,923 & 497,192 & 85,872 & 158,536 & 519,473 & $1,223,332$ & 500,346 & 945,044 & 356,550 & n.a. & $5,113,268$ \\
\hline 2012 & 835,839 & 491,260 & 89,656 & 158,017 & 532,986 & $1,372,483$ & 517,930 & 962,013 & 367,719 & n.a. & $5,327,903$ \\
\hline 2013 & 843,066 & 501,845 & 90,519 & 159,474 & 530,757 & $1,525,854$ & 528,638 & 975,980 & 385,936 & n.a. & $5,542,069$ \\
\hline 2014 & 854,155 & 494,996 & 89,233 & 155,008 & 544,494 & $1,659,225$ & 563,470 & $1,033,052$ & 409,046 & n.a. & $5,802,679$ \\
\hline
\end{tabular}

Source and notes as described in table A61.1. 
Chapter 6.

Table A6.1.10. Labor Productivity: Maquiladora (1990-2006) and IMMEX (2007-2014). Millions of Mexican Pesos (Constant Prices of 2008).

\begin{tabular}{|c|c|c|c|c|c|c|c|c|c|c|c|}
\hline Year & Food & Textiles & Shoes/Leather & Wood & Chemicals & Transport & Machinery & $\begin{array}{c}\text { Electrical } \\
\text { E. }\end{array}$ & Other M. & Services & Total \\
\hline 1990 & 189 & 68 & 89 & 118 & 94 & 110 & 164 & 399 & 133 & 97 & 154 \\
\hline 1991 & 123 & 69 & 80 & 112 & 116 & 120 & 164 & 426 & 134 & 84 & 155 \\
\hline 1992 & 115 & 69 & 82 & 108 & 104 & 132 & 149 & 361 & 115 & 87 & 147 \\
\hline 1993 & 97 & 65 & 76 & 89 & 93 & 107 & 131 & 331 & 95 & 90 & 126 \\
\hline 1994 & 114 & 60 & 75 & 104 & 104 & 104 & 123 & 316 & 103 & 95 & 126 \\
\hline 1995 & 141 & 81 & 104 & 134 & 144 & 111 & 175 & 450 & 134 & 97 & 158 \\
\hline 1996 & 142 & 92 & 115 & 162 & 179 & 146 & 206 & 576 & 139 & 117 & 187 \\
\hline 1997 & 126 & 90 & 90 & 162 & 142 & 88 & 180 & 444 & 119 & 104 & 151 \\
\hline 1998 & 114 & 83 & 78 & 150 & 147 & 91 & 174 & 485 & 125 & 106 & 149 \\
\hline 1999 & 136 & 79 & 98 & 156 & 166 & 101 & 171 & 519 & 122 & 120 & 154 \\
\hline 2000 & 130 & 77 & 89 & 161 & 156 & 97 & 171 & 544 & 121 & 108 & 152 \\
\hline 2001 & 123 & 101 & 148 & 184 & 158 & 111 & 178 & 629 & 142 & 140 & 177 \\
\hline 2002 & 144 & 97 & 133 & 177 & 150 & 121 & 166 & 489 & 132 & 121 & 163 \\
\hline 2003 & 204 & 105 & 132 & 173 & 145 & 141 & 168 & 495 & 138 & 146 & 176 \\
\hline 2004 & 159 & 102 & 155 & 165 & 123 & 148 & 151 & 423 & 130 & 131 & 167 \\
\hline 2005 & 175 & 114 & 129 & 145 & 138 & 144 & 171 & 418 & 127 & 136 & 172 \\
\hline 2006 & 191 & 110 & 117 & 153 & 144 & 149 & 193 & 442 & 138 & 132 & 182 \\
\hline Year & Food & Textiles & Shoes/Leather & Wood & Chemicals & Transport & Machinery & $\begin{array}{c}\text { Electrical } \\
\text { E. }\end{array}$ & Other M. & Services* & Total \\
\hline $2007^{a}$ & 574 & 131 & 187 & 281 & 551 & 620 & 599 & 182 & 141 & n.a. & 404 \\
\hline 2008 & 1,105 & 269 & 356 & 616 & 1,143 & 1,390 & 1,520 & 405 & 271 & n.a. & 896 \\
\hline 2009 & 1,201 & 276 & 380 & 666 & 1,818 & 1,156 & 1,198 & 394 & 301 & n.a. & 885 \\
\hline 2010 & 1,188 & 286 & 352 & 647 & 1,002 & 1,298 & 1,314 & 415 & 308 & n.a. & 865 \\
\hline 2011 & 1,093 & 299 & 286 & 642 & 1,048 & 1,341 & 1,359 & 420 & 281 & n.a. & 903 \\
\hline 2012 & 1,073 & 270 & 255 & 651 & 756 & 1,346 & 1,250 & 370 & 263 & n.a. & 856 \\
\hline 2013 & 1,152 & 258 & 264 & 684 & 1,347 & 1,300 & 1,359 & 381 & 249 & n.a. & 941 \\
\hline 2014 & 1,135 & 265 & 306 & 684 & 799 & 1,256 & 1,264 & 379 & 253 & n.a. & 860 \\
\hline
\end{tabular}

Source and notes as described in table A61.1. 
Table A6.1.11. Labor Productivity: Domestic Economy of Mexico. Millions of Mexican Pesos (Constant Prices of 2008).

\begin{tabular}{|c|c|c|c|c|c|c|c|c|c|c|c|}
\hline Year & Food & Textiles & $\begin{array}{l}\text { Shoes/ } \\
\text { Leather }\end{array}$ & Wood & Chemicals & Transport & Machinery & $\begin{array}{c}\text { Electrical } \\
\text { E. }\end{array}$ & Other M. & Services & Total \\
\hline 1990 & 609 & 136 & 151 & 597 & 482 & 249 & 593 & 132 & 1,071 & 2,149 & 564 \\
\hline 1991 & 714 & 142 & 158 & 594 & 527 & 398 & 598 & 132 & 1,142 & 2,283 & 627 \\
\hline 1992 & 637 & 140 & 159 & 572 & 512 & 365 & 529 & 127 & 1,040 & 2,239 & 596 \\
\hline 1993 & 528 & 123 & 149 & 547 & 455 & 263 & 459 & 115 & 975 & 2,129 & 540 \\
\hline 1994 & 528 & 119 & 150 & 555 & 460 & 277 & 472 & 121 & 972 & 2,148 & 555 \\
\hline 1995 & 691 & 143 & 204 & 757 & 743 & 446 & 740 & 156 & 1,078 & 2,548 & 740 \\
\hline 1996 & 868 & 171 & 250 & 839 & 883 & 594 & 946 & 207 & 1,230 & 2,804 & 858 \\
\hline 1997 & 753 & 136 & 206 & 733 & 629 & 332 & 745 & 167 & 861 & 2,247 & 655 \\
\hline 1998 & 651 & 114 & 192 & 667 & 574 & 321 & 663 & 140 & 833 & 2,192 & 597 \\
\hline 1999 & 687 & 96 & 183 & 632 & 589 & 329 & 636 & 113 & 719 & 2,173 & 585 \\
\hline 2000 & 705 & 87 & 163 & 561 & 590 & 309 & 588 & 103 & 677 & 1,955 & 543 \\
\hline 2001 & 650 & 77 & 154 & 538 & 553 & 280 & 504 & 92 & 693 & 1,878 & 527 \\
\hline 2002 & 640 & 82 & 169 & 549 & 557 & 308 & 505 & 100 & 643 & 1,757 & 540 \\
\hline 2003 & 634 & 75 & 173 & 532 & 583 & 323 & 518 & 97 & 644 & 1,803 & 563 \\
\hline 2004 & 665 & 84 & 182 & 532 & 585 & 361 & 658 & 104 & 564 & 1,734 & 583 \\
\hline 2005 & 768 & 114 & 238 & 436 & 861 & 386 & 743 & 224 & 692 & 1,726 & 666 \\
\hline 2006 & 775 & 132 & 247 & 453 & 1,251 & 431 & 782 & 252 & 705 & 1,686 & 726 \\
\hline Year & Food & Textiles & $\begin{array}{l}\text { Shoes/ } \\
\text { Leather }\end{array}$ & Wood & Chemicals & Transport & Machinery & $\begin{array}{c}\text { Electrical } \\
\text { E. }\end{array}$ & Other M. & Services* & Total \\
\hline $2007^{a}$ & 790 & 152 & 243 & 512 & 1,128 & 280 & 936 & 155 & 863 & n.a. & 513 \\
\hline 2008 & 788 & 124 & 228 & 544 & 1,167 & 213 & 841 & 30 & 745 & n.a. & 478 \\
\hline 2009 & 788 & 128 & 222 & 557 & 1,907 & 169 & 669 & 35 & 778 & n.a. & 537 \\
\hline 2010 & 806 & 146 & 230 & 568 & 1,223 & 237 & 774 & 34 & 764 & n.a. & 488 \\
\hline 2011 & 814 & 164 & 225 & 592 & 1,177 & 263 & 792 & 51 & 737 & n.a. & 501 \\
\hline 2012 & 822 & 177 & 213 & 637 & 1,022 & 278 & 815 & 69 & 729 & n.a. & 495 \\
\hline 2013 & 823 & 174 & 201 & 637 & 1,504 & 258 & 779 & 56 & 620 & n.a. & 510 \\
\hline 2014 & 821 & 174 & 195 & 689 & 994 & 277 & 801 & 67 & 607 & n.a. & 471 \\
\hline
\end{tabular}

Source and notes as described in table A61.1. 
Chapter 6.

Table. A6.1.12. Labor Productivity: Total Economy of Mexico. Millions of Mexican Pesos (Constant Prices of 2008).

\begin{tabular}{|c|c|c|c|c|c|c|c|c|c|c|c|}
\hline Year & Food & Textiles & Shoes/Leather & Wood & Chemicals & Transport & Machinery & $\begin{array}{c}\text { Electrical } \\
\text { E. }\end{array}$ & Other M. & Services & Total \\
\hline 1990 & 604 & 131 & 147 & 536 & 475 & 212 & 528 & 173 & 735 & 1,992 & 519 \\
\hline 1991 & 706 & 136 & 153 & 523 & 519 & 313 & 532 & 176 & 767 & 2,097 & 571 \\
\hline 1992 & 629 & 133 & 154 & 503 & 502 & 304 & 466 & 167 & 723 & 2,057 & 541 \\
\hline 1993 & 521 & 116 & 145 & 462 & 444 & 219 & 402 & 150 & 645 & 1,964 & 486 \\
\hline 1994 & 524 & 111 & 144 & 473 & 450 & 225 & 402 & 156 & 638 & 1,996 & 495 \\
\hline 1995 & 683 & 132 & 195 & 622 & 721 & 333 & 617 & 209 & 691 & 2,340 & 647 \\
\hline 1996 & 856 & 154 & 239 & 690 & 856 & 445 & 783 & 271 & 757 & 2,570 & 744 \\
\hline 1997 & 741 & 126 & 196 & 605 & 608 & 250 & 615 & 216 & 526 & 2,043 & 562 \\
\hline 1998 & 642 & 106 & 181 & 544 & 553 & 245 & 555 & 196 & 511 & 1,974 & 512 \\
\hline 1999 & 678 & 92 & 175 & 504 & 566 & 253 & 524 & 180 & 444 & 1,955 & 498 \\
\hline 2000 & 696 & 84 & 156 & 453 & 565 & 236 & 484 & 171 & 421 & 1,750 & 462 \\
\hline 2001 & 643 & 83 & 154 & 449 & 533 & 225 & 428 & 169 & 443 & 1,734 & 461 \\
\hline 2002 & 633 & 86 & 167 & 446 & 535 & 241 & 415 & 170 & 411 & 1,626 & 464 \\
\hline 2003 & 629 & 83 & 170 & 433 & 559 & 258 & 421 & 171 & 415 & 1,680 & 485 \\
\hline 2004 & 657 & 89 & 180 & 430 & 552 & 284 & 501 & 172 & 366 & 1,590 & 492 \\
\hline 2005 & 759 & 114 & 231 & 349 & 802 & 297 & 560 & 267 & 433 & 1,580 & 557 \\
\hline 2006 & 766 & 127 & 237 & 362 & 1,142 & 327 & 597 & 294 & 444 & 1,537 & 606 \\
\hline Year & Food & Textiles & Shoes/Leather & Wood & Chemicals & Transport & Machinery & $\begin{array}{c}\text { Electrical } \\
\text { E. } \\
\end{array}$ & Other M. & Services* & Total \\
\hline $2007^{\mathrm{a}}$ & 752 & 146 & 231 & 463 & 911 & 423 & 786 & 167 & 535 & n.a. & 474 \\
\hline 2008 & 844 & 167 & 253 & 559 & 1,158 & 702 & 1,139 & 183 & 532 & n.a. & 624 \\
\hline 2009 & 858 & 174 & 256 & 582 & 1,873 & 597 & 902 & 178 & 564 & n.a. & 660 \\
\hline 2010 & 871 & 189 & 259 & 588 & 1,132 & 703 & 1,019 & 187 & 559 & n.a. & 625 \\
\hline 2011 & 864 & 205 & 242 & 604 & 1,123 & 737 & 1,046 & 198 & 531 & n.a. & 649 \\
\hline 2012 & 867 & 206 & 225 & 641 & 906 & 749 & 1,013 & 189 & 519 & n.a. & 630 \\
\hline 2013 & 883 & 201 & 219 & 650 & 1,432 & 718 & 1,054 & 185 & 452 & n.a. & 675 \\
\hline 2014 & 879 & 202 & 226 & 688 & 903 & 710 & 1,022 & 192 & 446 & n.a. & 621 \\
\hline
\end{tabular}

Source and notes as described in table A61.1. 


\section{Appendix A6.2}

Table. A6.2.1 Contribution to Changes in Aggregate Labor productivity (\%)

\begin{tabular}{|c|c|c|c|c|c|}
\hline \multicolumn{6}{|c|}{ Food } \\
\hline Years & $\begin{array}{l}\text { A (gross output / } \\
\text { labor export } \\
\text { sector) }\end{array}$ & $\begin{array}{l}\text { B (upgrading } \\
\text { export sector) }\end{array}$ & $\begin{array}{c}\text { C (employment } \\
\text { share export } \\
\text { sector) }\end{array}$ & $\begin{array}{c}\text { D } \\
\text { (domestic } \\
\text { sector) }\end{array}$ & $\Delta(\mathrm{Y} / \mathrm{L})=\mathrm{A}+\mathrm{B}+\mathrm{C}+\mathrm{D}$ \\
\hline $1990-1994$ & -0.1 & -0.1 & 0.0 & -15.2 & -15.3 \\
\hline 1994-1998 & 0.0 & 0.0 & -0.5 & 18.9 & 18.4 \\
\hline 1998-2001 & 0.0 & 0.0 & 0.3 & -0.2 & 0.1 \\
\hline 2001-2006 & 0.3 & -0.1 & -0.1 & 16.1 & 16.1 \\
\hline 1994-2001 & 0.0 & 0.0 & -0.2 & 18.7 & 18.5 \\
\hline $1990-2006$ & 0.3 & -0.3 & -0.3 & 21.4 & 21.1 \\
\hline 2008-2014 & -0.4 & 1.1 & 0.2 & 3.3 & 4.2 \\
\hline \multicolumn{6}{|c|}{ Shoes/Leather } \\
\hline Years & $\begin{array}{l}\text { A (gross output / } \\
\text { labor export } \\
\text { sector) }\end{array}$ & $\begin{array}{l}\text { B (upgrading } \\
\text { export sector) }\end{array}$ & $\begin{array}{c}\text { C (employment } \\
\text { share export } \\
\text { sector) }\end{array}$ & $\begin{array}{c}\text { D } \\
\text { (domestic } \\
\text { sector) }\end{array}$ & $\Delta(\mathrm{Y} / \mathrm{L})=\mathrm{A}+\mathrm{B}+\mathrm{C}+\mathrm{D}$ \\
\hline $1990-1994$ & 0.8 & -1.4 & -0.5 & -0.4 & -1.5 \\
\hline 1994-1998 & 0.8 & -0.6 & -1.3 & 21.3 & 20.2 \\
\hline 1998-2001 & 3.5 & 0.8 & 0.1 & -22.0 & -17.7 \\
\hline 2001-2006 & -1.1 & 0.1 & -0.1 & 36.2 & 35.2 \\
\hline 1994-2001 & 4.2 & -0.6 & 0.0 & 2.6 & 6.1 \\
\hline $1990-2006$ & 2.4 & -1.6 & -0.6 & 38.1 & 38.2 \\
\hline $2008-2014$ & -0.9 & -3.0 & 3.8 & -10.5 & -10.6 \\
\hline \multicolumn{6}{|c|}{ Wood } \\
\hline Years & $\begin{array}{l}\text { A (gross output / } \\
\text { labor export } \\
\text { sector) }\end{array}$ & $\begin{array}{l}\text { B (upgrading } \\
\text { export sector) }\end{array}$ & $\begin{array}{c}\text { C (employment } \\
\text { share export } \\
\text { sector) }\end{array}$ & $\begin{array}{c}\text { D } \\
\text { (domestic } \\
\text { sector) }\end{array}$ & $\Delta(\mathrm{Y} / \mathrm{L})=\mathrm{A}+\mathrm{B}+\mathrm{C}+\mathrm{D}$ \\
\hline 1990-1994 & 1.1 & -1.5 & -5.2 & -7.8 & -13.4 \\
\hline 1994-1998 & 0.1 & 1.5 & -5.2 & 16.9 & 13.1 \\
\hline 1998-2001 & 1.6 & 0.2 & -1.1 & -22.0 & -21.2 \\
\hline 2001-2006 & 2.5 & -4.7 & -4.2 & -17.6 & -23.9 \\
\hline 1994-2001 & 1.0 & 2.3 & -5.4 & -3.1 & -5.3 \\
\hline $1990-2006$ & 4.1 & -2.9 & -14.4 & -34.8 & -47.9 \\
\hline 2008-2014 & 4.7 & -2.1 & -0.1 & 20.4 & 23.0 \\
\hline \multicolumn{6}{|c|}{ Chemicals } \\
\hline Years & $\begin{array}{l}\text { A (gross output / } \\
\text { labor export } \\
\text { sector) }\end{array}$ & $\begin{array}{l}\text { B (upgrading } \\
\text { export sector) }\end{array}$ & $\begin{array}{c}\text { C (employment } \\
\text { share export } \\
\text { sector) }\end{array}$ & $\begin{array}{c}\text { D } \\
\text { (domestic } \\
\text { sector) }\end{array}$ & $\Delta(\mathrm{Y} / \mathrm{L})=\mathrm{A}+\mathrm{B}+\mathrm{C}+\mathrm{D}$ \\
\hline $1990-1994$ & 0.1 & -0.1 & -1.1 & -4.6 & -5.7 \\
\hline 1994-1998 & 0.1 & 0.2 & -1.4 & 19.9 & 18.7 \\
\hline 1998-2001 & 0.3 & -0.2 & -0.1 & -3.7 & -3.7 \\
\hline $2001-2006$ & -0.1 & 0.0 & -4.7 & 58.0 & 53.3 \\
\hline 1994-2001 & 0.2 & 0.1 & -1.5 & 16.9 & 15.7 \\
\hline $1990-2006$ & 0.1 & 0.0 & -8.0 & 66.3 & 58.4 \\
\hline 2008-2014 & -6.5 & -4.4 & -1.7 & -9.5 & -22.1 \\
\hline
\end{tabular}

Sources and notes as described in table 6.3 
Table. A6.2.3. Contribution to Changes in Aggregate Labor productivity (\%)

\begin{tabular}{|c|c|c|c|c|c|}
\hline \multicolumn{6}{|c|}{ Machinery } \\
\hline Years & $\begin{array}{l}\text { A (gross output / } \\
\text { labor export } \\
\text { sector) }\end{array}$ & $\begin{array}{l}\text { B (upgrading export } \\
\text { sector) }\end{array}$ & $\begin{array}{l}\text { C (employment } \\
\text { share export } \\
\text { sector) }\end{array}$ & $\begin{array}{c}\text { D } \\
\text { (domestic } \\
\text { sector) }\end{array}$ & $\Delta(\mathrm{Y} / \mathrm{L})=\mathrm{A}+\mathrm{B}+\mathrm{C}+\mathrm{D}$ \\
\hline 1990-1994 & 0.3 & -1.8 & -4.2 & -25.7 & -31.5 \\
\hline 1994-1998 & 3.1 & -1.2 & -1.9 & 27.7 & 27.6 \\
\hline $1998-2001$ & -1.5 & 1.7 & -1.0 & -28.9 & -29.8 \\
\hline $2001-2006$ & 4.5 & -3.9 & -7.8 & 35.5 & 28.3 \\
\hline $1994-2001$ & 2.4 & 0.2 & -2.7 & 6.1 & 6.0 \\
\hline $1990-2006$ & 5.9 & -5.2 & -16.1 & 26.8 & 11.5 \\
\hline $2008-2014$ & -4.3 & -5.5 & 1.6 & -2.0 & -10.2 \\
\hline \multicolumn{6}{|c|}{ Other Manufacturing } \\
\hline Years & $\begin{array}{l}\text { A (gross output / } \\
\text { labor export } \\
\text { sector) }\end{array}$ & $\begin{array}{c}\text { B (upgrading export } \\
\text { sector) }\end{array}$ & $\begin{array}{l}\text { C (employment } \\
\text { share export } \\
\text { sector) }\end{array}$ & $\begin{array}{c}\text { D } \\
\text { (domestic } \\
\text { sector) }\end{array}$ & $\Delta(\mathrm{Y} / \mathrm{L})=\mathrm{A}+\mathrm{B}+\mathrm{C}+\mathrm{D}$ \\
\hline 1990-1994 & -0.1 & -1.6 & -3.6 & -10.0 & -15.2 \\
\hline 1994-1998 & 2.0 & -0.3 & -9.9 & -16.7 & -24.9 \\
\hline $1998-2001$ & 2.1 & -0.3 & 0.1 & -17.3 & -15.4 \\
\hline $2001-2006$ & 1.9 & -2.3 & -0.8 & 1.5 & 0.3 \\
\hline 1994-2001 & 4.1 & -0.6 & -8.7 & -38.9 & -44.1 \\
\hline $1990-2006$ & 6.7 & -6.2 & -13.1 & -53.0 & -65.6 \\
\hline 2008-2014 & 2.5 & -4.0 & -0.5 & -14.2 & -16.2 \\
\hline \multicolumn{6}{|c|}{ Services } \\
\hline Years & $\begin{array}{l}\text { A (gross output / } \\
\text { labor export } \\
\text { sector) }\end{array}$ & $\begin{array}{l}\text { B (upgrading export } \\
\text { sector) }\end{array}$ & $\begin{array}{c}\text { C (employment } \\
\text { share export } \\
\text { sector) }\end{array}$ & $\begin{array}{c}\text { D } \\
\text { (domestic } \\
\text { sector) }\end{array}$ & $\Delta(\mathrm{Y} / \mathrm{L})=\mathrm{A}+\mathrm{B}+\mathrm{C}+\mathrm{D}$ \\
\hline 1990-1994 & 0.1 & -0.1 & 0.2 & 0.0 & 0.2 \\
\hline 1994-1998 & 0.4 & -0.4 & -3.2 & 2.1 & -1.1 \\
\hline $1998-2001$ & 0.2 & 0.0 & 2.2 & -16.2 & -13.9 \\
\hline $2001-2006$ & -0.1 & 0.0 & -1.3 & -11.5 & -12.8 \\
\hline 1994-2001 & 0.8 & -0.6 & -0.9 & -14.4 & -15.1 \\
\hline $1990-2006$ & 1.0 & -0.9 & -1.9 & -27.9 & -29.6 \\
\hline $2008-2014$ & n.a. & n.a. & n.a. & n.a. & n.a. \\
\hline
\end{tabular}

Sources and notes as described in table 6.3 


\section{Appendix A6.3}

Table A6.3.1 Operationalization of Independent Variables.

\begin{tabular}{|c|c|c|}
\hline Variables & $\begin{array}{c}\text { Variable name } \\
\text { (only those include in the } \\
\text { regressions) }\end{array}$ & Operationalization. \\
\hline $\begin{array}{l}\text { TFP (index } \\
\text { numbers): Solow } \\
\text { Residual }\end{array}$ & & $\begin{array}{l}\ln \_T F P_{i}=v a_{i}-\left(1-s_{l, i}\right) k_{i}-s_{l, i} l_{i} \\
\text { Following Gal }(2013), \text { Total Factor productivity at the } \\
\text { firm-level }\left(\ln \_T F P_{i}\right) \text { is here measured with index } \\
\text { numbers. Index equals one for the initial year of } \\
\text { observation for each firm. } v a_{i}, l_{i} \text { and } k_{i} \text { denotes gross } \\
\text { value added, labor and capital stock for firm } i \text {, } \\
\text { respectively. }\end{array}$ \\
\hline $\begin{array}{l}\text { Firm-level } \\
\text { Investment }\end{array}$ & & $\begin{array}{l}\text { Domestic purchases of machinery and equipment and, } \\
\text { the rental of buildings. }\end{array}$ \\
\hline Initial capital stock & & $\begin{array}{l}\text { In line with Timmer (1999), initial capital stocks are here } \\
\text { measured by applying the average of incremental capital } \\
\text { value added ratios (ICVARs) in the first five years of the } \\
\text { series to total value added in the initial year. }\end{array}$ \\
\hline Capital stock & & $\begin{array}{l}\text { Capital stock }\left(K_{t 1}\right) \text { measured following the Perpetual } \\
\text { Inventory Method (PIM): } \\
\qquad K_{t 1}=\left[(1-\delta) K_{t 0}\right]+I_{t 1} \\
\text { Where } K_{t 0}=\text { initial capital stock; } \delta=\text { depreciation rate; } \\
I=\text { firm-level investment. Depreciation rates as } \\
\text { determined by OECD (2001). }\end{array}$ \\
\hline Size & size & Total number of employees per year \\
\hline Age & age & Number of years reported by the establishment \\
\hline Economies of Scale & In_output & The logarithm of output \\
\hline $\begin{array}{l}\text { Use of imported } \\
\text { intermediate inputs }\end{array}$ & imp_interm & $\begin{array}{l}\text { The ratio of imported intermediate to total intermediate } \\
\text { consumption }\end{array}$ \\
\hline $\begin{array}{l}\text { Export intensity for } \\
\text { IMMEX firms }\end{array}$ & foreign_income & $\begin{array}{l}\text { The ratio of foreign income earned by IMMEX firms to } \\
\text { gross output by IMMEX firms. }\end{array}$ \\
\hline Capital deepening & capital_labor & The ratio of capital stock to labor. \\
\hline Quality of labor & Blue_white_hours & $\begin{array}{l}\text { Hours worked by Low qualified labor/ Hours worked by } \\
\text { high qualified labor }\end{array}$ \\
\hline $\begin{array}{l}\text { Share of highly- } \\
\text { skilled in total } \\
\text { employment }\end{array}$ & tech_empleo & $\begin{array}{l}\text { Total number of technicians / Total number of } \\
\text { employees }\end{array}$ \\
\hline Labor composition & labor_comp & Average remuneration/ Total number of employees \\
\hline
\end{tabular}




\section{Appendix A6.4}

Table A6.4.1 Maquiladora: Basic statistics for the Dependent and Independent Variables

\begin{tabular}{|c|c|c|c|c|c|c|c|c|}
\hline & Mean & Std. & Variance & Skewness & Kurtosis & Smallest & Largest & Obs \\
\hline ln_pmaq & 4.6 & 0.7 & 0.6 & -0.3 & 5.4 & 0.4 & 9.1 & 34725 \\
\hline size & 415 & 810 & 656,830 & 6.7 & 81.3 & 3.0 & 19,878 & 34728 \\
\hline size_squared & 829,274 & $6,402,498$ & $4.1 \mathrm{E}+13$ & 28 & 1,172 & 9 & 4.E+08 & 34,728 \\
\hline age & 4.3 & 4.0 & 15.9 & 1.0 & 3.3 & 0.0 & 16.0 & 34728 \\
\hline age_squared & 34.0 & 53.0 & 2811.2 & 2.2 & 7.6 & 0.0 & 256.0 & 34728 \\
\hline imp_interm & 0.7 & 0.3 & 0.1 & -1.3 & 3.4 & 0.0 & 1.0 & 34657 \\
\hline ln_output & 10.9 & 1.9 & 3.7 & 0.0 & 2.8 & 3.3 & 17.5 & 34728 \\
\hline capital_labor & 218,119 & $3,107,467$ & $9.66 \mathrm{E}+12$ & 139 & 22,989 & $-6,360$ & $5 . E+08$ & 34,728 \\
\hline blue_white_hours & 5.8 & 7.0 & 49.0 & 16.2 & 603.2 & 0.0 & 363.7 & 23267 \\
\hline tech_to_empleo & 0.2 & 0.1 & 0.0 & 1.6 & 6.9 & 0.0 & 1.0 & 34728 \\
\hline labor_comp & 52 & 69 & 4,701 & 21 & 854 & 0 & 3,870 & 34,728 \\
\hline
\end{tabular}

Table A.6.4.2 IMMEX: Basic Statistics for the Dependent and Independent Variables

\begin{tabular}{lrrrrrrrr}
\hline & Mean & Std. & Variance & Skewness & Kurtosis & Smallest & Largest & Obs \\
\hline \hline ln_pmaq & 5.9 & 1.2 & 1.3 & 0.1 & 5.2 & -4 & 11 & 34,793 \\
size & 410 & 801 & 642,206 & 7 & 73 & 2 & 16,035 & 34,948 \\
size_squared & 810,156 & $5,957,108$ & $3.55 \mathrm{E}+13$ & 22 & 653 & 4 & $2.57 \mathrm{E}+08$ & 34,948 \\
age & 2.9 & 2.2 & 5.0 & 0.3 & 1.9 & 0 & 7 & 34,948 \\
age_squared & 13 & 15 & 232 & 1 & 3 & 0 & 49 & 34,948 \\
imp_interm & 0.2 & 0.3 & 0.1 & 1.4 & 3.9 & 0 & 1 & 34,657 \\
export_int & 0.6 & 0.4 & 0.1 & -0.5 & 1.7 & 0 & 1 & 34,948 \\
ln_output & 11.23 & 2.06 & 4.23 & -0.16 & 3.28 & -0.20 & 18.94 & 34,948 \\
capital_labor & $3,576,278$ & $3 . \mathrm{E}+07$ & $9.3 \mathrm{E}+14$ & 24.7 & 735.5 & 0 & $1.34 \mathrm{E}+09$ & 34,948 \\
blue_white_hours & 8.9 & 13.3 & 176.9 & 7.8 & 119.1 & 0 & 368 & 34821 \\
tech_to_empleo & 0.19 & 0.15 & 0.02 & 1.51 & 5.72 & 0.00 & 0.97 & 34,948 \\
labor_comp & 104 & 106 & 11,153 & 8 & 222 & 0 & 4,217 & 34,948 \\
\hline \hline
\end{tabular}

Sources and notes as described in table (6.3). 


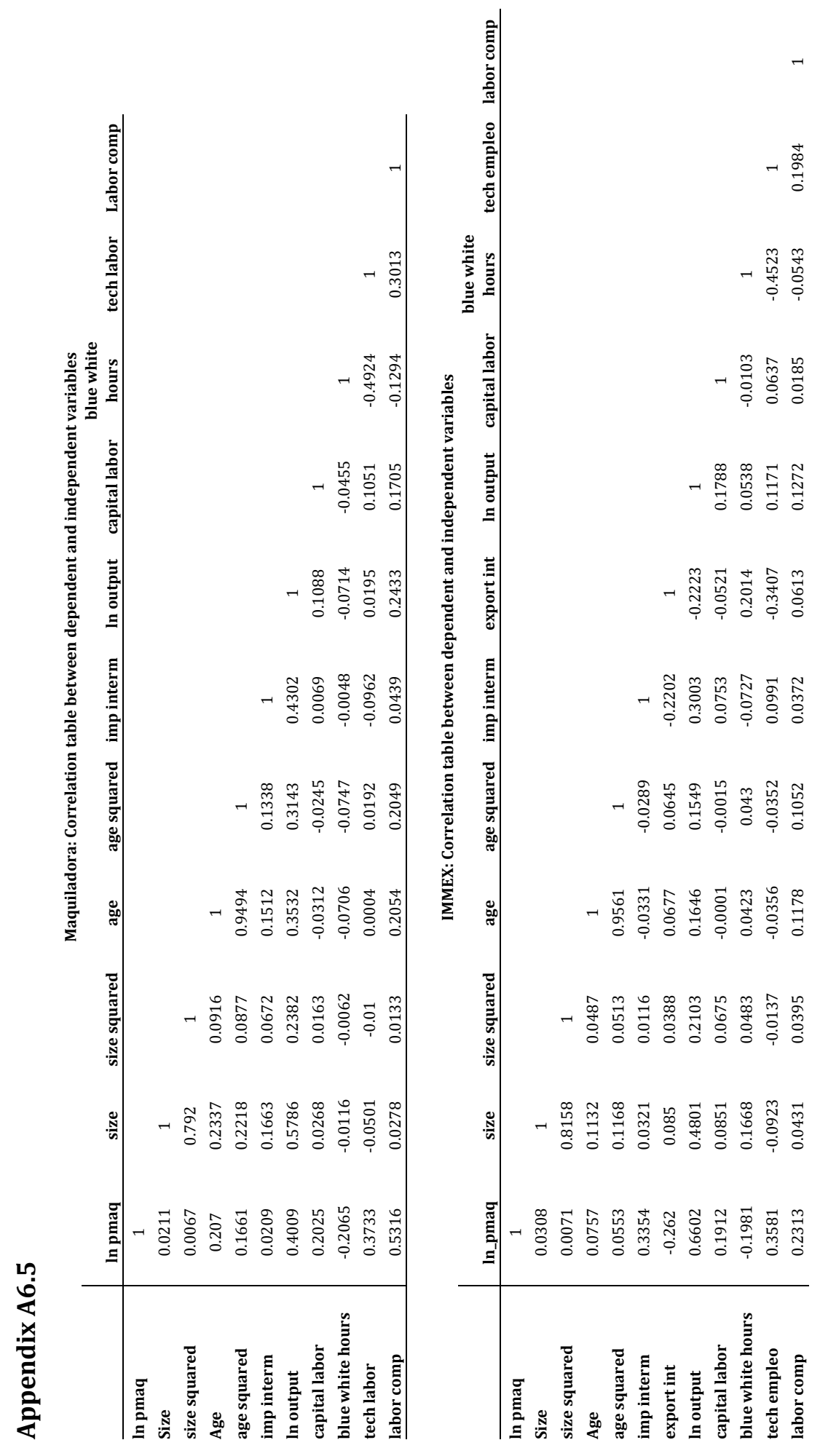





\section{Chapter 7.}

\section{Concluding remarks.}

This final chapter summarizes our general conclusions and raises some points for further discussion. Section 7.1 briefly summarizes the main methodological and policy contributions from this dissertation in the analysis of countries participating in international production networks, as well as the main contributions we provide in the study of Mexican manufacturing. Section 7.2 presents our key empirical findings. In general, here we indicate that as a result of successful production for exports Mexico has become one of the largest manufacturing producers in the global economy. It has successfully increased industrial employment, as well as the share of the export sector in total manufacturing and has even redefined its position in global value chains. Nonetheless, we also highlight that despite these measures of success, the country has achieved insufficient upgrading. Given the importance from this latter finding, section 7.3 further discusses the different factors that account for the lack of upgrading in Mexico's exporting sector. Section 7.4, on the other hand, indicates some policy recommendations for other developing countries wishing to follow Mexico's successful attempt to increase output and employment at its exporting sector. Finally, section 7.5 indicates some key arguments derived from this dissertation to be considering during the 2017-2018 renegotiation of NAFTA regarding the role of Mexico's exporting sector in creating trade deficit with the US as well as the possible avenues to further strength the competitiveness from the North American region.

\subsection{Methodological and Policy Contributions.}

This dissertation has some important empirical and policy contributions for the study of developing countries seeking to participate in international production networks. Let us first refer to the empirical ones. Chapter 3 provided a framework that highlights that manufacturing is still a regional phenomenon for most countries and regions of the World economy, despite drastic decreases in communication and transportation costs. Chapter 4 , on the other hand, offers one of the first long run studies on the domestic content of exports for countries highly engaged in Exports Processing Zones (EPZs). Such objective was achieved by constructing a unique dataset that projects (over 25 years) an official input output table to study EPZs with detail yearly information on inputs and outputs. Chapter 5 goes one step forward and includes some of those input output tables (IOTs) from chapter 4 in a larger multiregional IOT framework. By relying on official bilateral trade statistics for EPZ and for domestic manufacturing, Chapter 5 is also one of the first attempts to slice up an economy included in a World IOT dataset into its export processing and domestic manufacturing component, for more than 10 years. Slicing up a developing economy into those two components permits studying the value added contribution from the export sector and domestic manufacturing in the final output produced by a given country. Following the same reasoning, chapter 6 provides an new decomposition technique to account for the contribution of the export sector and 
of domestic manufacturing in changes in aggregate labor productivity levels for the total economy. In this new decomposition, we observe that 3 factors within the export sector (changes in output per worker, changes in value added to output ratio, and changes in labor shares with respect to total labor) and one factor within domestic manufacturing (changes in value added per worker) play a role in inducing changes in total labor productivity at the aggregate level. Finally, regarding the policy contribution from this dissertation, chapter 2 indicates that successful production for exports implies supporting firms participating in EPZs as well as domestic manufacturers producing for exports by means of different (and realistic) export performance requirements for each type of firm. This strategy will permit the industrial development of domestic manufacturers so as to eventually create one single export promoting framework where those latter firms can receive the same incentives as firms in EPZs (for details, please refer to section 7.5).

In addition, this dissertation also offers some interesting contributions with regard to the specific analysis of Mexican manufacturing. First of all, we provide here a thorough assessment of Mexico's export promoting policies over the last 50 years (Chapter 2). Not only does this review offers a detail analysis about the differences and complementarities between Mexico's two major export promoting programs (Maquiladora and PITEX), but also, we provide arguments to better understand the well thought policy reasoning that lead to the creation of the IMMEX program.

Providing long-run perspectives on the domestic content in final output and of labor productivity at Mexico's export sector are important contributions. Nonetheless, further providing a single framework to analyze the ways in which the export and domestic sector contribute to the value added structure of final output and, to changes in labor productivity for total manufacturing make this thesis unique. For instance, long-run perspectives on domestic and foreign value added content are provided in Chapter 4 (1981-2006), while long-run insights from labor productivity can also be inferred from Chapter 4 and in Chapter 6 (1990-2014). The joint contribution from the domestic and export sector in the value added structure of final manufacturing output can be observed in Chapter 5, while the contribution from those two in total labor productivity levels can be found in Chapter 6. Lastly, it is also worth mentioning that this dissertation provides two empirical comparative analysis with respect to the old and the new statistical tools to analyze production for exports in Mexico. Chapter 5 relies on aggregate information for Maquiladora and for the new statistical concept of Manufactura Global, while chapter 6 utilizes both firm-level and aggregate information for Maquiladora and the IMMEX program.

\subsection{Key Empirical Findings.}

In Chapter 3, we empirically observed that Mexico has succeeded in becoming one of the largest manufacturing producers in the global economy. According to our calculation using the EORA dataset, by 2011 Mexico's production for exports ranked in the top list of manufacturing exporters along with developed economies (Germany, USA, Japan and Italy) and other emerging countries (China). Chapter 6 further confirmed this idea by highlighting the growing importance of the export sector in total manufacturing 
production in Mexico over the last decades. Since the opening of the Mexican economy to foreign markets, the export sector increased from rather low shares in output to almost half of manufacturing production and half of gross value added in Mexico, with a growing share in industrial employment.

Chapter 2 provides some interesting insights regarding the policy reasoning behind successful production for exports in Mexico. In general, here we argue that it is not only the Maquiladora program that account for the growing importance of the exporting sector. A carefully designed program that slowly induced the production for exports from small and medium enterprises within domestic manufacturing producers (PITEX program) complemented with other policy instruments (such as drawback systems, DIMMEX and so forth) also played an important role in explaining successful export production. Unique and preferential access to one of the top export markets in the World economy, as well as the set of competitive advantages enjoyed by Mexican manufacturing (as described in Chapter 5) also account for this issue.

Other important finding, that also highlights to the growing importance of Mexican manufacturing, is the changing position of this country in global value chains since the beginning of the millennium (Chapter 5). While domestic producers continue participating in local and regional value chains (with US and Canada) in most manufacturing sectors, the export sector showed drastic changes in their value added structure. Depending on the manufacturing sector being analyzed at the export sector, Mexican manufacturing can participate in local value chains (Transport sector), regional value chains with North America (Textiles) or global value chains with East Asia (Electronics). Given the predominance of the electronic sector within total production for exports, we conclude that such exporting sector in Mexico mostly participates in global value chains. Nevertheless, this latter conclusion (the export sector mostly organized in the context of global value chains) is only reflecting the fact that US firms (previously sourcing input to the export sector in Mexico) relocate their intermediate production to China and Asia, thus increasing the share of value added embodied in Mexican exports to the US.

Finally, the most important finding from this dissertation is the existence of insufficient upgrading in the production for exports. This finding is corroborated when assessing the four dimensions of upgrading studied by this dissertation as proposed during the introductory chapter; (1) domestic content of exports (Chapter 4 and 5); (2) value added to output ratios (Chapter 6) ; (4) labor productivity (Chapter 4 and 6), and; (2) participation of skilled labor (Chapter 5). To better understand my view on the modest upgrading in the production for exports, figure (7.1) presents our key empirical results regarding the four dimensions of upgrading that were studied in chapters 4 to 6 in this dissertation. The main objective behind presenting different results that followed different methodologies and datasets is to understand their trends over the years.

Following previous figures and tables in this dissertation, figure (7.1) is divided in two main panels with the first one presenting results for different dimensions of upgrading for Maquiladora from 1981 to 2006 and, with the second indicating the respective results for new statistical tools to analyze production for exports from 2008-2014 (Manufactura Global and IMMEX, respectively). In the next paragraphs, we will explain 
how those dimensions of upgrading are related to each other, which are their main differences and, more importantly, how all those measures lead us to conclude insufficient upgrading in production for exports.

Let us start with the first dimension, i.e. the domestic content of exports. Here, DVA (Chapter 4) in figure (7.1) indicates the domestic value added content of Maquiladora final output from 1981 to 2006. DVA-Maq (Chapter 5) extended this analysis from 1998 to 2011 by relying on a different methodology and a larger multiregional dataset than Chapter 4. By connecting both findings in those chapters, we can conclude that the domestic content of exports has experienced a long-run decline from 1981 to 2014. Chapter 5 is only capturing one specific period of such long-run decline where modest increases in DVA are observed with respect to the pre-NAFTA levels. The latter means that the domestic value added structure in total exports induced by NAFTA in 1994 has basically remain unaltered by 2011 . One important additional insight is obtained by comparing our DVA results in Chapter 4 and 5. The total DVA calculated in Chapter 4 is higher than the DVA computed in Chapter 5. This is because calculating the total domestic value added contribution in exports in Chapter 4 implies adding the concepts of DVA-Maq and DVA-Dom observed in figure (7.1). Having two different domestic value added contributions for a single country is the result of slicing up Mexico in Maquiladora and domestic components in a multiregional dataset. Such DVA-Dom (Chapter 5) in figure (7.1) remains unaltered further confirming my view on lack of changes in upgrading since 1994.

Regarding the second dimension of upgrading, figure (7.1) presents the average firmlevel value added to output ratio obtained in Chapter 6. Given that this ratio is reflecting shares from 0 to 1 , the reader should note that this variable is measured on the right axis of figure (7.1). In general, we observe that the average firm-level value added to output ratios also remains unaltered by evolving around 0.4 for Maquiladora (19902006) and 0.7 for IMMEX (2008-2014). In addition, we notice that, for some years, this ratio does not necessarily follow the same trend as the DVA calculations in Chapter 4 and 5. For instance, while we observe an increase in the average value added to output ratios by 1995, that same year implied a decrease in the DVA content in Chapter 4. Likewise, the years from 1997 to 2001 implies slight increases in DVA (Chapter 4), while the average value added to output ratio presents decreases. These slight differences between the trend in the firm-level value added to output ratio and the trend of DVA are related to the fact that the first variable is only taking into account the contribution of direct domestic suppliers, while the computation of the second variable (i.e., DVA) implied considering the contribution of direct suppliers and indirect exports. In my view, if we had incorporated firm-level information on the value added contribution from indirect exporters to our firm-level measure of value added to output, we would have surely seen an approximate trend to the one described by DVA in Chapter 4 . 
Figure (7. 1): Different Dimensions of Upgrading in Mexico's Export Sector: 1981-2014.

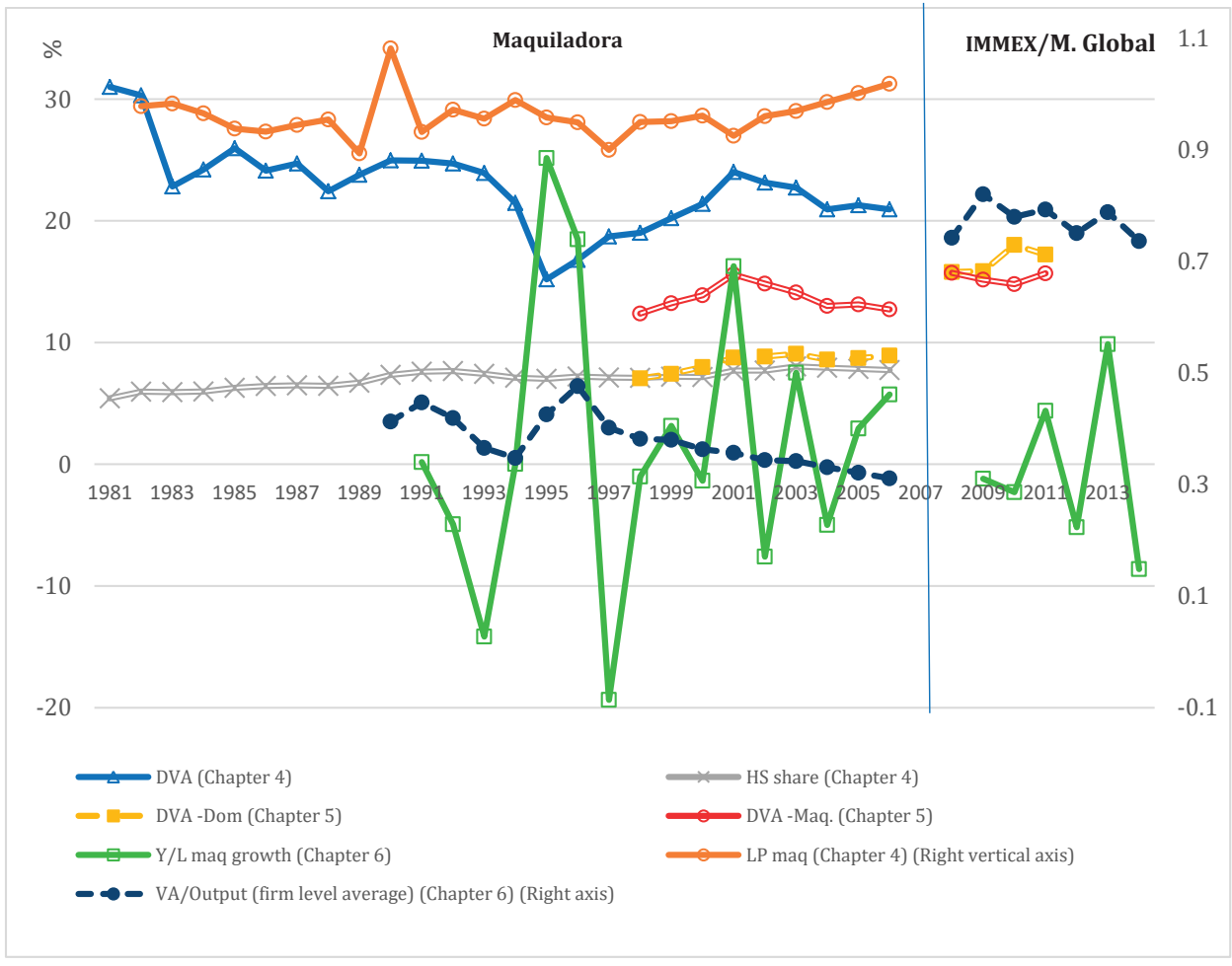

Source: Author's calculation based on aggregate data for EMIME (1981-2006), IMMEX (2008-2014), Manufactura Global (20082014), as well as firm-level information for EMIME (1990-2006) and IMMEX (2008-2014).

Notes: DVA (Chapter 4), DVA-Maq (Chapter 5) and, DVA-Dom (Chapter 5) refer to the percentage share of domestic value added embodied in final output for maquiladora production and for domestic manufacturing, respectively. HS-Share (Chapter 4) refers to the percentage share of highly-skilled workers in total workers. Y/L maq growth (Chapter 6) refers to the annual labor productivity growth in Maquiladora and IMMEX, respectively. Since all these measures refer to percentages, they have to be read on the left axis of figure (7.1). On the other hand, VA/Output (firm level average) refers to the average ratio of value added to output for Maquiladora and IMMEX, while LP maq (Chapter 4) refers to the annual labor productivity in Maquiladora from 1981 to 2006 using the first year of observation as a base year (1981=1). Given that these two measures evolve around 1, they have to be read on the right vertical axis of figure (7.1).

In the case of our third dimension of upgrading, figure (7.1) presents two different measures of labor productivity. On the one hand, Chapter 4 measured labor productivity for Maquiladora by dividing real value added by hours worked from 1981 to 2006. With such information, an index was constructed which equals 1 in 1981. Given this situation, the reader should note that the variable LP maq (Chapter 4) has to be read on the right axis of figure (7.1) On the other hand, Chapter 6 measured labor productivity as gross value added per worker from 1990 to 2014. In this context, the variable Y/L maq (Chapter 6) in Figure (7.1) is indicating the annual aggregate productivity growth in the export sector. At first glance, by comparing those two productivity measures, one could argue that they are reflecting two different trends. Nonetheless, in my view both measures suggest that the export sector in Mexico has experienced (in general) modest positive increases in labor productivity over the last decades. 
LP maq (Chapter 4) indicates modest positive growth with respect to the labor productivity levels observed in 1981. Y/L maq (Chapter 6) studies annual productivity growth and indicates far more pronounced changes than the ones observed in the previous measure of productivity. Nonetheless, from the variable Y/L maq (Chapter 6) we can also infer modest productivity increases given that most of the changes observed from 1991 to 2006 are negative or close to zero and thus, they even out with the positive ones. One important additional finding from Chapter 6 is that despite the modest increases in productivity, firm-level gross value added per workers shows heavy variation over the years, thus suggesting large differences in productivity levels between firms.

Chapter 6 also mentioned that productivity at the export sector increase rapidly from 1990 to 2014. This conclusion is still valid. Nonetheless, the reader should note that the last year of observation for this latter conclusion is 2014 and, thus in achieving this conclusion we are no longer considering only exporting firms (as we did in 1990) but a broader set of firms that produce both for domestic and foreign markets (IMMEX).

In the case of our last dimension of upgrading, we observe that the share of highly skilled workers in total employment for Maquiladora (1981-2006) remained with no changes. This is the variable HS share (Chapter 4) in figure (7.1). According to Chapter 6, increasing such share is remarkably important as positive increases in the share of highly-skilled workers were found to have a statistically significant and positive impact on firm-level productivity. Alternatively, to further confirm the positive impact of highlyskilled workers, Chapter 6 also indicated that increasing the working hours of lowskilled workers with respect to those of the highly-skilled will have a negative and statistically significant impact on firm-level productivity.

With these ideas in mind, we now proceed to next section where we aim to explain the reasons for the lack of upgrading in Mexico's export sector.

\subsection{Factors (and their Implications) that Account for the Lack of Upgrading in Mexico's Exporting Sector.}

A general finding from this dissertation is that the domestic value added content embodied in Mexico' final manufacturing output has been progressively declining in the last decades. The extent of this decline differs greatly depending on the type of production being analyzed (total output produced in Mexico, domestic manufacturing and production for exports) and even considering different manufacturing sectors. Each chapter in this dissertation attempts to provide answers as to why the domestic content of Mexico's final output has been decreasing over the years.

Chapter 3 decomposed the value added content embodied in the final output produced by top exporters (including Mexico) and regions of the world economy for 1990 and 2011. In this chapter, we observe that for any given country the final output of which is decomposed into different value added contributions by country of origin, domestic value added represents the lion's share in final output. Over time, foreign value added content tends to increase, indicating that domestic producers are increasingly participating in international production networks. Nevertheless, the top exporters in 
key manufacturing sectors (textiles and electronics) in advanced and emerging economies tend to present greater increases in the foreign value added embodied in their final output than the rest of countries (developing world). The reason for this is that, in recent decades, top exporters have faced stiff competition in terms of price and quality and have been pushed to increase their ties with efficient foreign producers that are located not only within their region but also outside of it. In contrast, domestic producers in most of the developing world have faced less competitive pressures and, thus, they present lower foreign value added content in their output than the top exporters. In this context, this chapter indicates that one reason for the decreasing domestic value added content embodied Mexico's total final output is that this country is a major top manufacturing exporter that has increased its interaction with other foreign producers that are mostly located in North America. Nevertheless, despite these decreases in domestic value added content, most manufacturing production is Mexico is still organized locally.

While chapter 3 takes a global perspective, Chapter 4 zooms in on the Mexican Maquiladora sector. It examines the domestic and foreign value added content embodied in Maquiladora final output for 25 years (1981-2006). Here, we observe that the production for exports shows different patterns than total manufacturing output (as discussed in Chapter 3). In Maquiladora, foreign value added has the lion's share final output, while domestic content is relatively small (in contrast to the high domestic content in total Mexican manufacturing. More importantly, the domestic content of Maquiladora output shows a long-run decline from 1981 to 2006, far more pronounced than the decline for the case of total final output in chapter 3. Two key factors account for the long-run decline in the domestic content of Maquiladora output. First, the aggregate decline is driven in particular by the falling domestic content within the electrical equipment sector. Second, policy shifts and major currency devaluations (in 1981 and 1994) drastically altered the foreign sourcing structure of maquiladora firms and limited their demand for local inputs in the years thereafter. Therefore, we conclude that the domestic content of exports in Maquiladora depends on the upgrading or downgrading trends in the sector that has the highest shares in output (electronics) and on a set of external shocks that the economy is subject to: increasing outward orientation and economic crisis.

Chapter 5 provides a further analysis of why the decline in the domestic content of exports in Maquiladora has been more pronounced than the decline in the domestic content of total manufacturing output. In this chapter, it is argued that what happens in total manufacturing closely reflects the sourcing structure from domestic manufacturing. Let us elaborate on this. To produce final output (both for domestic and foreign consumption), domestic producers primarily source their intermediate inputs from other domestic suppliers in Mexico. As a result of the increasing globalization of production that took place at the beginning of the 2000's, domestic producers in Mexico did increase their ties with their North American counterparts but they did not drastically modify their high demand for local inputs. Therefore, the domestic value added embodied in the final output from domestic manufacturing did not substantially decreased. Conversely, for the case of Maquiladora output, the increasing fragmentation of production implied an interesting change in its foreign value added structure. Foreign 
value added in Maquiladora output switched from the dominance of the US foreign value added content in every single manufacturing sector to a much more diversified value added structure. In the electronic sector, the East Asian share in the value added content of final output is increasingly high. In the transport equipment sector, value added from domestic producers accounts for the lion's share, while US value added share is the highest in the textile sector. We conclude that the domestic content of maquiladora output has had a more pronounced decline than that of total manufacturing because such production has become increasingly integrated in global and regional value chains. Domestic manufacturing production is still mostly organized locally despite increasing ties with North American producers. Given the weight of domestic manufacturing in total manufacturing, this affects the domestic value share in total manufacturing output.

Chapter 6 shows that one of the main implications of the decreasing domestic value added content in Maquiladora exports is related with the limited contribution of the export sector to aggregate labor productivity in total manufacturing. Upgrading in the export sector (defined as increases in the value added to output ratio) both for the case of Maquiladora and IMMEX was never strong in 24 years of analysis (1990-2014). In this chapter, we observe that the contribution of upgrading to changes in aggregate labor productivity was small and negative.

Labor productivity in the export sector has a different impact than the upgrading variable. In this case, the contributions from productivity at the export sector to changes in aggregate labor productivity were positive but still small. The small effect has to do with the fact that labor productivity in domestic manufacturing makes by far the largest contribution to aggregate productivity. Firm-level labor productivity in the export sector shows great variation over time than the upgrading variable during the same years. In my view, there are two main channels by which low levels of upgrading prevent the realisation of higher labor productivity in the export sector. First, the use of domestic inputs of low technological complexity would prevent the Maquiladora to compete with other foreign producers in terms of price of quality. Second, introducing new machinery and equipment in a Maquiladora might increase labor productivity but labour productivity increases depend on other complementary factors such as better training and higher qualification of labor that were not forthcoming.

According to our results in chapter 4 and chapter 6, higher labor productivity at the expense of lower upgrading was specially seen in 1994. Such situation can be observed in figure (7.1) by comparing the labor productivity results in 1994 for the variable Y/L maq growth (Chapter 6) and the domestic value added results in 1994 for the variable DVA (Chapter 4). Chapter 4 states that in 1994, as a result of NAFTA and the currency crisis, the domestic content of exports experienced a drastic decline from $21 \%$ to $15 \%$ in 1995. On the other hand, chapter 6 indicates that in the 1994 labor productivity levels and labor productivity growth in the export sector experienced a substantial increase (from $0 \%$ to $25 \%$ in 1995, for the case of the latter). Therefore, in the immediate years that followed the signing of NAFTA, higher aggregate productivity at the export sector was realized at the expense of lower domestic value added content in final output. After 2001 , we observe that productivity growth is mostly positive while the domestic content of exports is mostly declining. 
Despite modest increases in labor productivity and low upgrading, the export sector should not be regarded as a stagnant one. Between 1990 and 2014, the export sector increased from rather low shares in output to almost half of manufacturing production and half of manufacturing gross value added in Mexico, with important and increasing shares in manufacturing employment. In this context, it can be concluded that the export sector has rapidly increased its contribution to output and employment, but it could have made a much larger contribution if it had experienced more upgrading (higher domestic value added content and higher value added output ratios) and more rapid growth of labour productivity.

Considering all these arguments, we can now identify the factors that induce decreasing domestic content for final output in Mexican manufacturing and, that can also be observed for the case of any other developing countries highly engaged in international production networks. When we only study total final output produced by the country, the domestic value added content will only present small decreases. Given the aggregate nature of total final manufacturing output (i.e. jointly considering in a single category the production for foreign and domestic markets), this small decline can be attributed to higher interaction with foreign suppliers. Declines in the domestic content of output will be higher than average for top manufacturing exporters such as Mexico, because manufacturing producers in such countries had an incentive to drastically increased their interaction with foreign producers located within and outside their own region.

On the other hand, when we consider the final output in the exporting sectors only, foreign value added content will be much higher than the domestic one. In light of the increasing (and ongoing) fragmentation of production, the domestic content of exports must show on average a tendency to decline. In a long-run perspective, attention must be paid to the changing sourcing structure in the sectors with the largest shares in output and to the external shocks observed at the exporting sector (increasing outward orientation and crises). When comparing domestic content in exports and domestic content in total final output, we will observe that the former experiences much more pronounced declines than the latter. The reason for this is the fact the production for exports might be organized in the context of regional and global production networks depending on the modularity from each manufacturing sector and the competitive advantages offered by the exporting sector to foreign producers wishing to reallocate production to such country. Declines in the domestic content from total manufacturing, on the other hand, will not be as pronounced as the ones at the exporting sector because total manufacturing reflects a sourcing structure in which domestic producers mostly rely on local suppliers.

Upgrading (or the lack thereof) in the exporting sector will play a major role in determining its contribution to aggregate labor productivity. Given the large size of domestic manufacturing (when compared to the export sector) in terms of gross output, gross value added and employment, the domestic component of total manufacturing will drive aggregate changes in labor productivity growth for total manufacturing. Limited and even decreasing upgrading in the export sector can result in net negative contributions to aggregate labor productivity. Even if the export sector shows labor productivity growth, lack of upgrading will result in a much smaller contribution to 
aggregate changes in the productivity growth and levels for total manufacturing than would be the case if value added output ratios were much higher.

\subsection{Policy Lessons from Mexico's Export Promoting Experiences.}

As mentioned in previous paragraphs, one of the key findings of this dissertation is the decreasing domestic content in exports. Nevertheless, another key finding is that the exporting sector in Mexico has continuously increased its shares in total manufacturing output, total gross value added and employment. The factors that usually mentioned in accounting for the success of the exporting sector are the Maquiladora framework, the signing of NAFTA in 1994 and the competitive advantages offered by Mexico. This dissertation makes the case that Mexico's export promoting policies for domestic manufacturing firms also play a major role in explaining successful production for foreign markets. Mexico's increasing production for exports should not exclusively be associated with the implementation of export processing zones (the Maquiladora framework) or the signing of free trade agreements (NAFTA) but also with specific policies to induce increasing exports from firms in the domestic sector (the PITEX program, in this case). As discussed in chapter 2, the PITEX program (with the help of other complementary programs such as DIMMEX) was designed to gradually stimulate the production for exports by domestic firms with no prior experience in international markets. By coexisting with the Maquiladora program, the PITEX program proved to be successful as it allowed the integration in global markets and the industrial development of different kind of domestic manufacturing firms (including SMEs). A merging between the two export promoting schemes into a single scheme (IMMEX) was necessary to further ensure the continuous development of exporting capabilities within the domestic sector.

In my view, implementing two parallel export promoting programs (similar to Maquiladora and PITEX) and eventually merging them into a single framework (such as IMMEX) constitutes a valid policy alternative which could be replicated by developing countries seeking to increase their production for exports and to employ more labor in manufacturing industries outside the informal sector. Therefore, in line with the Mexican experience with Maquiladora and PITEX and the eventual emergence of the IMMEX program, this dissertation will propose here a number of specific policies to be followed in order for other developing to obtain the previously mentioned objectives of higher exports and employment.

First of all, the general export promoting framework at any given developing country should explicitly support the development of two specific type of firms; (1) manufacturing firms that seek to produce excusively for foreign markets (i.e. those foreign firms that participate in export processing zones) and, (2) manufacturing firms that seek to produce for both the domestic and foreign markets (and which can be of foreign or domestic origin). An increasing interaction between the first and the second group of firms is a key factor to ensure the development of exporting capabilities for domestic manufacturing firms.

For the first group of firms, policy makers should implement incentives for foreign firms to reallocate production to the country. Tariff exemptions and tax incentives should be 
provided for the imports of several intermediate goods as well as imports of machinery and equipment. Further incentives should be granted for the domestic purchases of intermediate goods locally produced.

For the second group of firms, the government at the developing economy should promote the aim that their domestic firms become as competitive as the foreign firms that operate in the country's EPZ. In this regard, the Mexican experience highlights that the context in which domestic producers operate should be taken into account to successfully achieve the latter objective. For instance, if the developing country is currently at the early stages of industrialization, this would suggest that local manufacturing lacks the necessary skills to produce for exports as they might be only producing for the domestic market. This latter fact (domestic firms exclusively producing for the domestic market) would also suggest that those firms mostly rely on domestic intermediate inputs as they also might lack of the necessary means to interact with foreign producers of intermediate goods. Thus, the government should implement a program similar to that of the EPZs but aimed at the industrial development of all the firms in domestic manufacturing (major local firms, SMEs and local suppliers to those two firms). Nonetheless, unlike foreign firms in EPZ, granting tariff and tax incentives should be provided conditioned on export performance. Tariff and tax incentives on the import of raw materials can be provided to all firms in the domestic manufacturing of our developing country provided that those firms export at least $10 \%$ of their total production. A minimum of $10 \%$ is here imposed precisely to allow for the participation in this program of more and more SMEs that want to produce for foreign markets but that can only start doing this slowly. On the other hand, tariff incentives for the imports of machinery and equipment can be provided to those domestic firms in the developing country that export more than $30 \%$ of their final output. This second export performance requirement is set for those major firms that can already export a larger amount of their final output than firms of small size. It is also set as additional objective for the development of SMEs. If SMEs in our developing country start exporting progressively more (beyond 10\%) not only should they be able to import raw materials free of duty but also machinery and equipment. The same set of rules should be established for the local suppliers of intermediate goods in our developing country. Additional tariff and tax incentives can be provided to major firm and SMEs provided that they continue (or increase) their purchases of inputs from local suppliers. The continuous development of all firms in the domestic sector from our developing country will mobilize more resources (capital, labor, etc.) in favor of manufacturing and against the informal sector.

The Mexican experience with Maquiladora and PITEX also teaches us that the difference in rules of operation governing the export processing zone and the program for the exports of domestic manufacturers should progressively decrease over time. Eventually, these rules of operation (export performance requirements to obtain tariff incentives) should eventually become identical for firms registered within the two programs. This final step (merging the two export promoting programs) should be implemented once domestic manufacturers have achieved sufficient capabilities that allow them to properly compete in international markets. Finally, one important thing to highlight is that these policy recommendations to achieve higher output and employment in the 
exporting sector are complementary to other key factors that determine successful production for exports such as the network of trade agreements signed by the developing country and the set of competitive advantages offered by the same economy. The current context of stiff competition triggered by the emergence of well-defined and efficient international production networks in East Asian countries should also be considered when deciding which industries are the key priorities for the successful production of exports in our given developing economy.

\subsection{General Guidelines for the 2017-2018 Renegotiation of NAFTA: Some Insights from the Maquiladora Industry.}

The renegotiation of NAFTA started in mid-August 2017 and it is expected to continue during 2018. One of the key concerns of the current US administration (that took office in January 2017) is to reduce the existing trade deficit with Mexico. In this regard, the exporting sector in Mexico (and more specifically the Maquiladora industry) is at the very center of such debate. In the view of the US administration, the source of the trade deficit is the fact that goods previously manufactured in the US are now being produced in Mexico, as a result of the continuous (and ongoing) reallocation of manufacturing facilities from the first country to the latter as induced by NAFTA. In the view of US policy makers, NAFTA should be modified in order to reduce the US trade deficit with Mexico and allow for a fairer exchange of goods between the two countries with less negative effects for the US economy.

The general findings of this dissertation can be used to debate the current negative perspective from the US administration attached to the signing of NAFTA. Let us first discuss what trade deficit implies for a country in the context of international production networks. According to chapter 2, given the interaction of many countries in the production of a given manufacturing good, we see a context where intermediate goods cross international borders several times before turning into a final good. Therefore, trade imbalances (such as the one between the US and Mexico) do not simply reflect the fact that one country is selling less and buying more output from another nation. In the context of international production networks what a trade imbalance reflects is the fact that this country (in this case the US) is obtaining a higher return for their investment in the production of intermediate inputs (which eventually return to the country in the form of a final good), than the returns that it could have obtained if those intermediates had been domestically assembled in the US. In a nutshell, domestically selling those imported goods manufactured in Mexico (with no import tariff imposed by the latter) implies higher value added and higher profits for US firms than what they could have achieved had assembly operations stayed in the US.

Indeed, more and more manufacturing firms are reallocating operations from the US to Mexico. However, with very few exceptions (the transport sector), they are still mostly reallocating the labor intensive part of manufacturing (assembling operations) to Mexico. Such argument is further confirmed by one of the key findings from this dissertation, i.e. the fact that the exporting sector in Mexico has not yet experienced a substantial process of industrial upgrading. In this perspective, since assembly is now outsourced and henceforth labor costs are now being reduced, US firms can increase 
their investment in the production of technologically complex intermediate goods. With no import tariffs imposed by neighboring Mexico neither on the exports of intermediates by the US nor on imports of final goods by the same country, US firms obtain a high return on their investment on intermediate goods after locally selling output assembled by Mexico. Even if assembled in Mexico, chapter 5 from this dissertation indicates that those final goods imported by the US from Maquiladora have a large US foreign value added content, in spite of increasing value added shares of East Asian countries in the same final output.

Let us now debate the idea of pursuing a "fairer" exchange of goods with less negative effects for the US. Imposing trade barriers to the current free exchange of manufacturing goods between the US and Mexico will have far worse consequences for both countries rather than simply reducing the US trade deficit in favor a "fairer" economic relationship. New tariffs on the imports of Maquiladora output by the US will definitely have negative effects on Mexico's exporting sector; output will be reduced and consequently so will manufacturing employment. Even if the US imposes tariffs on the deliveries of Maquiladora output from Mexico, it is quite likely that Mexico will still permit the free delivery of intermediate inputs coming from the US. This is one of the key policy guidelines governing the Maquiladora framework since the 1960s and still continues in the context of the IMMEX program given the objective of the Mexican government to incentivize the reallocation of manufacturing facilities to the country. However, tariff barriers for the deliveries of Maquiladora output to the US market will imply less profits for US firms, higher prices for US consumers and, consequently, an eventual reduction of US manufacturing employment.

In the logic of the current US administration, the underlying reason for limiting imports from Mexico is inducing more US firms to return to their country of origin to create more employment in regions that were heavily affected by the reallocation of manufacturing capabilities to Mexico. As can be seen from our previous arguments, limiting manufacturing imports from Mexico will have the precise opposite effect and can even lead more US firms to abandoning not only Mexico, but also the US, in favor of East Asia. On the one hand, to adjust their decreased profitability and to counteract the price increases in the local market resulting from higher import tariffs, it is likely that many US firms will decide to cut labor expenses, further decreasing the already declining levels of US manufacturing employment. On other hand, it is widely known that many foreign firms are located in Mexico in order to benefit from the Maquiladora framework (that allows the free imports of intermediate inputs from anywhere in the world), from the Mexico's cheap labor supply and, more importantly, from the free access to the US market provided within NAFTA framework. As seen in chapter 4 from this dissertation, for Maquiladora production, this is specially the case of firms within electronic manufacturing which, according to chapter 5, have integrated Mexico into global production networks with East Asia. This is because US electronics firms located in East Asia send intermediate inputs to Mexico which are later transformed into final goods that have duty free access to the US market, provided that some North American inputs are being used in such production. 
If Mexico loses its duty-free access to the US market, firms within electronics manufacturing in East Asia will lose their main incentive to produce in Mexico. They will find the previously mentioned mandatory use of North American inputs, which is expected to remain unaltered, increasingly inconvenient. Given that most of their inputs are sourced from East Asia, and the evident lack of upgrading in Mexico's exporting sectors, those East Asian firms will have an incentive to reallocate back to their region of origin and produce directly for the US market from there. If paying import tariffs to gain access to the US market becomes inevitable, those firms would prefer to pay it by sending their goods directly from the Asia, given the high value to weight ratios governing its production.

Likewise, American firms that decide to abandon Mexico in order to avoid import tariffs might find reallocating to the US costly as labor costs are much higher in such country than in Mexico. Just like the case of East Asian firms, if paying import duties to access the US market becomes inevitable, then those American firms might also be willing to reallocate to cheaper locations in East Asia (not only in terms of labor but also considering the price of intermediate inputs) and to produce for the US market directly from such region. In this scenario, one may conclude that imposing trade barriers to Mexico (and to the Maquiladora industry in specific) could actually help the US reduce its trade deficit with this country. Nevertheless, the current US administration should be aware that imposing trade barriers with Mexico will also imply, at in least in the short run, higher levels of manufacturing unemployment, less profits for US firms, higher prices for final goods for US consumers, firms abandoning the North American region and, more importantly, an increasing trade deficit with East Asian countries (specially China).

Now, with regard to Mexico, there is one important final question. Can Mexico and its exporting sector survive in a world without NAFTA? In my view, Mexican manufacturing could survive such a negative shock, but this would come at the expense of further reducing the incipient process of industrial upgrading at the export sector. The imposing of higher US tariff and non-tariff barriers on Mexican imports, the disappearance of NAFTA or Mexico's withdrawal from the agreement would inevitably imply a large contraction of output in the export sector, an eventual decline in the levels of manufacturing employment and, lower levels of foreign direct investment in the economy. Assuming the end of the agreement, and in order to alleviate the previously listed negative effects for the economy, policy makers in Mexico would immediately modify the IMMEX framework to stop including some of the obligations imposed by NAFTA.

In line with chapter 2, to further strength productive linkages between the North American region, NAFTA required its signatory countries to impose tariffs on the imports of goods that had not been previously produced within the region, effective as of 2001. The latter meant that from 1994 to 2001, Maquiladora firms would enjoy unique privileges by importing free of duty to Mexico intermediate inputs produced anywhere in the world (within the Maquiladora framework) and by exporting, also free of duty, final manufacturing goods to the US (within the NAFTA framework). By 2001, the Maquiladora framework had to be modified in order to only allow for the free imports of 
those intermediate goods that have only been previously produced by the US or Canada (no longer from anywhere the world).

Nevertheless, chapter 2 also indicates that the Mexican government decided not to completely follow the latter requirement imposed by NAFTA. To prevent Maquiladora firms from leaving the country as a result of the new NAFTA regulation, policy makers in Mexico designed a list of those intermediate inputs that were more commonly imported by Maquiladora firms. Inputs falling within such list could still be imported by Maquiladora firms free of duty, regardless of what NAFTA required, and could still enjoy free access to the US market as long as the production of final goods used North American inputs. This is what we know as the Sectoral Promotion program (or PROSECs) which was defined by chapter 2 of this dissertation as a NAFTA framework designed by Mexico for non-NAFTA countries. In this context, if NAFTA ends, Mexican policy makers will eliminate the PROSECs regulations which are now included within the IMMEX framework. The objective here will be the exact same that lead to the creation of PROSECS, i.e. preventing Maquiladora firms from leaving the country. Further providing tariff and tax incentives within the IMMEX program in order for Mexico to continue participating in international production networks will be the main objective.

Permitting the imports of intermediate goods from anywhere in the world (again) with no restriction regarding a specific category of inputs listed by the government (PROSECs), the competitive advantages offered by the country to exports to the US (with some import tariffs imposed by the US) and the exports free of duty to other countries by which Mexico has signed a trade agreement with could become the new set of policies for the government in a post-end-of-NAFTA framework. The main problem now is whether those new policies would still be designed to induce higher output and employment in the sector export and could disregard and/or overlook, as in previous historic episodes, the situation faced by indirect exporter or local producers of intermediate inputs. In a nutshell, it is quite likely that in a scenario without NAFTA the government in Mexico would prefer implementing policies that reduce the already low domestic content of exports in favor of higher and/or stable levels of output and of employment. Given that the end of NAFTA can become a large negative shock for the Mexican economy, like the ones that took place in 1982 and 1994 as described in to chapter 4, we can expect a drastic decline in the domestic content of Maquiladora exports that will alter the sourcing structure of most Maquiladora firms and that will restrict their demand for domestic inputs to even lower levels in the years to come.

One important thing to mention is that the set of manufacturing capabilities that the exporting sector in Mexico has developed over the last 20 years as result of NAFTA constitute an important factor that could enable the country to survive, even without the existence of such agreement. The rather drastic scenario described in the very last paragraphs mostly refers to the case of electronics manufacturing which still accounts for the largest share in output at the export sector. On the other hand, as observed in chapter 6, the transportation sector is a key factor in the upgrading efforts. In my view, this sector would keep its rather harsh rules of origin (more than 60\% of North American inputs) even in the absence of the trade agreement. This is because, as 
described in chapter 2 , harsh requirements on the use of imports locally produced were present in the transportation sector even before NAFTA. In light of the specific characteristics of this sector (which demand close proximity to end markets), a large number of multinational firms within the PITEX framework established operations in Mexico by also setting up a network of suppliers in the country. This network of suppliers in Mexico has helped to increase the domestic content of exports in this industry. Given its development in the last twenty years, we regard it as unlikely that it would be reallocated to other countries, as would be the case for firms in electronics that only have assembly operations in Mexico and, nothing else.

So, which aspects of NAFTA need to be renegotiated? For the discussions regarding manufacturing goods, the North American region should aim to achieve further integration so as to properly compete with other regions in the world, such as East Asia and Europe. From the previous arguments elaborated here, I conclude that any attempt to limit the current free exchange of goods between Mexico and the US would have negative effects for the region, in favor of the regions that they are supposed to be competing with.

In my view, there are two ways to increase the North American competitiveness that would imply some changes in the current IMMEX framework. The first one is for Mexico to limit its support to other non-NAFTA countries in the context of the PROSECs program. It is clear that Mexico has prioritized its participation in international production networks outside the NAFTA region given the large amount of East Asian firms registered within its export promoting program. Nevertheless, this has come at the expense of the less upgrading in the export sector as well as lower competitiveness for the region. The scope for limiting the PROSEC program, however, will be limited and no immediate increases in upgrading or productivity can be expected if these changes are implemented. The second alternative is more realistic and has to do with the transport sector. Chapter 5 indicated that further bilateral cooperation between Mexico and the US in the transport sector could be associated with a higher domestic content in the exports of this sector. US and Canadian reallocating facilities to Mexico are behind those upgrading efforts and benefit by being able to operate under economies of scale, reducing costs and thus sending higher profits to their own economies. The resulting competitiveness of the North American transport sector that emerged as a result of this bilateral cooperation is out of question. The IMMEX framework should then be modified during the renegotiation of NAFTA to allow for further institutional cooperation in different areas of technology creation within most manufacturing sectors with a special emphasis on the transport sector.

This latter idea highlights what Maquiladora production really means for North America. From its inception, this industry has to be analyzed as a binational industry that has historically benefitted from preferential access both in Mexico's and US's customs regulations. Its expansion since the mid-1990s has benefited both economies. Henceforth, any renegotiation of NAFTA should aim at further expanding this binational industry, rather than destroying it. 


\section{Valorisation Addendum.}

In line with article 23.5 of the Regulation Governing the Attainment of Doctoral Degrees at Maastricht University, this addendum discusses the valorization opportunities provided by this Ph.D. dissertation.

Developing economies are continuously seeking for industrial alternatives to catch up with the developed World. In light of the increasing fragmentation of manufacturing production, developing economies should also seek for strategies to integrate into these new ways to organize manufacturing production and capture as much benefits as possible. The key to successfully integrate in international production networks, however, goes beyond obtaining immediate benefits in terms of higher output for exports, foreign direct investment and employment. More importantly, a successful (and complete) integration in global manufacturing should also imply an important transformation of domestic manufacturing capabilities by means of higher labor productivity levels, higher use of skilled-workers and increasing domestic content in manufacturing exports.

This dissertation explored the industrial strategy followed by Mexico to integrate its manufacturing firms into international production networks. It also explored and quantified the different set of benefits that Mexico obtained after having pursued such strategy. This dissertation claims that developing economies should pay special attention to the Mexican case if their objective is to maximize the set of immediate benefits that global manufacturing offers to less developed economies (higher output, employment and foreign direct investment). Developing economies, on the other hand, should look somewhere else if they also aim to substantially transform their export sector towards more technologically complex activities. By means of any relevant indicator (labor productivity, domestic content of exports, etc.), Mexican manufacturing has mostly failed to advance towards more complex activities in the value chain.

Three aspects of the industrial strategy in Mexico studied on this dissertation deserve special attention. They can easily be replicated by developing economies that seek to become a manufacturing powerhouse. The first one is that the strategy for the industrial development of exporting firms should be a regional one. A regional strategy that is implemented not only at the country level, but that also considers regional complementarities with neighboring countries. On the one hand, at the country level, exporting firms should be located in a single region that benefits of close proximity to harbors and foreign markets. Beyond the potential benefits for exporting firms triggered by specialization and spill-over effects, this industrial strategy should also aim to increase the levels of income and of employment within that region. The Mexican case highlights that once a successful pattern of manufacturing specialization has been achieved within a given region, policy makers should aim to induce other type of exporting firms to locate elsewhere in the country (i.e. a second regional strategy). On the other hand, at the level of neighboring economies, the first regional strategy should also be designed by explicitly addressing potential complementarities with other 
countries located nearby. Complementarities not only in terms of infrastructure or factor endowments that are scarce one county but that are not in other. More importantly, complementarities in terms of benefits that are offered to investors and exporting firms and even some sort of institutional complementarities. One more time, the Mexican case highlights the fact that further bilateral cooperation between Mexico and neighboring US (not explicitly included in trade agreements) further strengthen the competitiveness of Mexico's transport sector.

A second aspect from the Mexican experience that is worth highlighting is that not all manufacturing sectors can offer the same opportunities for successful industrial development and integration in international production networks. Inducing the industrial development of firms within Electronics, Textiles and Other manufacturing will guarantee the presence of the immediate set of benefits for developing economies (output, employment and FDI). Those three sectors, however, will play a very limited role in transforming the export sector towards more technologically advanced activities. The governance of the manufacturing production within those three sectors, as well as the specific incentives for multinational firms to reallocate specific labor-intensive activities to developing economies account for this issue. Transportation equipment sector stands as a clear exception to Mexico's attempt to substantially transform its domestic manufacturing capabilities. Unique access to major foreign end markets, growing Mexican middle class, the existence of protectionist rules of origin and, so forth, were factors that led to a successful transformation within this sector. In a nutshell, the Mexican experience highlights that the manufacturing sectors that can induce a complete and successful industrial transformation are those where the developing economy can fully exploit its country specific competitive advantages and, that are not subject to stiff global competition.

The third important aspect from the Mexican experience is that successful production for exports does not only imply supporting highly competitive multinational firms. More importantly, any export promoting strategy should also aim to slowly induce the production for exports from those domestic firms that are currently mostly producing for the domestic market. Any developing country seeking to strength its exporting sector should then devise two export promoting programs; one for the highly competitive firms, and other that aims at the industrial development of domestic firms seeking to produce for exports. Each export promoting program should provide different trade and tax incentives based on realistic performance requirements for the firms there participating. Those two programs have to coexist with one another and, the differences in performance requirements between them should slowly be lifted. Once the export promoting program for domestic firms has proven successful, the final objective of policy makers in developing economies should be then to merge those two export promoting programs into a single framework to further strength the competitiveness of its manufacturing sector.

The target audience for this dissertation is not strictly limited to policy makers. Scholars seeking to understand (and test) the different set of alternatives that developing economies face to join and upgrade in global value chains would also greatly benefit from the main ideas and conclusions discussed by this Ph.D. dissertation. Long term 
empirical perspectives on the firm-level and aggregate trends of exporting firms make this thesis unique on the field of international trade. The results from this dissertation have been presented at international conferences and at seminars in Universities and Policy institutions. Chapter 4 has been already published as a journal article at the Journal of International Trade and Economic Development, while Chapter 3 and 5 are part of the UNIDO Inclusive and Sustainable Industrial Development Working Paper Series. 

Juan Carlos A. Castillo Sánchez was born in Mexico City. He conducted his PhD studies in UNU-MERIT, Maastricht University (2018), under the specialization track on "Structural Change and Industrialization" which was sponsored by the United Nations Industrial Development Organization (UNIDO). He also holds a Master's degree in Economics and Business (research) from the University of Groningen in the Netherlands (2012) and, a Licenciatura degree in Economics (honors) from the National Autonomous University of Mexico (2009). During his PhD studies, he also acted as a tutor for several bachelor level courses (International Economics, Network Economics and, Macroeconomics), as well as a master level course (Innovation). As a research intern for UNIDO and, as a consultant for the United Nations Conference on Trade and Development (UNCTAD), he provided technical assistance for two major policy reports; UNIDO's 2016 Industrial Development Report and, UNCTAD's 2018 World Investment Report.

His main areas of interest are manufacturing micro-level datasets, global input-output systems, multinational firms, industrial policy, global value chains and export processing zones. 



\section{General Appendix.}

\section{Data sources used in this Dissertation.}

\section{GA. 1. Introduction.}

This appendix briefly summarizes all the sources of information we relied on during the different empirical chapters from this dissertation. In general, this thesis utilized two types of data which are aggregate information and firm-level datasets. Let us explain now the exact information contained on each type of data.

Aggregate information refers to the following; (a) multiregional Input Output tables (IOTs) (the EORA and the WIOD dataset); (b) national IOTs for the Mexican economy for the base year of 2003; (c) international trade statistic for Mexico per product category at the 8 digit level (Harmonized System) by country of origin (imports) and by country of destination (exports); (d) information per manufacturing sector for gross output, gross value added, domestic and imported intermediate consumption (reported in line with Mexico's National Accounting System), as well as; (e) information for the qualification of labor. One important advantage from this dissertation is that the aggregate data for the case of Mexico (items b to e) was available according to three categories which are the total economy of Mexico, domestic manufacturing and Maquiladora industry. Since information for Maquiladora is only available up to 2006, our research also employed two additional sources of aggregate information to further extend the analysis of Mexico's exporting sector up to more recent years. These two additional aggregate datasets are; (f) the concept of Manufactura Global, which is Mexico's statistical office latest attempt to measure the participation of firms located in Mexico in international production networks from 2003 onwards, and; (g) official information for the new exporting framework that replace Maquiladora by 2007 which is known as the IMMEX program. One important thing to mention from these last two aggregate datasets is that they also offer time series information per manufacturing sector for different years. Nevertheless, only the concept of Manufactura Global reports information in line with Mexico's National Accounting System (NAS). Thus, to match our IMMEX data with our information for Maquiladora as close as possible, our research had to create its own definitions to measure variables such as gross output and gross value added.

Firm-level information refers to official (unbalanced) panel datasets for exporting firms published by Mexico's statistical office (INEGI) under rather strict confidentiality issues. Here, we utilize two datasets which are the one for Maquiladora firms (1990-2006) and the one for IMMEX firms (June 2007-2014). The Maquiladora panel dataset reports information in the same fashion as the previously described aggregate Maquiladora statistics, which means that firm-level information for this dataset is also reported in terms of Mexico's NAS. On the other, as previously mentioned, IMMEX data the firmlevel does not follow either the methodology from Mexico's NAS. Henceforth, the methodology we used to build concepts for IMMEX data at the aggregate level was also followed at the micro-level. 
Depending on the specific set of objectives from each chapter in this dissertation, we utilize different combinations of aggregate datasets, as well as a combination of both aggregate and firm-level dataset at the same time. For instance, chapter three relied on aggregate item (a), chapter four used items (b) (d) and (e), chapter five employed items (a), (b) (c), (d) and (f), while chapter six utilized aggregate items (d) and (g) as well as our two firm-level datasets. The forthcoming paragraphs explain in detail the specific characteristics from each type of data that we utilize according to each chapter in this dissertation.

\section{GA.2 Data sources for Chapter 3.}

The main objective of this paper was to decompose final output produced by top exporters and regions of the World economy into the value added contribution from different countries. Given that these objectives implied analyzing all the international production networks in the World, we decided to use the EORA multiregional IOT dataset. Following Lenzen et al. (2013), the EORA dataset covers the inter-industry flows between more than 187 countries from 1990 to 2011. To construct such large dataset, Lenzen et al. (2013) relied on different data sources such National Accounting dat provided by different UN agencies, the COMTRADE databases, Eurostat, IDE/JETRO, as well as a great number of national agencies. Information within the EORA dataset is provided both for basic and purchaser's price.

\section{GA.3 Data sources for Chapter 4.}

This chapter projected official IOTs for the Maquiladora industry and for domestic manufacturing for a period of 25 years. To meet this objective, we relied on the following information; (1) official IOTs for the total economy of Mexico (base year) and; data from Mexico's national accounting system from 1981 to 2006.

\section{GA. 3.1 Official IOT for the Total Economy of Mexico (2003).}

In 2008, INEGI released an IOT (with the base year 2003) for the total Mexican economy. An important novelty was the fact that INEGI decided to divide such IOT for the total economy into two main components; (1) the Maquiladora industry and, (2) the Domestic manufacturing of Mexico. Such situation means that for the year 2003, Mexico provides one specific IOT to study the Maquiladora and one specific IOT to study Domestic manufacturing.

In line with INEGI (2010), maquiladora firms are defined as the economic units that perform activities for assembling and/or transforming intermediate goods that have been temporarily imported and whose processing is meant to produce a manufacturing good that is to be exported. Following the same reasoning, domestic firms can be defined as all those economic units within the Mexican territory that do not belong to the maquiladora program. Specific supply and Use tables for Maquiladora and of the domestic economy were used by INEGI to construct the respective IOTs. All the data is there reported in basic (and purchaser's) price for 20 manufacturing sectors (and 79 subsectors) which are classified in line with the North American Industrial Classification System (NAICS) (INEGI, 2011b). 


\section{GA.3.2. Data from Mexico's National Accounting System for Maquiladora and Domestic Manufacturing (1981-2006).}

Projecting IOT for Maquiladora and for the domestic economy of Mexico required retrieving complementary information from Mexico in terms of its National Accounting system (NAS). Information for gross output, gross value added, domestic and imported intermediate consumption, as well as for blue-collars and white-collar workers was readily available from 1990 to 2006 (http://www.inegi.org.mx/sistemas/bie) both for Maquiladora and for domestic manufacturing. As for the case of information from 1981 to 1989 , information in line with the NAS was only available online for the case of domestic manufacturing. Thus, to obtain information for that same period for Maquiladora firms, we digitalized hard copies from old documents published by INEGI that were not accessible via the internet (INEGI, 1991).

Finally, once we gathered all the necessary information, we projected IOTs for domestic intermediate consumption and for imported intermediate consumption (for each component from Mexican manufacturing) by relying on the aforementioned official IOTs and using the G-RAS procedure (Temurshoev and Timmer, 2011).

\section{GA.4 Data sources for Chapter 5.}

In this chapter, our research divided Mexico, as presented by the World Input Output Tables dataset (WIOD), into Mexican domestic manufacturing and Mexican maquiladora industry. To meet this objective, we relied on the data created in chapter 4 and required the following data additional: (1) WIOD dataset; (2) data reported in terms of the NAS for domestic manufacturing as well as the new statistical concept to measure Mexico's participation in international production networks from 2007 to 20111, and; (3) International trade statistics for each component of Mexican manufacturing.

\section{GA.4.1 World Input Output Database (WIOD): 1998-2011.}

On its 2012 release, WIOD included 40 developed and emerging economies that together represented more than 85\% from the total World GDP (Timmer et al., 2014). Furthermore, along with those 40 economies, WIOD also includes in the dataset a representative developing economy categorized as the rest of the World. Such information is provided from 1994 to 2011 (2012 release). When compared to other multiregional IOT datasets, one important advantage from WIOD is the fact that such dataset relies on the official information provided by National Statistical Offices to construct its data. This official information (in terms of gross output, imported intermediate consumption and so forth) is then linked by means of international trade statistics to describe multiregional inter-industry flows across countries.

\section{GA.4.2 NAS Data for Domestic Manufacturing (1998-2011), for Maquiladora (1998-2006) and the Concept of Manufactura Global (2007-2011).}

As mentioned before, aggregate information for Maquiladora firms reported in terms of Mexico's NAS is only available online from 1981-2006. Given the time period covered by WIOD on its 2012 release (1994-2011), and the available international trade statistics for Maquiladora (1998-2006), we could only use such NAS Maquiladora information 
from 1998-2006. The next challenge for our research was obtain data to study NAS Maquiladora from 2007 to 2001. INEGI (2014) published a new statistical tool to measure Mexico's participation in global production networks which is called "Manufactura Global". From the whole universe of manufacturing firms in Mexico, INEGI (2014) identified those firms that belong to international production networks if they meet one of the following criteria; (a) their production should be for exports and most of their imported inputs should be imported ( a ratio of 2/3 with respect to their exports); (b) they should be mostly foreign owned, and; (3) they should produce intermediate goods that are exported for the production of other international production networks not located in Mexico. By definition, Maquiladora firms (within the framework of IMMEX) are included in the statistical concept of Manufactura Global. Similarly, given that Manufactura Global data is reported in terms of NAS from 2003 to 2014, we decided to use the information from 2007 to 2011 to account for the necessary data to study the participation of Mexico in international production networks from 2007 to 2011. As for the case of data from domestic manufacturing, we faced no major difficulties in obtaining such data from 1998 to 2011 as it is readily available at INEGI's official website. With all the required information for Manufactura Global and for domestic manufacturing, we projected IOT for each component of Mexican manufacturing from 2007 to 2011 using the same methodology proposed by the G-RAS procedure. By adding these new projected IOTs to the ones we previously created in Chapter 4, we obtained an updated IOT dataset with information from 1994 to 2011 which was necessary to divide Mexico as reported by WIOD.

\section{GA.4.3 International trade statistics for Maquiladora and for Domestic manufacturing (1998-2011).}

Detailed data for exports and imports per product category at 8 digit-level from the Harmonized System is available for each of two components from Mexican manufacturing from 1998 to $2006^{50}$. This means that during that period of time, INEGI reported specific data for exports and imports for Maquiladora and for domestic manufacturing, respectively. Nevertheless, as of 2007 such distinction is no longer made and INEGI only reports data for exports and for imports per product category. In light of this situation, our research could only initially divide Mexico as reported by WIOD from 1998-2006. One new challenge to extend the analysis from 2007 to 2011 was to identify from Mexico's available trade statistics those product categories that belong to Manufactura Global and those that belong to domestic manufacturing. To meet this objective, we follow the same methodology that INEGI (2014) followed in order to identify firms belonging to Manufactura Global. From the previous statistics that separately studied Maquiladora and Domestic manufacturing, we built a ratio of Maquiladora to total manufacturing. If the ratio was higher than $2 / 3$, i.e. more than $70 \%$, (both for the case of exports and imports respectively) we conclude that such product category belong to Manufactura Global. Those items that do not meet such criterion (a ratio of Maquiladora to total manufacturing lower than 2/3) were then regarded as product categories belonging to domestic manufacturing. Once we obtained the

\footnotetext{
${ }^{50}$ http://www.inegi.org.mx/est/lista_cubos/consulta.aspx?p=adm\&c=9
} 
respective lists of product categories at the 8 digit-level, we utilize it to identify data for exports and for imports for Manufactura Global and domestic manufacturing.

\section{GA.5 Data sources for Chapter 6.}

In this chapter, we analyze labor productivity and labor productivity growth in total manufacturing, domestic manufacturing and the exporting sector at the aggregate and firm-level. At the aggregate level, this chapter utilizes three sources of information per year and per manufacturing sector (available at www.inegi.gob.mx). The first source of information is data from Mexico's total manufacturing (1990-2014). The second source is data for Maquiladora retrieved from EMIME (1990-2006) and, the third one is information for the IMMEX program (available from July 2007 to 2014). Our estimates for domestic manufacturing were always obtained as the difference between the data for total manufacturing and the one for exporting firms (Maquiladora or IMMEX program), respectively.

For maquiladora firms, gross value added was computed as the sum of labor remuneration, utilities and the rental cost of machinery and equipment. For the same set of firms, intermediate consumption was regarded as the sum of imported and domestic intermediate goods and total intermediate expenses. The sum of gross value added and of intermediate consumption provides our estimate of maquiladora gross output. On the other hand, information for IMMEX was more difficult to compute. Unlike EMIME, IMMEX does not publish data entirely in line with the NAS. In this context, following the concepts from INEGI (2012) and the information provided in the official IMMEX industrial surveys, gross value added had to be computed as a residual. From the IMMEX variable named "Ingresos por Maquila, Submaquila and Remanufactura51" (i.e., income obtained as a result of maquiladora-related operations) we subtract the value of domestic intermediate inputs. The residual of this computation is our measure of gross value added for IMMEX firms. Gross output for IMMEX firms was regarded as the sum of the variable named income obtained as a results of maquiladora related operations and the variable accounting for imported intermediate consumption. Total intermediate consumption for IMMEX were computed following the same procedure as for maquiladora firms. Once we obtained all this information for total manufacturing, Maquiladora and IMMEX, value added and output deflators were utilized to present such data in constant Mexican pesos of 2008. Finally, for the case of variables measuring employment, we faced no major difficulties since INEGI directly publishes such information for total manufacturing, Maquiladora firms and firms under the IMMEX program.

For our micro analysis, our research will rely on two official unbalanced firm level data sets collected and compiled by INEGI; the first one is the EMIME (maquiladora) firm level dataset from 1990 to 2006 and, the second one is the IMMEX firm level dataset (July 2007-2014). Both EMIME and IMMEX, report their own official variables at the aggregate and firm-level. Therefore, our own firm-level variables for EMIME and IMMEX

\footnotetext{
51 In line with "Cuestionario Mensual para Establecimientos Manufactureros-Programa IMMEX", the variable named "Ingresos por Maquila, Submaquila y Remanufactura" is computed considering the sum of production costs (labor, depreciation of capital, domestic inputs, etc.) plus total expenses and utility.
} 
were computed following the same procedure as in the aggregate section (4). Let us explain in detail the characteristics from each firm level dataset.

The full EMIME firm-level dataset consists of 34,728 plant year observations (19902006). For each plant, there is information on hours worked and the number of employees by job category (administrators, technicians and workers), wages paid by job category, as well as plant expenditures, domestic and imported intermediate consumption, value added, utilities etc. The EMIME dataset also contains one variable related to capital expenditures named "expenditures on machinery and equipment". According to Utar and Ruiz (2013), such variable refers to firm-level domestic expenditures on precision and resistance instruments, rotation bands, forklifts and, trucks with special containers (temperature and toxic waste). EMIME does not report plant-level information on owned imported capital equipment. The full IMMEX dataset consists of 41,500 observations (July 2007 to December 2014). Plant level data for wages, number of employees, hours worked is also reported by job category. Nevertheless, unlike EMIME, IMMEX only reports such data for two job categories, namely technicians and workers (reported in a single category) and, administrative staff. Similarly, IMMEX reports two different income categories that a given firm might obtained either from domestic or foreign market operations. Here, we are referring to the categories of income obtained as a result of maquiladora related operations (ingresos por maquila, submaquila y re-manufactura) and, the one for other income. IMMEX data for plant expenditures is less detailed than the one for EMIME. For instance, there is no IMMEX variable that directly quantifies firm-level expenditures on capital. Finally, IMMEX micro data for domestic and imported intermediate are reported in a similar fashion as EMIME 


\section{References.}

Acevedo Garat, M. (1987), "Las Importaciones de Insumos y los Exportadores Indirectos: Dos Elementos para Fomentar las Exportaciones", Comercio Exterior, Vol.37, No.6, pp. 439-448.

Ahmad, N. and S. Araujo (2011), "Measuring Trade in Value-Added and Income Using Firm Level data", Organization for Economic Co-operation and Development (OECD).

Angulo Parra, C. (1998), "How to Use Maquiladoras in Mexico Today", United States-Mexico Law Journal, Vol. 6, pp.111-116.

Arndt, S. W. and H. Kierzkowski (2001), Fragmentation: New Production Patterns in the World Economy. Oxford University Press.

Athukorala, P. (2010), "Production Networks and Trade Patterns in East Asia: Regionalization or Globalization?", $A D B$ Working Paper Series on Regional Economic Integration, No. 56, Asian Development Bank.

Baldwin, R. (2006), "Globalisation: The Great Unbundling(s)", Chapter 1, in Globalisation Challenges for Europe, Secretariat of the Economic Council, Finnish Prime Minister's Office, Helsinki, pp. 5-47.

Baldwin, R. and J. López-González (2015), "Supply-Chain Trade: A Portrait of Global Patterns and Several Testable Hypotheses", The World Economy, 38(11), pp.1682-1721.

Banco Nacional de Comercio Exterior (1979), "Sección Nacional", Comercio Exterior, vol. 29, no.5 pp.521534.

Barajas, R., Almaraz, A., Carrillo, J., Hualde, A., Rodríguez, C., and O. Contreras, (2003), Industria Maquiladora en México: Perspectivas del Aprendizaje Tecnológico-Organizacional y Escalamiento Industrial, Monografía, Aprendizaje Tecnológico y Escalamiento Industrial: Perspectivas para la Formación de Capacidades de Innovación en la Maquiladora de México.

Bartelsman E. and M. Doms (2000), "Understanding Productivity: Lessons from Longitudinal Microdata", Journal of Economic Literature, Vol. 38, No. 3, pp. 569-594.

Bergin, P. R., Feenstra, R. and G. H. Hanson (2009), “Offshoring and Volatility: Evidence from Mexico's Maquiladora Industry", American Economic Review, Vol. 99, No. 4. pp. 1664-1671.

Bernard A. B., \& C.I. Jones (1996), "Comparing Apples to Oranges: Productivity convergence and Measurement Across Industries and Countries", American Economic Review, 86(5), pp. 1216-1238.

Boston Consulting Group (2008), "Mexico's Evolving Sweet Spot in the Globalization Landscape", The Boston Consulting Group Inc.

Brannon, J. T., James D. D., and G. W. Lucker (1994), "Generating and Sustaining Backward Linkages Between Maquiladoras and Local Suppliers in Northern Mexico", World Development, 22(12), pp. 1933-1945.

Brown, F. (1997), La Industria de Autopartes Mexicana: Reestructuración Reciente y Perspectivas, México, Centro Internacional de Investigaciones para el Desarrollo, UNAM, México.

Brown, F. and L. Domínguez (1989), "Nuevas Tecnologías en la Industria Maquiladora de Exportación", Comercio Exterior, vol. 39, núm. 3, México, pp. 215-223.

Brown, F. and L. Domínguez (1999), "Productividad en Grandes y Pequeños Establecimientos con Distintas Intensidades en la Utilización de insumos", Economía Mexicana, 7(1), 79-114. 
Buitelaar, R.M. and R. Padilla Pérez (2000), "Maquila, Economic Reform and Corporate Strategies”, World Development, Vol. 28, No. 9, pp. 1627-1642.

Carrillo, J. (2007), “La Industria Maquiladora en México: ¿Evolución o Agotamiento?”, Comercio Exterior, vol. 57, núm. 8.

Carrillo, J. and A. Hualde (1997). "Maquiladoras de Tercera Generación. El Caso de Delphi-General Motors”, Comercio Exterior, vol. 47, núm. 9, pp. 747-758.

Carrillo, J. and A. Hualde (2002), "La Maquiladora Electrónica en Tijuana: Hacia un Cluster Fronterizo", Revista Mexicana de Sociología, año LXIV, No. 3, México, pp.125-171.

Carrillo, J. and R. Zárate-Cornejo (2003), “Limitaciones de los Proveedores Mexicanos de la Electrónica frente a los Extranjeros”, Región y Sociedad, Vol. XV, no. 28, pp. 161-191.

Carrrilo, J. and A. Lara (2004), “Nuevas capacidades de coordinación centralizada. ¿Maquiladoras de cuarta generación en México?”, Estudios Sociológicos, Vol. 22, No. 66, p. 647.

Carrillo, J. and A. Hualde (2013) “¿Una Maquiladora Diferente? Competencias Laborales Profesionales en la Industria Aeroespacial en Baja California” en Casalet M. (ed.), La Industria Aeroespacial: Complejidad Productiva e Institucional, Facultad Latinoamericana de Ciencias Sociales, pp. 135-162.

Castellaci, D. (2002), “Export Behavior and Productivity Growth: Evidence from Italian Manufacturing Firms", Review of World Economics, Weltwirtschaftliches Archi, Volume 138, Issue 4, pp. 605-628.

Castillo, J.C and G.J. De Vries (2018), “The Domestic Content of Mexico's Maquiladora Exports: A Long-Run Perspective", Journal of International Trade and Economic Development, 27(2), 200-219. DOI: 10.1080/09638199.2017.1353125

CEPAL (1996), "México: La Industria Maquiladora”, Estudios e Informes de la CEPAL, No.95, Naciones Unidas Comisión Económica para América Latina, Subsede de México, pp. 1-237.

CEPF (2016), Zonas Económicas Especiales: Aspectos Relevantes de la Iniciativa de Ley Aprobada, Centro de Estudios de las Finanzas Públicas, CEFP/010/2016, Palacio Legislativo de San Lázaro.

COLEF (2002), Encuesta “Aprendizaje Tecnológico y Escalamiento Industrial en Plantas Maquiladoras”, El Colegio de la Frontera Norte, Departamento de Estudios Sociales.

Contreras, O.F. and R. Evans (2003), "Más Allá de las Maquiladoras: El Complejo Manufacturero del Televisor en el Norte de México", en Contreras, O.F. y J. Carrillo (coord.), Hecho en Norteamérica: Cinco Estudios Sobre la Integración Industrial en América del Norte, Ediciones Cal y Arena, El Colegio de Sonora, pp. 27-67.

Contreras, O.F. and L.F. Munguía (2007), "Evolución de las Maquiladoras en México. Política Industrial y Aprendizaje Tecnólogico", Region y Sociedad, vol. XIX, pp. 72-87.

Cortez, W. (1999), "Restructuración y Productividad del Trabajo en el Sector Maquilador", Comercio Exterior, Banco Nacional de Comercio Exterior de México, número de Septiembre de 1999, pp. 811820.

Cortez-Ruiz, C. (1993), “El Sector Forestal Mexicano: ¿Entre la Economía y la Ecología?”, Comercio Exterior, Abril, Mexico pp.370-377.

Daudin, G., Rifflart C., and D. Schweisguth (2011), "Who Produces for Whom in the World Economy?" Canadian Journal of Economics , 44 (4), 1403-1437.

De Backer, K. and S. Miroudot (2013), "Mapping Global Value Chains”, OECD Trade Policy Papers, No. 159, OECD Publishing. http://dx.doi.org/10.1787/5k3v1trgnbr4-en

De Hoyos R.E. and L. Iacovone (2013), "Economic Performance under NAFTA: A Firm-Level Analysis of the Trade-productivity Linkages”, World Development, Vol. 44, pp. 180-193. 
De La Cruz, J., Koopman R., Wang Z. and S. Wei. (2011), “Estimating Foreign Value Added in Mexico’s Manufacturing Sector", United States International Trade Commission, Columbia University, CEPR and NBER, pp. 1-33.

De La Cruz J., Koopman R., Wang Z., and S. Wei (2013), “Foreign and Domestic Content in Mexico's Manufacturing Exports", in Mattoo, A., Z. Wang, and S. Wei, (eds.) (2013), Trade in Value Added: Developing New Measures of Cross-Border Trade, The International Bank for Reconstruction and Development/The World Bank, USA, pp. 135-160.

De la Madrid, E. (2009), “La Situación de la Industria de la Celulosa y el Papel en el Mundo”. Financiera Rural. México.

De Vries, G., Chen, Q., Hasan R. and Z. Li (2016), "Skills and Activity Upgrading in Global Value Chains: Trends and Drivers for Asia”, ADB Economics Working Paper Series, No. 496, Asian Development Bank.

Dedrick, J., Kraemer, K.L. and G. Linden (2010) "Who Profits from Innovation in Global Value Chains? A Study of the iPod and Notebook PCs", Industrial and Corporate Change, 19(1), p. 81- 116.

Díaz González, E. (2006), “La Productividad Total de Factores en la Industria Eléctrica y Electrónica. El Caso de la Industria Maquiladora en México", Economía Mexicana. Nueva Época, vol. XV, núm. 2, segundo semestre, 2006, pp. 251-287, Centro de Investigación y Docencia Económicas, A.C. Distrito Federal, México

Dietzenbacher, E., Hoen, A. \& B. Los, (2000), "Labor Productivity in Western Europe 1975-1985: an Intercountry, Interindustry Analysis”, Journal of Regional Science, vol. 40, pp. 425-452.

Dietzenbacher, E., Pei J. and C. Yang (2012), “Trade, Production Fragmentation, and China's Carbon Emissions," Journal of Environmental Economics and Management, vol. 64, pp. 88-101.

Dimaranan B. V., Editor (2005). Global Trade, Assistance, and Production: The GTAP 6 Data Base, Center for Global Trade Analysis, Purdue University.

Duran, R (2005), "Hacia un cambio en el paradigma de la competitividad", in M. Cimoli and B. García y Celso Garrido (eds.), El Camino Latinoamericano Hacia la Competitividad, Políticas Públicas para el desarrollo productivo y tecnológico. Siglo XXI.

Dussel Peters, E. (1995), "El Cambio Estructural del Sector Manufacturero Mexicano: 1988-1994", Comercio Exterior, Vol. 45, No.6.

Dussel Peters, E. (2000), Polarizing Mexico: The Impact of Liberalization Strategy, Lynne Rienner Publishers.

Dussel Peters, E. (2005), “Economic Opportunities and Challenges Posed by China for Mexico and Central America", German Development Institute (DIE), Studies Series, Bonn.

Dussel Peters, E. and J. Katz (2006), “Diferentes Estrategias en el Nuevo Modelo Latinoamericano: Importaciones Temporales para su Reexportación y Transformación de Materias Primas", en K.J. Middlebroek and E. Zepeda (coord.), La Industria Maquiladora de Exportación: Ensamble, Manufactura y Desarrollo Económico, Universidad Autónoma Metropolitana - Azcapotzalco, México, pp.49-103.

Dutrénit, G. and A. Vera-Cruz (2002), "Rompiendo Paradigmas: Acumulación de Capacidades Tecnológicas en la Maquila de Exportación”, Innovación y Competitividad, Publicación trimestral de ADIAT, año II, Núm. 6.

Dutrenit, G., Vera-Cruz, A., Arias, A., Sampedro, J., and A. Urióstegui (2006), Acumulacion de Capacidades Tecnológicas en Subsidiarias de Empresas Globales En Mexico: El Caso de La Industria Maquiladora De Exportación, Miguel Ángel Porrúa, Universidad Autónoma Metropolitana, p.205. 
E\&Y (2010), Mexican government enacts important changes to IMMEX (formerly Maquiladora) regime, Ernst \& Young Global, IMMEX Newsletter.

Engle, R. and C. Granger (1987), "Co-integration and Error Correction: Representation, Estimation, and Testing", Econometrica, vol. 55, issue 2, 251-76

Feenstra, R.C. and G.H. Hanson (1996), "Foreign Investment, Outsourcing and Relative Wages," in Political Economy of Trade Policy: Essays in Honor of Jagdish Bhagwati, ed. by R. Feenstra and G. Grossman (Cambridge MA: MIT Press).

Feenstra R.C. and G. H. Hanson (1999), "Productivity Measurement and the Impact of Trade and Technology on Wages: Estimates for the U.S., 1972-1990," Quarterly Journal of Economics, 114(3), p. 907-940.

Feenstra, R.C., Hanson, G.H. and D. Swenson (2000), "Offshore Assembly from the United States: Production Characteristics of the 9802 Program", in R.C. Feenstra (ed.), The Impact of International Trade on Wages, University of Chicago Press, pp. 85-122.

Feenstra R.C. and A.M. Taylor (2014), International Trade, Third Edition, Worth MacMillan.

Foster-McGregor, N., and R. Stehrer (2013), "Value added content of trade: A comprehensive approach", Economics Letters, Vol. 120, Issue 2, pp. 354-357.

Fragoso, E. (2002), "Apertura Comercial y Productividad en la Industria Manufacturera Mexicana", Economía Mexicana. Nueva Época, vol. XII, núm. 1., pp. 5-38. Centro de Investigación y Docencia Económicas, A.C. Distrito Federal, México.

Gal, P. (2013), "Measuring Total Factor Productivity at the Firm Level using OECD-Orbis." OECD Economics Department Working Paper 1049, OECD, Paris.

Gallagher, K. and M. Shafaeddin (2010),"Policies for Industrial Learning in China and Mexico”, Technology in Society, Vol. 32, Issue 2, pp. 81-99.

Gallagher, K. and L. Zarsky (2007), The Enclave Economy: Foreign Investment and Sustainable Development in Mexico's Silicon Valley, The MIT Press, Cambridge, MA.

Gallagher, K. P., Moreno-Brid J.C. and R. Porzecanski (2008) "The Dynamism of Mexican Exports: Lost in (Chinese) Translation?", World Development, vol. 36, no. 8, pp. 1365-1320.

Gambrill, M. (2002) "La Subcontratación Internacional: entre la Regionalización y la Globalización” en Gambrill, M. (coord.), La Globalización y sus Manifestaciones en América del Norte, Centro de Investigaciones sobre América del Norte, Universidad Nacional Autónoma de México, México.

Gambrill, M (2008). "IMMEX: Convergencia de la Maquiladora y la Industria Manufacturera de Exportación", Comercio Exterior, Vol.58, No.4. pp. 315-321.

Gantz, A.D. (2004), "NAFTA, Article 303, PROSEC and the New Maquiladora Regime in Mexico", in M. Irish (ed.), The Auto Pact: Investment, Labour and the WTO, Kluwer Law International, NY.

GATT (1986), Protocolo de Adhesión de México al Acuerdo General sobre Aranceles Aduaneros y Comercio, Ginebra, Julio 17.

Gereffi G. and O. Memedovic (2003), The Global Apparel Value Chain: What Prospects for Upgrading for Developing Countries (Report), United Nations Industrial Development Organization (UNIDO). Vienna, Austria.

Gereffi G., Humphrey J. and T. Sturgeon. (2005), "The Governance of Global Value Chains", Review of International Political Economy, 12:1, p. 78-104.

GGDC (2015), World Input-Output Database, Groningen Growth and Development Centre, http://www.rug.nl/research/ggdc/data/ 
González, A. (1990), El Desarrollo de la Inversión Extranjera en México. SEGUMEX: Reseña anual de la industria maquiladora, Thomas Madison, México DF.

González-Aréchiga B. and J.C. Ramírez (1989), “Productividad sin Distribución: Cambio Tecnológico en la Industria Maquiladora Mexicana", Frontera Norte, vol. I, núm. 1, pp. 97-124.

González-Aréchiga, B., Ramírez J.C., and F. Aguas Gómez (1991), “Los Servicios en la Industria Maquiladora y las Negociaciones de un Tratado de Libre Comercio con Estados Unidos y Canadá", Revista Mexicana de Sociología, Vol. 53, No. 3, El Tratado de Libre Comercio y la Frontera Norte, pp. 201219.

Government of Mexico (1989). Decreto para el fomento y la operación de la industria maquiladora de exportación. Diario Oficial de la Federación, December 22.

Grossman, G.M. and E. Rossi-Hansberg (2008), "Trading Tasks: A Simple Theory of Offshoring”, American Economic Review, vol. 98, pp. 1978-1997.

Haltiwanger, J.C, Lane, J.I. and J.R. Spletzer (1999), "Productivity Differences across Employers: The Roles of Employer Size, Age, and Human Capital", The American Economic Review, Vol. 89, No. 2, Papers and Proceedings of the One Hundred Eleventh Annual Meeting of the American Economic Association, pp.94-98.

Hernández Laos, E. (2000), La Competitividad Industrial en México, Plaza y Valdés, Universidad Autónoma Metropolitana-Iztapalapa.

Hummels, D., Ishii, J. and K.M. Yi (2001), "The Nature and Growth of Vertical Specialization in World Trade", Journal of International Economic, 54(1), p. 75-96.

Humphrey, J. and H. Schmitz (2002), "How Does Insertion in Global Value Chains Affect Upgrading in Industrial Clusters", Regional Studies, Vol. 36, Issue 9, pp. 1-16

Iacovone, L., Gordian Rauch, F. and L.A. Winters (2013) "Trade as an Engine of Creative Destruction: Mexican Experience with Chinese Competition". Journal of International Economics, vol. 89 (2). pp. 379-392.

INEGI (1991), Estadística de la Industria Maquiladora de Exportación, 1979-1989, Instituto Nacional de Estadística, Geografía e Informática. México p.1-53.

INEGI (2001), "La Producción, Salarios, Empleo y Productividad de la Industria Maquiladora de Exportación; Total Nacional (1988-2000)", Sistema de Cuentas Nacionales de México, Instituto Nacional de Estadística e Informática, México, pp. 1-115.

INEGI (2005), "La Producción, Salarios, Empleo y Productividad de la Industria Maquiladora de Exportación; Total Nacional (1999-2004)", Sistema de Cuentas Nacionales de México, Instituto Nacional de Estadística e Informática, México, pp. 1-109.

INEGI (2010), "La Producción, Salarios, Empleo y Productividad de la Industria Maquiladora de Exportación, Total Nacional; Metodología", Sistema de Cuentas Nacionales de México, Instituto Nacional de Estadística e Informática, México, pp. 1-7.

INEGI (2011a), "Estadística Mensual Sobre Establecimientos Manufactureros con Programa IMMEX, Cifras Durante Marzo de 2011". Comunicado No. 247-11. Instituto Nacional de Estadística y Geografía, Aguascalientes, México.

INEGI (2011b), "Matriz de Insumo Producto de México 2003- Clasificación SCIAN 2002", Sistema de Cuentas Nacionales de México, Dirección General de Estadísticas Económicas, Dirección General Adjunta de Cuentas Nacionales, Instituto Nacional de Estadística e Informática, México, pp. 1-64.

INEGI (2012), “Conceptos y Precisiones Metodológicas para el Llenado del Cuestionario Mensual para Establecimientos Manufactureros", Encuestas Económicas Nacionales, Instituto Nacional de Estadística y Geografía. 
INEGI (2014), "Sistema de Cuentas Nacionales de México. Valor Agregado de Exportación de la Manufactura Global. Fuentes y Metodología”, Instituto Nacional de Estadística, Geografía e Informática. México.

Javorcik, B. S., Keller, W. and J. Tybout, (2008) "Openness and Industrial Response in a Wal-Mart World: A Case Study of Mexican Soaps, Detergents and Surfactant Producers", World Economy, 31(12), p. 1558-1580.

Jenkins, M., Larraín, F., and G. Esquivel (2001), “Export Processing Zones in Central America”, In Larraín, F. (ed), Growth and Internationalizations, Issue no. 1, Economic Development in Central America, Cambridge, Massachusetts, John F. Kennedy, University of Harvard.

Johanssen H. and L. Nilsson (1998), "Export Processing Zones as Catalyst", World Development, vol. 25, issue 12, pp. 2115-2128.

Johnson R. and G. Noguera (2012), “Accounting for Intermediates: Production Sharing and Trade in Value Added”, Journal of International Economics, 86 (2), p. 224-236.

Johnson, R., and G. Noguera (2014). “A Portrait of Trade in Value Added Over Four Decades." Mimeo, Dartmouth college.

Jones, R.W. (2000), Globalization and the Theory of Input Trade, Cambridge: MIT Press.

Jones, R. W. and H. Kierzkowski (2001), “A Framework for Fragmentation”, in S. W. Arndt and Henryk Kierzkowski (eds), Fragmentation: New Production Patterns in the World Economy, New York: Oxford University Press, p. 17-34.

Jordaan, J. A. (2011), “FDI, Local Sourcing, and Supportive Linkages with Domestic Suppliers: The Case of Monterrey, Mexico. World Development, 39(4), pp. 620-631.

Kaplinsky, R. (2000), "Globalization and Unequalisation: What Can Be Learned from Value Chains Analysis", Journal of Development Studies, 37(2), pp.117-46.

Kaplinsky, R., Memedovic, O, Morris, M. and J. Readman (2003). The Global Wood Furniture Value Chain: What prospects for Upgrading by Developing Countries. The case of South Africa. UNIDO: Vienna

Kasahara, H. and J. Rodrigue (2008), "Does the use of imported intermediates increase productivity? Plant-level evidence", Journal of Development Economics, 87, pp. 106-118

Koopman, R., Wang, Z. and S. Wei (2008), “How Much Chinese Exports Is Really Made in China: Assessing Foreign and Domestic Value-added in Gross Exports", NBER Working Paper, 14109.

Koopman, R., Wang, Z., and S. Wei. (2014), "Tracing Value-Added and Double Counting in Gross Exports." American Economic Review, 104(2): 459-94.

Lee, J.W. and P. Swagel (1997) "Trade Barriers and Trade Flows Across Countries and Industries", The Review of Economics and Statistics, Vol. 79, No. 3, p. 372-82

Lenzen, M., Wood R. and B. Gallego (2007), "Some Comments on the GRAS method" Economic Systems Research, vol. 19 (4), pp. 461-465.

Lenzen, M., Kanemoto K., Moran, D. and A. Geschke (2012), "Mapping the Structure of the World Economy”, Environmental Science and Technology, 46(15), p. 8374-8381. DOI:10.1021/es300171x

Lenzen, M., Moran D., Kanemoto K., and A. Geschke (2013), “Building Eora: A Global Multi-regional InputOutput Database at High Country and Sector Resolution”, Economic Systems Research, 25:1, p. 2049 ,

León-Santacruz R. and F. Luján (2014), "Implications for Maquiladoras of the 2014 Mexican Tax Reform”, International Tax Review, Vol. 25, No.16, pp.32-35. 
Los, B., Timmer M.P and G. J. De Vries (2015), "How Global Are Global Value Chains? A New Approach to Measure International Fragmentation of Value Chains", Journal of Regional Science, 55 (1), pp. 6692.

Los, B., Timmer, M.P., and G.J. de Vries (2016) "Tracing Value-Added and Double Counting in Gross Exports: Comment." American Economic Review 106 (7): 1958-1966.

Lung, Y. (2004), "The Changing Geography of the European Automobile System", International Journal of Automotive Technology and Management, Vol. 4, issue 2/3, pp. 137-165.

Mc Eachern, W. (2014). Macroeconomics: A Contemporary Approach, 10th edition, South-Western Cengage Learning, USA.

Mendoza, J.E. (2004), "Labor Productivity in the Export Maquiladora Industry of Mexico: A Convergence Analysis", EconoQuantum, Vol 1, núm. 1, pp. 57-82.

Miller, R.E. and P.D. Blair (2009) Input-Output Analysis: Foundations and Extensions, 2nd edition (Cambridge UK: Cambridge University Press).

Mollick, A. V. and R. Cabral (2008), "Productivity Effects on Mexican Manufacturing Employment", North American Journal of Economics and Finance, 20, pp. 66-81.

Montes-Rojas G. and M. Santamaria (2007), "Sources of Productivity Growth: Evidence from the "Mexican Manufacturing Sector", North American Journal of Economics and Finance, no. 17, pp.263-278.

Moore Stephens (2017), Doing Business in Mexico 2017, Moore Stephens Mexico, pp.1-59.

Nelson, R.R. and H. Pack (1999), "The Asian Miracle and Modern Growth Theory", The Economic Journal, Vol. 109, No. 457, pp. 416-436.

Nomaler Ö. and Verspagen B. (2014), "Analyzing Global Value Chains Using Input-Output Economics: Proceed with Care", MERIT Working Papers, 070, United Nations University - Maastricht Economic and Social Research Institute on Innovation and Technology (MERIT).

OECD (2001), Measuring capital, measurement of capital stocks, consumption of fixed capital and capital services. Paris: Organization for Economic Co-operation and Development.

OECD-WTO (2015), Trade in Value Added: Mexico, OECD-WTO, Trade in Value Added, October 2015, https://www.oecd.org/sti/ind/tiva/CN_2015_Mexico.pdf

Ollivier-Fierro J.O. (2007), "Proveeduría Nacional a la Industria Maquiladora en México: Un reto Tecnológico", Frontera Norte, vol. 19, núm. 38, pp.191-218.

Ortiz, A. and A. Martínez (2000), "Factores de Competitividad, Situación Nacional y Cadena Productiva de la Industria del Calzado en León, Guanajuato", Economía, Sociedad y Territorio, Vol. II No. 7, pp. 53368.

Porter, M. (1990), The Competitive Advantage of Nations, Macmillan, London.

PWC (2013), PwC-IMMEX Maquiladora Guide: Doing Business in Mexico, 1-42. Mexico: PricewaterhouseCoopers S.C.

Rabellotti, R. (1999), "Recovery of a Mexican Cluster: Devaluation Bonanza or Collective Efficiency?", World Development, vol. 27, no. 9, pp. 1571-1585

Rama, R. (1984), "El Papel de las Empresas Transnacionales en la Agricultura Mexicana”, Comercio Exterior, vol. 34, No. 11, México, pp. 1083-1095.

Ramos, C. (1989), "PITEX: Una Opción en el Comercio Internacional Mexicano", Comercio Internacional Banamex, Vol. 1, No.2, pp.94-95. 
Rice, J. G. (1998), "PITEX and Maquiladora Import Programs: A Working Guide and Comparative Evaluation", Texas International Law Journal, 33 (2): 365-380.

Ruiz Durán C., Piore, M. and A. Schrank (2005), "Los Retos para el Desarrollo de la Industria del Software”, Comercio Exterior, Vol. 55, no. 9, pp. 743-755.

Salinas Chavez, A. (1990), "Los PITEX y la Exportación Manufacturera", Sección Nacional, Comercio Exterior, Enero de 1990, pp.16-22.

Salomón, A. (1995), "La Industria del Cemento: Las Pruebas del Tiempo", Comercio Exterior, Sección Nacional, Noviembre, México, pp. 832-836.

Sargent, J. and L. Mathews (2001), "Combining Export Processing Zones and Regional Free Trade Agreements: Lessons From the Mexican Experience", World Development, Volume 29, Issue 10, pp. 1739-1752.

Sargent, J. and L. Mathews (2008), “Capital Intensity, Technology Intensity, and Skill Development in Post China/WTO Maquiladoras", World Development, Vol. 36, Issue 4, pp. 541-559.

Sargent, J. and L. Mathews (2009), "China versus Mexico in the Global EPZ Industry: Maquiladoras, FDI Quality, and Plant Mortality”, World Development, Volume 37, Issue 6, pp. 1069-1082.

Schwartz, S.M. (1987), "The Border Industrialization Program of Mexico", Southwest Journal of Business and Economics, 4:4, pp.1-51.

Schwentesius Rindermann, R., and M.Á. Gómez-Cruz (2001), "El TLCAN y el sector Agroalimentario de México", Comercio Exterior, Vol. 51, no. 6, pp. 545-554.

SECOFI (1990), "Decreto para el Fomento y Operación de las Empresas Altamente Exportadoras (ALTEX)", Diario Oficial de la Federación, 3 de Mayo de 1990.

SECOFI (1993), "RESOLUCION definitiva sobre las importaciones de calzado y sus partes, mercancías comprendidas en las fracciones arancelarias de las partidas 64.01, 64.02, 64.03, 64.04, 64.05 y 64.06 de la Tarifa de la Ley del Impuesto General de Importación, originarias de la República Popular China, independientemente del país de procedencia", Secretaría de Comercio y Fomento Industrial, Diario Oficial de la Federación, Diciembre 30 de 1993.

Secretaria de Comercio y Fomento Industrial (SECOFI, 1994), Decreto que promueve la creación de empresas comercializadoras de insumos para la industria maquiladora de exportación, Diario Oficial de la Federación, México,3 de agosto de 1994.

Secretaria de Comercio y Fomento Industrial (SECOFI, 1998), Decreto para el Fomento y Operación de la Industria Maquiladora de Exportación, México, Diario Oficial de la Federación 1 de Junio de 1998

Secretaría de Economía (2002), "Decreto que Establece Diversos Aranceles para la Competitividad de la Industria Electrónica y la Economía de Alta Tecnología", Diario Oficial de la Federación, Septiembre 4, México.

Secretaría de Economía (2007), "ACUERDO por el que se da a conocer el Protocolo de Adhesión de la República Popular China a la Organización Mundial del Comercio", Diario Oficial de la Federación, Agosto 15 de 2007.

Secretaría de Economía (2010), Industria Manufacturera, Maquiladora y de Servicio de Exportación (IMMEX), Instrumentos de Comercio. http://www.2006-2012.economia.gob.mx/comunidadnegocios/industria-y-comercio/instrumentos-de-comercio-exterior/immex

Secretaría de Economía (2013), "Estudio de la Cadena Productiva del Yeso: Documento de Análisis", Coordinación General de Minería, Dirección General de Desarrollo Minero, Dirección de Fomento y Organización, México. 
Secretaría de Economía (2016), Cadenas Globales de Valor: Un Modelo de Integración de Empresas Mexicanas, ProMéxico, Primera Edición, Ciudad de México.

Secretaría de Economía (2016), Cadenas Globales de Valor: Un Modelo de Integración de Empresas Mexicanas, ProMéxico, Primera Edición, Ciudad de México.

Skliar, L. (1993), Assembling for Development: The Maquila Industry in Mexico and the United States, U.S.Mexico Contemporary Perspectives Series 5, Center for U.S.-Mexican Studies, University of California, San Diego.

Sturgeon, T.J., and G. Gereffi (2009), "Measuring success in the global economy: international trade, industrial upgrading, and business function outsourcing in global value chains", Transnational Corporations, 18(2).

Temurshoev, U. and M.P. Timmer (2011), "Joint Estimation of Supply and Use Tables", Papers in Regional Science, 90(4), pp. 863-882.

Temurshoev, U., Webb C., and N. Yamano (2011) "Projection of Supply and Use Tables: Methods and their Empirical Assessment”, Economic Systems Research, Vol. 23, no 1, pp. 91-123.

Timmer, M.P. (1999), "Indonesia's Ascent on the Technology Ladder: Capital Stock and Total Factor Productivity in Indonesian Manufacturing, 1975-95", Bulletin of Indonesian Economic Studies, 35 (1), pp.75-97

Timmer, M. P., Dietzenbacher E., Los B., Stehrer R. and G.J. de Vries (2015), "An Illustrated User Guide to the World Input-Output Database: the Case of Global Automotive Production", Review of International Economics, 23, p. 575-605

Timmer, M. P., E. Dietzenbacher, B. Los, R. Stehrer, G. J. de Vries (2014), "The World Input-Output Database: Contents, Concepts, and Applications." GGDC research memorandum no. 144, University of Groningen, The Netherlands.

Tucker, A. and E. Dietzenbacher (2013), "Global Multiregional Input-Output Frameworks: An Introduction and Outlook", Economic Systems Research, 25(1), pp.1-19.

UNIDO (2015), Industrial Development Report 2016: The Role of Technology and Innovation in Inclusive and Sustainable Industrial Development, United Nations Industrial Development Organization, Vienna, Austria.

Urias, H. (1978), "La Industria Maquiladora: Evolución Reciente y Perspectivas", Comercio Exterior Vol. 28. No. 4.

USITC (1993), "Potential Impact on the U.S. Economy and Selected Industries of the North American FreeTrade Agreement”, United States International Trade Commission, SITC Publication 2596.

USITC (1998) "Production Sharing: Use of U.S. Components and Materials in Foreign Assembly Operations, 1994-1997," USITC, Publication 3146, December, Washington, DC.

Utar H. and L.B. Torres-Ruiz (2013), "International Competition and Industrial Evolution: Evidence from the Impact of Chinese Competition on Mexican Maquiladoras", Journal of Development Economics, no. 105 , pp. 267-287.

Van Biesebroeck, J. (2003), "Revisiting Some Productivity Debates", NBER Working Paper series, No. 10065.

Van Biesebroeck, J. and T. J. Sturgeon (2010), "Effects of the 2008-09 Crisis on the Automotive Industry in Developing Countries: A Global Value Chain Perspective" in O. Cattaneo, G. Gereffi and C. Staritz (eds.) Global Value Chains in a Postcrisis World, The World Bank, Washington 
Verdoorn, P.J., (1949). Fattori che Regolano lo Sviluppo della Produttivita del Lavoro, L'Industria. In: Ironmonger, D., Perkins, J., Hoa, T. (Eds.), National Income and Economic Progress: Essays in Honour of Colin Clark. Macmillan, London, UK Translated by A.P. Thirlwall

Verhoogen, E. A. (2008), "Trade, Quality Upgrading and Wage Inequality in the Mexican Manufacturing Sector," Quarterly Journal of Economics, 123(2).

Verhoogen, E. A. (2012), "Industrial Structure and Innovation: Notes Toward a New Strategy for Industrial Development in Mexico," Forthcoming, Boletin Informativo Techint.

Vicencio Miranda, A. (2007),"La Industria Automotriz en México. Antecedentes, Situación Actual y Perspectivas", Contaduría y Administración, no. 221. pp.211-248.

Watkins R. (2007), “El Reto de China a las Manufacturas de México” en Dussel E., Oportunidades en la relación económica y comercial entre China y México, Naciones Unidas.

Williamson, O. (1975), Markets and Hierarchies: Analysis and Antitrust Implications. New York: Free Press.

Wilson, P.A. (1992), Export and Local Development: Mexico's New Maquiladoras, $1^{\text {st }}$ Edition, University of Texas Press, Austin.

Woodruff, C. (1998), “Contract Enforcement and Trade Liberalization in Mexico's Footwear Industry”, World Development, vol. 26 No. 6, pp. 979-91.

Yang, C., E. Dietzenbacher, J. Pei, X. Chen, K. Zhu and Z. Tang (2015), "Processing Trade Biases The Measurement of Vertical Specialization in China”, Economic Systems Research, Vol. 27, No.1, 60-76. 


\section{UNU-MERIT/MGSoG Dissertation Series}

2018

\section{Juan Carlos A. Castillo Sánchez}

Assessing the Role of the Export Sector in Mexican

Economic Development,1965-2014

UNU-MERIT/MGSoG Dissertation

Series № 209

\section{Tareq Abuelhaj}

Food Security Policy Impact Analysis: The

Econometrics of Cash and Food Assistance Cost

Effectiveness

UNU-MERIT/MGSoG Dissertation

Series № 208

Marta Férnandez de Arroyabe Arranz

Essays on MEAS and Innovation

UNU-MERIT/MGSoG Dissertation

Series № 207

\section{Clotilde Mahé}

Essays on Migration and Occupational Choice

UNU-MERIT/MGSoG Dissertation

Series № 206

\section{Simone Sasso}

Talent on the move. Essays on Human Capital, Graduate Mobility and Economic Development UNU-MERIT/MGSoG Dissertation Series № 205

\section{Khaled Walid Rajab}

Strategic Planning under Fragility

UNU-MERIT/MGSoG Dissertation

Series № 204

\section{Mutinta Hambayi Nseluke}

A Tall Order: Improving Child Linear Growth UNU-MERIT/MGSoG Dissertation

Series № 203

\section{Elvis Korku Avenyo}

Innovations and Firm Performance

in sub-Saharan Africa: Empirical Analyses

UNU-MERIT/MGSoG Dissertation

Series № 202

\section{Ni Zhen}

Employment Dynamics, Firm Performance and Innovation Persistence in the Context of Differentiated Innovation Types: Evidence from Luxembourg UNU-MERIT/MGSoG Dissertation Series № 201

\section{Caroline Wehner}

Too Scared to Achieve: The Relation

Between Neuroticism, Conscientiousness

and Socioeconomic Outcomes

UNU-MERIT/MGSoG Dissertation

Series № 200

\section{Stefania Innocenti}

On Institutional Persistence

UNU-MERIT/MGSoG Dissertation Series № 199

\section{Hassen Abda Wako}

Economic Globalization, Institutions and Development: Essays on Aid, Foreign Direct Investment and Trade

UNU-MERIT/MGSoG Dissertation

Series № 198

2017

\section{Hans-Erik Edsand}

Winds of Change

UNU-MERIT/MGSoG Dissertation Series № 197

Ana Patricia Silva Vara

Redressing the Gender Gap

UNU-MERIT/MGSoG Dissertation Series № 196

\section{Andrés Iván Mideros Mora}

Essays on the Economic Effects of Noncontributory Social Protection

UNU-MERIT/MGSoG Dissertation Series № 195

Tobias Broich

New Actors in the Global Economy

UNU-MERIT/MGSoG Dissertation Series № 194 


\section{Bernard Nikaj}

From No-government to E-government

UNU-MERIT/MGSoG Dissertation Series № 193

\section{Ali Safarnejad}

Prioritizing the HIV Response

UNU-MERIT/MGSoG Dissertation Series № 192

\section{Clovis Freire}

Diversification and Structural Economic Dynamics UNU-MERIT/MGSoG Dissertation Series № 191

\section{Michael Verba}

Innovation and Knowledge Dynamics: Essays on the Knowledge Economy UNU-MERIT/MGSoG Dissertation Series № 190

\section{Pui Hang Wong}

The Hearts and Minds in Conflict and Peace: The Economics of Counterinsurgency and the Psychology of Reconstruction UNU-MERIT/MGSoG Dissertation Series № 189

\section{Brenda Yamba}

Schooling Despite All Odds: Evidence from Lesotho on Female Child Carers who Stayed in School UNU-MERIT/MGSoG Dissertation Series № 188

\section{Sheng Zhong}

Moving towards An Energy Efficient Future: Essays on Energy Efficiency, Technology and Development

UNU-MERIT/MGSoG Dissertation Series № 187

\section{Julieta Marotta}

Access to Justice and Legal Empowerment of Victims of Domestic Violence through Legal Organizations in the City of Buenos Aires: A Qualitative Empirical Legal Study UNU-MERIT/MGSoG Dissertation Series, № 186

\section{Andrea Franco-Correa}

On the Measurement of Multidimensional Poverty as a Policy Tool: Empirical Applications to Chile, Colombia, Ecuador and Peru

UNU-MERIT/MGSoG Dissertation Series, № 185

\section{6}

\section{Yesuf Awel}

Insurance for Growth: Empirical Essays on Insurance Demand and Impacts in Africa

UNU-MERIT Dissertation Series, № 108

\section{Tigist Mekonnen Melesse}

Grow More Food using Fewer Resources:

Agricultural Technology Adoption and Innovation Practices for Inclusive and Sustainable

Development

UNU-MERIT Dissertation Series, № 107

\section{Eleni Yitbarek}

Getting Ahead or left Behind? Essays on Poverty Dynamics and Social Mobility in Africa

UNU-MERIT Dissertation Series, № 106

\section{Thuy Dieu Nguyen}

Firm-Level Theory and Evidence of Corruption

UNU-MERIT Dissertation Series, № 105

\section{Raquel Tsukada Lehman}

Essays on Household Production with Labor-

Saving Technology

UNU-MERIT Dissertation Series, № 104

\section{Eva Barteková}

Multi-Problem Challenges for a Renewable Future: Empirical Studies on Competitive Disadvantages from Electricity Price Differentials and Mineral Supply Risk in an Open Economy UNU-MERIT Dissertation Series, № 103

\section{Jocelyn Olivari}

Entrepreneurial Traits and Innovation: Evidence from Chile

UNU-MERIT Dissertation Series, № 102

\section{Muhammad Shafique}

Essays on the role of knowledge, RED, and

Technology-based Firms in the Evolution of Sociotechno-economic System

UNU-MERIT Dissertation Series, № 101 


\section{Serdar Türkeli}

Governance of Innovation Policy: Empirical

Studies on Applied Political Economy by Multi-

Methods Analysis

UNU-MERIT Dissertation Series, № 100

\section{Ayokunu Adedokun}

Pathways to Sustainable Peace building in Divided Societies: Lessons and Experiences from

Mozambique

MGSoG Dissertation Series, № 75

\section{Luiz Rothier Bautzer}

Organizing Concurrent Engineering through ICT Platforms

Blueprinting Product Lifecycle Management

Platforms across Disciplinary Agencies

MGSoG Dissertation Series, № 74

\section{Natalia Popova}

Migration in the Periphery of the European Union: Determinants of Successful and Sustainable Labour Market Integration of Return Migrants in Albania, Egypt, Moldova and Tunisia

MGSoG Dissertations Series, № 73

\section{Richard A. Martina}

Uncertainty and Resource Constraint in the Small Island Developing States:

Essays in Entrepreneurial Cognition

MGSoG Dissertations Series, № 72

\section{Cécile Cherrier}

The Expansion of Basic Social Protection in Lowincome Countries:

An Analysis of Foreign Aid Actors' Role in the Emergence of Social Transfers in Sub-Saharan Africa

MGSoG Dissertations series, № 71

\section{Paul Caldron}

The Tacit Bargain in Short-Term Medical Missions: Why U.S. physicians go and what it costs

MGSoG Dissertation Series, № 70

\section{Mahmut Kobal}

Customs \& Excellence: A Comparative Approach on Administrative and Regulatory Compliance Perspectives of the EU-Turkey Customs Union MGSoG Dissertation Series, № 69

\section{Craig Loschmann}

Essays on Conflict-related Migration and Development in the Case of Afghanistan

MGSoG Dissertations Series, № 68

\section{Andrea Milan}

Rural Livelihoods, Location and Vulnerable Environments: Approaches to Migration in Mountain areas of Latin America

MGSoG Dissertation Series, № 67

\section{Farida Lada}

On Guarding the Welfare of Clinical Trial Subjects While Promoting Novel Drug Innovation

A Game Theoretical Approach

MGSoG Dissertation Series, № 66

\section{5}

Hibret Belete Maemir

Dissecting Aggregate Productivity: International Integration and Growth with Heterogeneous Firms UNU-MERIT Dissertation Series, № 96

\section{Giorgio Triulzi}

Looking for the Right Path: Technology Dynamics, Inventive Strategies and Catching-up in the Semiconductor Industry

UNU-MERIT Dissertation Series, № 95

Abdul Baseer Qazi

Knowledge flows and networks in the ICT sector: The case of Pakistan

UNU-MERIT Dissertation Series, № 94

Ajay Thutupalli

Technology Paradigm Shifts in Agriculture:

Drivers of Sustainability and Catch up

UNU-MERIT Dissertation Series, № 93

\section{Eduardo Urias}

Improving access to HIVIAIDS treatment in Brazil: When are Compulsory Licenses effective in Price Negotiations?

UNU-MERIT Dissertation Series, № 92

\section{Francesca Guadagno}

Why have so few Countries Industrialised?

UNU-MERIT Dissertation Series, № 91 


\section{Daniel Opolot}

The Evolution of Beliefs and Strategic Behaviour

UNU-MERIT Dissertation Series, № 90

\section{Alejandro Lavopa}

Structural Transformation and Economic

Development: Can Development Traps be Avoided

UNU-MERIT Dissertation Series, № 89

\section{Jinjin Zhao}

Urban water management reform: The Case of

China

UNU-MERIT Dissertation Series, № 88

\section{Simona Vezzoli}

Borders, Independence and Post-colonial Ties: the Role of the State in Caribbean Migration

MGSoG Dissertation Series, № 65

\section{Silvia Consuelo Gómez Soler}

Civil Conflict and Education: How Does Exposure to Civil Conflict Affect Human Capital

Accumulation? Evidence from Standardized Exit

Exams in Colombia

MGSoG Dissertation Series, № 64

\section{Paula Nagler}

Occupational Choice in the Developing World

MGSoG Dissertation Series, № 63

\section{Jasmin Kientzel}

Determinants of Professional Commitment to

Environmental Sustainability

MGSoG Dissertation Series, № 62

\section{Mehmet Güney Celbiş}

Regional Policies: Convergence, Trade, and the Allocation of Public Capital

MGSoG Dissertation Series, № 61

\section{Florian Henning}

Living Up to Standard: Interoperability

Governance and Standards Adoption in

Government Information Networks

MGSoG Dissertation Series, № 60

\section{Niels P. Groen}

The Never-Ending Project

Understanding E-Government Project Escalation

MGSoG Dissertation Series, № 59

\section{Derek Copp}

Teacher-Based Reactivity to Provincial Large-scale Assessment in Canada

MGSoG Dissertation Series, № 58

\section{Michaella Vanore}

Family-Member Migration and the Psychosocial Health Outcomes of Children in Moldova and Georgia

MGSoG Dissertation Series, № 57

\section{Sonja Fransen}

The Economic and Social Effects of Remittances and Return Migration in Conflict-Affected Areas: The Case of Burundi

MGSoG Dissertation Series, № 56

\section{Ibrahim Khalil Conteh}

The Impact of Floods on Primary School Education in Zambia

MGSoG Dissertation Series, № 55

\section{Richard Bluhm}

Growth Dynamics and Development

Essays in Applied Econometrics and Political

Economy

MGSoG Dissertation Series, № 54

\section{Nevena P. Zhelyazkova}

Work-Family Reconciliation and Use of Parental Leave in Luxembourg: Empirical Analysis of

Administrative Records

MGSoG Dissertation Series, № 53

2014

\section{Dirk Crass}

The Impact of Brands on Innovation and Firm Performance: Empirical Evidence from Germany UNU-MERIT Dissertation Series, № 87

\section{Samyukta Bhupatiraju}

The Geographic Dimensions of Growth and

Development

UNU-MERIT Dissertation Series, № 86

\section{François Lafond}

TheEvolution of Knowledge Systems

UNU-MERIT Dissertation Series, № 85 


\section{Annalisa Primi}

Promoting Innovation in Latin America: What Countries Have Learned (and What They Have Not) in Designing and Implementing Innovation and Intellectual Property Policies

UNU-MERIT Dissertation Series, № 84

\section{Fatoumata Lamarana Diallo}

Evaluation of Meal and Deworming Programs for Primary Schools in Rural Senegal

UNU-MERIT Dissertation Series, № 83

\section{Sachin Kumar Badkas}

Metachoice and Metadata: Innovating with Environmental Policy Analysis in Europe

MGSoG Dissertation Series, № 52

\section{Irina S. Burlacu}

An Evaluation of Tax-Benefit Systems Impact on the Welfare of Frontier Worker:

The Case of Luxembourg and Belgium

MGSoG Dissertation Series, № 51

\section{Özge Bilgili}

Simultaneity in Transnational Migration Research: Links Between Migrants' Host and Home Country Orientation

MGSoG Dissertation Series, № 50

\section{Yulia Privalova Krieger}

Reshaping the Big Agenda: Transnational Politics and Domestic ResistanceFinancial crisis and social protection reform in Bosnia and Herzegovina

MGSoG Dissertation Series, № 49

\section{Marieke van Houte}

Moving Back or Moving Forward? Return

migration after Conflict

MGSoG Dissertation Series, № 48

\section{Oxana Slobozhan}

Global Governance in the Management of Natural Resources: The Case of the Extractive Industries Transparency Initiative (EITI)

MGSoG Dissertation Series, № 47

\section{Luis Bernardo Mejia Guinand}

The Changing Role of the Central Planning Offices in Latin America: A Comparative Historical Analysis Perspective (1950-2013)

MGSoG Dissertation Series, № 46

\section{Cheng Boon Ong}

Ethnic Segregation in Housing, Schools and Neighbourhoods in the Netherlands

MGSoG Dissertation Series, № 45

\section{Luciana V. Cingolani}

Bureaucracies for Development: Oxymoron or

Reality? Studies on State Capacity in Challenging

Governance Contexts

MGSoG Dissertation Series, № 44

\section{Carlos Cadena Gaitán}

Green Politics in Latin American Cities -

Sustainable Transport Agendas

MGSoG Dissertation Series, № 43

\section{Katie Kuschminder}

Female Return Migration and Reintegration

Strategies in Ethiopia

MGSoG Dissertation Series, № 42

\section{Metka Hercog}

Highly-Skilled Migration and New Destination

Countries

MGSoG Dissertation Series, № 41

\section{Margaret Agaba Rugadya}

Can Remittances Influence the Tenure and Quality of Housing in Uganda?

MGSoG Dissertation Series, № 40

\section{Ilire Agimi}

New Governance Under Limited Statehood: The Case of Local Government Reform in Kosovo MGSoG Dissertation Series, № 39

2013

\section{Anant Kamath}

Information Sharing through Informal Interaction in Low-Tech Clusters

UNU-MERIT Dissertation Series, № 82

\section{Flavia Pereira de Carvalho}

What we talk about when we talk about Brazilian Multinationals: An Investigation on Brazilian FDI, Economic Structure, Innovation and the Relationship between them UNU-MERIT Dissertation Series, № 81 


\section{Jun Hou}

Complementarity in Innovation and Development:

A Cross-country Comparison

UNU-MERIT Dissertation Series, № 80

\section{Rufin Baghana}

Impacts of Government Incentives to RED, Innovation and Productivity:

A Microeconometric Analysis of the Québec Case UNU-MERIT Dissertation Series, № 79

\section{Lilia I. Stubrin}

High-Tech Activities in Emerging Countries: A Network perspective on the Argentinean Biotech Activity

UNU-MERIT/MGSoG Dissertation Series, № 78

\section{Kristine Farla}

Empirical Studies on Institutions, Policies and Economic Development

MGSoG Dissertation Series, № 38

\section{Marina Petrovic}

Social Assistance and Activation in the Pursuit of Happiness: Shedding New Light on Old Policy

Solutions to Social Exclusion

MGSoG Dissertation Series, № 37

\section{Laura Torvinen}

Assessing Governance Assessments: The Case of Mozambique: Governance Assessments in the Context of Aid Effectiveness Discourse

MGSoG Dissertation Series, № 36

\section{Biniam Egu Bedasso}

Institutional Change in the Long Shadow of Elite: Essays on Institutions, Human Capital and Ethnicity in Developing Countries

MGSoG Dissertation Series, № 35

\section{Sepideh Yousefzadeh Faal Deghati}

Childhoods Embargoed: Constructing and

Reconstructing Multidimensional Child Poverty in Iran 1984-2009

MGSoG Dissertation Series, № 34

\section{Robert Bauchmüller}

Investing in Early Childhood Care and Education: The Impact of Quality on Inequality MGSoG Dissertation Series, № 33

\section{Martin Rehm}

Unified Yet Separated: Empirical Study on the Impact of Hierarchical Positions within

Communities of Learning

MGSoG Dissertation Series, № 32

2012

\begin{abstract}
Abdul Waheed
Innovation Determinants and Innovation as a Determinant: Evidence from Developing Countries

UNU-MERIT Dissertation Series, № 77
\end{abstract}

\section{Bilal Mirza}

Energy Poverty and Rural Energy Markets in

Pakistan

UNU-MERIT Dissertation Series, № 76

\author{
Benjamin Engelstätter \\ Enterprise Software and Video Games: An \\ Empirical Analysis \\ UNU-MERIT Dissertation Series, № 75
}

\section{Fulvia Farinelli}

Natural Resources, Innovation and Export Growth: The Wine Industry in Chili and Argentina UNU-MERIT Dissertation Series

Rodolfo Lauterbach

Innovation in Manufacturing: From Product

Variety and Labor Productivity Growth to

Economic Development in Chile

UNU-MERIT Dissertation Series

\section{Kirsten Wiebe}

Quantitative Assessment of Sustainable Development and Growth in Sub-Saharan Africa

UNU-MERIT Dissertation Series, № 74

\section{Julio Miguel Rosa}

Organizational Strategies, Firms' Performance and Spatial Spillovers: The Canadian Case in Research and Development.

UNU-MERIT Dissertation Series, № 73

Johannes Wilhelmus Marie Boels

Joseph Schumpeter, Honderd Jaar Economische Ontwikkeling: Een Historisch-theoretische Beschouwing.

UNU-MERIT Dissertation Series 


\section{Dorcas Mbuvi}

Utility Reforms and Performance of the Urban

Water Sector in Africa

MGSoG Dissertation Series, № 31

\section{Lina Salanauskaite}

Distributional Impacts of Public Policies: Essays in Ex-Ante and Ex-Post Evaluation

MGSoG Dissertation Series, № 30

\section{Esther Schüring}

To Condition or not - is that the Question?

An Analysis of the Effectiveness of Ex-Ante and Ex-Post Conditionality in Social Cash Transfer Programs

MGSoG Dissertation Series, № 29

\section{Joe Abah}

Strong Organisations in Weak States: Atypical

Public Sector Performance in Dysfunctional

Environments

MGSoG Dissertation Series, № 28

\section{Zina Samih Nimeh}

Social Citizenship Rights: Inequality and Exclusion MGSoG Dissertation Series, № 27

\section{1}

\section{Daniel Vertesy}

Interrupted Innovation: Emerging Economies in the Structure of the Global Aerospace Industry

UNU-MERIT Dissertation Series, № 72

\section{Tina Saebi}

Successfully Managing Alliance Portfolios:

AnAlliance Capability View

UNU-MERIT Dissertation Series, № 71

\section{Nora Engel}

Tuberculosis in India: A Case of Innovation and Control

UNU-MERIT/MGSoG Dissertation Series, № 70

\section{Evans Mupela}

Connectivity and growth in Sub-Saharan Africa: The Role of Communication Satellites

UNU-MERIT Dissertation Series, № 69

\section{Nantawan Kwanjai}

Cross Cultural Intelligence amid Intricate Cultural Webs: A Tale of the UnDutchables in the Land of 1002 Smiles

UNU-MERIT Dissertation Series, № 68

\section{Lina Sonne}

Innovation in Finance to Finance Innovation: Supporting Pro-poor Entrepreneur-based Innovation

UNU-MERIT Dissertation Series, № 67

\section{Lenka Eisenhamerová}

Legitimacy of 'Humanitarian Military

Intervention'

MGSoG Dissertation Series, № 26

\section{Sonila Tomini}

Informal Payments for Health Care Services in Albania

MGSoG Dissertation Series, № 25

\section{Jinjing Li}

Dynamic Microsimulation in Public Policy

Evaluation

MGSoG Dissertation Series, № 24

\section{Aziz Atamanov}

Rural Nonfarm Employment and International Migration as Alternatives to Agricultural Employment: The Case of Kyrgyzstan

MGSoG Dissertation Series, № 23

\section{Frieda Vandeninden}

Poverty Alleviation: Aid and Social Pensions

MGSoG Dissertation Series, № 22

\section{Juliana Nyasha Tirivayi}

The Welfare Effects of Integrating AIDS Treatment with Food Transfers: Evidence from Zambia

MGSoG Dissertation Series, № 21

\section{Agnieska Ewa Sowa}

Who's Left Behind? Social Dimensions of Health Transition and Utilization of Medical Care in Poland

MGSoG Dissertation Series, № 20 


\section{Emmanaouil Sfakianakis}

The Role of Private Actors in the Provision of Public Goods with Applications to Infrastructure and Financial Stability

MGSoG Dissertation Series, № 19

\section{Siu Hing Lo}

White Collars Green Sleeves: An Interorganizational Comparison of Determinants of Energy-Related Behaviors among Office Workers MGSoG Dissertation Series, № 18

\section{Treena $\mathbf{W u}$}

Constraints to Human Capital Investment in Developing Countries:

Using the Asian Financial Crisis in Indonesia as a Natural Experiment

MGSoG Dissertation Series, № 17

\section{Henry Espinoza Peña}

Impact Evaluation of a Job-Training Programme for Disadvantaged Youths:

The Case of Projoven

MGSoG Dissertation Series, № 16

\section{Fernando Santiago}

Human Resources Management Practices and Learning for Innovation in Developing Countries: Pharmaceutical Firms in Mexico

UNU-MERIT Dissertation Series, № 66

\section{Zakaria Babutsidze}

Essays on Economies with Heterogeneous Interacting Consumers

UNU-MERIT Dissertation Series, № 65

\section{Bertha Vallejo}

Learning and Innovation Under Changing Market Conditions: The Auto Parts Industry in Mexico

UNU-MERIT Dissertation Series, № 64

\section{Donatus Ayitey}

Technical Change, Competitiveness and Poverty

Reduction: A Study of the Ghanaian Apparel

Industry

UNU-MERIT Dissertation Series, № 63

\section{Sergey Filippov}

Multinational Subsidiary Evolution: Corporate Change in New EU Member States

UNU-MERIT Dissertation Series, № 62

\section{Asel Doranova}

Technology Transfer and Learning under the Kyoto Regime: Exploring the Technological Impact of CDM Projects in Developing Countries UNU-MERIT Dissertation Series, № 61

\section{Florian Tomini}

Between Family and Friend: Understanding the Interdependency of Private Transfers MGSoG Dissertation Series, № 15

\section{Michał Polalowski}

The Institutional Transformation of Social Policy in East Central Europe: Poland and Hungary in Comparative and Historical Perspective MGSoG Dissertation Series, № 14

Maha Ahmed

Defining, Measuring and Addressing Vulnerability: The Case of Post Conflict

Environments

MGSoG Dissertation Series, № 13

\section{Pascal Beckers}

Local Space and Economic Success: The Role of Spatial Segregation of Migrants in the Netherlands MGSoG Dissertation Series, № 12

\section{Victor Cebotari}

Conflicting Demands in Ethnically Diverse Societies: Ethno political Contention and Identity Values in Europe MGSoG Dissertation Series, № 11

\section{Dennis Gyllensporre}

Competing and Complementary Perspectives on the EU as a Crisis Management Actor:

An Examination of the Common Security and Defence Policy through the Lenses of Idealism and Realism

MGSoG Dissertation Series, № 10 


\section{Judit Vall Castello}

Business Cycle and Policy Effects on Labour

Market Transitions of Older and Disabled Workers in Spain

MGSoG Dissertation Series, № 9

\section{Keetie Roelen}

False Positives or Hidden Dimensions: The Definition and Measurement of Child Poverty

MGSoG Dissertation Series, № 8

\section{Denisa Maria Sologon}

Earning Dynamics in Europe

MGSoG Dissertation Series, № 7

\section{Melissa Siegel}

Money and Mobility: Migration and Remittances

MGSoG Dissertation Series, № 6

\section{Jessica S. Hagen-Zanker}

Modest Expectations: Causes and Effects of

Migration on Migrant Households inSource

Countries

MGSoG Dissertation Series, № 5

\section{9}

\author{
Alexis Habiyaremye \\ From Primary Commodity Dependence to \\ Diversification and Growth: Absorptive Capacity \\ and Technological Catch Up in Botswana and \\ Mauritius.
}

UNU-MERIT Dissertation Series, № 60

\section{Yoseph Getachew}

The Role of Public Capital in Economic

Development

UNU-MERIT Dissertation Series, № 59

\section{Sandra Leitner}

Embodied Technological Change and Patterns of Investment in Austrian Manufacturing

UNU-MERIT Dissertation Series, № 58

\section{Semih Akçomak}

The Impact of Social Capital on Economic and

Social Outcomes

UNU-MERIT Dissertation Series, № 57

\section{Abraham Garcia}

The Role of Demand in Technical Change UNU-MERIT Dissertation Series, № 56

\section{Saurabh Arora}

Coherence in Socio-technical Systems: A Network Perspective on the Innovation Process

UNU-MERIT Dissertation Series, № 55

\section{Mirtha R. Muniz Castillo}

Human Development and Autonomy in Project Aid: Experiences from four bilateral projects in Nicaragua and El Salvador

MGSoG Dissertation Series, № 4

\section{Christiane Arndt}

Governance Indicators

MGSoG Dissertation Series, № 3

\section{Britta Augsburg}

Microfinance: Greater Good or Lesser Evil?

MGSoG Dissertation Series, № 2

\section{8}

\section{Rutger Daems}

Medicines for the Developing World

UNU-MERIT Dissertation Series, № 54

\section{Johannes Hanel}

Assessing Induced Technology: Sombart's

Understanding of Technical Change in the History

of Economics

UNU-MERIT Dissertation Series, № 53

\section{Rifka Weehuizen}

Mental Capital: the Economic Significance of

Mental Health

UNU-MERIT Dissertation Series, № 52

\section{Danielle Cloodt}

The Relationship between RED Partnership

Formation, Social Embeddedness and Innovative

Performance

UNU-MERIT Dissertation Series, № 51

\section{Sabine Fuss}

Sustainable Energy Development under

Uncertainty

UNU-MERIT Dissertation Series, № 50

\section{Geranda Notten}

Measuring and Managing Poverty Risks

MGSoG Dissertation Series, № 1 


\section{Tobias Kronenberg}

Reconciling Environmental Conservation with

Economic Prosperity: The Feasibility of Double

Dividends in the Short and Long Run

UNU-MERIT Dissertation Series, № 49

\section{Viktoria Kravtsova}

Assessing the Impact of Foreign Direct Investment in Transition Economies

UNU-MERIT Dissertation Series, № 48

\section{Suhail Sultan}

The Competitive Advantage of Small and Medium Sized Enterprises: The Case of Jordan's Natural Stone Industry

UNU-MERIT Dissertation Series, № 47

2006

\section{Bulat Sanditov}

Essays on Social Learning and Imitation

UNU-MERIT Dissertation Series, № 46

\section{Mamata Parhi}

Dynamics of New Technology Diffusion: A Study of the Indian Automotive Industry

UNU-MERIT Dissertation Series, № 45

\section{Andreas Reinstaller}

Social Structures and the Innovation Process: Their Role in the Demand of Firms and Consumers UNU-MERIT Dissertation Series, № 44

\section{Rose Kiggundu}

Innovation systems and Development: The Journey of a Beleaguered Nile Perch Fishery in Uganda UNU-MERIT Dissertation Series, № 43

\section{Thomas Pogue}

The Evolution of Research Collaboration in South African Gold Mining: 1886-1933

UNU-MERIT Dissertation Series, № 42

\section{Geoffrey Gachino}

Foreign Direct Investment, Spillovers and Innovation: The Case of Kenyan Manufacturing Industry

UNU-MERIT Dissertation Series, № 41
Technological Change, International Trade and Growth: An Evolutionary, Multi-Agents-Based Modeling Approach

UNU-MERIT Dissertation Series, № 40

2005

\section{Samia Satti Osman Mohamed-Nour}

Change and Skill Development in the Arab Gulf Countries

UNU-MERIT Dissertation Series, № 39

\section{Elad Harison}

Intellectual Property Rights: Economics and Policy Analysis

UNU-MERIT Dissertation Series, № 38

\section{Daniel Dalohoun}

The Relationship between RED Partnership Formation, Social Embeddedness and Innovative Performance: a Multi-level Approach of Social Embeddedness

UNU-MERIT Dissertation Series, № 37

\section{Müge Ozman}

Networks, Organizations and Knowledge UNU-MERIT Dissertation Series, № 36

\section{Bas Straathof}

Product Variety and Economic Growth: The

Counteracting Effects of Scale and Idiosyncrasy

UNU-MERIT Dissertation Series, № 35

\section{Wilfred Schoenmakers}

Knowledge Flows between Multinational Companies: A Patent Data Analysis

UNU-MERIT Dissertation Series, № 34

\section{Myriam Cloodt}

Mergers and Acquisitions ( $M$ and As) in HighTech Industries: Measuring the Post- $M$ and $A$ Innovative Performance of Companies UNU-MERIT Dissertation Series, № 33

\section{4}

\section{Paola Criscuolo}

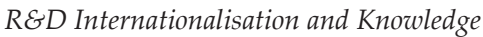
Transfer: Impact on MNEs and their Home Countries

UNU-MERIT Dissertation Series, № 32 
Maarten Verkerk

Trust and Power on the Shop Floor

UNU-MERIT Dissertation Series, № 31

\section{Gottfried Leibbrandt}

Adoption, Harmonization and Succession of

Network Technologies across Countries

UNU-MERIT Dissertation Series, № 30

\section{Mark Sanders}

Skill Biased Technical change: Its Origins, the Interaction with the Labour Market and Policy Implications

UNU-MERIT Dissertation Series, № 29

2003

\section{Nadine Roijakkers}

Inter-firm Cooperation in High-tech Industries: a Study of RED Partnerships in Pharmaceutical Biotechnology

UNU-MERIT Dissertation Series, № 28

Viki Sonntag

Speed, Scale and Sustainability

UNU-MERIT Dissertation Series, № 27

\section{Masaru Yarime}

From End-of-Pipe Technology to Clean Technology UNU-MERIT Dissertation Series, № 26

\section{Stéphane Malo}

The Combinatorial Chemistry Revolution: Sustaining a Superior Performance Position through Technological Learning

UNU-MERIT Dissertation Series, № 25

2002

\section{Annelies Hogenbirk}

Determinants of Inward Foreign Direct Investment: the Case of the Netherlands

UNU-MERIT Dissertation Series, № 24

\section{Bastiaan Johan terWeel}

The Computerization of the Labour Market UNU-MERIT Dissertation Series
2001

John Adeoti

Technology Investment in Pollution Control in

Sub-Saharan Africa: The Case of the Nigerian

Manufacturing Industry

UNU-MERIT Dissertation Series, № 23

\section{Edward Huizenga}

Innovation Management: How Frontrunners Stay Ahead: An Empirical Study on Key Success Factors in the ICT sector

UNU-MERIT Dissertation Series, № 22

2000

\section{Machiel van Dijk}

Technological Change and the Dynamics of Industries: Theoretical Issues and Empirical evidence from Dutch Manufacturing

UNU-MERIT Dissertation Series, № 21

1999

\section{Jan Cobbenhagen}

Managing Innovation at the Company Level: A Study on Non-Sector-Specific Success Factors UNU-MERIT Dissertation Series, № 20

\section{Marjolein Caniëls}

Regional Growth Differentials: The Impact of Locally Bounded Knowledge Spillovers

UNU-MERIT Dissertation Series, № 19

1998

\section{Aldo Geuna}

Resource Allocation and Knowledge production: Studies in the Economics of University Research UNU-MERIT Dissertation Series, № 18

1996

\section{Reinoud Joosten}

Dynamics, Equilibria, and Values

UNU-MERIT Dissertation Series, № 17

\section{Hugo Kruiniger}

Investment, RED, and the Financing Decisions of the Firm

UNU-MERIT Dissertation Series, № 16 


\section{Hans van Meijl}

Endogenous Technological Change: The Case of

Information Technology, Theoretical

Considerations and Empirical Results

UNU-MERIT Dissertation Series, № 15

\section{René Kemp}

Environmental Policy and Technical Change: A

Comparison of the Technological Impact of Policy Instruments

UNU-MERIT Dissertation Series, № 14

\section{Rohini Acharya}

The Impact of New Technologies on Economic Growth and Trade: A Case Study of Biotechnology UNU-MERIT Dissertation Series, № 13

\section{Geert Duysters}

The Evolution of Complex Industrial Systems: The Dynamics of Major IT Sectors

UNU-MERIT Dissertation Series, № 12

\section{Marjan Groen}

Technology, Work and Organisation: A Study of the Nursing Process in Intensive Care Units

UNU-MERIT Dissertation Series, № 11

\section{4}

\section{Huub Meijers}

On the Diffusion of Technologies in a Vintage

Framework: Theoretical Considerations and

Empirical Results

UNU-MERIT Dissertation Series, № 10

\section{Theon van Dijk}

The Limits of Patent Protection: Essays on the Economics of Intellectual Property Rights

UNU-MERIT Dissertation Series, № 9

\section{Hans Voordijk}

Naar Integrale Logistiek in Bedrijfsketens:

Ontwikkelingen in de Bouw

UNU-MERIT Dissertation Series, № 8

\section{Paul Diederen}

Technological Progress in Enterprises and

Diffusion of Innovation: Theoretical Reflections and Empirical Evidence

UNU-MERIT Dissertation Series, № 7

\section{Ben Dankbaar}

Economic Crisis and Institutional Change: The Crisis of Fordism from the Perspective of the Automobile Industry

UNU-MERIT Dissertation Series, № 6

\section{Hanno Roberts}

Accountability and Responsibility: The Influence of Organisation Design on Management Accounting UNU-MERIT Dissertation Series, № 5

1992

\section{Bart Verspagen}

Uneven Growth between Interdependent Economies: An Evolutionary View on Technology Gaps, Trade and Growth

UNU-MERIT Dissertation Series, № 4

\section{Sjoerd Romme}

A Self-organization Perspective on Strategy

Formation

UNU-MERIT Dissertation Series, № 3

1989

\section{John Spangenberg}

Economies of Scale, and Atmosphere in Research Organisations

UNU-MERIT Dissertation Series, № 2

\section{8}

\section{John Hagedoorn}

Evolutionary and Heterodox Innovation Analysis: A Study of Industrial and Technological Development in Process Control and Information Technology

UNU-MERIT Dissertation Series, № 1 

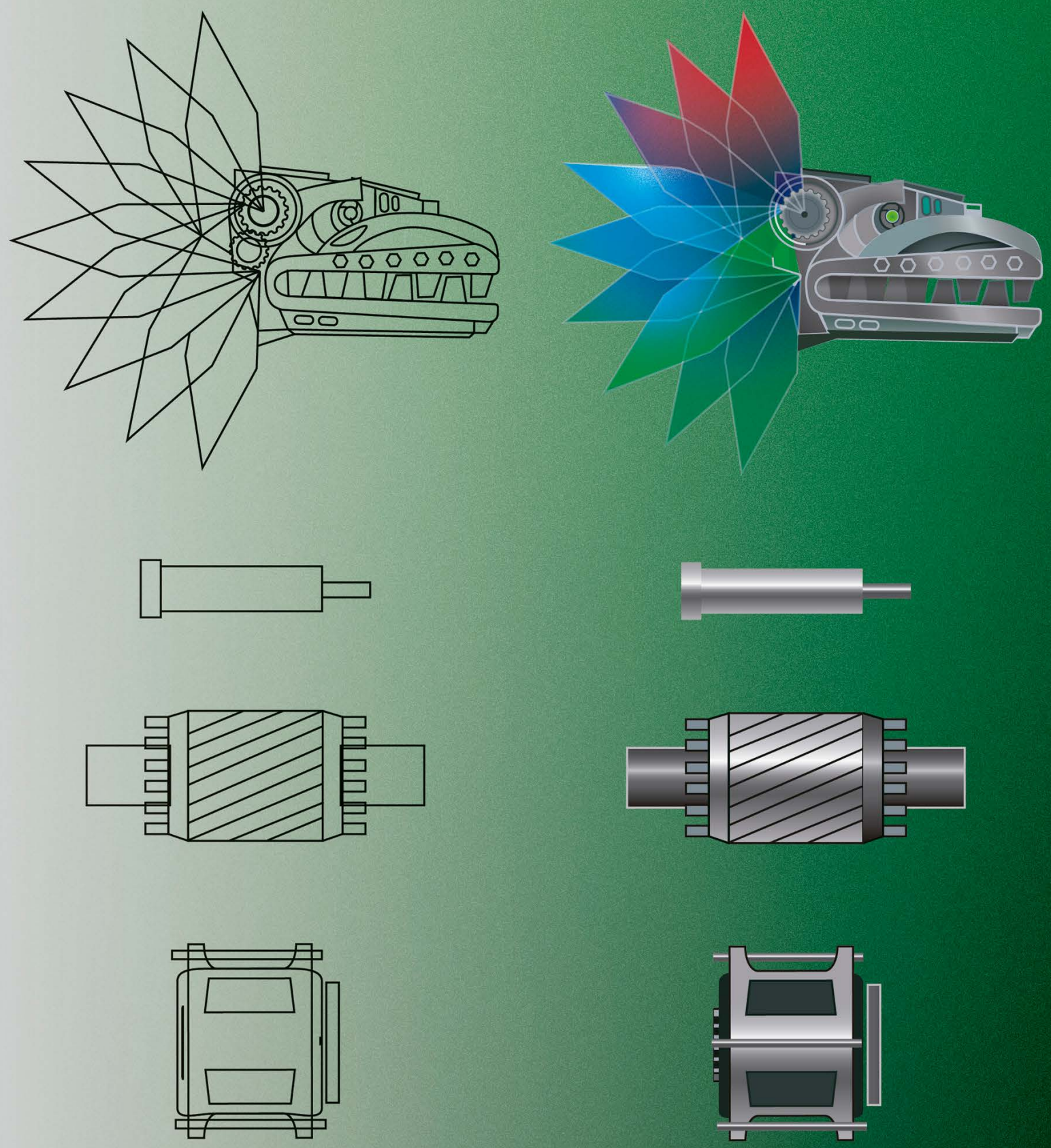